DEPARTAMENTO DE ESTRUCTURAS Y FÍSICA DE EDIFICACIÓN ESCUELA TÉCNICA SUPERIOR DE ARQUITECTURA DE MADRID

\title{
LA VIGA MIXTA CON MADERA: VERIFICACIÓN EXPERIMENTAL DEL MÉTODO GAMMA Y ESTUDIO DE POSIBLES ALTERNATIVAS DE ANÁLISIS
}

TESIS DOCTORAL

Miguel Ávila Nieto

Arquitecto

DIRECTOR:

José Miguel Ávila Jalvo

Dr. Arquitecto 





\section{ÍNDICE}

página

RESUMEN

VII

$\begin{array}{lll}\text { ABSTRACT } & \text { IX }\end{array}$

$\begin{array}{ll}\text { AGRADECIMIENTOS } & \text { XI }\end{array}$

$\begin{array}{ll}\text { CAPÍTULO 1.- INTRODUCCIÓN } & 013\end{array}$

1.1 CAMPODE TRABAJO DE ESTA TESIS 015

1.2 ENFOQUE DE LA TESIS 023

$\begin{array}{lll}1.3 & \text { OBJETIVOS } & 027\end{array}$

$\begin{array}{lll}1.4 & \text { ESTRUCTURA DEL DOCUMENTO } & 029\end{array}$

$\begin{array}{ll}\text { CAPÍTULO 2.- ESTADO DEL ARTE } & 031\end{array}$

$\begin{array}{lll}2.0 & \text { INTRODUCCIÓN } & 033\end{array}$

2.1 PRIMERAS PUBLICACIONES 034

2.2 TIPOS DE CONEXIONES 035

2.2.1 CONEXIÓN CONTINUA

2.2.2 CONEXIÓN DISCRETA

2.3 FÓRMULAS DEL MÓDULO DE DESLIZAMIENTO $\left(\mathrm{K}_{\mathrm{ser}}\right)$

2.3.1 NORMATIVA

2.3.2 FÓRMULAS EMPÍRICAS DE DIFERENTES AUTORES

$\begin{array}{ll}\text { CAPÍTULO 3.- TRABAJOS DE LABORATORIO } & 055\end{array}$

$\begin{array}{lll}3.0 & \text { INTRODUCCIÓN } & 067\end{array}$

3.1 ESTUDIO DE LOS MATERIALES 059

3.1.1 HORMIGÓN

3.1.2 MADERA LAMINADA Y ASERRADA

3.1.3 MADERA MICROLAMINADA

3.1.4 CONECTORES

3.1.5 ESTUDIO DEL HENDIMIENTO

3.2 CONEXIONES A RASANTE

069

3.2.1 TRABAJOS PREVIOS 
Esbeltez del conector en madera aserrada

Esbeltez del conector en madera microlaminada

Número adecuado de conectores por probeta

\subsubsection{LA PROBETA}

Diseño

Dimensiones, materiales y conectores

\subsubsection{PROCEDIMIENTOS DEL ENSAYO}

Protocolo

Instrumentación

Resumen fotográfico

\subsubsection{CRITERIOS TOMADOS PARA OBTENER EL $\mathrm{K}_{\mathrm{ser}}$}

Gráfica representativa de cada tipo de ensayo

Fuerza máxima estimada para obtener el $\mathrm{K}_{\mathrm{ser}}$

\subsection{VIGAS A FLEXIÓN}

\subsubsection{TRABAJOS PREVIOS}

Sistema de aplicación de la carga

Pruebas para la reutilización de las piezas

\subsubsection{LA VIGA MIXTA}

Dimensiones, materiales y conexiones

Reportaje del proceso de construcción

Primer criterio de agrupación de ensayos

Segundo criterio de agrupación de ensayos

3.3.3 PROCEDIMIENTOS DEL ENSAYO E INFORMACIÓN DE LA ROTURA

Protocolo

Instrumentación

Información tras la rotura. Vigas

Información tras la rotura. Conexiones

\subsubsection{TRANSFORMACIÓN DE LOS DATOS DE LABORATORIO}

Paso de 4 cargas puntuales a uniforme

Corrección de asimetrías

Corrección de la flecha de cortante

Resumen de resultados corregidos

Desestimación de puesta en carga 


\section{CAPÍTULO 4.- RESULTADO DE CONEXIÓN A RASANTE}

\section{1}

$\begin{array}{lll}4.0 & \text { INTRODUCCIÓN } & 133\end{array}$

4.1 MÓDULO DE DESLIZAMIENTO DEL ENSAYO $\left(\mathrm{K}_{\mathrm{ser}}\right)$

4.1.1 CRITERIO DE REPRESENTACIÓN DE K $\mathrm{K}_{\text {ser }}$

4.1.2 VALORES DE K $\mathrm{K}_{\mathrm{ser}}$ EN EL EUROCÓDIGO

4.1.3 VALORES DEL $K_{\text {ser }}$ EN LOS ENSAYOS

4.1.4 COMPARACIÓN CON OTROS AUTORES

4.2 COMPARACIÓN ENTRE DISTINTOS PRETALADROS Y APRIETES 141

4.3 COMPARACIÓN DE ENSAYOS CON / SIN RESINA 143

4.4 HORMIGÓN vs MADERA MICROLAMINADA 144

CAPÍTULO 5.- RESULTADO DE LAS VIGAS A FLEXIÓN 149

$\begin{array}{lll}5.0 & \text { INTRODUCCIÓN } & 151\end{array}$

5.1 RELACIÓN DEL TRABAJO CON LA EDIFICACIÓN URBANA 153

5.2 INFLUENCIA DEL ROZAMIENTO 155

5.3 INFLUENCIA DE LA PRESIÓN ENTRE VIGUETA Y CAPA DE COMPRESIÓN 158

5.4 INFLUENCIA DEL ÁNGULO DE INCIDENCIA (45) 162

5.5 HORMIGÓN vS DE MADERA MICROLAMINADA 166

5.6 MEJORA DE RIGIDEZ DE LAS DISTINTAS CONEXIONES 171

\section{CAPÍTULO 6.- MÉTODO DE CÁLCULO 175}

$\begin{array}{ll}6.0 & \text { INTRODUCCIÓN } \\ & 177\end{array}$

6.0.1 EL DESLZAMIENTO EN EL CÁLCULO DE FORJADOS REFORZADOS

6.0.2 ASPECTOS ESENCIALES DEL MÉTODO GAMMA

$\begin{array}{lll}6.1 & \text { BASE DE PARTIDA } & 181\end{array}$

6.1.1 DESCRIPCIÓN

6.1.2 PRESENTACIÓN GRÁFICA DEL RESULTADO BUSCADO

6.1.3 REPRESENTACIÓN GRÁFICA GENERAL DEL PROCESO

6.2 LÍMITES DE ESTE TIPO DE REFUERZO 183

6.3 RIGIDEZ NECESARIA PARA NO EXCEDER LA FLECHA LÍMITE 184

6.3.1 LEY DE VARIACIÓN DE LA FLECHA EN FUNCIÓN DEL GRADO DE CONEXIÓN

6.3.2 RELACIÓN ENTRE RIGIDEZ CON CONEXIÓN FLEXIBLE ( $\left.\boxminus_{C F}\right)$ Y SIN CONEXIÓN ( $\left.\Xi_{S C}\right)$

6.3.3 REPRESENTACIÓN GRÁFICA

6.4 RELACIÓN ENTRE MOMENTOS DE FLEXIÓN PROPIA Y EL MOMENTO TOTAL

187 
6.5 REPARTO DEL MOMENTO DE FLEXIÓN PROPIA ENTRE LAS PARTES 189

6.6 ESTUDIO DE LAS DEFORMACIONES UNITARIAS $\varepsilon_{m}$, CURVATURA Y GIRO 190

6.6.1 DEFORMACIONES UNITARIAS DE LA SECCIÓN

6.6.2 CURVATURA DE LA SECCIÓN

6.6.3 GIRO EN EL EXTREMO DE LA PIEZA

6.7 DESLIZAMIENTO DE LA CONEXIÓN

6.7.1 DESLIZAMIENTO DEBIDO A LAS DEFORMACIONES UNITARIAS DE FLEXIÓN

6.7.2 DESLZAMIENTO DEBIDO A LAS DEFORMACIONES UNITARIAS DE COMPRESIÓN Y TRACCIÓN

6.7.3 DESLIZAMIENTO FINAL

6.7.4 REPRESENTACIÓN GRÁFICA

6.8 PAR DE FUERZAS N'Z

196

6.8.1 AXIL EN LA CAPA DE COMPRESIÓN Y LA VIGUETA PARA FORMAR EL PAR

6.8.2 DEFORMACIÓN UNITARIA AXIAL $\varepsilon_{N}$

6.8.2 REPRESENTACIÓN GRÁFICA DE LOS TRES MOMENTOS

6.9 ESFUERZO RASANTE

6.9.1 VALORACIÓN

6.9.2 RELACIÓN ENTRE EL DESLIZAMIENTO Y EL RASANTE

6.10 RIGIDEZ DE LA CONEXIÓN Y CONCLUSIÓN 201

6.11 APROXIMACIÓN DE LA RIGIDEZ OBTENIDA POR EL MÉTODO GAMMA 203

CAPÍTULO 7.- COMPARACIÓN DE ENSAYOS DE RASANTE Y FLEXIÓN 205

$\begin{array}{lll}7.0 & \text { INTRODUCCIÓN } & 207\end{array}$

7.1 OBTENCIÓN DE R, $v$ y $\mathrm{K}_{\text {uni }}$ (rasante, deslizamiento y rigidez) 209

7.1.1 ENSAYO DE RASANTE

7.1.2 ENSAYO DE FLEXIÓN

7.2 HORMIGÓN VS MADERA MICROLAMINADA

7.2.1 YUXTAPOSICIÓN DE GRÁFICAS

7.2.2 LAS DOS GRÁFICAS VISTAS DESDE SUS $K_{\text {ser }}$

7.2.3 EL CURIOSO CASO DEL HORMIGÓN BIPOLAR

7.3 COMPARACIÓN DE TODOS LOS K $\mathrm{K}_{\text {ser }} 218$

7.4 MAGNITUD DEL DESLIZAMIENTO EN AMBOS ENSAYOS 228

7.3.1 ANÁLISIS DE PROBETAS DESPUÉS DE LA ROTURA

7.3.2 SUPERPOSICIÓN EN LA ZONA DE ROTURA

7.3.3 SUPERPOSICIÓN EN LA ZONA DE SERVICIO 
8.1 MODELO DE CÁLCULO 237

8.2 DISTINTOS ASPECTOS DETECTADOS EN LOS ENSAYOS 239

8.3 AUSENCIA DE NORMATIVA 241

8.4 DISCREPANCIAS CON LA NORMATIVA 242

CAPÍTULO 9.- FUTUROS TRABAJOS

BIBLIOGRAFÍA

ANEJO I.- ESTUDIO DE LOS MATERIALES

265

ANEJO I.1 HORMIGÓN

ANEJO I.2 MADERA ASERRADA

ANEJO I.3 MADERA LAMINADA

ANEJO I.4 MADERA MICROLAMINADA

ANEJO I.5 CONECTORES

ANEJO I.6 HENDIMIENTO MADERA

ANEJO II. CONEXIONES A RASANTE. TRABAJOS PREVIOS

305

ANEJO II.1 ESBELTEZ DEL CONECTOR EN MADERA ASERRADA

ANEJO II.2 ESBELTEZ DEL CONECTOR EN MADERA MICROLAMINADA

ANEJO III. CONEXIONES A RASANTE

373

ANEJO III.1 LISTADO DE ENSAYOS

ANEJO III.2 TIRAFONDOS

ANEJO III.3 BARRA CORRUGADA

ANEJO III.4 CLAVOS

ANEJO III.5 TORNILLOS

ANEJO IV. -VIGAS A FLEXIÓN. TRABAJOS PREVIOS

449

ANEJO IV.1 SISTEMA DE APLICACIÓN DE LA CARGA

ANEJO IV.2 PRUEBAS PARA LA REUTILIZACIÓN DE LAS PIEZAS

ANEJO IV.3 ENSAYOS PARA MEDIR LA FLECHA DE CORTANTE 
ANEJO V.1 LISTADOS DE ENSAYOS

V.1.1 DESCRIPCIÓN

V.1.2 MEJORAS DE RIGIDEZ DEL REFUERZO

V.1.3 DIFERENCIAS ENTRE ENSAYOS Y MÉTODO GAMMA

ANEJO V.2 ENSAYOS CON VIGUETA DE MADERA LAMINADA

V.2.1 TIRAFONDOS

V.2.2 BARRA CORRUGADA

V.2.3 CLAVOS

V.2.4 TORNILLOS

V.2.5 SIN CONEXIÓN

ANEJO V.3 ENSAYOS CON VIGUETA DE MADERA ASERRADA

V.3.1 TIRAFONDOS

V.3.2 CLAVOS

V.3.3 TORNILLOS

V.3.4 SIN CONEXIÓN

ANEJO V.4 ENSAYOS CON/ SIN PRESIÓN ENTRE VIGUETA Y CAPA DE COMPRESIÓN

ANEJO VI.-CONSECUENCIAS MECÁNICAS DE LA ESCALA DE LOS ENSAYOS 589 


\section{RESUMEN}

Esta tesis estudia, de manera fundamentalmente experimental, el refuerzo de forjados de madera existentes al añadirles una capa de compresión conectada. Se han realizado 95 ensayos de vigas a corto plazo y un conjunto de ensayos complementarios. La intención es cruzar un gran número de las variables que intervienen en este tipo de refuerzos.

Como alternativa al método de cálculo que recoge el Anejo B del Eurocódigo 5, el denominado "método Gamma" se ha desarrollado un método que relaciona esfuerzos, tensiones, y deformaciones entre sí mediante leyes de proporción y que enlaza directamente la rigidez de flexión con la rigidez de la conexión. Este método permite no solo proyectar estos refuerzos y peritarlos sino disponer de una herramienta con la que se han seguido paso a paso los ensayos realizados en el laboratorio.

El parámetro que se ha estudiado en los ensayos ha sido el módulo de deslizamiento (rigidez de la conexión), ya que es el que sirve para compararlos entre ellos y con la normativa.

De todos los estudios realizados, los aspectos a destacar son los siguientes:

En los refuerzos con capas de compresión de madera microlaminada se ha observado una rigidez superior a lo que establece la normativa.

La colocación de los conectores a $45^{\circ}$ prácticamente elimina el deslizamiento, lo que supone una gran mejora en la rigidez y una gran simplificación en el cálculo.

La diversidad de aspectos que intervienen en el diseño de los conectores no queda contemplada en las dos expresiones que emplea la normativa.

El pretensado, entendido como presión entre viguetas y capa de compresión, supone una gran ganancia de rigidez de la conexión, no incluida en la normativa.

Se han encontrado discordancias entre la Norma UNE EN 26891 "Estructuras de Madera. Uniones realizadas con elementos de fijación mecánicos. Principios generales para la determinación de las características de resistencia y deslizamiento", las expresiones del Eurocódigo 5 y los ensayos realizados. 


\section{ABSTRACT}

This thesis studies, essentially from an experimental perspective, the reinforce in existing timber floor framings when adding a connected compression layer. 95 sort term tests have been carried out with beams, together with a set of supplementary tests. The aim is to cross a large number of variables that intervene in such type of reinforces.

As an alternative to the calculation method described in the Annex B of Eurocode 5, the socalled "Gamma Method", it has been developed a method that connects stresses, tensions and strains by means of laws of proportion, and which connects in a direct manner, flexion stiffness and connection stiffness. This method allows not only to design and judge expertly these reinforces, but also to provide a tool that simulate step by step the laboratory tests.

Slip modulus (connection stiffness) has been the parameter analysed in the laboratory tests, since it is the one to compare tests results and ruling standards.

The following are the aspects to be highlighted from all the studies carried out:

A stiffness larger than the specified in the standards has been observed in reinforces with LVL compression layers.

Connectors placed at $45^{\circ}$ almost eliminate sliding, which drives to an improvement in stiffness and a huge simplification in the calculations.

The multiple aspects that intervene in the connectors design is not considered in any of the two expressions provided by the standards.

The prestressing, understood as pressure between joists and compression layer, brings a strong improvement in the connection stiffness, not included in the standards.

Some discrepancies have been found between the standard UNE EN 26891 "Wooden structures made with mechanical fixing elements. General principles for the determination of strength and sliding performance", the Eurocode 5 formulas and the tests carried out.

Madrid, july 1st, 2017 
THE TIMBER COMPOSITE BEAM: experimental verification of the Gamma Method and study of possible alternative analyses 


\section{AGRADECIMIENTOS}

A mi madre

Son muchas las personas que han ayudado de alguna forma a que este trabajo saliera adelante y a las que debo mi gratitud:

A José Miguel Ávila Jalvo, padre, maestro y director de tesis. Sería incorrecto que estuviera en la dedicatoria ya que esta tesis ha ido en tándem y es tan suya como mía. Su claridad para distinguir cada tipo de árbol dentro del bosque ha sido fundamental para poder llegar a algún sitio. Además, cada vez que yo flojeaba, miraba atrás y él continuaba pedaleando ( $y$ le quedaban fuerzas para sacar la fusta y azotar).

A Rafael Díez Barra, por sus conocimientos y ayuda en la construcción (y destrucción) de todas las piezas ensayadas. En especial por ser el gran maestro de la logística, capaz de conseguir cualquier cosa que haya podido necesitarse a lo largo de todo el trabajo. Por no hablar de la cantidad de cafés y pinchos de tortilla que le debo, y algún día espero me deje empezar a pagarle.

A José Luis Fernández Cabo, motor de arranque de toda esta aventura, por todos los conocimientos científicos aportados, su dedicación y estímulo para que el trabajo siguiera siempre adelante. Siento de corazón no haberle podido enseñar los frutos de lo que él sembró.

La mayor parte de los trabajos de esta tesis se realizaron en el Laboratorio de Estructuras de la E.T.S de Arquitectura de Madrid, quisiera agradecer al Departamento todos los medios puestos a mi alcance. En especial quisiera agradecer a Javier Rasines Sánchez, por su colaboración en los trabajos de laboratorio y sobre todo, porque entre él y José Luis Fernández Cabo, con su trabajo y dedicación, consiguieron que el Laboratorio diera un gran salto de calidad.

A Ramón Cañil, que en cierto momento de flojera se dejó engañar y se unió a la causa donando los tableros de madera microlaminada, que en definitiva han sido auténticos protagonistas de este trabajo.

A José Ramón Duro, por su desinteresada ayuda en la traducción.

En lo personal, agradecimiento eterno a mis padres, ella, fuerza y coraje, él, paciencia y sabiduría. Intento siempre hacer uso de estas virtudes (lo difícil es saber emplear la que convenga en cada momento, su uso incorrecto puede ser desastroso).

A mis hermanos, por su infinita paciencia.

A Ana, por su amor, su manera de entender la vida y porque la vida con espetos sabe mejor.

Al Team Rocket, por las aventuras vividas y las penurias que quedan por vivir.

Por último, a mis abuelos, por enseñarme a mojar el pan en el vino, por su tortilla de patatas, por los regalos del banco y por los paseos por el parque los domingos. Y a mi tío Nacho, porque nunca me olvidaré del Scalextric que nos construyó. 


\section{CAPÍTULO 1. - INTRODUCCIÓN}

1.1 CAMPO DE TRABAJO DE ESTA TESIS

1.2 ENFOQUE DE LA TESIS

1.3 OBJETIVOS

1.4 ESTRUCTURA DEL DOCUMENTO 


\subsection{CAMPO DE TRABAJO DE ESTA TESIS}

Esta tesis estudia un caso muy específico de conexión entre materiales, que como es bien sabido, suele ser uno de los puntos más conflictivos en el diseño de las estructuras. Con esta conexión se busca reducir el deslizamiento que se produce cuando se colocan dos piezas longitudinales una encima de la otra para que trabajen conjuntamente a flexión. El campo en el que se va a trabajar es el del refuerzo de forjados de madera existentes en edificios urbanos y que resultan excesivamente flexibles para las condiciones normativas actuales, pero que, sin embargo, pueden ser conservados si se les coloca encima una capa de compresión conectada a ellos para dotarlos de rigidez suficiente.

Este forjado reforzado (viga mixta) deberá tener una rigidez a flexión (EI) que asegure el cumplimiento de una flecha límite establecida en los reglamentos, y es fácil colegir que dicha rigidez a flexión va a depender del grado de conexión ${ }^{1}$ conseguido al unir las viguetas de madera con la capa de compresión, porque el valor de dicho grado de conexión depende de la rigidez a deslizamiento de la unión (denominada $\mathrm{K}_{\mathrm{uni}}$ ).

\section{PROCEDIMIENTO DE DIMENSIONADO}

El límite inferior de este grado de conexión se alcanza cuando se superpone la capa de compresión sin más $(\psi=0)$ : dando lugar a la rigidez mínima de la viga, y el límite superior cuando se anula el deslizamiento entre ambas partes ( $\psi=1$ y rigidez máxima).

Esto conduce a que el dimensionado del refuerzo de un forjado tenga una fase previa para ver si la rigidez necesaria se encuentra entre los límites mínimo y máximo descritos. Si esto se cumple, el cálculo del refuerzo se limita a definir el diámetro y separación de los conectores. ${ }^{2}$

\footnotetext{
${ }^{1}$ En esta tesis se ha empleado la letra griega $\psi$ para indicar el grado de conexión, que va a variar desde 0 cuando no hay conexión, es decir, el deslizamiento no está impedido y 1 , cuando la conexión es total y el deslizamiento es nulo. Alternativamente esta misma variable $\psi$ también se representa en porcentajes.

${ }^{2}$ Se ha dado preferencia al término conector, que figura en el diccionario de la R.A.E. como adjetivo -"adj. Que conecta"- por ser el establecido en la literatura técnica, aunque a veces aparece el término conectador, que puede entenderse más adecuado, ya que figura en el mismo diccionario como sustantivo " $m$. Aparato $o$ medio que se emplea para conectar".
} 
El camino natural para abordar este dimensionado debería partir de la rigidez a flexión necesaria, con ella obtener el grado de conexión ( $\psi$ entre 0 y 1 ) y la rigidez a deslizamiento $\left(K_{\text {uni }}\right)$ asociada a él, para concluir eligiendo la combinación de diámetro y separación de conectores que alcance dicha rigidez. Curiosamente este camino no existe, de modo que para dimensionar el refuerzo de un forjado hay que elegir un diámetro y separación, y comprobar, siguiendo un procedimiento aproximado, que la configuración elegida alcanza la rigidez a flexión buscada.

Este procedimiento, denominado "método gamma" ${ }^{3}$, es la forma con la que se consiguió resolver el cómo afectaba la rigidez a deslizamiento $\left(\mathrm{K}_{\mathrm{uni}}\right)$ a la rigidez a flexión (EI) de la viga, y es aproximado porque, para poder resolver el sistema de ecuaciones diferenciales que describe esta relación, hay que sustituir la carga uniforme por una carga sinusoidal. ${ }^{4}$

\section{LÍMITES DE VALIDEZ DE ESTE TIPO DE REFUERZO}

Para determinar los límites de rigidez de un forjado reforzado se dispone de la geometría y módulo de elasticidad de las viguetas. En lo referente a la capa de compresión, también se conocerá esta información cuando se elija su espesor y el material con el que se va a realizar. Por tanto, la capacidad de decisión es muy reducida.

Las siguientes expresiones valoran la rigidez de estos dos límites: ${ }^{5}$

$$
\begin{gathered}
\mathrm{EI}_{\text {mín }}=\mathrm{E}_{\mathrm{cc}} \mathrm{I}_{\mathrm{cc}}+\mathrm{E}_{\mathrm{vig}} \mathrm{I}_{\mathrm{vig}} \\
\mathrm{EI}_{\text {máx }}=\mathrm{EI}_{\text {mín }}+(\mathrm{EA})_{\mathrm{vig}} \cdot \mathrm{a}_{\mathrm{vig}}{ }^{2}+(\mathrm{EA})_{c c} \cdot \mathrm{a}_{\mathrm{cc}}{ }^{2}
\end{gathered}
$$

Teniendo en cuenta que el objeto de este trabajo son los forjados de edificación urbana, la mayoría de las variables de estas expresiones están interrelacionadas. Por ejemplo, la relación entre el módulo de elasticidad de la capa de compresión y el de la vigueta oscila entre vez y media (madera microlaminada) y dos veces y media (hormigón a corto plazo); la anchura de la capa de compresión es poco más que el doble que la anchura de la vigueta; y el espesor de la capa de compresión es prácticamente una constante que depende de aspectos no estructurales, sino funcionales.

Introduciendo estas relaciones en aquellas expresiones se llega a la conclusión de que, si la esbeltez del forjado inicial $\left(\lambda_{\text {ini }}=L / h_{\text {vig }}\right)$ es superior a 33 , o la esbeltez final $\left(\lambda_{\text {fin }}=L /\left(h_{\text {vig }}+h_{\text {cc }}\right)\right.$ es

\footnotetext{
${ }^{3}$ El "método gamma" esta desarrollado en el anejo B del Eurocódigo EC-5 [ref. 013]

${ }^{4}$ El método tiene su origen en los años 50 en Alemania (Möhler, 1956) [ref. 104]

${ }^{5}$ Las variables $a_{c c}$ y $a_{\text {vig }}$ son las distancias desde los centros de gravedad de la capa de compresión y de la vigueta al centro de gravedad de la sección compuesta.
} 
superior a 23, este tipo de refuerzo es inviable, ya que, aun evitando totalmente el deslizamiento, las flechas son superiores a las normativas.

\section{CLASIFICACIÓN DE LOS CONECTORES}

Vistos los parámetros de la geometría, se entra ahora a describir los elementos con los que se consigue conectar la capa de compresión a las viguetas, o sea, los conectores. Igual que la geometría y los módulos de elasticidad están delimitados en este tipo de refuerzos, lo mismo ocurre con la gama de conectores empleados. En este apartado se trata de describir y diferenciar aquellos que se han utilizado en esta tesis.

La denominación general de estos conectores es "clavija". En esta denominación, la normativa incluye a anillos, placas y grapas, que en este caso no son de aplicación, por dar lugar a resistencias a rasantes muy superiores a las necesarias en estos edificios. Dentro de las clavijas empleadas en estos forjados cabe distinguir entre varillas lisas o corrugadas, clavos y tirafondos o tornillos. La normativa añade además los términos "pasador" y "perno", pero no cita a los "tornillos", ya que posiblemente los considera incluidos en "tirafondos". Todas estas denominaciones, según dicha Normativa, se resumen en dos expresiones que definen su módulo de deslizamiento: una para los clavos sin pretaladro, y otra para todos los demás.

En esta tesis se emplearán los siguientes términos: Varillas (lisas o corrugadas sin cabeza), clavos (lisos, con cabeza y punta para ser introducidos con un martillo y de diámetro pequeño para no necesitar pretaladro) y por último tornillos o tirafondos (barras con cabeza y rosca, que podrán requerir pretaladro en función de su diámetro).

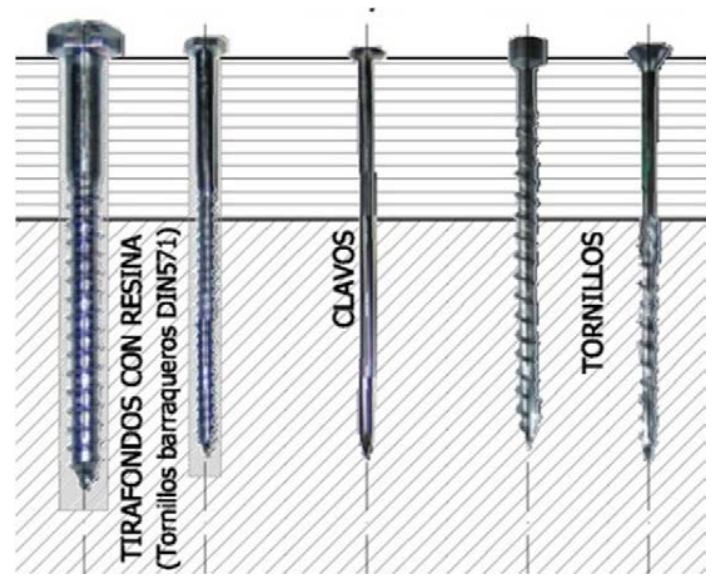

figura 1. Conectores utilizados en la tesis

Los tornillos y tirafondos con los que se realiza la mayor parte de las conexiones en este refuerzo de forjados, y también en esta tesis, conviene diferenciarlos más detalladamente. Hemos denominado "tirafondos" a los que se han confeccionado según la Norma DIN-571, conocidos en el 
ámbito de la construcción como "tornillos barraqueros", y "tornillos" a todos los demás (concretamente a los denominados HBS y VGZ).

Resulta especialmente importante para el cálculo prestar atención al diámetro con el que se deben calcular estos elementos, porque todos ellos están identificados con 3 diámetros: el $\varnothing$ del cuello o caña, el $\varnothing$ interior de la rosca y el $\varnothing$ exterior de la rosca, que coincide con el $\varnothing$ nominal. En el caso de los tirafondos, el $\varnothing$ de cálculo y el $\varnothing$ nominal es el mismo, mientras que en caso de los tornillos, el $\varnothing$ de cálculo, prácticamente coincide con el $\varnothing$ del cuello, que está entre el $70 \%$ y el $75 \%$ del $\varnothing$ nominal, circunstancia que puede conducir a errores notables si se usa el $\varnothing$ nominal como $\varnothing$ de cálculo. ${ }^{6}$

Pero hay una serie de cuestiones que no están incluidas en este momento en la normativa que modifican notablemente su módulo de deslizamiento, como la forma de la cabeza, la existencia de caña o cuello liso, o el uso de diversas roscas.

\section{RIGIDEZ A DESLIZAMIENTO DEL CONECTOR Y SU RELACIÓN CON LA VIGA}

Una vez descritas las características generales de la vigueta y de la capa de compresión, así como los tipos de conectores con los que se consigue la unión entre ambas partes, se pasa a relacionar las distintas rigideces que intervienen.

La rigidez a flexión de la viga (EI) hay que relacionarla con la rigidez, o módulo de deslizamiento de la conexión $\left(\mathrm{K}_{\text {uni }}\right)$ y esta, con la rigidez de un conector a deslizamiento transversal $\left(\mathrm{K}_{\mathrm{ser}}\right)$. Asociar la rigidez a flexión (EI) con la de deslizamiento $\left(\mathrm{K}_{\mathrm{uni}}\right)$, que es lo que hace ahora de manera aproximada el "método gamma" utilizando un proceso de prueba y error, va a consumir un capítulo de esta tesis para desarrollar un modelo que recorra un camino directo, mientras que la relación entre $\mathrm{K}_{\text {uni }} \mathrm{y} \mathrm{K}_{\text {ser }}$ es inmediata:

Cuando se introduce un conector en la madera de la vigueta, su rigidez a deslizamiento $\left(\mathrm{K}_{\mathrm{ser}}\right)^{7}$ es la relación entre la fuerza rasante y el deslizamiento causado por la deformación de la clavija y por el hendimiento de la madera. Esta rigidez depende de su diámetro, de su tipo (los clavos y los demás) y de la densidad de la madera.

\footnotetext{
${ }^{6}$ En el CTE DB-SE-M, artículo 8.3.6 Se define cuál es diámetro de cálculo que hay que aplicar en las formulaciones referentes a la capacidad de carga lateral, es decir a resistencia (ELU). Sin embargo en el apartado 7.1 de Estados Limite de Servicio no especifica este diámetro para el calculo de la rigidez.

${ }^{7}$ En esta tesis se ha empleado, tanto el término rigidez a deslizamiento, que es su definición mecánica, como módulo de deslizamiento, que es la definición empleada normativamente, tanto para el $\mathrm{K}_{\text {ser }}$ como para el $K_{\text {uni }}$.
} 
$\mathrm{K}_{\mathrm{ser}}$ es la rigidez a deslizamiento de un conector $(\mathrm{N} / \mathrm{mm})$, mientras que $\mathrm{K}_{\mathrm{uni}}$ es la rigidez de ese conector por unidad de longitud de la viga, por tanto $K_{\text {uni }}=K_{\text {ser }} / \mathrm{s}\left(\mathrm{N} / \mathrm{mm}^{2}\right){ }^{8}$ Cuando se hace referencia al conector, lo lógico es emplear el término $\mathrm{K}_{\text {ser, }}$ mientras que cuando se hace referencia a la viga, lo lógico es emplear el término $K_{\text {uni, }}$ estando ambos, como se acaba de indicar, relacionados por la distancia "s" a la que se coloquen los conectores dentro de la viga.

\section{INFLUENCIA DE LA INCLINACIÓN DE LOS CONECTORES}

En la mayor parte de los casos los conectores se colocan perpendiculares a las viguetas, y al entrar en carga, se produce un deslizamiento, que será menor cuanto mayor sea el módulo de deslizamiento. Para que este módulo aumente, hay que disponer diámetros mayores o separaciones menores, pero también cabe usar otra estrategia: Inclinar los conectores lo suficiente para conseguir que se forme una biela de compresión. Puesto que la deformación del conector a flexión y cortante más el hendimiento de la madera son muy superiores a la deformación del sistema tirante-biela, que además no hiende la madera. Este sistema es tan rígido, que la normativa establece que, bajo determinadas circunstancias, se puede considerar que la conexión es total, tal como refleja en el siguiente texto, extraído del artículo 10.1.2 del DB SE-M del Código Técnico de la Edificación:

"si el sistema permite la formación de un mecanismo de biela tirante con la biela inclinada formando ángulos entre $40^{\circ}$ y $60^{\circ}$ con el plano de contacto, y para piezas cuya luz sea menor de $12 \mathrm{~m}$, se podrá prescindir del deslizamiento de la unión y realizar el análisis con la sección total a través de la teoría clásica de resistencia de materiales."

\section{PRETENSADO}

Otro modo muy eficaz de reducir el deslizamiento es provocar un rozamiento suficientemente grande presionando la capa de compresión contra la vigueta. Si se consigue mantener esta fuerza transversal a largo plazo o en situaciones dinámicas, la rigidez de la viga puede también crecer sustancialmente, incluso llegar también hasta la conexión total. Esta mejora, sin embargo, no está contemplada en la Normativa.

\footnotetext{
8 "s" representa la distancia entre conectores.
} 


\section{NORMATIVA}

No existe normativa específica para la estructura mixta entre madera y hormigón, como ocurre por ejemplo en el caso de las estructuras mixtas acero-hormigón. ${ }^{9}$

Si existe normativa para este tipo de refuerzo cuanto la capa de compresión también es de madera o sus derivados. Concretamente el anejo B del Eurocódigo 5, que se limita a la aplicación del "método gamma".

Los módulos de deslizamiento de los distintos conectores quedan especificados en la tabla 7.1 (apartado Estados Límite de Servicio. Deslizamiento de las uniones), tanto en el Eurocódigo EC-5 como en el CTE DB SE-M. La única referencia que aparece del hormigón está incluida en esta tabla, en la que se duplica la rigidez de la conexión cuando la capa de compresión es de este material, considerando así al hormigón indeformable, como también lo hace con el acero.

En cuanto al estudio de las clavijas en las uniones, desarrolladas en el capítulo 8, tanto del EC-5 como del CTE, se estudia la resistencia de los distintos conectores para unir madera-madera, madera-tablero y madera-acero, de nuevo no contempla uniones madera-hormigón.

Finalmente, la mención que se ha hecho antes sobre la anulación del deslizamiento, en determinadas condiciones, cuando los conectores están inclinados está extraída del artículo 10.1.2 (Vigas mixtas unidas con medios de fijación mecánicos) del CTE, sin embargo en el artículo homólogo del Eurocódigo no se hace mención a esta cuestión tan relevante.

En definitiva, la normativa va ayudar poco en el desarrollo de este trabajo, que esencialmente se basará en el estudio de los resultados de ensayos de laboratorio.

\section{REOLOGÍA}

En cuanto a la reología, la peculiaridad de la estructura hormigón-madera y maderamadera es que todos los materiales son reológicos, incluso resulta reológico el comportamiento de la conexión al depender de ellos.

Una complicación añadida es que las viguetas de madera de los edificios existentes pueden llevar colocadas un tiempo más que suficiente como para que sus deformaciones diferidas hayan tenido lugar, y que la estabilidad higrométrica que se le supone al edificio reformado prácticamente garantizará la ausencia de nuevas deformaciones, entendiendo que va a haber poco incremento de cargas. Sin embargo la capa de compresión de hormigón recién vertido empezará a

\footnotetext{
${ }^{9}$ Existe un borrador del Eurocódigo de estructuras mixtas de madera y hormigón EC-5 1.3 
fluir desde el momento de aplicación del refuerzo, de modo que un estudio a largo plazo que contemple este aspecto resulta bastante más complejo.

Como todo lo anterior son solo fluctuaciones de los módulos de elasticidad, su simulación puede quedar simplificada dándoles distintos a cada material, posiblemente reduciendo el del hormigón.

Los ensayos con cargas mantenidas a largo plazo, en donde todas las circunstancias anteriores no pueden ser contempladas, tienen un interés específico para medir el aumento de flecha, y por tanto de deslizamiento de la conexión, si bien este objetivo parece más fácil de alcanzar mediante ensayos cíclicos o de carga dinámica.

\section{ENSAYOS}

Para valorar experimentalmente la magnitud del módulo de deslizamiento de las conexiones $\left(\mathrm{K}_{\mathrm{ser}}\right)$ basta con realizar ensayos simples, generalmente denominados de rasante, en los que se aplica una fuerza transversal al conector y se mide el deslizamiento producido. La relación entre fuerza y deslizamiento, como ha quedado dicho, determina la rigidez a lo largo del proceso de carga.

Por otra parte, para valorar experimentalmente la relación entre la rigidez a flexión (EI) y la rigidez de la conexión $\left(K_{\text {uni }}\right)$ es necesario realizar ensayos bastante más complejos, puesto que hay que confeccionar vigas, y someterlas a un ensayo flexión, midiendo durante el proceso de carga la flecha en el punto central y el deslizamiento entre la vigueta y la capa de capa de compresión en varios lugares. La rigidez a flexión queda determinada directamente al relacionar flecha con carga, pero la rigidez de la conexión necesita una elaboración para determinar cuál es el esfuerzo rasante que se está produciendo en las secciones donde se mida el deslizamiento.

Igual que se ha establecido más arriba la necesidad de relación entre las tres rigideces desde un punto de vista teórico, hacerlo aquí desde un punto de vista experimental requiere el enlace entre los resultados de los ensayos de rasante con los ensayos de vigas. Se podría decir, para aclararlo, que conocido el deslizamiento en una sección de la viga, se conocería el esfuerzo rasante ahí localizado buscando los resultados del ensayo simple de rasante realizado con la misma madera y el mismo conector.

Esto es fácil de decir pero imposible de lograr, ya que la madera y el conector, aunque fueran los mismos, no se van a comportar de la misma forma al estar colocados en medios tan distintos. Basta indicar como ejemplo que en el ensayo de rasante el rozamiento es prácticamente nulo, mientras que en el ensayo de la viga, la aplicación transversal de la carga, y la presión 
ejercida con el conector al clavarlo, producen un rozamiento relevante que desemboca en una reducción del deslizamiento, desvirtuando la equivalencia entre los valores de un ensayo y otro.

Esto complica, pero no invalida, la posibilidad de relación entre los dos tipos ensayos. Si existiera un modelo de cálculo que relacionara las tres rigideces se dispondría de una herramienta de contraste que complementara los resultados de los ensayos. Siguiendo el mismo ejemplo, sería conocido el rasante y el deslizamiento en cualquier zona de la viga. Pero cualquier modelo también incorpora imprecisiones causadas por sus hipótesis simplificadoras.

Lo que si es cierto es que la asociación de estos tres elementos (ensayo de rasante, ensayo de viga y modelo de cálculo) es fundamental para tener un conocimiento del comportamiento de este sistema constructivo, ya que cada uno por separado no lo abarca adecuadamente. Por poner un último ejemplo, los deslizamientos que se obtienen en el ensayo de rasante con los que se mide el $\mathrm{K}_{\mathrm{ser}}$ son tan grandes para este tamaño de forjados que en el ensayo de vigas no se pueden alcanzar por haber roto mucho antes a flexión. 


\subsection{ENFOQUE DE LA TESIS}

\section{LABORATORIO Y PROYECTO DE INVESTIGACIÓN}

Esta tesis tiene un carácter experimental. Se han realizado un conjunto de ensayos en el laboratorio de Estructuras del Departamento de Estructuras y Física de la Edificación de la Escuela Técnica Superior de Arquitectura de Madrid. Este laboratorio se encuentra situado en un sótano, a temperatura y humedad prácticamente constantes y, por este motivo no se ha prestado especial atención a medir esta información a lo largo de la ejecución de todos estos trabajos. Este laboratorio dispone de una cámara con temperatura $20^{\circ}\left( \pm 2^{\circ}\right)$ y humedad $65 \%( \pm 5 \%)$ en la cual se conservaron las probetas de los ensayos simples.

Su realización es consecuencia directa del proyecto de investigación: BIA 2004 07317: Definición de un protocolo para la rehabilitación de forjados de madera mediante conexión con la nueva capa de compresión de hormigón. En el punto C1 (formación de personal en el proyecto) del informe final de dicho proyecto, de fecha 5 de marzo de 2009, se incluía al doctorando como colaborador para la realización de los ensayos de laboratorio y con idea de desarrollar más adelante el doctorado en esta área.

Los trabajos de laboratorio, que incluyen la caracterización de los materiales empleados, el diseño y preparación de las probetas, los trabajos previos para determinar diferentes aspectos de los ensayos y los ensayos finales tanto de conexiones a rasante como de vigas a flexión, fueron realizados entre los años 2006 y 2011. 


\section{RELACIÓN ENTRE ENSAYOS Y EDIFICACIÓN URBANA}

El objeto de esta tesis es revisar el estado de la cuestión referente al refuerzo de forjados de madera existentes en la edificación urbana, fundamentalmente en vivienda colectiva. La herramienta de trabajo son un conjunto de ensayos de laboratorio. Se trata por tanto de un estudio experimental.

Para asociar los ensayos de laboratorio a la edificación se establecen unas relaciones. Aunque este enlace no pueda traducirse fácilmente, se ha establecido una correlación que aparece en toda la documentación presentada. Esta relación consiste en incluir en los gráficos unas cotas de deformación y carga asociadas a la obra real: flechas de L/300, L/500 etc... y cargas de servicio (ELS), límite (ELU), etc...

Los gráficos de la figura 2 muestran esa correlación. En el izquierdo está representado el ensayo de una viga hasta su carga de rotura en el que se ha sombreado la zona en la que se mueven los valores de edificación urbana. En el derecho, esa zona ampliada:
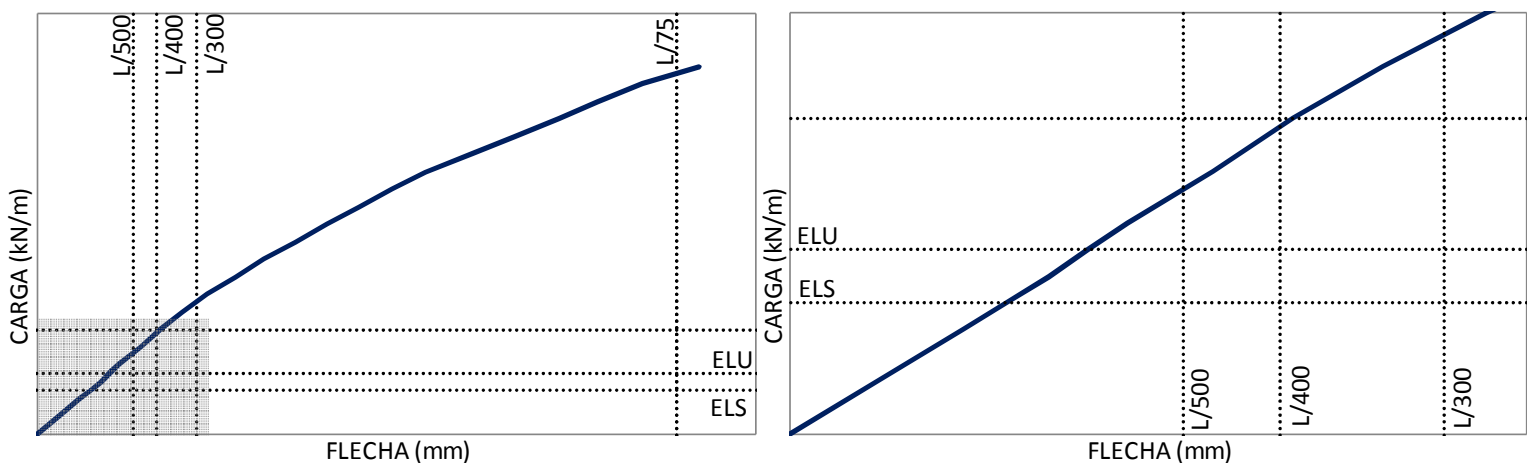

figura 2. Gráficas de carga flecha. Ensayo hasta rotura y ámbito del edificio

\section{TAMAÑO DE LAS VIGAS DE LABORATORIO}

Los ensayos proyectados simulan casos reales de rehabilitación. Se toma como base de partida la esbeltez. A partir de este parámetro se definen los demás, siempre acomodados a esa realidad construida que se trata de emular.

El tamaño de las vigas ensayadas se ajusta a la maquinaria del laboratorio y a la necesidad de mover su peso entre dos personas. Eso lleva a trabajar con vigas de luz 3,20 m, cantos de entre $10 \mathrm{~cm}$ y $14 \mathrm{~cm}$, lo que da lugar a esbelteces de vigueta entre 32,00 y 22,86 y ancho de la vigueta de $9 \mathrm{~cm}$. Todo lo cual se ajusta razonablemente a lo construido y a las escuadrías disponibles para realizar los ensayos.

La capa de compresión tiene un ancho de $20 \mathrm{~cm}$, porque este tipo de forjados tiene las viguetas separadas de modo el entrevigado es un poco más ancho que la vigueta, a fin de que se 
crucen sobre los muros en los que apoyan dos crujías adyacentes ocupando todo el muro con esas maderas, con una holgura que permita, en ese cruce de viguetas sobre el muro, la irregularidad e imperfecciones de las piezas.

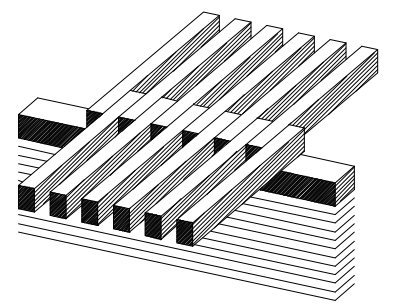

figura 3. Apoyo de viguetas en muro

Como los tamaños de edificación para este tipo de forjado están frecuentemente entre 4,00 y $5,00 \mathrm{~m}$ de luz, se puede decir que se ha trabajado a una escala del orden de $2 / 3$. La capa de compresión en estos forjados suele ser de $6 \mathrm{~cm}$, por lo que en los ensayos se fijan $4 \mathrm{~cm}$ de espesor para mantener esa proporción.

\section{CONSECUENCIAS MECÁNICAS DE LA ESCALA DE LOS ENSAYOS}

Se considera que al cambiar el tamaño la esbeltez no varía.

\section{Carga superficial}

Una vez descrita la geometría, queda establecer la carga superficial de las vigas ensayadas. Tomando $12 \mathrm{~cm}$ como canto de vigueta representativo de los tres empleados $(10 \mathrm{~cm}, 12 \mathrm{~cm}$ y 14 $\mathrm{cm})$, el peso por $\mathrm{m}^{2}$ es:

$\begin{array}{ll}\text { Factores fijos de la carga (solado + tabiquería + uso): }{ }^{10} & 4,00 \mathrm{kN} / \mathrm{m}^{2} \\ \text { Factores de la carga que varían con la escala (relleno y p.p.): }{ }^{11} & 2,25 \mathrm{kN} / \mathrm{m}^{2}\end{array}$

La carga superficial considerada para simular el peso de edificación en laboratorio es $Q=4$ $+2,25 \cdot \zeta \mathrm{kN} / \mathrm{m}^{2}$, que se puede simplificar en $Q_{\text {real }}=Q_{\text {lab }} \cdot \sqrt{ }(\zeta)$. La siguiente tabla representa para distintos valores de $\xi$, la carga, la carga aproximada y el error entre ambas:

\footnotetext{
${ }^{10}$ solado $0,80 \mathrm{kN} / \mathrm{m}^{2}+$ acabado inferior $0,20 \mathrm{kN} / \mathrm{m}^{2}+$ tabiquería $1,00 \mathrm{kN} / \mathrm{m}^{2}+$ sobrecarga de uso 2,00 $\mathrm{kN} / \mathrm{m}^{2}$

${ }^{11}$ La c.c. de hormigón ocupa el espacio del relleno eliminado.

$\begin{array}{llllll}\text { Hormigón } & 25 \mathrm{kN} / \mathrm{m}^{3} & 0,04 & 1 & & 1,00 \mathrm{kN} / \mathrm{m}^{2} \\ \text { Madera } & 6 \mathrm{kN} / \mathrm{m}^{3} & 0,12 & 9 / 20 & 0,32 \mathrm{kN} / \mathrm{m}^{2} & \\ \text { entrevigado } & 14 \mathrm{kN} / \mathrm{m}^{3} & 0,12 & 11 / 20 & 0,92 \mathrm{kN} / \mathrm{m}^{2} & 1,25 \mathrm{kN} / \mathrm{m}^{2}\end{array}$
}




\begin{tabular}{|c|c|c|c|c|c|}
\hline $\mathbf{\zeta}$ & $\mathbf{1 , 0 0}$ & $\mathbf{1 , 2 5}$ & $\mathbf{1 , 5 0}$ & $\mathbf{1 , 7 5}$ & $\mathbf{2 , 0 0}$ \\
\hline $\mathbf{L}$ & 3,20 & 4,00 & 4,80 & 5,60 & 6,40 \\
\hline $\mathbf{Q}$ & 6,25 & 6,81 & 7,38 & 7,94 & 8,50 \\
\hline $\mathbf{Q}$ aprox & 6,25 & 6,99 & 7,65 & 8,27 & 8,84 \\
\hline error & $0 \%$ & $3 \%$ & $4 \%$ & $4 \%$ & $4 \%$ \\
\hline
\end{tabular}

\section{Variación de la flecha con la escala}

Si a la expresión de la flecha $(\delta)$ de una viga biapoyada sometida a carga uniforme se le incorpora el factor de escala, el cambio de tamaño se ve afectado según la siguiente expresión:

$$
\delta=\frac{5 \cdot[\mathrm{Q} \sqrt{\zeta}] \cdot[\mathrm{s} \zeta] \cdot[\mathrm{L} \zeta]^{4}}{384 \cdot \mathrm{E} \frac{[\mathrm{b} \zeta] \cdot[\mathrm{h} \zeta]^{3}}{12}}=\frac{5 \cdot \mathrm{QsL}^{4}}{384 \cdot \mathrm{E} \frac{\mathrm{bh}^{3}}{12}} \cdot \zeta \sqrt{\zeta}
$$

La siguiente tabla incluye los valores concretos que relacionan la flecha que se obtendría en un edificio a partir de los resultados obtenidos en el laboratorio:

\begin{tabular}{|c|c|c|c|c|c|}
\hline $\boldsymbol{\zeta}$ & $\mathbf{1 , 0 0}$ & $\mathbf{1 , 2 5}$ & $\mathbf{1 , 5 0}$ & $\mathbf{1 , 7 5}$ & $\mathbf{2 , 0 0}$ \\
\hline $\mathbf{L}$ & 3,20 & 4,00 & 4,80 & 5,60 & 6,40 \\
\hline $\boldsymbol{\delta}_{\text {edif }} / \boldsymbol{\delta}_{\text {lab }}$ & 1,00 & 1,40 & 1,84 & 2,32 & 2,83 \\
\hline
\end{tabular}

Esto supone que si se quiere conocer la flecha de una viga de luz distinta a la del laboratorio, basta aplicar a la viga del laboratorio una carga $Q^{\prime}=Q \cdot \zeta \sqrt{ }(\zeta)$ para obtener esa información. Como en los ensayos de laboratorio se va aplicando una carga creciente, al paso por la carga $6,25 \mathrm{kN} / \mathrm{m}^{2}$ se alcanza la flecha de la viga de luz 3,20 m (tamaño del laboratorio ; $\zeta=1$ ). Si se quiere conocer la flecha de una viga de luz $4,80 \mathrm{~m}(\zeta=1,5)$, ese dato se obtiene en el laboratorio cuando la carga del ensayo alcance $\mathrm{Q}^{\prime}=6,25 \cdot 1,5 \sqrt{ }(1,5)=11,48 \mathrm{kN} / \mathrm{m}^{2}$.

Este ejemplo representa cuáles van a ser los valores de las deformaciones que se producen en una viga de un edificio a partir de la medición de las deformaciones obtenidas de la viga de tamaño reducido del laboratorio. Se ha aplicado al caso de la flecha para trabajar solo con la rigidez a flexión, pero como se desarrolla más adelante, los deslizamientos entre la vigueta y capa de compresión varían según la misma ley (para las hipótesis lineales con las que se trabaja ${ }^{12}$, y al estar el deslizamiento asociado a la rigidez de la conexión, basta con aumentar la carga del ensayo para tener la información necesaria de esa rigidez en cualquier tamaño.

En consecuencia, se podrían hacer ensayos con luces mayores a la empleada en este trabajo, pero sus resultados, en principio, están contenidos aquí, ya que las cargas alcanzadas en los ensayos son muy superiores a las necesarias para cubrir este factor de escala.

\footnotetext{
${ }^{12}$ Según lo normativa, en estos tipos de estructuras, los cálculos deberán realizarse suponiendo una relación lineal entre fuerza y deslizamiento (Eurocódigo EC-5 artículo 9.1.3 "vigas con uniones mecánicas" y CTE DB SE-M artículo 10.1.2 "Vigas mixtas unidas con medios de fijación mecánicos"
} 


\subsection{OBJETIVOS}

La tesis se centra en el estudio experimental de los refuerzos de forjados de madera mediante capa de compresión, unidas con conexión flexible. El objetivo principal consiste en revisar prácticamente todos los aspectos que pueden influir en el comportamiento de la conexión. Todo el trabajo se enfoca desde la óptica de la de rigidez, puesto que se están relacionando cargas con deformaciones, ya que es el valor más condicionante del diseño y el único que se puede obtener de una manera puramente experimental. En general no se entra a valorar cuestiones que tengan que ver con la resistencia.

Este trabajo es discreto estadísticamente, la intención no era hacer muchas probetas de pocos tipos de conexión sino pocas probetas de muchos tipos para estudiarlos de una manera no exhaustiva y detectar las diferencias básicas entre ellos.

El primer objetivo es desarrollar un modelo de cálculo que permita no solo proyectar estos refuerzos y peritarlos sino disponer de una herramienta de cálculo con la que seguir paso a paso los ensayos realizados en el laboratorio.

El segundo objetivo es comparar los resultados de los ensayos de rasante, con los que se obtiene la rigidez a deslizamiento $\left(\mathrm{K}_{\mathrm{ser}}\right)$, con los ensayos de vigas a flexión. Esto se podrá hacer gracias al modelo de cálculo, que relaciona todos los esfuerzos y deformaciones de las vigas mixtas. Efectivamente, la información sobre los deslizamientos de ambos ensayos, tanto medidos como calculados, permitirá contrastar los valores asignados a la rigidez de deslizamiento de los ensayos de rasante con los deslizamientos producidos en las vigas.

El tercer objetivo es realizar una revisión de la esbeltez del empotramiento de conector en la vigueta (madera aserrada) y en la capa de compresión (madera microlaminada) para conseguir que su trabajo de flexión y cortante sea el adecuado.

El cuarto objetivo es estudiar las diferentes variables que influyen en la conexión. Para este estudio se realizarán tanto ensayos de rasante como ensayos de flexión de vigas mixtas. Se analizarán distintos tipos de conectores (clavos, tirafondos y barra corrugada con resina y tornillos), varias esbelteces de vigas, diferentes materiales tanto de la vigueta como de la capa de compresión y varias separaciones entre los conectores. 
El quinto objetivo es analizar aspectos de las conexiones de vigas mixtas que no están contemplados en la normativa. Entre estos aspectos están:

-El pretensado de las vigas, que consiste en apretar los conectores en la construcción de las vigas para provocar una presión entre la vigueta y la capa de compresión, puede conseguir un aumento en el rozamiento, que traería como consecuencia una mejora en la rigidez de la viga.

-La ganancia de rigidez que supone colocar los conectores inclinados, cosa que no está muy desarrollada en la normativa, como muestra el hecho de quedar incluida en el CTE pero no en el EC-5.

-La última variable para estudiar en este apartado es el diseño de los tornillos. En la normativa todos los tornillos están sujetos a la misma formulación y sin embargo existen varios parámetros del diseño de los mismos que les harían funcionar de modos muy distintos, entre ellos están la forma de la cabeza y la longitud de la rosca (si tienen una parte sin rosca o no).

El sexto objetivo es detectar aspectos en los que se encuentren discrepancias entre la normativa y los ensayos. 


\subsection{ESTRUCTURA DEL DOCUMENTO}

La presente tesis se ha estructurado en nueve capítulos y cinco anejos, cuyo contenido se expone a continuación de forma sintética:

Capítulo 1 Se define el campo de trabajo que se enmarca dentro de la rehabilitación de forjados, su base experimental mediante ensayos de laboratorio, la relación entre la escala de edificación y laboratorio y los objetivos principales a alcanzar.

Capítulo 2 Se revisa la literatura existente relacionada con los sistemas de conexión de vigas mixtas de madera, centrándolo en trabajos que tengan un componente experimental importante.

Capítulo 3 Se describen todos los trabajos realizados en el laboratorio en la realización de la tesis. Incluyen los ensayos para la caracterización de los diferentes materiales empleados, los trabajos previos realizados para definir las probetas y los ensayos, los ensayos tanto de rasante como de flexión realizados para analizar el comportamiento de las distintas conexiones y el análisis de las probetas después de los ensayos.

Capítulo 4 Se exponen aquí los resultados obtenidos en los ensayos de rasante de las distintas conexiones analizadas. Se analizan los módulos de deslizamiento obtenidos en los ensayos y se comparan con los valores obtenidos en la normativa y en trabajos de otros autores.

Capítulo 5 Se incluyen los resultados de los ensayos de flexión de las vigas mixtas, analizando varios aspectos que se han considerado importantes en el funcionamiento de las conexiones.

Capítulo 6 Se desarrolla el método de cálculo creado para estudiar este tipo de estructuras.

Capítulo 7 Se superponen los resultados de los dos tipos de ensayos de rasante y de flexión.

Capítulo 8 Se enumeran las conclusiones de la investigación.

Capítulo 9 Se muestran las futuras líneas de investigación planteadas.

Por último, se incorporan diferentes anejos con información adicional relevante. Su contenido se resume a continuación: 
Anejo I Resultados de todos los ensayos de caracterización de los diferentes materiales empleados en la tesis.

Anejo II Ensayos realizados para determinar la esbeltez óptima de empotramiento del conector, tanto en madera aserrada como en madera microlaminada.

Anejo III Resultados de los ensayos de rasante.

Anejo IV Ensayos realizados para asegurar el buen funcionamiento de los ensayos finales de flexión de vigas.

Anejo V Resultados de los ensayos de flexión de vigas mixtas. 


\section{CAPÍTULO 2. - ESTADO DEL ARTE}

2.0 INTRODUCCIÓN

2.1 PRIMERAS PUBLICACIONES

2.2 TIPOS DE CONEXIONES

2.3 FÓRMULAS DEL MÓDULO DE DESLIZAMIENTO $\left(\mathrm{K}_{\mathrm{ser}}\right)$ 


\subsection{INTRODUCCIÓN}

En este capítulo se hace una revisión de la literatura existente relacionada con los sistemas de conexión de vigas mixtas, con carácter general se podría indicar que los trabajos, que se iniciaron hacia la segunda mitad del siglo XX, tienen como material de refuerzo la capa de compresión de hormigón. Se centra fundamentalmente en trabajos que tengan un componente experimental importante.

En el apartado 2.1 (Primeras publicaciones) se describen las primeras investigaciones realizadas (en los años 40 del siglo XX) sobre vigas mixtas con madera y hormigón.

El resto de trabajos de otros autores, mostrados en el apartado 2.2 (Tipos de conexiones) se ha ordenado según los tipos de conexión estudiadas, primero en dos grandes grupos (conexiones continuas y conexiones discretas) y después subdividas por tipos.

Por último, en el apartado $\mathbf{2 . 3}$ (Fórmulas del módulo de deslizamiento $\left(\mathbf{K}_{\mathbf{s e r}}\right)$ ) se enumeran los trabajos de los autores que han desarrollado en sus trabajos fórmulas empíricas para la obtención del módulo de deslizamiento de las conexiones.

En la presente tesis se ha trabajado con uniones tipo clavija. En primer lugar se ha estudiado la esbeltez óptima de empotramiento de un conector de varilla lisa en madera aserrada (8 esbelteces distintas y 4 ensayos de cada una) y en madera microlaminada (4 esbelteces y 4 ensayos cada una). Para el estudio de la esbeltez de empotramiento se han realizado 48 ensayos de rasante.

Los conectores que se han estudiado han sido clavos, tornillos, barra corrugada encolada y tirafondos (tornillos barraqueros) encolados, utilizando diámetros entre $\varnothing 4 \mathrm{~mm}$ y $\varnothing 12 \mathrm{~mm}$. Se han estudiado viguetas de madera aserrada y madera laminada; capas de compresión de hormigón y de tablero de madera microlaminada; 3 esbelteces distintas $(18,20$ y 23) y el efecto del rozamiento y del pretensado en la conexión. Para el estudio de las diferentes conexiones se han realizado 51 ensayos de rasante y 95 ensayos de flexión. 


\subsection{PRIMERAS PUBLICACIONES}

Los primeros trabajos publicados de vigas mixtas que contienen ensayos de flexión fueron realizados en EEUU por Richart y Williams en 1943 [ref. 127]. En ellos se ensayaron 32 vigas mixtas a flexión con 4 sistemas de conexión distintos (placas de acero triangulares, placas triangulares con conectores verticales, tornillos y entalladuras). Estos trabajos incluyen también los primeros ensayos de largo plazo de vigas mixtas madera-hormigón ( 2 años y medio).

También en EEUU y en 1943, se publicó el trabajo de McCullough [ref. 100] que contenía los ensayos a flexión de 22 vigas mixtas. Se emplearon cinco sistemas de conexión (Clavijas verticales, entalladuras en la madera, combinación de clavijas y entalladuras, tubos de acero y placas de acero). Los principales objetivos de estos ensayos fueron determinar la resistencia a flexión relativa y flecha relativa de las vigas mixtas en comparación con vigas de madera de las mismas dimensiones y bajo la misma carga, investigar el efecto de cargas cíclicas o alternas, investigar los efectos de los cambios térmicos y desarrollar una teoría de diseño de estructuras mixtas.

Johansen en 1949 [ref. 070] realizó un estudio teórico sobre las resistencias de conexiones con pasadores ensayadas a rasante. Este estudio lo contrastó con ensayos de rasante de diferentes piezas. Finalmente, enunció unas ecuaciones sobre la resistencia de las conexiones según su tipo de rotura. En estas ecuaciones están basadas las actuales expresiones contenidas en el Eurocódigo 5. 


\subsection{TIPOS DE CONEXIONES}

\subsubsection{CONEXIÓN CONTINUA}

\section{ADHESIVOS EPOXI}

Por lo general, este sistema consigue una conexión casi total entre la vigueta y la capa de compresión, puesto que prácticamente no hay deslizamiento entre ellas. La mayor dificultad que encuentran los distintos autores es la construcción, debido por un lado, al tiempo de fraguado de las resinas y por otro a que la humedad producida por el hormigonado in situ puede dañar las propiedades adhesivas. Se han estudiado también casos con hormigón prefabricado.

Este sistema de conexión fue estudiado por Pincus en 1970 [ref 120]. Se ensayaron a flexión 8 vigas de 3,60 m de luz. En 5 de ellas la conexión fue solo el adhesivo y en 3 se añadieron unos clavos para reforzar la conexión.
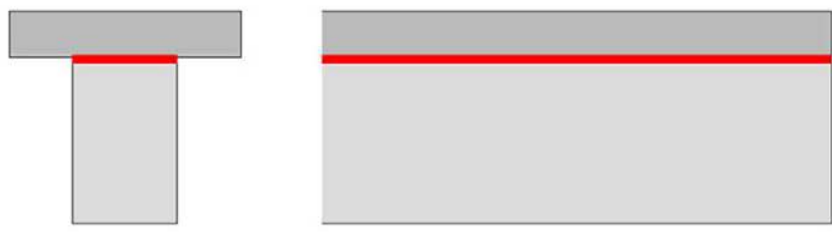

ADHESIVO EPOXI

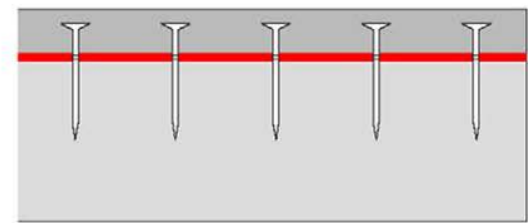

ADHESIVO EPOXI Y CLAVOS

figura 1. Pincus (1970)

Brunner y Schnüriger en 2007 [ref 032] realizaron un estudio parecido al de Pincus, ensayando a flexión 4 tipos de uniones con adhesivos epoxi ( 3 ensayos de cada tipo). La diferencia entre los tipos es el espesor tanto de la madera como del hormigón. Este trabajo incluye también 2 ensayos de flexión con el área de contacto entre la vigueta y la capa de compresión reducido. También se realizaron dos ensayos a largo plazo de estos dos últimos durante 1 año.

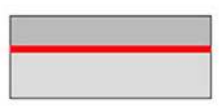

luz $5 \mathrm{~m}$
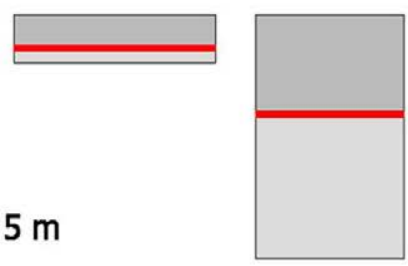

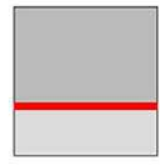

luz $8 \mathrm{~m}$
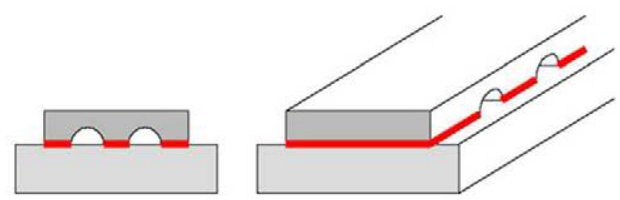

luz $5 \mathrm{~m}$

figura 2. Brunner y Schüriger (2007) 
Schäfers y Seim en 2008 [ref. 129] estudiaron conexiones con adhesivos epoxi uniendo viguetas de madera aserrada (haya), madera laminada (picea abies) y madera microlaminada con capas de compresión de hormigón de altas prestaciones (UHPC). Estudiaron 21 tipos distintos (3 ensayos por tipo) con ensayos de rasante. También realizaron 2 vigas mixtas de 3,8 m de luz, ensayándolas con carga cíclica (20 ciclos hasta el $40 \%$ de la carga estimada de rotura) y posteriormente hasta la rotura.

Negrão et al en 2010 [ref. 112] estudiaron 16 tipos de conexión con adhesivos. El objetivo principal del trabajo es comparar las diferencias entre la conexión con resinas de un hormigón prefabricado y otro realizado in situ (8 tipos de cada). El resto de variables entre los tipos son los contenidos de humedad de la madera suministrada, en el pegado y en el ensayo, el espesor de la capa de adhesivo y la rugosidad de la interfase. De cada tipo se realizaron 20 ensayos de rasante. Posteriormente se ensayaron a flexión 29 vigas de 4,5 m de luz.

\section{CONEXIÓN CONTINUA METÁLICA ADHERIDA CON RESINA}

Piazza y Ballerini en 2000 [ref. 119] realizaron ensayos de rasante y de flexión de vigas mixtas de $6 \mathrm{~m}$ de luz, con 8 tipos de conexiones distintas. Entre ellas, se estudió una conexión que consiste en realizar una acanaladura en la vigueta de madera e introducir un palastro metálico continuo de $2 \mathrm{~mm}$ de espesor adherido a la vigueta con resina. La rotura se producía debido al esfuerzo rasante en la zona de madera cercana a la superficie adherida con una flecha de $70 \mathrm{~mm}$ (L/86).
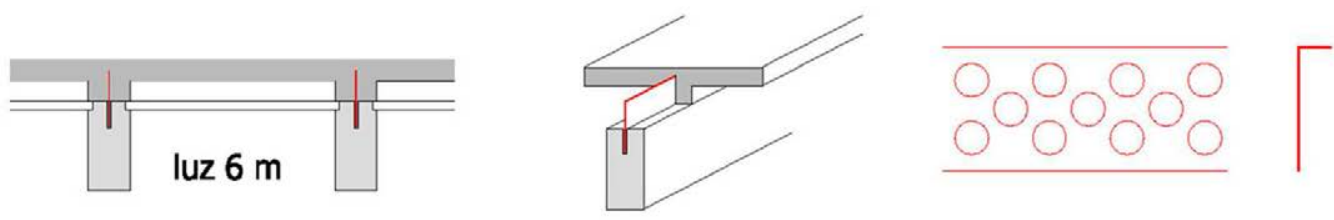

figura 3. Piazza y Barrerini (2000)

Bathon y Graff en 2002 [ref. 025] estudian una conexión parecida a la anterior, pero en lugar de un palastro, se introduce una malla metálica. Se realizaron 60 ensayos de rasante y 2 de flexión con vigas de 5,40 m de luz. La vigas rompieron con una flecha de 42 mm (L/128).

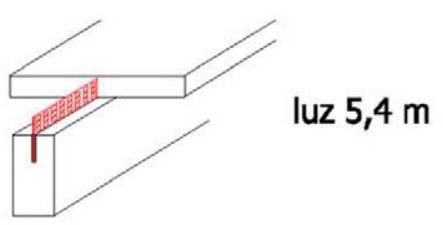

figura 4. Bathon y Graff (2002) 
Clouston en el mismo año [ref. 039] realizó un estudio con la misma conexión. Hizo 6 ensayos de rasante y 1 de flexión a una viga con $10 \mathrm{~m}$ de luz. Obtuvo un módulo de deslizamiento $\left(\mathrm{K}_{\mathrm{ser}}\right)$ de $21,35 \mathrm{kN} / \mathrm{mm}$.

Lukaszewska en su tesis doctoral en 2009 [ref. 093] estudió entre otras conexiones la de una malla continua introducida en la vigueta a través de una acanaladura y adherida con resina epoxi. Realizó 4 ensayos de rasante de esta conexión.

\section{CONEXIÓN CONTINUA METÁLICA CON UNIONES MECÁNICAS}

En el trabajo de Piazza y Ballerini de 2000 comentado anteriormente [ref. 119] se estudió también una conexión formada por un chapa ondulada continua (de $2 \mathrm{~mm}$ de espesor) unida a la vigueta de forma discreta mediante tornillos ( $\varnothing 6$ cada $20 \mathrm{~mm}$ ). Se realizaron ensayos de rasante y de flexión de vigas de $6 \mathrm{~m}$ de luz. Este sistema está comercializado con el nombre de "LPR" por la empresa Peter Cox.
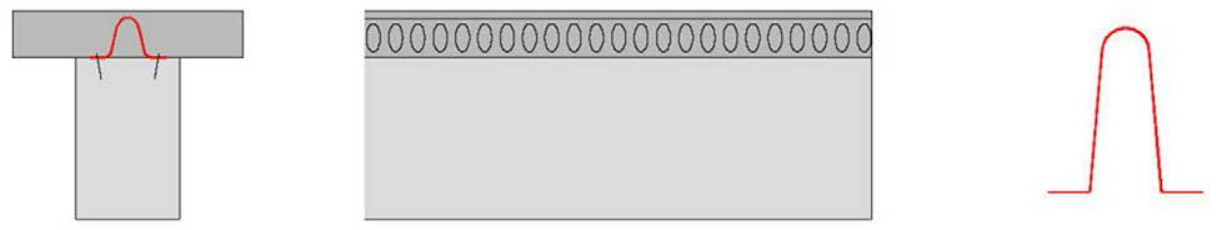

figura 5. Piazza y Ballerini (2000) 


\subsubsection{CONEXIÓN DISCRETA}

\section{CONECTORES TIPO CLAVIJA CON PRETALADRO Y RESINA}

En este apartado se estudian las uniones realizadas con pretaladro relleno con resina para encolar el conector con la madera de la vigueta. Según los estudios, los forjados mixtos unidos de esta forma son menos sensibles (que las clavijas sin resina) a los ciclos de carga/descarga.

Otra de las conexiones estudiadas por Piazza y Ballerini en 2000 [ref. 119] es la realizada con barra de acero doblada encolada. Los conectores son de $\varnothing 16$ y los taladros realizados son de $\varnothing 18$. Entre ellos se inyecta resina. El comportamiento de estos conectores se caracterizó por una respuesta lineal hasta aproximadamente el $50 \%$ de la carga de rotura, seguido de una zona con ganancia de rigidez debida sobre todo al comportamiento no lineal de las conexiones.

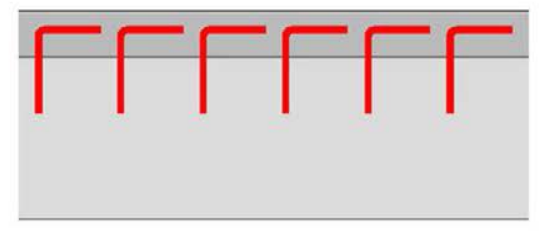

conectador $\varnothing 16$

taladro $\varnothing 18$ con resina

luz $6 \mathrm{~m}$

figura 6. Piazza y Ballerini (2000)

En la Universidad de Helsinki, Makipuro et al en 1996 [ref. 094] estudian distintos tipo de conexión. Entre las que pertenecen a este grupo se encuentran 3 tipos: uno de ellos con barras inclinadas cruzadas y los otros dos con barras verticales ( $\varnothing 16$ y $\varnothing 30 \mathrm{~mm}$. En estos dos tipos la capa de compresión está fabricada con tablero de madera, no con hormigón). Se realizan 8 ensayos de. El trabajo incluye también los ensayos a flexión de 2 vigas.

Dentro del mismo grupo de trabajo de la Universidad de Helsinki, Jutila y Salokangas en 2000 [ref. 076] presentaron trabajos de ensayos de rasante cíclicos de estos mismos tipos de conexión.
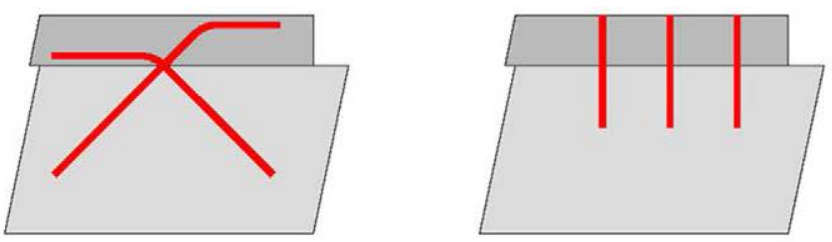

figura 7. Makipuro et al (1996)

Amadio et al en 2000 [ref. 003] realizaron un ensayo de flexión de una viga mixta de 5,70 $\mathrm{m}$ de luz conectada con barras encoladas verticales. Para estudiar el comportamiento de la conexión a largo plazo la viga permaneció cargada durante 5 años. 


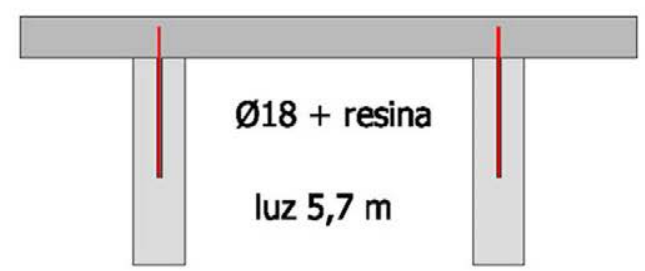

figura 8. Amadio et al (2000)

En Argentina, Astori en 2000 [ref. 017] estudió también una conexión con barra encolada inclinada simple, y anclada en el hormigón. Se realizaron 10 ensayos de rasante.

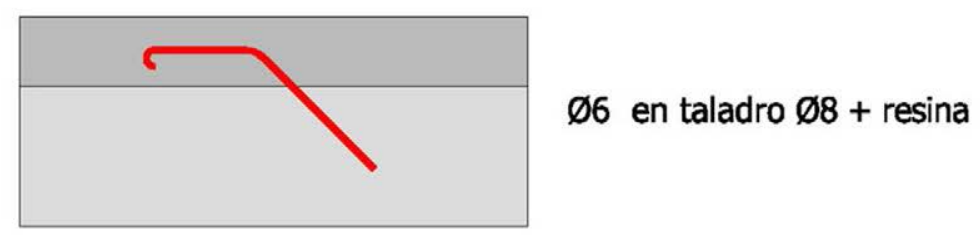

figura 9. Astori (2000)

Pires Carvalho, en su tesis de 2008 [ref. 2008], estudió conexiones con barras encoladas y dobladas con forma de gancho, usando 3 diámetros distintos $(\varnothing 8, \varnothing 10$ y $\varnothing 12,5)$. Con cada diámetro de conectores realizó 3 configuraciones distintas para los ensayos de rasante, y de cada una de estas ensayó 4 probetas (un total de 36 ensayos de rasante). También ensayó 7 vigas mixtas a flexión con luces entre 2 y $2,30 \mathrm{~m}$.
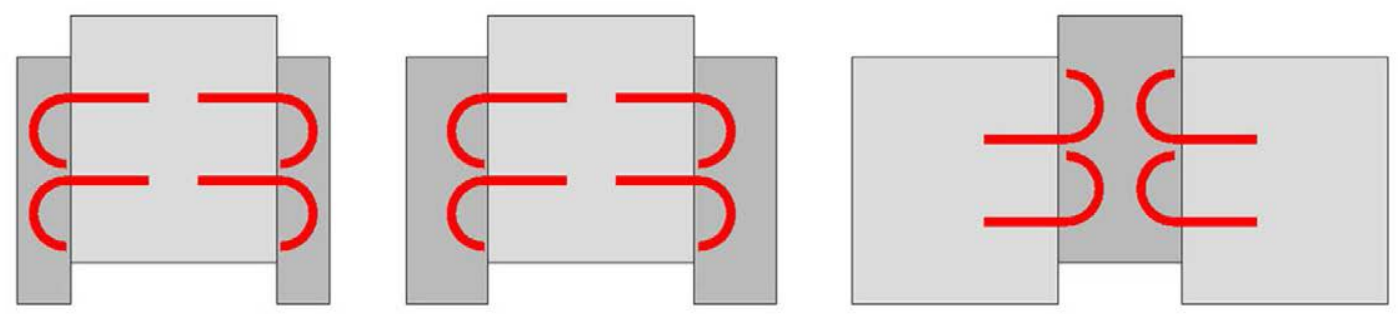

figura 10. Pires Carvalho (2008)

Ceccotti et al en 2006 [ref. 036] ensayaron conexiones de barra corrugada encolada de $\varnothing 18 \mathrm{~mm}$ colocada verticalmente. La separación entre los conectores variaba a lo largo la viga, desde $150 \mathrm{~mm}$ en los extremos hasta 300 y $450 \mathrm{~mm}$ en el centro. Se realizó un ensayo hasta rotura de dos vigas de 5,70 $\mathrm{m}$ de luz y posteriormente se realizaron ensayos de rasante con segmentos cortados del extremo de una de las vigas, con los que se obtuvo un $\mathrm{K}_{\mathrm{ser}}$ de $25 \mathrm{kN} / \mathrm{mm}$. 


\section{CONECTORES TIPO CLAVIJA SIN RESINA}

\section{CLAVOS}

Unnikrishna en 1977 [ref. 144] utilizó clavos de $\varnothing 3$ y $\varnothing 5$ mm. Realizó 28 ensayos de rasante. Los clavos fueron colocados tanto perpendiculares como inclinados. Las fuerzas rasantes alcanzadas por conector fueron notablemente superiores en los clavos perpendiculares que en los inclinados. Estos valores no sorprenden si se tiene en cuenta que los clavos se colocaron inclinados en el sentido contrario al deslizamiento.

Amadi y Saka en 1993 [ref. 001] trabajaron también con clavos colocados verticalmente. Hicieron ensayos de rasante con 7 tipos distintos de clavos introducidos en la madera a tres profundidades distintas $(8 \varnothing, 11 \varnothing$ y $\varnothing 15)$ para comprobar la esbeltez correcta del empotramiento. Su conclusión fue que a partir de $11 \varnothing$ de empotramiento no existen mejoras de la conexión. Después hicieron una serie de ensayos de flexión de forjados mixtos de madera-hormigón de 3,7 $\mathrm{m}$ de luz. Se ensayaron dos sistemas de forjado con las mismas dimensiones: el primero sin conexión y el segundo con clavos verticales, usando 3 tipos de clavos. Los resultados dieron valores de carga de rotura dos veces superiores con conexión que sin conexión.

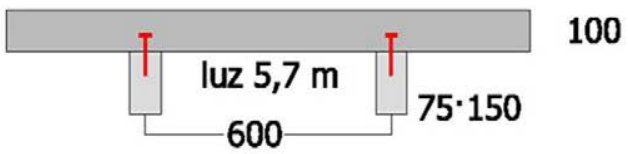

figura 11. Amadi y Saka (1993)

Posteriormente, con los 2 tipos de clavos que mejor había funcionado, se hicieron más ensayos de flexión, estudiando dos espesores distintos de la capa de compresión y haciendo ensayos cíclicos (100 repeticiones de carga, aumentando progresivamente la carga) y ensayos a largo plazo (4 meses).

Norlin, en su tesis doctoral de 1993 [ref. 115] realizó un estudio de conexión de vigas mixtas de madera/madera unidas con clavos. Dado el espesor de las piezas, realizó un taladro previo para que el clavo se empotrara la misma longitud en ambas. Hizo 4 ensayos de rasante, 5 de vigas a flexión y 6 ensayos sometiendo a la viga a flexión y a axil simultáneamente.
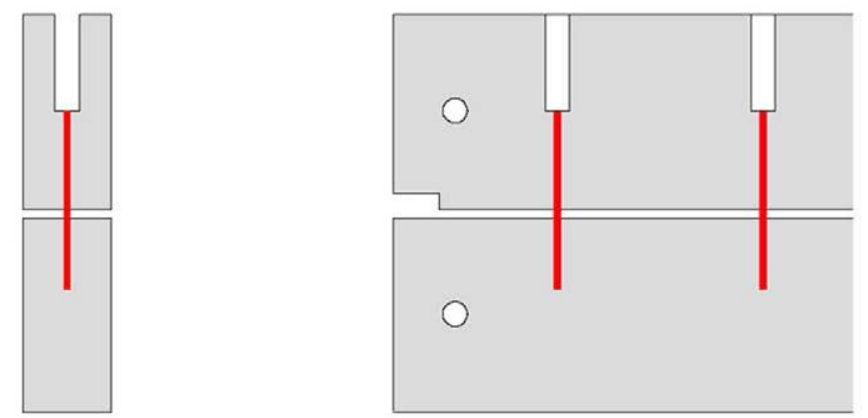

luz $3 \mathrm{~m}$

figura 12. Norlin (1993) 
Aicher en 2000 [ref. 002] también realizó ensayos de algún tipo de clavo colocado perpendicularmente.

Branco en su tesis doctoral en 2003 [ref. 030] hizo 76 ensayos de rasante para analizar el comportamiento de uniones con clavos. Sus ensayos incluían uniones entre madera-madera y entre madera-hormigón. Estudió 4 conexiones distintas con clavos, tanto en un material como en otro: 3 con clavos de sección circular $\left(a 0^{\circ}, 45^{\circ}\right.$ y 1350) y 1 con clavos cuadrados a 900; Realizando 10 ensayos de cada de estas configuraciones. En general obtuvo valores de $\mathrm{K}_{\text {ser }}$ muy inferiores a lo que marca el Eurocódigo 5.
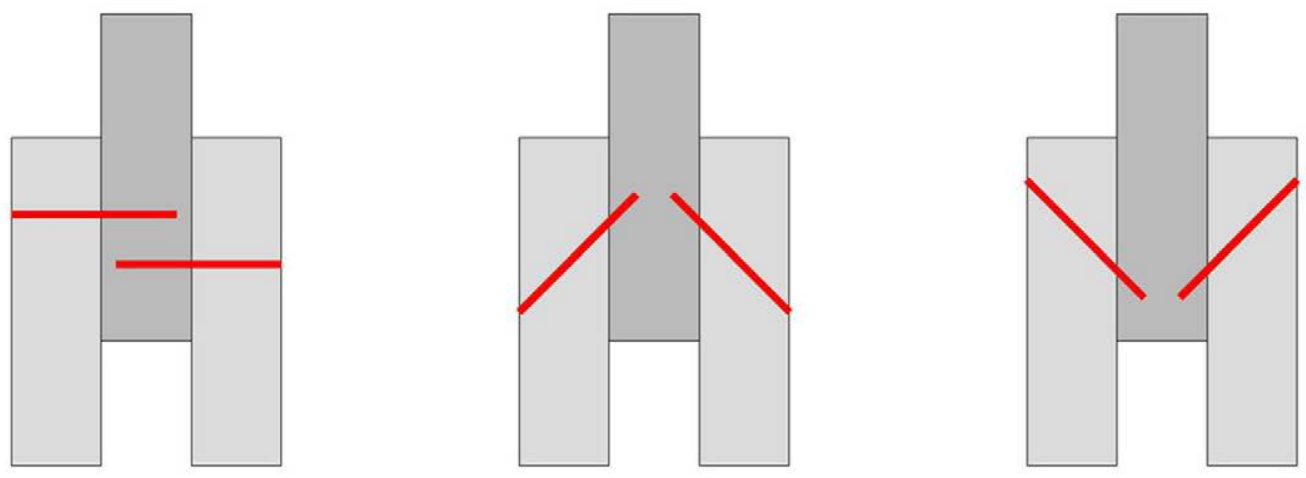

figura 13. Branco (2003)

Lopes et al en 2004 [ref. 091] realizaron ensayos con clavos para analizar las diferencias entre la conexión de madera y hormigón cuando ambas están en contacto directo y cuando existe una capa intermedia entre ambas. Realizaron 3 ensayos de flexión de cada tipo, utilizando forjados mixtos de $4 \mathrm{~m}$ de luz, conectado viguetas y capa de compresión con clavos de $\varnothing 6 \mathrm{~mm}$ y pretaladro de $\varnothing 4,5$, introducidos en la madera $10 \varnothing$.
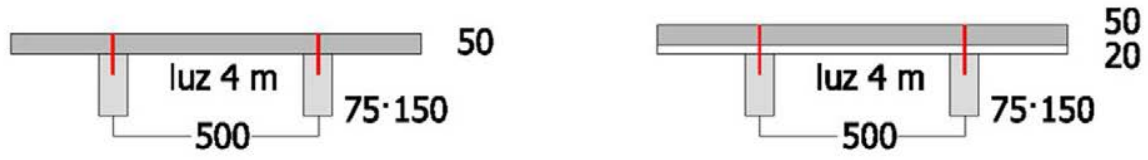

figura 14. Lopes et al (2004)

Mascia y Soriano en 2004 [ref. 099] realizaron un estudio de diferentes conexiones entre madera y hormigón. Entre estas conexiones estaban los clavos. Hicieron 1 ensayo de rasante y 1 de flexión de un forjado de 2,80 m de luz con los que obtuvieron un $\mathrm{K}_{\text {ser }}$ de 6,01 kN/mm.
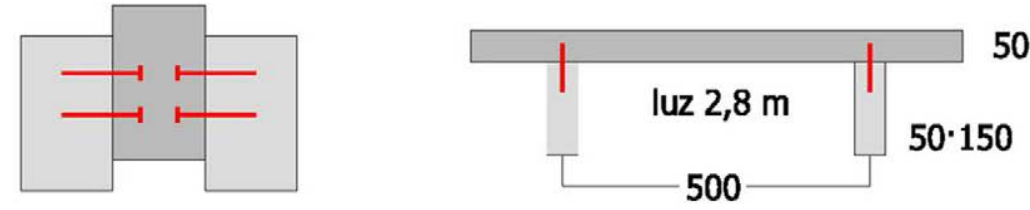

figura 15. Mascia y Soriano (2004) 


\section{$\underline{\text { TORNILLOS }}$}

Meierhofer en 1993 [ref. 101] estudió el sistema RF 2000, que era uno de los primeros tipos de conectores de acero especiales para la unión de madera y hormigón (Tornillo SFS, VB-48$7,5 \times 100 \mathrm{~mm}$ ). El conector tiene dos cabezas para controlar la entrada del tornillos en la vigueta.

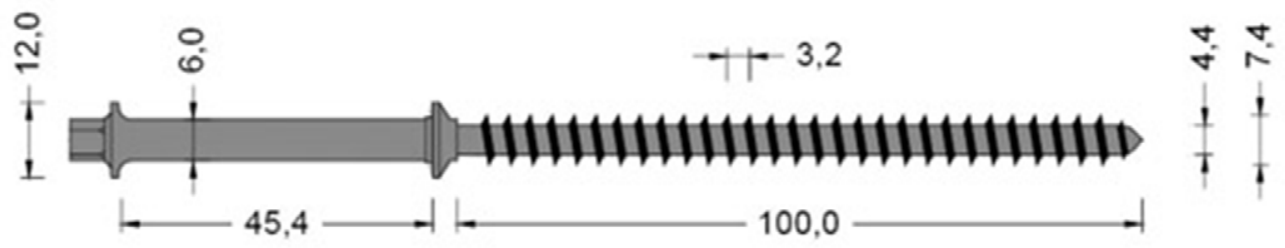

figura 16. Conector SFS

El trabajo incluye ensayos de extracción, de rasante y 12 de flexión a corto y largo plazo. Estudió 5 configuraciones distintas de la conexión, variando la inclinación de los conectores. La conexión más rígida resultó ser la configuración con la pareja de conectores inclinados "d" y la menos rígida la de conectores verticales "a".
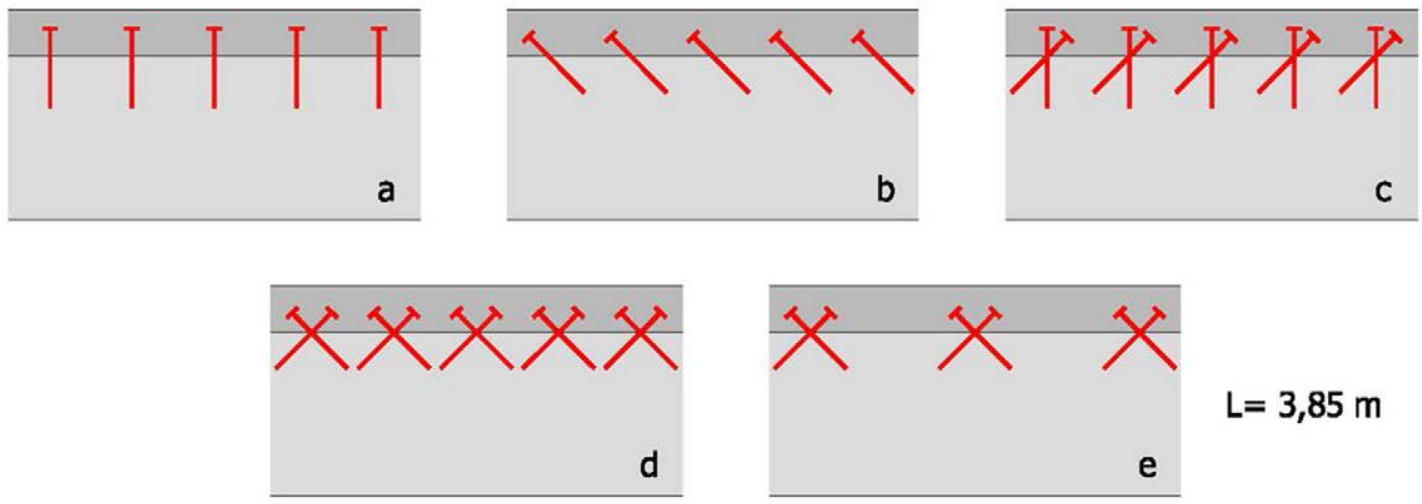

$$
\mathrm{L}=3,85 \mathrm{~m}
$$

figura 17. Meierhofer (1993)

Otros investigadores estudiaron este tipo de conector, entre ellos están Blass et al [ref. 027], Van der Linden [ref. 145], Steinberg et al [ref. 131], Frangi y Fontana [ref. 062], Dias [ref. 045 y 046], Deam et al [ref. 042], Faust y Selle [ref. 049] y Jorge [ref. 071].

Van der Linden en su tesis doctoral de 1999 [ref. 145] realizó un total de 51 ensayos a rasante con este conector, incluyendo parejas de tornillos inclinados a $45^{\circ} \mathrm{con}$ vigueta de madera aserrada y laminada y con y sin separación entre vigueta y capa de compresión. También realizó 10 ensayos a flexión con vigas mixtas de luz 5,40 m.

Steinberg en 2003 [ref. 131], empleando este y otros conectores, hizo ensayos empleando hormigón ligero en la capa de compresión.

Faust y Selle obtuvieron un $\mathrm{K}_{\text {ser }}$ (según la Norma UNE 26891) de 20,14 kN/mm para los conectores inclinados y de $16,54 \mathrm{kN} / \mathrm{mm}$ para los conectores verticales. 
Jorge et al en 2005 [ref. 073] también estudiaron este conector, haciendo 40 ensayos de rasante y 6 ensayos de flexión.

Gelfi y Giuriani en 1999 [ref. 063] estudiaron la conexión con barra de acero sin utilizar resina. Realizaron un pretaladro ligeramente inferior a las barras las introdujeron con un martillo. Analizaron 2 tipos de conexión, con y sin contacto directo entre madera y hormigón. Ensayaron a rasante 6 probetas de cada tipo y a flexión 1 viga de cada, de $4 \mathrm{~m}$ de luz.
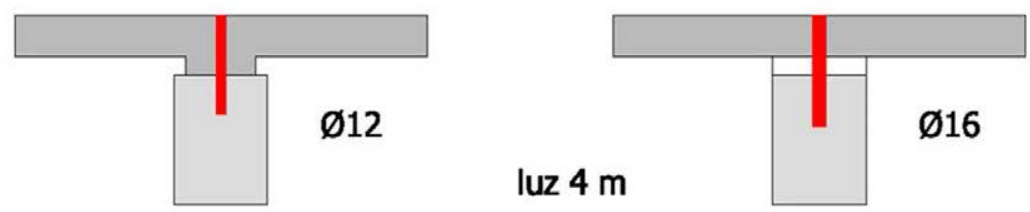

figura 18. Gelfi y Giuriani (1999)

Otras de las conexiones estudiadas por Piazza y Ballerini en 2000 [ref. 119] en su trabajo anteriormente comentado están en este grupo. Una de ellas realizada con tornillos de $\emptyset 16 \mathrm{~mm}$ colocados a una distancia constante de $200 \mathrm{~mm}$ y la otra compuesta por barras lisas de $\varnothing 16 \mathrm{~mm}$ colocados sin resina y con una inclinación de $45^{\circ}$.

Lehmann et al en 2001 [ref. 090] estudiaron dos conexiones con barras lisas inclinadas $5^{\circ}$ respecto a la vertical (en el sentido del rasante). Una con un resalto en la madera formado por un tablero pegado a la vigueta (en sentido longitudinal) y otra sin resalto. Realizaron 10 ensayos de rasante de cado tipo y 5 ensayos de flexión de vigas mixtas con luces de 4,8 m.
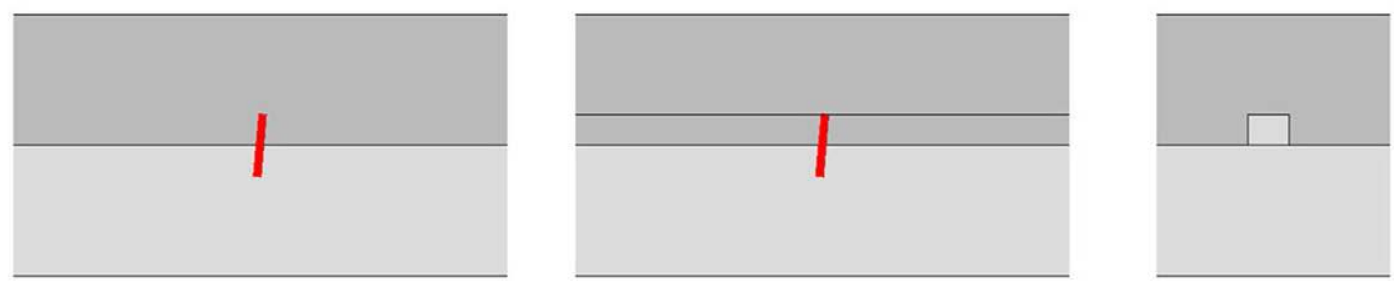

figura 19. Lehmann et al (2001)

Mascia y Soriano en 2004 [ref. 099] además de los clavos ya comentados antes, estudiaron dos tipos de tornillos. Hicieron 1 ensayo de rasante y 1 de flexión de un forjado de 2,80 m de luz con cada tipo.

Dias en su tesis doctoral en 2005 [ref. 044] realizó un total de 147 ensayos de rasante estudiando 7 tipos de conexiones, con varios tipos de madera en la vigueta y de hormigón en la capa de compresión y varios tipos de conector tipo clavija.

Kavaliuskas et al en 2007 [ref. 078] estudiaron la conexión con tornillos inclinados $45^{\circ}$. Formularon unas ecuaciones de resistencia basándose en las de Johansen. Para contrastarlas realizaron ensayos de rasante de 6 probetas. 
Relea et al en 2008 [ref. 126] estudiaron la conexión entre madera y hormigón con tirafondos (DIN 571). Se ensayaron a rasante un total de 36 probetas.

Cárdenas et al en 2010 [ref. 034] estudiaron las conexiones entre madera laminada y hormigón para puentes, con tirafondos colocados a $90^{\circ}$ y a $45^{\circ}$. Realizaron 6 ensayos de rasante.

\section{CONECTORES ESPECIALES}

Son varios los autores que han publicado trabajos para estudiar el comportamiento del conector "Tecnaria". Entre ellos se encuentran Branco [ref. 030], Steinberg et al [ref. 131] y Fragiacomo et al [ref. 060].

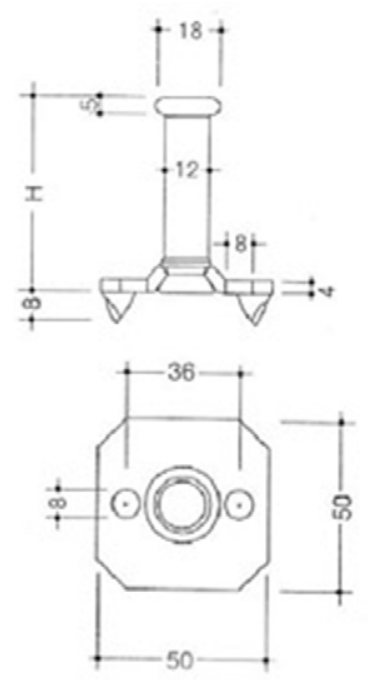

figura 20. Conector Tecnaria

Branco realizó tres ensayos de rasante utilizando este conector con hormigón ligero.

En el trabajo de Steinberg et al se realizaron 4 ensayos de rasante, el primero llevado a rotura y los otros 3 para realizar el ensayo según la Norma EN 26891.

El trabajo de Fragiacomo et al fue más exhaustivo. Realizaron 18 ensayos de rasante con este conector, con dos tipos de hormigón distintos. 6 de los ensayos se llevaron a rotura a corto plazo ( 3 con cada tipo de hormigón) y 12 se ensayaron a largo plazo con ensayos cíclicos (6 con cada tipo).

Bou Said en su tesis doctoral de 2003 [ref. 028] estudió el funcionamiento de un conector de la marca Hilti (HIT-RE500). Este conector tiene una parte cilíndrica que se introduce en la 
madera y se pega con resina y una parte cónica que asegura el reparto de esfuerzos en el hormigón. Realizó 3 ensayos de rasante y un ensayo de flexión de un forjado de 8 m de luz.
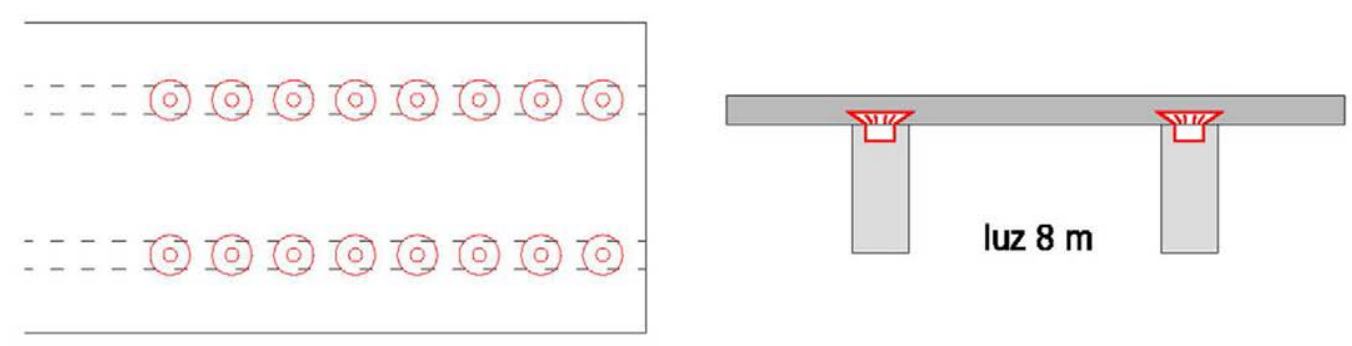

figura 21. Bou Said (2003)

Benitez en 2000 [ref. 026] ensayó 3 conexiones distintas, una barra lisa de $\varnothing 20 \mathrm{~mm}$ colocada con una inclinación de $60^{\circ}$, una sección circular hueca introducida en una entalladura en la madera del mismo diámetro y con un tornillo, y una sección de un perfil metálico unido a la madera con tornillos. Realizó en primer lugar 3 ensayos de rasante de cada tipo, y posteriormente, descartando la barra lisa (mucho menos rígida que los otros dos) realizó 14 ensayos adicionales de rasante, 6 con carga estática y 8 con carga dinámica (100.000 ciclos). El $\mathrm{K}_{\mathrm{ser}}$ obtenido en el perfil "I" fue de $204,5 \mathrm{kN} / \mathrm{mm}$ y en el tubo circular de $115,5 \mathrm{kN} / \mathrm{mm}$.

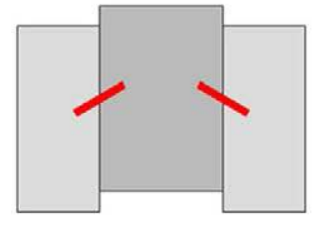

pasador $60^{\circ} \varnothing 20$

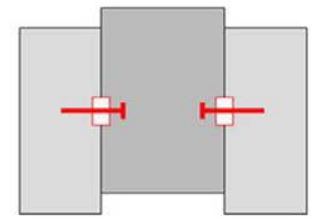

tubo hueco circular tornillo Ø16

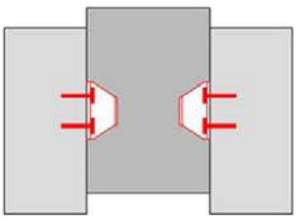

perfil "I" tornillos $\varnothing 16$

figura 22. Benitez (2000)

Simon, A en su tesis de 2008 [ref. 130] estudió una conexión que consistía en pernos soldados a una placa metálica. Para construir la conexión realizó una entalladura en la vigueta de madera. Estudió 4 configuraciones de conector, variando diámetros, número de pernos y espesores de chapa. Hizo 27 ensayos de rasante de las distintas configuraciones y 11 ensayos de flexión de vigas con luces entre 5 y 15 m y estudiando conexiones con y sin separación entre vigueta y capa de compresión.
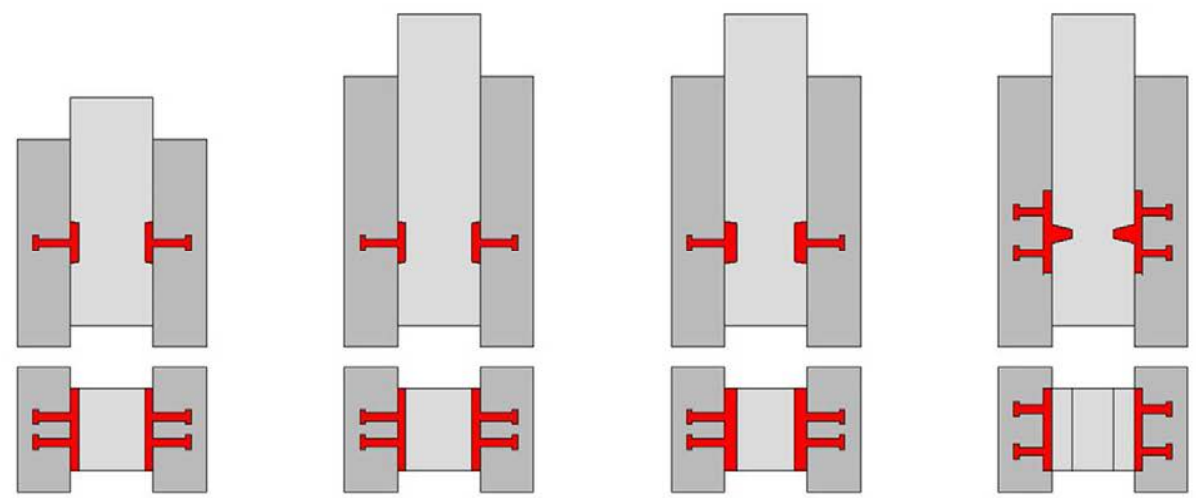

figura 23. Simon (2008) 
Fernández Cabo et al en 2010 [ref. 050] estudiaron el comportamiento del conector HSB (Habitat System Beton). Realizaron 8 ensayos de rasante.
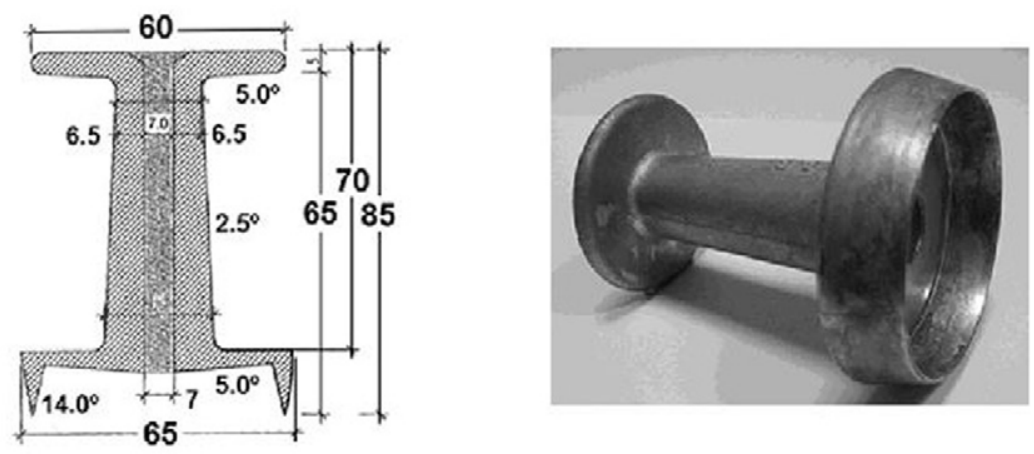

figura 24. Conector HSB

Lukaszewska en su tesis doctoral de 2009 [ref. 093] comentada anteriormente, también estudió una serie de conectores que se puede considerar que están dentro de este grupo. Estos conectores están construidos con tubos y placas metálicos combinados con tornillos. De cada tipo hizo 4 ensayos de rasante. Además, de los tipos "a" y "f" ensayó a flexión 5 vigas de luz 4,8 m. Incluyendo 2 ensayos dinámicos y 2 a largo plazo.

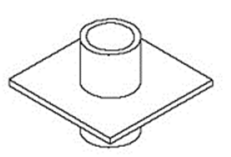

a

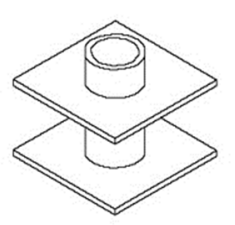

b
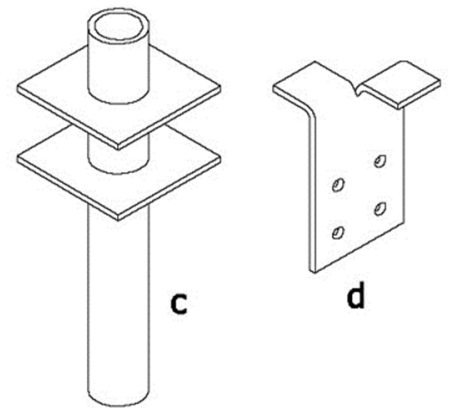

d

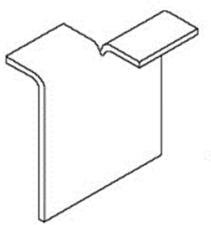

$\mathrm{e}$

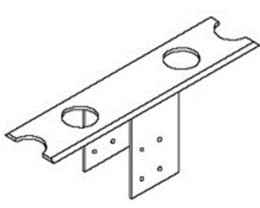

f

figura 25. Lukaszewska (2009)

\section{PLACAS CLAVADAS}

Las primeras investigaciones con este sistema de conexión las realizó Girhammar en 1984 [ref. 065], que ensayó 50 probetas a rasante. En general, se llegó a la conclusión de que las placas tenían unas deformaciones excesivas a cortante.

Este tipo de conexión también la estudiaron Van der Linden [ref. 145], Aicher [ref. 002] y Jorge [ref. 071].
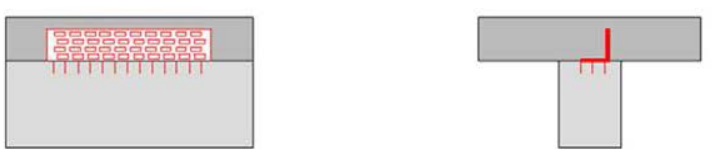

figura 26. Van der Linden (1999) 
Yeoh en su tesis doctoral en 2010 [ref. 149] estudió un sistema para realizar forjados mixtos prefabricados. Para ello, entre otras conexiones entre madera y hormigón empleó 3 tipos de placas dentadas longitudinales. Realizó 6 ensayos de rasante y un ensayo a flexión de dos forjados con $8 \mathrm{~m}$ de luz, uno llevado a rotura, y otro ensayado a largo plazo (1 año). La vigueta es de madera microlaminada y está formada por dos piezas, así se puede clavar la placa a ambas.
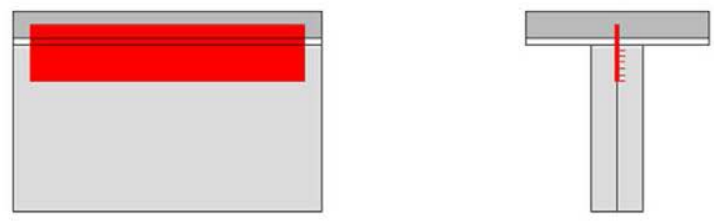

luz $8 \mathrm{~m}$

figura 27. Yeoh (2010)

En la tesis doctoral de Lukaszewska [ref. 093] también se analizó un sistema de conexión utilizando placas dentadas clavadas en la madera. Realizó 4 ensayos de rasante de esta conexión.

\section{ENTALLADURAS CON Y SIN CLAVIJA}

Entre los tipos de conexiones estudiados por Piazza y Ballerini en 2000 [ref. 119] uno se encuentra en este grupo. Emplearon barras de acero corrugado rectas de $\varnothing 16$ con un pretaladro de $\emptyset 18$ y resina, que quedaban en el centro de una entalladura de $\varnothing 65 \mathrm{~mm}$.

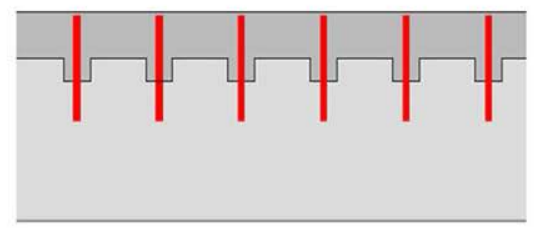

entalladura Ø65 en vigueta

conectador $\varnothing 16$

taladro Ø18 con resina

luz $6 \mathrm{~m}$

figura 28. Piazza y Ballerini (2000)

En la Universidad de Helsinki, Makipuro et al en 1996 [ref. 094] estudiaron distintas conexiones entre madera y hormigón. Entre las que pertenecen a este grupo se encuentran los siguientes tipos: entalladura sin conector, barra inclinada con entalladura en la vigueta y dos barras inclinadas cruzadas con entalladura. Realizaron 12 ensayos de rasante de estos tipos. El trabajo incluía también los ensayos a flexión de 4 vigas con los dos primeros tipos de conexión.

Dentro del mismo grupo de trabajo de la Universidad de Helsinki, Jutila y Salokangas en 2000 [ref. 076] y Tommola et al [ref. 141] presentaron trabajos de ensayos de rasante cíclicos de estos mismos tipos de conexiones. 

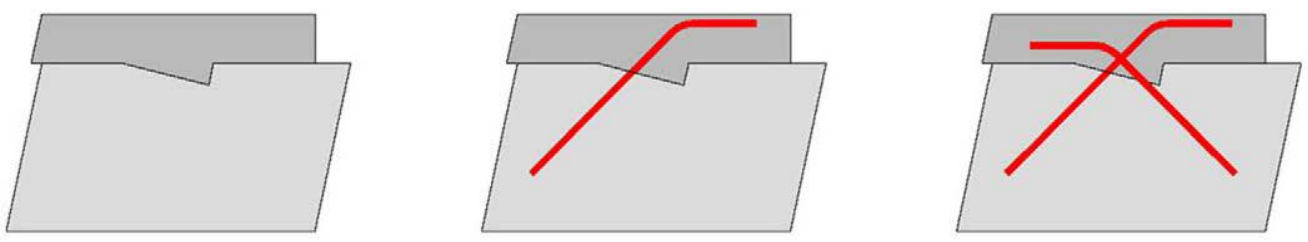

figura 29. Tommola et al (1999)

Ytrupp en 2002 [ref. 150] estudió conexiones entre madera y hormigón con pequeñas entalladuras en las viguetas de madera. Para hacer este estudio realizó ensayos de flexión utilizando madera laminada y microlaminada. Realizó ensayos con y sin entalladura para comprobar el funcionamiento de la conexión. Estas pequeñas entalladuras proporcionan una transferencia eficaz del rasante.

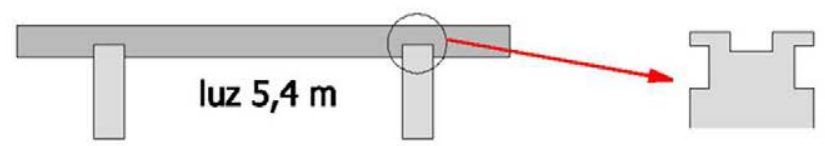

figura 30. Ytrupp (2002)

Dias en su tesis doctoral en 2005 [ref. 044] estudió 3 tipos de uniones con entalladuras, realizando un total de 41 ensayos de rasante. Para crear los resaltos en la madera, en vez de entallar la vigueta, pega con resina trozos de madera sobre la vigueta.

En la tesis doctoral de Yeoh [ref. 149] también se analizó el comportamiento de diferentes tipos de uniones con entalladura. Ensayó 12 tipos distintos, de diferentes formas, tamaños y con y sin clavija adicional. Realizó 24 ensayos de rasante, 12 ensayos a flexión de forjados con 8 y $10 \mathrm{~m}$ de luz, hasta rotura, y dos ensayados a largo plazo (1 año).
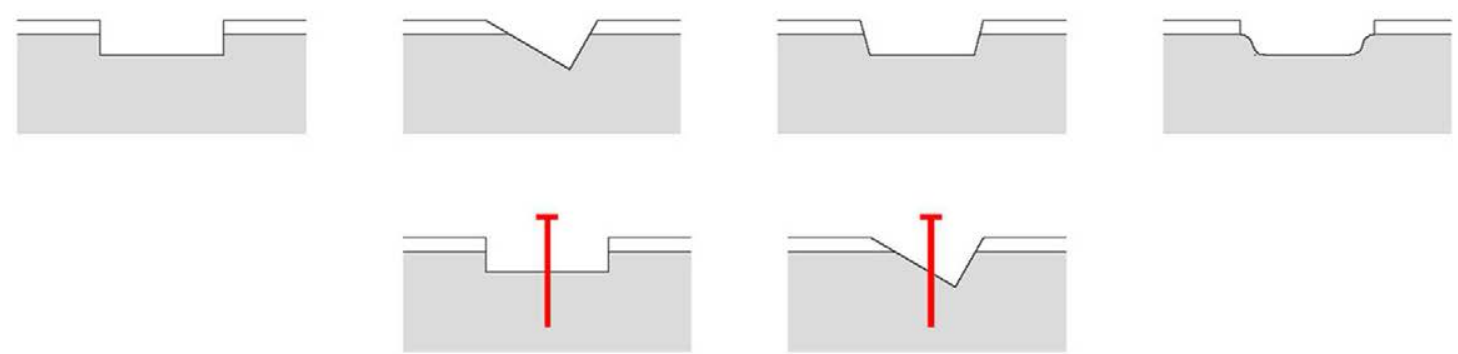

figura 31. Yeoh (2010)

Van der Linden [ref. 145] estudió varios tipos de uniones con entalladura. El primero de ellos, con vigueta de madera laminada y entalladura cilíndrica de $\varnothing 50 \mathrm{~mm}$ con un conector adicional de barra encolada de $\emptyset 16$. El segundo tipo es similar al primero pero realizado con vigueta de madera aserrada, entalladura de $\varnothing 70 \mathrm{~mm}$ y barra encolada de $\varnothing 20 \mathrm{~mm}$. De estos tipos realizó 51 ensayos de rasante y 10 ensayos de flexión de vigas de 5,4 m de luz. Estudió también otro tipo con madera microlaminada de espesor $27 \mathrm{~mm}$ y capa de compresión de hormigón de 
espesor $70 \mathrm{~mm}$ y conexión realizada mediante entalladuras de $\varnothing 115 \mathrm{~mm}$ y sin conector adicional. De este tipo realizó 71 ensayos de rasante y 10 ensayos de vigas mixtas de 4,5 m de luz a flexión.

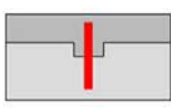

luz $5,4 \mathrm{~m}$

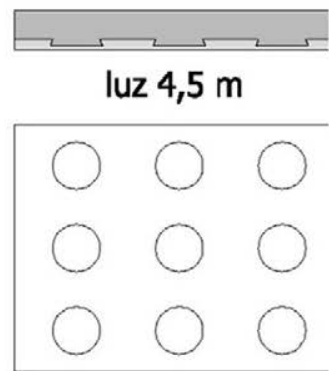

figura 32. Van der Linden (1999)

Deam et al en 2007 [ref. 042] estudiaron diferentes sistemas de conexión entre madera microlaminada y hormigón, entre ellas, cuatro tipos con entalladuras en la madera. El primero formado por una entalladura cilíndrica de $\varnothing 48,5 \mathrm{~mm}$ y $20 \mathrm{~mm}$ de profundidad, el segundo y el tercer tipo con la misma entalladura, una con un tornillo adicional de $\varnothing 12 \mathrm{~mm}$, y otra con un tubo de $\varnothing 48,5$ y de longitud $40 \mathrm{~mm}$. El cuarto tipo de conexión tenía una entalladura rectangular de 50 $\mathrm{mm}$ de longitud y profundidad $20 \mathrm{~mm}$ con un tornillo de $\varnothing 12 \mathrm{~mm}$. Realizaron 2 ensayos de rasante de cada tipo.

\section{CONECTORES POSTENSADOS}

El interés en las estructuras mixtas de madera y hormigón aumentó en muchos países en los años 80 y 90, cuando se prestó especial atención a su posible uso en edificios de varios pisos y públicos. Los trabajos más importantes para este desarrollo fueron los de Natterer en 1996 y 1999 [ref. 107 y 108], que propuso un sistema en el que las viguetas de madera eran tablas clavadas entre sí, dando como resultado una superficie plana. Las viguetas y la capa de compresión estaban unidas por un sistema de entalladuras en la madera y por unas clavijas postensadas después del curado del hormigón. La ventaja de este postensado es que el espacio causado por la retracción del hormigón se minimiza. El grado de conexión resultó ser del 85-90\%.
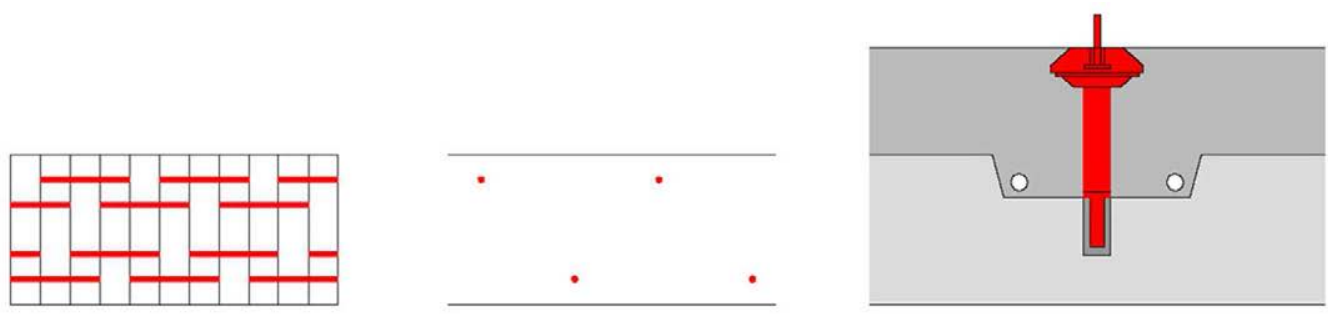

figura 33. Natterer (1996) 
Capozzucca en 1998 [ref. 033] desarrolló el sistema propuesto por Natterer, pero sin ninguna entalladura en la madera. El sistema rediseñado se basaba en el uso de conectores axiales de acero pretensado, utilizando arandelas para aplicar una presión entre vigueta y capa de compresión y mejorar así la rigidez de la conexión. Ensayó 3 vigas mixtas de $4 \mathrm{~m}$ de luz a flexión. Utilizando esta técnica, la rigidez inicial aumentó considerablemente al no hacer entalladuras en la madera, pudiéndose considerar el sistema con conexión total y eliminando así los numerosos problemas relacionados con el análisis de la flexibilidad del conector. Consideró de fundamental importancia evaluar las pérdidas de la conexión debido a los ciclos, los cambios de humedad y de temperatura. Las pérdidas de tensión después de 3 meses estuvieron entre el 6 y el 10\%.

Gutkowski et al en 2007 [ref. 067] presentaron un sistema de conexión comparable al desarrollado por Natterer. Ensayaron conexiones con entalladura, con dos conectores adicionales (conector Hilti y perno). Estudiaron dos tipos de resina para anclar el conector en la madera y tres tipos de entalladuras distintas. Ensayaron a rasante 120 probetas y a flexión 20 vigas de 3,5 m de luz.

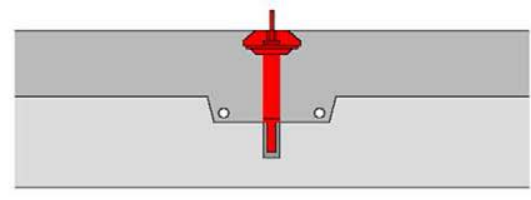

figura 34. Gutkowski. Conector Hilti (2007)

Esta conexión con entalladura y conector Hilti fue estudiada también por Balogh et al en 2008 [ref. 022]. Realizaron 12 ensayos de flexión con cargas cíclicas ( 21.600 ciclos) y 4 ensayos a largo plazo (185 días). Posteriormente ensayó todas las vigas hasta rotura.

Kuhlmann et al [ref. 083, 084 y 086] estudiaron unas conexiones con entalladura con y sin tornillo. Los tornillos de $\varnothing 12 \mathrm{~mm}$ podían ser apretados después del endurecimiento del hormigón. Hicieron 30 ensayos de rasante con diferentes tipos y diámetros de tornillos y sin ellos, con diferentes geometrías de las entalladuras y con dos tipos de hormigón. También hicieron 3 ensayos de rasante a largo plazo, 1 sin tornillo y 2 con tornillo. Por último ensayaron a flexión 3 vigas mixtas con entalladuras y tornillos. 


\subsection{FORMULAS DEL MÓDULO DE DESLIZAMIENTO $\left(K_{\text {ser }}\right)$}

\subsubsection{NORMATIVA}

Para las conexiones más habituales no objeto de patente, CTE: SE-M, transcribiendo a EC5, aporta la siguiente tabla para uniones entre maderas en contacto:

\begin{tabular}{l|c}
\multicolumn{1}{c}{ Tabla 7.1 Valores de $K_{\text {ser }}\left(=k_{s}\right.$ en la norma UNE EN 26891) para elementos de fijación de tipo } \\
clavija en N/mm.
\end{tabular}

figura 35. Tabla 7.1 Eurocódigo EC-5

Para uniones de madera a otro material más rígido como acero u hormigón, admite duplicar el módulo de deslizamiento, como si este fuera causado en su totalidad por aplastamiento de la madera, considerando que el acero y el hormigón son infinitamente rígidos.

Los valores del módulo $\mathrm{K}_{\mathrm{ser}}$ indicados por EC-5 son para el análisis en estado límite de servicio. Para los estados límites últimos propone reducir estos valores por el factor "2/3", utilizando con ello un módulo secante en previsión de un comportamiento no lineal.

Para que el módulo $\mathrm{K}_{\mathrm{ser}}$ no resulte limitado por la distancia de penetración de la clavija en la madera, es conveniente que esta no resulte limitante de la carga de rotura. Un análisis detallado puede verse, por ejemplo, en el trabajo de P. Gelfi, et al. en 2002 [ref. 064]. Otro estudio referente a la influencia de la esbeltez del anclaje es el de Fernández Cabo, Ávila Nieto y López Rodríguez en 2002 [ref. 053]. 


\subsubsection{FÓRMULAS EMPÍRICAS DE DIFERENTES AUTORES}

\section{A. Ceccotti [ref. 035]}

La expresión es válida para uniones entre madera y hormigón, con ambos materiales en contacto y clavijas verticales:

$$
\mathrm{K}_{\mathrm{ser}}=0,125 \cdot \mathrm{E}_{0, \text { medio }} \cdot \varnothing
$$

Posteriormente, A. Ceccotti, M. Fragiacomo y R. Gutkowski propusieron considerar para el corto plazo la siguiente fórmula:

$$
\mathrm{K}_{\text {ser }}=0,16 \cdot \mathrm{E}_{0, \text { medio }} \cdot \varnothing
$$

Sin embargo, aconsejaban que a largo plazo se adopte para la conexión un coeficiente de fluencia del orden del doble que el de la madera:

$$
K_{r e r, \infty}=\frac{K_{s e r}}{1+2 K_{d e f}}
$$

\section{P. Gelfi et al. [ref. 064$]$}

P. Gelfi, E. Giuriani, y A. Marini en 2002 hicieron la siguiente formulación para clavijas verticales, considerando la posibilidad de que exista una separación entre materiales:

$$
\begin{aligned}
& K_{s e r}=\frac{12\left(\alpha_{c} \alpha_{w}\right)^{3} E_{s} I_{s}}{Z}=\frac{12 E_{s} I_{s}}{l_{*}^{3}} \\
& \alpha_{c}=\sqrt[4]{\frac{k_{c}}{4 E_{s} I_{s}}} ; \alpha_{w}=\sqrt[4]{\frac{k_{w}}{4 E_{s} I_{s}}} \\
& Z=3\left(\alpha_{c}^{2}+\alpha_{w}^{2}\right)\left(\alpha_{c}+\alpha_{w}\right)+3 t \alpha_{c} \alpha_{w}\left(\alpha_{c}+\alpha_{w}\right)^{2}+3\left(t \alpha_{c} \alpha_{w}\right)^{2}\left(\alpha_{c}+\alpha_{w}\right)+\left(t \alpha_{c} \alpha_{w}\right)^{3}
\end{aligned}
$$

siendo " $\mathrm{t}$ " la separación entre materiales y " $\mathrm{k}_{\mathrm{c}}$ " $\mathrm{y}$ " $\mathrm{k}_{\mathrm{w}}$ " los balastos (fuerza / longitud ${ }^{2}$ con efecto resorte $\left.k_{i} \varnothing\right)$ :

En el caso de madera-hormigón, en el entorno de los habituales valores de los parámetros $\left(7<\mathrm{k}_{\mathrm{c}}<14 \mathrm{kN} / \mathrm{mm}^{2} ; 1<\mathrm{k}_{\mathrm{w}}<1,4 \mathrm{kN} / \mathrm{mm}^{2} ; 12<\mathrm{d}<20 \mathrm{~mm} ; 0<\mathrm{t}<50 \mathrm{~mm}\right)$, los autores propusieronn la siguiente expresión simplificada (con un error máximo del $15 \%$ ) para "I*":

$$
l_{*} \approx 17,3-0,000572 k_{c}-0,00894 k_{w}+0,880 t+4,34 \varnothing
$$


Para $\mathrm{k}_{\mathrm{c}}=10 \mathrm{kN} / \mathrm{mm}^{2}$ y $\mathrm{k}_{\mathrm{w}}=1,3 \mathrm{kN} / \mathrm{mm}^{2}$ e incluyendo " $\mathrm{I}_{\mathrm{s}}=\pi \varnothing^{4} / 64^{\prime \prime}$ y el habitual módulo elástico del acero dedujeron la siguiente expresión simplificada:

$$
K_{\text {ser }}=\frac{124.000 \cdot \emptyset}{(4,34+t / \varnothing)^{3}}
$$

\section{Conectores inclinados}

Con clavijas inclinadas se consiguen rigideces de unión notablemente más elevadas que en el caso de disposición ortogonal. SE-M, bajo ciertas condiciones (art. 10.1.2) permite el cálculo simplificado sin considerar el deslizamiento.

La disposición inclinada es bastante laboriosa. Un sistema mecanizado para tal finalidad en la estructura mixta madera-hormigón es el de los conectores "SFS intec ", a modo de tirafondos. Se colocan en la posición inclinada mediante un taladro especial para ello. Referencias sobre este sistema pueden consultarse en "Finnforest" [ref. 153]; para parejas de conectores de este tipo se ofrecen los siguientes valores:

$$
\begin{array}{ll}
\text { Pareja de conectores a } 45^{\circ} \text { y } 90^{\circ}: & \mathrm{K}_{\mathrm{ser}}=8.000-100 \cdot \mathrm{t} \\
\text { Pareja de conectores a } 45^{\circ} \text { y } 135^{\circ}: & \mathrm{K}_{\mathrm{ser}}=16.600-100^{\circ} \mathrm{t}
\end{array}
$$

siendo " $t$ " la separación entre madera y hormigón.

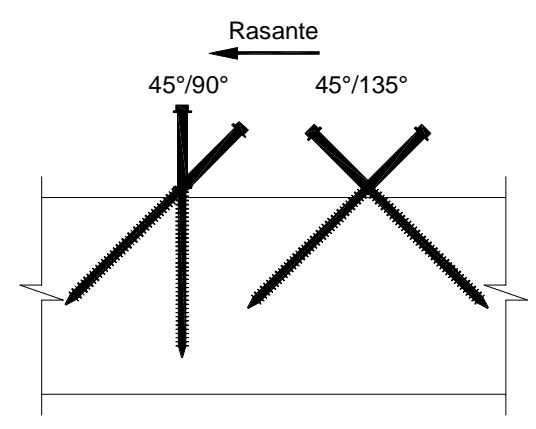

figura 36. Conectores inclinados

\section{Turrini y M. Piazza [ref. 143]}

Para estructuras mixtas de madera y hormigón conectadas con barras encoladas con contacto entre vigueta y capa de compresión, propusieron la siguiente formulación:

$$
\mathrm{K}_{\mathrm{ser}}=0,08 \cdot \mathrm{E}_{0, \text { medio }} \cdot \varnothing
$$


Aconsejaban un diámetro de taladro entre " $\varnothing+2 "$ " $\varnothing+4 " \mathrm{~mm}$, y la disposición de los conectores a distancias comprendidas entre 8 y 15 diámetros.

En el caso de separación entre madera y hormigón y barras encoladas verticales ofrecieron la siguiente formulación:

$$
\mathrm{K}_{\mathrm{ser}}=\mathrm{c}\left(0,08 \cdot \mathrm{E}_{0, \text { medio }} \cdot \varnothing\right) \quad c=\frac{3}{\left(\alpha h_{0}-1\right)^{3}+4} \quad \alpha=\frac{0,7413}{d}\left(\frac{E_{0, \text { medio }}}{E_{S}}\right)^{1 / 3}
$$

siendo $h_{0}$ el espesor del tablero que separa hormigón y escuadría de madera y $E_{s}$ el módulo de elasticidad del acero.

En el caso de conectores inclinados aconsejaban disposiciones entre $45^{\circ}$ y $60^{\circ}$ con longitudes de anclaje $(\mathrm{I})$ en la madera entre 15 y 18 veces el diámetro del taladro $\left(\emptyset_{\mathrm{f}}\right)$ y propusieron la siguiente expresión:

$$
K_{\text {ser }}=0,7 l \emptyset_{f}^{0,6} \cdot E_{0, \text { medio }}
$$

Por otra parte, para una pareja de conectores dispuestos simétricamente, a compresióntracción, e inclinados un mismo ángulo " $\varphi$ ":

$$
K_{\text {ser }}=1,4 l \emptyset_{f}^{0,6} \cdot E_{0, \text { medio }} \cdot \cos ^{2} \varphi
$$

\section{Natterer et al [ref. 109]}

Para barras lisas encoladas verticales con contacto entre hormigón y madera, propusieron:

$$
\mathrm{K}_{\mathrm{ser}}=120 \cdot \emptyset^{1,7}
$$

Como consideraciones constructivas citaban una longitud de penetración en la madera de al menos $8 \mathrm{~d}$ y un diámetro de taladro de solamente " $\varnothing+0,5$ " a " $\varnothing+1 " \mathrm{~mm}$.

\section{Branco [ref. 030]}

Otra expresión para el módulo de deslizamiento de clavijas verticales con madera y hormigón en contacto es la de Branco (2003).

$$
K_{\text {ser }}=0,15 \emptyset^{0,95} \cdot E_{0, \text { medio }}^{0,9}
$$




\section{CAPÍTULO 3. - TRABAJOS DE LABORATORIO}

\subsection{INTRODUCCIÓN}

3.1 ESTUDIO DE LOS MATERIALES

3.1.1 HORMIGÓN

3.1.2 MADERA LAMINADA Y ASERRADA

3.1.3 MADERA MICROLAMINADA

3.1.4 CONECTORES

3.1.5 ESTUDIO DEL HENDIMIENTO

\subsection{CONEXIONES A RASANTE}

\subsubsection{TRABAJOS PREVIOS}

Esbeltez del conector en madera aserrada

Esbeltez del conector en madera microlaminada

Número adecuado de conectores por probeta

\subsubsection{LA PROBETA}

Diseño

Dimensiones, materiales y conectores

\subsubsection{PROCEDIMIENTOS DEL ENSAYO}

Protocolo

Instrumentación

Resumen fotográfico

3.2.4 CRITERIOS TOMADOS PARA OBTENER EL $\mathrm{K}_{\text {ser }}$ Gráfica representativa de cada tipo de ensayo

Fuerza máxima estimada para obtener el $\mathrm{K}_{\text {ser }}$

\subsection{VIGAS A FLEXIÓN}

\subsubsection{TRABAJOS PREVIOS}

Sistema de aplicación de la carga

Pruebas para la reutilización de las piezas

3.3.2 LA VIGA MIXTA

Dimensiones, materiales y conexiones

Reportaje del proceso de construcción

Primer criterio de agrupación de ensayos

Segundo criterio de agrupación de ensayos

3.3.3 PROCEDIMIENTOS DEL ENSAYO E INFORMACIÓN DE LA ROTURA Protocolo 
Instrumentación

Información tras la rotura. Vigas

Información tras la rotura. Conexiones

3.3.4 TRANSFORMACIÓN DE LOS DATOS DE LABORATORIO

Paso de 4 cargas puntuales a uniforme

Corrección de asimetrías

Corrección de la flecha de cortante

Resumen de resultados corregidos

Desestimación de puesta en carga 


\subsection{INTRODUCCIÓN}

Este capítulo contiene la descripción de todos los trabajos realizados en el laboratorio con el fin de obtener los datos necesarios sobre el comportamiento de las conexiones de las vigas mixtas con los que se ha elaborado esta tesis. Incluye la descripción de los distintos ensayos realizados, así como los ensayos previos que se consideraron necesarios para el buen funcionamiento de los anteriores y los trabajos posteriores para la elaboración de los resultados.

En la fabricación de las vigas mixtas se han empleado distintos materiales (en las viguetas, madera laminada y madera aserrada, y en las capas de compresión, hormigón y tablero de madera microlaminada). En el apartado 3.1 (Estudio de los materiales) se describen dichos materiales y los ensayos realizados para determinar sus propiedades mecánicas.

Para analizar el comportamiento de las diferentes conexiones de las vigas mixtas, se han realizado dos tipos de ensayos:

En los ENSAYOS DE RASANTE, descritos en el apartado 3.2. se estudia el trabajo de los conectores de forma aislada, ya que en estos ensayos solo intervienen el trabajo a cortante del conector y el aplastamiento de la madera. Antes de la realización de estos ensayos, se hicieron una serie de ensayos preliminares (apartado 3.2.1) para determinar, tanto en la madera aserrada como en microlaminada, la profundidad necesaria de penetración del conector en la madera para que se produzca un empotramiento.

En los ensayos de rasante se han estudiado 17 casos de conexión, contemplando distintos tipos de conector, varios diámetros, con y sin resina, con y sin pretaladro, con y sin apriete, con capas de compresión de hormigón y de madera microlaminada y con viguetas de madera aserrada y madera laminada. De cada caso se han realizado 3 probetas (51 ensayos en total).

En el apartado 3.2.2 (La probeta) se describen los casos ensayados, se explican los motivos condicionantes del diseño de las piezas, así como los materiales y conectores empleados. En el apartado 3.2.3 (Procedimientos del ensayo) se describen el protocolo de los ensayos realizados y la instrumentación realizada durante los ensayos y también se expone un resumen fotográfico de las probetas después ser ensayadas. 
Como solo se han realizado 3 ensayos de cada tipo, no se pueden obtener medias estadísticas fiables. En el apartado 3.2.4 (Criterios tomados para obtener el $\mathbf{K}_{\mathbf{s e r}}$ ) se describe cómo se han elegido los valores representativos de cada tipo.

Los ENSAYOS DE VIGAS A FLEXIÓN, descritos en el apartado 3.3. estudian las conexiones dentro del funcionamiento global de la viga a flexión. En estos ensayos se miden todas las deformaciones de la viga (flecha, giro y deslizamiento). Estos deslizamientos servirán para realizar comparaciones con los ensayos anteriores de rasante.

En el apartado 3.3.1 (Trabajos previos) se describen los trabajos preliminares realizados para asegurar el buen funcionamiento de los ensayos de las vigas (ensayos para una correcta aplicación de la carga y ensayos cíclicos para estudiar una posible reutilización de las vigas ensayadas).

Se han ensayado 58 tipos de conexión en un total de 95 vigas mixtas. El único parámetro invariable es la luz, el resto va cambiando para poder estudiar una gran gama de conexiones (esbeltez, materiales, tanto de la vigueta como de la capa de compresión, conectores, presión entre materiales...). Según el procedimiento de realización de los ensayos de flexión, las vigas se agrupan en dos: En el primero se llevan las vigas a rotura y en el segundo solo hasta que la flecha alcanza L/300, lo que permitió en este caso hacer del orden de 7 ensayos con la misma viga cambiando la configuración de los conectores. En el apartado 3.3.2 (La viga mixta) se describen todas las variables estudiadas en la construcción de las vigas así como las dos agrupaciones comentadas.

En el apartado 3.3.3 (Procedimientos del ensayo e información de la rotura) se describen los ensayos de flexión, el protocolo de cargas, y la instrumentación realizada y también se muestra un resumen fotográfico de las vigas después de la rotura.

Antes de hacer un análisis y comparación de los ensayos -entre ellos y con el modelo de cálculo-, a los datos obtenidos con la instrumentación se les han aplicado una serie de coeficientes: para pasar de 4 cargas puntuales a carga uniforme, para corregir asimetrías y para descontar la flecha de cortante. Todas estas correcciones se muestran en el apartado 3.3.4 (Transformación de los datos de laboratorio). 


\subsection{ESTUDIO DE LOS MATERIALES ${ }^{13}$}

En este apartado se describen los ensayos que se han realizado de todos los materiales empleados en la fabricación de las probetas para determinar sus características mecánicas.

\subsubsection{HORMIGÓN}

\section{Descripción de las probetas}

De cada amasada de hormigón se han fabricado 3 probetas cúbicas de dimensiones $10 \mathrm{x}$ 10 x $10 \mathrm{~cm}$ (dimensiones según Norma UNE EN 12390-1 [ref. 015]) para determinar su resistencia a compresión mediante ensayos regulados por la Norma UNE EN 12390-3. En los mismos ensayos se ha obtenido también su módulo de deformación longitudinal. Las probetas fueron ensayadas con una edad entre 67 y 115 días.
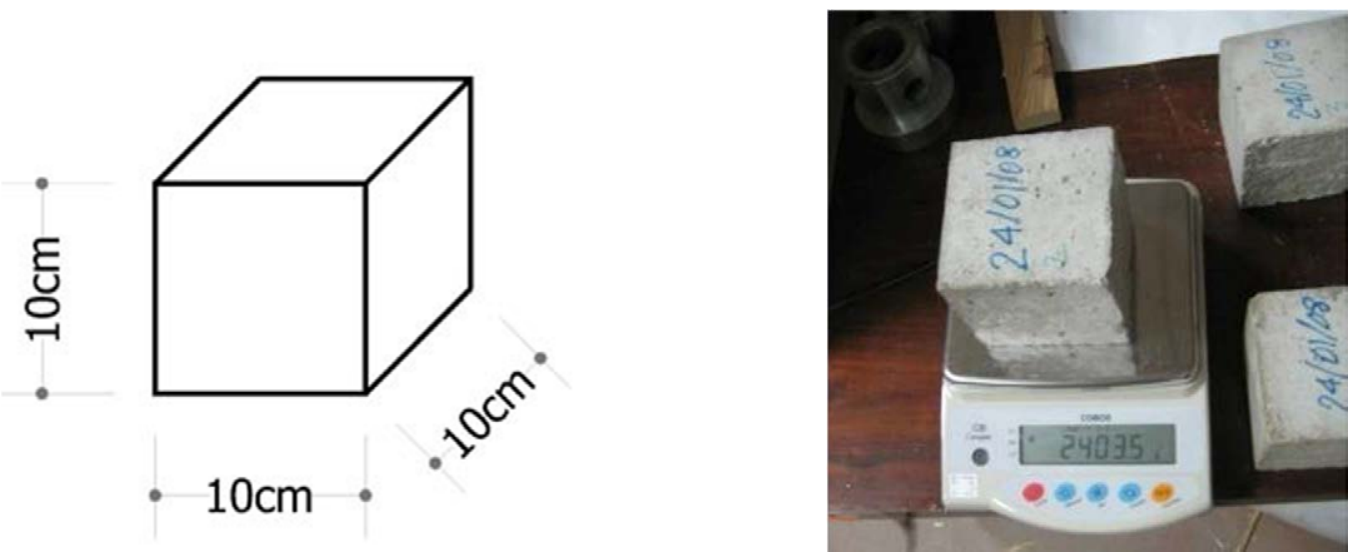

figura 1. Dimensiones de las probetas

\section{Descripción del ensayo}

Se han realizado tres ensayos de compresión de cada probeta de la siguiente manera:

-Primero 2 ensayos hasta una carga de $40 \mathrm{kN}$ (15\% de la carga de rotura estimada) para obtener su módulo de deformación longitudinal.

-Un tercer ensayo hasta la rotura para obtener su resistencia a compresión.

\footnotetext{
${ }^{13}$ Los resultados de estos ensayos están detallados en el Anejo I. "Estudio de los materiales".
} 
La aplicación de carga se ha configurado para un acortamiento constante de $1 \mathrm{~mm} / \mathrm{min}$.

Los datos medidos en los ensayos son los siguientes:

-Carga.

-Acortamiento. Medido con dos extensómetros colocados en dos de las caras de la probeta como se muestra en la figura 2. (Se colocan dos para obtener un valor más fiable, sin embargo debido a su dificultad de colocación y a las imprecisiones de las caras muchas veces no dan valores coherentes).
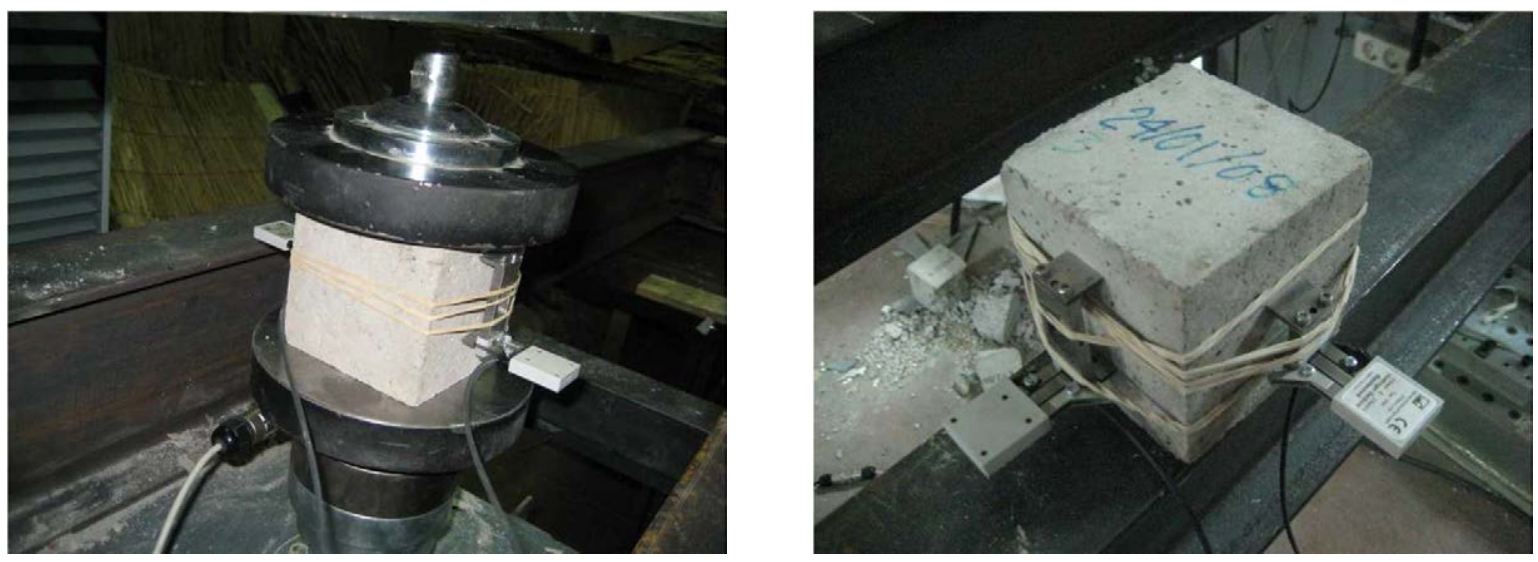

figura 2. Realización del ensayo de compresión

\section{Resultados: ${ }^{14}$}

\begin{tabular}{|c|c|c|c|c|c|}
\hline \multicolumn{7}{|c|}{ HORMIGÓN (16 PROBETAS) } \\
\hline $\begin{array}{c}\text { edad } \\
(67-115 \text { días) }\end{array}$ & $\begin{array}{c}\text { densidad } \\
\left(\mathrm{kg} / \mathrm{m}^{2}\right)\end{array}$ & $\mathrm{E}\left(\mathrm{N} / \mathrm{mm}^{2}\right)$ & $\begin{array}{c}\text { carga de } \\
\text { rotura }(\mathrm{kN})\end{array}$ & $\begin{array}{c}\text { tensión de } \\
\text { rotura } \\
\left(\mathrm{N} / \mathrm{mm}^{2}\right)\end{array}$ & $\begin{array}{c}\text { fk (límite } \\
\text { caracteristico } \\
95 \%) \mathrm{N} / \mathrm{mm}^{2}\end{array}$ \\
\hline medias & 2.378 & 24.209 & 245 & 24,5 & 23,9 \\
\hline CoV & $1,5 \%$ & $14,3 \%$ & $1,8 \%$ & $1,8 \%$ & $2 \%$ \\
\hline
\end{tabular}

figura 3. Resumen de resultados de ensayos de hormigón

\footnotetext{
${ }^{14}$ Los resultados de estos ensayos están detallados en el Anejo I.1. "Estudio de los materiales. Hormigón".
} 


\subsubsection{MADERA LAMINADA Y ASERRADA}

\section{Descripción de las probetas}

Las viguetas con las que se han realizado los ensayos de flexión son de madera laminada y aserrada, de escuadrías (b · h) $9 \cdot 14 \mathrm{~cm}, 9 \cdot 12 \mathrm{~cm}$ y $9 \cdot 10 \mathrm{~cm}$ y tienen una longitud de $375 \mathrm{~cm}$. A todas ellas (35 piezas de madera laminada y 10 de madera aserrada) se las sometió a una serie de ensayos previos no destructivos destinados a determinar los valores de los diferentes módulos de elasticidad.

Las viguetas de madera laminada son de abeto (Picea abies) de clase resistente GL24h. Las viguetas de madera aserrada pertenecen a la especie Pino Silvestre (Pinus sylvestris) de clase resistente $\mathrm{C} 18$.

\section{Descripción de los ensayos}

\section{ENSAYO MECÁNICO $^{15}$}

Para realizar el ensayo (con todas las viguetas) se aplicaron dos cargas en los tercios de la luz y se midió su flecha en el centro con un LVDT, como muestra la figura 4. Se alcanzó un nivel de carga suficiente como para obtener su Módulo de Elasticidad pero sin llegar en ningún caso a cargas que pudieran alterar las propiedades mecánicas de la madera.

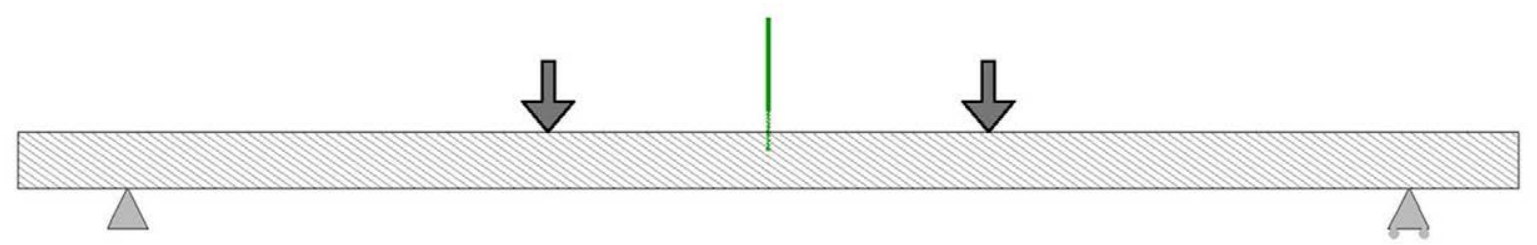

figura 4. Esquema del ensayo mecánico

\section{ENSAYO DE VIBRACIÓN LONGITUDINAL (Frecuencia natural de vibración longitudinal)}

Este ensayo se realiza con un PLG (Portable Lumber Grader), que obtiene la frecuencia de vibración longitudinal y el peso de cada una de las probetas. El equipo consta de una balanza, un micrófono unidireccional y un software propio.

\footnotetext{
${ }^{15}$ El ensayo de flexión de las viguetas de madera laminada fue realizado en el laboratorio del INIA (Instituto Nacional de Investigación y Tecnología Agraria y Alimentaria).
} 

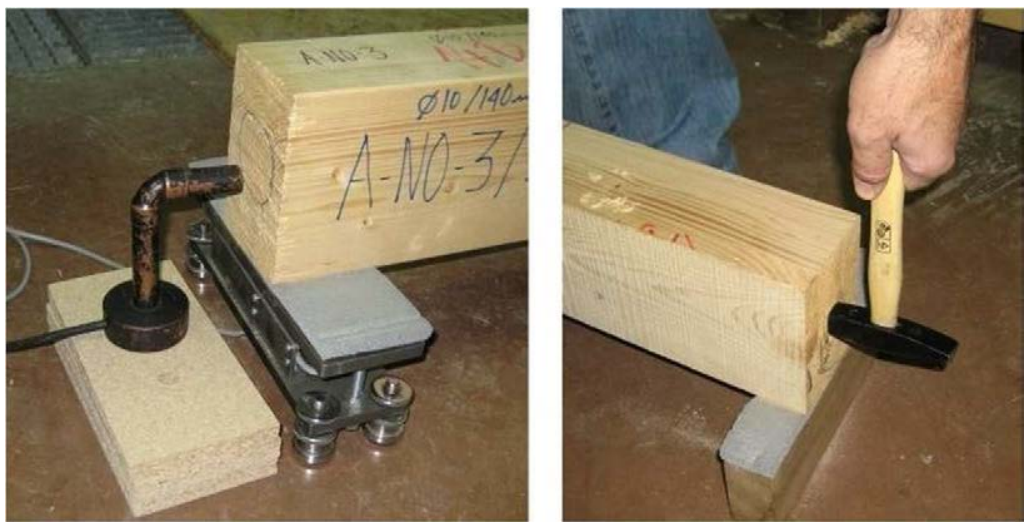

figura 5. Realización del ensayo de vibración longitudinal

La pieza se apoya en los extremos sobre unas bandas de poliuretano que aseguran la vibración libre de la misma. Uno de los apoyos lleva una balanza, registrando la mitad del peso de la pieza. Se sitúa un micrófono en uno de los extremos de la viga y próximo al centro de la sección de la testa, pero sin entrar en contacto con ella. El ensayo consiste en hacer vibrar la pieza mediante un impacto con un martillo en la testa opuesta a la del micrófono (figura 5). El micrófono capta el sonido procedente de la vibración y lo traslada al programa informático que procesa la señal y determina la frecuencia de vibración.

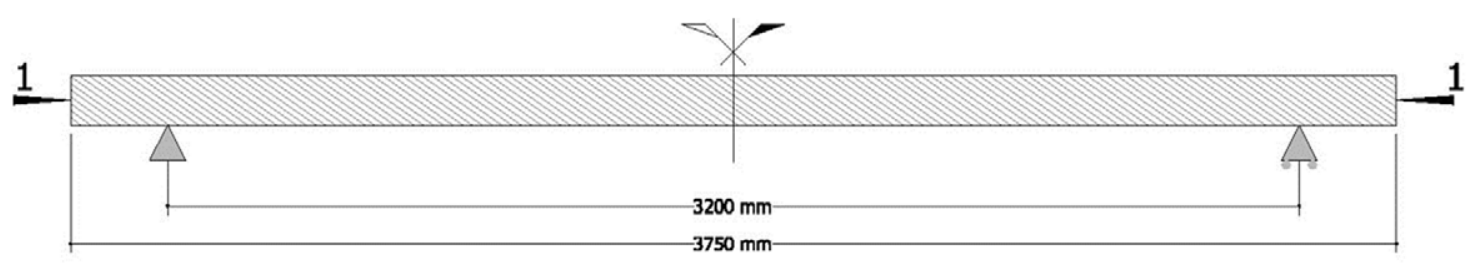

figura 6. Esquema del ensayo de vibración longitudinal

Conociendo la frecuencia de vibración longitudinal $(f$, en $\mathrm{Hz}$ ) y la longitud de la pieza $(\mathrm{L}$, en $\mathrm{m})$ se calcula la velocidad de propagación $(\mathrm{v}$, en $\mathrm{m} / \mathrm{s}$ ) mediante la relación:

$$
v=2 \cdot L \cdot f
$$

Con el semi-peso medido en uno de los apoyos y las dimensiones de la probeta se calcula la densidad mediante la fórmula:

$$
\rho=2 P /(b \cdot h \cdot L)
$$

La siguiente expresión relaciona la velocidad de propagación de las ondas longitudinales con el módulo de elasticidad longitudinal dinámico y la densidad, como conocemos la densidad y la velocidad, hallamos $\mathrm{E}_{\mathrm{din}}$. Este módulo se denomina dinámico para diferenciarlo del que se obtiene mediante métodos de ensayo mecánicos:

$$
E_{\text {din }}=\rho \cdot V^{2}
$$




\section{ENSAYO DE ONDAS DE IMPACTO}

El ensayo consiste en colocar un emisor y un receptor clavados en la probeta, golpear al emisor con un pequeño martillo y medir el tiempo que tardan las ondas en llegar al receptor.

De cada probeta se realizan 4 lecturas por ultrasonidos, 1 directa (1) y 3 indirectas (2, 3 y 4), colocando los sensores emisor/receptor como se indica en la figura 7.

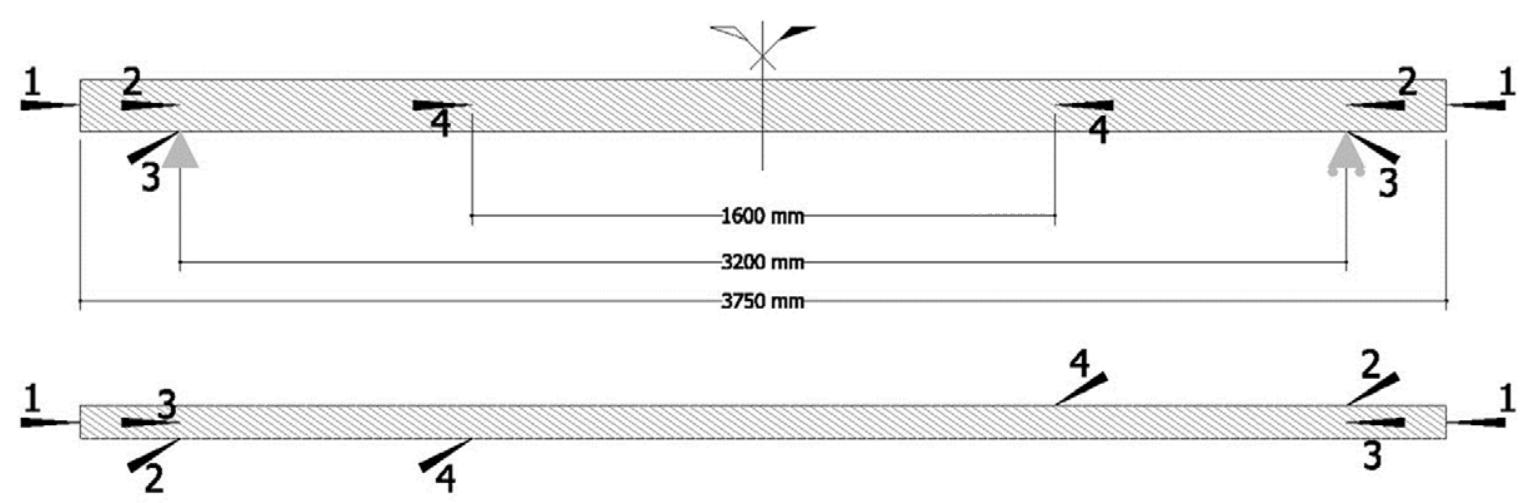

figura 7. Alzado y planta del ensayo de ondas de impacto

Las lecturas indirectas (en las caras inferior y laterales) tienen por objeto aproximarse a los ensayos en los edificios, ya que estas caras son las únicas accesibles. Con la lectura directa (en las testas) se trata de ver si los indirectos dan lecturas similares.

Con el tiempo de transmisión se obtiene la velocidad de propagación de las ondas mediante la fórmula:

$$
\mathrm{V}=\mathrm{s} / \mathrm{t}
$$

El fenómeno físico es el mismo que el del método vibratorio anterior. Obtenida la velocidad se aplica la misma expresión del E dinámico

$$
E_{\text {din }}=\rho \cdot V^{2}
$$

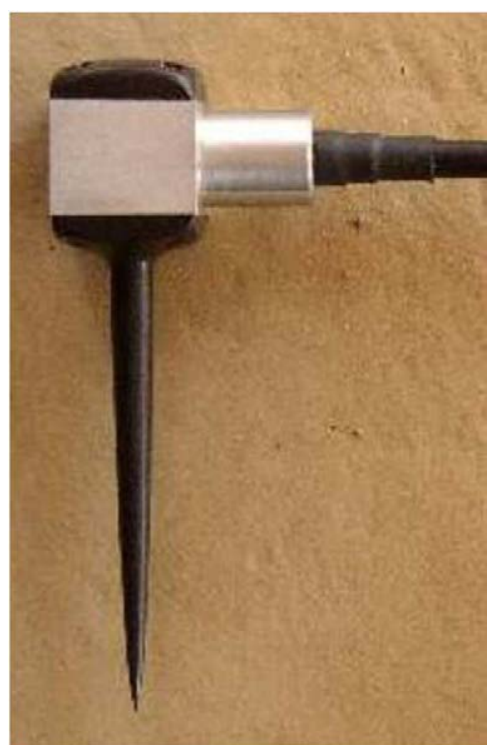

figura 8. Emisor que se clava en la probeta 


\section{Resultados: ${ }^{16}$}

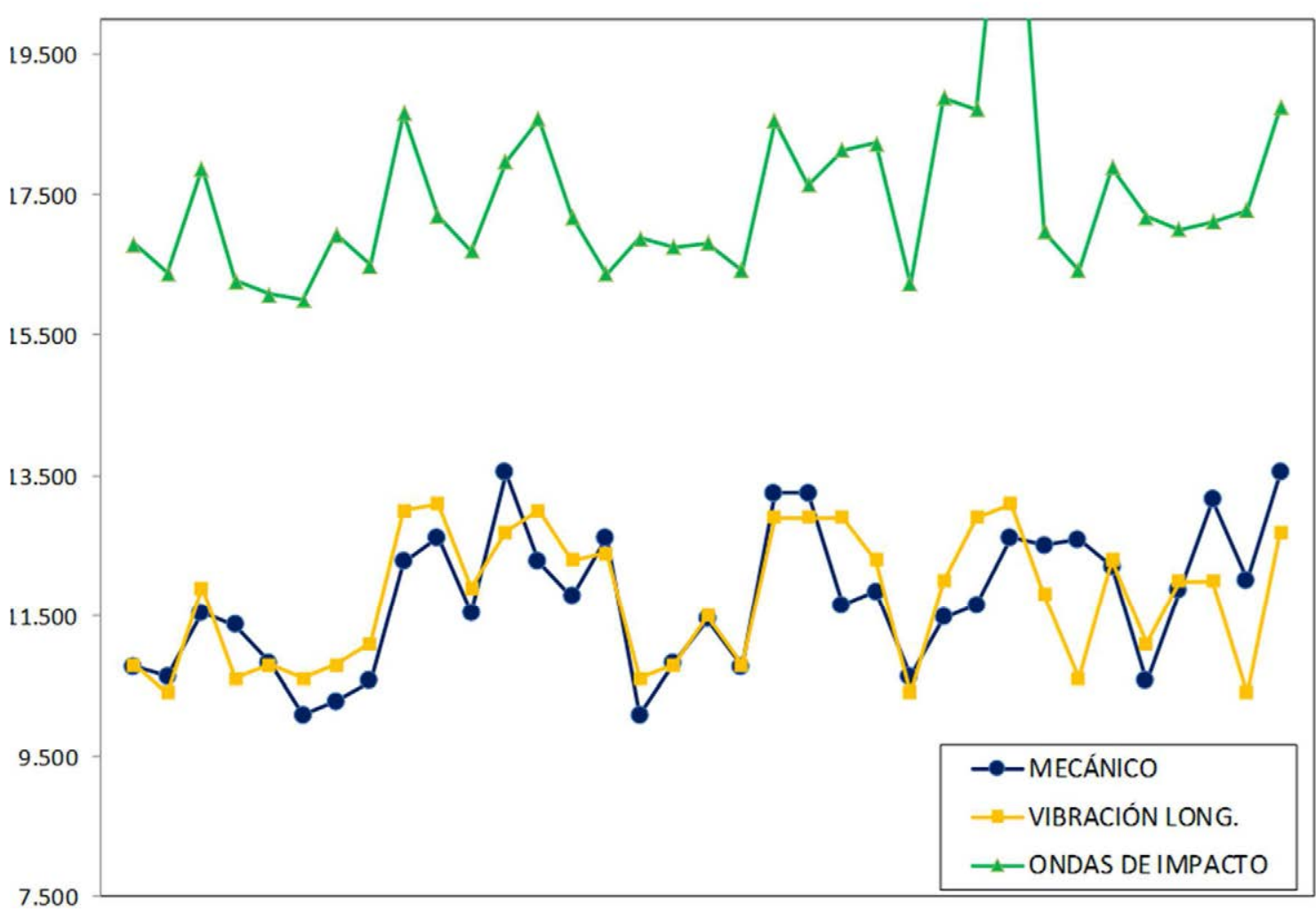

figura 9. Módulos de Elasticidad de madera laminada

\begin{tabular}{|c|c|c|c|c|}
\hline & \multicolumn{4}{|c|}{ MADERA LAMINADA(35 VIGUETAS) } \\
\hline & & FLEXIÓN & $\begin{array}{c}\text { VIBRACIÓN } \\
\text { LONGITUDINAL }\end{array}$ & $\begin{array}{l}\text { ONDAS DE } \\
\text { IMPACTO }\end{array}$ \\
\hline & densidad & MoE & $\mathrm{E}_{\text {din }}(\mathrm{PLG})$ & $\mathrm{E}_{\text {din }}$ (Microsecond) \\
\hline & $\left(\mathrm{kg} / \mathrm{m}^{3}\right)$ & $\left(\mathrm{N} / \mathrm{mm}^{2}\right)$ & $\left(\mathrm{N} / \mathrm{mm}^{2}\right)$ & $\left(\mathrm{N} / \mathrm{mm}^{2}\right)$ \\
\hline medias & 463 & 11.729 & 11.754 & 17.454 \\
\hline CoV & $5,0 \%$ & $8,4 \%$ & $8,1 \%$ & $7,7 \%$ \\
\hline
\end{tabular}

figura 10. Resumen de resultados de madera laminada

Teniendo en cuenta que el ensayo mecánico es el más fiable, se aprecia que el ensayo de vibración longitudinal produce resultados muy similares, aunque tiene el inconveniente de no poderse realizar en los edificios, puesto que no se suele tener acceso a las testas de las viguetas. En los ensayos de ondas de impacto, algunas de sus variantes $(2,3$ y 4$)$ son viables en la obra construida, sin embargo dan valores muy superiores a los obtenidos con los otros dos, bien es cierto que ese exceso se encuentra siempre entre el $40 \%$ y el $60 \%$.

\footnotetext{
${ }^{16}$ Los resultados de estos ensayos están detallados en el Anejo I.2. "Estudio de los materiales. Madera aserrada", y Anejo I.3. "Estudio de los materiales. Madera laminada”.
} 


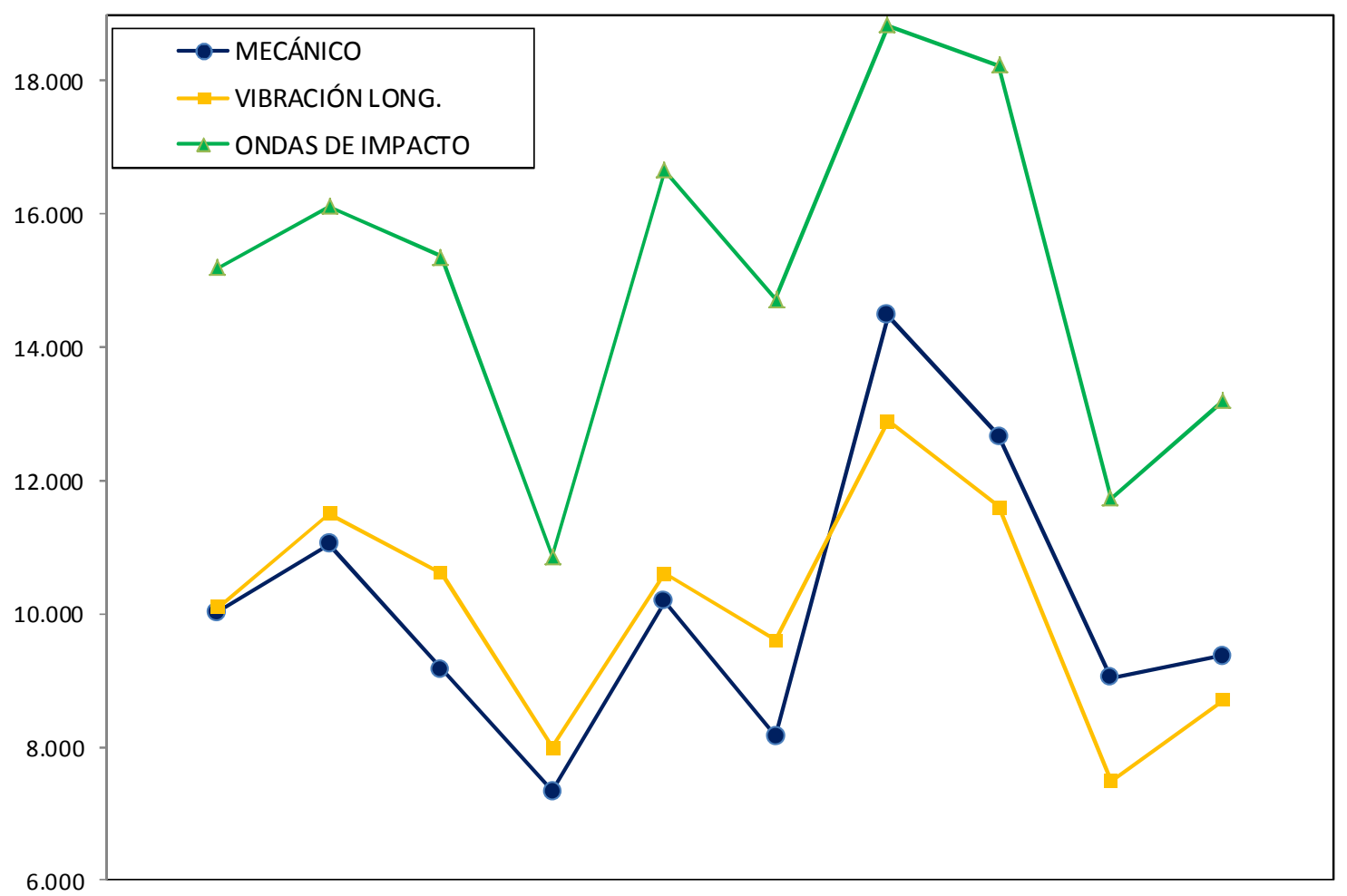

figura 11. Módulos de Elasticidad de madera aserrada

\begin{tabular}{|c|c|c|c|c|}
\cline { 2 - 5 } & \multicolumn{4}{|c|}{ MADERA ASERRADA(10 VIGUET AS) } \\
\cline { 2 - 5 } & & FLEXIÓN & $\begin{array}{c}\text { VIBRACIÓN } \\
\text { LONGITUDINAL }\end{array}$ & $\begin{array}{c}\text { ONDAS DE } \\
\text { IMPACTO }\end{array}$ \\
\cline { 2 - 5 } & densidad & MoE & $E_{\text {din }}($ PLG) & $E_{\text {din }}$ (Microsecond) \\
\hline medias & $\left.556 / \mathrm{m}^{3}\right)$ & $\left(\mathrm{N} / \mathrm{mm}^{2}\right)$ & $\left(\mathrm{N}^{2} \mathrm{~mm}^{2}\right)$ & $\left.15 \mathrm{~mm}^{2}\right)$ \\
\hline CoV & $6,0 \%$ & 10.148 & 10.112 & 15.091 \\
\hline
\end{tabular}

figura 12. Resumen de resultados de madera aserrada

Como muestran los gráficos, en la madera aserrada se obtienen las mismas conclusiones que en la madera laminada. 


\subsubsection{MADERA MICROLAMINADA}

\section{Descripción de las probetas}

Las probetas con las que se han realizado los ensayos son las propias capas de compresión, la longitud de 3,30 m y la escuadría (b · h) 200 × 39 mm. Se han ensayado 7 capas de compresión.

La madera laminada ha sido fabricada por la empresa Finnforest con el nombre comercial de Kerto. Está formada por láminas de abeto de $3 \mathrm{~mm}$ de espesor. La empleada en este trabajo es del tipo KERTO-S (con todas las láminas orientadas en la misma dirección longitudinalmente) y tiene un Módulo de Elasticidad Medio de $13.800 \mathrm{~N} / \mathrm{mm}^{2}$ según el fabricante.

\section{Descripción del ensayo}

En los ensayos de flexión realizados se ha alcanzado una flecha de $\mathrm{L} / 300$, para obtener el Módulo de elasticidad. El esquema del ensayo se muestra en la figura 13.

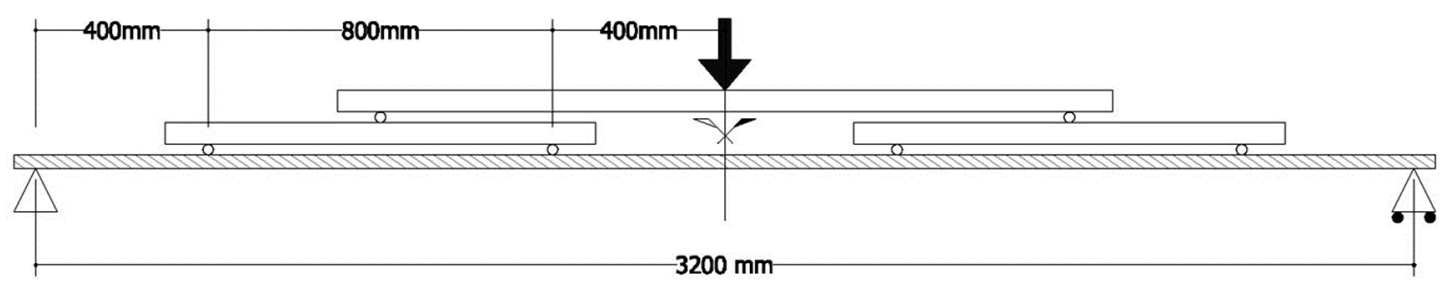

figura 13. Esquema de ensayo de flexión. Madera microlaminada

Durante el ensayo se toman medidas de la carga aplicada mediante una célula de carga y de la flecha del punto central con un LVDT, obteniendo con ambas el MoE de la pieza.

\section{Resultados: ${ }^{17}$}

\begin{tabular}{|c|c|}
\hline \multicolumn{2}{|c|}{ MADERAMICROLAMINADA } \\
(7 CAPAS DE COMPRESIÓN) \\
\hline & FLEXÓN \\
\hline & MoE (N/mm²) \\
\hline medias & 17.032 \\
CoV & $6,9 \%$ \\
\hline
\end{tabular}

figura 14. Resumen de resultados de madera microlaminada

Aunque el fabricante indique un valor de $13.800 \mathrm{~N} / \mathrm{mm}^{2}$, en estos ensayos se ha obtenido $17.032 \mathrm{~N} / \mathrm{mm}^{2}$ ( $23 \%$ mayor), que será el valor empleado en el resto de la tesis.

\footnotetext{
${ }^{17}$ Los resultados de estos ensayos están detallados en el Anejo I.4. "Estudio de los materiales. Madera Microlaminada".
} 


\subsubsection{CONECTORES}

\section{Descripción de las probetas}

Las probetas con las que se han realizado los ensayos son clavos $(\varnothing 4,4$ y $\varnothing 5,4)$ y tirafondos $(\varnothing 8, \varnothing 10$ y $\varnothing 12)$, todos de acero.

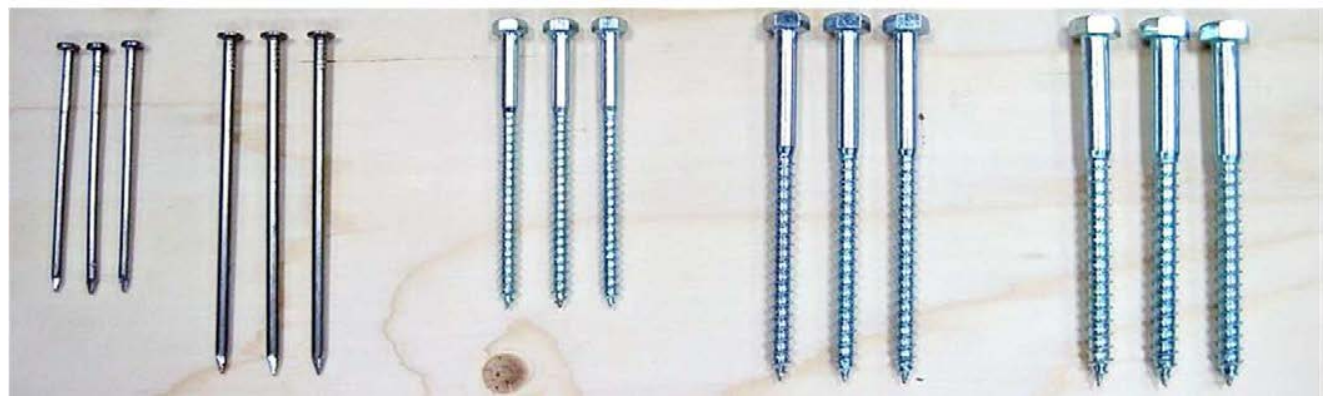

figura 15. Conectores ensayados

\section{Descripción del ensayo}

Los ensayos de flexión, para obtener la tensión de rotura y el módulo de elasticidad se han realizado siguiendo aproximadamente lo que marca la Norma UNE EN 409, como se aprecia en la figura 16. En la aplicación de la carga se han dispuesto dos pequeñas varillas para simular la doble carga que hay que aplicar según la Norma.
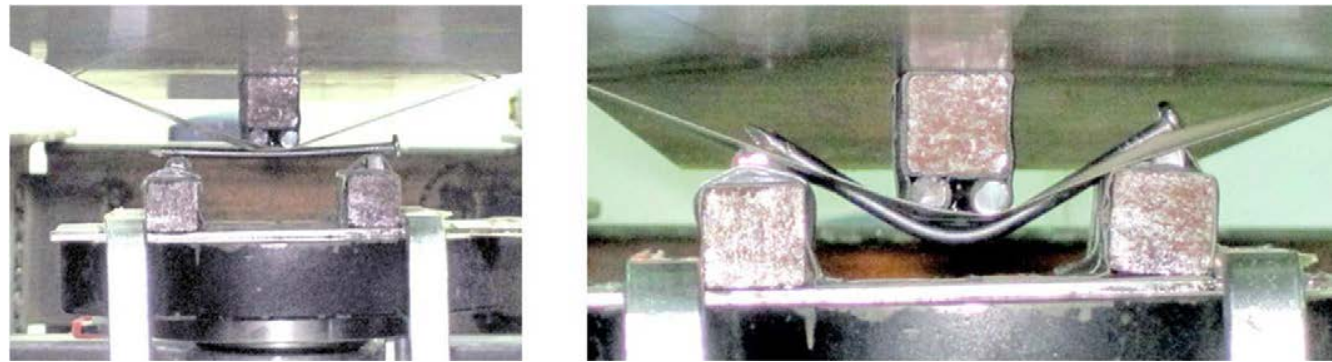

figura 16. Realización del ensayo

\section{$\underline{\text { Resultados: }}{ }^{18}$}

\begin{tabular}{|c|c|c|c|c|c|c|c|c|}
\hline & \multicolumn{8}{|c|}{ ENSAYO DE FLEXIÓN. CONECTADORES } \\
\hline & $\varnothing$ & Luz & W & $\mathrm{I}$ & $F_{\text {max }}$ & $M \max$ & $\sigma$ de rotura & $E$ \\
\hline & $\mathrm{cm}$ & $\mathrm{cm}$ & $\mathrm{cm}^{3}$ & $\mathrm{~cm} 4$ & $\mathrm{kN}$ & $\mathrm{kN} \cdot \mathrm{m}$ & $\mathrm{N} / \mathrm{mm}^{2}$ & $\mathrm{kN} / \mathrm{cm}^{2}$ \\
\hline $\begin{array}{l}\text { CLAVOS } \\
\varnothing 4,4 \mathrm{~mm}\end{array}$ & 0,44 & 8,5 & 0,008363 & 0,00184 & 0,68 & 0,01 & 1.718 & 168.732 \\
\hline $\begin{array}{c}\text { CLAVOS } \\
\varnothing 5,4 \mathrm{~mm}\end{array}$ & 0,54 & 10 & 0,015459 & 0,004174 & 0,81 & 0,02 & 1.317 & 155.482 \\
\hline $\begin{array}{c}\text { TIRAFONDOS } \\
\varnothing 8 \\
\end{array}$ & 0,56 & 9 & 0,017241 & 0,004827 & 1,29 & 0,03 & 1.690 & 149.990 \\
\hline $\begin{array}{c}\text { TIRAFONDOS } \\
\varnothing 10\end{array}$ & 0,72 & 10 & 0,036644 & 0,013192 & 2,07 & 0,05 & 1.482 & 113.899 \\
\hline $\begin{array}{c}\text { TIRAFONDOS } \\
\varnothing 12 \\
\end{array}$ & 0,86 & 10 & 0,062445 & 0,026851 & 4,00 & 0,11 & 1.682 & 90.542 \\
\hline
\end{tabular}

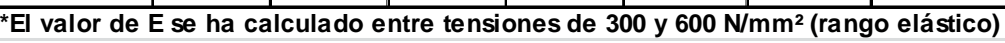

figura 17. Resumen de resultados de ensayos de conectores

${ }^{18}$ Los resultados en detalle están en el Anejo I.5. "Estudio de los materiales. Conectores". 


\subsubsection{ESTUDIO DEL HENDIMIENTO}

Estos ensayos tienen por objeto medir el hendimiento en las diferentes maderas utilizadas en este trabajo.

\section{Descripción de las probetas}

Las probetas ensayadas son de madera aserrada, madera laminada y madera microlaminada, con la forma que se muestra en la figura 18. En cada probeta se colocan 3 clavos que son presionados en cabeza para medir su hendimiento.
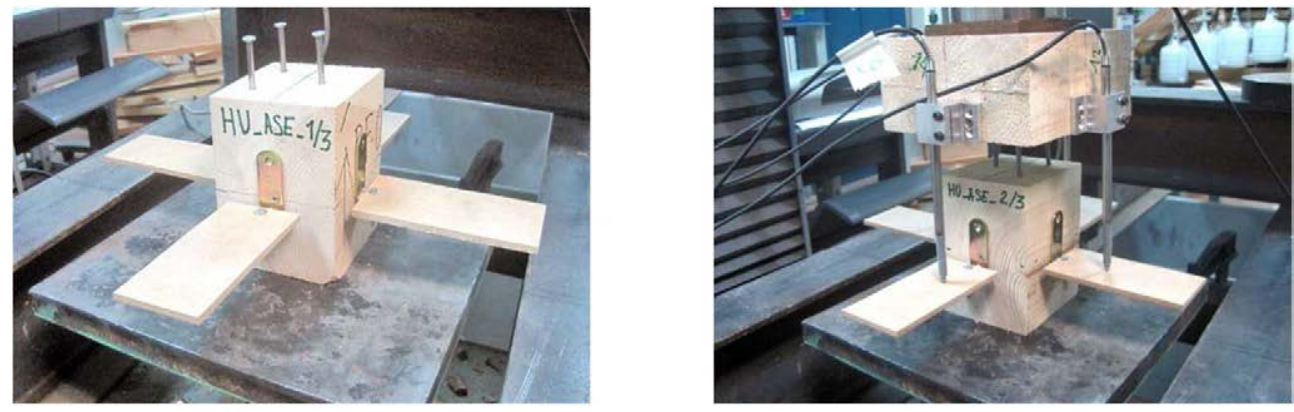

figura 18. Realización del ensayo de hendimiento

\section{Descripción del ensayo}

Se midieron los descensos de las 4 caras del prisma, utilizando el valor medio. Cada probeta se ensayó colocando los clavos paralela y perpendicularmente a las fibras.

\section{Resultados: ${ }^{19}$}

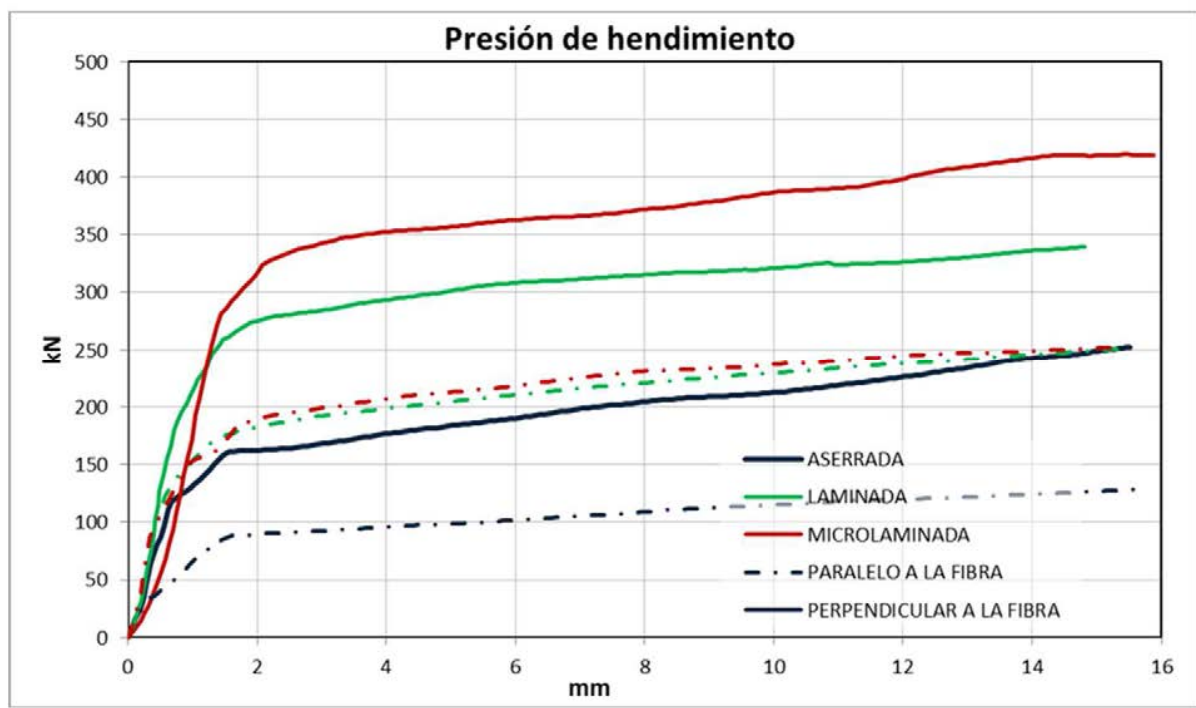

figura 19. Resultados de los ensayos de hendimiento

\footnotetext{
${ }^{19}$ Los resultados de estos ensayos están en el Anejo I.6. "Estudio de los materiales. Hendimiento madera".
} 


\subsection{CONEXIONES A RASANTE}

En este apartado se describen todos los ensayos que se realizaron para simular la unión a rasante de las dos partes que componen una viga mixta, estudiando el conector independientemente (su propio trabajo y el aplastamiento de la madera).
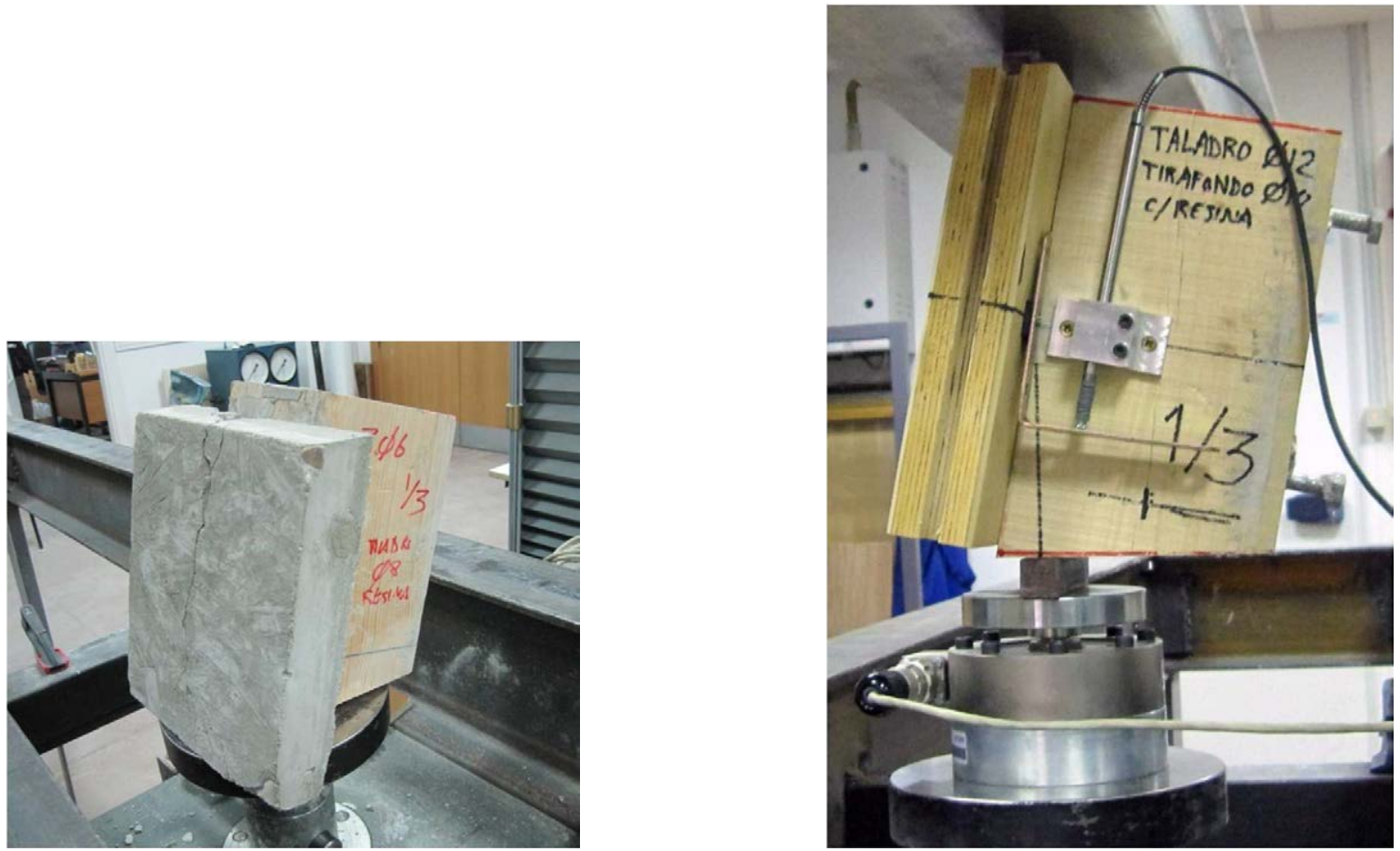

figura 20. Probetas con capa de compresión de hormigón y de madera microlaminada
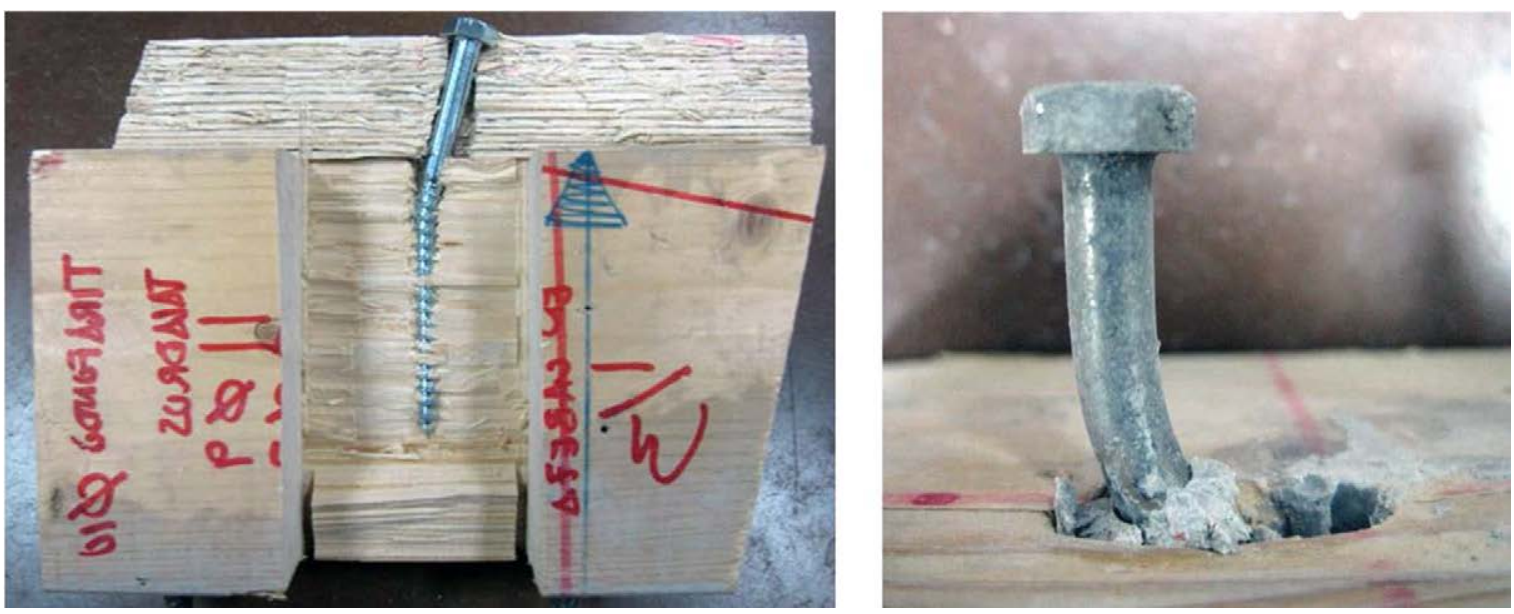

figura 21. Deformación del conector después del ensayo 


\subsubsection{TRABAJOS PREVIOS 20}

\section{$\underline{\text { Resumen de los Trabajos }}$}

Estos ensayos tienen como finalidad determinar la longitud de empotramiento del conector en las piezas de madera aserrada y microlaminada. De este estudio se obtiene la esbeltez mínima para que se produzca el empotramiento. No se analiza el hormigón puesto que sus condiciones de empotramiento son muy superiores.

Los ensayos se han realizado siguiendo la Norma UNE EN 26891.

\section{Descripción de las probetas}

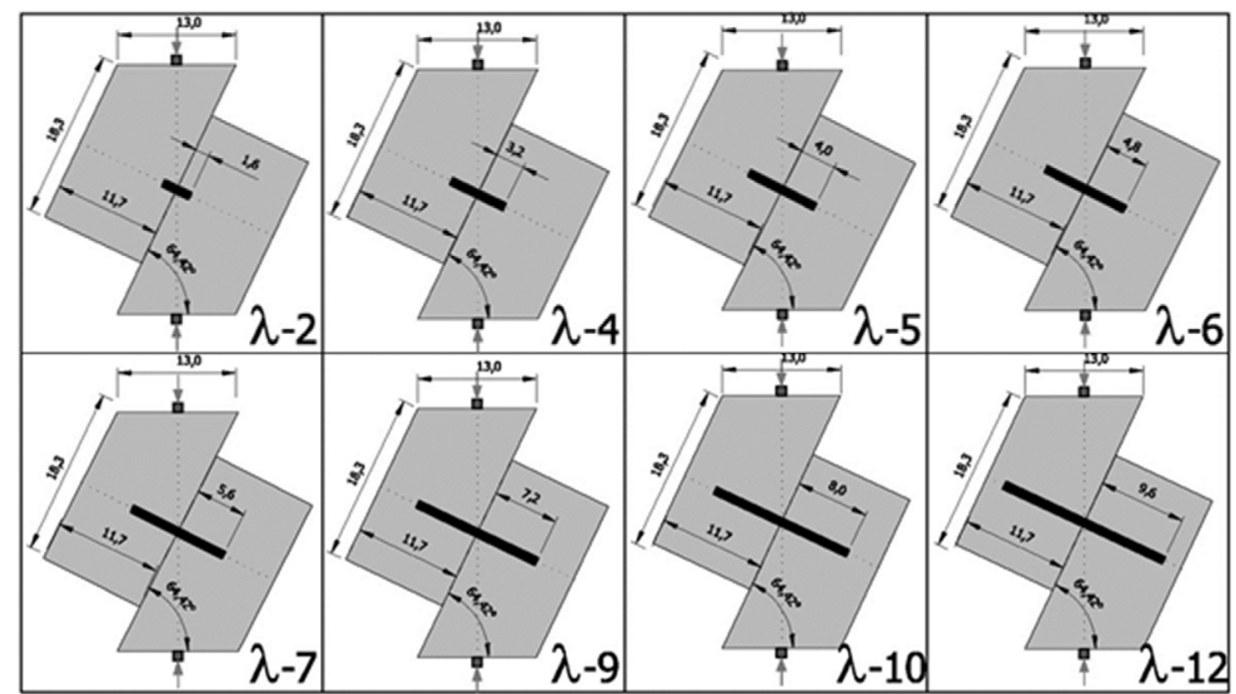

figura 22. Probetas de madera aserrada

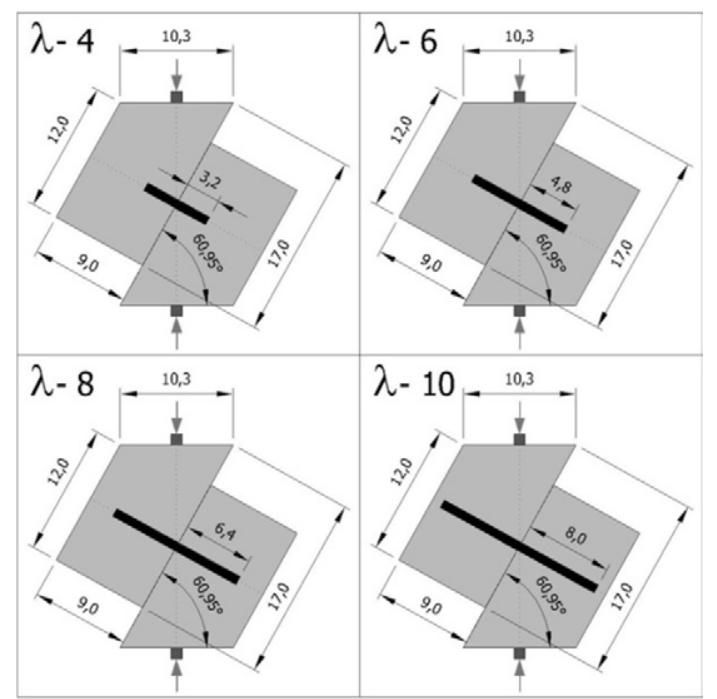

figura 23. Probetas de madera microlaminada

\footnotetext{
${ }^{20}$ Los resultados de estos ensayos están detallados en el Anejo II. "Conexiones a rasante. Trabajos previos".
} 
El conector empleado ha sido un pasador (barra lisa) de $\varnothing 8 \mathrm{~mm}$ introducido con pretaladro del mismo diámetro, y los resultados obtenidos se aplicarán en los conectores estudiados: clavos, tirafondos, tornillos y barras corrugadas; con y sin resina. En estos ensayos previos se ha empleado este pasador para poder tener una barra simétrica.

En los ensayos realizados se va modificando la longitud de empotramiento de los pasadores de acero en la madera. Se han estudiado 8 esbelteces distintas en madera aserrada y 4 en madera microlaminada. De cada una de ellas se han realizado 4 ensayos (un total de 48 ensayos).

Se emplea el término esbeltez $(\lambda)$ para describir la relación entre longitud de uno de los lados del empotramiento y el $\varnothing$.

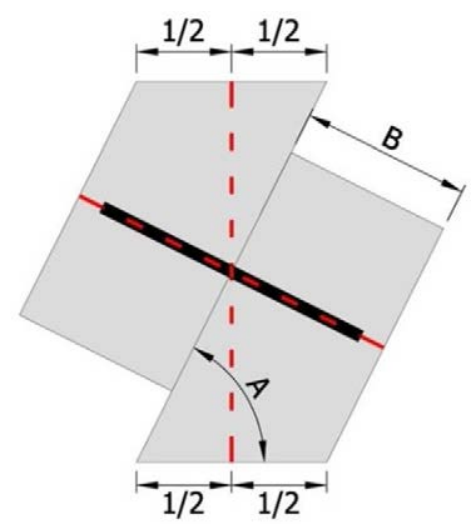

figura 24. Geometría de las probetas

En la figura 24 se muestra la geometría de las probetas. La dimensión B es la necesaria para poder estudiar todas las esbelteces con el mismo tamaño de pieza.

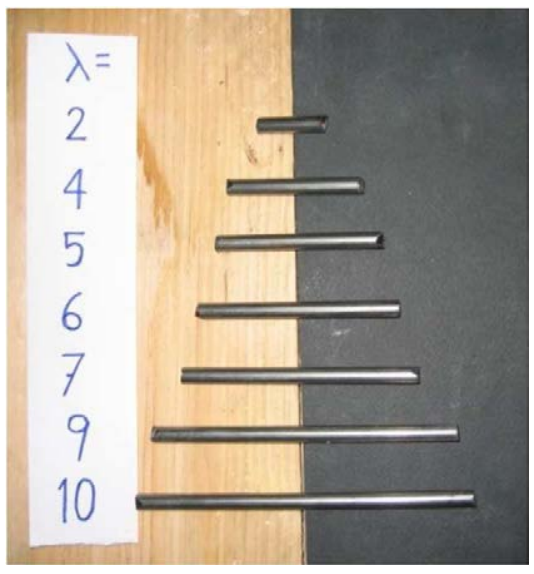

MADERA ASERRADA

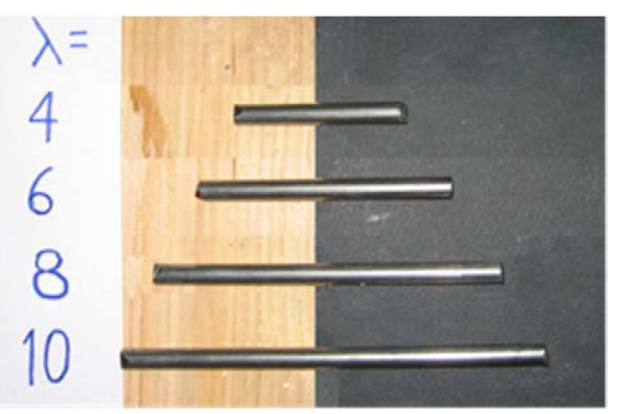

MADERA MICROLAMINADA

figura 25. Esbelteces ensayadas ${ }^{21}$

\footnotetext{
${ }^{21}$ En madera aserrada también se estudió la esbeltez 12, aunque no haya sido incluida en la figura 25.
} 


\section{Preparación de las Probetas}

Antes de unir las dos piezas de madera, se frotan sus caras de contacto con jabón para minimizar efectos locales de adherencia entre las caras de las piezas.

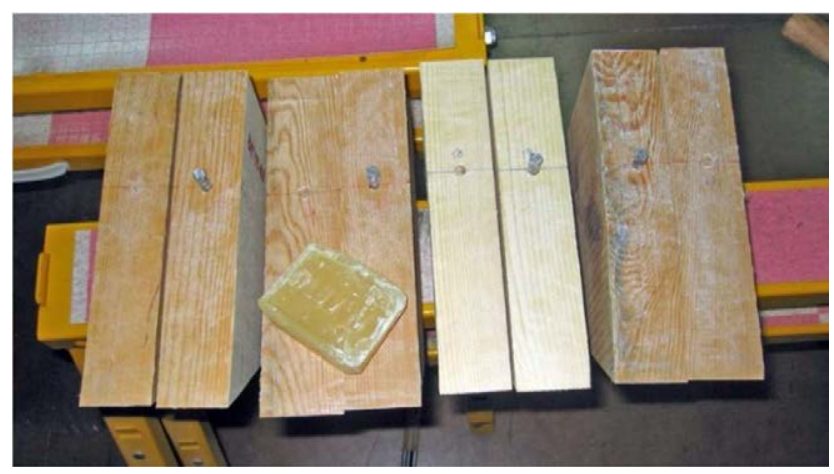

figura 26. Preparación de probetas para minimizar el rozamiento

\section{ESBELTEZ DEL CONECTOR EN MADERA ASERRADA}

\section{$\underline{\text { Resultados }}^{22}$}

Los resultados se van a presentar de dos formas: La primera, representando las curvas de esbeltez referidas a unos ejes de rasante y deslizamiento (figura 27), la segunda, representando las curvas de deslizamiento en unos ejes de rasante y esbeltez (figura 28). La primera es el resultado directo del ensayo y la segunda la elaboración que permite obtener conclusiones con más claridad.

\section{GRÁFICAS RASANTE-DESLIZAMIENTO}

El gráfico de la izquierda de la figura 27 muestra los resultados de las 34 probetas ensayadas, pero la lectura de su contenido resulta imposible. Las descargas que se observan en la zona de deslizamientos menores a $2 \mathrm{~mm}$ corresponden con el protocolo de aplicación de carga de la Norma UNE EN 26891.

En el gráfico de la derecha se han sustituido todos los ensayos por los valores medios de cada esbeltez, y también se ha eliminado el proceso de descarga citado. La curva de esbeltez 7 se representa en negro y regruesada por ser la referencia habitual.

\footnotetext{
${ }^{22}$ Los resultados de estos ensayos están detallados en el Anejo II.2. "Conexiones a rasante. Trabajos previos. Esbeltez del conector en madera aserrada".
} 

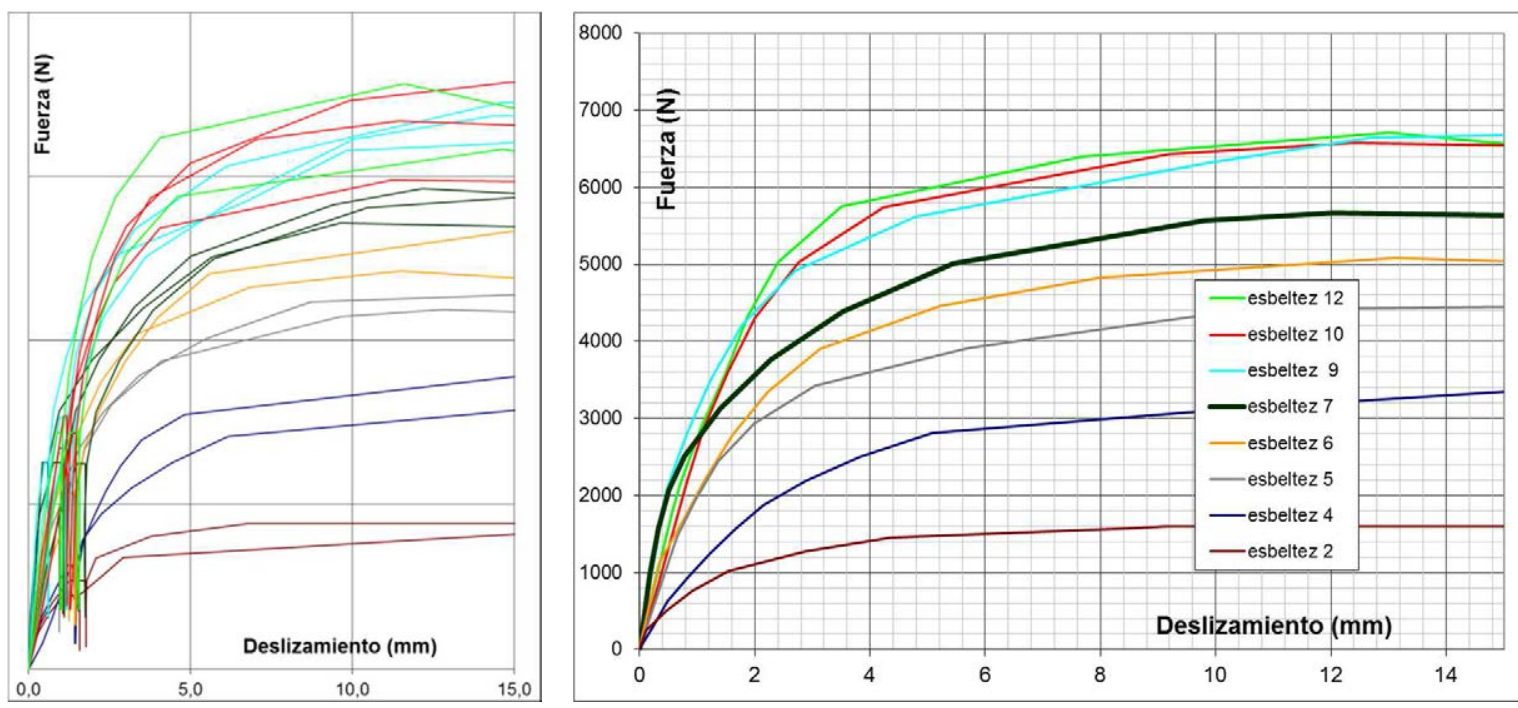

figura 27. Graficas de rasante-deslizamiento

Puede observarse que la carga queda prácticamente estabilizada a partir de la esbeltez 9.

\section{GRÁFICAS RASANTE-ESBELTEZ}

En la figura 28 se representan ahora en el eje horizontal las distintas esbelteces ensayadas y cada curva corresponde a un valor concreto de deslizamiento. En esta presentación se aprecia con claridad que el valor de rasante resistido crece hasta una determinada esbeltez (esbeltez mínima) y a partir de ahí se estabiliza. La esbeltez 7 está regruesada igual que en el caso anterior.

Los deslizamientos alcanzados en las vigas ensayadas apenas superan los $3 \mathrm{~mm}$ cuando se alcanza la rotura y no llegan al milímetro para cargas de servicio en edificación urbana.

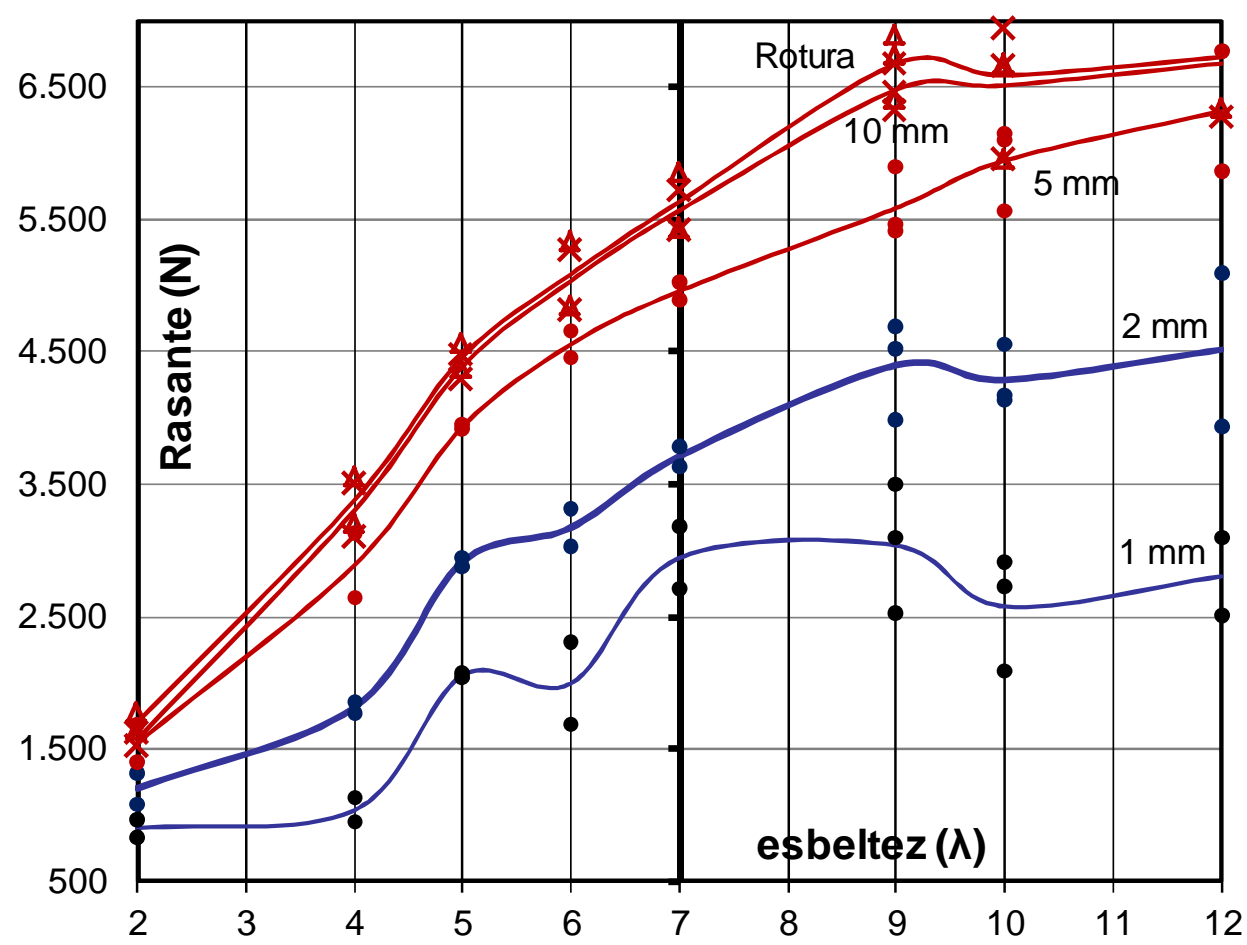

figura 28. Gráficas de rasante-esbeltez 
Analizando la curva de deslizamiento $1 \mathrm{~mm}$ se observa que los puntos que representan a los ensayos estabilizan el rasante a partir de una esbeltez 7. Como se ha comentado, esta magnitud de deslizamientos son los esperables en la banda de cargas y luces en las que se centra este trabajo. ${ }^{23}$

En el caso de la curva de deslizamiento $2 \mathrm{~mm}$, el rasante sigue subiendo hasta esbeltez 9 .

Se han dibujado también el resto de las curvas, pero deslizamientos superiores a $2 \mathrm{~mm}$ no entran en el rango de estructuras reales de cualquier tamaño en el que se emplee esta conexión.

En la figura 29 se muestran los valores medios de $\mathrm{K}_{\text {ser }}$ obtenidos para cada esbeltez de pasador. Se señala también el coeficiente de variación obtenido:

\begin{tabular}{|c|c|c|c|c|c|}
\hline esbeltez & $\begin{array}{c}\mathrm{K}_{\mathrm{ser}} \\
(\mathrm{N} / \mathrm{m} \mathrm{m})\end{array}$ & CoV & esbeltez & $\begin{array}{c}\mathrm{K}_{\mathrm{ser}} \\
(\mathrm{N} / \mathrm{m} \mathrm{m})\end{array}$ & CoV \\
\hline 2 & 881 & $11,5 \%$ & 7 & 3.112 & $7,3 \%$ \\
\hline 4 & 959 & $3,4 \%$ & 9 & 2.892 & $12,2 \%$ \\
\hline 5 & 2.544 & $34,3 \%$ & 10 & 2.728 & $12,2 \%$ \\
\hline 6 & 1.727 & $13,0 \%$ & 12 & 2.648 & $11,4 \%$ \\
\hline \multicolumn{3}{|c|}{ Kser: } & & 2994 & $\mathrm{~N} / \mathrm{mm}$ \\
\hline
\end{tabular}

figura 29. Resumen de resultados

${ }^{23}$ La gran dispersión de resultados que se observa en este caso cabe achacarla a que son los estados iniciales, Ilenos de desajustes; esta dispersión es mucho menor a medida que aumenta el deslizamiento. 


\section{Resumen Fotográfico}

Terminado el ensayo se han extraído los pasadores y se han fotografiado sobre las probetas de madera (figura 30) para mostrar con claridad los tipos de deformación obtenido. Aquí se ve claramente que la deformación que marca la esbeltez en la que el pasador está bien empotrado en las dos piezas de madera, más que a partir de 7 se sitúa a partir de 9 (coincide con lo que se ve en la figura 28).

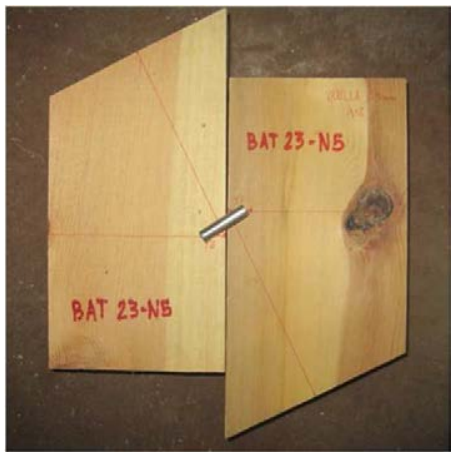

ESBELTEZ 2

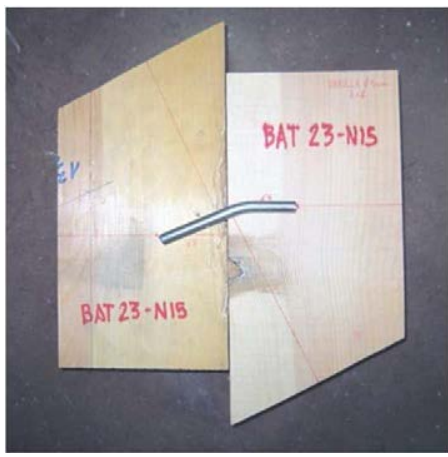

ESBELTEZ 6

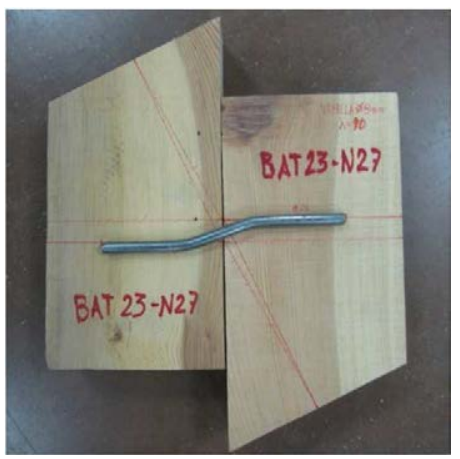

ESBELTEZ 10

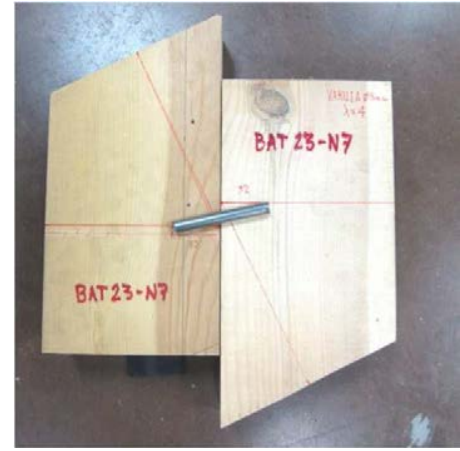

ESBELTEZ 4

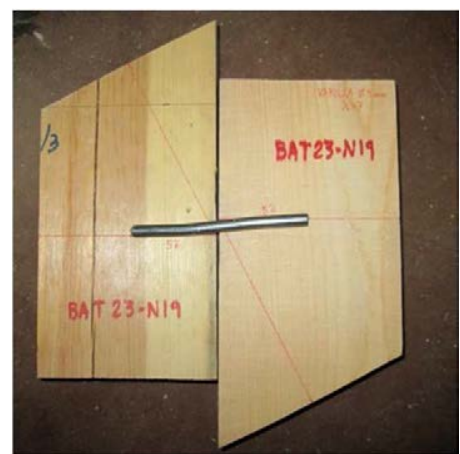

ESBELTEZ 7

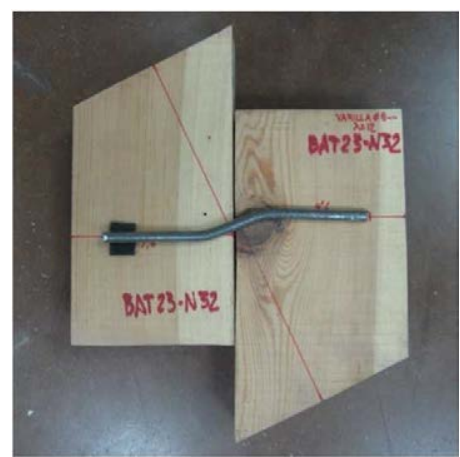

ESBELTEZ 12

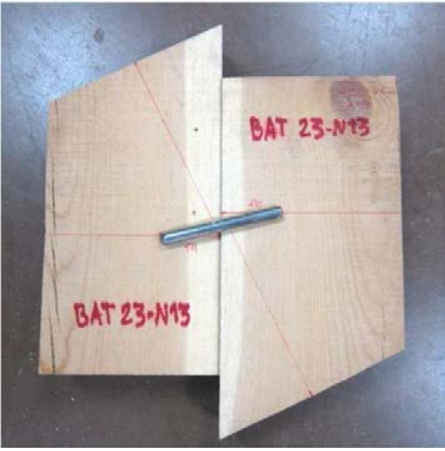

ESBELTEZ 5

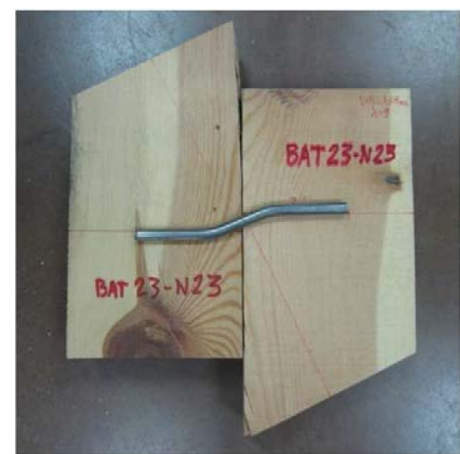

ESBELTEZ 9

figura 30. Deformación de los conectores 


\section{CONCLUSIONES}

Analizando los resultados de fuerza/deslizamiento de los ensayos y los conectores deformados se realizan las siguientes observaciones:

-Las piezas unidas con pasadores de esbelteces $2,4,5$ y 6 no tienen profundidad suficiente para alcanzar el empotramiento, y eso conduce a que la rigidez (módulo de

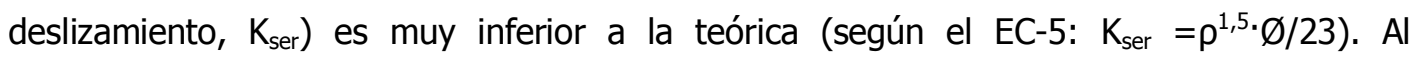
seccionar estas piezas después de realizar los ensayos y observar la deformación de los conectores (figura 28), no se aprecia (salvo en un caso de esbeltez 6 ) ninguna rótula en los pasadores.

-En las piezas unidas con pasadores de esbeltez 7 se puede apreciar que algunos de ellos están doblados, por lo que ha empezado a funcionar el empotramiento entre estos y una de las dos piezas de madera. Por lo que se puede deducir que el empotramiento comenzará a funcionar con una profundidad de pasador superior a 7 diámetros.

-En las piezas unidas con pasadores de esbelteces 9, 10 y 12 diámetros, se aprecia perfectamente una homogeneidad en los resultados y de hecho, no existe mejoría de las rigideces $\left(\mathrm{K}_{\mathrm{ser}}\right)$ a partir de los 9 diámetros de empotramiento. Igualmente, viendo las deformaciones de los conectores después de ser ensayados, se aprecia en todos los casos la doble rótula que indica que se ha empotrado en ambas piezas de madera.

Por lo tanto, en todos los ensayos de esta tesis, los conectores se han introducido en la madera un mínimo de 8 diámetros para asegurar el buen funcionamiento de la unión.

Aunque obviamente el número de ensayos es mínimo para alterar estudios perfectamente decantados, no puede dejarse de anotar que la esbeltez segura puede que sea al menos 8 . 


\section{ESBELTEZ DEL CONECTOR EN MADERA MICROLAMINADA}

\section{Resultados $^{24}$}

Los resultados se presentan de las mismas dos formas que en el apartado anterior.

\section{GRÁFICAS RASANTE-DESLIZAMIENTO}

En la figura 31 solo se incluye el gráfico del valor medio de cada esbeltez.

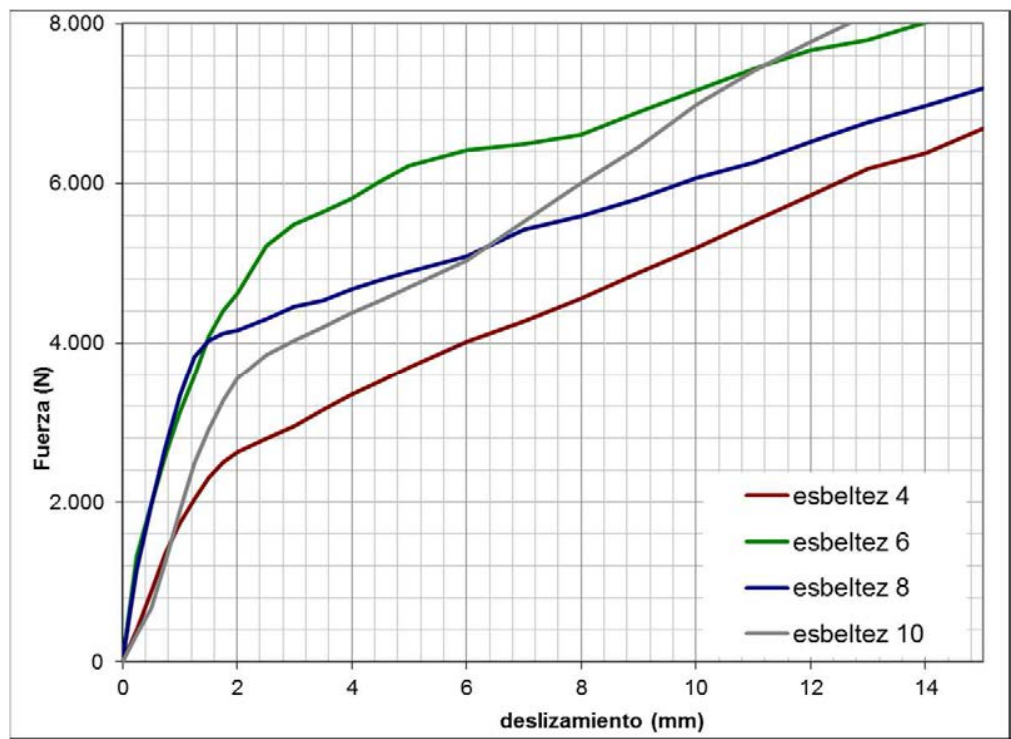

figura 31. Gráficas de rasante-deslizamiento

\section{GRÁFICAS RASANTE-ESBELTEZ}

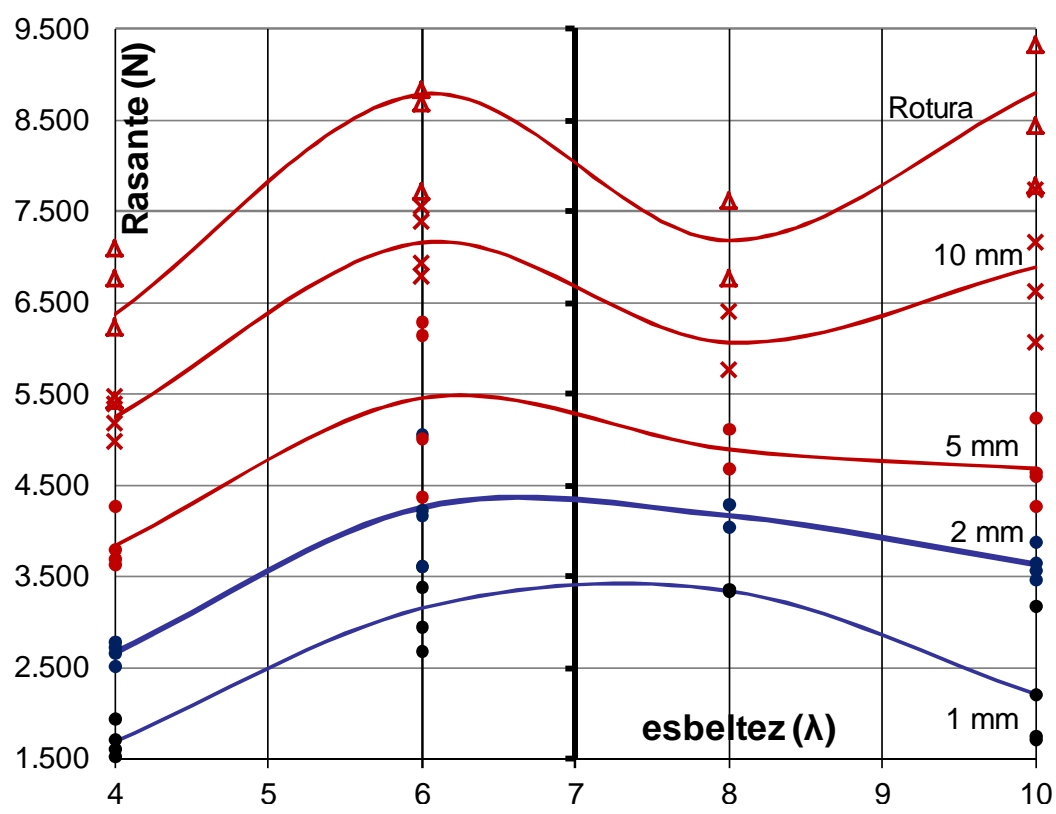

figura 32. Gráficas de rasante-esbeltez

24 Los resultados de estos ensayos están detallados en el Anejo II.3. "Conexiones a rasante. Trabajos previos. Esbeltez del conector en madera microlaminada". 
Analizando las curvas de deslizamientos (figura 32) se observa que el rasante queda estabilizado a partir de una esbeltez 6 .

\begin{tabular}{|c|c|c|c|c|c|}
\hline esbeltez & $\begin{array}{c}\mathrm{K}_{\text {ser }} \\
(\mathbf{N} / \mathbf{m ~ m})\end{array}$ & CoV \\
\hline 4 & $\mathbf{1 . 3 9 2}$ & $13,3 \%$ \\
\hline 6 & 2.249 & $24,5 \%$ \\
\hline
\end{tabular}

figura 33. Resumen de resultados de ensayos

\section{Resumen Fotográfico}

En la figura 34 se ve que con $\lambda=6$ ya hay empotramiento. ${ }^{25}$

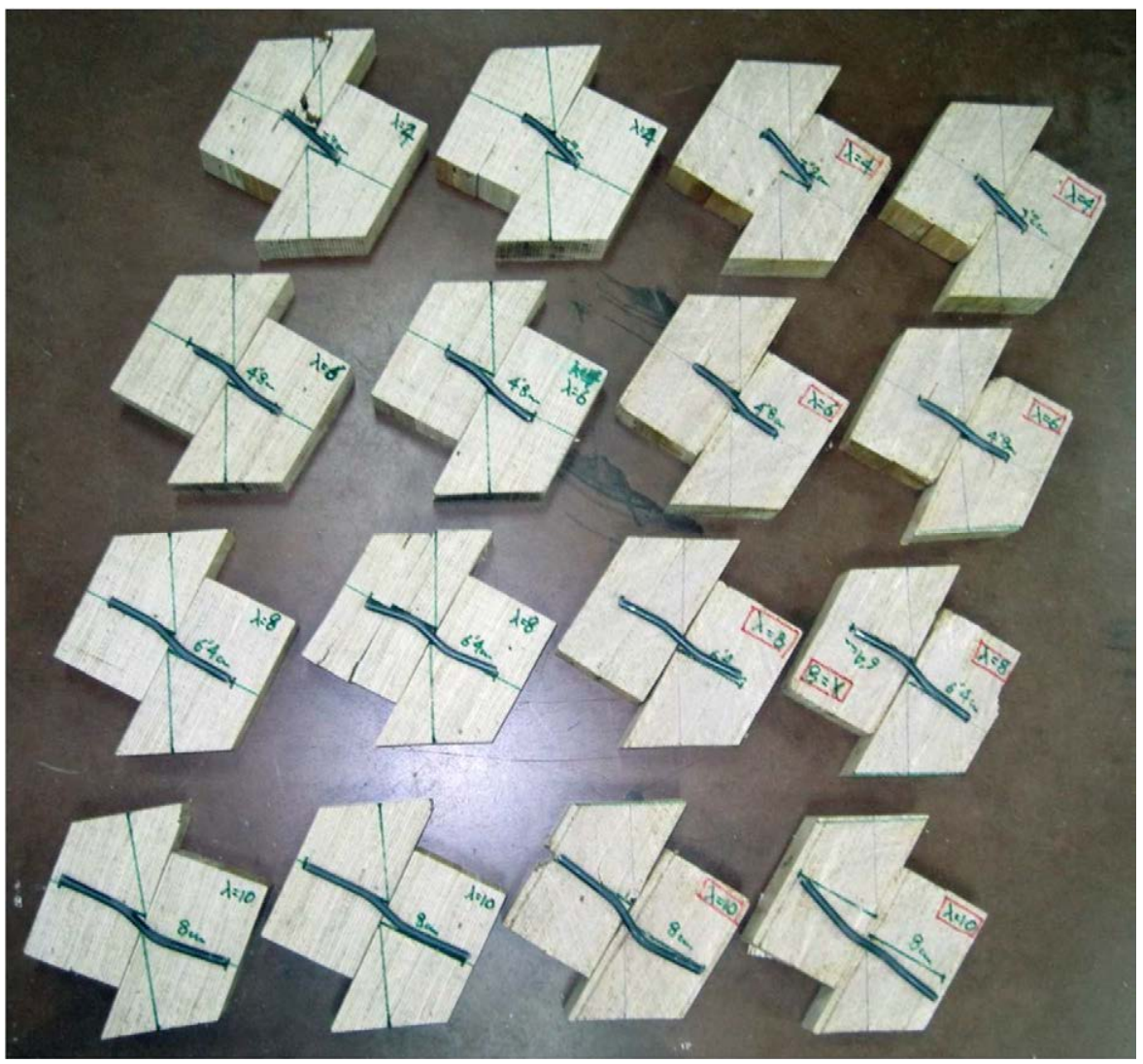

figura 34. Deformación de los conectores

${ }^{25}$ En las fotografías de las figuras 34, 35 y 36 las probetas se han montado al revés por error. 


\section{CONCLUSIONES}

Analizando los resultados de fuerza/deformación de los ensayos y los conectores deformados se aprecia que las piezas unidas con pasadores de esbeltez 4 no tienen profundidad suficiente para producir el empotramiento (figura 35).

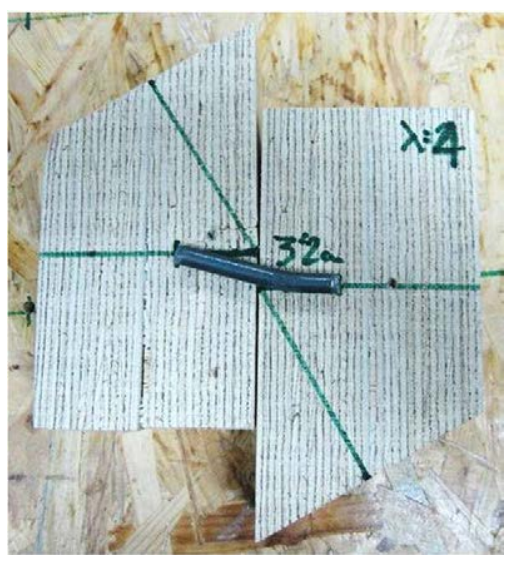

figura 35. Esbeltez 4

Sin embargo, se puede apreciar que alguno de los pasadores está doblado, por lo que ha empezado a funcionar el empotramiento entre este y una de las dos piezas de madera microlaminada.

En el resto de los modelos ensayados, de esbelteces 6,8 y 10 diámetros, se aprecia perfectamente una homogeneidad en los resultados y de hecho, no existe mejoría de las rigideces $\left(\mathrm{K}_{\mathrm{ser}}\right)$ a partir de los 6 diámetros de empotramiento. En las fotografías de la figura 36 se aprecia el doble empotramiento en todas las piezas de madera.

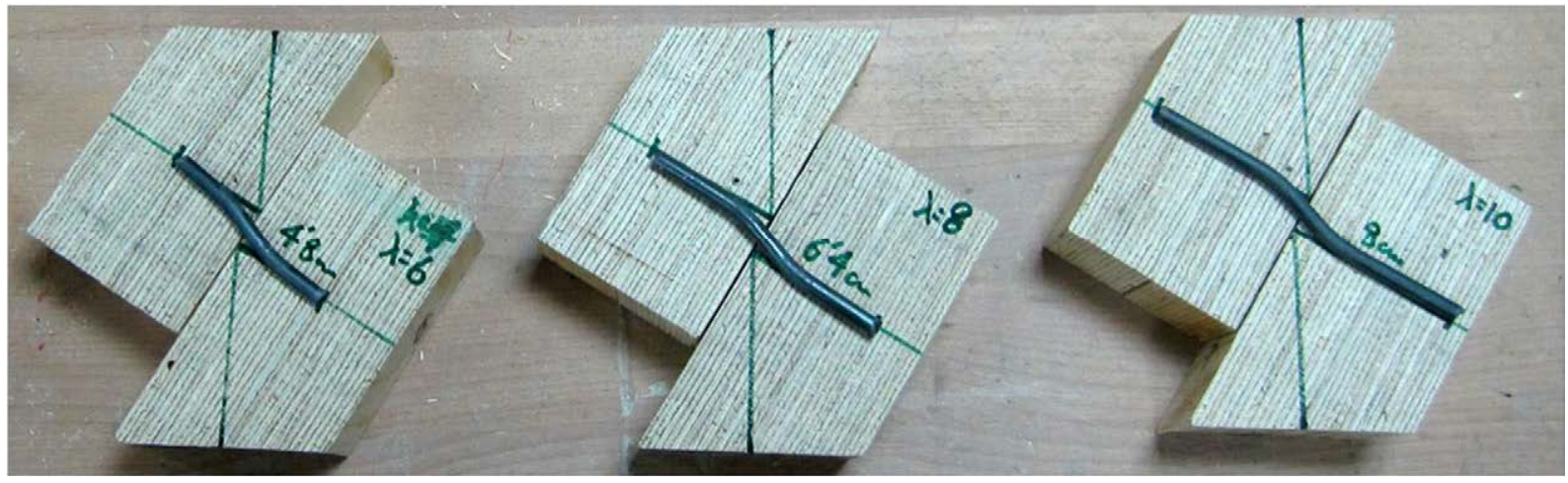

figura 36. Esbelteces 6, 8 y 10

Por lo tanto, en todos los ensayos de esta tesis, los conectores se introducen en la madera microlaminada un mínimo de 6 diámetros para asegurar el buen funcionamiento de la unión. 


\section{NÚMERO ADECUADO DE CONECTORES POR PROBETA}

La Norma UNE 26891, que regula los ensayos para la determinación de las características de resistencia y deslizamiento de las uniones tipo clavija, no indica qué características geométricas (dimensiones, forma o número de conectores) deben tener las probetas ensayadas.

Como en general en este trabajo se van a realizar pocas probetas de cada tipo de conexión ( 3 ensayos por tipo), no se van a obtener valores demasiado fiables estadísticamente. Esto hace tomar una serie de decisiones en el diseño de las probetas que permitan obtener unos resultados lo más homogéneos posibles.

Para este estudio se han realizado varias configuraciones de la conexión en las probetas, todas ellas con el mismo conector (clavos $\varnothing 4,4$ ) para comprobar la influencia del número y la colocación de los elementos de fijación en los resultados de los ensayos (figura 37). De cada configuración se han realizado 3 ensayos.

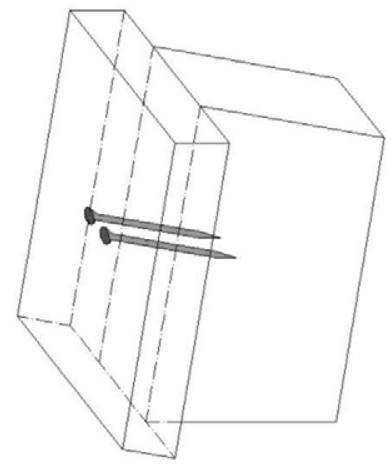

1

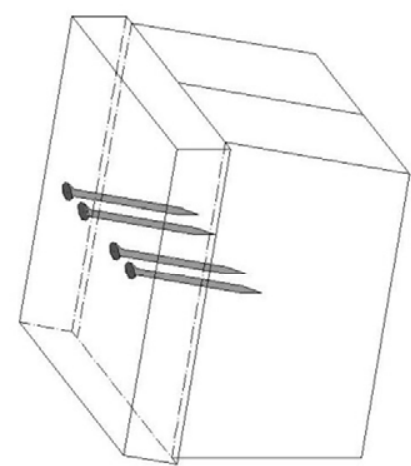

2

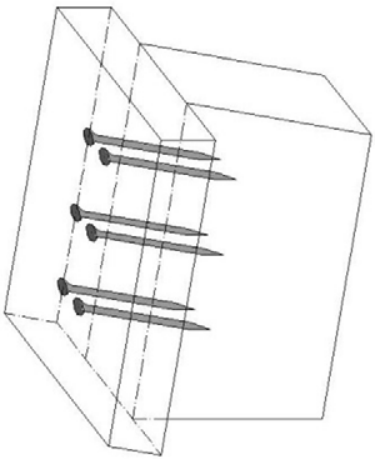

3

figura 37. Diferentes probetas ensayadas

En los ensayos con dos conectores puestos en línea (figura 37. 1) se han obtenido resultados muy poco homogéneos, con un coeficiente de variación del $23 \%$ en el módulo de deslizamiento $\left(\mathrm{K}_{\mathrm{ser}}\right)$.

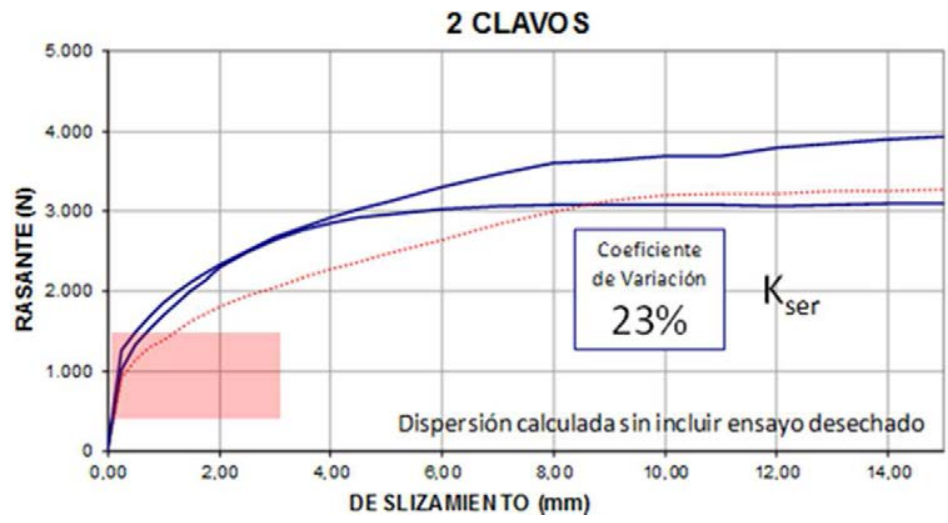

figura 38. 2 clavos 
En los ensayos de las probetas realizadas con 4 conectores puestos en línea (figura 37. 2) se obtienen resultados más homogéneos (coeficiente de variación del 6\%), sin embargo han resultado ser mucho más rígidas que las anteriores. Esto se debe a que al estar todos los conectores puestos en línea, para cumplir con las separaciones mínimas entre ellos, se construyeron las probetas con dos viguetas pegadas entre sí, y este factor ha resultado tener una gran influencia. Además durante la realización del ensayo se producía un giro extraño entre la vigueta y la capa de compresión. Por todo esto, se ha descartado el uso de este tipo de probetas en el resto del trabajo.

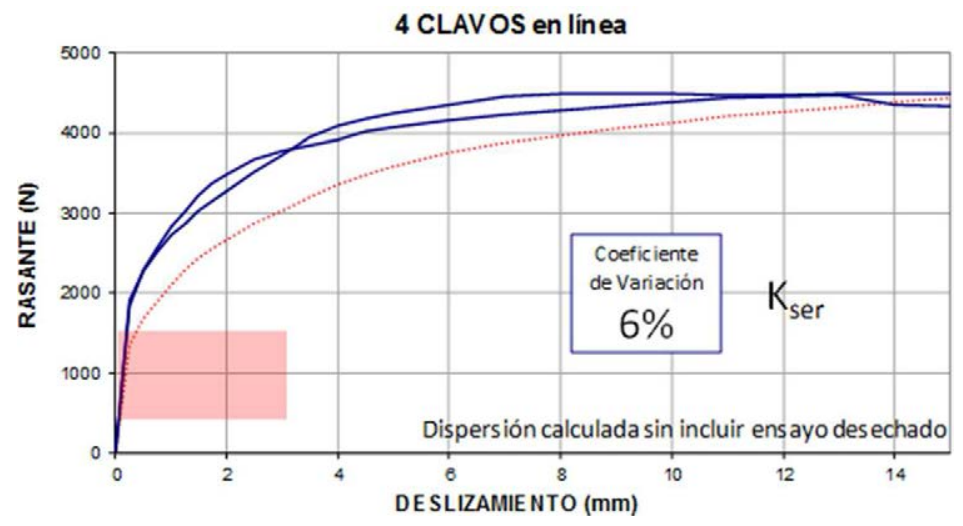

figura 39. 4 clavos

Por último, las probetas con 6 conectores colocados en dos filas (figura 37. 3), que tienen el inconveniente de que la línea de carga no pasa en los conectores extremos por el punto de unión de la viga y la capa de compresión, pudiendo producir este hecho un efecto de palanca entre los conectores superiores e inferiores. No obstante, aunque pudiera existir un pequeño aumento de rigidez debido a este efecto, los resultados obtenidos fueron homogéneos (CoV del 2\%). Debe indicarse que este efecto, que se considera pernicioso en este ensayo simple (por poder alterar al alza los resultados de resistencia o de rigidez), es lo que ocurre en la conexión de las vigas así reforzadas. Además, en las gráficas comparativas de la figura 41 se observa que este efecto, de producirse, no tiene una gran relevancia en la rigidez de los ensayos.

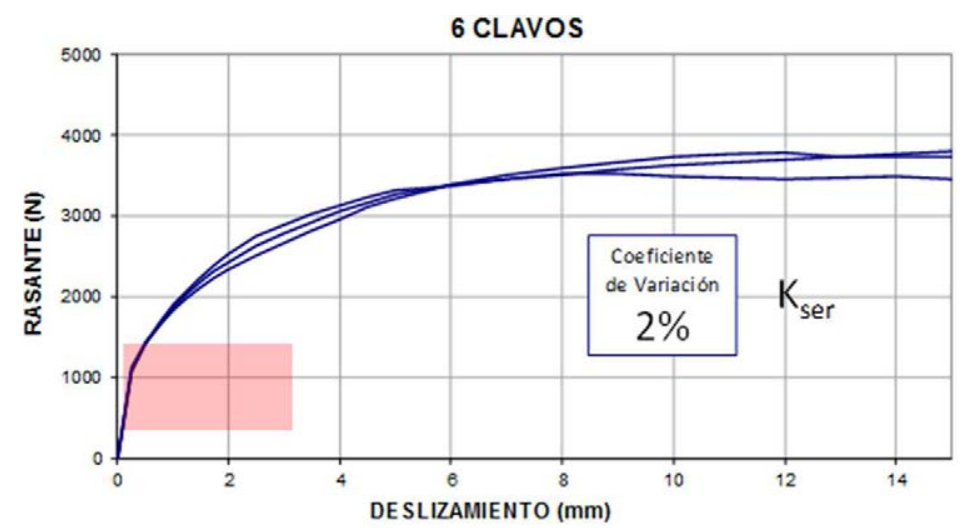

figura 40. 6 clavos

En la figura 41 están representados los valores medios de los 3 casos, apreciándose la cercanía entre resultados de 1 y 3 , pero este con valores mucho más homogéneos ( $2 \%$ de CoV). LA VIGA MIXTA CON MADERA: verificación experimental del método gamma y estudio de posibles alternativas de análisis 


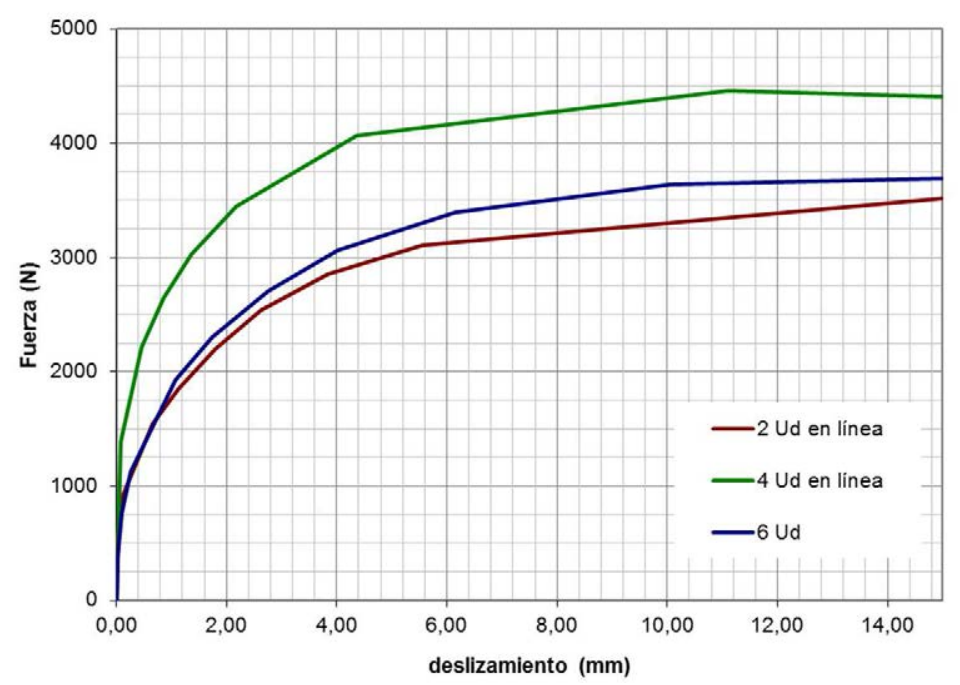

figura 41. Gráficas de Rasante-deslizamiento de los ensayos

\begin{tabular}{|c|c|c|c|c|c|c|c|}
\hline \multicolumn{7}{|c|}{ CLAVOS DIÁMETRO $4,4 \mathrm{~mm}$} & \multirow[b]{2}{*}{$K_{\text {ser }} E C-5$} \\
\hline $\begin{array}{c}\varnothing \\
\text { CLAVO }\end{array}$ & & $\begin{array}{l}F \text { para } \\
V=5 \mathrm{~mm}\end{array}$ & $\begin{array}{c}\begin{array}{c}F \text { para } \\
\mathrm{V}=10 \mathrm{~mm}\end{array}\end{array}$ & $\begin{array}{c}F \text { para } \\
v=15 \mathrm{~mm}\end{array}$ & $\mathrm{~K}_{\mathrm{ser}}$ & CoV & \\
\hline 4,4 & $2 \mathrm{Ud}$ & 2.955 & 3.079 & 3.092 & 1.886 & & \\
\hline 4,4 & en línea & 2.468 & 3.189 & 3.270 & 1.082 & & \\
\hline \multirow[t]{2}{*}{4,4} & & 3.111 & 3.678 & 3.937 & 3.038 & & \\
\hline & media & 2.844 & 3.315 & 3.433 & 2.462 & $23 \%$ & 1.232 \\
\hline 4,4 & $4 \mathrm{Ud}$ & 3.583 & 4.120 & 4.444 & 2.967 & & \\
\hline 4,4 & en línea & 4.062 & 4.388 & 4.337 & 9.532 & & \\
\hline \multirow[t]{2}{*}{4,4} & & 4.236 & 4.494 & 4.482 & 10.732 & & \\
\hline & media & 3.961 & 4.334 & 4.421 & 10.132 & $6 \%$ & 1.232 \\
\hline$\overline{4,4}$ & $6 \mathrm{Ud}$ & 3.311 & 3.626 & 3.794 & 2.123 & & \\
\hline 4,4 & & 3.214 & 3.726 & 3.737 & 2.219 & & \\
\hline \multirow[t]{2}{*}{4,4} & & 3.258 & 3.494 & 3.531 & 2.135 & & \\
\hline & media & 3.261 & 3.615 & 3.687 & 2.159 & $2 \%$ & 1.232 \\
\hline & & dens & ad medi & 503,58 & & & \\
\hline
\end{tabular}

figura 42. Resultados de los ensayos

Todo esto lleva a tomar la determinación de construir las probetas para los ensayos de rasante con 6 conectores (siempre que los diámetros de los conectores y las separaciones mínimas que haya que cumplir lo permitan). 


\subsubsection{LA PROBETA}

\section{DISEÑO}

La Norma de este ensayo (UNE EN 26891. Estructuras de madera. Uniones realizadas con elementos de fijación mecánicos) no hace referencia a dimensiones, geometría o conexión de las probetas.

La mayoría de los ensayos realizados en otros trabajos para estudiar el esfuerzo rasante corresponden a los casos A y B de la figura 43. En estos sistemas, la oblicuidad de la línea de transmisión de carga obliga a crear un apoyo horizontal auxiliar (caso A) o a realizar sistemas de ensayo simétricos que inducen esas mismas fuerzas horizontales introduciendo un efecto mordaza en la unión (caso B).

En esta tesis se ha girado la probeta para que la línea de acción de la carga aplicada sea vertical, evitando la necesidad de fuerzas transversales auxiliares (figura 43. C). El ángulo entre la fuerza y el plano de deslizamiento es muy inferior al ángulo de rozamiento, ${ }^{26}$

Las dos piezas se unen mediante distintos tipos de conectores que las atraviesan perpendicularmente a su superficie de contacto.

La directriz del conector, la línea de acción de la fuerza aplicada y la superficie de contacto de las dos piezas coinciden en un punto (centro geométrico del conjunto).

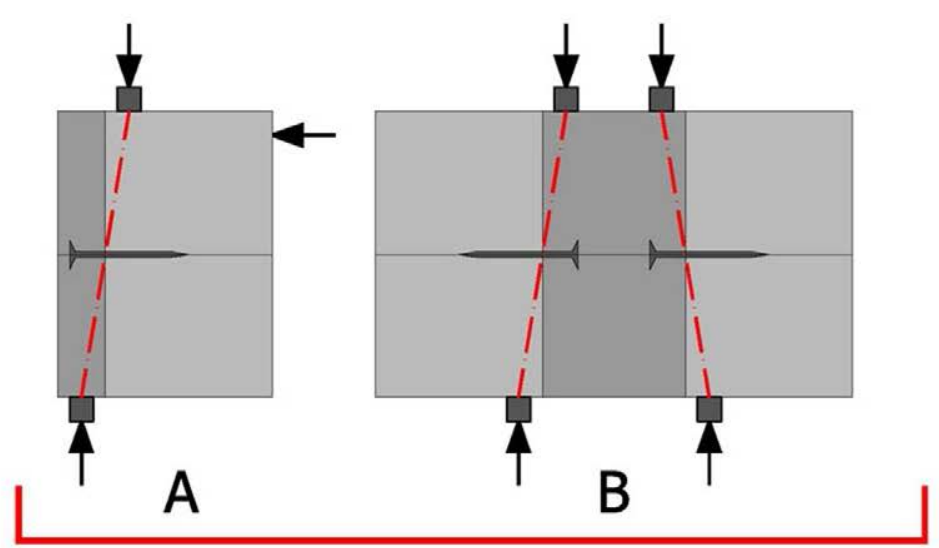

TRABAJOS DE OTROS AUTORES

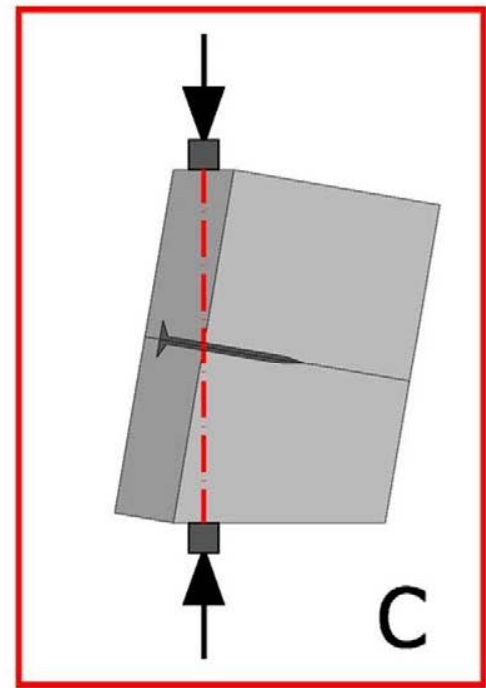

PROBETAS ENSAYADAS

figura 43. Tipos de probetas de ensayos de rasante

\footnotetext{
${ }^{26}$ En Helsinki, los autores Jutila, Makipuro, Salokangas y Tommola [ref. 076, 094, 141 y 142] también utilizan probetas con el diseño " $C$ ".
} 


\section{DIMENSIONES, MATERIALES Y CONECTORES}

Las dimensiones nominales de las piezas ensayadas son las indicadas en la figura 44, aunque cada probeta está medida con exactitud después de su montaje, para tener en cuenta las modificaciones provocadas por su construcción. Se han ensayado 17 conexiones distintas, y de cada tipo se han realizado 3 ensayos.
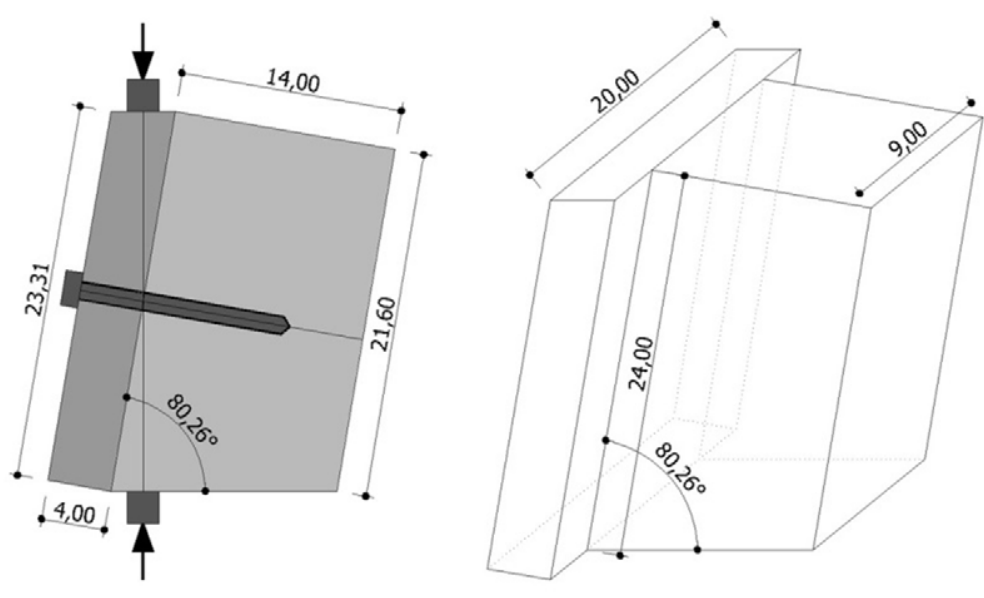

figura 44. Geometría de la probeta

\section{Materiales Empleados}

Los ensayos se han realizado para simular localmente la capa de compresión y la vigueta de una estructura mixta. La capa de compresión se ha hecho con hormigón (3 ensayos), madera aserrada ( 2 ensayos) (pino silvestre $\mathrm{C} 18$ ) y madera microlaminada (12 ensayos) (Abeto) y la vigueta se ha hecho con madera serrada ( 2 ensayos) (pino silvestre C18) y madera laminada (15 ensayos) (picea abies GL24h).

\section{Tipos de conectores}

Los conectores usados en estos ensayos son los mismos que los de las vigas mixtas:

TIRAFONDOS (Tornillos barraqueros. DIN571) de diámetros 6 a $12 \mathrm{~mm}$

(9 ensayos) Con pretaladro de diámetro mayor y relleno de resina Con pretaladro de diámetro menor y sin resina

BARRA CORRUGADA de diámetros 10 y $12 \mathrm{~mm}$.

(1 ensayo)

CLAVOS

(5 ensayos)

TORNILLOS HBS

(1 ensayo)

TORNILLOS VGZ

(1 ensayo)
Con pretaladro de diámetro mayor y relleno de resina de diámetro $5 \mathrm{~mm}$.

Sin pretaladro y sin resina

de diámetro de cálculo 4,3 (Ønominal 6 mm)

Sin pretaladro y sin resina

de diámetro de cálculo 5,0 (Ønominal 7 mm)

Sin pretaladro y sin resina 


\subsubsection{PROCEDIMIENTOS DEL ENSAYO}

\section{PROTOCOLO}

Los ensayos se realizaron según marca la Norma UNE EN 26891 (Estructuras de madera. Uniones realizadas con elementos de fijación mecánicos).

\section{Estimación de la carga máxima}

La Norma establece que el proceso de carga depende de la carga máxima que alcanzará el ensayo. Por este motivo la primera probeta de cada modelo se ha ensayado sin seguir el protocolo de la Norma para obtener este valor de rotura, denominado $F_{\text {est. }}$.

\section{Proceso de carga}

Siguiendo esta Norma, en la primera fase la carga crece hasta llegar al $40 \%$ de $\mathrm{F}_{\text {est }}$ (Fuerza estimada de rotura), se mantiene ahí 30 segundos, después se reduce hasta el $10 \%$ de $\mathrm{F}_{\text {est }}$ se mantiene de nuevo 30 segundos y finalmente se incrementa la carga hasta $F_{\text {est }} O$ hasta un deslizamiento de $15 \mathrm{~mm}$.

En la figura 45 se representa un ensayo donde se ven las diferentes fases de carga:

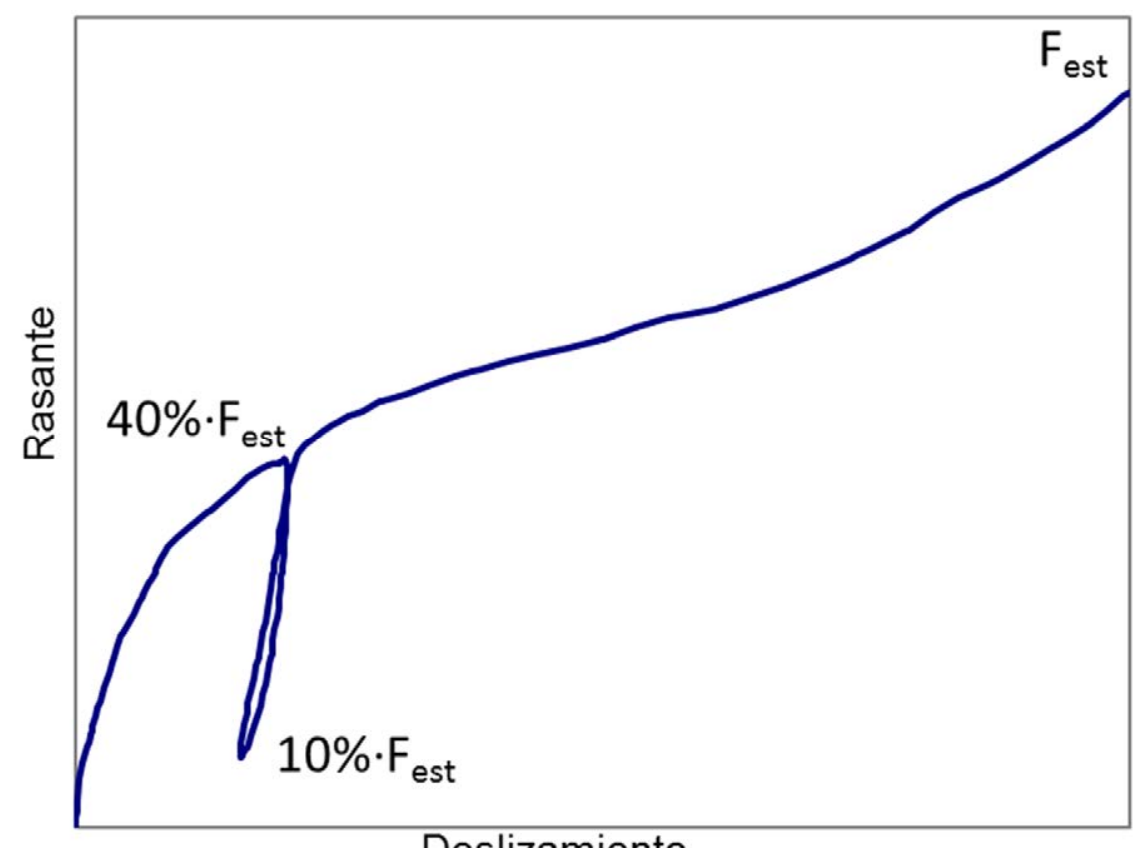

Deslizamiento

figura 45. Gráfica de ensayo de rasante 


\section{INSTRUMENTACIÓN}
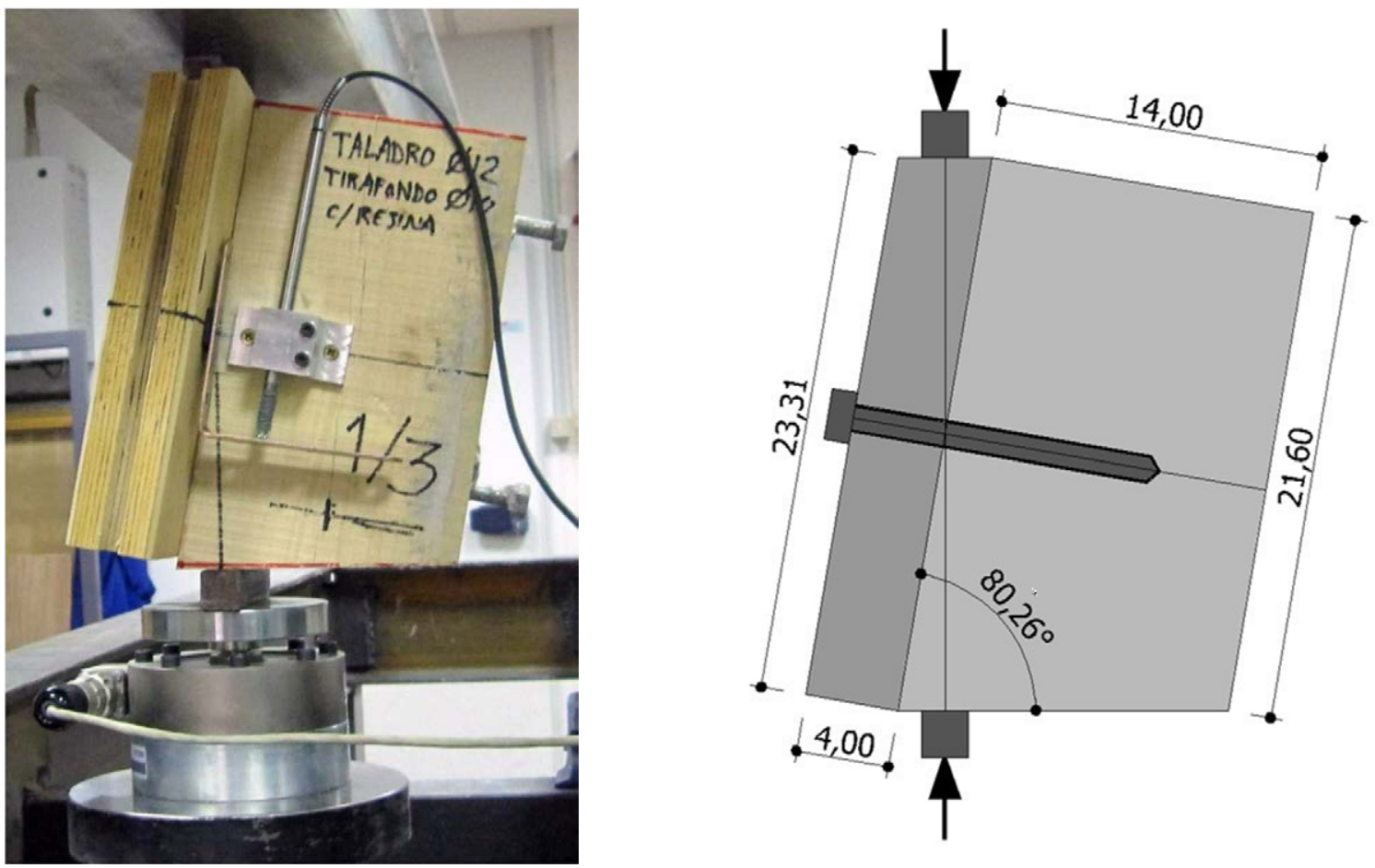

figura 46. Realización del ensayo e instrumentación

Los ensayos se realizaron con una máquina de ensayos universal electromecánica con $20 \mathrm{t}$ de capacidad.

-La carga aplicada se midió con una célula de carga con las siguientes características:

$\begin{array}{ll}\text {-Capacidad de carga } & 5.000 \mathrm{~kg} \\ \text {-Precisión } & 0,1 \mathrm{~kg}\end{array}$

La fuerza rasante $\mathrm{R}$ aplicada en el conector es:

$$
R=N \cdot \operatorname{sen}\left(80,26^{\circ}\right)
$$

-El deslizamiento entre las dos piezas se midió con un LVDT (Linear Variable Differential Transformer) con las siguientes características:

$\begin{array}{ll}\text {-Modelo } & \text { Solartron AX/10/S } \\ \text {-Rango de medida } & \pm 10 \mathrm{~mm} \\ \text {-Precisión } & 0,01 \mathrm{~mm}\end{array}$




\section{RESUMEN FOTOGRÁFICO}

Después de realizar los ensayos y llevar las probetas hasta su rotura, se seccionaron las piezas para poder ver el estado de los conectores (figura 47).
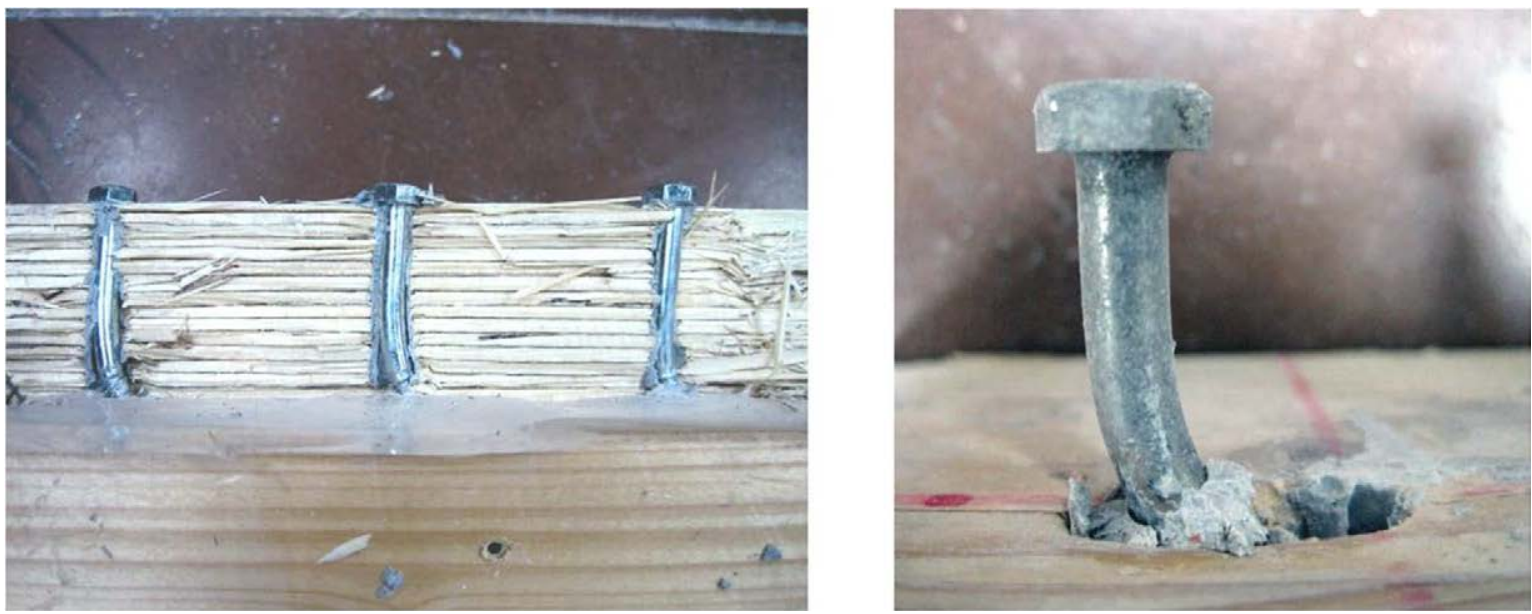

TIRAFONDOS
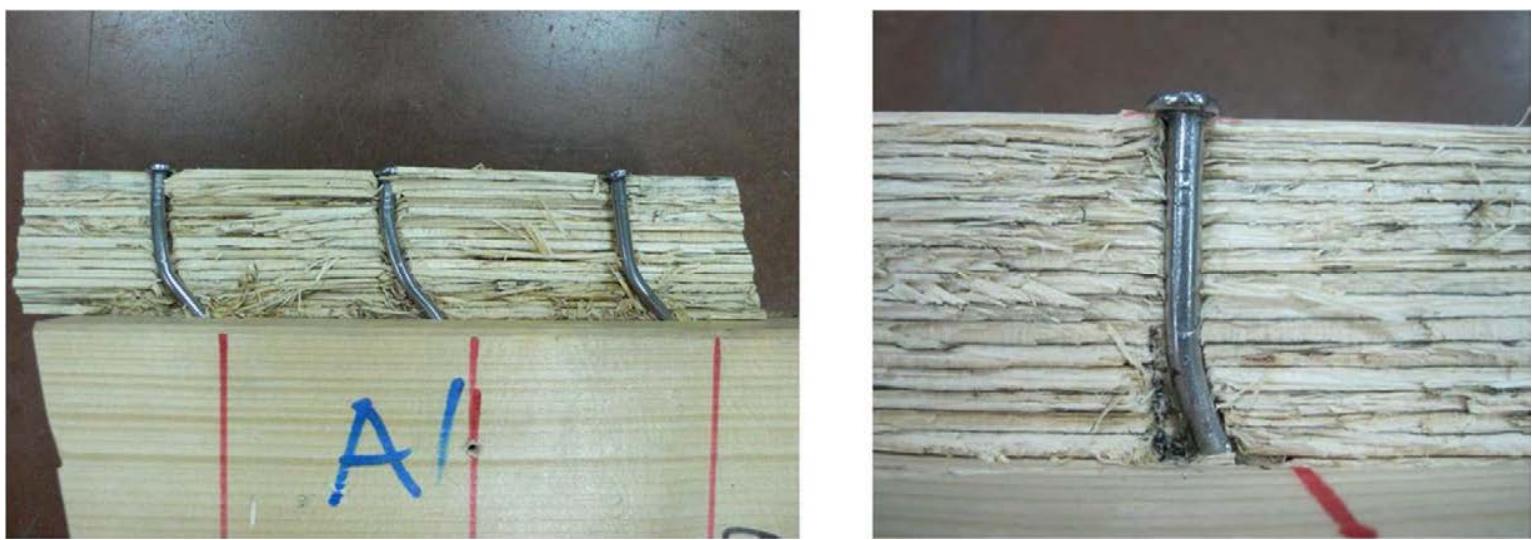

CLAVOS
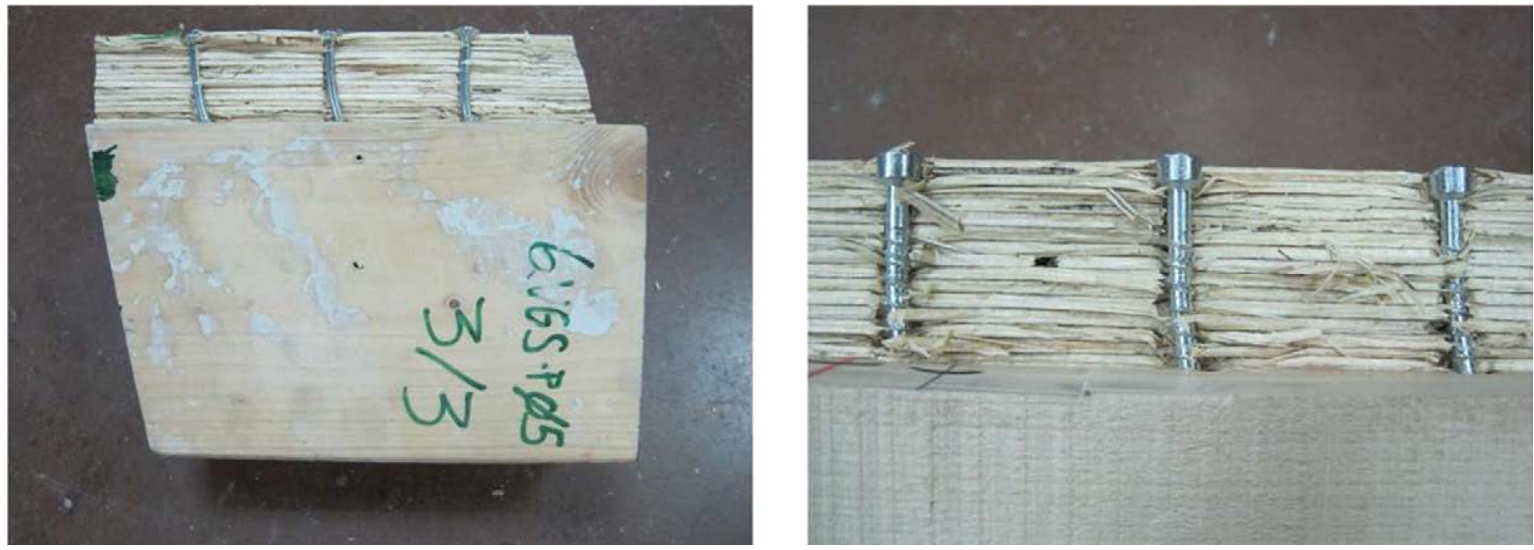

TORNILLOS

figura 47. Deformación de los conectores después del ensayo 


\subsubsection{CRITERIOS TOMADOS PARA OBTENER EL $K_{\text {ser. }}$ GRÁFICA REPRESENTATIVA DE CADA TIPO DE ENSAYO}

Se han realizado 3 ensayos de cada tipo de conexión. Un ensayo no detectaría errores en el procedimiento $y$, si hubiera grandes diferencias entre dos, tampoco se podría conocer si uno o ambos han fallado, de modo que eso ha fijado el mínimo en tres ensayos por tipo.

En los resultados pueden ocurrir tres cosas:

1- Cuando los resultados de los 3 ensayos son similares se toma como gráfica representativa la media de los 3.

2- Cuando los resultados de 2 ensayos son similares, y el otro no, se descarta este resultado disperso y se obtiene la gráfica representativa usando los 2 ensayos parecidos.

3 Cuando los resultados de los 3 ensayos difieren: Se obtiene la gráfica representativa usando los 3 ensayos, ya que no se dispone de más datos.

En la figura 48 se muestran los 3 casos posibles tomados de ensayos realizados.
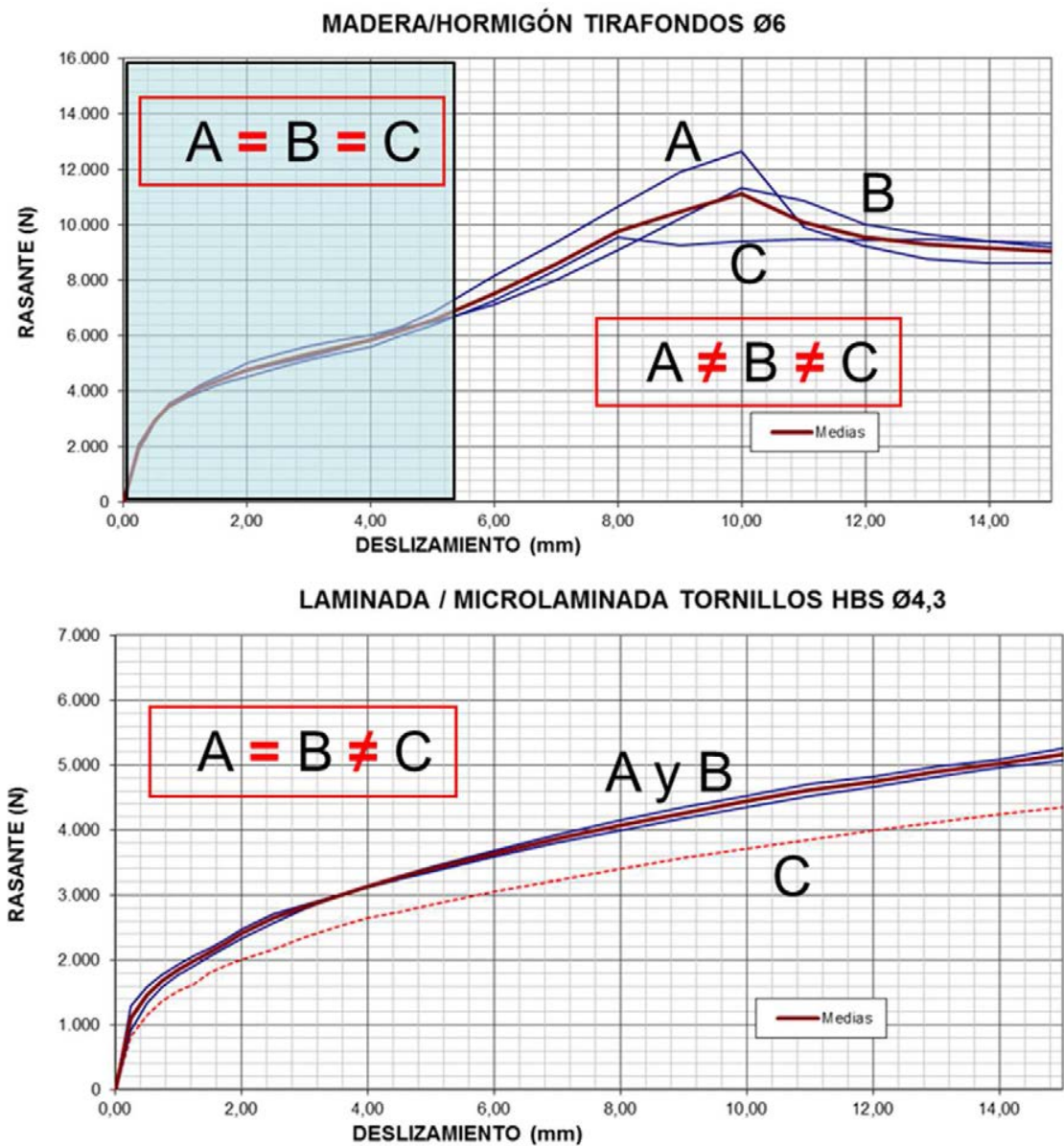

figura 48. Homogeneidad en los ensayos 


\section{FUERZA MÁXIMA ESTIMADA ( $\left.F_{\text {est }}\right)$ PARA OBTENER EL $K_{\text {ser }}$}

En un primer análisis de los resultados se detectó una gran variabilidad de los Módulos de Deslizamiento $\left(\mathrm{K}_{\mathrm{ser}}\right)$ obtenidos según la Norma para ensayos sensiblemente iguales, por lo que se analiza a continuación esta dispersión de los resultados.

\section{Especificaciones de la Norma EN 26891:1991 sobre la Fest}

El propósito principal de la realización de estos ensayos de rasante es obtener el módulo de deslizamiento $\left(\mathrm{K}_{\mathrm{ser}}\right)$ de las conexiones. Según la Norma, el valor del módulo de deslizamiento es:

$$
\mathrm{K}_{\mathrm{ser}}=0,4 \cdot \mathrm{F}_{\mathrm{est}} / \mathrm{V}_{\mathrm{i}, \mathrm{mod}}
$$

donde $\mathrm{F}_{\text {est }}$ es la fuerza estimada de rotura y $\mathrm{v}_{\mathrm{i} \text {,mod }}$ es valor de deslizamiento inicial obtenido por la siguiente expresión:

$$
\mathrm{v}_{\mathrm{i}, \bmod }=4 / 3 \cdot\left(\mathrm{v}_{04}-\mathrm{v}_{01}\right)
$$

siendo $v_{04}$ y $v_{01}$ los valores de los deslizamientos para $0,4 \cdot F_{\text {est }}$ y $0,1^{\cdot} F_{\text {est }}$.

Como se necesita saber la fuerza máxima estimada, la primera de las probetas se lleva a rotura para averiguar esta fuerza máxima y emplearla en los dos ensayos siguientes.

La Norma también indica que, si el valor medio de la carga máxima durante los ensayos se desvía en más de un $20 \%$ de la estimada, esta se reajustará para los ensayos siguientes. En el caso de que se reajuste la carga máxima estimada, se ajustarán los módulos de deslizamiento de las piezas anteriormente ensayadas para que correspondan con los valores de esta carga.

\section{Aplicación de estas especificaciones a los ensayos realizados}

Para aplicar esta Norma se entiende que se realiza un gran número de ensayos. En este caso solo son 3, lo que impide hacer cualquier elaboración estadística. Con el primero se ha obtenido la $F_{\text {est, }}$ en el segundo se ha aplicado ese valor, y en el tercero se tomaron decisiones en función de la relación entre los dos primeros. A modo de ejemplo se incluye el siguiente ensayo:

\section{Elección de la Fuerza máxima estimada en los ensayos}

El orden en el que fueron ensayadas las probetas es el que se indica en la figura 49:

-Se ensayó la probeta 1 y se obtuvo una carga de rotura de 12.667 N.

-En la probeta 2 se usó como carga estimada de rotura la obtenida en la probeta 1. La carga de rotura obtenida fue de $9.698 \mathrm{~N}$ (77\% la carga estimada). 
-Para la probeta 3, como carga estimada de rotura se utilizó la media de las dos anteriores. La probeta 3 rompió con una carga de 10.513.

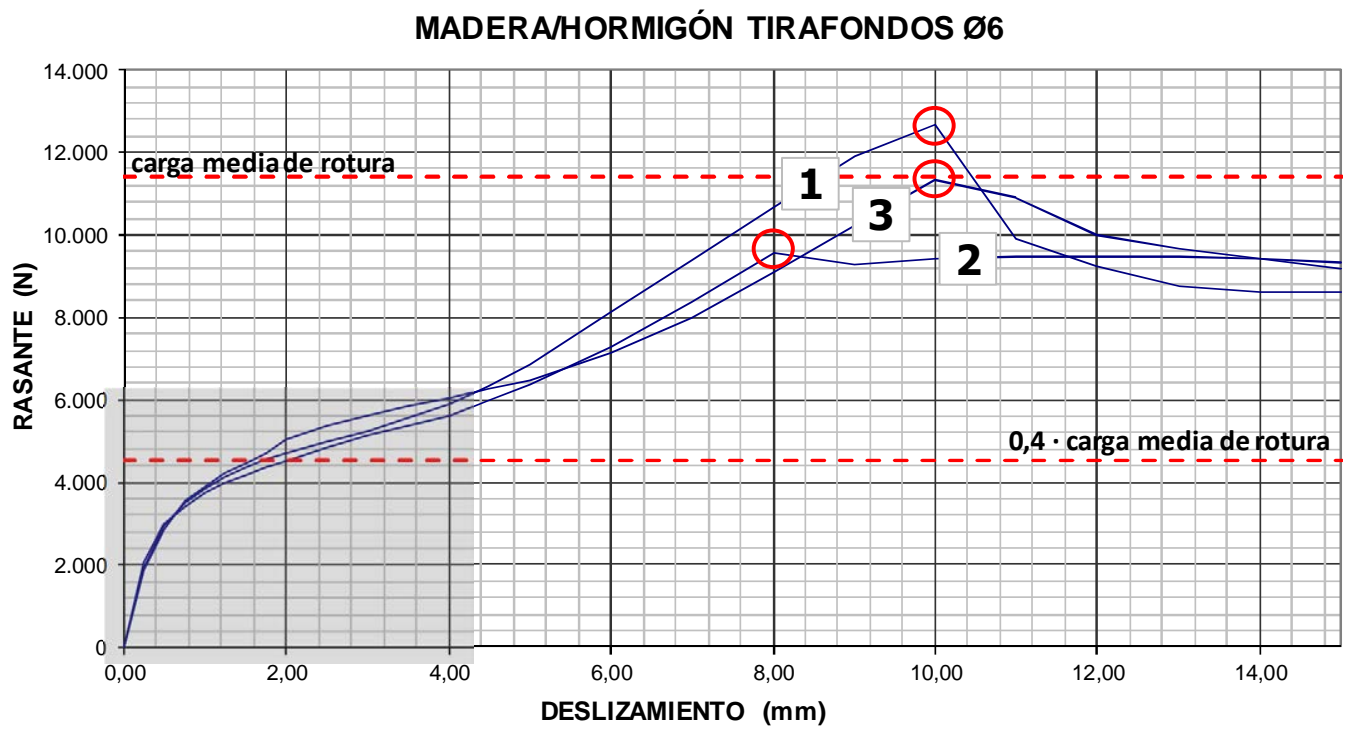

figura 49

Para obtener el $\mathrm{K}_{\text {ser }}$ de las 3 probetas existen las siguientes opciones:

-Cada probeta con su carga estimada de rotura:

\begin{tabular}{|c|c|c|}
\hline PROBETA & Kser (N/mm) & carga utilizada \\
\hline 1 & - & - \\
\hline 2 & 1.412 & 12.484 \\
\hline 3 & 2.772 & 10.513 \\
figura 50
\end{tabular}

-Cada probeta con su carga real de rotura:

\begin{tabular}{|c|c|c|}
\hline PROBETA & Kser (N/mm) & carga utilizada \\
\hline 1 & 1.412 & 12.667 \\
\hline 2 & 2.731 & 9.698 \\
\hline 3 & 2.297 & 11.781 \\
figura 51
\end{tabular}

-Todas las probetas con la media de las 3 cargas de rotura:

\begin{tabular}{|c|c|c|}
\hline PROBETA & Kser (N/mm) & carga utilizada \\
\hline 1 & 2.097 & 11.382 \\
\hline 2 & 1.765 & 11.382 \\
\hline 3 & 2.324 & 11.382 \\
figura 52
\end{tabular}

Con la tercera opción (figura 52 ) se obtienen unos de $\mathrm{K}_{\mathrm{ser}}$ más parecidos entre ellos, por lo que será la opción que se tome para todos los ensayos. Por lo tanto, se han ensayado las 3 probetas de cada tipo de conexión y se ha obtenido el $\mathbf{K}_{\text {ser }}$ con la carga media de rotura.

No obstante, por lo que se observa viendo la figura 49 (donde los 3 ensayos son muy parecidos en su tramo inicial), parece que hay demasiada variación entre los $\mathrm{K}_{\mathrm{ser}}$ obtenidos. En capítulos posteriores se analiza esto detenidamente. 


\subsection{VIGAS A FLEXIÓN}

En este apartado se describen todos los ensayos de flexión que se han realizado para analizar el comportamiento de las diferentes conexiones en una viga mixta, estudiándola en su conjunto (trabajos de la vigueta y la capa de compresión y el trabajo de la conexión).

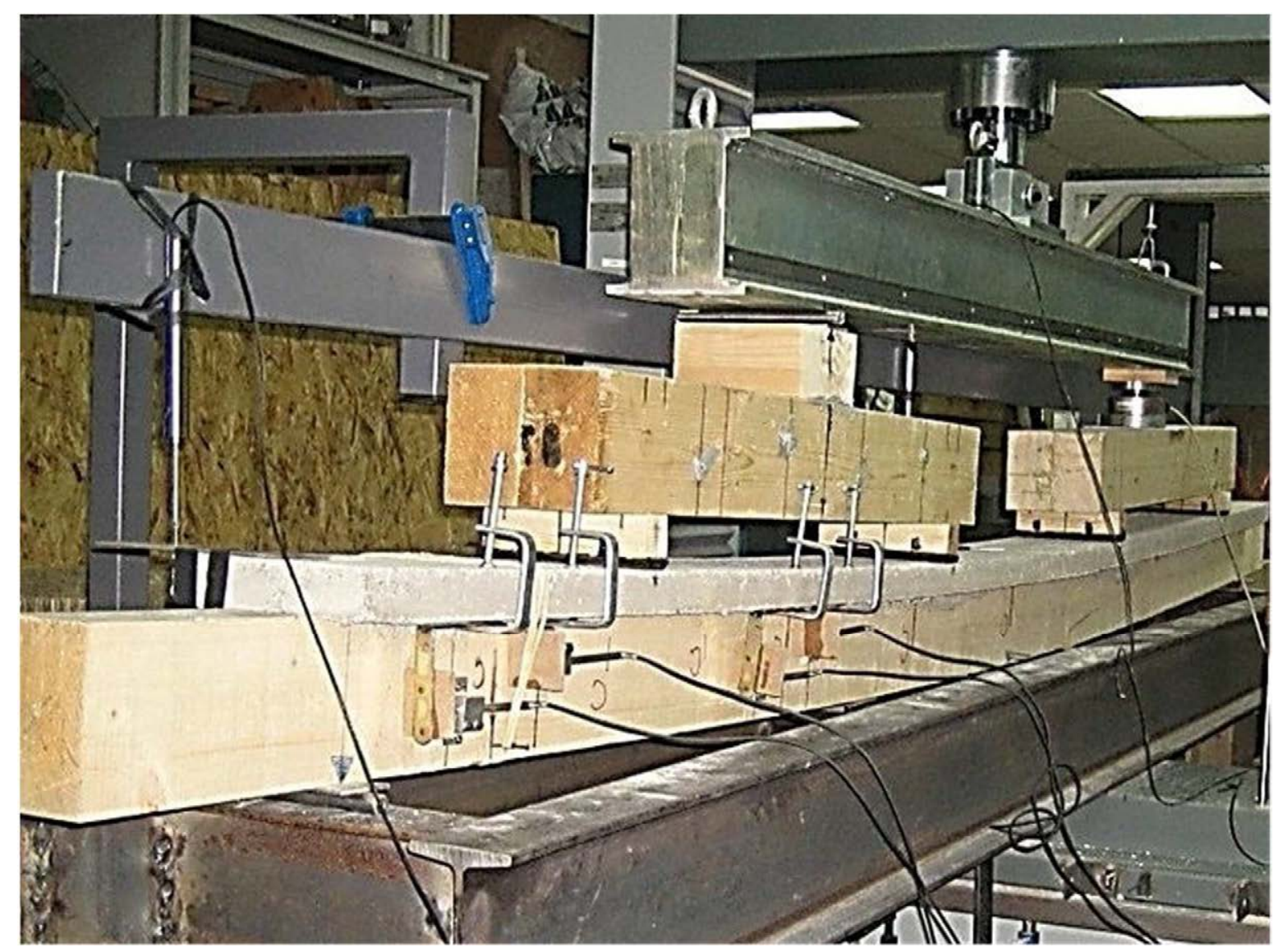

figura 53. Ensayo de flexión de viga mixta 


\subsubsection{TRABAJOS PREVIOS 27}

Previamente a los ensayos de flexión de las vigas mixtas, se realizaron una serie de trabajos para asegurar el buen funcionamiento del protocolo de ensayos:

El primero se dedica a la construcción del sistema de aplicación de las 4 cargas sobre la viga a ensayar. Su interés estriba en reducir el tiempo de montaje cada vez que se ensaya una nueva pieza.

El segundo es valorar si se alteran las propiedades físicas tras un determinado número de ciclos de carga. Esto no está relacionado con análisis dinámico, sino por una razón mucho más básica, que es poder utilizar algunas piezas varias veces en aquellos casos en los que no se han alcanzado cargas ni mucho menos críticas.

\section{SISTEMA DE APLICACIÓN DE LA CARGA ${ }^{28}$}

A diferencia de los procedimientos habituales empleados en laboratorio para realizar este tipo de ensayos, consistentes en aplicar dos cargas simétricas sobre la viga, poner cuatro complica el montaje al necesitarse tres vigas auxiliares en lugar de una. $Y$ todo un sistema de apoyos desde la carga central hasta los apoyos de la pieza ensayada que transmitan solo cargas verticales. La solución es emplear rodillos, pero el conjunto resulta muy inestable y obliga a mucho tiempo de preparación de cada ensayo. En el otro extremo se puede buscar una solución que simplifique toda esta obra auxiliar aunque tendrá el inconveniente de limitar la libre dilatación de todos los apoyos intermedios y puede ocasionar la formación de arcos de descarga. Lo que se describe en este apartado es el conjunto de ensayos realizados para conseguir la convergencia de ambas situaciones.

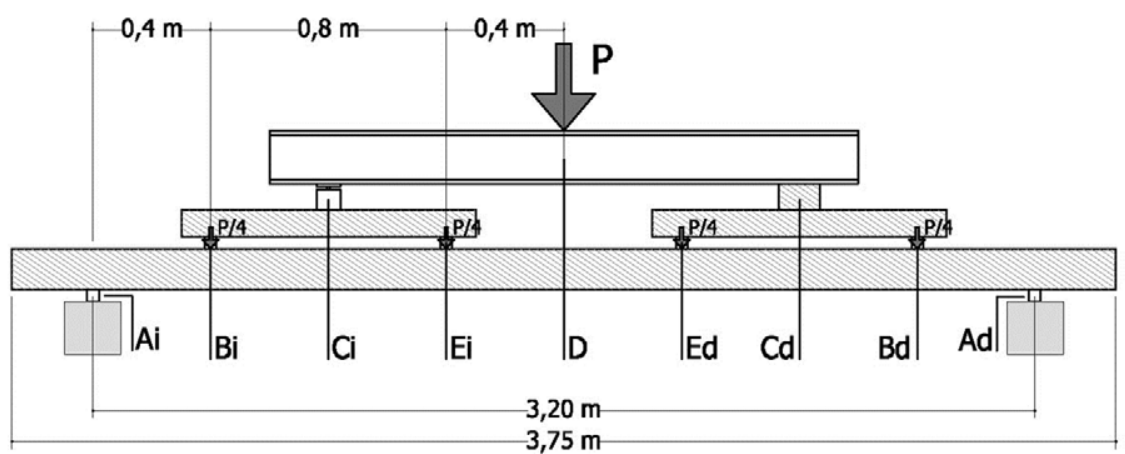

figura 54. Esquema de aplicación de carga

\footnotetext{
${ }^{27}$ Los resultados de estos ensayos están detallados en el Anejo IV. "Vigas a flexión. Trabajos previos".

${ }^{28}$ Los resultados de estos ensayos están detallados en el Anejo IV.1 "Vigas a flexión. Trabajos previos. Sistema de aplicación de carga".
} 
En la figura 54 se muestra el esquema de la aplicación de carga en los ensayos. Se tomaron datos de la carga total, la semicarga en la sección Cd de la figura y el descenso del punto central (sección D)

\section{Prueba 1 Ensayos 1,2 y 3}

Se disponen apoyos buscando una configuración con apoyos en dilatación que impidan coacciones horizontales. En un extremo rodillos metálicos y en el otro un cuadradillo metálico. En todos los casos, se coloca una placa metálica para evitar el aplastamiento de la madera. Los resultados dan flechas entre 10,06 y $10,08 \mathrm{~mm}$.

\section{Prueba 2 Ensayos 4,5 y 6}

El siguiente paso es construir la obra auxiliar más sencilla. Todos los apoyos son tacos de madera ( 4 × 4 × $20 \mathrm{~cm}$ ) para evitar el aplastamiento y la necesidad de placas metálicas. Las flechas resultantes son $8,208,22$ y $8,16 \mathrm{~mm}$ (entre el $76 \%$ y el $82 \%$ de la prueba 1 ). Por tanto hay un importante efecto arco que impide simplificar el procedimiento hasta estos niveles.

Por otro lado, se detecta una distribución de carga algo asimétrica (hasta del 6,6\%), posiblemente acentuada por la dificultad de precisión en la colocación de todos los elementos. ${ }^{29}$

\section{Prueba 3 Ensayos 10,11, 12 y 13}

Se sustituyen rodillos y cuadradillos metálicos de los cuatro puntos de aplicación de carga sobre la vigueta ( $\mathrm{Bi}, \mathrm{Ei}, \mathrm{Ed}$ y $\mathrm{Bd})$ por placas de neopreno realzadas con tacos de madera $(4 \times 4 \times 20 \mathrm{~cm})$ para permitir los movimientos del proceso de carga. Desde el ensayo 10 con una placa de neopreno hasta el 13 con cuatro.

El número de estas placas se fue aumentando hasta que los resultados obtenidos indicasen la desaparición del efecto arco debido al rozamiento entre materiales. La flecha del último ensayo (13) fue $9,90 \mathrm{~mm}$ ( $98 \%$ de la prueba 1 ) y lo más importante es que la carga es sensiblemente simétrica.

\section{Prueba $4 \quad$ Ensayo 14}

Teniendo ya un modelo fiable y sencillo de montar, se realiza la rotura de la pieza (figuras 55 y 56$)$.

\footnotetext{
${ }^{29}$ Estas asimetrías se detectaron gracias a medir durante los ensayos la carga total aplicada por la máquina de ensayos y la semicarga en uno de los lados.
} 


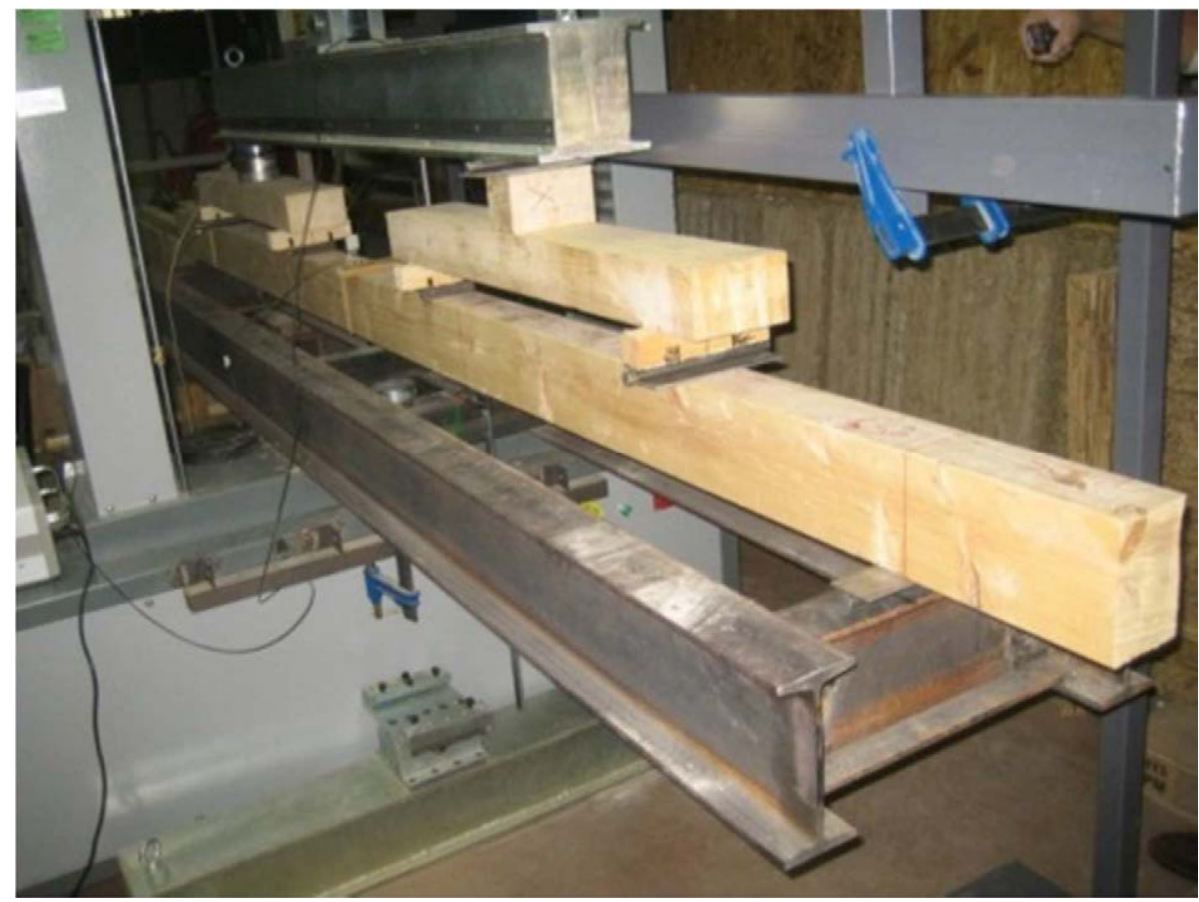

figura 55. Ensayo de rotura (ensayo 14)

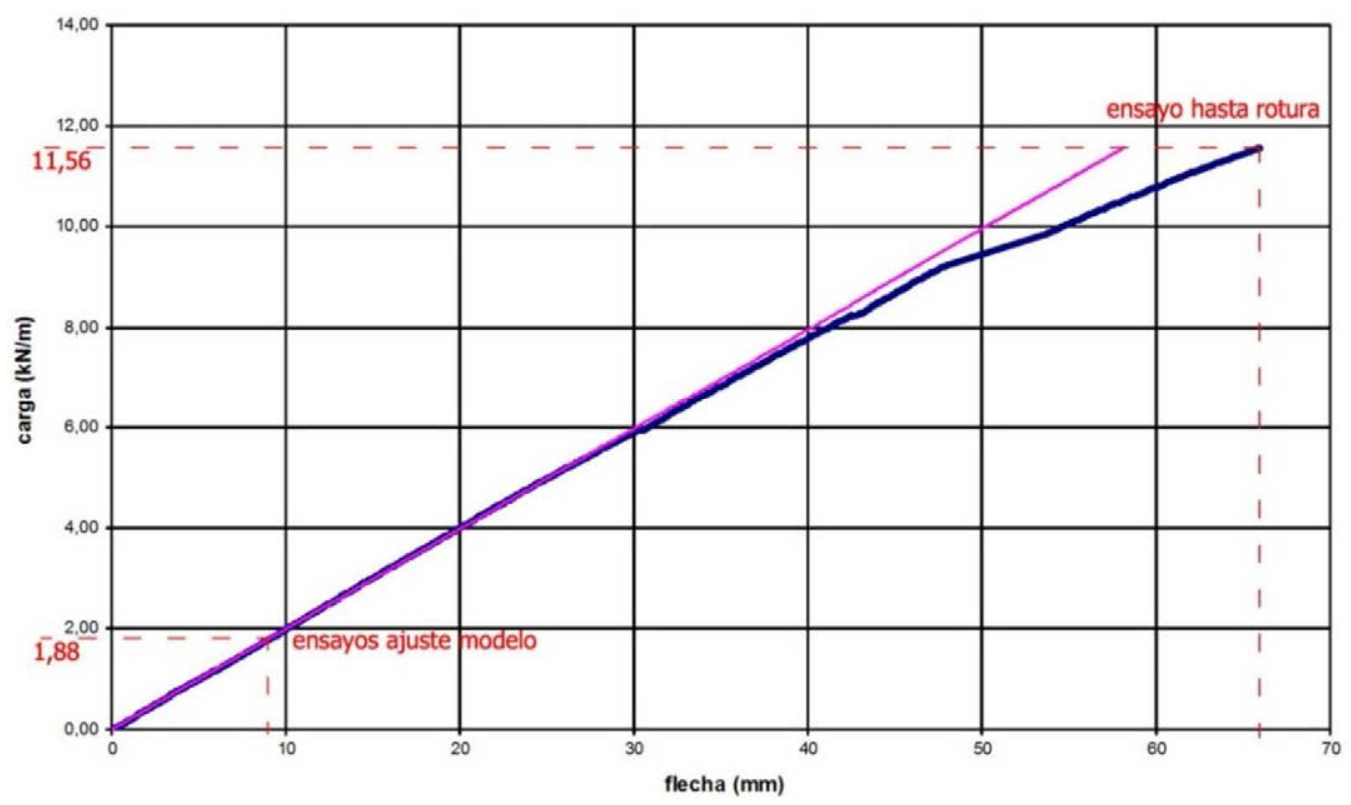

figura 56. Gráfica carga-flecha de ensayo de rotura (ensayo 14)

La viga rompe con una carga de $37,1 \mathrm{kN}$, lo que implica una tensión de rotura $55 \mathrm{~N} / \mathrm{mm}^{2}$, 2,3 veces superior a la tensión característica de la madera GL24h a flexión ( $24 \mathrm{~N} / \mathrm{mm}^{2}$ ). Esto aconsejó reforzar algunos elementos del ensayo (vigas inferiores de la transmisión de carga) que no disponían de holguras resistentes suficientes para los niveles de carga alcanzados en este ensayo preliminar de puesta a punto. 


\section{PRUEBAS PARA LA REUTILIZACIÓN DE LAS PIEZAS ${ }^{30}$}

Como algunos de los ensayos de vigas mixtas no se llevan hasta la rotura de la pieza sino hasta alcanzar una flecha de L/300, se reaprovechan las viguetas, por lo que se realizó el siguiente ensayo de flexión con 60 ciclos de carga/descarga a una vigueta para comprobar si se perdían propiedades.

\section{Descripción de los ensayos}

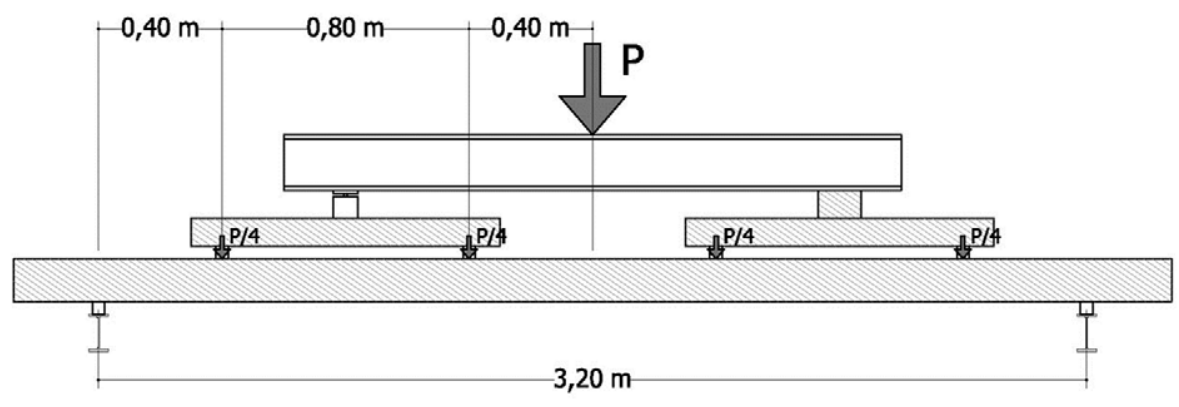

figura 57

Los ciclos se realizaron de forma consecutiva. La aplicación de carga se configuró para una velocidad de ascenso y descenso de $10 \mathrm{~mm} / \mathrm{min}$, por lo que cada ciclo duró aproximadamente 2'30" y el ensayo completo $2 \mathrm{~h} \mathrm{30'.} \mathrm{Cada} \mathrm{ciclo} \mathrm{de} \mathrm{carga} \mathrm{se} \mathrm{llevó} \mathrm{hasta} \mathrm{una} \mathrm{flecha} \mathrm{de} 13 \mathrm{~cm}$ (L/250), con lo que se sobrepasaba claramente la flecha del L/300 prevista en los ensayos.

\section{$\underline{\text { Resultados }}$}

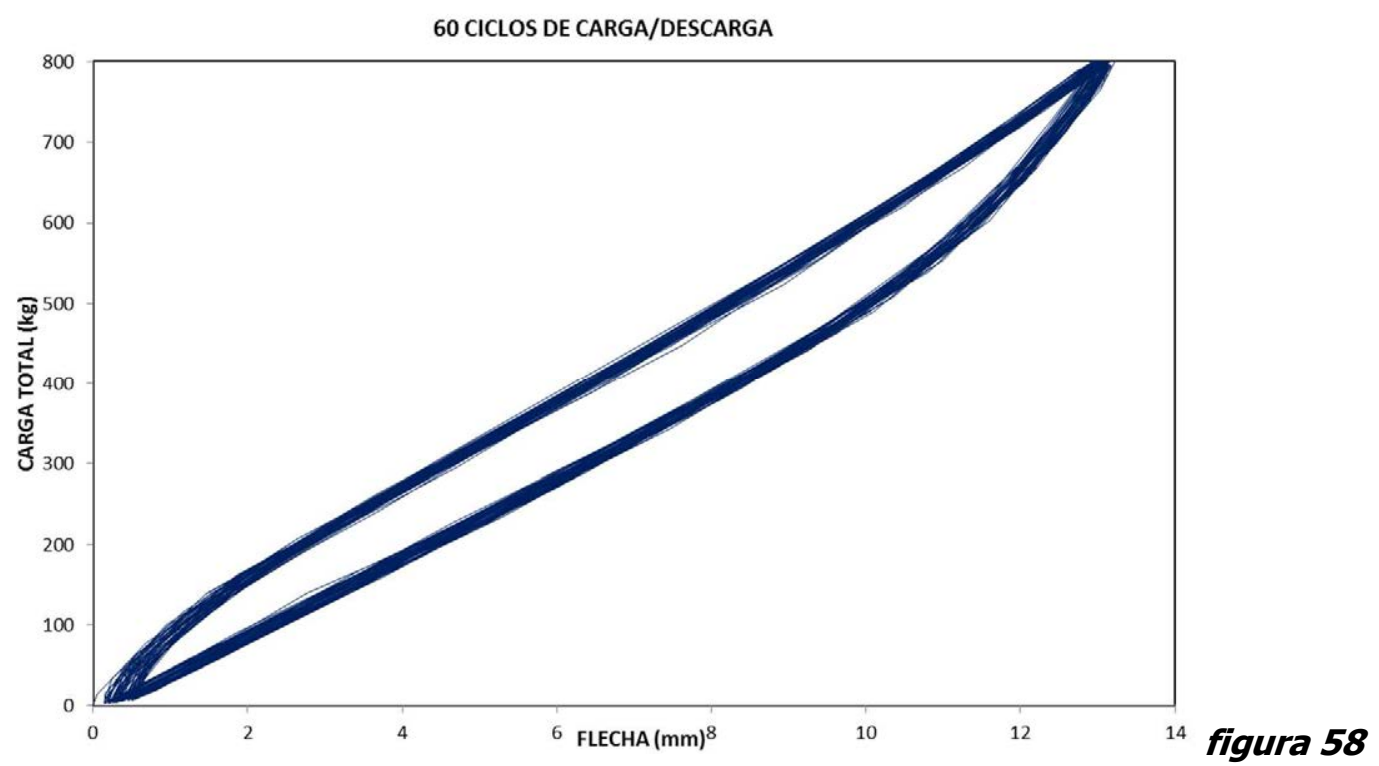

El resultado es que no se produce ninguna pérdida de rigidez en el transcurso del ensayo, por lo que en estos niveles de carga y deformación se consideró que no había ningún problema en reutilizar las viguetas.

30 Los resultados de estos ensayos están detallados en el Anejo IV.3 "Vigas a flexión. Trabajos previos. Pruebas para la reutilización de las piezas". 


\subsubsection{LA VIGA MIXTA}

El estudio consiste en analizar y comparar el comportamiento a flexión de 95 piezas formadas por viguetas de madera conectadas con una capa de compresión. En el conjunto de ensayos se han estudiado 58 tipos distintos de conexión.

\section{DIMENSIONES, MATERIALES Y CONEXIONES}

Canto de vigueta

Material de vigueta

Material de capa de compresión

Conectores

Separaciones entre conectores

Presión entre vigueta y c.c.
$14 \mathrm{~cm}$ (esbeltez 22,86)

$12 \mathrm{~cm}$ (esbeltez 26,67)

$10 \mathrm{~cm}$ (esbeltez 32,00)

Madera aserrada

Madera laminada

Hormigón

Madera microlaminada

Tirafondos (Tornillos barraqueros)

Barra de acero corrugado

Clavos

Tornillos HBS

Tornillos VGZ

Sin conexión

Equidistantes

Equidistantes muy juntos

Equidistantes muy separados

Dos densidades: Extremos y centro

Con Presión

Sin Presión
(45 ensayos)

(24 ensayos)

(26 ensayos)

(43 ensayos)

(52 ensayos)

(16 ensayos)

(79 ensayos)

(15 ensayos)

(2 ensayos)

(12 ensayos)

(29 ensayos)

(27 ensayos)

(10 ensayos)

(29 ensayos)

(27 ensayos)

(23 ensayos)

(6 ensayos)

(29 ensayos)

(56 ensayos) 


\section{Conectores}

Los conectores se han elegido entre los que resultan más económicos para la ejecución en la obra. Para los tirafondos (tornillos barraqueros) y redondos se taladra la madera con una holgura de $2 \mathrm{~mm}$ respecto del diámetro del conector, se inyecta resina y se introduce el conector.

El modelo patrón es el tirafondo, del que hay suficiente información previa, lo que permite comparar nuestros resultados con los de otros trabajos.

La elección del redondo corrugado se basa en colocar un elemento que, manteniendo las labores y costes de puesta en obra (taladrado y resina), prácticamente anula el coste del propio conector al tratarse de barras corrugadas cortadas en la propia obra. Se trata de medir dos cosas: si la capacidad adherente de las corrugas es suficiente para evitar el despegue del hormigón y si hay pérdida de resistencia a rasante derivada de la falta de cabeza. ${ }^{31}$

Las conexiones sin resina corresponden a clavos y tornillos. El empleo de clavos, minimiza el coste de ejecución y reduce el de material a cambio de una de capacidad resistente a rasante muy débil. Se han empleado tornillos por su fácil montaje, que reduce el coste de ejecución.
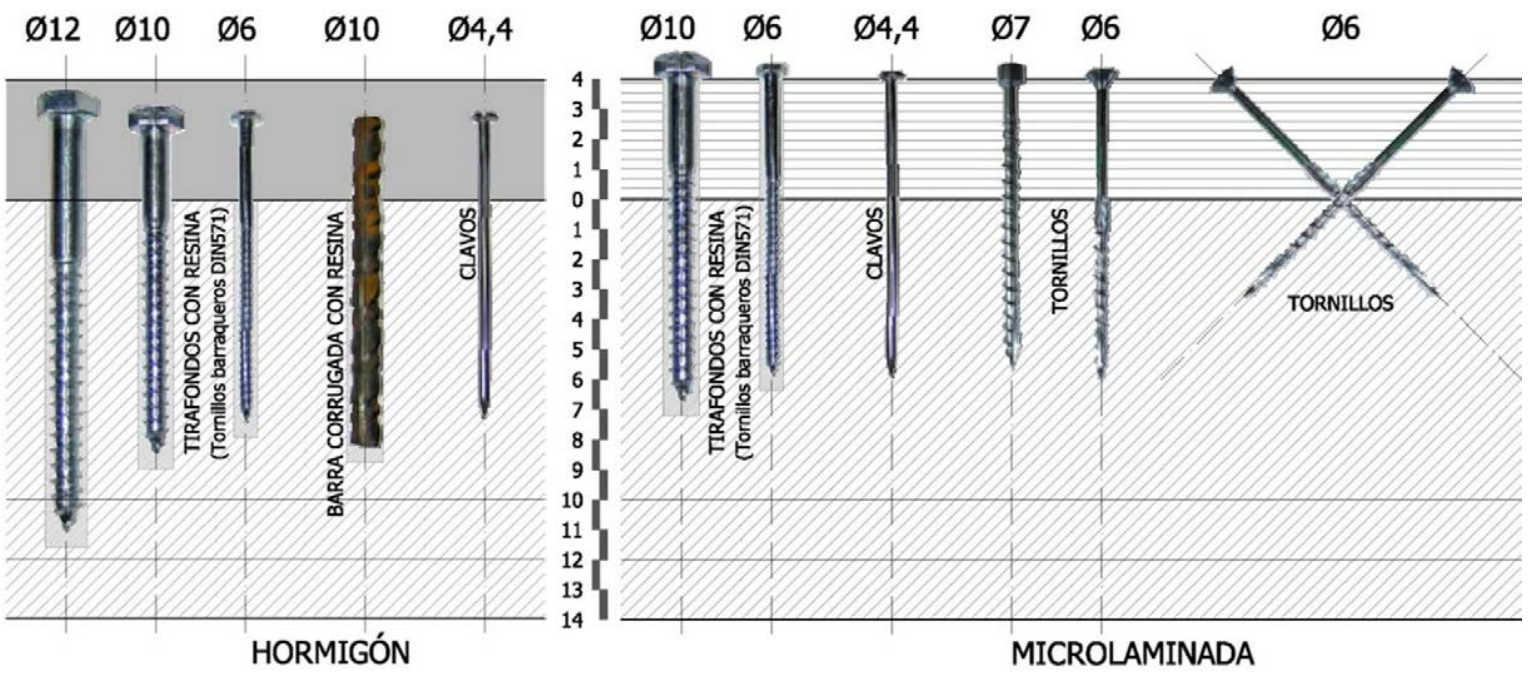

figura 59. Conectores empleados en la fabricación de vigas mixtas

\section{Separaciones}

Los conectores se han distribuido de dos formas: separación uniforme y variable (doble en la mitad central que en los dos cuartos extremos). La mayor parte de la bibliografía, modelos

\footnotetext{
${ }^{31}$ Conviene aclarar por qué la barra corrugada no se ha anclado. La forma natural de anclar un redondo es con patilla. Para diámetros pequeños el radio de doblado también lo es y todo queda embebido en la capa de compresión, pero su resistencia a rasante es también pequeña, por lo que el número es elevado, lo que repercute en el coste de taladros y resina. En consecuencia, si se usan diámetros grandes, el doblado de la patilla obligaría a cuestiones más costosas como aumentar el esperor de la capa de compresión..
} 
matemáticos y normativa está realizada disponiendo los conectores equidistantes. Por esa razón se han estudiado 79 casos de este tipo y 6 de separación variable.

En los de separación uniforme se incluyen los de separación densa $(50-70 \mathrm{~mm})$ para detectar si la menor distancia podría suponer una mejora de rigidez derivada de la formación de bielas entre la cabeza de un conector y la base del siguiente.

En la figura 60 están representadas todas las distribuciones de conectores del trabajo:
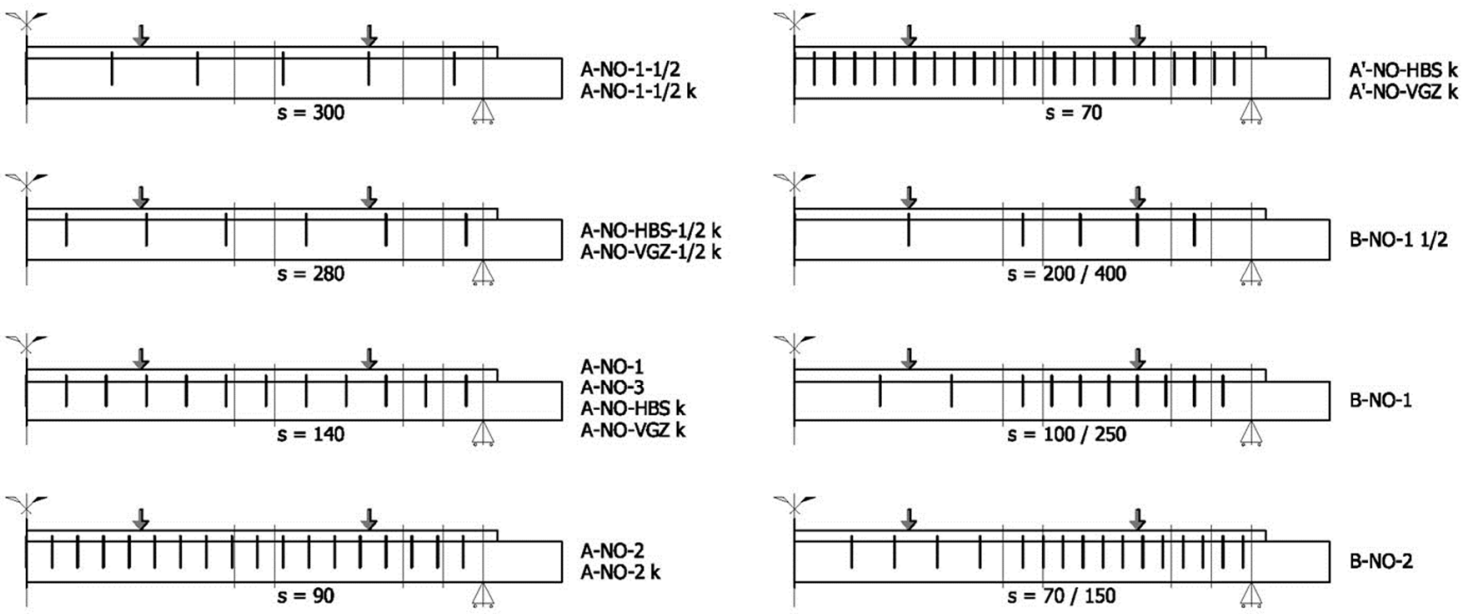

A-NO-2
A-NO-2 k
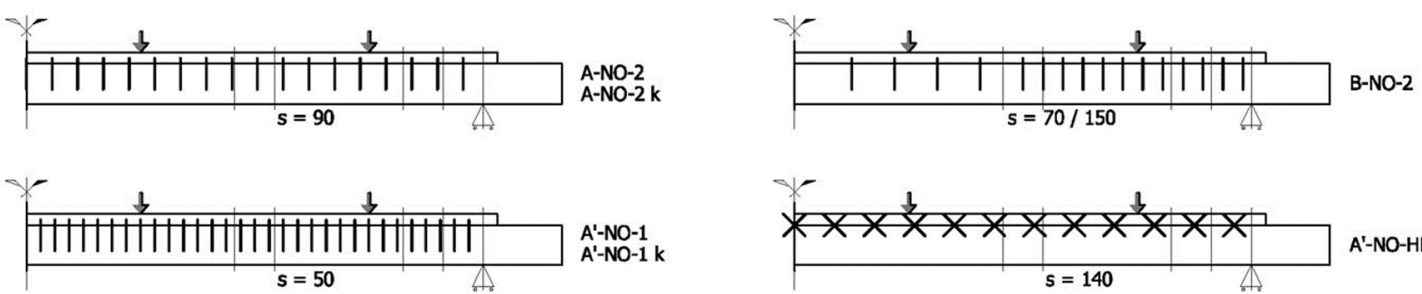

A'-NO-HBS I k

figura 60. Separaciones entre conectores empleadas en los ensayos

\section{Presión entre vigueta y capa de compresión}

Cuando el refuerzo de las viguetas se realiza con madera microlaminada, la conexión puede mejorar fácilmente si se aprietan los conectores gracias a la presión que se ejerce entre los dos elementos y aumentar así el rozamiento entre ellos.

Se han realizado una serie de ensayos de las mismas vigas ejerciendo esta presión y sin hacerlo, para comprobar la influencia de este factor.

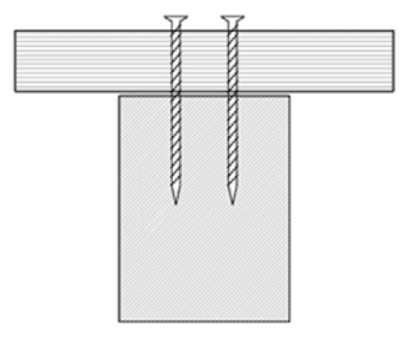

SIN PRESIÓN

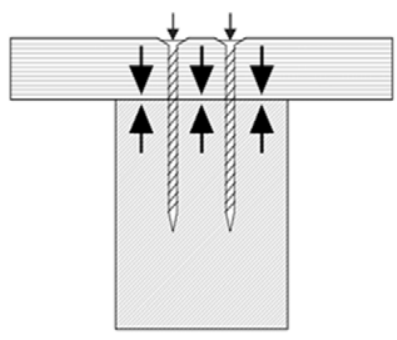

CON PRESIÓN

figura 61. Secciones de las probetas CON/SIN Presión 


\section{REPORTAJE DEL PROCESO DE CONSTRUCCIÓN}

Se presenta un reportaje fotográfico de los pasos más significativos del proceso constructivo de las vigas mixtas.

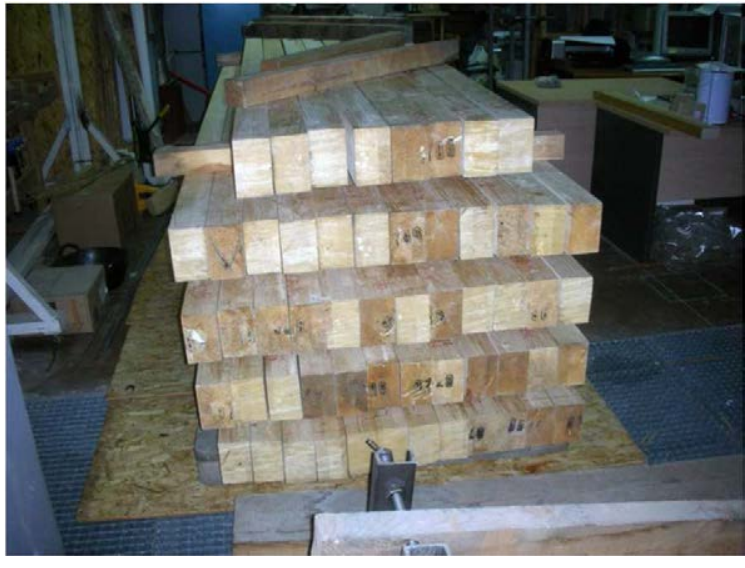

VIGUETAS DE MADERA

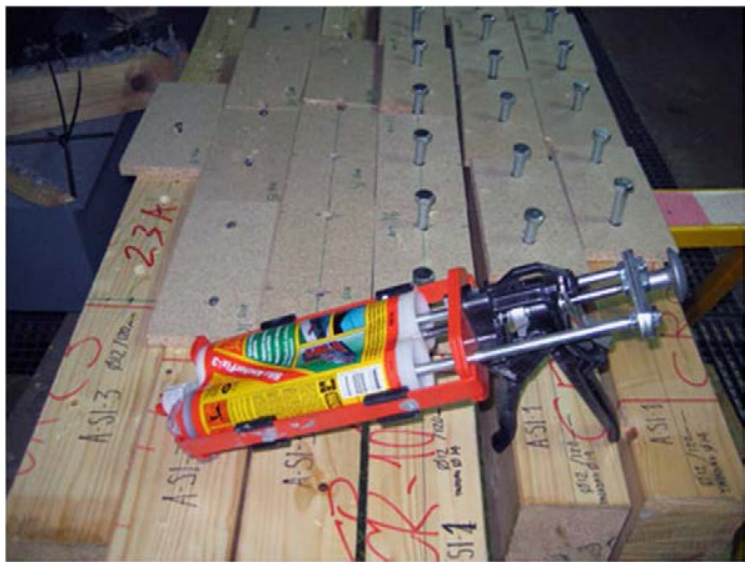

CONECTORES: TIRAFONDOS CON RESINA ${ }^{32}$

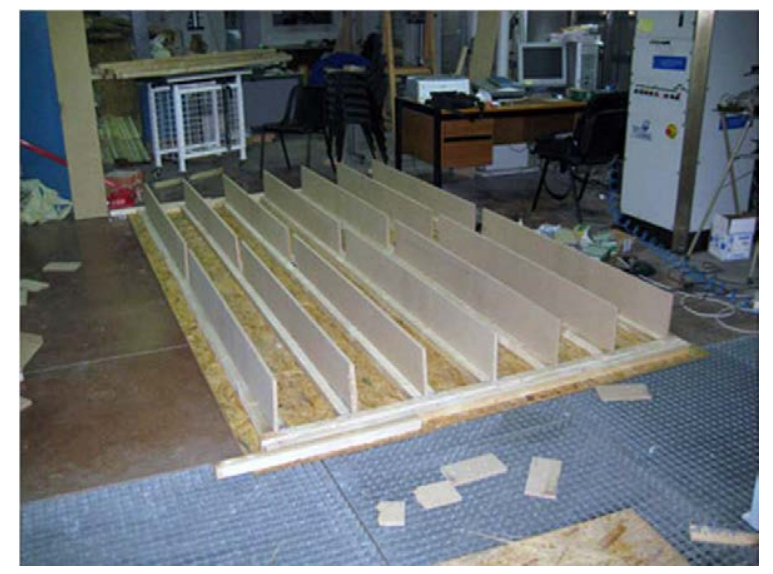

PREPARACIÓN DE ENCOFRADOS

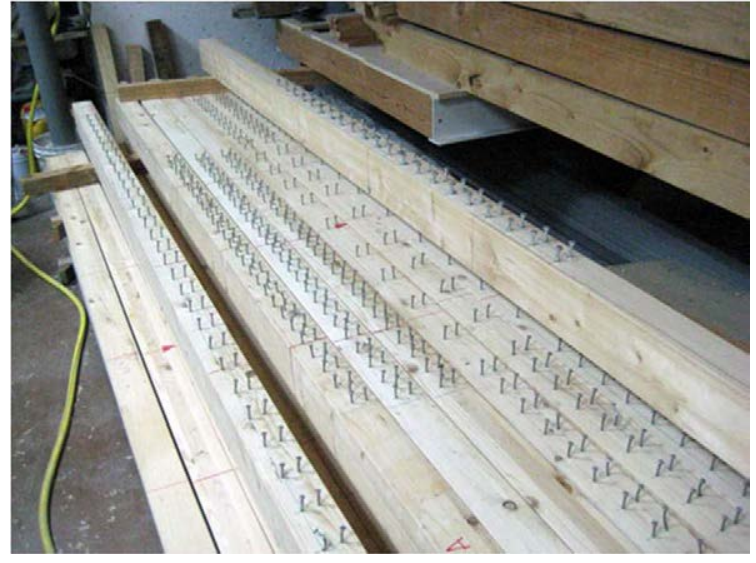

CONECTORES: CLAVOS

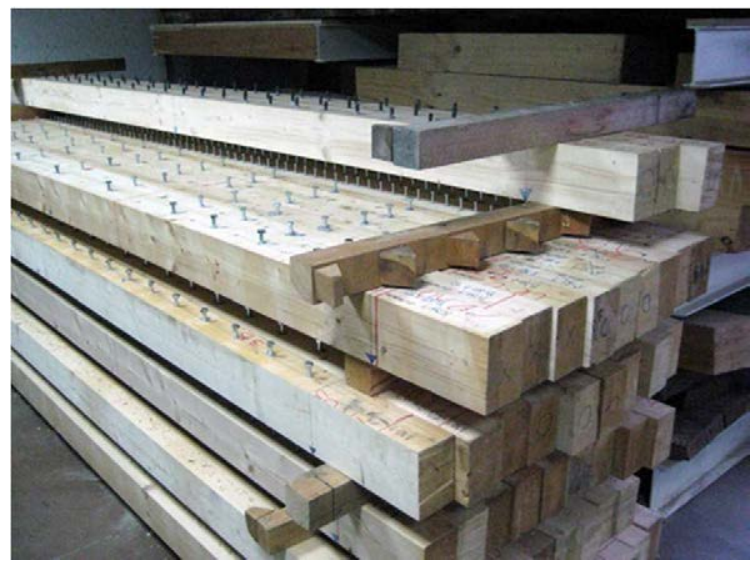

VIGUETAS CON CONECTORES

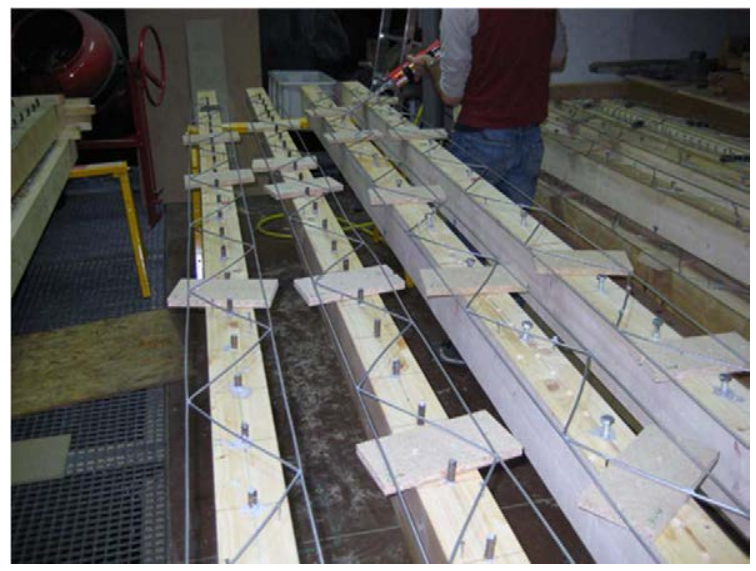

ARMADO DE CAPAS DE COMPRESIÓN

figura 62. Preparación de las vigas mixtas

\footnotetext{
${ }^{32}$ La resina empleada para el encolado de los conectores en la vigueta es bicomponente, de nombre comercial: Sika AnchorFix-3

LA VIGA MIXTA CON MADERA: verificacón experimental del método gamma y estudio de posibles alternativas de análisis
} 


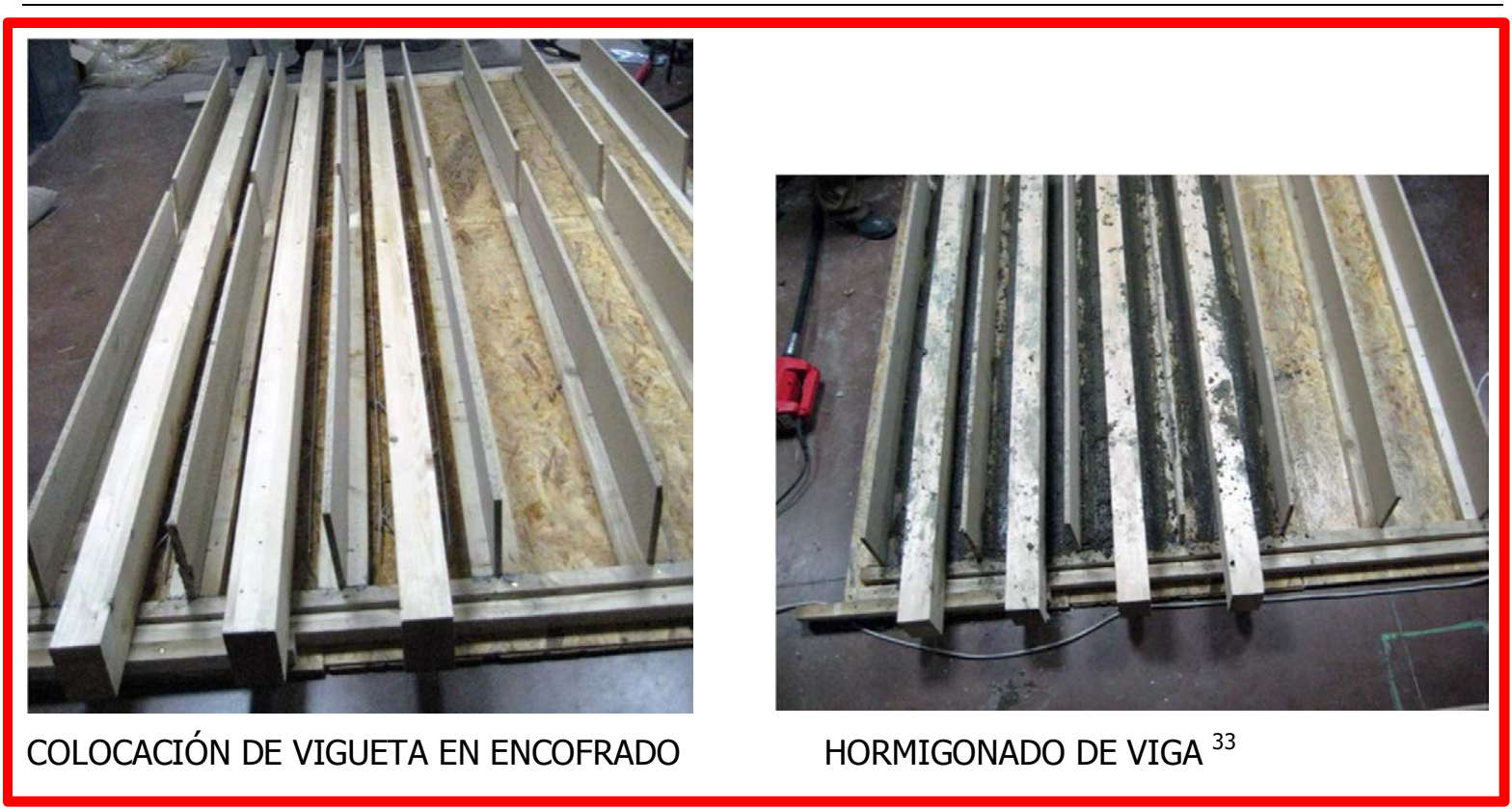

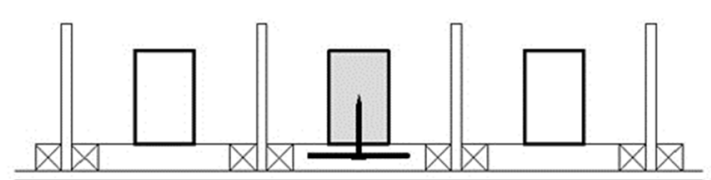

Esquema de Encofrado y hormigonado

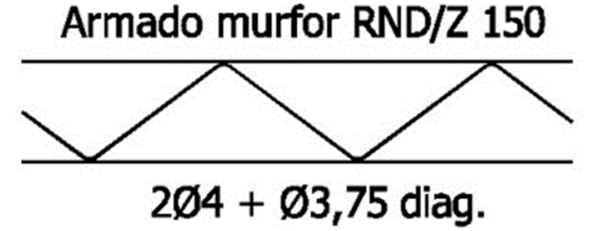

Armado de las capas de compresión

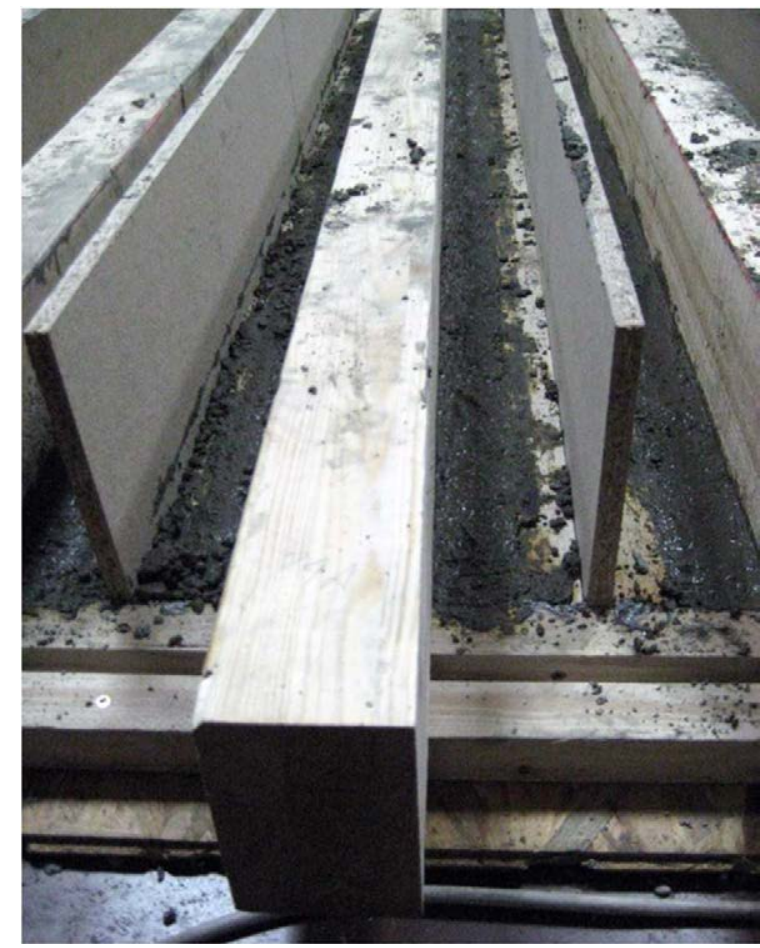

HORMIGONADO DE VIGA

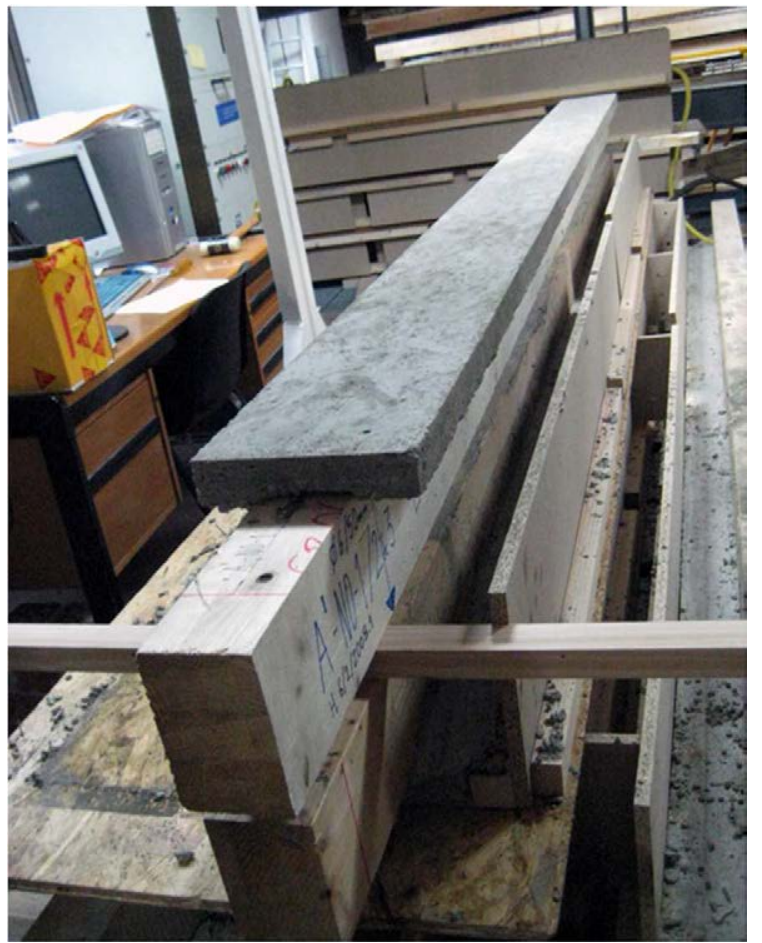

VIGA MIXTA

figura 63. Hormigonado de las vigas mixtas

\footnotetext{
${ }^{33}$ Nótese la colocación de las vigas para el hormigonado (al revés que en una obra de refuerzo de un edificio existente). Se han construido de esta manera por razones evidentes de facilidad de montaje, pero tendrá influencia en el funcionamiento de la conexión, como se verá en capítulos posteriores.
} 


\section{PRIMER CRITERIO DE AGRUPACIÓN DE ENSAYOS}

La idea del trabajo consistía en que los ensayos se realizaran de 3 en 3 (siguiendo la misma pauta que lo hecho en los ensayos de rasante), con el fin de que con cada configuración de viga ensayada ( $\varnothing$ y separación de conectores, esbeltez, etc.) se obtuvieran 3 resultados, esperando que al menos 2 resultaran razonablemente similares y trabajar así con el valor medio que representara a cada tipo.

Posteriormente se planteó dejar uno de los 3 especímenes para someterlo a ensayo de largo plazo, aunque esta etapa no se llegó a desarrollar. Eso ha supuesto que cada tipo cuente con dos casos, resultando unas dispersiones inferiores al $5 \%$ en el $55 \%$ de los ensayos, inferiores al $10 \%$ en el $70 \%$ de los ensayos y llegando hasta un $20 \%$ en el $30 \%$ restante. Esta estrategia ha impedido trabajar con valores medios fiables complicando la extracción de resultados.

Salvo los 3 casos finales, estos ensayos se han llevado a rotura.

PRIMER CRITERIO: ENSAYOS GEMELOS

\begin{tabular}{|c|c|c|c|c|c|c|c|c|}
\hline \multirow{3}{*}{ № } & \multicolumn{2}{|c|}{ VIGUETA } & \multicolumn{2}{|c|}{ CAPA COMPRESIÓN } & \multicolumn{2}{|c|}{ CONEXIÓN } & \multirow{2}{*}{\multicolumn{2}{|c|}{$\begin{array}{l}\text { Diferencia de Rigideces } \\
\qquad \mathrm{El}_{1} / \mathrm{El}_{2}\end{array}$}} \\
\hline & \multirow{2}{*}{ material } & \multirow{2}{*}{\begin{tabular}{|c|}
$(\mathrm{h} \times \mathrm{b})$ \\
$(\mathrm{cm})$ \\
\end{tabular}} & \multirow{2}{*}{ material } & \multirow{2}{*}{\begin{tabular}{|r|}
$(\mathbf{h} \times \mathbf{b})$ \\
$(\mathrm{cm})$ \\
\end{tabular}} & \multirow{2}{*}{$\begin{array}{c}\text { TIPO DE } \\
\text { CONECTOR }\end{array}$} & \multirow{2}{*}{$\begin{array}{c}\varnothing y \\
\text { SEPARACIÓN }\end{array}$} & & \\
\hline & & & & & & & $q=1,25 \mathrm{kN} / \mathrm{m}$ & $q=1,75 \mathrm{kN} / \mathrm{m}$ \\
\hline $1-2$ & LAMINADA & $14 \times 9$ & HORMIGÓN & $4 \times 20$ & TIRAFONDO & $\varnothing 10 / 300 / 300$ & $96 \%$ & $96 \%$ \\
\hline $4-5$ & LAMINADA & $14 \times 9$ & HORMIGÓN & $4 \times 20$ & TIRAFONDO & $\varnothing 10 / 140 / 140$ & $93 \%$ & $91 \%$ \\
\hline $6-7$ & LAMINADA & $14 \times 9$ & HORMIGÓN & $4 \times 20$ & TIRAFONDO & $\varnothing 6 / 50 / 50$ & $96 \%$ & $97 \%$ \\
\hline $10-11$ & LAMINADA & $14 \times 9$ & HORMIGÓN & $4 \times 20$ & CLAVO & $2 \varnothing 4,4 / 90 / 90$ & $92 \%$ & $93 \%$ \\
\hline $14-15$ & LAMINADA & $14 \times 9$ & HORMIGÓN & $4 \times 20$ & BARRA CORR. & $\varnothing 10 / 140 / 140$ & $81 \%$ & $82 \%$ \\
\hline $16-17$ & LAMINADA & $14 \times 9$ & HORMIGÓN & $4 \times 20$ & TIRAFONDO & $\varnothing 12 / 200 / 400$ & $85 \%$ & $84 \%$ \\
\hline $18-19$ & LAMINADA & $14 \times 9$ & HORMIGÓN & $4 \times 20$ & TIRAFONDO & $\varnothing 10 / 100 / 250$ & $79 \%$ & $77 \%$ \\
\hline $20-21$ & LAMINADA & $14 \times 9$ & HORMIGÓN & $4 \times 20$ & CLAVO & $2 \not 4,4 / 70 / 150$ & $99 \%$ & $99 \%$ \\
\hline $8-9$ & LAMINADA & $14 \times 9$ & MICROLAMINADA & $4 \times 20$ & TIRAFONDO & $\varnothing 6 / 50 / 50$ & $96 \%$ & $98 \%$ \\
\hline $12-13$ & LAMINADA & $14 \times 9$ & MICROLAMINADA & $4 \times 20$ & CLAVO & $2 \varnothing 4,4 / 90 / 90$ & $89 \%$ & $90 \%$ \\
\hline $90-91$ & ASERRADA & $14 \times 9$ & MICROLAMINADA & $4 \times 20$ & TIRAFONDO & $\varnothing 6 / 50 / 50$ & $98 \%$ & $99 \%$ \\
\hline $92-94$ & ASERRADA & $14 \times 9$ & MICROLAMINADA & $4 \times 20$ & CLAVO (S/P) & $2 \varnothing 4,4 / 90 / 90$ & $97 \%$ & $97 \%$ \\
\hline $93-95$ & ASERRADA & $14 \times 9$ & MICROLAMINADA & $4 \times 20$ & CLAVO (C/P) & $2 \not 4,4 / 90 / 90$ & $97 \%$ & $96 \%$ \\
\hline
\end{tabular}

figura 64. Listado de ensayos gemelos

\section{SEGUNDO CRITERIO DE AGRUPACIÓN DE ENSAYOS}

Vistas las limitaciones que supuso el criterio anterior, al haber perdido un espécimen, en una segunda etapa se realizó otro conjunto de ensayos, que ya no fueron llevados a rotura, sino hasta alcanzar una flecha de $\mathrm{L} / 300$, con el fin de que se pudiera reaprovechar el material, no solo por un criterio de ahorro, sino porque las piezas ensayadas tuvieran los mismos parámetros mecánicos (módulo de elasticidad, situación de los nudos, irregularidades geométricas, etc.). 
Fueron realizados del siguiente modo: La vigueta y la capa de compresión, en este caso microlaminada, se conectaron con tornillos cada $70 \mathrm{~mm}$, tras ese ensayo se quitó la mitad de los conectores para que quedaran a $140 \mathrm{~mm}$ y después a $280 \mathrm{~mm}$. Después se quitaron los que quedaban para ensayar las dos piezas sin conexión y finalmente se ensayó cada pieza por separado para obtener sus módulos de elasticidad. Cada uno de los pasos con y sin presión.

\begin{tabular}{|c|c|c|c|c|c|c|c|}
\hline \multirow{3}{*}{ 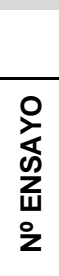 } & \multicolumn{3}{|c|}{ VIGUETA LAMINADA } & & \multicolumn{3}{|c|}{ VIGUETA ASERRADA } \\
\hline & \multirow{2}{*}{$(h \times b)$} & \multicolumn{2}{|c|}{ CONEXIÓN (TORNILLOS) } & \multirow{2}{*}{ 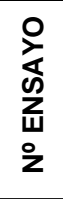 } & \multirow{2}{*}{$(h \times b)$} & \multicolumn{2}{|c|}{ CONEXIÓN (TORNILLOS) } \\
\hline & & $\begin{array}{c}\varnothing y \\
\text { SEPARACIÓN }\end{array}$ & $\begin{array}{c}\text { OTROS } \\
\text { PARÁMETROS }\end{array}$ & & & $\begin{array}{c}\emptyset y \\
\text { SEPARACIÓN }\end{array}$ & $\begin{array}{c}\text { OTROS } \\
\text { PARÁMETROS }\end{array}$ \\
\hline 29 & $12 \times 9$ & $2 \varnothing 6 / 70 / 70$ & CON presión & 53 & $14 \times 9$ & $2 \varnothing 6 / 70 / 70$ & CON presión \\
\hline 30 & $12 \times 9$ & $2 \varnothing 6 / 70 / 70$ & SIN & 54 & $14 \times 9$ & $2 \varnothing 6 / 70 / 70$ & SIN \\
\hline 31 & $12 \times 9$ & $2 \varnothing 6 / 140 / 140$ & SIN & 55 & $14 \times 9$ & $2 \varnothing 6 / 140 / 140$ & CON presión \\
\hline 32 & $12 \times 9$ & $2 \varnothing 6 / 280 / 280$ & SIN & 56 & $14 \times 9$ & $2 \varnothing 6 / 140 / 140$ & SIN \\
\hline 33 & $12 \times 9$ & SIN CONEXIÓN & & 57 & $14 \times 9$ & $2 \varnothing 6 / 280 / 280$ & CON presión \\
\hline 34 & $12 \times 9$ & $2 \varnothing 7 / 70 / 70$ & CON presión & 58 & $14 \times 9$ & $2 \varnothing 6 / 280 / 280$ & SIN \\
\hline 35 & $12 \times 9$ & $2 \varnothing 7 / 70 / 70$ & SIN & 59 & $14 \times 9$ & SIN CONEXIÓN & \\
\hline 36 & $12 \times 9$ & $2 \varnothing 7 / 140 / 140$ & SIN & 60 & $14 \times 9$ & $2 \varnothing 7 / 70 / 70$ & CON presión \\
\hline 37 & $12 \times 9$ & $2 \varnothing 7 / 280 / 280$ & SIN & 61 & $14 \times 9$ & $2 \varnothing 7 / 70 / 70$ & SIN \\
\hline 38 & $12 \times 9$ & SIN CONEXIÓN & & 62 & $14 \times 9$ & $2 \varnothing 7 / 140 / 140$ & SIN \\
\hline 39 & $10 \times 9$ & $2 \varnothing 6 / 70 / 70$ & CON presión & 63 & $14 \times 9$ & $2 \varnothing 7 / 280 / 280$ & CON presión \\
\hline 40 & $10 \times 9$ & $2 \varnothing 6 / 70 / 70$ & SIN & 64 & $14 \times 9$ & $2 \varnothing 7 / 280 / 280$ & SIN \\
\hline 41 & $10 \times 9$ & $2 \varnothing 6 / 140 / 140$ & CON presión & 65 & $14 \times 9$ & SIN CONEXIÓN & \\
\hline 42 & $10 \times 9$ & $2 \varnothing 6 / 140 / 140$ & SIN & 66 & $12 \times 9$ & $2 \varnothing 6 / 70 / 70$ & CON presión \\
\hline 43 & $10 \times 9$ & $2 \varnothing 6 / 280 / 280$ & CON presión & 67 & $12 \times 9$ & $2 \varnothing 6 / 70 / 70$ & SIN \\
\hline 44 & $10 \times 9$ & $2 \varnothing 6 / 280 / 280$ & SIN & 68 & $12 \times 9$ & $2 \varnothing 6 / 140 / 140$ & SIN \\
\hline 45 & $10 \times 9$ & SIN CONEXIÓN & & 69 & $12 \times 9$ & $2 \varnothing 6 / 280 / 280$ & ON presión \\
\hline 46 & $10 \times 9$ & $2 \varnothing 7 / 70 / 70$ & CON presión & 70 & $12 \times 9$ & $2 \varnothing 6 / 280 / 280$ & SIN \\
\hline 47 & $10 \times 9$ & $2 \varnothing 7 / 70 / 70$ & SIN & 71 & $12 \times 9$ & SIN CONEXIÓN & \\
\hline 48 & $10 \times 9$ & $2 \varnothing 7 / 140 / 140$ & CON presión & 72 & $12 \times 9$ & $2 \varnothing 7 / 70 / 70$ & CON pres \\
\hline 49 & $10 \times 9$ & $2 \varnothing 7 / 140 / 140$ & SIN & 73 & $12 \times 9$ & $2 \varnothing 7 / 70 / 70$ & SIN \\
\hline 50 & $10 \times 9$ & $2 \varnothing 7 / 280 / 280$ & CON presión & 74 & $12 \times 9$ & $2 \varnothing 7 / 140 / 140$ & SIN \\
\hline 51 & $10 \times 9$ & $2 \varnothing 7 / 280 / 280$ & SIN & 75 & $12 \times 9$ & $2 \varnothing 7 / 280 / 280$ & CON presión \\
\hline \multirow[t]{14}{*}{52} & $10 \times 9$ & SIN CONEXIÓN & & 76 & $12 \times 9$ & $2 \varnothing 7 / 280 / 280$ & SIN \\
\hline & & & & 77 & $12 \times 9$ & SIN CONEXIÓN & \\
\hline & & & & $\overline{7 \varepsilon}$ & $10 \times 9$ & $2 \varnothing 6 / 70 / 70$ & CON presión \\
\hline & & & & 7 & $10 \times 9$ & $2 \varnothing 6 / 70 / 70$ & SIN \\
\hline & & & & 8 & $10 \times 9$ & $2 \varnothing 6 / 140 / 140$ & SIN \\
\hline & & & & 8 & $10 \times 9$ & $2 \varnothing 6 / 280 / 280$ & CON presión \\
\hline & & & & 8 & $10 \times 9$ & $206 / 280 / 280$ & SIN \\
\hline & & & & 8 & $10 \times 9$ & SIN CONEXIÓN & \\
\hline & & & & 8 & $10 \times 9$ & $2 \varnothing 7 / 70 / 70$ & CON presión \\
\hline & & & & 8 & $10 \times 9$ & $2 \varnothing 7 / 70 / 70$ & SIN \\
\hline & \multirow{2}{*}{\begin{tabular}{|c|}
$(\mathrm{h} \times \mathrm{b})$ \\
$(\mathrm{cm})$
\end{tabular}} & \multirow{2}{*}{\multicolumn{2}{|c|}{ CAPA DE COMPRESIÓN }} & 8 & $10 \times 9$ & $2 \varnothing 7 / 140 / 140$ & SIN \\
\hline & & & & 8 & $10 \times 9$ & $2 \varnothing 7 / 280 / 280$ & CON presión \\
\hline & \multirow{2}{*}{$3,9 \times 20$} & \multirow{2}{*}{\multicolumn{2}{|c|}{ MADERA MICROLAMINADA }} & $8 \varepsilon$ & $10 \times 9$ & $2 \varnothing 7 / 280 / 280$ & SIN \\
\hline & & & & 8 & $10 \times 9$ & SIN CONEXIÓN & \\
\hline
\end{tabular}

figura 65. Listado de ensayos en serie 


\subsubsection{PROCEDIMIENTOS DEL ENSAYO}

Los ensayos se realizaron con una máquina de ensayos universal electromecánica con 20 t de capacidad.

\section{PROTOCOLO}

\section{Simulación de carga uniforme}

Se han construido unas vigas auxiliares con madera para trasladar la carga puntual que ejerce la máquina de ensayos a la viga en cuatro puntos, simulando así una carga continua.

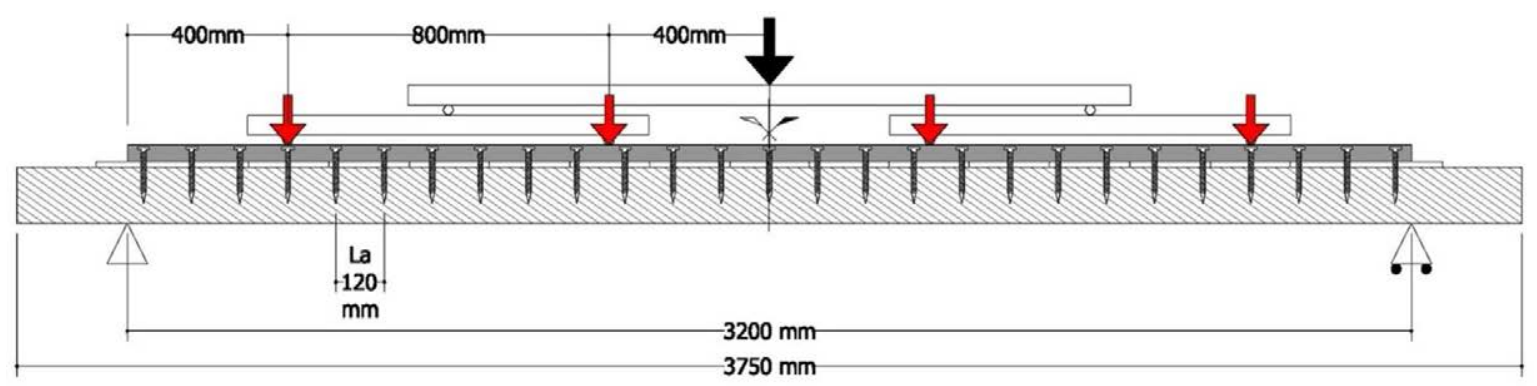

figura 66. Esquema de aplicación de carga

\section{Nivel de carga}

Unos ensayos fueron llevados hasta la rotura de la viga (primer criterio de agrupación de ensayos - 28 casos-) y el resto (segundo criterio de agrupación de ensayos -67 casos-) se pararon al alcanzar una flecha de L/300. Este nivel es suficiente para analizar el comportamiento de la conexión pero no provoca ningún daño a los elementos, pudiendo así reutilizarlas.

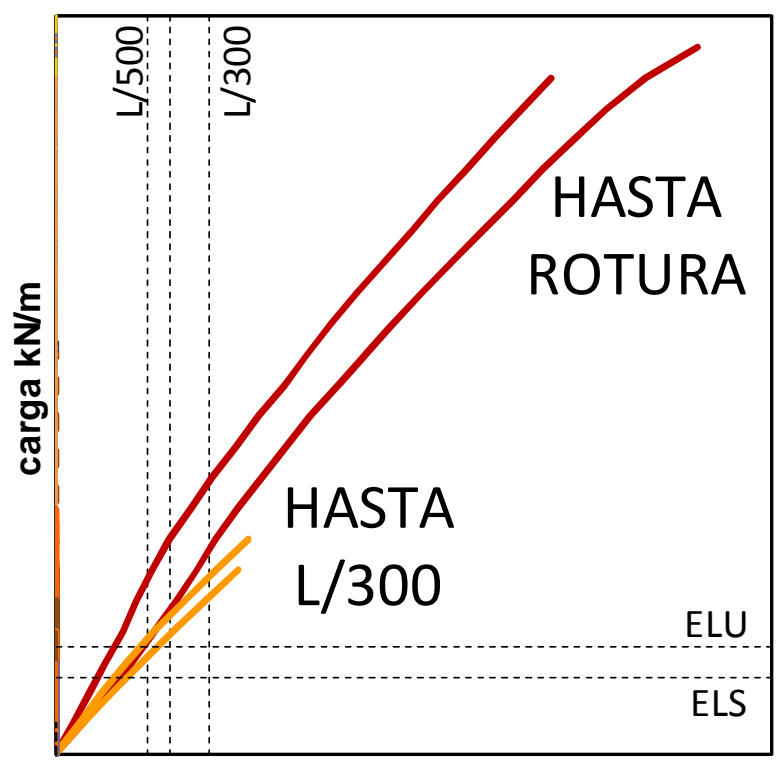

flecha $\mathrm{mm}$ 


\section{INSTRUMENTACIÓN}

\section{Carga}

Durante los ensayos se tomaron las siguientes medidas de carga:

- Carga total aplicada por la máquina de ensayos.

-Semicarga, con una célula de carga adicional de $5.000 \mathrm{~kg}$ de capacidad y 0,01 kg de precisión.

De esta forma, comparando ambos valores se pueden controlar y corregir las pequeñas asimetrías que puedan aparecer en la transmisión de la carga.

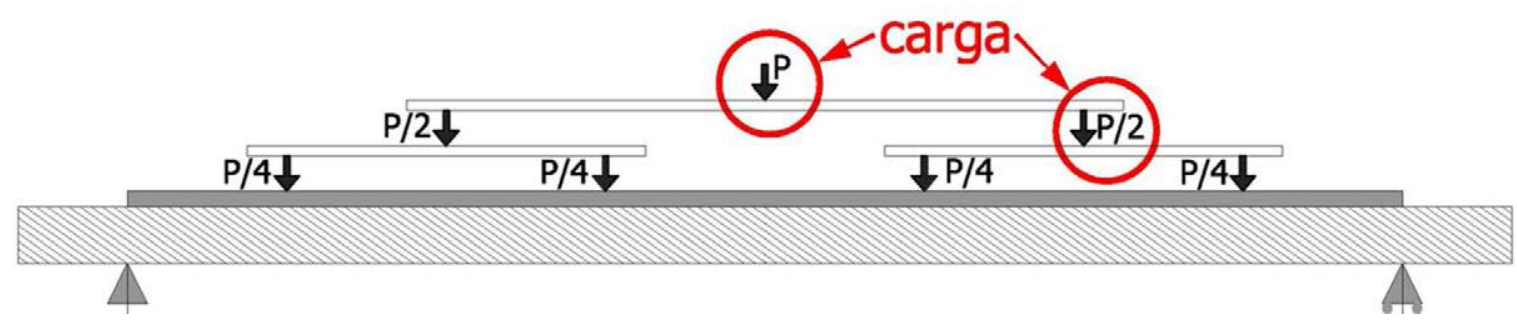

figura 68. Puntos de medida de carga aplicada

\section{Flecha}

Se ha medido la flecha central con dos LVDT (Solartron BS 50 . Rango $\pm 50 \mathrm{~mm}$ y precisión 0,01 mm) en ambos lados de la sección central para que no influyeran en la medida posibles alabeos de las vigas durante el ensayo. Estos LVDT se fijan en unas miras asociadas al mismo apoyo de la vigueta, para eliminar cualquier movimiento que no pertenezca a la propia viga.

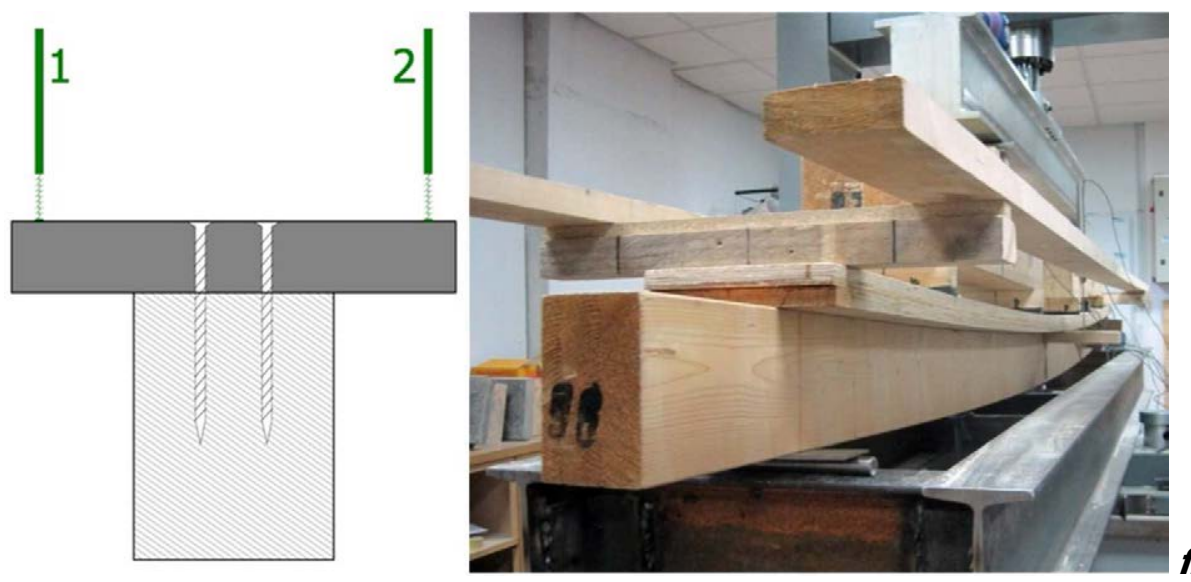

figura 69. Sección central

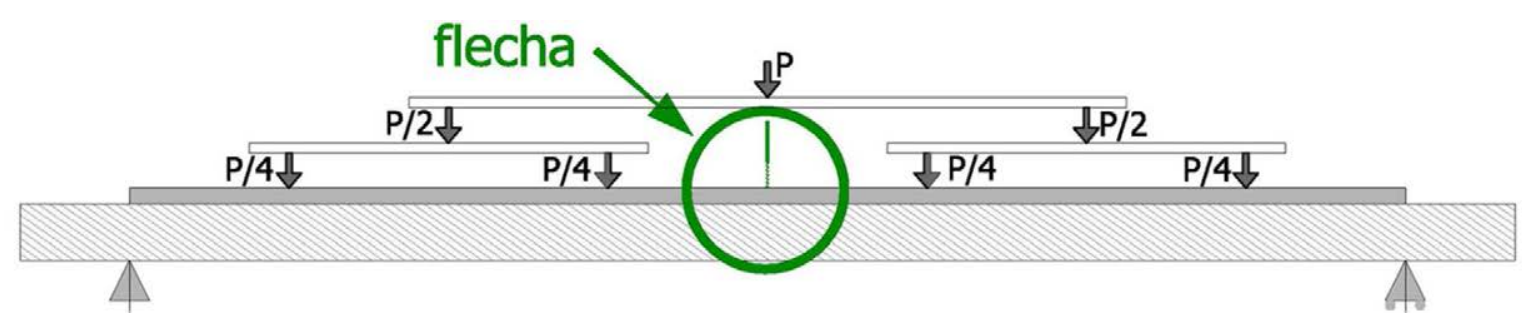

figura 70. Medición de flecha 


\section{Giros}

Se tomaron las medidas de los giros con dos inclinómetros (miden la rotación en los ejes $\mathrm{X}$ e $\mathrm{Y}$ con una precisión de $0,01^{\circ}$ ) situados a 21 y $80 \mathrm{~cm}$ del apoyo. Los giros obtenidos se emplean básicamente como medida de contraste entre las flechas y los deslizamientos.

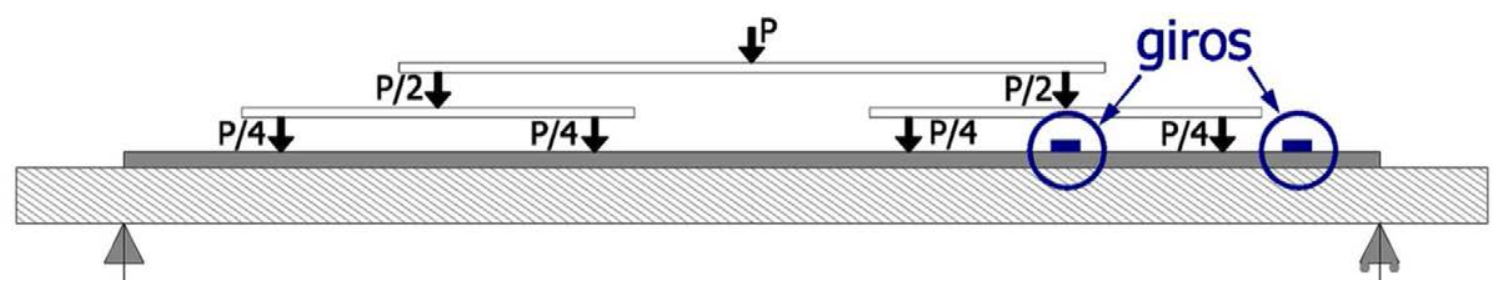

figura 71. Puntos de medida del giro

\section{Deslizamientos}

Se han medido los deslizamientos entre la vigueta y la capa de compresión con LVDT (Solartron $A X / 10 / S$. Rango $\pm 10 \mathrm{~mm}$ y precisión $0,01 \mathrm{~mm}$ ) en 3 puntos que corresponden a los 3 diferentes tramos de cortante $\left(\mathrm{V}_{100 \%}, \mathrm{~V}_{50 \%}\right.$ y $\left.\mathrm{V}_{0 \%}\right)$.

Se ha tomado una cuarta medida en un punto simétrico a uno de ellos $\left(\mathrm{V}_{50 \%}\right)$ para corregir posibles asimetrías que se detecten en los deslizamientos.
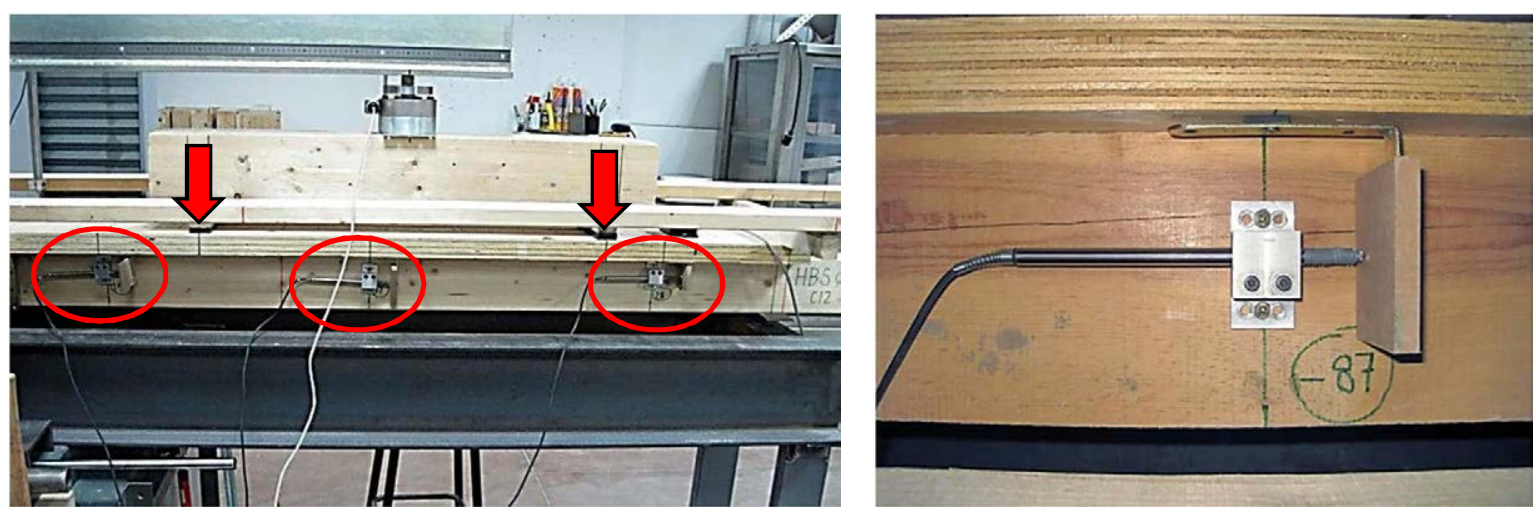

figura 72. $\angle V D T$

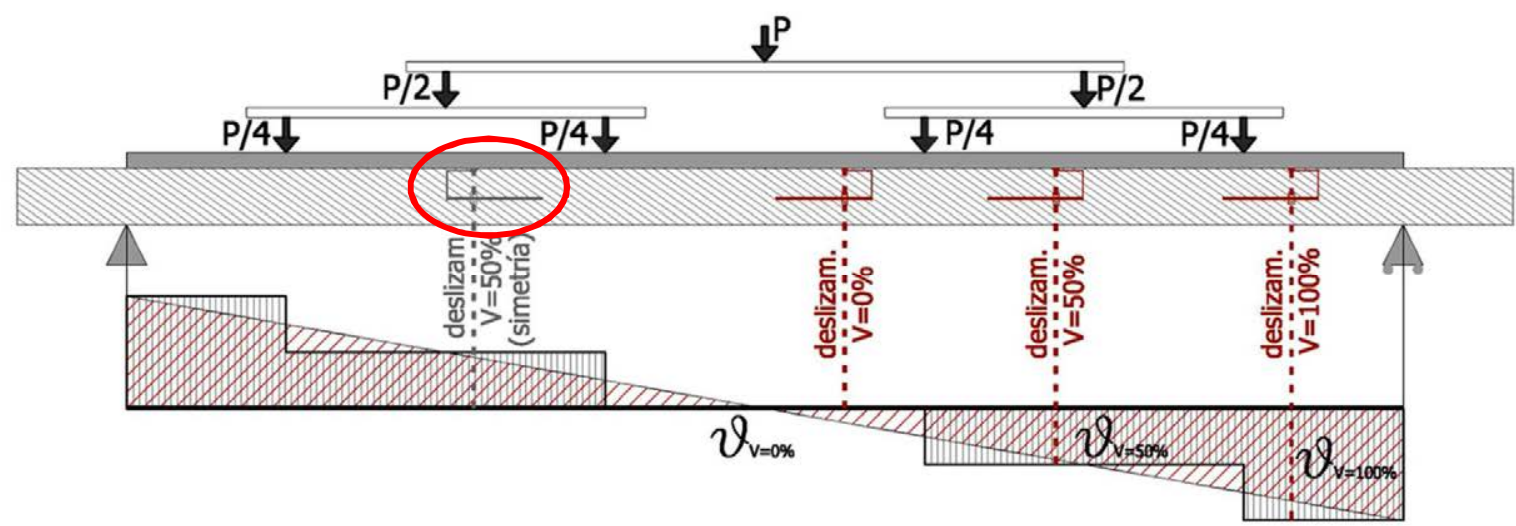

figura 73. Puntos de medida de los deslizamientos 


\section{INFORMACIÓN TRAS LA ROTURA. VIGAS}

En la figura 74 se muestran las cargas, tensiones y flechas alcanzadas en la rotura de las vigas mixtas. La carga y la flecha son valores medidos en los ensayos y las tensiones de las distintas partes están obtenidas mediante el modelo de cálculo explicado en el capítulo 6. En la tabla están puestos los casos más y menos resistentes de cada tipo de viga.

\begin{tabular}{|c|c|c|c|c|c|c|c|c|}
\hline & \multicolumn{8}{|c|}{ CAPA DE COMPRESIÓN DE HORMIGÓN } \\
\hline & \multicolumn{4}{|c|}{ CASO MÁS RESISTENTE } & \multicolumn{4}{|c|}{ CASO MENOS RESISTENTE } \\
\hline & q MÁX & flecha MÁX & \multicolumn{2}{|c|}{$\sigma$ MÁX (N/mm²) } & q MÁX & flecha MÁX & \multicolumn{2}{|c|}{$\sigma \mathrm{MÁX}\left(\mathrm{N} / \mathrm{mm}^{2}\right)$} \\
\hline & $(\mathrm{kN} / \mathrm{m})$ & $(\mathrm{mm})$ & vigueta & c. compresión & $(\mathrm{kN} / \mathrm{m})$ & $(\mathrm{mm})$ & vigueta & c. compresión \\
\hline $\mathrm{H}_{\text {vig }} 14[$ & $16,00(7)$ & $53,34(\mathrm{~L} / 60)$ & 43,81 & $-15,13 / 6,00$ & $10,87(2)$ & $47,91(\mathrm{~L} / 67)$ & 33,87 & $-10,67 / 7,30$ \\
\hline
\end{tabular}

\begin{tabular}{|c|c|c|c|c|c|c|c|c|}
\hline & \multicolumn{8}{|c|}{ CAPA DE COMPRESIÓN DE MADERA MICROLAMINADA } \\
\hline & \multicolumn{4}{|c|}{ CASO MÁS RESISTENTE } & \multicolumn{4}{|c|}{ CASO MENOS RESISTENTE } \\
\hline & q MÁX & flecha MÁX & $\sigma M A ́$ & $\left(\mathrm{~N} / \mathrm{mm}^{2}\right)$ & q MÁX & flecha MÁX & $\sigma$ MÁ & $\left(\mathrm{N} / \mathrm{mm}^{2}\right)$ \\
\hline & $(\mathrm{kN} / \mathrm{m})$ & $(\mathrm{mm})$ & vigueta & c. compresión & $(\mathrm{kN} / \mathrm{m})$ & $(\mathrm{mm})$ & vigueta & c. compresión \\
\hline $\mathrm{H}_{\text {vig }} 14$ & $16,95(9)$ & $86,45(\mathrm{~L} / 37)$ & 60,12 & 19,37 & $10,52(3)$ & $46,49(\mathrm{~L} / 69)$ & 32,67 & 9,86 \\
\hline$f_{\text {via }} 14\left(45^{\circ}\right)$ & $17,96(26)$ & $55,79(\mathrm{~L} / 57)$ & 44,77 & 19,2 & & & & \\
\hline $\mathrm{H}_{\text {viq }} 10$ & $7,4(41)$ & $65,79(\mathrm{~L} / 49)$ & 37,24 & 15,45 & $6,91(48)$ & $55,14(\mathrm{~L} / 58)$ & 30,03 & 12,81 \\
\hline
\end{tabular}

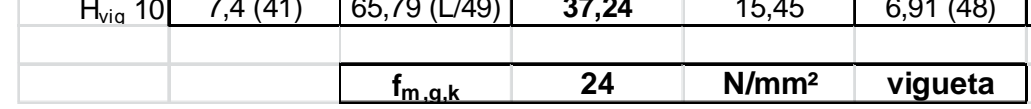

figura 74. Cargas, flechas y tensiones de rotura de las vigas

\section{Rotura de vigas. Vistas generales}
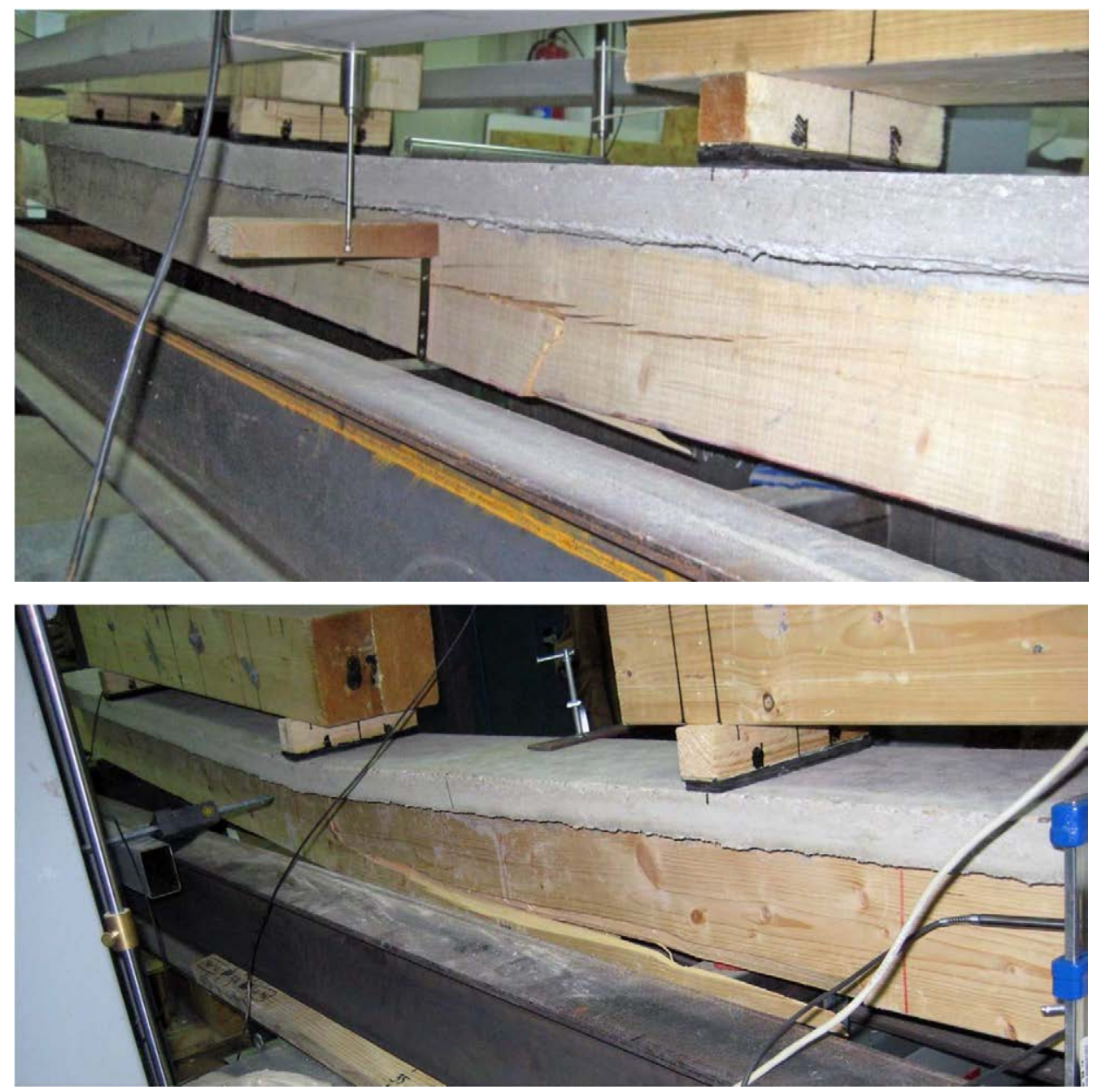

figura 75. Rotura por agotamiento de la vigueta 

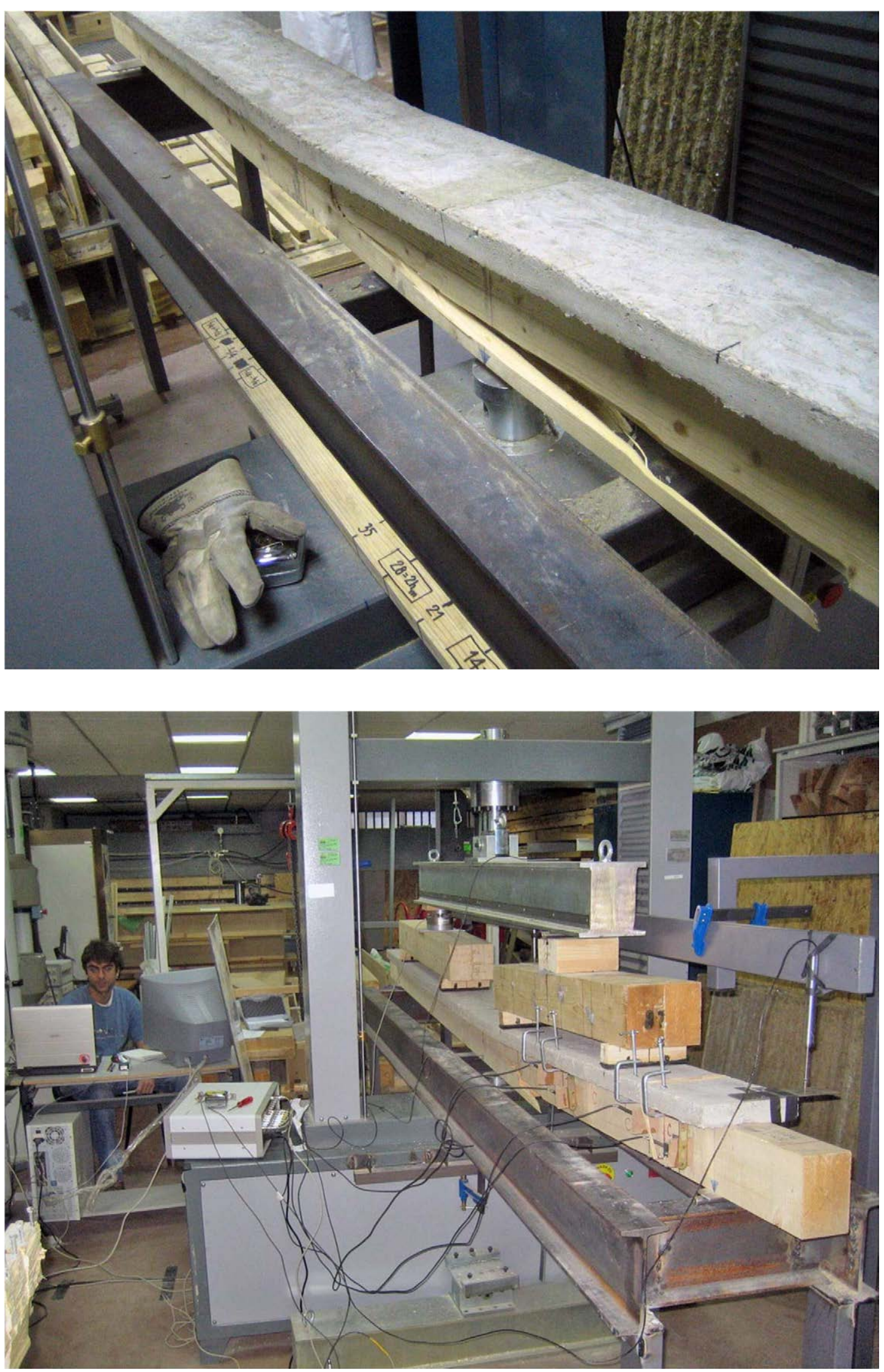

figura 76. Rotura de la vigueta en el tercio central de la luz

Todas las vigas rompen en el tercio central por agotamiento a flexión de la vigueta, que es el elemento más solicitado. Las tensiones alcanzadas están entre 1,25 y 2,50 veces por encima de la resistencia característica de la madera GL24h $\left(\mathrm{f}_{\mathrm{m}, \mathrm{g}, \mathrm{k}}=24 \mathrm{~N} / \mathrm{mm}^{2}\right)$ 


\section{Grieta en capa de compresión}

En los primeros ensayos se detectó el nacimiento de una grieta longitudinal en la capa de compresión de hormigón (figura 77). A partir de ahí, en los siguientes ensayos se colocó un LVDT transversal a la capa de compresión (figura 78) para medir la apertura de esta grieta.
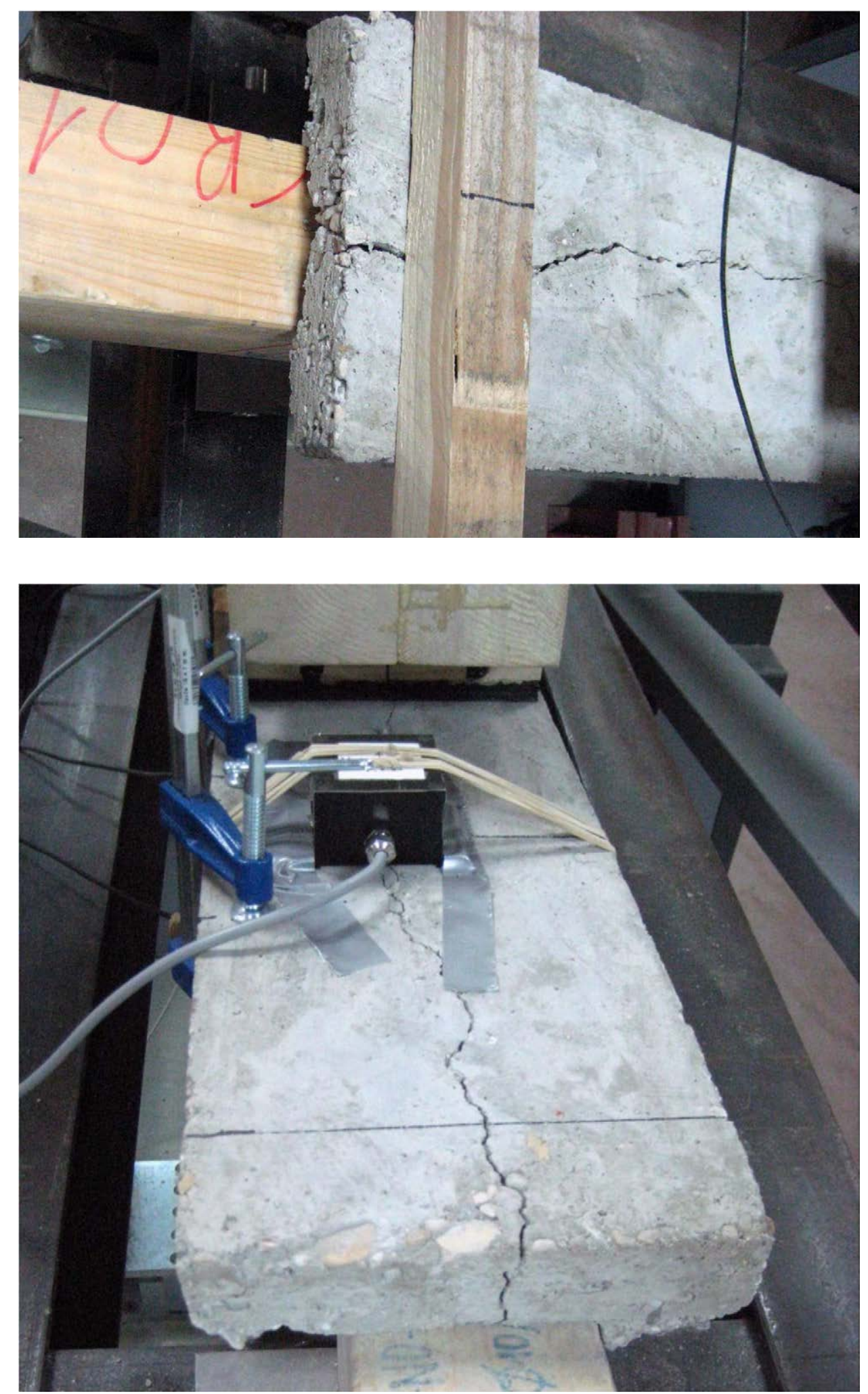

figura 77. Grieta en la capa de compresión de hormigón 


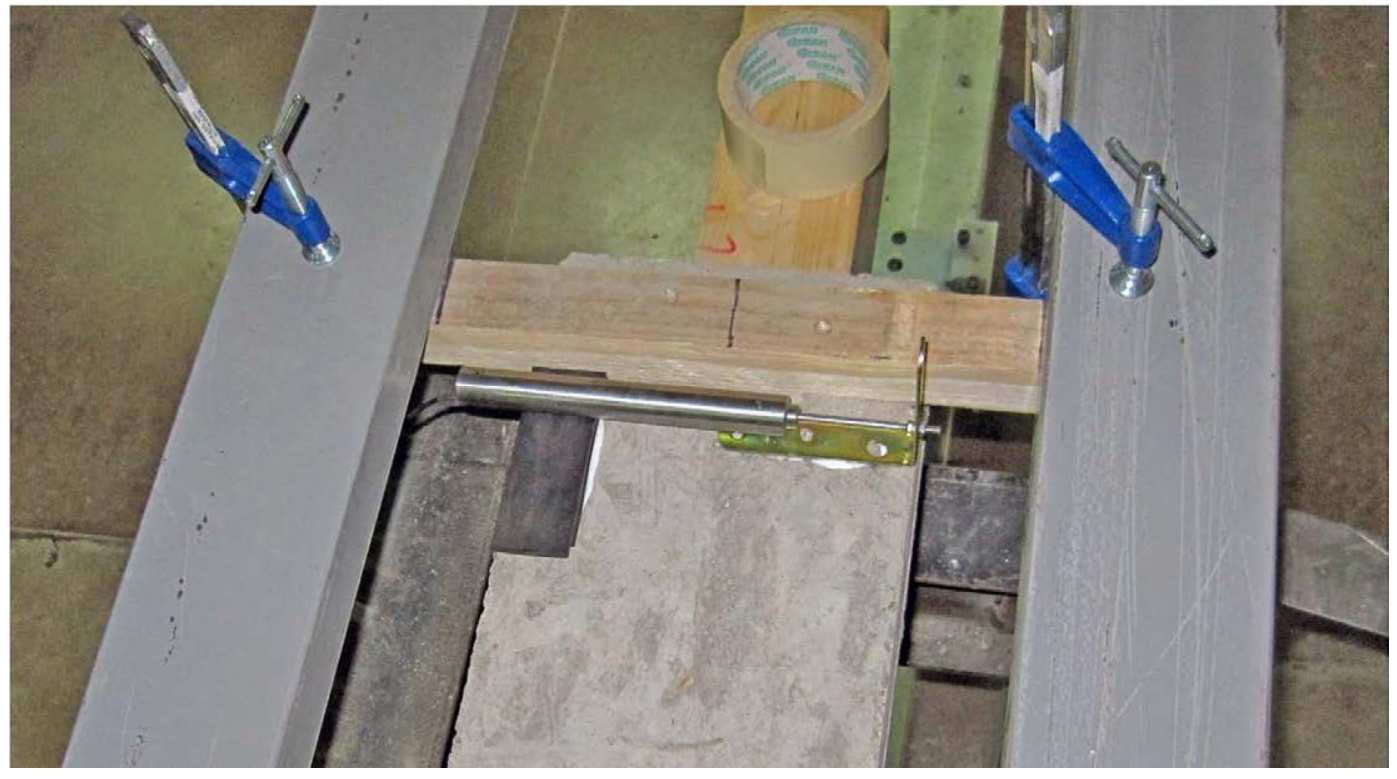

figura 78. Medición de la grieta en el hormigón

La figura 79 muestra la medida de esta grieta (aumentada de escala) superpuesta a la gráfica carga/flecha de la viga.

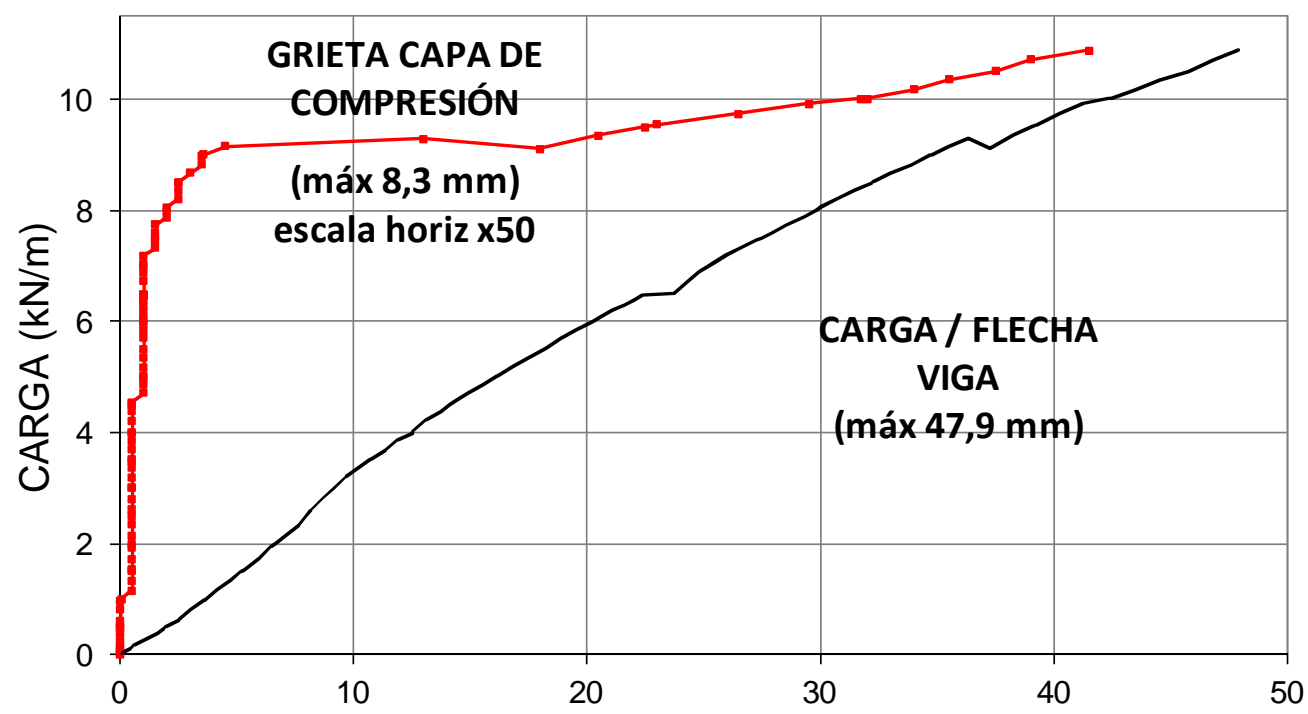

figura 79. Grafica de la apertura de la grieta

En el mismo nivel de carga que aparece la grieta en el hormigón ( $9 \mathrm{kN} / \mathrm{m})$ se aprecia que hay una correspondencia con un pico en la curva carga/flecha de la viga debido a la rotura parcial de algunas fibras de la madera. Lo que no se sabe es si el uno es la causa del otro, o viceversa.

Esta grieta no da pie a pensar que haya un déficit de armado en la capa de compresión, ya que aparece en unos niveles de carga muy cercanos a la rotura de la viga. 


\section{Rotura por zonas débiles. Nudos}

La rotura de las vigas se produce en zonas donde existe alguna debilidad, que generalmente son nudos o uniones dentadas de la madera laminada.

Las fotografías de la figura 80 corresponden a la misma viga en el nacimiento de la grieta de rotura entre dos nudos y al final del proceso.
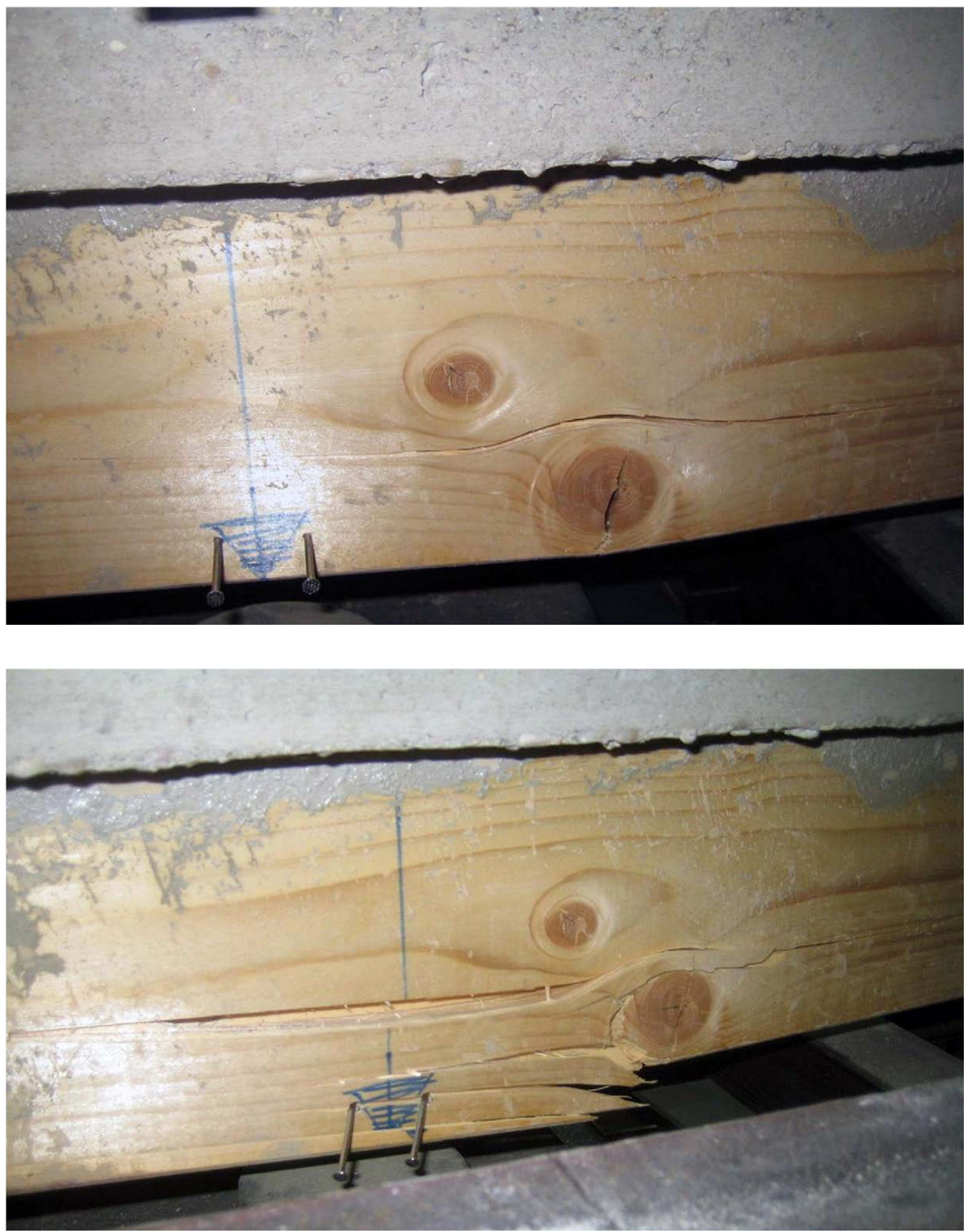

figura 80. Rotura en zona con nudos

LA VIGA MIXTA CON MADERA: verificación experimental del método gamma y estudio de posibles alternativas de análisis 

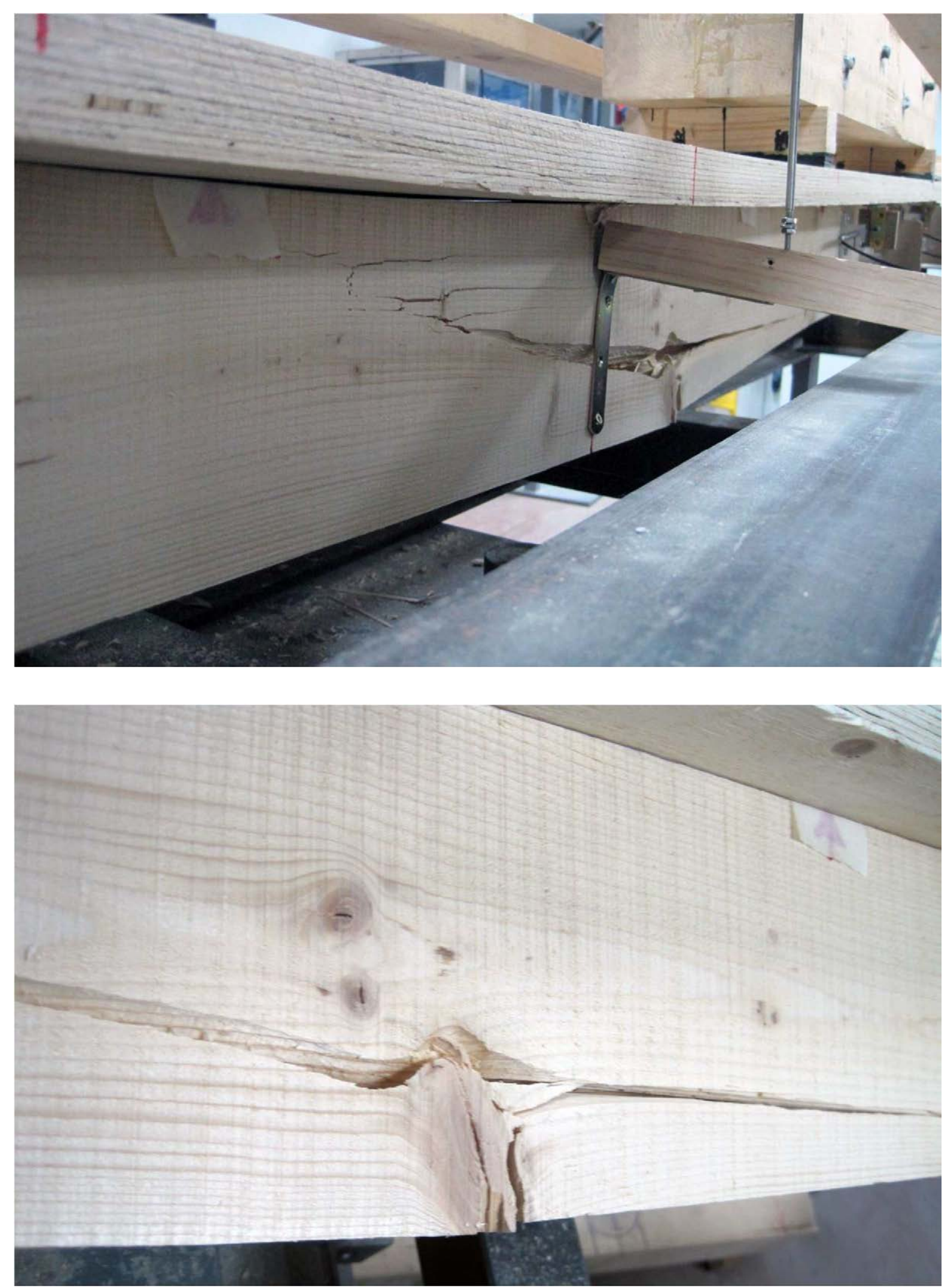

figura 81. Rotura en zona de nudos 

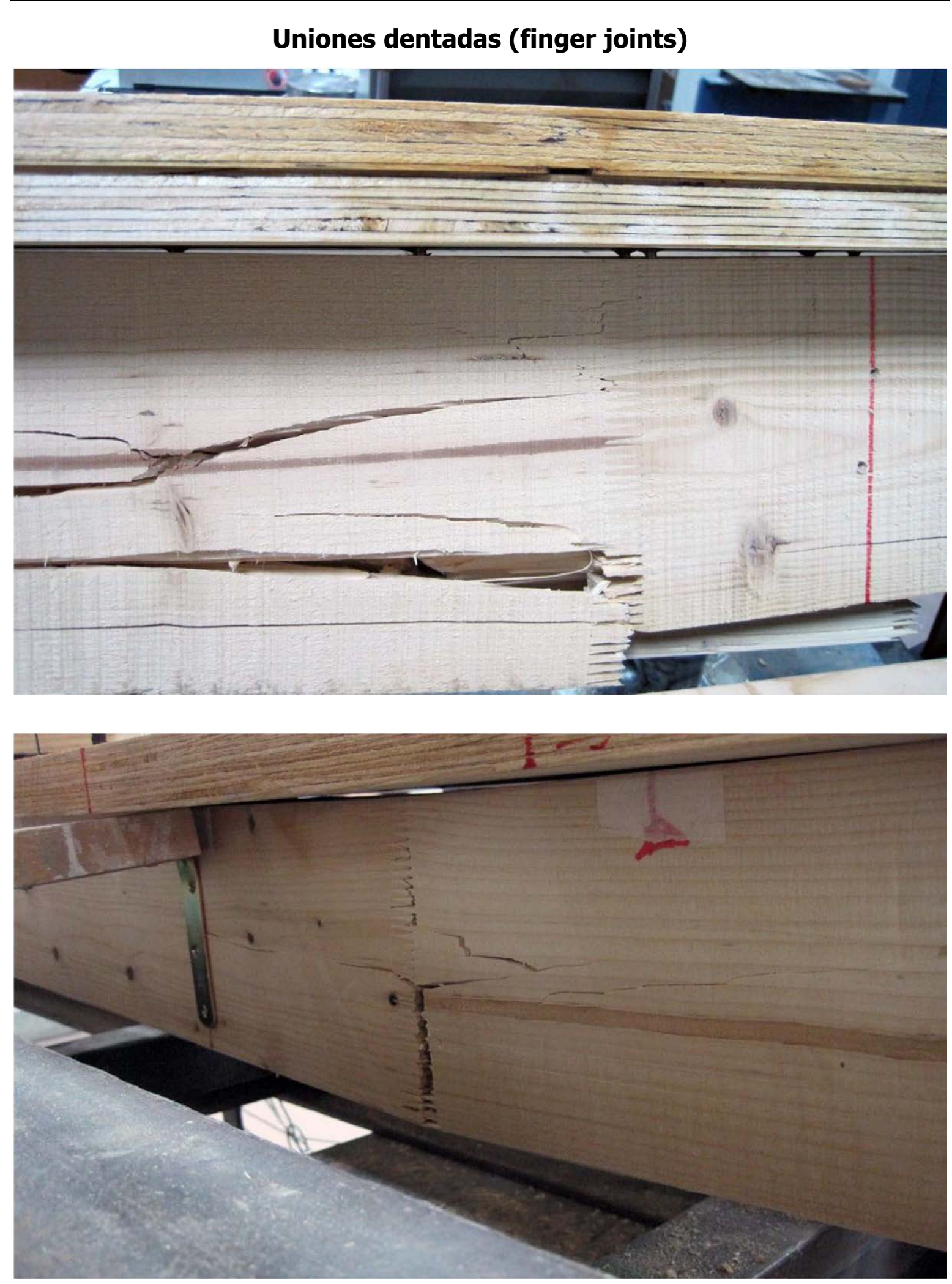

figura 82. Rotura en uniones dentadas 

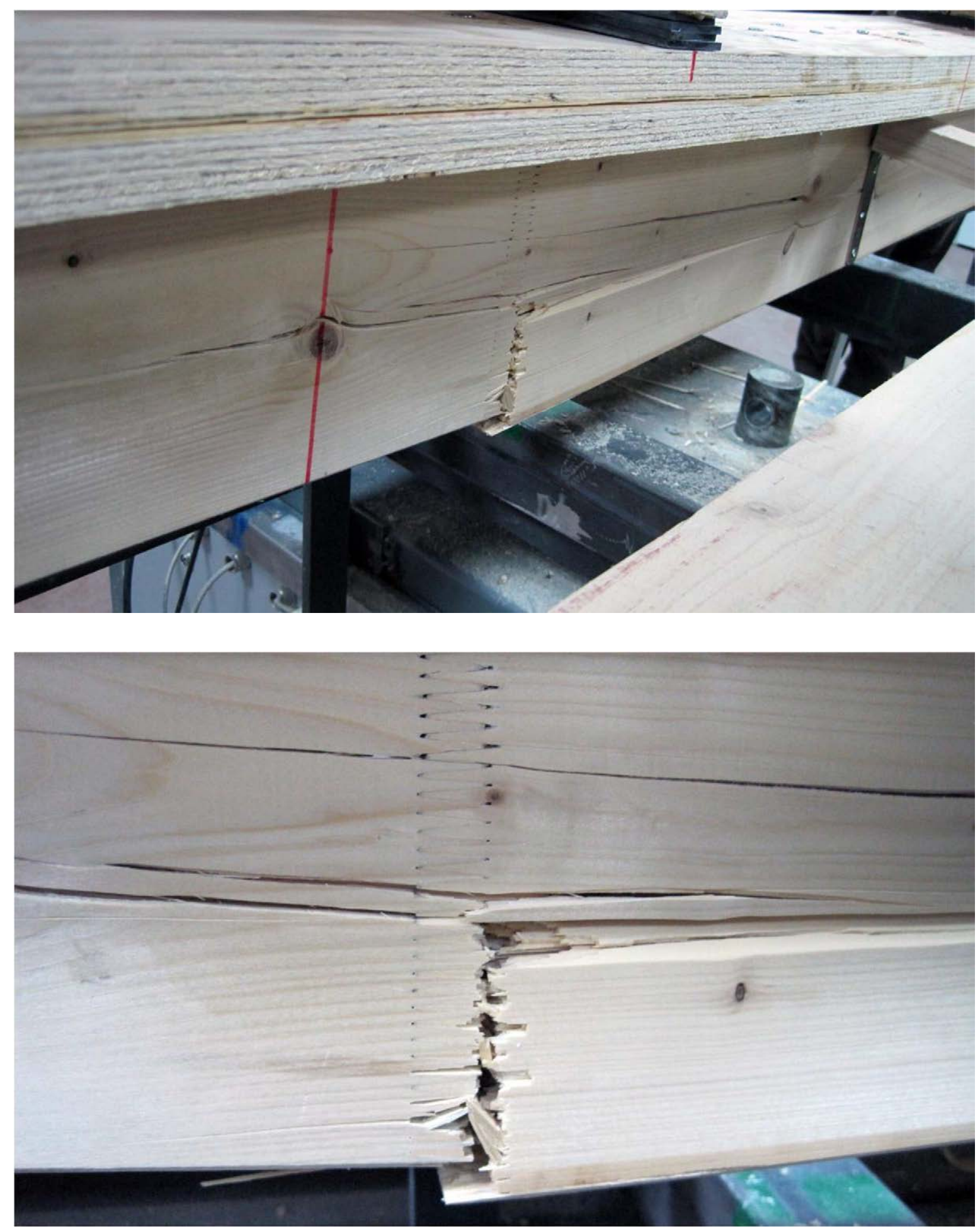

figura 83. Rotura en uniones dentadas 


\section{INFORMACIÓN TRAS LA ROTURA. CONEXIONES}

Después de realizar los ensayos, en las vigas que se llevaron hasta su rotura, se realizó un análisis del estado de los conectores. Para poder ver los conectores, la capa de compresión se eliminaba, en el caso del hormigón con una demolición cuidadosa, y en el caso del microlaminado cortándola. Una vez que quedó la vigueta libre, en el primer caso se eliminó la madera hasta poder ver el estado de los conectores, pero dado la cantidad de tiempo consumido, en el resto se hicieron radiografías para ver el interior.

Las radiografías de la figura 84 corresponden a media viga. Los conectores que aparecen en rojo son elementos dibujados para mantener la cadencia en las partes no radiografiadas.
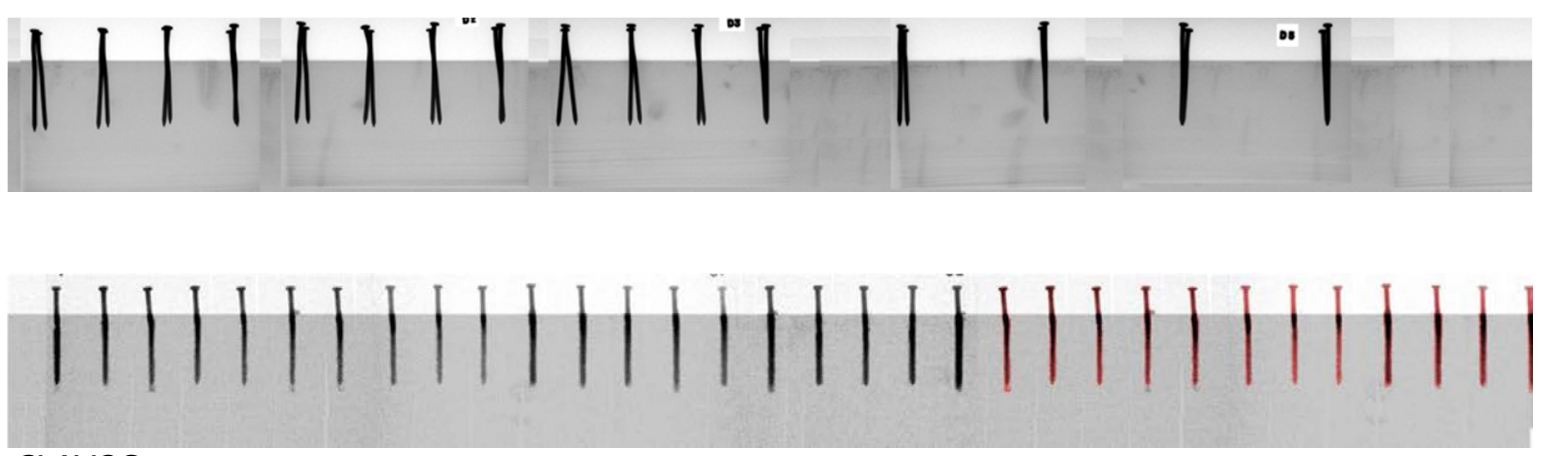

\section{CLAVOS}
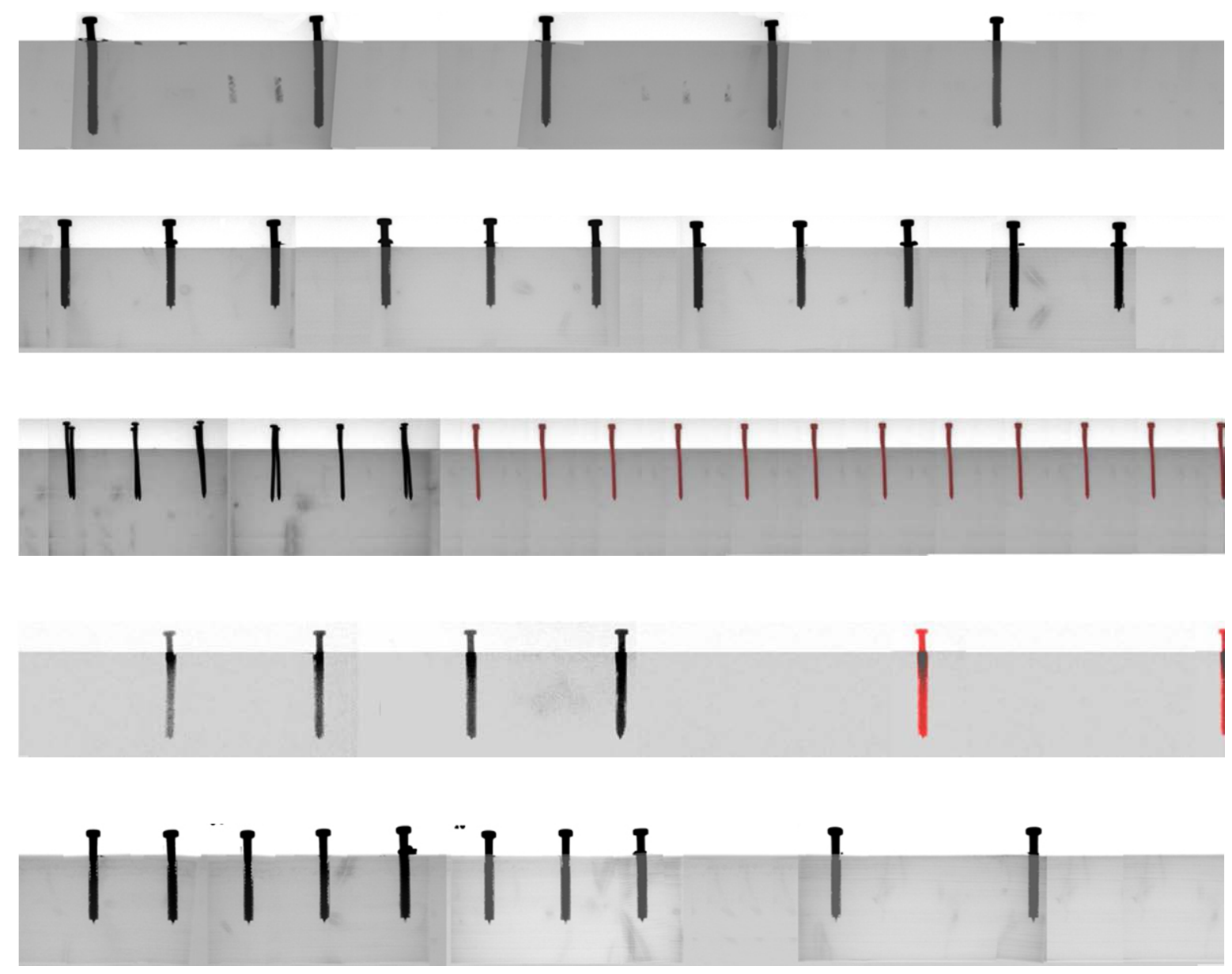

figura 84. Radiografías después de la rotura 

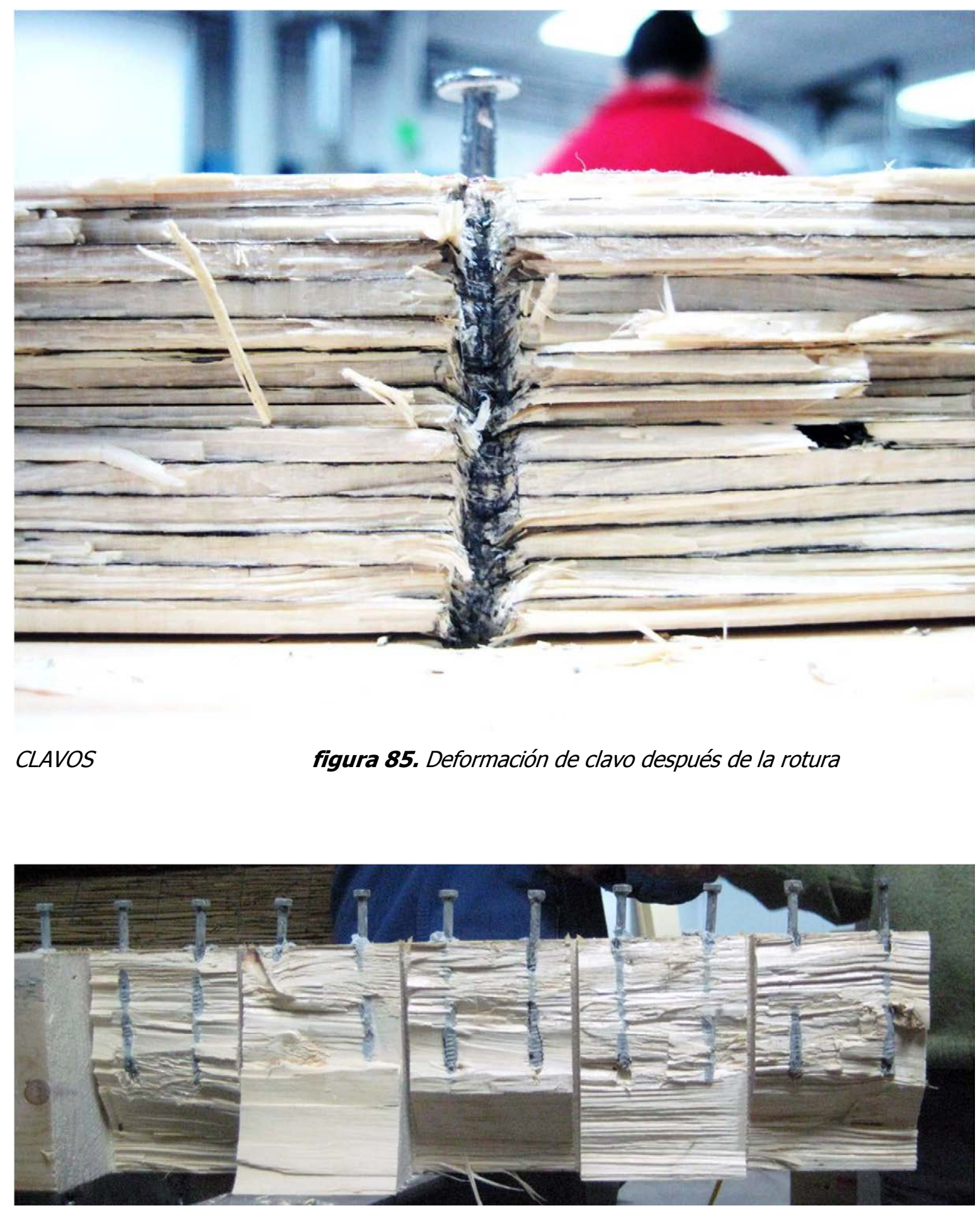

TIRAFONDOS

figura 86. Deformación de tirafondos con resina después de la rotura

Como se puede apreciar, todos los conectores permanecen prácticamente rectos a pesar de que la rotura de la viga se produjo para flechas del orden de $L / 80$ y con cargas diez veces superiores a los valores de servicio de la edificación. 


\subsubsection{TRANSFORMACIÓN DE DATOS DE LABORATORIO}

Todos los ensayos se han realizado aplicando 4 cargas, las deformaciones obtenidas son la suma de flexión y cortante, y además lógicamente se han detectado pequeñas asimetrías. Las conclusiones que se van a extraer al final de este trabajo se van a realizar suponiendo carga uniforme, considerando únicamente la flecha de flexión y lógicamente sin asimetrías. En este capítulo se aborda la traducción de lo primero a lo segundo.

\section{PASO DE 4 CARGAS PUNTUALES A UNIFORME}

Aquí se muestran solo los gráficos de carga, solicitaciones y deformaciones y las relaciones que permiten hacer la transformación a carga uniforme.

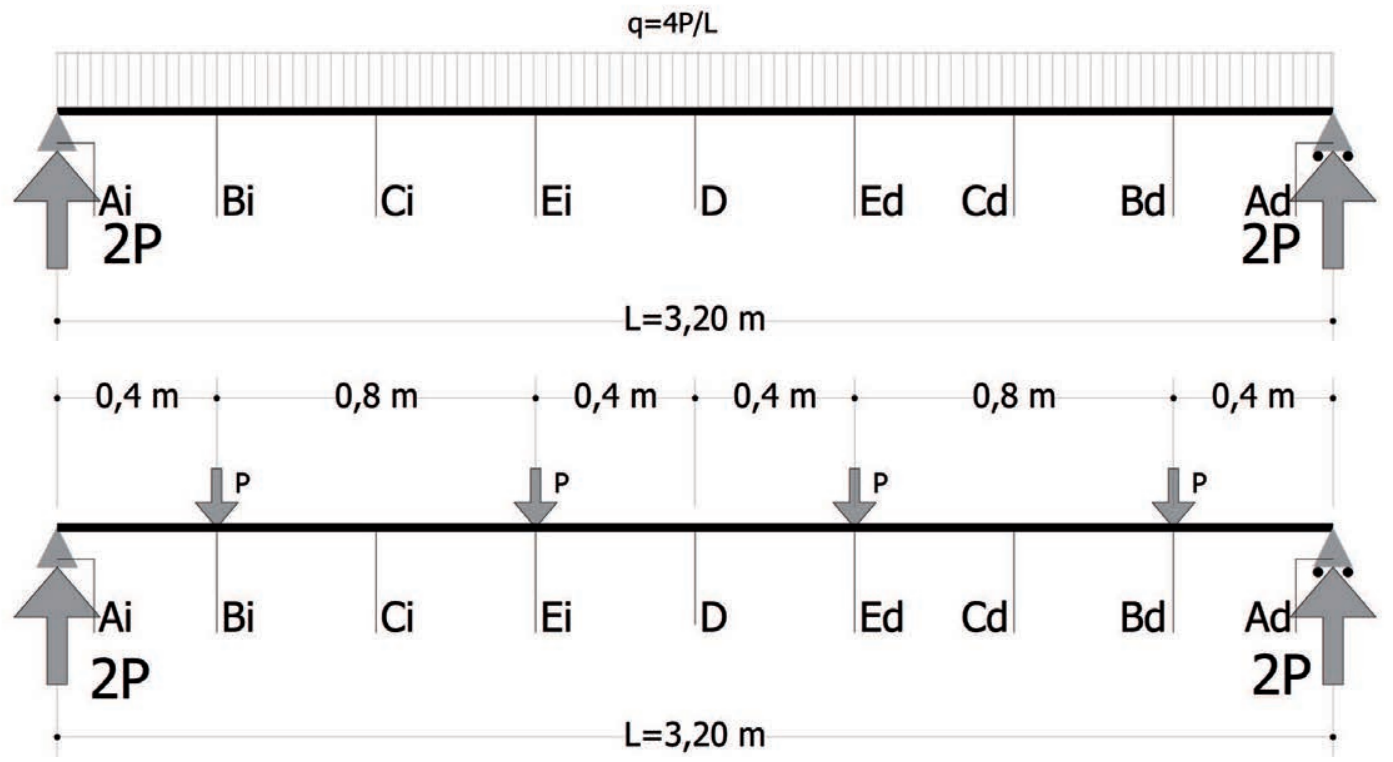

figura 87. Esquemas de carga uniforme y de 4 cargas puntuales

\section{Relación entre $q_{u n i f} \mathbf{y}$ 4P. Solicitaciones: cortante y momento}

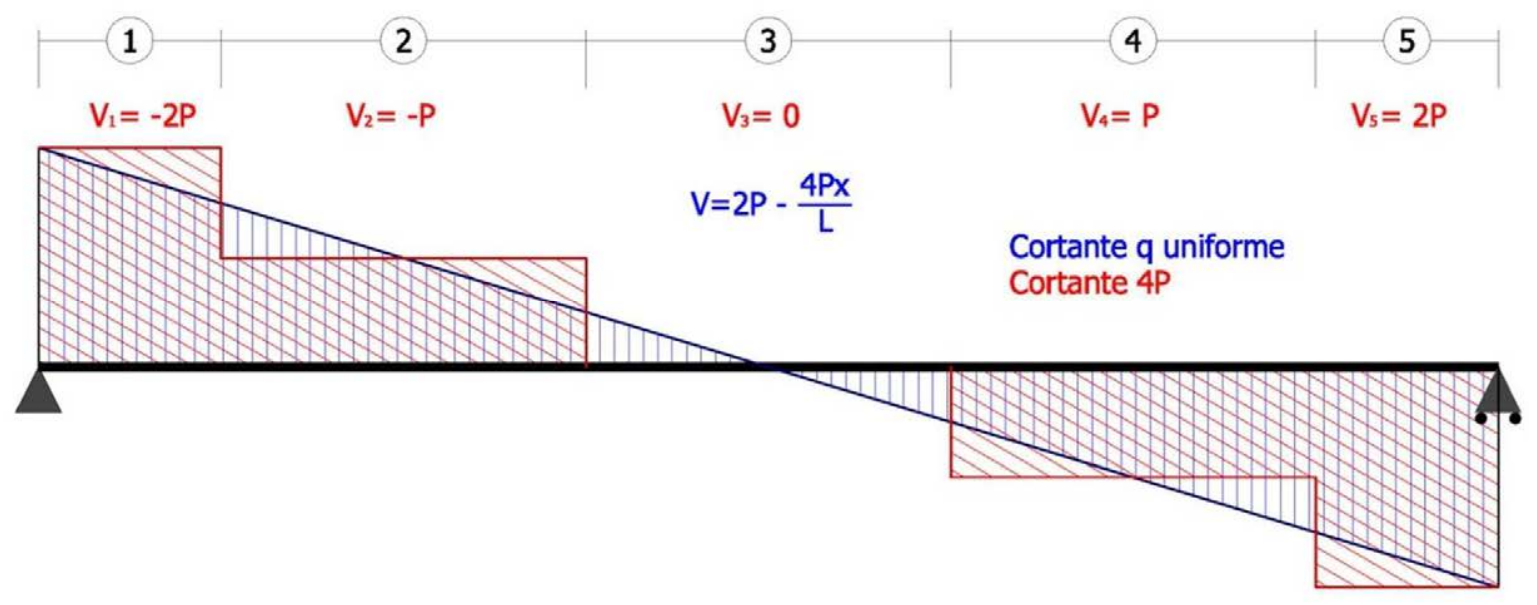

figura 88. Diagramas de cortantes 
El cortante máximo es el mismo en los dos casos, y ambos diagramas tienen el mismo área de cortante, aunque repartida de distinta forma.

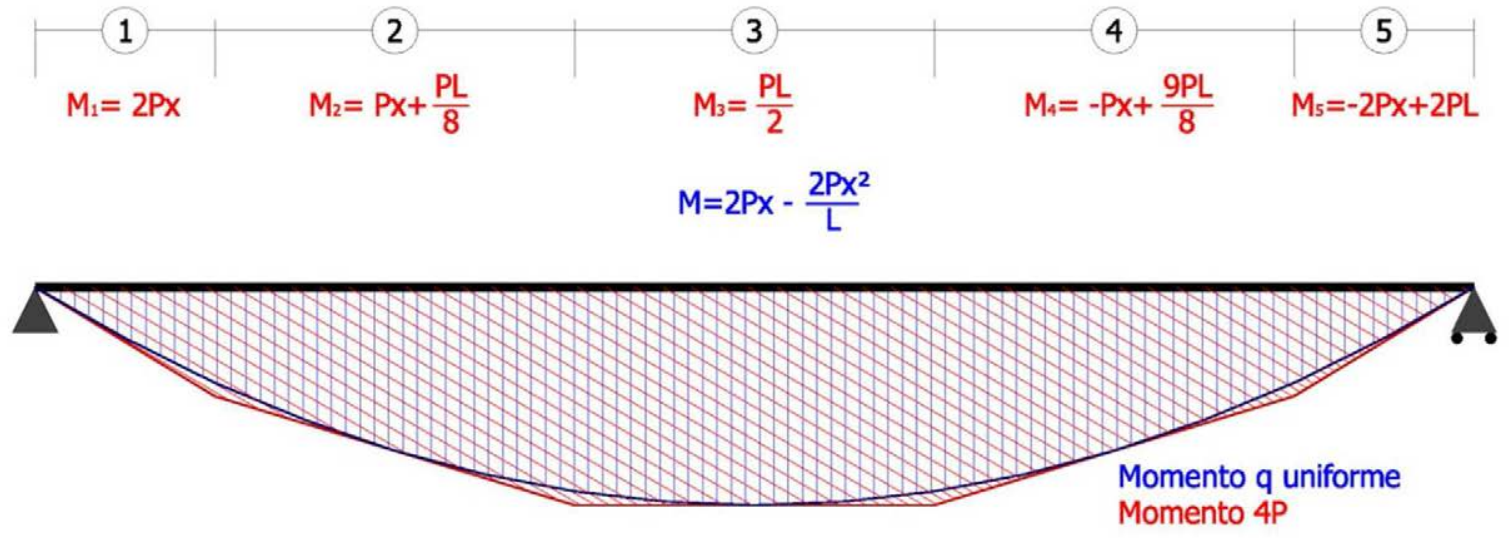

figura 89. Diagramas de momentos

El momento en el centro de la viga sometida a carga uniforme $\left(q=\frac{4 P}{L}\right)$ es de:

$$
\mathrm{M}=\frac{\mathrm{qL}^{2}}{8}=\frac{4 \mathrm{P}}{\mathrm{L}} \frac{\mathrm{L}^{2}}{8}=\frac{\mathrm{PL}}{2}
$$

El momento en el centro de la viga sometida a 4 cargas puntuales $\left(X=\frac{L}{2}\right)$ es de:

$$
\mathrm{M}=2 \mathrm{P} \frac{\mathrm{L}}{2}-\mathrm{P} \frac{3 \mathrm{~L}}{8}-\mathrm{P} \frac{\mathrm{L}}{8}=\frac{\mathrm{PL}}{2}
$$

Por lo tanto, el momento máximo es equivalente en los dos casos, sin embargo en el diagrama de momentos se puede apreciar que el área de momentos de la viga con 4 cargas puntuales es mayor que la viga con carga uniforme, lo que influye en la flecha.

\section{Relación entre qunif $\mathbf{y}$ 4P. Flecha}

La flecha máxima de una viga biapoyada sometida a carga uniforme $\left(q=\frac{4 P}{L}\right)$ es:

$$
\delta_{\text {unif }}=\frac{5}{384} \frac{q L^{4}}{E I}=\frac{5}{96} \frac{P L^{3}}{E I}=\frac{1}{19,20} \frac{P L^{3}}{E I}
$$

La flecha máxima de una viga con 4 cargas puntuales situadas en $\frac{L}{8}, \frac{3 L}{8}, \frac{5 L}{8}$ y $\frac{7 L}{8}$, es:

$\delta_{4 P}=\frac{1}{18,73} \frac{P L^{3}}{E I}$, por lo que es $\left(\frac{19,20}{18,73}\right)=1,025$ veces mayor que con carga uniforme. Por lo tanto, se ha aplicado el factor $\delta_{4 P}=1,025 \delta_{\text {unif }}$ en los resultados de la flecha. 


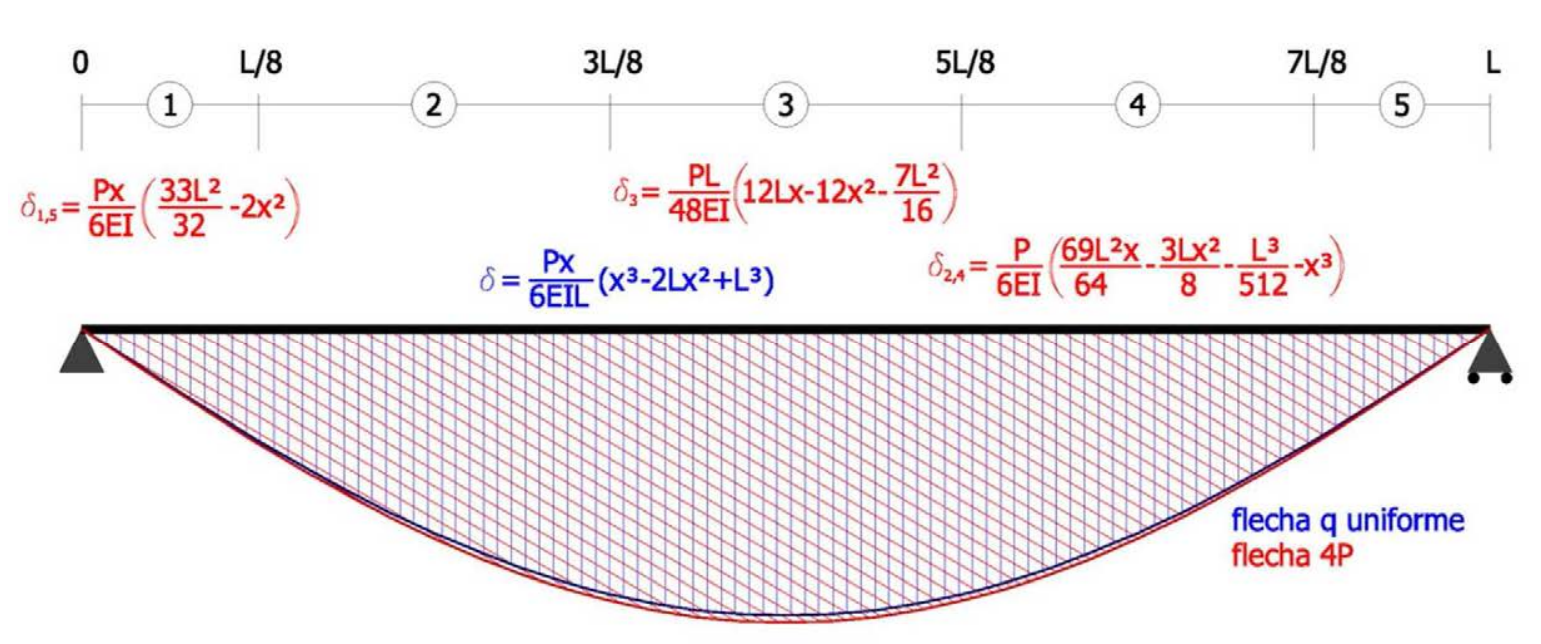

figura 90. Elásticas de $q_{u n i f}$ Y $4 P$

\section{Relación entre $q_{u n i f}$ y 4P. Deslizamientos entre vigueta y capa de compresión}

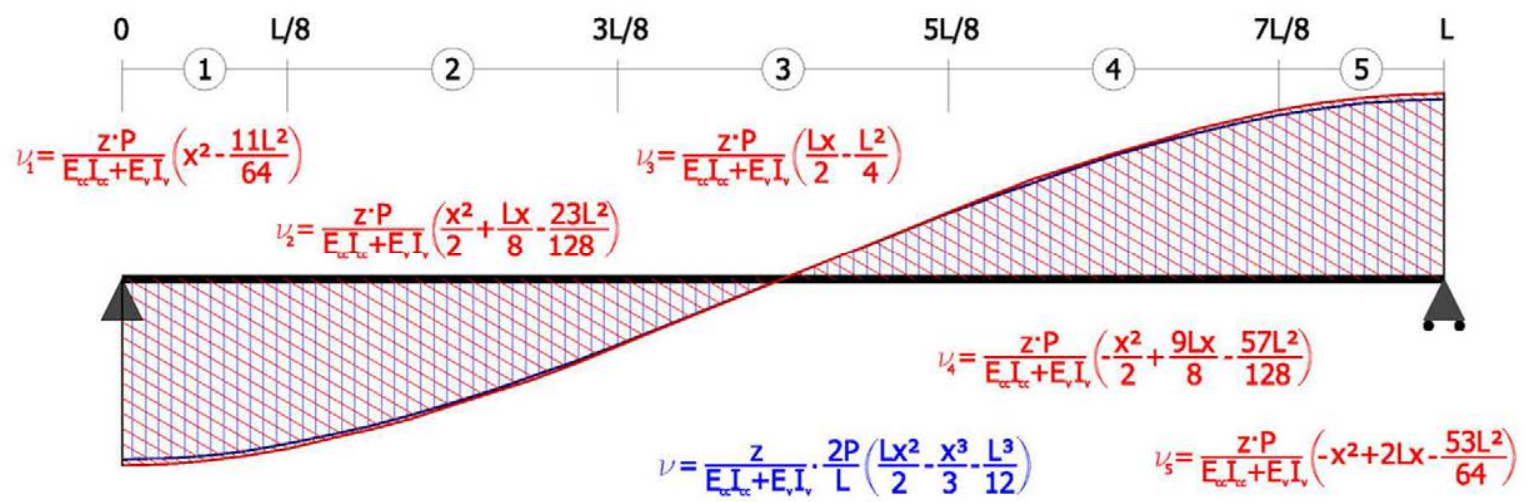

figura 91. Deslizamientos de $q_{\text {unif }}$ y $4 P$

El deslizamiento máximo (en $\mathrm{x}=0$ ) de una viga biapoyada con carga uniforme $\left(q=\frac{4 P}{L}\right)$ es:

$$
v_{\text {unif }}=-\frac{z P L^{2}}{6(E I c c+\text { EIvig })}
$$

El deslizamiento máximo $\left(\right.$ en $\mathrm{x}=0$ ) de una viga con 4 cargas puntuales en $\frac{L}{8}, \frac{3 L}{8}, \frac{5 L}{8}$ y $\frac{7 L}{8}$, es:

$$
v_{4 P}=-\frac{11 z P L^{2}}{64(\text { EIcc }+ \text { EIvig })}
$$

Por lo que el deslizamiento máximo de la viga con 4 cargas puntuales es 1,03125 veces mayor que con carga uniforme. En los puntos de medida tomados en los ensayos, la relación es:

$$
\begin{array}{ll}
X=21 \mathrm{~cm} & V_{4 P}=1,03088 v_{\text {unif }} \\
X=80 \mathrm{~cm} & V_{4 P}=1,02273 v_{\text {unif }} \\
X=140 \mathrm{~cm} & V_{4 P}=1,00524 v_{\text {unif }}
\end{array}
$$

Por lo tanto se emplearon estos factores correctores en los deslizamientos medidos. 


\section{CORRECCIÓN DE ASIMETRÍAS}

Los ensayos realizados tienen dos medidas de la carga aplicada, en el punto $D$ se obtiene la carga total aplicada por la máquina de ensayos, y en el punto Cd se mide la mitad de la carga. Al comparar estos dos valores tras realizar los primeros ensayos se detectaron pequeñas asimetrías en la aplicación de la carga.

\section{Cálculo de la influencia de pequeñas asimetrías de la carga}

En este apartado se ha calculado cómo afecta teóricamente a los resultados (en la sección central) una serie de valores de desviación de la carga. ${ }^{34}$

Se compara en primer lugar el caso completamente simétrico (figura 92) con el caso de mayor desviación apreciada en los ensayos, que ha resultado ser del 6\% (figura 93):

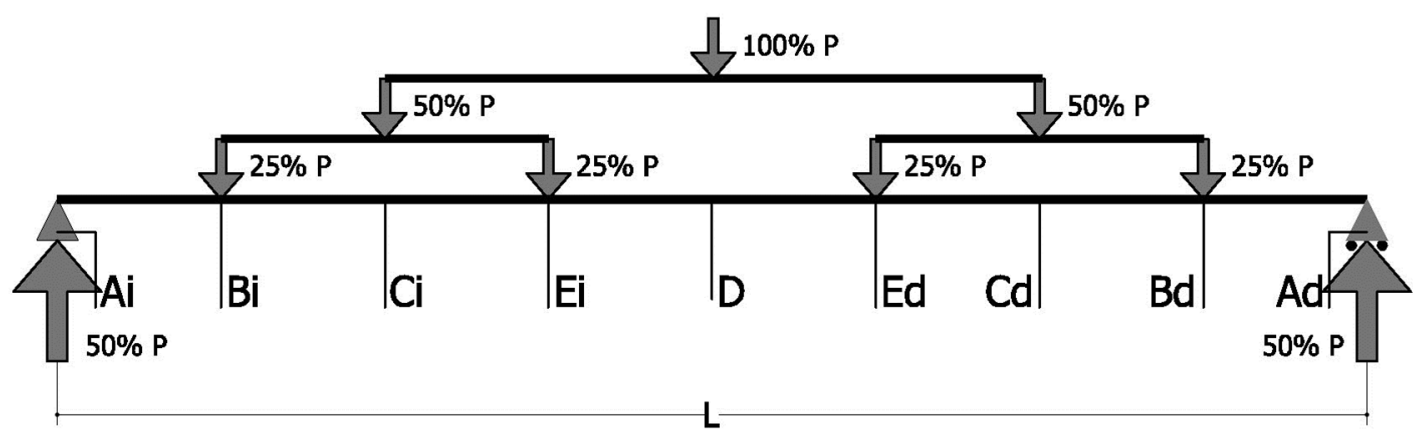

fig 92

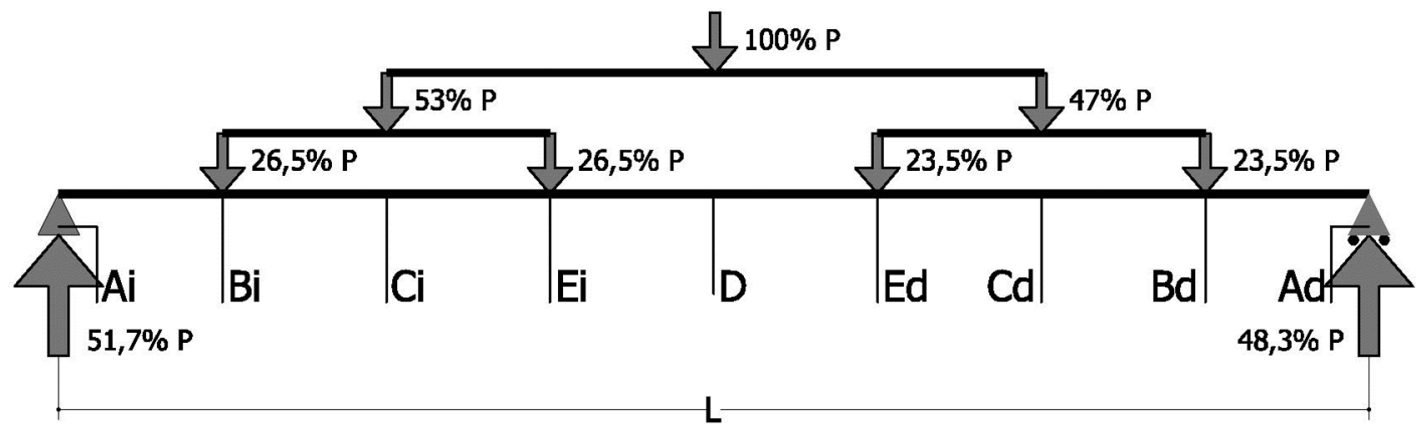

fig 93

\footnotetext{
${ }^{34}$ Se han realizado todos los cálculos con una vigueta biapoyada, de escuadría $(\mathrm{b} \cdot \mathrm{h}) 9 \cdot 14 \mathrm{~cm}$, luz 3,20 m, Módulo de Elasticidad $\mathrm{E}=11.600 \mathrm{~N} / \mathrm{mm}^{2}$ y una carga total aplicada de $6 \mathrm{kN}$.

En el caso 1 (fig. 90) la carga se reparte igualmente en las secciones $\mathrm{Bi}$, Ei, Ed y Bd (1,5 kN en cada una). Se obtiene un momento en $D$ de $2,40 \mathrm{kN} \cdot \mathrm{m}$ y una flecha en $D$ de $11,04 \mathrm{~cm}$.

En el caso 2 (fig. 91) se aplica la carga de 1,59 kN en Bi y Ei y 1,41 kN en Ed y Bd. Obteniendo $\mathrm{Md}=2,40 \mathrm{kN}$, Mei $=2,44 \mathrm{kN}, \delta \mathrm{d}=11,04 \mathrm{~cm}$.

En el caso 3 (fig. 92) se aplican 1,8 kN en Bi y Ei y 1,2 kN en Ed y Bd. Se obtiene $\mathrm{Md}=2,40 \mathrm{kN}$, Mei = 2,50 kN, $\delta \mathrm{d}=11,04 \mathrm{~cm}$.

En el caso 4 (fig. 93) se aplican 2,1 kN en Bi, 1,5 kN en Ei y Ed y 0,9 kN en Bd. Se obtiene Md =2,40 kN, Mei = $2,46 \mathrm{kN}, \delta \mathrm{d}=11,04 \mathrm{~cm}$.

En el caso 5 (fig 94) se aplica la carga de 1,59 kN en Bi y Ei y 1,41 kN en Ed y Bd. Las cargas de Bi y Ei se desplazan $5 \mathrm{~cm}$ a la derecha (lado más desfavorable). Obteniendo $M d=2,48 \mathrm{kN}, \mathrm{Mei}=2,53 \mathrm{kN}, \delta \mathrm{d}=11,30 \mathrm{~cm}$. 
El momento en el punto central D es el mismo en los dos casos, en el caso asimétrico, el momento máximo está en la sección $\mathrm{E}_{\mathrm{i}}$, siendo este un $1,5 \%$ mayor que en el caso simétrico.

La flecha en el punto central $D$ es igual en ambos casos.

Ahora se analiza un caso más extremo de asimetría de cargas (figura 94):

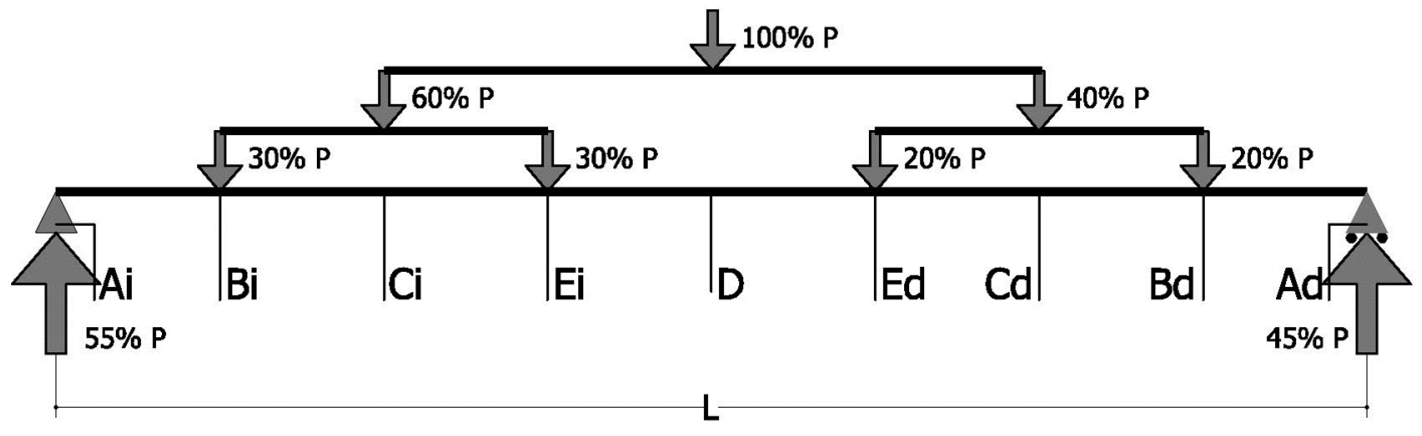

fig 94

El momento en el punto central D es el mismo en los dos casos, en el caso asimétrico, el momento máximo está en la sección $\mathrm{E}_{\mathrm{i}}$, siendo este un $4,0 \%$ mayor que en el caso simétrico.

La flecha en el punto central $D$ es igual en ambos casos.

Se analiza ahora un caso en el que la distribución de cargas es también asimétrica en cada mitad de la viga (figura 95):

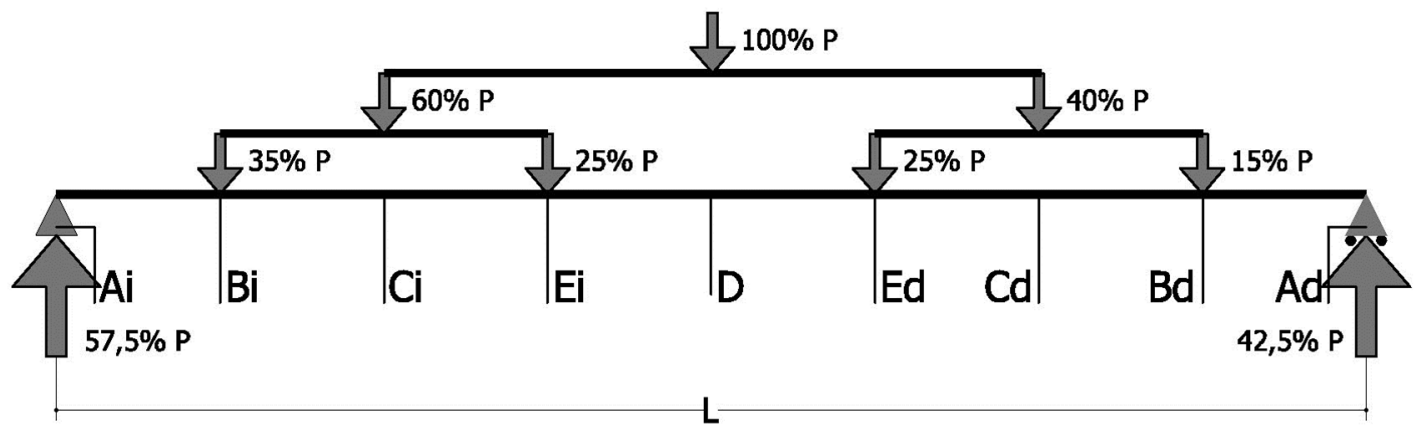

fig 95

El momento en D es el mismo en los dos casos, en el caso asimétrico, el momento máximo en $\mathrm{E}_{\mathrm{i}}$, es un $2,5 \%$ mayor que en el caso simétrico.

La flecha en $D$ es igual en ambos casos. 
Por último se ha analizado un caso con 2 de las cargas colocadas con una desviación de 5 cm (figura 96):

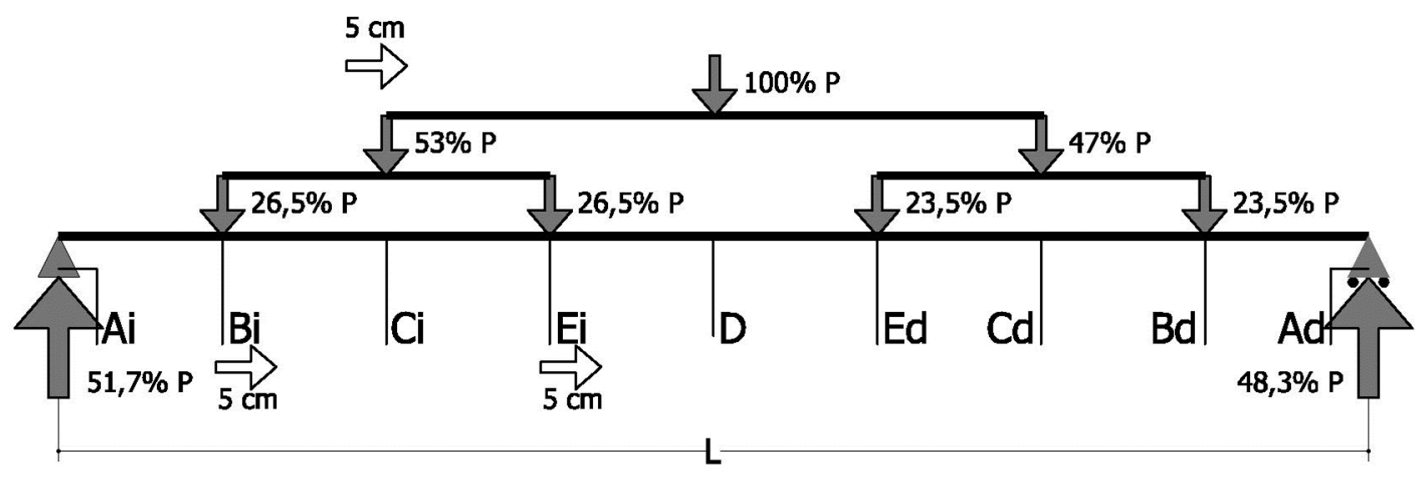

fig 96

El momento en el punto central es un $3 \%$ superior en el caso asimétrico, el momento máximo es un $5 \%$ mayor en el caso asimétrico.

La flecha en el punto central del caso asimétrico es un $2,3 \%$ superior que en caso simétrico.

Un desplazamiento en la colocación de las cargas sí que puede producir variaciones algo superiores a las distribuciones asimétricas de la magnitud de la carga. No obstante, se ha estudiado un caso con un desplazamiento de $5 \mathrm{~cm}$, muy superior a cualquier pequeña imperfección que se pueda realizar en la preparación del ensayo.

\section{Corrección de las asimetrías en los ensayos}

En cualquier caso, al tener medida la asimetría real de los ensayos, se realizarán las correcciones necesarias en los resultados para rectificar las desviaciones encontradas.

Carga

Como se tienen datos de la carga y una de las semicargas durante los ensayos, se ha realizado la siguiente corrección en los datos obtenidos: ${ }^{35}$

La carga total del ensayo no queda registrada en el archivo de datos del ensayo, solo queda grabada la semicarga, si no, no haría falta esta corrección. Sin embargo, los datos de la carga total se podían ver durante el ensayo y se fueron tomando datos cruzados de ambas cargas en diferentes momentos de cada ensayo. (figura 97)

\footnotetext{
${ }^{35}$ Las asimetrías encontradas en los ensayos, por lo general han estado entre el $1 \%$ y el $3 \%$ en los niveles de carga analizados lejanos a la rotura y entre el $1 \%$ y $5 \%$ en cargas cercanas a la rotura.
} 

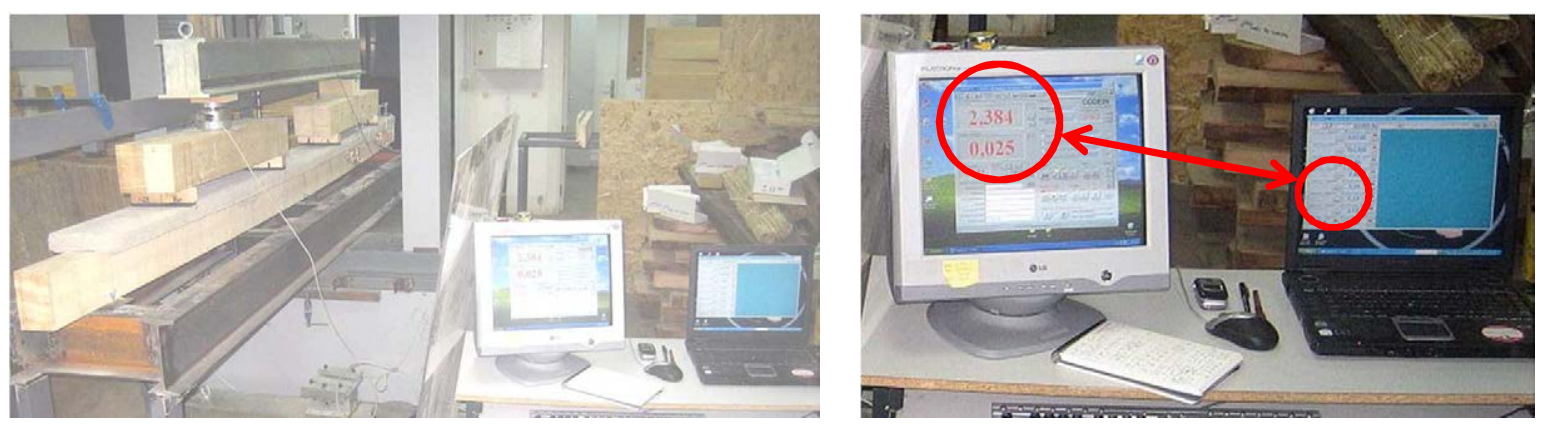

figura 97. Contraste de simetría en la aplicación de carga durante el ensayo

\begin{tabular}{|c|c|c|c|c|}
\hline CARGA & SEMI & & CARGA & CARGA \\
\hline TOTAL & CARGA & DESVIACIÓN & TOTAL & UNIFORME \\
\hline (visual) & (medida) & $\%$ & (utilizada) & (utilizada) \\
\hline $\mathbf{P}_{\text {TOTAL }}$ & $\mathbf{P}_{\text {SEMI }}$ & $+\mathbf{P}_{\text {SEMI }} / \mathbf{P}_{\text {TOTAL }}$ & $+\mathrm{P}_{\mathrm{SEMI}} / \%_{\mathrm{D}}$ & $+\mathrm{P}_{\mathrm{SEMI}} /(\% \mathrm{\%} \times \mathrm{L})$ \\
\hline kg & $\mathbf{k g}$ & & $\mathbf{k g}$ & $\mathrm{kN} / \mathrm{m}$ \\
\hline 820 & 429 & 0,52 & 820 & 2,56 \\
\hline
\end{tabular}

figura 98. Corrección de asimetrías en la carga

Durante el proceso de carga se tomaron entre 6 y 8 datos de la carga total, obteniendo las correspondientes asimetrías de carga en cada uno de ellos. Para hacer esta corrección se ha tomado la media de estas lecturas (6/8 medidas).

\section{Deslizamientos}

Como se ha dicho en el capítulo de instrumentación, se tomaron medidas del deslizamiento en 4 puntos $\left(\mathrm{V}_{28}, \mathrm{~V}_{87}, \mathrm{~V}_{140}\right.$ y $\left.\mathrm{V}_{-87}\right)$. Los dos valores de medida simétricos $\left(\mathrm{V}_{87} \mathrm{y}_{-87}\right)$ han servido para hacer las correcciones de los deslizamientos de la siguiente manera:

\begin{tabular}{|c|c|c|c|}
\hline \multicolumn{4}{|c|}{ Deslizamientos medidos (mm) } \\
\hline \multicolumn{4}{|c|}{ distancia al apoyo (cm) } \\
\hline $\mathbf{2 8}$ & $\mathbf{8 7}$ & $\mathbf{1 4 0}$ & $\mathbf{- 8 7}$ \\
\hline $\mathbf{V}_{\mathbf{2 8}}$ & $\mathbf{V}_{\mathbf{8 7}}$ & $\mathbf{V}_{\mathbf{1 4 0}}$ & $\mathbf{V}_{-87}$ \\
\hline & & & \\
\hline 0,40 & 0,20 & 0,05 & 0,16 \\
\hline
\end{tabular}

\begin{tabular}{|c|c|c|}
\hline \multicolumn{3}{|c|}{ Deslizamientos corregidos $(\mathrm{mm})$} \\
\hline \multicolumn{3}{|c|}{ distancia al apoyo (cm) } \\
\hline 28 & $\mathbf{8 7}$ & $\mathbf{1 4 0}$ \\
\hline $\mathrm{V}_{\mathrm{C28}}$ & $\mathrm{V}_{\mathrm{C} 87}$ & $\mathrm{~V}_{\mathrm{C} 140}$ \\
\hline $\mathrm{V}_{\mathbf{2 8}}-\mathrm{V}_{87}+\mathrm{V}_{\mathrm{C} 87}$ & $\left(\mathrm{~V}_{87}+\mathrm{V}_{-87}\right) / 2$ & $\mathrm{~V}_{140}-\mathrm{V}_{87}+\mathrm{V}_{\mathrm{C} 87}$ \\
\hline 0,38 & 0,18 & 0,03 \\
\hline
\end{tabular}

figura 99. Corrección de asimetrías en los deslizamientos 


\section{CORRECCIÓN DE LA FLECHA DE CORTANTE}

\section{Ensayos para medir la flecha de cortante ${ }^{36}$}

En este apartado se quiere comprobar la influencia de la flecha debido al esfuerzo cortante respecto a la flecha total en una viga, para lo que se realiza una serie de ensayos con una viga de madera laminada de clase GL24h y dimensiones $(b \cdot h) 9 \cdot 14 \mathrm{~cm}$.

\section{Descripción de los ensayos}

El módulo de elasticidad de la viga empleada ya había sido obtenido previamente $\left(E_{0, \text { g,medio }}=11.476 \mathrm{~N} / \mathrm{mm}^{2}\right) .{ }^{37}$

La viga inicialmente era de dimensiones $(\mathrm{b} \cdot \mathrm{h}) 14 \cdot 18 \mathrm{~cm}$ y se cortó longitudinalmente para adaptarse a la escala de los ensayos, por lo que una de las láminas de la madera laminada quedó cortada por la mitad. En estos ensayos se comprobará también la posible influencia de este corte en las características mecánicas de la pieza.
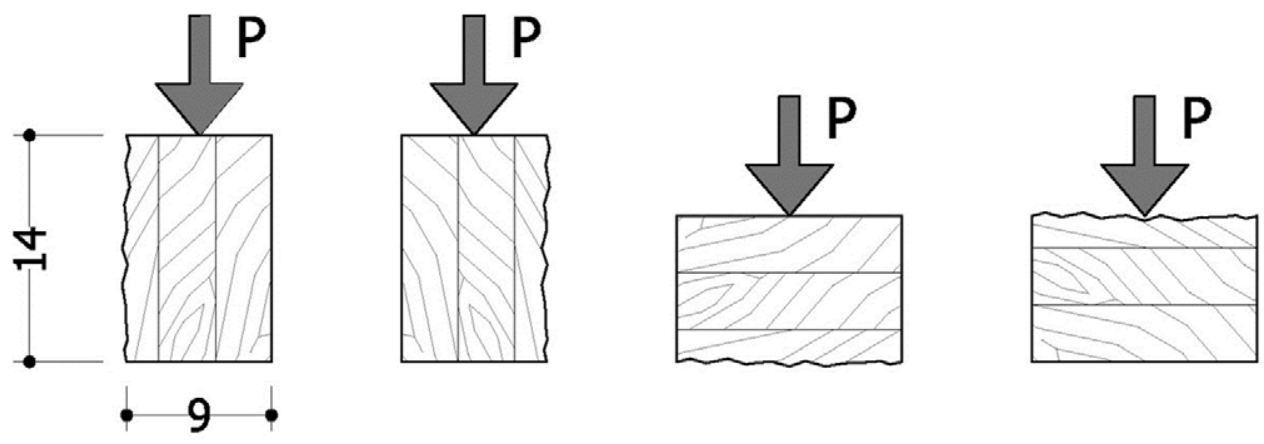

figura 100

Se realizan ensayos a flexión de la viga, se emplean 4 esbelteces distintas y se varía la orientación de la lámina de madera laminada cortada, quedando un total de 8 ensayos:

\begin{tabular}{|c|c|c|c|c|}
\hline 1 & Luz $=3,20 \mathrm{~m}$ & $\mathrm{~b} \times \mathrm{h}=14 \cdot 9 \mathrm{~cm}$ & $\lambda(L / h)=35,6$ & lámina cortada: abajo \\
\hline 2 & $\mathrm{Luz}=3,20 \mathrm{~m}$ & $\mathrm{~b} \times \mathrm{h}=14 \cdot 9 \mathrm{~cm}$ & $\lambda(L / h)=35,6$ & lámina cortada: arriba \\
\hline 3 & $\mathrm{Luz}=3,20 \mathrm{~m}$ & $\mathrm{~b} \times \mathrm{h}=9 \cdot 14 \mathrm{~cm}$ & $\lambda(L / h)=22,9$ & lámina cortada: izq \\
\hline 4 & $\mathrm{Luz}=3,20 \mathrm{~m}$ & $\mathrm{~b} \times \mathrm{h}=9 \cdot 14 \mathrm{~cm}$ & $\lambda(L / h)=22,9$ & lámina cortada: der \\
\hline 5 & Luz $=2,40 \mathrm{~m}$ & $\mathrm{~b} \times \mathrm{h}=14 \cdot 9 \mathrm{~cm}$ & $\lambda(L / h)=26,7$ & lámina cortada: abajo \\
\hline 6 & $\operatorname{Luz}=2,40 \mathrm{~m}$ & $\mathrm{~b} \times \mathrm{h}=14 \cdot 9 \mathrm{~cm}$ & $\lambda(L / h)=26,7$ & lámina cortada: arriba \\
\hline 7 & $\operatorname{Luz}=2,40 \mathrm{~m}$ & $\mathrm{~b} \times \mathrm{h}=9 \cdot 14 \mathrm{~cm}$ & $\lambda(L / h)=17,1$ & lámina cortada: izq \\
\hline & $\mathrm{Luz}=2,40 \mathrm{~m}$ & $\mathrm{~b} \times \mathrm{h}=9 \times 14 \mathrm{~cm}$ & $\lambda(L / h)=17,1$ & lámina cortada: der \\
\hline
\end{tabular}

\footnotetext{
${ }^{36}$ Los resultados de estos ensayos están detallados en el Anejo IV.3 "Vigas a flexión. Trabajos previos. Ensayos para medir la flecha de cortante".

${ }^{37}$ No coincide con el E del listado de ensayos, porque el otro está obtenido con la viga ya cortada a $9 \cdot 10$.
} 
En los ensayos de luz 3,20 m la aplicación de carga se realiza en 4 puntos, y en los de luz 2,40 m los puntos de aplicación son 2 .

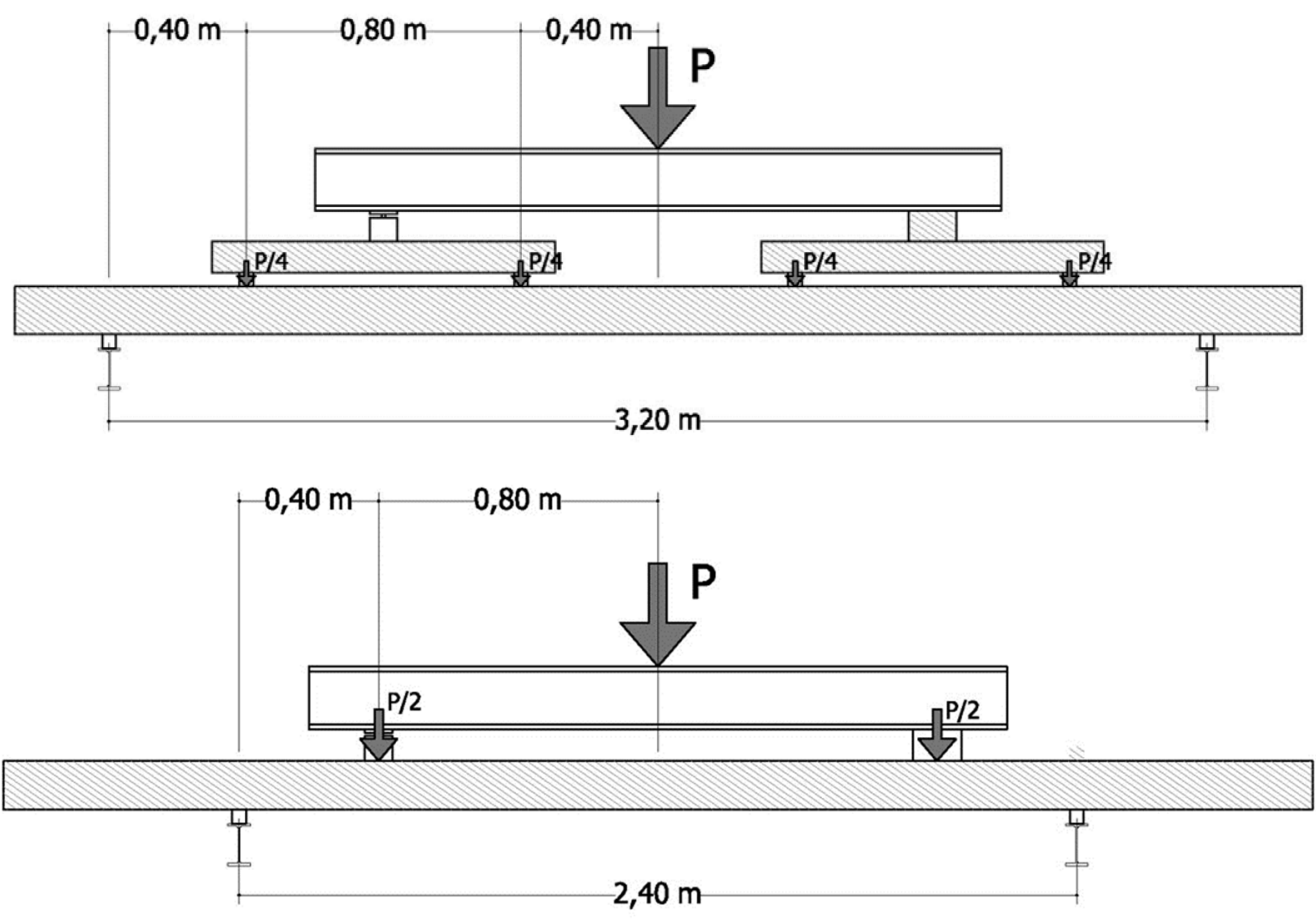

Figura 101. Esquemas de ensayos

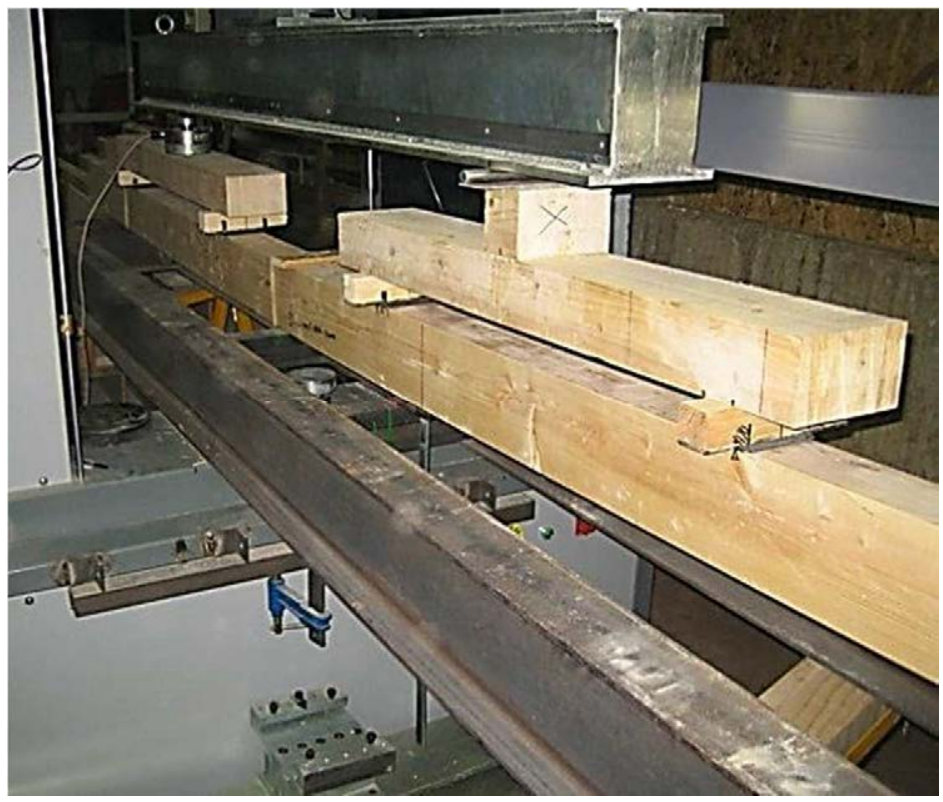

figura 102. Realización de los ensayos

Todos los ensayos se realizan con la misma viga, cargando esta siempre hasta tensiones perfectamente admisibles y que no alteren su capacidad mecánica en los siguientes ensayos. Por esta razón, los ensayos se realizan hasta que la viga alcanza una flecha de 1/200 de la luz. 
Los datos que se obtienen durante los ensayos son la semi-carga, medida con una célula de carga de $5.000 \mathrm{~kg}$ (punto $\mathrm{Ci}$ ) y la flecha, media con dos LVDT, uno en cada cara de la viga (punto D).

\section{$\underline{\text { Resultados obtenidos }}$}

\begin{tabular}{|c|c|c|c|c|c|c|c|}
\hline \multicolumn{2}{|c|}{ ENSAYO 1} & \multicolumn{2}{|c|}{ ENSAYO 2} & \multicolumn{2}{|c|}{ ENSAYO 3} & \multicolumn{2}{|c|}{ ENSAYO 4} \\
\hline Luz & 3,20 & Luz & 3,20 & Luz & 3,20 & Luz & 3,20 \\
\hline Canto & 9,00 & Canto & 9,00 & Canto & 14,00 & Canto & 14,00 \\
\hline Esbeltez & 35,56 & Esbeltez & 35,56 & Esbeltez & 22,86 & Esbeltez & 22,86 \\
\hline$Q$ unif & flecha & $Q$ unif & flecha & $Q$ unif & flecha & $Q$ unif & flecha \\
\hline $\mathrm{kN} / \mathrm{m}$ & $\begin{array}{c}\mathrm{mm} \\
(\mathrm{L} / \mathbf{2 0 0})\end{array}$ & $\mathrm{kN} / \mathrm{m}$ & $\begin{array}{c}\mathrm{mm} \\
(\mathrm{L} / \mathbf{2 0 0})\end{array}$ & $\mathrm{kN} / \mathrm{m}$ & $\begin{array}{c}\mathrm{mm} \\
(\mathrm{L} / \mathbf{2 0 0})\end{array}$ & $\mathrm{kN} / \mathrm{m}$ & $\begin{array}{c}\mathrm{mm} \\
\text { (L/200) }\end{array}$ \\
\hline 1,01 & 16,00 & 0,95 & 16,00 & 2,66 & 16,00 & 2,65 & 16,00 \\
\hline \multicolumn{2}{|c|}{ ENSAYO 5} & \multicolumn{2}{|c|}{ ENSAYO 6} & \multicolumn{2}{|c|}{ ENSAYO 7} & \multicolumn{2}{|c|}{ ENSAYO 8} \\
\hline Luz & 2,40 & Luz & 2,40 & Luz & 2,40 & Luz & 2,40 \\
\hline Canto & 9,00 & Canto & 9,00 & Canto & 14,00 & Canto & 14,00 \\
\hline Esbeltez & 26,67 & Esbeltez & 26,67 & Esbeltez & 17,14 & Esbeltez & 17,14 \\
\hline$Q$ unif & flecha & $Q$ unif & flecha & $Q$ unif & flecha & $Q$ unif & flecha \\
\hline $\mathrm{kN} / \mathrm{m}$ & $\begin{array}{c}\mathrm{mm} \\
(\mathrm{L} / \mathbf{2 0 0})\end{array}$ & $\mathrm{kN} / \mathrm{m}$ & $\begin{array}{c}\mathrm{mm} \\
(\mathrm{L} / 200)\end{array}$ & $\mathrm{kN} / \mathrm{m}$ & $\begin{array}{c}\mathrm{mm} \\
(\mathrm{L} / \mathbf{2 0 0})\end{array}$ & $\mathrm{kN} / \mathrm{m}$ & $\begin{array}{c}\mathrm{mm} \\
(\mathrm{L} / \mathbf{2 0 0})\end{array}$ \\
\hline 2,35 & 12,00 & 2,08 & 12,00 & 5,19 & 12,00 & 5,37 & 12,00 \\
\hline
\end{tabular}

figura 103. Resultados de los ensayos

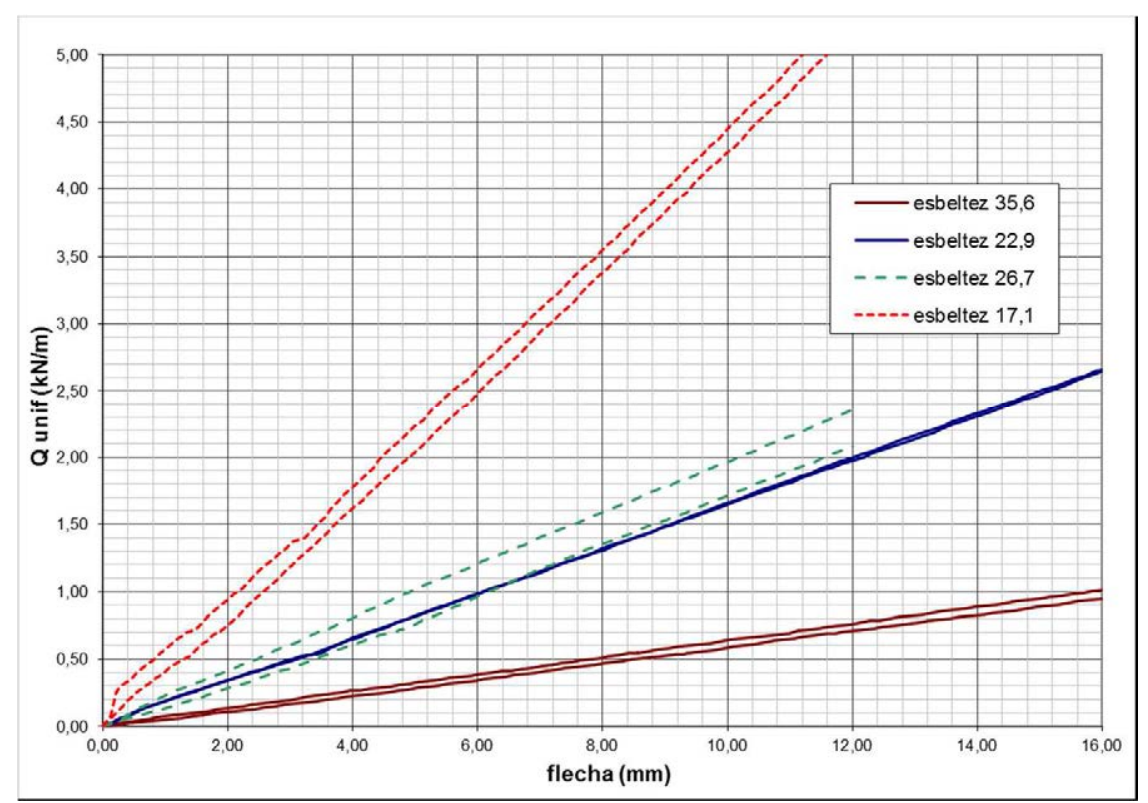

figura 104. Gráficas de carga-flecha de los ensayos

A estas flechas, que son las totales, se les deduciría la flecha de cortante tal como se desarrolla a continuación. 
De la flecha total medida en los ensayos se ha eliminado la flecha debida al cortante con el fin de poder comparar los resultados con un modelo de cálculo sencillo (que solo calcule deformaciones de flexión). Para hacerlo, a la flecha de los ensayos se le ha aplicado la siguiente corrección:

Las flechas de momento y de cortante, en secciones rectangulares, para vigas doblemente apoyadas y carga uniforme, obedecen a las siguientes expresiones: ${ }^{38}$

$$
\begin{gathered}
\delta \mathrm{M}=\frac{5 \mathrm{q} L^{4}}{384 \cdot \mathrm{EI}}=\frac{\mathrm{M}}{\mathrm{EA}} \cdot \frac{5}{48} \cdot \frac{\mathrm{L}^{2}}{(0,289 \mathrm{~h})^{2}}=1,25 \cdot \lambda^{2} \frac{\mathrm{M}}{\mathrm{EA}} \\
\left.\delta \mathrm{V}=\delta \mathrm{M} \frac{24}{25} \frac{\mathrm{E}}{\mathrm{G}} \frac{1}{\lambda^{2}}=19,2 \frac{\mathrm{M}}{\mathrm{EA}} \quad \text { (sustituyendo } \mathrm{E} / \mathrm{G}=16\right)
\end{gathered}
$$

Luego la flecha total de la viga, que corresponde a la flecha del ensayo es:

$$
\delta \text { ens }=\delta \mathrm{M}+\delta \mathrm{V}=\frac{M}{E A} \cdot\left(\frac{5}{48} \cdot \frac{\lambda^{2}}{(0,289)^{2}}+19,2\right)=\frac{M}{E A} \cdot\left(1,25 \cdot \lambda^{2}+19,2\right)
$$

Por tanto se ha aplicado el siguiente factor corrector a las flechas de los ensayos:

$$
\frac{\delta_{\mathrm{M}}}{\delta_{\text {ens }}}=\frac{1,25 \cdot \lambda^{2}}{1,25 \cdot \lambda^{2}+19,2}
$$

Quedando para los casos anteriores:

$$
\begin{array}{ll}
\lambda=35,56 & 98,8 \% \\
\lambda=26,67 & 97,9 \% \\
\lambda=22,86 & 97,1 \% \\
\lambda=17,14 & 95,0 \%
\end{array}
$$

Y para las esbelteces de las vigas mixtas utilizadas en los ensayos: ${ }^{39}$

$$
\begin{array}{lll}
\lambda=22,86 & 97,1 \% & \text { (viguetas de canto } 14 \mathrm{~cm} \text { ) } \\
\lambda=26,67 & 97,9 \% & \text { (viguetas de canto } 12 \mathrm{~cm} \text { ) } \\
\lambda=32,00 & 98,5 \% & \text { (viguetas de canto } 10 \mathrm{~cm} \text { ) }
\end{array}
$$

En la figura 105 se muestra un ejemplo con los datos obtenidos en el ensayo y en la figura 106 las diferentes correcciones realizadas con los coeficientes obtenidos aquí.

\footnotetext{
38 ‘Argüelles Álvarez, R.; Arriaga Martitegui, F. y Martínez Calleja, J. (2003). [ref. 005]

${ }^{39}$ Se ha considerado que el cortante lo asume la vigueta. En consecuencia las esbelteces que aparecen en este apartado son las de la vigueta.
} 


\section{EJEMPLO DE DATOS OBTENIDOS DEL ENSAYO}

\section{A-NO-1-1/2 C14 1/3 (01)}

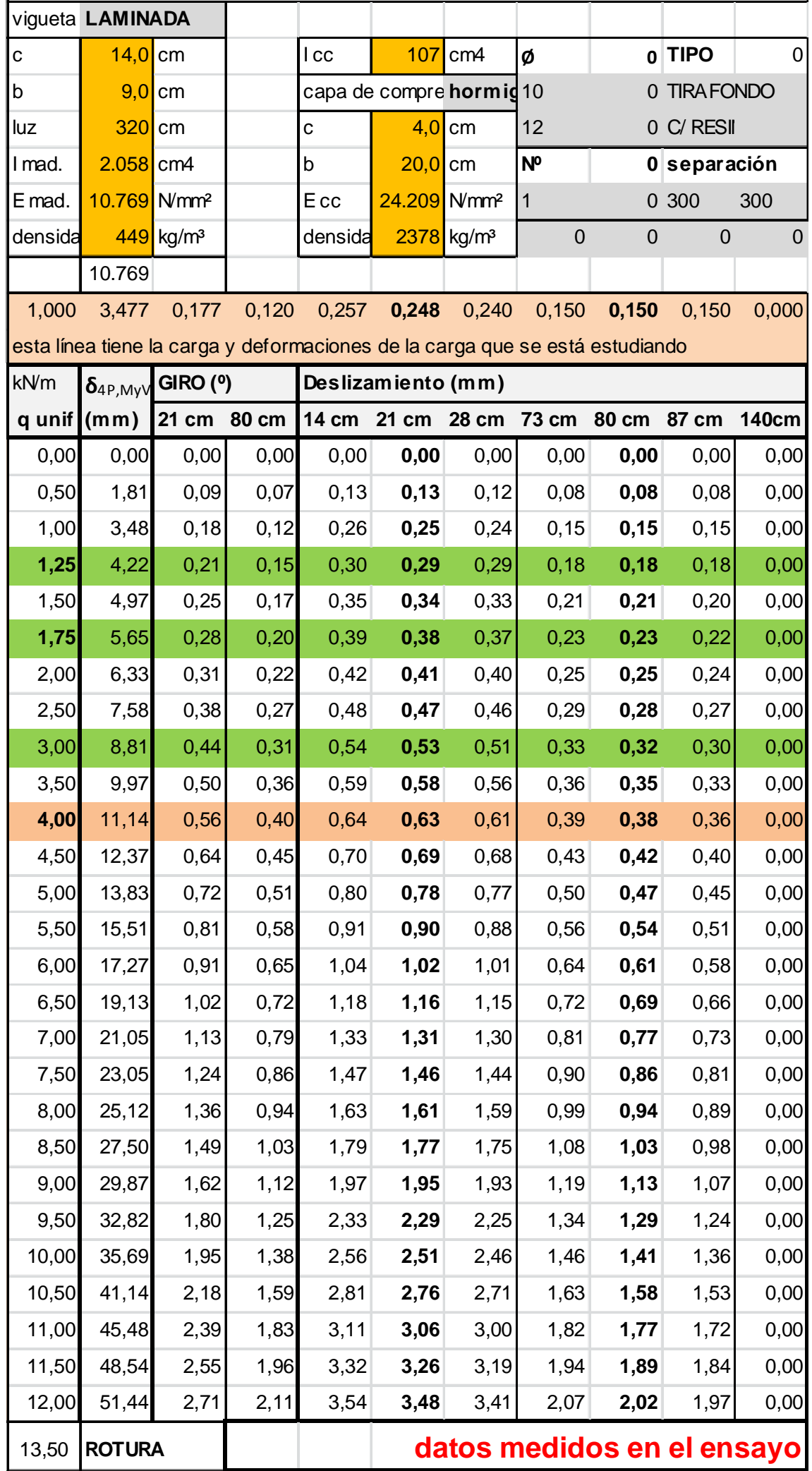

figura 105. Datos medidos en los ensayos 


\section{EJEMPLO DE DATOS CORREGIDOS}

\begin{tabular}{|c|c|c|}
\hline $\begin{array}{l}\delta_{\text {ens }}=(\mathrm{dM}+\mathrm{dV})_{4 \mathrm{P}}=(\mathrm{MEA}) \cdot\left(1,025 \cdot 5 / 48 \cdot\left(\mathrm{L} /(0,289 \mathrm{~h})^{2}+19,2\right)\right. \\
\text { porque } \delta_{\mathrm{M}, \mathrm{q}}=(\mathrm{MEA}) \cdot 5 / 48 \cdot\left(\mathrm{L} /(0,289 \mathrm{~h})^{2} \text { y } \delta_{\mathrm{V}}=19,2 \cdot \mathrm{MEA}\right. \\
\text { NOTA: Considerando que el cortante lo as ume la vigueta }\end{array}$ & $\begin{array}{ll}\delta_{\mathrm{M}, \mathrm{q}} / & 0,948 \\
\delta_{\text {ens }} & \end{array}$ & $\begin{array}{ll}\text { siendo } & 0,029 \\
\delta_{\mathrm{V}} / \delta_{\mathrm{Mq}} & \end{array}$ \\
\hline
\end{tabular}

En esta tabla se modifican los resultados del ensayo (tabla izqda) para transformarlos en q uniforme y sin flecha de cortante. Estas flechas son las que 'hubieran resultado' con 'q unif' y sin ' $\delta \mathrm{V}$ '.

$$
\begin{array}{|l|l|}
\hline 1,025 & \text { coef } \delta_{4 p} / \delta_{q} \\
\hline
\end{array}
$$

Giros y deslizamientos se dividen por estos factores para simular $\mathrm{q}^{\star}$

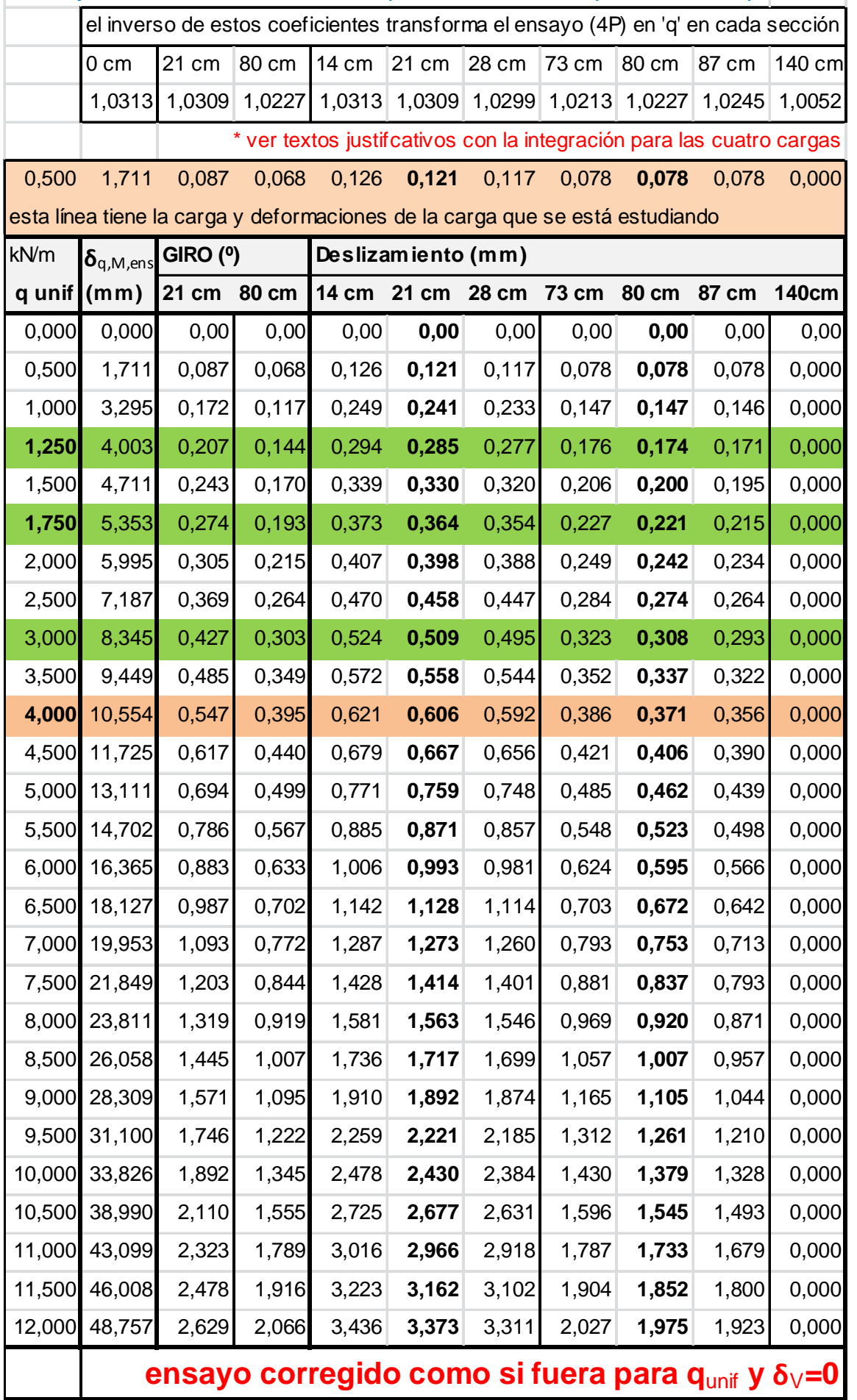

figura 106. Datos corregidos 


\section{DESESTIMACIÓN DE PUESTA EN CARGA}

De la mayoría de los ensayos (66 de 95) se han realizado 3 ciclos de carga/descarga, llegando en todos ellos a una flecha de L/300. Se analizan en este apartado las diferencias de los valores obtenidos en los 3 ciclos para poder tomar decisiones sobre qué datos utilizar en los análisis de los ensayos.

\section{Ensayos analizados (63):}

Materiales:

Vigueta de madera aserrada 43 ensayos

Vigueta de madera laminada 20 ensayos

Canto de la vigueta:

Canto 14 (esbeltez 22,86)

19 ensayos

Canto 12 (esbeltez 26,67)

20 ensayos

Canto 10 (esbeltez 32,00)

24 ensayos

Capa de compresión de madera microlaminada, de dimensiones $20 \times 3,9 \mathrm{~cm}$ para tornillos y 20 x 4,0 cm para tirafondos y clavos.

Conexión:

Sin conexión

HBS $2 \varnothing 6$ cada 70,140 y 280

VGZ $2 \varnothing 7$ cada 70,140 y 280

Tirafondo $1 \varnothing 6,0$ cada 50

clavo $2 \varnothing 4,4$ cada 90
9 ensayos

25 ensayos

21 ensayos

2 ensayos

6 ensayos

Presión entre vigueta y capa de compresión:

Con Presión

Sin Presión
22 ensayos

41 sin presión

\section{Resultados:}

En la figura 107 están los resultados de los ensayos sin presión entre vigueta y capa de compresión. Se muestran las diferencias de rigidez entre el primer ciclo de ensayos y la media de los otros dos (tabla de la izquierda) y las diferencias entre los ciclos 2 y 3 (derecha):

\begin{tabular}{|c|c|c|c|c|}
\cline { 2 - 5 } & \multicolumn{4}{|c|}{ SIN PRESIÓN (41 CASOS) } \\
\cline { 2 - 5 } & \multicolumn{4}{|c|}{ CICLO 1 MEDIA CICLOS 2 Y 3 } \\
\hline El $_{\mathbf{1}} / \mathbf{E l}_{\mathbf{2 - 3}}$ & $\mathbf{0 - 1 \%}$ & $\mathbf{1 - 3 \%}$ & $\mathbf{3 - 5 \%}$ & $\mathbf{5 - 1 0 \%}$ \\
\hline № CASOS & 12 & 11 & 10 & 8 \\
\hline \% CASOS & $29 \%$ & $27 \%$ & $24 \%$ & $20 \%$ \\
\hline
\end{tabular}

\begin{tabular}{|c|c|c|c|c|}
\cline { 2 - 5 } \multicolumn{1}{c|}{} & \multicolumn{4}{c|}{ SIN PRESIÓN (41 CASOS) } \\
\cline { 2 - 5 } & \multicolumn{4}{c|}{ CICLO 2 / CICLO 3 } \\
\hline $\mathrm{EI}_{\mathbf{2}} / \mathbf{E l}_{\mathbf{3}}$ & $\mathbf{0 - 1 \%}$ & $\mathbf{1 - 3} \%$ & $\mathbf{3 - 5} \%$ & $\mathbf{5 - 1 0 \%}$ \\
\hline № CASOS & 23 & 14 & 2 & $\mathbf{2}$ \\
\hline \% CASOS & $56 \%$ & $34 \%$ & $5 \%$ & $5 \%$ \\
\hline
\end{tabular}

figura 107. Diferencias entre los 3 ciclos de carga en los ensayos SIN Presión 
Comparando los resultados del ciclo 1 con los ciclos 2 y 3 se puede comprobar que existe bastante diferencia entre los resultados (en el $44 \%$ de las piezas ensayadas la diferencia es mayor del $4 \%$ ). Sin embargo, hay una gran homogeneidad de los resultados entre el ciclo 2 y el ciclo 3 (en el $90 \%$ de los casos la diferencia es menor del $3 \%$ ).

Por lo general, el primer ciclo ha resultado menos rígido que el segundo y el tercero, que son prácticamente coincidentes entre sí.

En la figura 108 están los ensayos de las vigas con presión entre la vigueta y la capa de compresión:

\begin{tabular}{|c|c|c|c|c|c|}
\cline { 2 - 6 } \multicolumn{1}{c|}{} & \multicolumn{5}{c|}{ CON PRESIÓN (22 CASOS) } \\
\cline { 2 - 6 } & \multicolumn{5}{c|}{ CICLO 1 / MEDIA CICLOS 2 Y 3 } \\
\hline El $_{\mathbf{1}} / \mathbf{E l}_{\mathbf{2 - 3}}$ & $\mathbf{0 - 1 \%}$ & $\mathbf{1 - 3} \%$ & $\mathbf{3 - 5 \%}$ & $\mathbf{5 - 1 0 \%}$ & $\mathbf{> 1 0 \%}$ \\
\hline № CASOS & 1 & 1 & 3 & 3 & 14 \\
\hline \% CASOS & $5 \%$ & $5 \%$ & $14 \%$ & $14 \%$ & $64 \%$ \\
\hline
\end{tabular}

\begin{tabular}{|c|c|c|c|c|c|}
\cline { 2 - 6 } \multicolumn{1}{c|}{} & \multicolumn{5}{c|}{ CON PRESIÓN (22 CASOS) } \\
\cline { 2 - 6 } & \multicolumn{5}{c|}{ CICLO 2 CICLO 3 } \\
\hline $\mathrm{El}_{\mathbf{2}} / \mathbf{E l}_{\mathbf{3}}$ & $\mathbf{0 - 1 \%}$ & $\mathbf{1 - 3} \%$ & $\mathbf{3 - 5} \%$ & $\mathbf{5 - 1 0 \%}$ & $>\mathbf{1 0 \%}$ \\
\hline № CASOS & 12 & 6 & 1 & 3 & 0 \\
\hline \% CASOS & $55 \%$ & $27 \%$ & $5 \%$ & $14 \%$ & $0 \%$ \\
\hline
\end{tabular}

figura 108. Diferencias entre los 3 ciclos de carga en los ensayos CON Presión

En este caso la diferencia entre los resultados del ciclo 1 con los ciclos 2 y 3 es mucho mayor (en el $91 \%$ de los casos es mayor del $4 \%$, y en el $64 \%$, mayor del $10 \%$ ). Nuevamente comparando los resultados entre el ciclo 2 y el ciclo 3 se obtienen valores bastante homogéneos (en el $82 \%$ de los casos la diferencia es menor del $3 \%$ ).

En este caso, debido a la presión inicial entre los materiales, el primer ciclo es mucho más rígido que los ciclos 2 y 3 . Sin embargo, esta mejora de rigidez inicial debida al gran rozamiento entre los materiales no se tendrá en cuenta.

\section{CONCLUSIÓN:}

Se entiende que el caso 1, al ser el primero, ha supuesto un pequeño ajuste de puesta en carga que lo hace algo menos rígido en los casos sin presión y más rígido en los casos con presión. Como los ensayos 2-3 son muy similares entre sí en ambos casos (0-1\%), se ha tomado como valor representativo de los 3 ciclos de ensayo la media del segundo y el tercero. 


\section{CAPÍTULO 4. - RESULTADO DE LA CONEXIÓN A RASANTE}

4.0 INTRODUCCIÓN

4.1 MÓDULO DE DESLIZAMIENTO DEL ENSAYO $\left(\mathrm{K}_{\mathrm{ser}}\right)$

4.1.1 CRITERIO DE REPRESENTACIÓN DE $K_{\text {ser }}$

4.1.2 VALORES DE $K_{\text {ser }}$ EN EL EUROCÓDIGO

4.1.3 VALORES DEL $K_{\text {ser }}$ EN LOS ENSAYOS

4.1.4 COMPARACIÓN CON OTROS AUTORES

4.2 COMPARACIÓN ENTRE DISTINTOS PRETALADROS Y APRIETES

4.3 COMPARACIÓN DE ENSAYOS CON / SIN RESINA

4.4 HORMIGÓN vs MADERA MICROLAMINADA 


\subsection{INTRODUCCIÓN}

Este capítulo incluye los resultados de los ensayos de rasante de las conexiones estudiadas.

Como toda la tesis se centra en la rigidez y no en la resistencia, el parámetro más importante que se va a analizar de los ensayos es la rigidez a deslizamiento de las conexiones, representada por el Módulo de deslizamiento $\left(\mathrm{K}_{\mathrm{ser}}\right)$, que es la relación entre la fuerza rasante que actúa en el conector y el deslizamiento que provoca en él. En el apartado 4.1 (Módulo de deslizamiento del ensayo $\left(\mathbf{K}_{\text {ser }}\right)$ ) se describen tanto el procedimiento para la obtención del $K_{\text {ser }}$ de los ensayos (según la aplicación de la Norma UNE 26891 [ref. 010]), como las formulaciones indicadas en la normativa (Eurocódigo EC-5 [ref. 013] y Código Técnico de la Edificación CTE DBSE-M [ref. 103]). Finalmente se comparan entre ellos y con los obtenidos por fórmulas descritas por otros autores: (Ceccotti [ref. .35], Turrini y Piazza [ref. 143], Natterer et al [ref. 109] y Branco [ref. 030]).

En el apartado 4.2 (Comparación entre distintos pretaladros y aprietes) se analizan las diferencias que se han encontrado entre ensayos del mismo conector, pero realizando distintos pretaladros y también la influencia de apretar el conector durante la construcción de la probeta para crear una presión entre los dos materiales.

En el apartado 4.3 (Comparación de ensayos con / sin resina) se indica alguna particularidad que diferencia el comportamiento de los conectores con resina en los ensayos.

El aumento del uso de tableros de madera microlaminada como capa de compresión, por la rapidez de ejecución y la ventaja que supone una obra seca, ha sido el motivo por el cual, durante toda la tesis, se ha realizado un estudio comparativo entre las vigas con capa de compresión de hormigón y de tablero de madera microlaminada. Esta visión general comienza en este capítulo de conexión a rasante en el apartado 4.4 (Hormigón vs madera microlaminada). 


\subsection{MÓDULO DE DESLIZAMIENTO DEL ENSAYO ( $\left.K_{\mathrm{ser}}\right)$}

En este apartado se detallan los módulos de deslizamiento obtenidos en los ensayos según marca la Norma UNE 26891:1991 y se comparan con los obtenidos según la normativa (Eurocódigo 5 y CTE) y según fórmulas descritas por otros autores: (Ceccotti [ref. .35], Turrini y Piazza [ref. 143], Natterer et al [ref. 109] y Branco [ref. 030]).

\subsubsection{OBTENCIÓN DEL K $K_{\text {ser }}$ SEGÚN LA NORMA UNE 26891}

El valor $\mathrm{K}_{\mathrm{ser}}$ se obtiene, a partir de un ensayo (representado en la figura 1 con la curva roja), aplicando la siguiente fórmula:

$$
\mathrm{K}_{\text {ser }}=0,4 \cdot \mathrm{F}_{\text {est }} / \mathrm{v}_{\mathrm{i}, \text { mod, }} \quad \text { donde } \mathrm{F}_{\text {est }} \text { es la fuerza estimada de rotura } \mathrm{y} \mathrm{v}_{\mathrm{i} \text {,mod }}=4 / 3 \cdot\left(\mathrm{v}_{04}-\mathrm{v}_{01}\right) \text {, }
$$
siendo $v_{04}$ y $v_{01}$ los valores de los deslizamientos en $0,4 \cdot F_{\text {est }}$ y para $0,1 \cdot F_{\text {est }}$ respectivamente.

Este $\mathrm{K}_{\mathrm{ser}}$ está representado en la figura 1 con la línea de trazos, y es la rigidez secante entre $0,1 \cdot F_{\text {est }}$ y $0,4 \cdot F_{\text {est. }}$. Como no pasa por el origen, mientras que las expresiones incluidas en el EC-5 sí lo hacen, se ha trasladado para poder compararlas (línea continua negra).

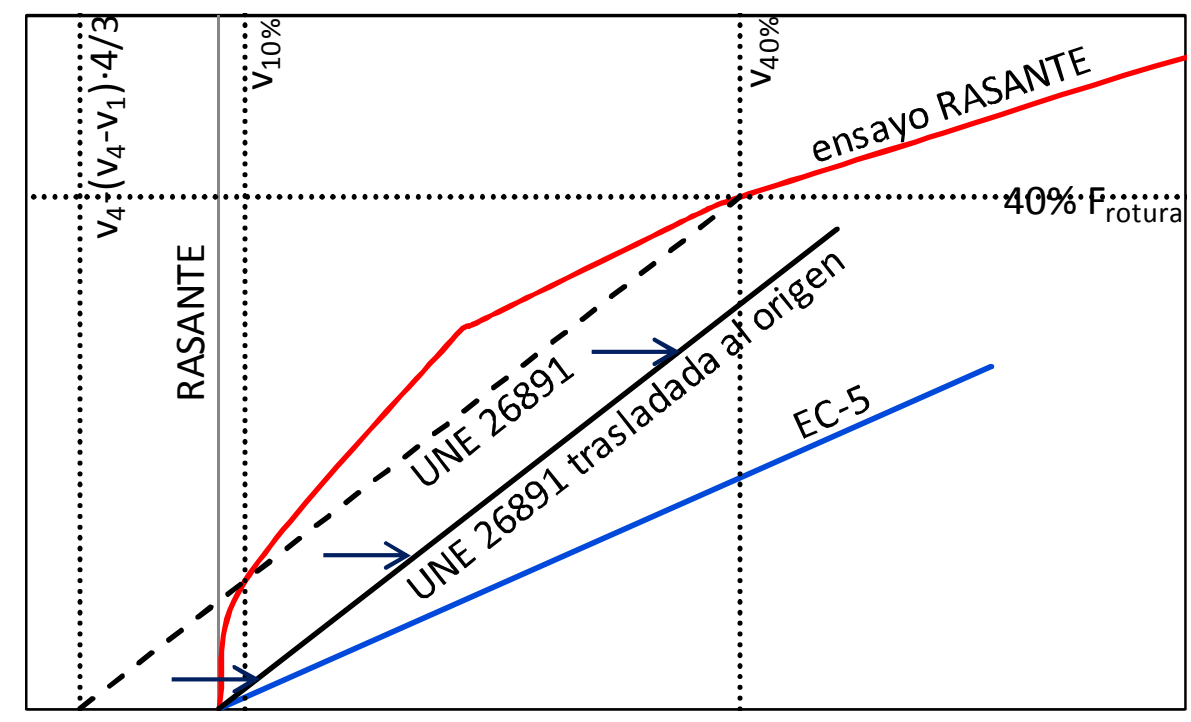

$$
\text { DESLIZAMIENTO }
$$

figura 1. Obtención del $K_{\text {ser }}$ según la Norma UNE 26891

A modo de ejemplo se ha añadido la línea azul (EC-5), que es el resultado gráfico se la expresión del $\mathrm{K}_{\mathrm{ser}}$ indicado en esa normativa. De este modo, el ensayo UNE y las expresiones del EC-5 se pueden comparar directamente. 


\subsubsection{VALORES DEL $K_{\text {ser }}$ EN EL EUROCÓDIGO}

El Eurocódigo EC-5 (madera) en su capítulo 7 "Estados Límite de Servicio" contiene la tabla de la figura 2, con la que se obtienen los Módulos de Deslizamiento de las Uniones: ${ }^{40}$

\subsection{Deslizamiento de las uniones}

1 El módulo de deslizamiento $\mathrm{K}_{\text {ser }}$, cociente entre la fuerza aplicada en servicio y el deslizamiento local de la unión, con la hipótesis de régimen lineal y elástico, y para los estados límite de servicio, puede determinarse mediante ensayos según la norma UNE EN 26891 (método de determinación de $\mathrm{k}_{\mathrm{s}}=$ $\left.\mathrm{K}_{\text {ser }}\right)$, $\mathrm{u}$ obtenerse de la manera indicada en el párrafo siguiente.

2 Para uniones de tipo clavija colocadas de forma ortogonal a las piezas que unen y además a la dirección de la fibra, bajo solicitaciones de servicio, el módulo de deslizamiento $\mathrm{K}_{\text {ser }}$ por plano de cortadura y por elemento de fijación puede elegirse de la tabla $7.1 \mathrm{con}$ la densidad media, $\rho_{\mathrm{m}}$ en $\mathrm{kg} / \mathrm{m}^{3}$, y d $o ́$ $d_{c}$, en $\mathrm{mm}$, (siendo - d- el diámetro de la clavija y $-d_{c}$ - el diámetro del conector según se define en la norma UNE EN 13271).

Tabla 7.1 Valores de $\mathrm{K}_{\text {ser }}\left(=\mathrm{k}_{\mathrm{s}}\right.$ en la norma UNE EN 26891) para elementos de fijación de tipo clavija en $\mathrm{N} / \mathrm{mm}$.

\begin{tabular}{l|c}
\multicolumn{1}{c}{ clavija en N/mm. } & $\begin{array}{c}\text { Madera - madera } \\
\text { Tablero - madera }\end{array}$ \\
\hline Tipo de elemento de fijación & $\rho_{\mathrm{m}}^{1,5} \cdot \mathrm{d} / 23$ \\
\hline $\begin{array}{l}\text { Pasadores } \\
\text { Pernos sin holgura }{ }^{(1)}\end{array}$ & \\
$\begin{array}{l}\text { Tirafondos } \\
\text { Clavos con pretaladro }\end{array}$ & $\rho_{\mathrm{m}}^{1,5} \cdot \mathrm{d}^{0,8} / 30$ \\
\hline Clavos sin pretaladro & $\rho_{\mathrm{m}}^{1,5} \cdot \mathrm{d}^{0,8} / 80$ \\
\hline Grapas & $\rho_{\mathrm{m}} \cdot \mathrm{d}_{\mathrm{c}} / 2$ \\
\hline $\begin{array}{l}\text { Conectores de placa (tipo A según norma UNE EN 912) } \\
\text { Conectores de anillo (tipo B según norma UNE EN 912) }\end{array}$ & $\rho_{\mathrm{m}} \cdot \mathrm{d}_{\mathrm{c}} / 4$ \\
\hline Conectores dentados & $\rho_{\mathrm{m}} \cdot \mathrm{d}_{\mathrm{c}} / 2$ \\
\hline $\begin{array}{l}\text { Conectores de una cara (tipos C1 a C9 y C11 según norma UNE EN 912) } \\
\text { Conectores de doble cara (tipo C10 según UNE EN 912) }\end{array}$
\end{tabular}

(1) La holgura debe añadirse independientemente a la deformación.

Si las densidades medias de las dos piezas unidas derivadas de la madera son diferentes $\left(\rho_{m 1}, \rho_{m 2}\right)$, se tomará como valor de $\rho_{m}$ el siguiente: $\rho_{m}=\sqrt{\rho_{m 1} \cdot \rho_{m 2}}$

Para uniones entre madera acero o madera hormigón, $\mathrm{K}_{\text {ser, }}$ se multiplicará por 2.

figura 2. Tabla 7.1 del Eurocódigo EC-5 y del CTE SE-M

NOTA: En los ensayos con pretaladro $2 \mathrm{~mm}$ mayor que el $\varnothing$ del conector y resina (tirafondos y barra corrugada), se ha optado por usar el $\varnothing$ nominal del conector $y$ no el del pretaladro, ya que las propiedades mecánicas de la resina son más cercanas a la madera que al acero.

En los ensayos con tornillos se ha empleado como diámetro de cálculo el correspondiente al diámetro del cuello, no el nominal (VGZ Ø5,0; HBS Ø4,3).

\footnotetext{
${ }^{40}$ Se adjuntan las prescripciones que indica el El CTE en su capítulo "Estados Límite de Servicio" cuya tabla es la misma que la del Eurocódigo 5. Contiene además la alternativa para la obtención de $\mathrm{K}_{\text {ser }}$ con la UNE 26891, y la aplicación del factor 2 para el caso de conexión madera/hormigón.
} 


\subsubsection{VALORES DEL $K_{\text {ser }}$ EN LOS ENSAYOS}

La figura 3 compara los valores del $\mathrm{K}_{\text {ser }}$ de los ensayos obtenidos con la Norma UNE (azul) con los que resultarían de aplicar los mismos datos de los ensayos ( $\varnothing$ del conector y características de la madera) en las expresiones del EC-5 (rojo). ${ }^{41}$

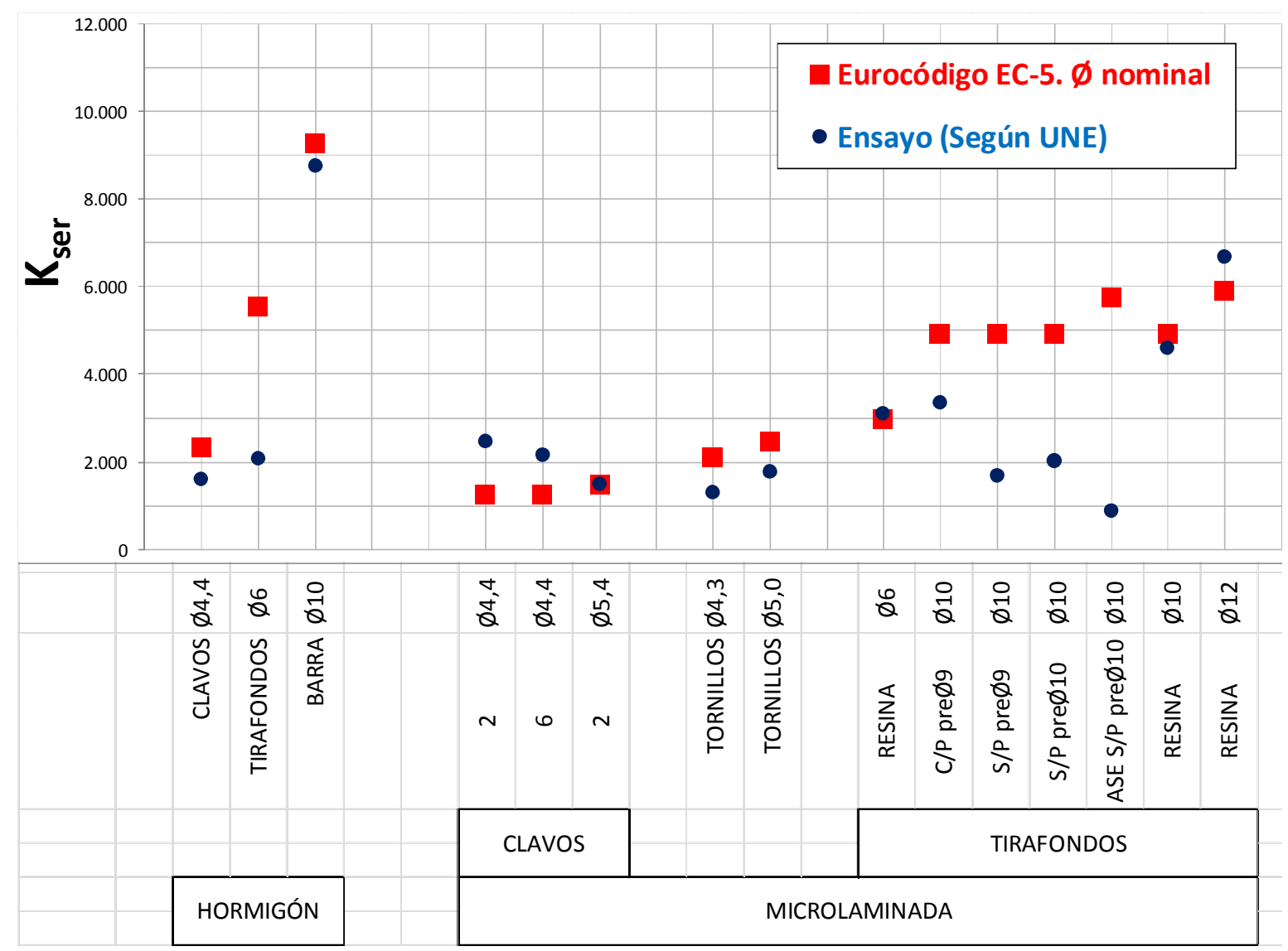

figura 3. $K_{\text {ser }}$ obtenidos en los ensayos y $K_{\text {ser }}$ según el EC-5

En los casos de clavos con madera microlaminada, se obtienen valores de $K_{\text {ser }}$ superiores a lo que dice el EC-5. Hay dos causas que pueden haber influido: La presión que los clavos ejercen entre las dos piezas y la distinta formulación.

Con carácter general se puede observar, tanto en hormigón como en madera microlaminada, que los valores de $\mathrm{K}_{\mathrm{ser}}$ de los ensayos son inferiores al EC-5, incluso muy inferiores en algún caso.

Aunque, como se ha comentado, el número de ensayos realizados en esta tesis no alcanza el menor valor estadístico, conviene apuntar que las diferencias que se muestran aquí por primera vez, van a seguir apareciendo, con carácter general, hasta el final del trabajo.

\footnotetext{
${ }^{41}$ Para el cálculo del $\mathrm{K}_{\text {ser }}$ según el EC- 5 se han usado las siguientes densidades: madera aserrada $\rho=559$ $\mathrm{kg} / \mathrm{m}^{3}$, madera laminada $\rho=483 \mathrm{~kg} / \mathrm{m}^{3}$, madera microlaminada $\rho=525 \mathrm{~kg} / \mathrm{m}^{3}$, obtenidas en la capítulo 3 .
} 


\subsubsection{COMPARACIÓN CON OTROS AUTORES}

Se incluyen finalmente, con los mismos datos (diámetro de los conectores y características de la madera) el valor de $K_{\text {ser }}$ que resulta de aplicar la formulación de distintos autores. Solo se incluyen los casos de capa de compresión de hormigón, ya que en revisión bibliográfica realizada no se han encontrado formulaciones para tablero microlaminado. Los valores están obtenidos de las siguientes expresiones:

$\begin{array}{lll}\text { Eurocódigo EC-5 [ref. 0,13] } & \begin{array}{c}\text { (tirafondos) } \\ \text { (clavos) }\end{array} & \mathrm{K}_{\mathrm{ser}}=2 \cdot \rho^{1,5} \cdot \emptyset^{0,8} / 30 \\ & & \mathrm{~K}_{\mathrm{ser}}=2 \cdot \rho^{1,5} \cdot \emptyset / 23 \\ \text { A. Ceccotti [ref. 035]: } & \mathrm{K}_{\mathrm{ser}}=0,16 \cdot \mathrm{E}_{0, \text { medio }} \cdot \emptyset \\ \text { Turrini y M. Piazza [ref. 143] } & \mathrm{K}_{\mathrm{ser}}=0,08 \cdot \mathrm{E}_{0, \text { medio }} \cdot \emptyset \\ \text { Natterer et al [ref. 109] } & \mathrm{K}_{\mathrm{ser}}=120 \cdot \emptyset^{1,7} \\ \text { Branco [ref. 030] } & K_{\text {ser }}=0,15 \emptyset^{0,95} \cdot E_{0, \text { medio }}^{0,9}\end{array}$

En la figura 4 se muestra gráficamente la comparación de los módulos de deslizamiento $\left(\mathrm{K}_{\mathrm{ser}}\right)$ de todos los autores.

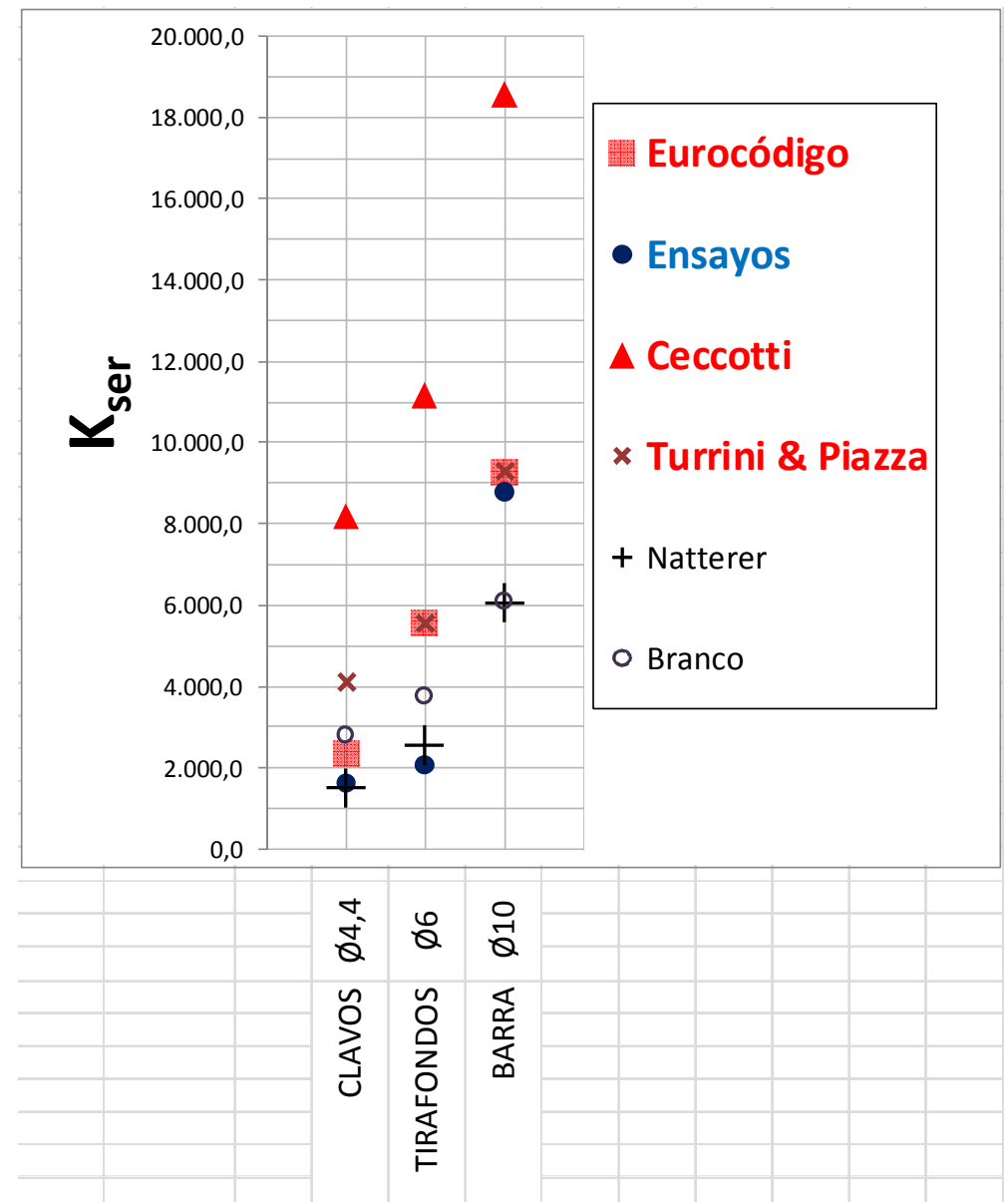

figura 4. Gráfico comparativo del $K_{\text {ser }}$ con otros trabajos 
Lo que se desprende del conjunto de resultados representados en este gráfico es la gran diferencia entre las estimaciones de rigidez obtenidas por distintos autores, por el Eurocódigo y en esta misma tesis, a la hora de aplicar la misma Norma UNE (que no admite posibles interpretaciones, como se ha visto en el apartado 4.1.1) en ensayos similares. Esto hace pensar que la forma de obtener el $\mathrm{K}_{\text {ser }}$ no está suficientemente depurada. 
La dos tablas representan numéricamente lo representado en los gráficos anteriores. ${ }^{42,43}$

\begin{tabular}{|c|c|c|c|c|c|c|c|c|c|c|c|}
\hline \multirow{3}{*}{$\begin{array}{l}\text { № } \\
\text { orden }\end{array}$} & \multirow{3}{*}{$\begin{array}{c}\text { MATERIALES } \\
\text { Vigueta / } \\
\text { C. Compresión }\end{array}$} & \multirow{3}{*}{ CONECTADOR } & \multirow{3}{*}{$\varnothing$} & \multirow{3}{*}{ RESINA } & \multirow{3}{*}{$\begin{array}{c}\varnothing \\
\text { pretaladro }\end{array}$} & \multirow{3}{*}{ PRESIÓN } & \multirow{3}{*}{$\begin{array}{c}\rho \\
\text { media }\end{array}$} & \multicolumn{3}{|c|}{ Kser } & \multirow{3}{*}{$\begin{array}{c}\text { F rotura } \\
\text { (kN) }\end{array}$} \\
\hline & & & & & & & & \multicolumn{2}{|c|}{ UNE 26891} & \multirow[b]{2}{*}{ EC-5 } & \\
\hline & & & & & & & & media & CoV & & \\
\hline 1 & $\begin{array}{l}\text { Laminada / } \\
\text { Hormigón }\end{array}$ & Barra Corrugada & 10 & SI & 12 & NO & 483 & 8.753 & $2 \%$ & 9.236 & 13,2 \\
\hline 2 & $\begin{array}{l}\text { Laminada / } \\
\text { Hormigón }\end{array}$ & Clavo (6) & 4,4 & NO & NO & NO & 483 & 1.593 & $2 \%$ & 2.317 & 5,6 \\
\hline 3 & $\begin{array}{c}\text { Laminada / } \\
\text { Microlaminada } \\
\end{array}$ & Clavo (2) & 4,4 & NO & NO & NO & 504 & 2.462 & $23 \%$ & 1.232 & 3,4 \\
\hline $3 b$ & $\begin{array}{c}\text { Laminada / } \\
\text { Microlaminada } \\
\end{array}$ & Clavo (4) & 4,4 & NO & NO & NO & 504 & 10.132 & $6 \%$ & & 3,9 \\
\hline $3 c$ & $\begin{array}{c}\text { Laminada / } \\
\text { Microlaminada }\end{array}$ & Clavo (2) & 5,4 & NO & NO & NO & 504 & 1.485 & $62 \%$ & 1.452 & 4,3 \\
\hline 4 & $\begin{array}{c}\text { Laminada / } \\
\text { Microlaminada }\end{array}$ & Clavo (6) & 4,4 & NO & NO & NO & 504 & 2.159 & $2 \%$ & 1.232 & 3,7 \\
\hline 5 & $\begin{array}{l}\text { Laminada / } \\
\text { Hormigón }\end{array}$ & Tirafondo & 6 & SI & 8 & NO & 483 & 2.062 & $11 \%$ & 5.542 & 11,4 \\
\hline 6 & $\begin{array}{c}\text { Laminada / } \\
\text { Microlaminada }\end{array}$ & Tirafondo & 6 & SI & 8 & NO & 504 & 3.097 & $34 \%$ & 2.948 & 7,7 \\
\hline 7 & $\begin{array}{c}\text { Laminada / } \\
\text { Microlaminada } \\
\end{array}$ & Tirafondo & 12 & SI & 14 & NO & 504 & 6.685 & & 5.896 & 16,0 \\
\hline 8 & $\begin{array}{c}\text { Laminada / } \\
\text { Microlaminada }\end{array}$ & Tirafondo & 10 & SI & 12 & NO & 504 & 4.596 & $2 \%$ & 4.913 & 14,5 \\
\hline 9 & $\begin{array}{c}\text { Laminada / } \\
\text { Microlaminada }\end{array}$ & Tirafondo & 10 & NO & $9 / 7$ & SI & 504 & 3.354 & $3 \%$ & 4.913 & 11,4 \\
\hline 10 & $\begin{array}{c}\text { Laminada / } \\
\text { Microlaminada }\end{array}$ & Tirafondo & 10 & NO & $9 / 7$ & NO & 504 & 1.690 & $2 \%$ & 4.913 & 7,9 \\
\hline 11 & $\begin{array}{c}\text { Laminada / } \\
\text { Microlaminada }\end{array}$ & Tirafondo & 10 & NO & $10 / 7$ & NO & 504 & 2.005 & & 4.913 & 8,7 \\
\hline 12 & $\begin{array}{c}\text { Aserrada / } \\
\text { Aserrada }\end{array}$ & Tirafondo & 10 & NO & $10 / 7$ & NO & 559 & 883 & $23 \%$ & 5.740 & 8,3 \\
\hline 13 & $\begin{array}{c}\text { Aserrada / } \\
\text { Aserrada }\end{array}$ & Tirafondo & 10 & SI & 12 & NO & 559 & 4.133 & $8 \%$ & & 9,9 \\
\hline 14 & $\begin{array}{c}\text { Laminada / } \\
\text { Microlaminada }\end{array}$ & Tornillo HBS & 4,3 & NO & NO & NO & 504 & 1.304 & $8 \%$ & 2.113 & 4,9 \\
\hline 15 & $\begin{array}{c}\text { Laminada / } \\
\text { Microlaminada }\end{array}$ & Tornillo VGZ & 5 & NO & NO & NO & 504 & 1.764 & $0 \%$ & 2.457 & 4,8 \\
\hline
\end{tabular}

figura 5. Resultados ( $K_{\text {ser }}$ medios) de los ensayos de rasante

\begin{tabular}{|c|c|c|c|c|c|c|c|c|c|c|c|}
\hline MATERIALES & & & & & & & Mód & lo de des & zamient & $\left(K_{\text {ser }}\right)$ & \\
\hline $\begin{array}{c}\text { Vigueta / } \\
\text { C. Compresión }\end{array}$ & CONECTADOR & $\emptyset$ nominal & RESINA & PRESIÓN & $\begin{array}{c}\text { densidad } \\
\text { media }\end{array}$ & $\begin{array}{c}\text { UNE } \\
\text { (medio) }\end{array}$ & EC-5 & Ceccotti & Turrini & Natterer & Branco \\
\hline $\begin{array}{l}\text { Laminada / } \\
\text { Hormigón }\end{array}$ & Clavo (6) & 4,4 & NO & NO & 483 & 1.593 & $2.316,7$ & $8.166,4$ & $4.083,2$ & $1.489,5$ & $2.788,6$ \\
\hline $\begin{array}{c}\text { Laminada / } \\
\text { Hormigón }\end{array}$ & Tirafondo & 6 & SI & NO & 483 & 2.062 & $5.541,7$ & $11.136,0$ & $5.568,0$ & $2.523,7$ & $3.744,1$ \\
\hline $\begin{array}{l}\text { Laminada / } \\
\text { Hormigón }\end{array}$ & $\begin{array}{c}\text { Barra } \\
\text { Corrugada }\end{array}$ & 10 & SI & NO & 483 & 8.753 & $9.236,2$ & $18.560,0$ & $9.280,0$ & $6.014,2$ & $6.082,8$ \\
\hline
\end{tabular}

figura 6. Tabla Comparativa del $K_{\text {ser }}$

\footnotetext{
${ }^{42}$ Los resultados de estos ensayos están detallados en el Anejo III “Conexiones a rasante".

${ }^{43}$ Los ensayos con clavo de diámetro 4,4 y madera microlaminada (3, 3b y 4) corresponden a la misma conexión, pero con distinto número de clavos en cada probeta, el más homogéneo es el ensayo 4 , que contiene 6 clavos en cada probeta y es el que se usa para los análisis.
}

Los casos en rojo no están incluidos en el gráfico de la figura 3 por considerarse ensayos fallidos. 


\subsection{COMPARACIÓN ENTRE DISTINTOS PRETALADROS Y APRIETES}

Todos los tirafondos de este apartado son de $\emptyset 10$. En el caso del pretaladro para $\varnothing>7$ $\mathrm{mm}$ (sin resina) se ha tratado de seguir la normativa actual (CTE), que indica que el pretaladro ha de tener un diámetro de $0,7 * \varnothing$ en la cuerda (parte roscada) y $\varnothing$ en la caña (parte no roscada). Sin embargo ocurre que los $\varnothing$ nominales de tirafondos, tornillos, etc difieren de sus $\varnothing$ reales, cosa que no ocurre con las brocas. Por ejemplo, en los tirafondos empleados con diámetro nominal de 10, la caña tiene realmente $9,41 \mathrm{~mm}$. Para valorar la influencia de este hecho es por lo que se han realizado los ensayos con pretaladros de $\varnothing 9$ y 10 . En este comparativo de ensayos, se añade también un caso (el más rígido en el gráfico de la figura 9) en el que aprietan los tirafondos creando una presión entre vigueta y capa de compresión.

\section{Ensayos analizados}

Todos los ensayos que se analizan están realizados con vigueta de madera laminada. Los parámetros que varían entre ellos se muestran en la tabla:

\begin{tabular}{|c|c|c|c|c|c|c|c|}
\hline \multirow[b]{2}{*}{ № orden } & \multirow{2}{*}{$\begin{array}{c}\mathrm{n} \text { o de } \\
\text { ensayos }\end{array}$} & MATERIALES & \multirow[b]{2}{*}{ CONECTADOR } & \multirow[b]{2}{*}{$\varnothing$ nominal } & \multirow[b]{2}{*}{ RESINA } & \multirow[b]{2}{*}{$\emptyset$ pretaladro } & \multirow[b]{2}{*}{ PRESIÓN } \\
\hline & & $\begin{array}{c}\text { Vigueta / } \\
\text { C. Compresión }\end{array}$ & & & & & \\
\hline 9 & 3 & $\begin{array}{c}\text { Laminada / } \\
\text { Microlaminada }\end{array}$ & Tirafondo & 10 & NO & $9 / 7$ & SI \\
\hline 10 & 3 & $\begin{array}{c}\text { Laminada / } \\
\text { Microlaminada }\end{array}$ & Tirafondo & 10 & NO & $9 / 7$ & NO \\
\hline 11 & 3 & $\begin{array}{c}\text { Laminada / } \\
\text { Microlaminada }\end{array}$ & Tirafondo & 10 & NO & $10 / 7$ & NO \\
\hline
\end{tabular}

figura 7. Tabla de ensayos analizados

\section{Resultados}

\begin{tabular}{|c|c|c|c|c|c|c|}
\hline Ø CLAVIJA & Ø TALADRO & PRESIÓN & F rotura (N) & Kser (N/mm) & CoV & Kser EC-5 \\
\hline 10 & $9 / 7$ & con presión & 10.910 & 3.354 & $3 \%$ & 4.913 \\
\hline 10 & $9 / 7$ & sin presión & 7.658 & 1.690 & $2 \%$ & 4.913 \\
\hline 10 & $10 / 7$ & sin presión & 8.661 & 1.865 & $8 \%$ & 4.913 \\
\hline
\end{tabular}

figura 8. Tabla resumen de resultados 


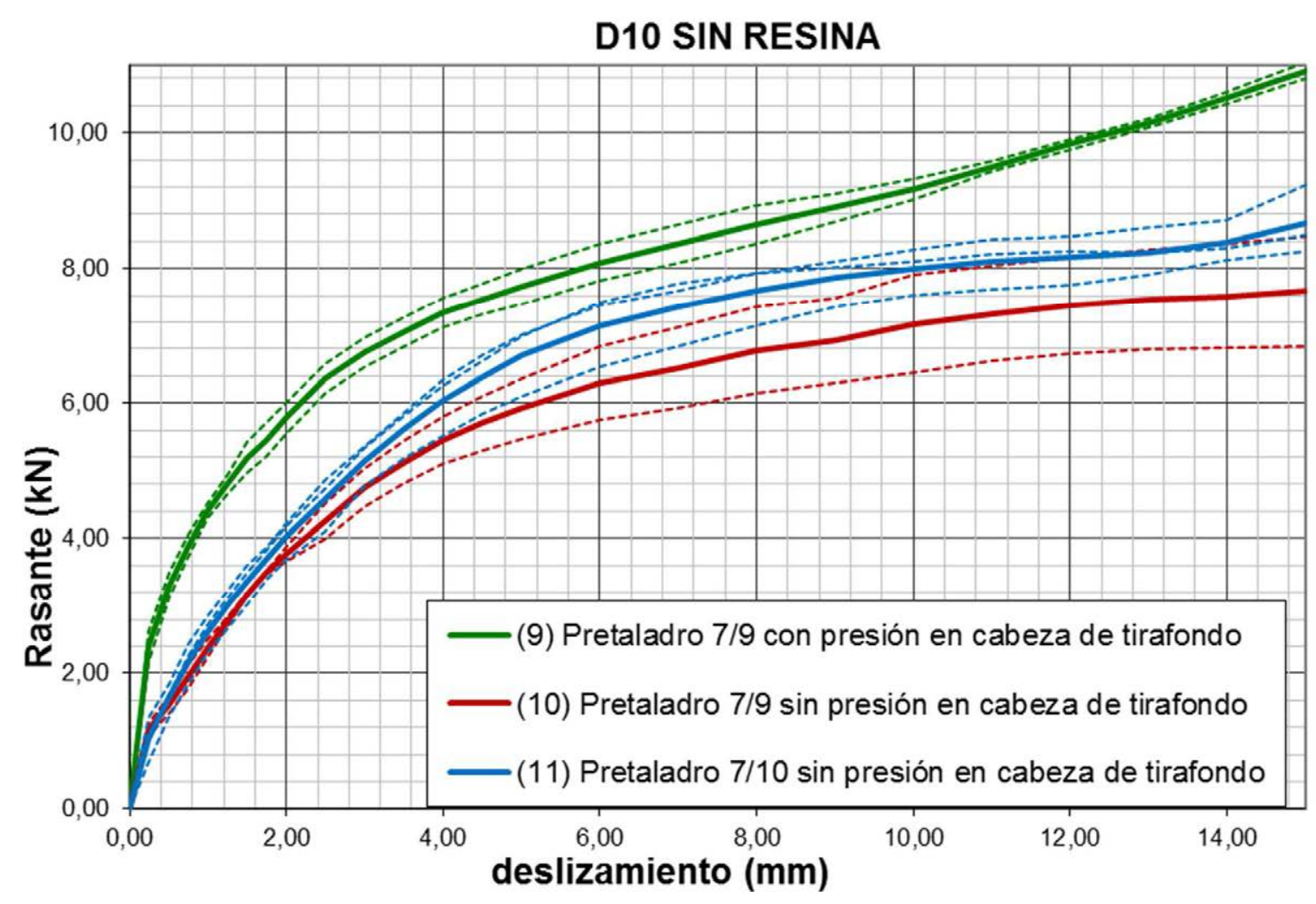

figura 9. Gráficas de rasante-deslizamiento de los ensayos

\section{CONCLUSIONES}

De la comparación entre un pretaladro en la zona de la caña de diámetro $9 \mathrm{~mm}$ y otro de diámetro $10 \mathrm{~mm}$ se observa que este factor no es excesivamente relevante en los resultados obtenidos, ya que la rigidez, y muy concretamente en el arranque es similar.

Sin embargo, donde sí que se aprecia una variación considerable en los resultados es en la comparación de piezas con tirafondos del mismo diámetro, y con el mismo pretaladro, pero con distinto par de apriete. Se observa que las piezas en las que los tirafondos se han atornillado hasta conseguir una presión considerable de la cabeza contra el tablero microlaminado tienen aproximadamente el doble de rigidez (según $\mathrm{K}_{\text {ser }}$ obtenido siguiendo la Norma UNE) que las piezas en las que no existe contacto entre la cabeza del tirafondo y la capa de compresión. Esta presión del tirafondo contra las piezas de madera favorece en gran medida la rigidez de la unión. 


\subsection{COMPARACIÓN DE ENSAYOS CON/SIN RESINA}

Los ensayos analizados en este apartado son muy heterogéneos, por lo que no se pueden extraer conclusiones definitivas. No obstante, se observa una diferencia clara en la forma de las curvas de los ensayos con resina y sin resina (gráficos de la figura 10 ): ${ }^{44}$

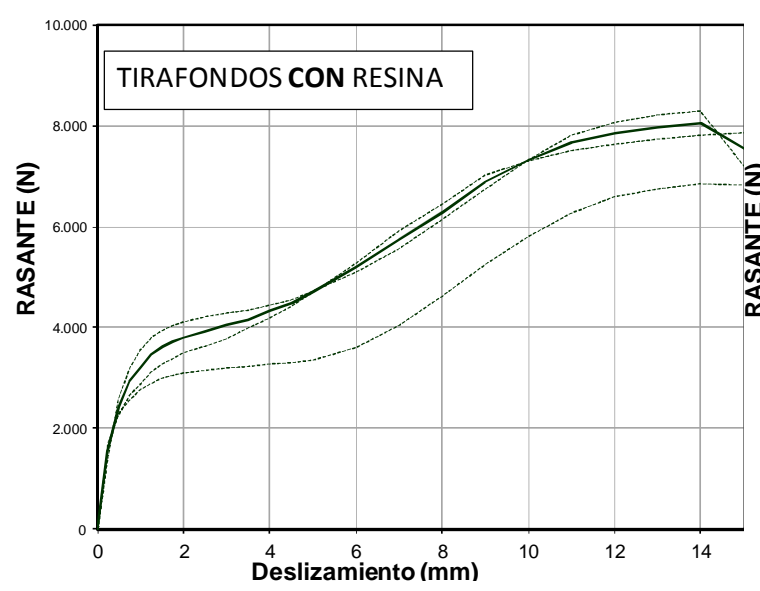

CON RESINA

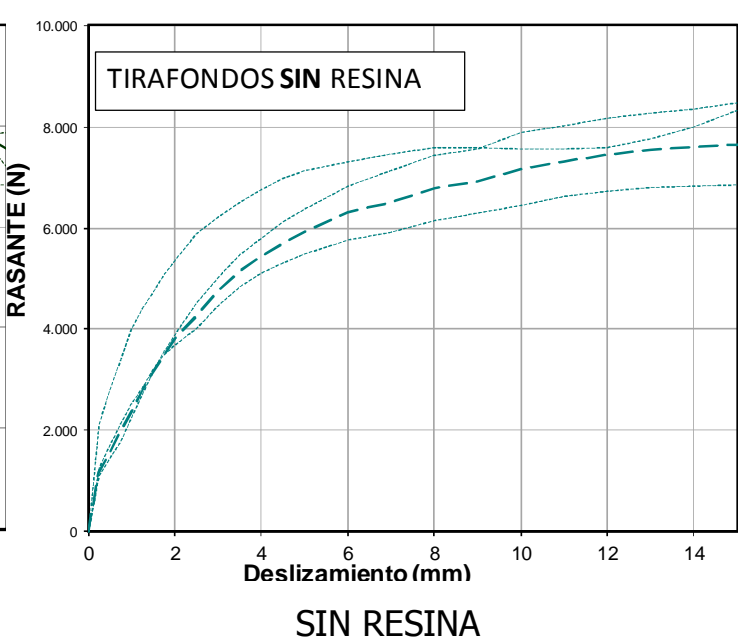

SIN RESINA

figura 10. Gráficas de rasante-deslizamiento CON/SIN Resina

Una vez pasada la etapa inicial del ensayo (similar en ambos casos), se observa que en las piezas con resina, hay un tramo de fluencia, pasado el cual vuelven a recuperar rigidez. Salvando las distancias, hay una semejanza con los aceros deformados en frío y los de dureza natural.

Una explicación podría ser que la plastificación de la resina hace perder rigidez a la conexión hasta que el conector se pone en contacto con la madera y vuelve a aumentar la rigidez. ${ }^{45}$

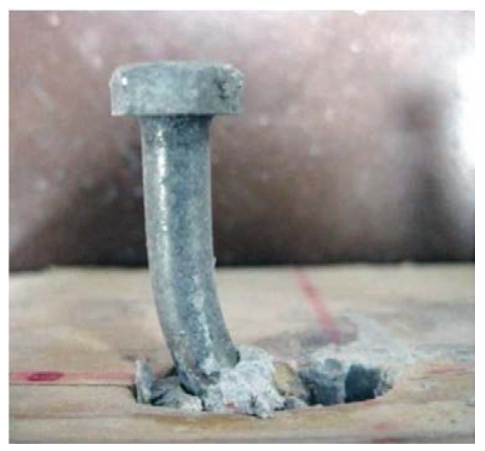

figura 11. Aplastamiento de la resina

\footnotetext{
${ }^{44}$ Para hacer esta comparación se han analizado ensayos con vigueta de madera laminada y capa de compresión de hormigón. Los conectores empleados en ensayos con resina son tirafondos de $\varnothing 6,10$ y 12 $\mathrm{mm}$ y barra corrugada de $\varnothing 10 \mathrm{~mm}$. Los ensayos sin resina están realizados con clavos de $\varnothing 4,4$.

${ }^{45}$ Este cedimiento es el motivo para elegir como diámetro de cálculo de los ensayos hechos con resina el correspondiente al conector y no al diámetro del pretaladro, y que completa la nota del apartado 4.1.2.
} 


\subsection{HORMIGÓN vS MADERA MICROLAMINADA}

En el guión general de la tesis se va a estudiar en paralelo el comportamiento de los dos materiales de la capa de compresión con los que se forman las vigas mixtas. También las diferencias entre cada uno de ellos con la normativa.

El EC-5 indica que se pueden usar los valores de $K_{\text {ser }}$ de la tabla que se adjunta en el apartado 4.1.2 o bien los obtenidos mediante el ensayo con la Norma UNE 26891. En este apartado se han obtenido los valores de $\mathrm{K}_{\mathrm{ser}}$ siguiendo estos dos criterios.

\section{Ensayos analizados}

Todos los ensayos que se analizan están realizados con vigueta de madera laminada. Los parámetros que varían entre ellos se muestran en la tabla:

\begin{tabular}{|c|c|c|c|c|c|c|}
\hline \multirow[b]{2}{*}{ № ensayo } & MATERIALES & \multirow[b]{2}{*}{ CONECTADOR } & \multirow{2}{*}{$\begin{array}{c}\varnothing \\
\text { conectador }\end{array}$} & \multirow[b]{2}{*}{ RESINA } & \multirow{2}{*}{$\begin{array}{c}\varnothing \\
\text { pretaladro }\end{array}$} & \multirow[b]{2}{*}{ PRESIÓN } \\
\hline & $\begin{array}{c}\text { Vigueta / } \\
\text { C. Compresión }\end{array}$ & & & & & \\
\hline 2 & $\begin{array}{l}\text { Laminada / } \\
\text { Hormigón }\end{array}$ & Clavo & 4,4 & NO & NO & NO \\
\hline 4 & $\begin{array}{c}\text { Laminada / } \\
\text { Microlaminada }\end{array}$ & Clavo & 4,4 & NO & NO & NO \\
\hline 5 & $\begin{array}{l}\text { Laminada / } \\
\text { Hormigón }\end{array}$ & Tirafondo & 6 & SI & 8 & NO \\
\hline 6 & $\begin{array}{c}\text { Laminada / } \\
\text { Microlaminada }\end{array}$ & Tirafondo & 6 & SI & 8 & NO \\
\hline
\end{tabular}

\begin{tabular}{|c|c|c|}
\hline densidad laminada & 483,2 & $\mathrm{~kg} / \mathrm{m}^{3}$ \\
\hline densidad microlaminada & 524,8 & $\mathrm{~kg} / \mathrm{m}^{3}$ \\
\hline
\end{tabular}

figura 12. Tabla de ensayos analizados

\section{$\underline{\text { Resultados obtenidos }}$}

En la figura 13 se muestran los gráficos de rasante/ deslizamiento de los ensayos. A la izquierda están representados los ensayos con capa de compresión de hormigón y a la derecha los de madera microlaminada. Se añade la recta que marca la pendiente del $\mathrm{K}_{\text {ser }}$ según la tabla del Eurocódigo EC-5.

Como criterio general en todos los gráficos comparativos entre la capa de compresión de hormigón y de madera microlaminada se representan en rojo las gráficas de capa de compresión de hormigón y en azul las de madera microlaminada. 


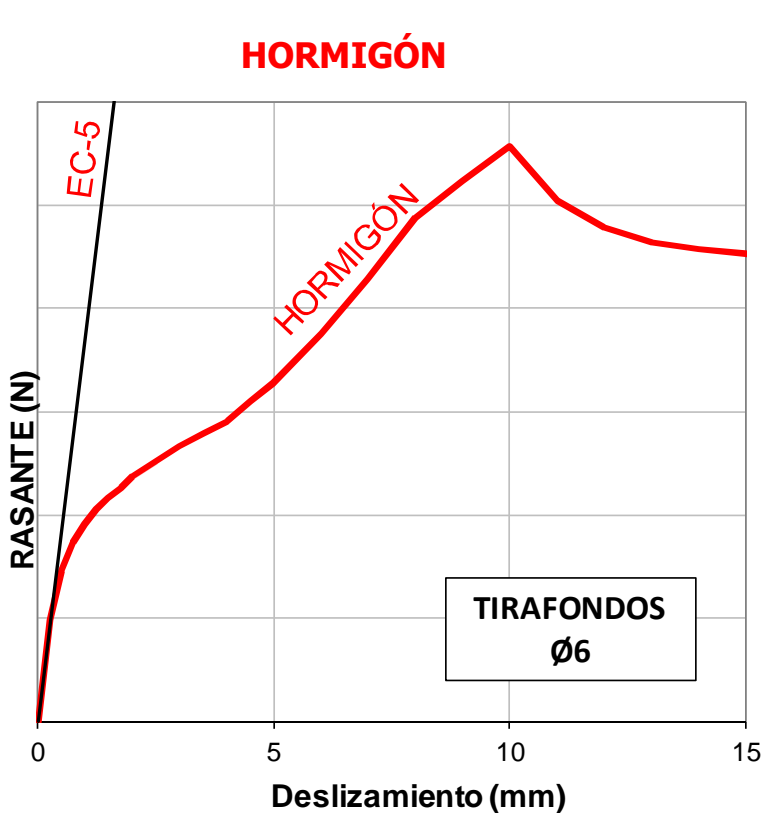

MADERA MICROLAMINADA
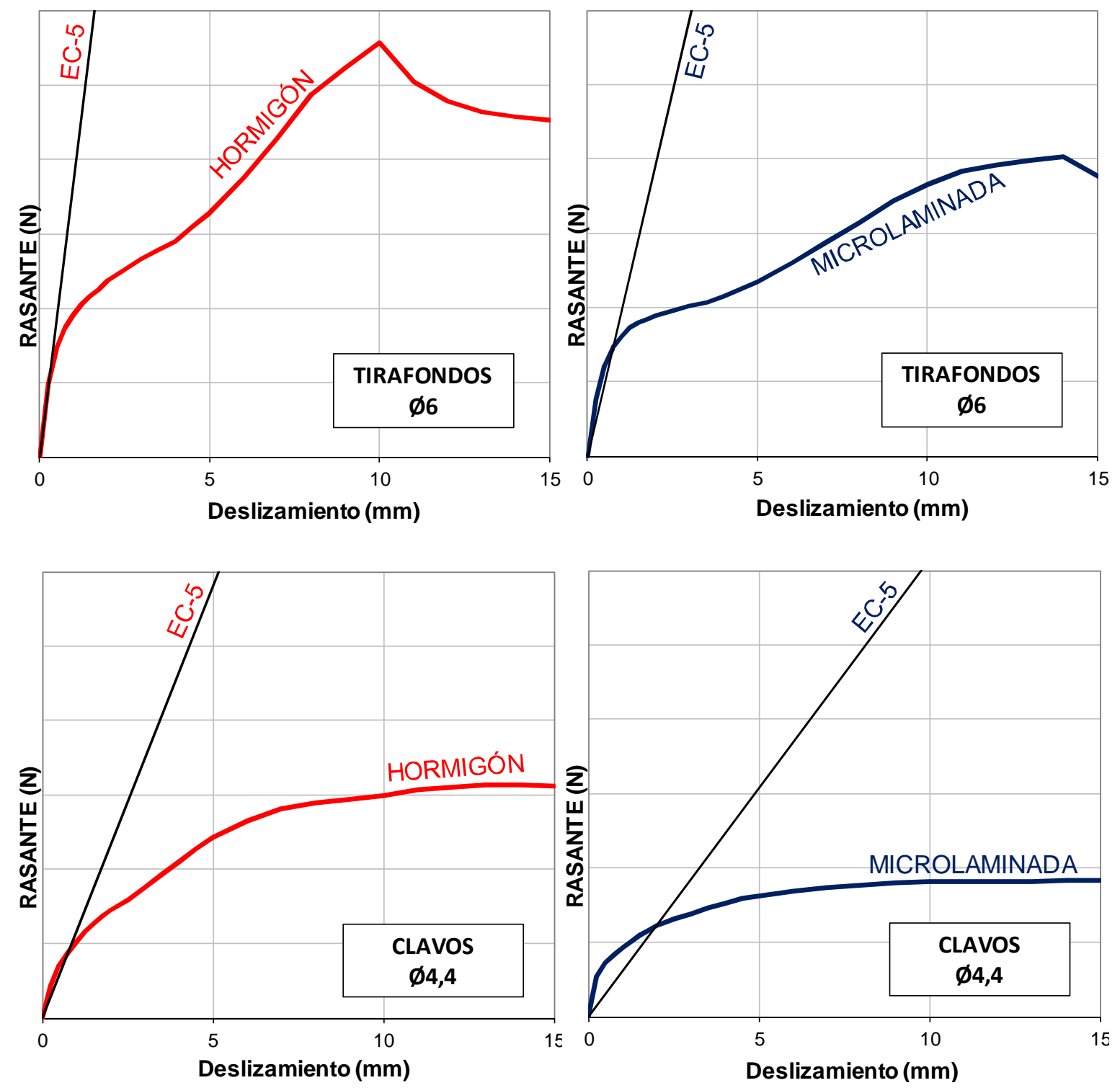

figura 13. Gráficas de rasante-deslizamiento hasta la rotura de las probetas

Los gráficos de la figura 13 contienen la totalidad del ensayo hasta el deslizamiento de 15 mm que marca la Norma UNE.

En las partes iniciales de todos los gráficos se observa que la pendiente que tienen las curvas de los ensayos $\left(\mathrm{K}_{\mathrm{ser}}\right)$ es similar o incluso superior a lo marcado por el Eurocódigo. Esto no ocurre en el caso de clavos y madera microlaminada, posiblemente debido a que existe una presión entre vigueta y capa de compresión provocada en el montaje de las piezas que hace a la conexión más rígida. 

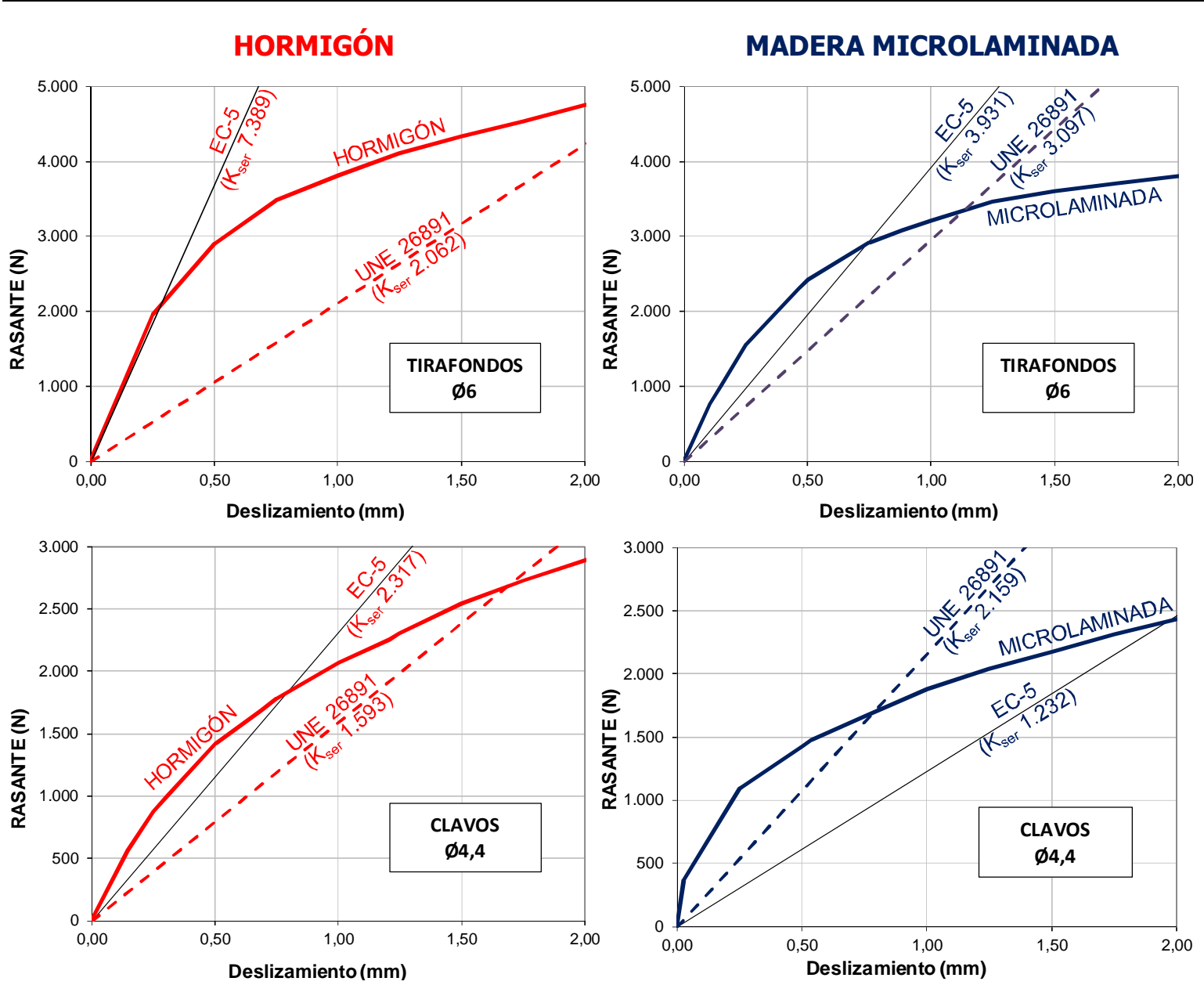

figura 14. Gráficas de rasante-deslizamiento en zona de obtención del $K_{\text {ser }}$

Los gráficos de la figura 14 incorporan las rectas de las rigideces $\left(\mathrm{K}_{\mathrm{ser}}\right)$ de los ensayos obtenidos aplicando la Norma UNE 26891 (como quedo indicado en el apartado 4.1.1) con el fin de comparar las distintas pendientes que resultan con el $\mathrm{K}_{\text {ser }}$ obtenido según el EC-5. Además se ha ampliado la escala de los gráficos a la zona inicial del ensayo, que es donde se obtiene el $\mathrm{K}_{\text {ser }}$.

\section{CONCLUSIONES}

Los valores de $\mathrm{K}_{\text {ser }}$ obtenidos de los ensayos con la Norma UNE son menores que los obtenidos con el EC-5 (como ya había quedado reflejado en el apartado 4.1.3) ${ }^{46}$. La causa es que la Norma UNE obtiene esos $\mathrm{K}_{\text {ser }}$ para la carga del $40 \%$ de la fuerza de rotura y a estas alturas la conexión ya ha perdido rigidez y, como se verá, queda muy lejos de la zona de trabajo de esta conexión en servicio.

Es posible que la formulación establecida en la tabla del EC- 5 se haya basado en unos niveles de carga y deslizamientos más cercanos a la escala de la edificación.

\footnotetext{
${ }^{46}$ Esto no ocurre en el caso de los clavos con madera microlaminada, cuya mayor rigidez puede estar relacionada con la presión ejercida al clavarlos.
} 
A modo de ejemplo ,en los gráficos de la figura 15 se ha añadido la recta que representa $\mathrm{K}_{\text {ser }}$ que se obtendría aplicando la Norma UNE en una carga de $0,3 \cdot \mathrm{F}_{\text {rotura }}$ (en verde) en vez de en $0,4 \cdot F_{\text {roturar }}$ sin otra intención de ver cómo esa modificación acerca ambas formulaciones propugnadas por el EC-5.
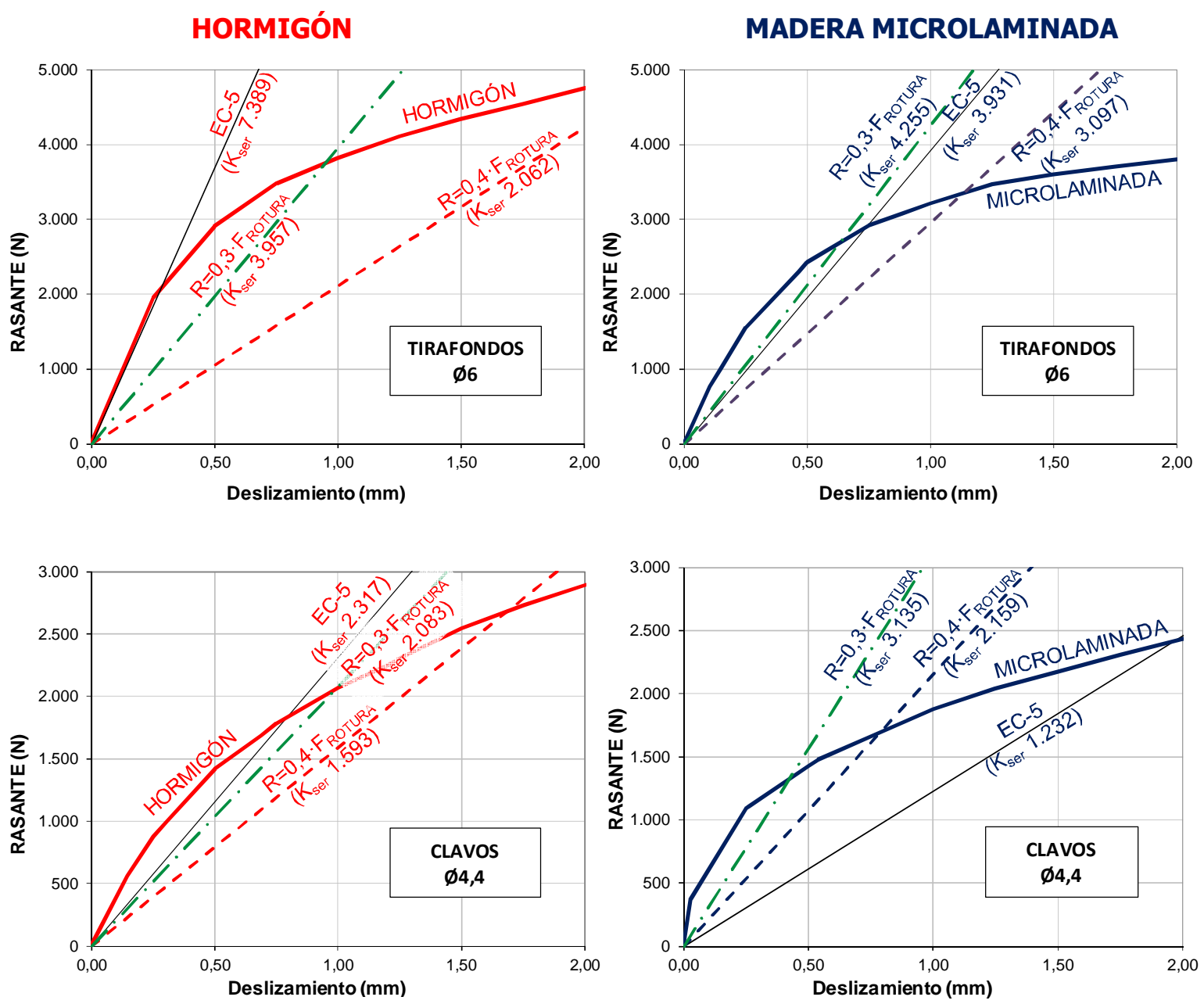

figura $15 . K_{\text {ser }}$ en $0,3 \cdot F_{\text {rotura }}$

Realmente, supongamos conocido el deslizamiento que se produce en una viga en servicio, por ejemplo $0,5 \mathrm{~mm}$, bastaría unir el origen con ese punto de la curva del ensayo para conocer cuál es la rigidez de la conexión. Naturalmente esto tiene muchas reservas que se irán viendo en los siguiente capítulos, pero lo que se quiere indicar aquí es que posiblemente la Norma UNE sería más eficaz si en lugar de estar relacionada con las fuerzas rasantes lo estuviera con los deslizamientos. 


\section{CAPÍTULO 5. - RESULTADO DE LAS VIGAS A FLEXIÓN}

5.0 INTRODUCCIÓN

5.1 RELACIÓN DEL TRABAJO CON LA EDIFICACIÓN URBANA

5.2 INFLUENCIA DEL ROZAMIENTO

5.3 INFLUENCIA DE LA PRESIÓN ENTRE VIGUETA Y CAPA DE COMPRESIÓN

5.4 INFLUENCIA DEL ÁNGULO DE INCIDENCIA (45)

5.5 HORMIGÓN vs MADERA MICROLAMINADA

5.6 MEJORAS DE RIGIDEZ DE LAS DISTINTAS CONEXIONES 


\subsection{INTRODUCCIÓN}

Este capítulo describe los resultados de los ensayos de flexión de las vigas mixtas. Se han desarrollado los temas que parecen de mayor interés para su aplicación en edificación.

En el apartado 5.1 (Relación del trabajo con la edificación urbana) se establecen las relaciones entre los ensayos realizados y la edificación urbana. Para ello, se ha traducido la carga aplicada en el laboratorio a la carga superficial de un forjado y las flechas del ensayo con las flechas límites en edificación (L/300, L/500, etc.). Por tanto, en los gráficos se han incluido tanto los datos de laboratorio como estas magnitudes de deformación y carga que los asocian al edificio.

A partir de tener relacionados los ensayos con la edificación urbana, se estudian diferentes aspectos detectados en los ensayos:

En primer lugar se analizan los ensayos con capa de compresión desconectada. Una vez obtenidos los módulos de elasticidad de la vigueta y de la capa de compresión, se hicieron los ensayos sin conexión, detectándose que la rigidez era superior a la suma de las dos partes, cosa que solo pueden deberse al efecto del rozamiento. Esta diferencia se analiza en el apartado 5.2 (Influencia del rozamiento). Es evidente que no se puede contar con el rozamiento si no hay una presión (de pretensado) que asegure su colaboración, por lo que el siguiente factor analizado fue esta presión.

En el apartado 5.3 (Influencia de la presión entre vigueta y capa de compresión) se analizan las ganancias de rigidez debido a este efecto de pretensado. Este estudio tuvo como intención inicial cuantificar groso modo si la ganancia de conexión gracias a la presión conseguida con el apriete de los tornillos (conector en la que este sistema es fácilmente aplicable) era relevante.

En el apartado 5.4 (Influencia del ángulo de incidencia $\left(\mathbf{4 5}^{\circ}\right)$ ) se comparan dos ensayos, uno con los conectores colocados perpendicularmente a la vigueta, y el otro con los conectores inclinados $45^{\circ}$. La conexión que se consigue con los conectores inclinados es casi absoluta durante toda la zona de trabajo de esta unión en los edificios. Hay que llegar a cotas de carga muy elevadas para que haya un cedimiento, que en todo caso no es excesivo (y menos que el que se produce en los ensayos con los conectores perpendiculares ante esa intensidad de carga). 
En el apartado 5.5 (Hormigón vs madera microlaminada) se continua con el estudio simultáneo de las dos capas de compresión, ahora desde el punto de vista de los ensayos de flexión.

El número de ensayos realizados para cada tipo de conexión ya se ha comentado que es pequeño, por lo que no se pueden obtener valores absolutos fiables. Por este motivo, todo el trabajo se centra en la obtención de valores relativos comparando unos tipos con otros cruzando las diferentes variables con las que se ha trabajado. Sin embargo, para tener un orden de magnitud de las mejoras que se consiguen con las diferentes conexiones, en el apartado 5.6 (Mejora de rigidez de las distintas conexiones) se cuantifican las mejoras obtenidas.

\section{NOTA PREVIA ACERCA DE LA REPRESENTACIÓN GRÁFICA DE LOS RESULTADOS}

Todos los resultados se van a presentar generalmente con dos tipos de gráficos. El de la izquierda corresponde a la forma habitual de fuerza/deformación (Carga/flecha), mientras que en la derecha, en el eje horizontal se representa el grado de conexión, desde el extremo sin conexión (SC - $\psi=0$-) hasta el extremo de conexión total (CT - $\psi=1-$ ), y en el eje vertical se representan diferentes variables según el caso.

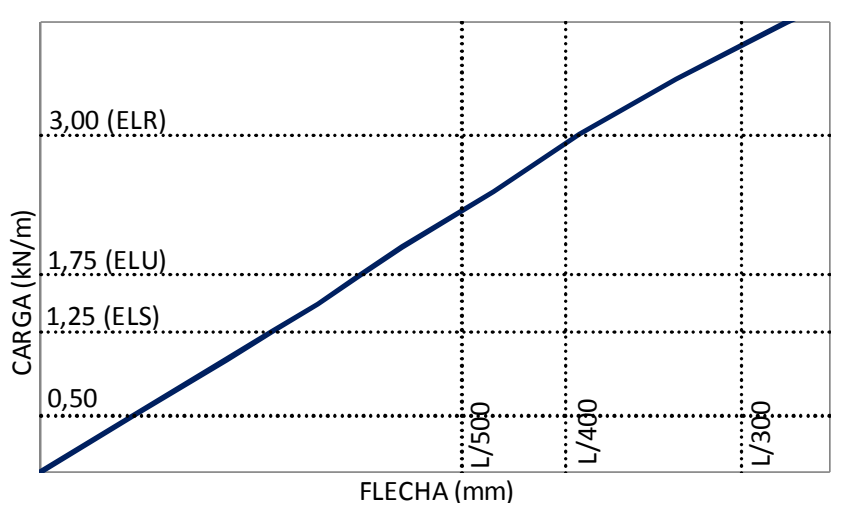

GRÁFICO CARGA/FLECHA

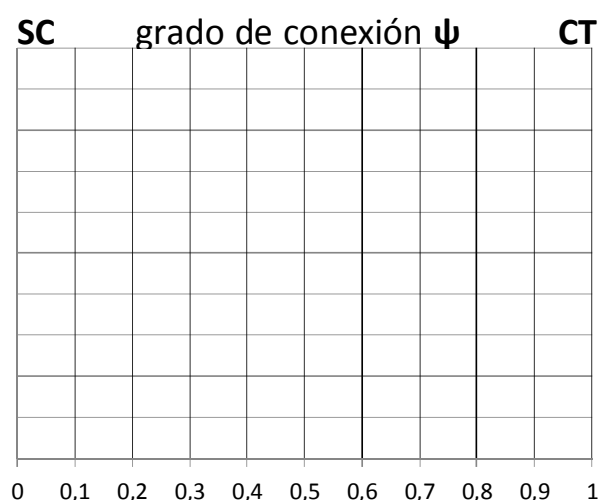

GRÁFICO GRADO DE CONEXIÓN

El grado de conexión $(\psi)$ alternativamente se representa en porcentajes. 


\subsection{RELACIÓN DEL TRABAJO CON LA EDIFICACIÓN URBANA}

Los ensayos realizados en el laboratorio han tenido la intención de servir para su aplicación a la edificación urbana. Aunque este enlace no pueda traducirse fácilmente, se ha establecido una correlación que aparece en toda la documentación presentada. Esta relación consiste en incluir en los gráficos unas cotas de deformación y carga asociadas a la obra real: flechas de L/300, L/500 etc... y cargas de servicio (ELS), límite (ELU), etc... A estos efectos se ha supuesto un edificio tipo con una carga total en valores de servicio de $Q_{k}=6,25 \mathrm{kN} / \mathrm{m}^{2}$ para una luz de 3,20 m. ${ }^{47}$

Los gráficos de la figura 1 muestran esa correlación. En el izquierdo está representado el ensayo de una viga hasta su carga de rotura. Se ha sombreado la zona en la que se mueven los valores de edificación urbana. En el derecho, esa zona ampliada:
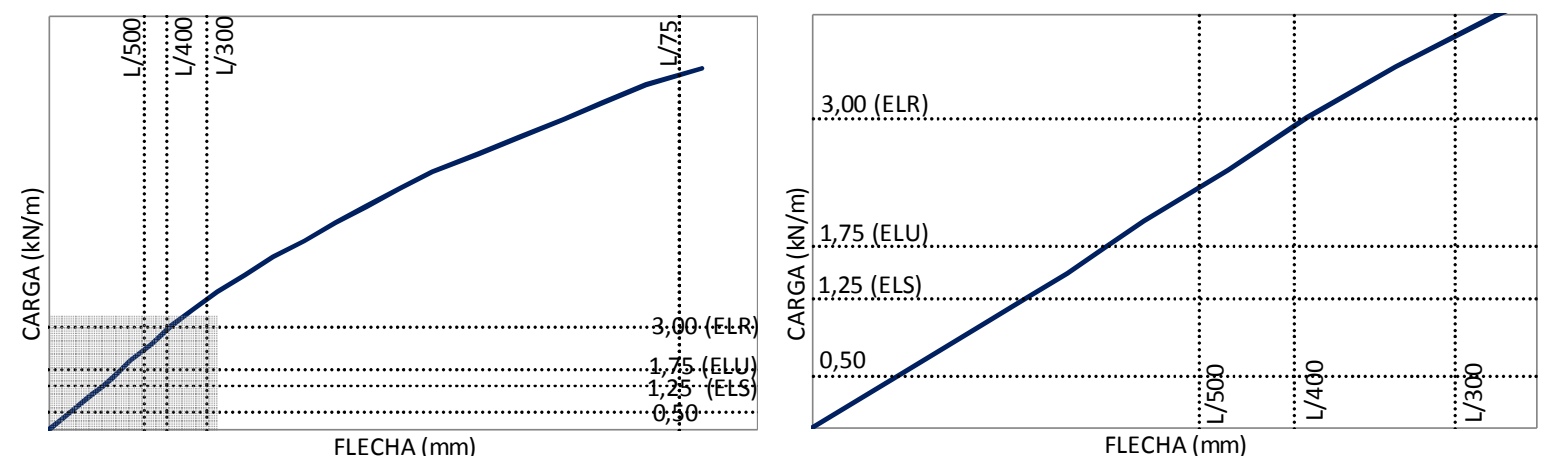

figura 1. Gráficas de carga flecha. Ensayo hasta rotura y ámbito del edificio

\section{Flechas asociadas a la edificación urbana}

En cuanto a valores de flecha, se analizan los comprendidos entre el $\mathbf{L} / \mathbf{5 0 0}$ y el $\mathbf{L} / \mathbf{3 0 0}$. Los valores alcanzados en laboratorio llegan a superar flechas de L/75 en la zona de rotura, valor que a veces se representa en las gráficas de los ensayos de las vigas.

\section{Cargas asociadas a la edificación urbana}

Las vigas ensayadas tienen una capa de compresión de $20 \mathrm{~cm}$ de ancho. Con la carga superficial definida arriba, a una vigueta del ensayo le corresponde una carga lineal de $q_{k}=6,25$.

\footnotetext{
${ }^{47}$ En el caso de capa de compresión de madera microlaminada, el peso propio es menor y podría tomarse como carga total de servicio $Q k=5,50 \mathrm{kN} / \mathrm{m}^{2}$
} 
0,20 = 1,25 $\mathbf{~ k N /} \mathbf{m}$. Como esta carga no lleva integrado ningún coeficiente de seguridad, se ha asociado al Estado Límite de Servicio (ELS).

Si consideramos un coeficiente de seguridad global de 1,4 resulta una carga de $q_{d}=1,25$. $1,4=\mathbf{1 , 7 5} \mathbf{~ k N} / \mathbf{m}$. Esta carga se asociada al Estado Límite Último (ELU)

Se ha considerado también una carga de $\mathbf{3 , 0 0} \mathbf{~ k N / m}$, que se alcanza al eliminar al material todos los coeficientes de seguridad. Esta carga se ha denominado ELR.

Los ensayos de mayor esbeltez o de menor conexión tienen una rigidez inferior al resto, por lo que por lo general no alcanzan las cargas anteriores, por eso en estos casos se analiza una carga situada en la zona inicial del ensayo $(0,50 \mathbf{~ k N / m})$.

Para tener una idea de la capacidad última alcanzada en los ensayos, las vigas han roto con una carga del orden de $\mathbf{1 3} \mathbf{~} \mathbf{~ N} / \mathbf{m}$ (Unas diez veces mayor que la carga de servicio).

Estos valores se han expresado como carga uniforme porque se ha preferido traducirlas a términos de obra construida, aunque las cargas aplicadas en el laboratorio son puntuales. 


\subsection{INFLUENCIA DEL ROZAMIENTO}

Los ensayos analizados en este apartado pertenecen al grupo de ensayos que solo se llevaron hasta alcanzar una flecha de L/300 con el fin de que se pudiera aprovechar el material. Están realizados del siguiente modo: La vigueta y la capa de compresión (microlaminada), se conectaron con tornillos cada $70 \mathrm{~mm}$, tras ese ensayo se quitó la mitad de los conectores para que quedaran a $140 \mathrm{~mm}$ y después a $280 \mathrm{~mm}$. Después se quitaron los que quedaban para ensayar la viga sin conexión y finalmente se ensayaron por separado la vigueta y la capa de compresión para obtener sus módulos de elasticidad. Cada uno de los pasos con y sin presión.

En este apartado se analiza la influencia del rozamiento en los ensayos de flexión. Para medir esta influencia se utilizan los ensayos de las vigas sin conexión entre la vigueta y la capa de compresión. Al haber ensayado las partes por separado y obtenido sus Módulos de Elasticidad, sabemos la rigidez teórica que tiene la viga mixta, ya que al estar sin conexión sería la suma de ambas rigideces. Un aumento de rigidez en el ensayo es debido obviamente al rozamiento entre ambas, ya que no hay más factores en juego.

\section{Ensayos analizados}

Se han realizado 10 ensayos sin conexión entre vigueta y capa de compresión, con esbelteces finales de 18 a 23, viguetas de madera aserrada y laminada y capa de compresión de tablero de madera microlaminada.

\begin{tabular}{|c|c|c|c|c|c|}
\hline \multicolumn{6}{|c|}{ ENSAYOS SIN CONEXIÓN } \\
\hline \multirow{3}{*}{ 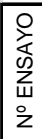 } & \multirow{3}{*}{$\boldsymbol{\lambda}$} & \multicolumn{2}{|c|}{ VIGUETA } & \multicolumn{2}{|c|}{ CAPA COMPRESIÓN } \\
\hline & & \multirow{2}{*}{ materia } & $(h \times b)$ & \multirow{2}{*}{ material } & $(h \times b)$ \\
\hline & & & (cm) & & (cm) \\
\hline 33 & 20,13 & \multirow{4}{*}{ 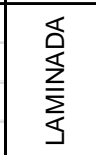 } & $12 \times 9$ & \multirow{10}{*}{ 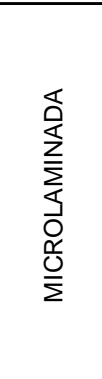 } & $3,9 \times 20$ \\
\hline 38 & 20,13 & & $12 \times 9$ & & $3,9 \times 20$ \\
\hline 45 & 23,20 & & $10 \times 9$ & & $3,9 \times 20$ \\
\hline 52 & 23,20 & & $10 \times 9$ & & $3,9 \times 20$ \\
\hline 59 & 17,88 & \multirow{6}{*}{ 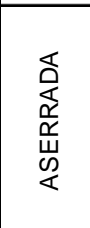 } & $14 \times 9$ & & $3,9 \times 20$ \\
\hline 65 & 17,88 & & $14 \times 9$ & & $3,9 \times 20$ \\
\hline 71 & 20,13 & & $12 \times 9$ & & $3,9 \times 20$ \\
\hline 77 & 20,13 & & $12 \times 9$ & & $3,9 \times 20$ \\
\hline 83 & 23,02 & & $10 \times 9$ & & $3,9 \times 20$ \\
\hline 89 & 23,02 & & $10 \times 9$ & & $3,9 \times 20$ \\
\hline
\end{tabular}

figura 2. Tabla de ensayos analizados 


\section{Resultados $^{48}$}

La figura 3 muestra el gráfico de carga/flecha. En todos los ensayos se ha aplicado un factor de escala para que coincidan todas las flechas teóricas, de esta manera se puede comparar en un solo gráfico la influencia del rozamiento en todos los ensayos. Para hacer el gráfico más legible, solo se han dibujado los dos ensayos que representan los límites de mejora de rigidez. Los porcentajes que se muestran indican el aumento de rigidez del ensayo con respecto al cálculo teórico (suma de los dos ensayos individuales) para la carga de 0,5 kN/m.

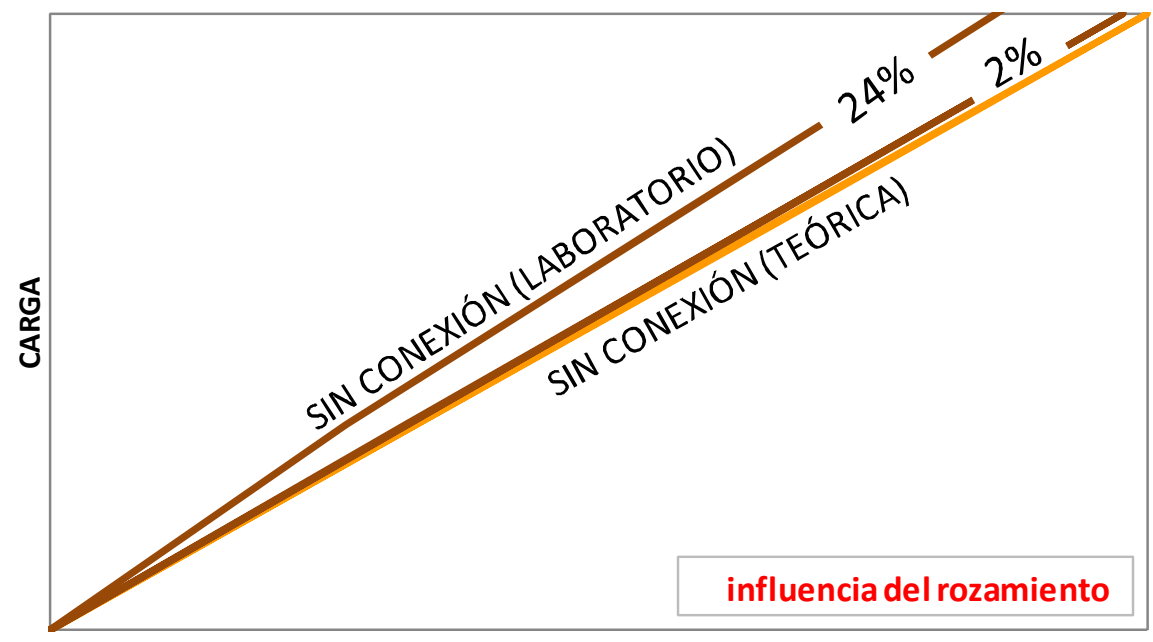

FLECHA (homogeneizada)

figura 3. Gráficas de carga-flecha de los ensayos SIN CONEXIÓN

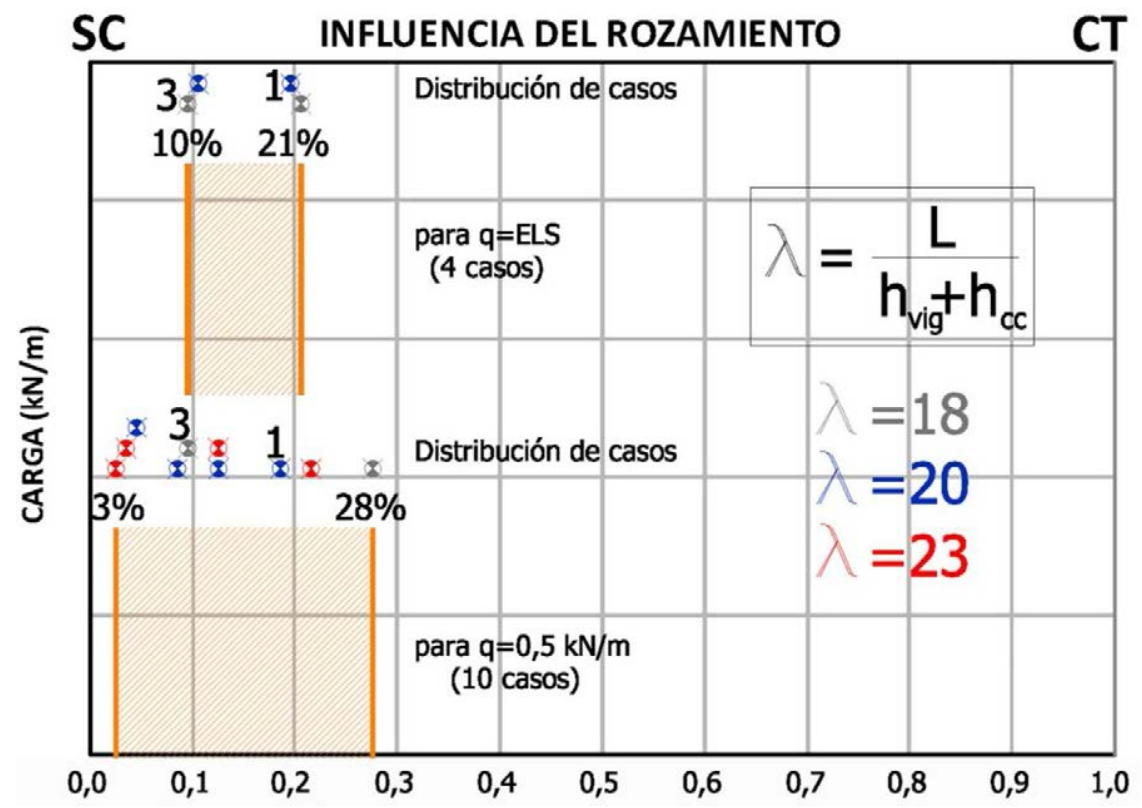

figura 4. Grado de conexión de los ensayos SIN CONEXIÓN

En la distribución de los casos del gráfico de la figura 4 se han dibujado en gris los puntos correspondientes a vigas de esbeltez final 18, en azul las de 20 y en rojo las de 23.

\footnotetext{
${ }^{48}$ Los resultados de estos ensayos están detallados en el Anejo V.2.5 "Vigas a flexión. Vigueta de madera laminada. Sin Conexión" y en el Anejo V.3.4 "Vigas a flexión. Vigueta de madera aserrada. Sin Conexión"
} 
En la siguiente tabla se muestran todos los resultados de los ensayos. De ella se han extraído los datos para elaborar los dos gráficos anteriores:

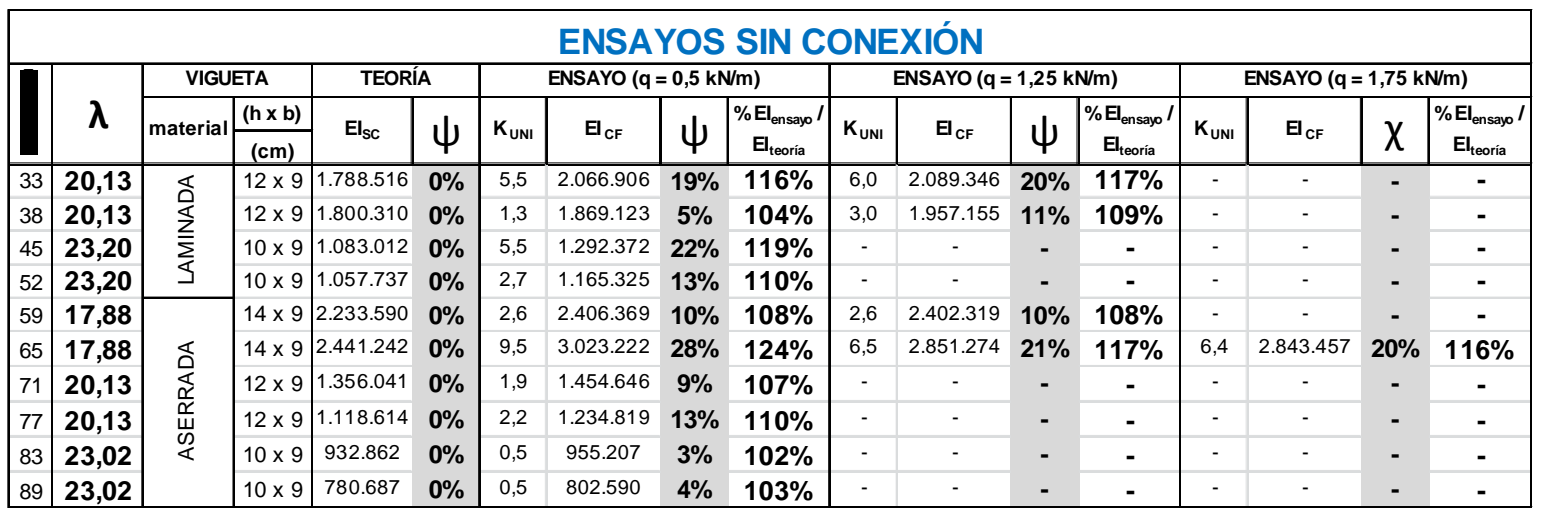

figura 5. Resultados de ensayos SIN CONEXIÓN

En la tabla de la figura 6 se muestran los valores medios del grado de conexión y del aumento de rigidez a flexión (EI) para cargas de 0,5 y $1,25 \mathrm{kN} / \mathrm{m}$ :

\begin{tabular}{|l|c|c|c|c|}
\cline { 2 - 5 } \multicolumn{1}{c|}{} & \multicolumn{2}{|c|}{$\mathbf{q}=\mathbf{0 , 5} \mathbf{~ k N / m}$} & \multicolumn{2}{c|}{$\mathbf{q}=\mathbf{1 , 2 5} \mathbf{~ k N / m}$} \\
\cline { 2 - 5 } & $\Psi$ & $\begin{array}{c}\% \mathrm{El}_{\text {ensayo }} \\
\mathbf{E}_{\text {teoria }}\end{array}$ & $\boldsymbol{\Psi}$ & $\begin{array}{c}\% \mathrm{El}_{\text {ensayo }} / \\
\mathrm{E}_{\text {teoria }}\end{array}$ \\
\hline media & $13 \%$ & $110 \%$ & $16 \%$ & $112 \%$ \\
\hline CoV & $62 \%$ & $6 \%$ & $32 \%$ & $4 \%$ \\
\hline
\end{tabular}

figura 6. Resumen de resultados de ensayos SIN CONEXIÓN

\section{CONCLUSIONES}

La rigidez mejora entre el $2 \%$ y el $24 \%$ respecto de la rigidez suma de las dos piezas por separado (rigidez teórica). Dicho en términos de grado de conexión, ese aumento representa de un $3 \%$ a un $28 \%$. No se aprecia una diferencia entre los casos con vigueta de madera aserrada y laminada. Tampoco hay una variación clara del efecto del rozamiento al cambiar la esbeltez.

De los 10 ensayos realizados, en la figura 7 se incluyen los cuatro casos que han superado la carga de $0,5 \mathrm{kN} / \mathrm{m}$. Se representa el grado de conexión de estas piezas para los niveles de carga $0,5 \mathrm{kN} / \mathrm{m}$, ELS y ELU. En general se puede apreciar la constancia del grado de conexión conseguido por el rozamiento (en los casos denominados (2) y (4) esto no ocurre. Se puede entender que a causa de reajustes iniciales, por lo que se muestran en rojo). Esa constancia está relacionada con que el coeficiente de rozamiento es independiente de la magnitud de la carga. Los casos (1) y (3) se han rotulado en la figura 4 para ver la correspondencia en las cargas 0,5 y ELS.

\begin{tabular}{|c|c|c|c|c|}
\hline & $\Psi_{0,5}$ & $\Psi_{\text {ELS }}$ & $\Psi_{\text {ELU }}$ & ensade \\
\hline $\mathbf{( 1 )}$ & $19 \%$ & $20 \%$ & - & 33 \\
\hline $\mathbf{( 2 )}$ & $5 \%$ & $11 \%$ & - & 38 \\
\hline $\mathbf{( 3 )}$ & $10 \%$ & $10 \%$ & - & 59 \\
\hline $\mathbf{( 4 )}$ & $28 \%$ & $21 \%$ & $20 \%$ & 65 \\
\hline
\end{tabular}

figura 7. Grado de conexión según la carga 


\subsection{INFLUENCIA DE LA PRESIÓN}

En este apartado se analiza la influencia de ejercer una presión entre la vigueta y la capa de compresión (no está cuantificada la fuerza aplicada, ya que el objetivo es localizar esta influencia y no medirla). Este efecto se analiza en vigas con capa de compresión de madera microlaminada generalmente con tornillos, y algún caso con clavos. ${ }^{49}$

\section{Ensayos analizados}

Estos ensayos pertenecen al mismo grupo que los ensayos de rozamiento anteriores. Se realizó un ensayo con presión, se quitó la presión de los conectores y se volvió a ensayar. Así con las tres separaciones estudiadas ( $70 \mathrm{~mm}, 140 \mathrm{~mm}$ y $280 \mathrm{~mm}$ ).

Se analizan 18 vigas mixtas con viguetas de madera laminada y madera aserrada y se emplean dos tipos de tornillos (figura 8).

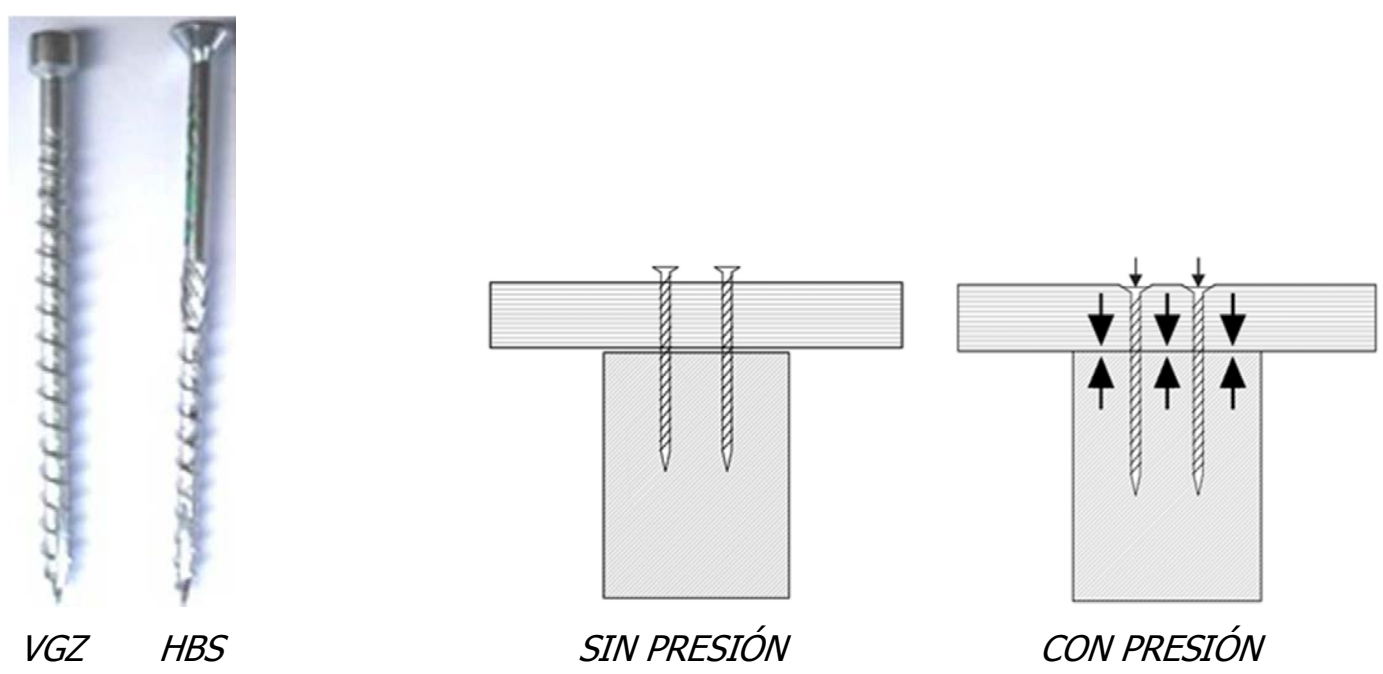

figura 8. Conectores utilizados y esquema de la sección de los ensayos CON/SIN Presión

Los tornillos VGZ son los que están en la izquierda, tienen la cabeza cilíndrica, son de diámetro nominal 7 ( $\varnothing$ de cálculo 5,0) y la rosca ocupa toda su longitud. Los tornillos HBS tienen la cabeza cónica, diámetro nominal 6 ( $\varnothing$ de cálculo 4,3) y la rosca solo en la parte correspondiente a la vigueta, la parte superior es lisa.

\footnotetext{
${ }^{49}$ Quizás el caso de los tornillos pueda ser extrapolable a la realidad, en el caso de los clavos parece lógico pensar que al no tener rosca, irán perdiendo capacidad de ejercer esta presión con el paso del tiempo.
} 


\section{Resultados $^{50}$}

La figura 9 corresponde al gráfico de carga/flecha. Se le ha aplicado un factor a cada pareja de ensayos (Con Presión / Sin Presión) para homogeneizar todas las flechas de las vigas Sin Presión en la carga correspondiente a ELS, y poder comparar en un solo gráfico todos los ensayos. Para hacer el gráfico más legible, de los ensayos Con Presión solo se han dibujado las dos que representan los límites de mejora de rigidez. Los porcentajes que se muestran indican el aumento de rigidez entre los ensayos Con Presión y Sin Presión (solo se han dibujado el ensayo más rígido y el menos rígido) en las 3 cotas de carga analizadas. En morado se representan los ensayos de los tornillos con la cabeza cónica (HBS) y en naranja los tornillos con la cabeza cilíndrica (VGZ).

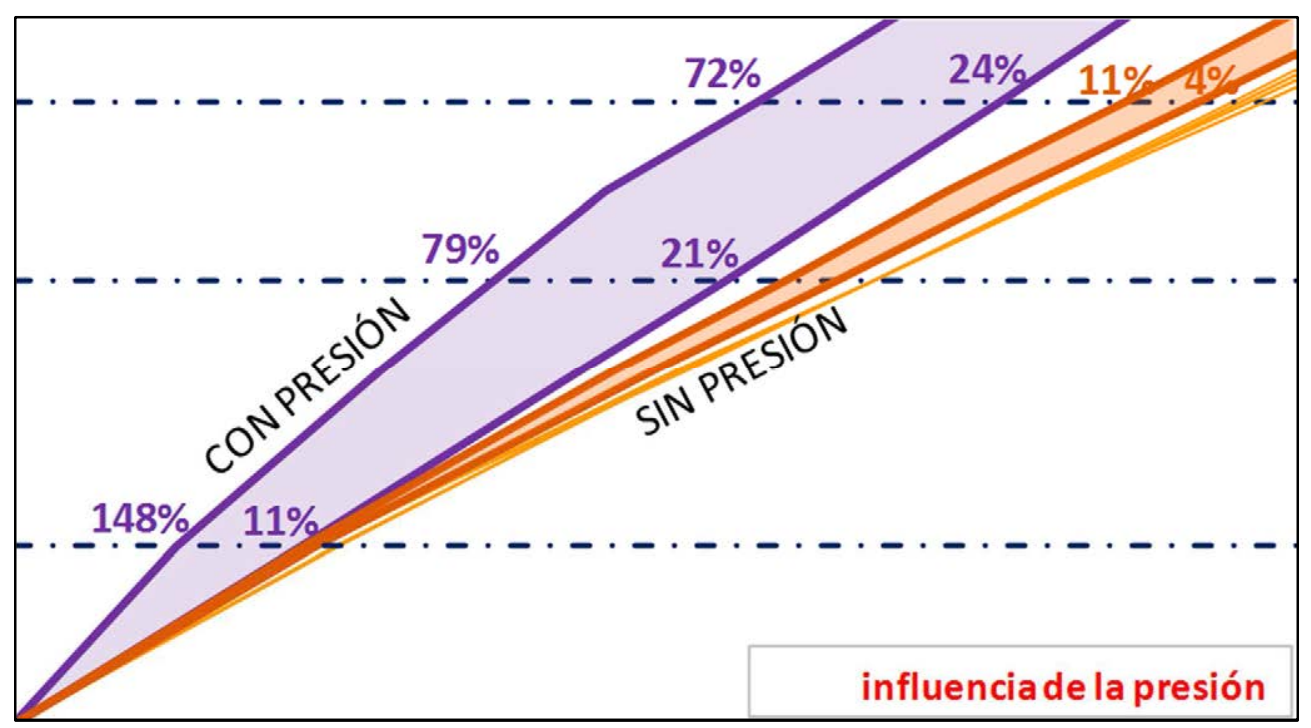

figura 9. Gráficas de carga-flecha CON/SIN Presión

La siguiente tabla incluye los valores medios de mejora de la rigidez (EI) para cada tipo de conector en las cargas $0,5 \mathrm{kN} / \mathrm{m}$, ELS y ELU.

\begin{tabular}{|c|c|c|c|c|c|}
\hline \multicolumn{3}{|c|}{ CON Y SIN PRESIÓN } & \multicolumn{3}{|c|}{ MEJORA DE RIGIDEZ } \\
\hline & & & $a=0,5$ & ELS & ELU \\
\hline \multicolumn{2}{|c|}{ CONEXIÓN } & & $\begin{array}{c}\text { CON PR / } \\
\text { SIN PR }\end{array}$ & $\begin{array}{c}\text { CON PR / } \\
\text { SIN PR }\end{array}$ & $\begin{array}{c}\text { CONPR / } \\
\text { SIN PR }\end{array}$ \\
\hline $\begin{array}{l}\text { TIPO DE } \\
\text { CONECTOR }\end{array}$ & $\varnothing$ & & $\mathrm{El}_{\mathrm{cp}} / \mathrm{EI}_{\mathrm{sp}}$ & $\mathrm{El}_{\mathrm{cp}} / \mathrm{El}_{\mathrm{sp}}$ & $\mathrm{El}_{\mathrm{cp}} / \mathrm{El}_{\mathrm{sp}}$ \\
\hline \multirow{2}{*}{ CLAVO } & \multirow{2}{*}{$2 \varnothing 4,4$} & MEDIA & $115 \%$ & $114 \%$ & $111 \%$ \\
\hline & & CoV & $1 \%$ & $3 \%$ & $4 \%$ \\
\hline \multirow{2}{*}{ TORNILLO VGZ } & \multirow{2}{*}{$2 \varnothing 5,0$} & MEDIA & $110 \%$ & $107 \%$ & $107 \%$ \\
\hline & & CoV & $7 \%$ & $3 \%$ & $2 \%$ \\
\hline \multirow{2}{*}{ TORNILLO HBS } & \multirow{2}{*}{$2 \varnothing 4,3$} & MEDIA & $164 \%$ & $152 \%$ & $145 \%$ \\
\hline & & CoV & $26 \%$ & $13 \%$ & $11 \%$ \\
\hline
\end{tabular}

figura 10. Tabla resumen de los resultados

\footnotetext{
50 Los resultados de estos ensayos están detallados en el Anejo V.4 "Vigas a flexión. Ensayos Con/ Sin Presión entre vigueta y capa de compresión".
} 
En la figura 11 se muestra el aumento del grado de conexión debido a la presión (solo para la carga de ELS). En la distribución de los casos están representados cada tipo de conector con diferentes colores. ${ }^{51}$

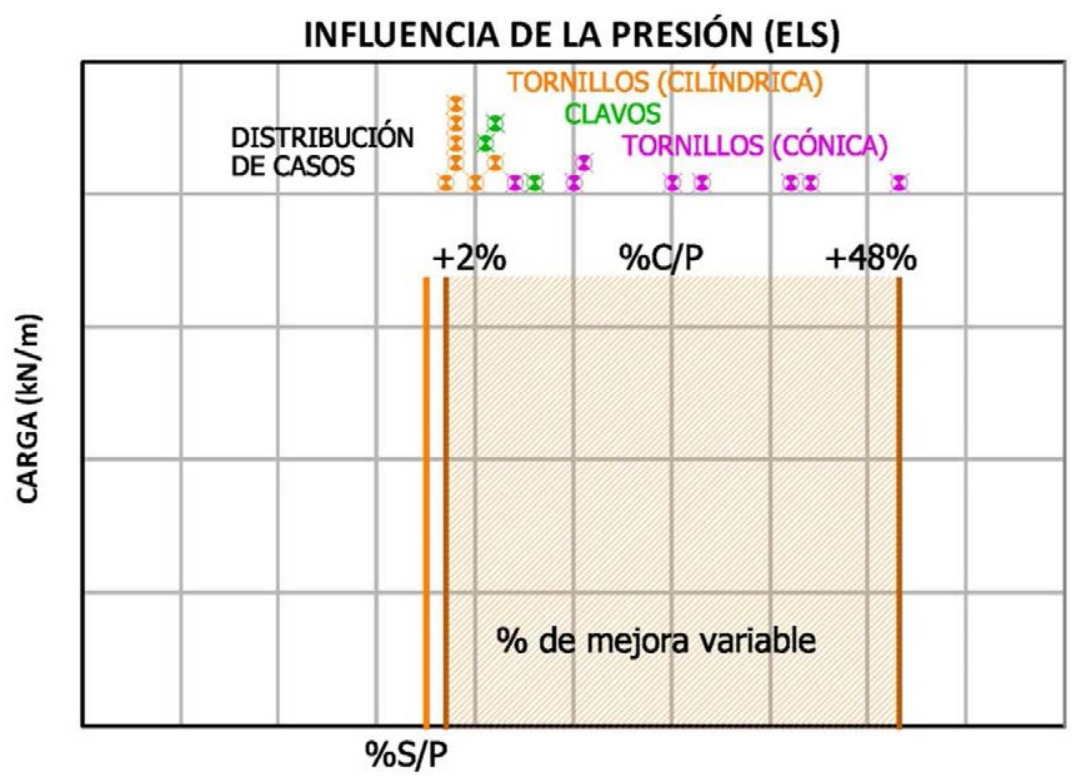

figura 11. Mejora del grado de conexión con la presión

\section{CONCLUSIONES}

En todos los casos hay una mejora en la rigidez de la pieza debida al aumento de presión entre los materiales. La mejora del grado de conexión, y consecuentemente de la rigidez es muy variable, ya que no se tiene información sobre la presión real que actúa entre las viguetas y las capas de compresión. La intención de este trabajo fue solo la detección de este fenómeno, y conocer el orden de magnitud.

Por lo general, al aumentar la carga se detecta una disminución de este efecto de pretensado, aunque en algún casos ocurre lo contrario. En la figura 12 se muestran todos los casos:

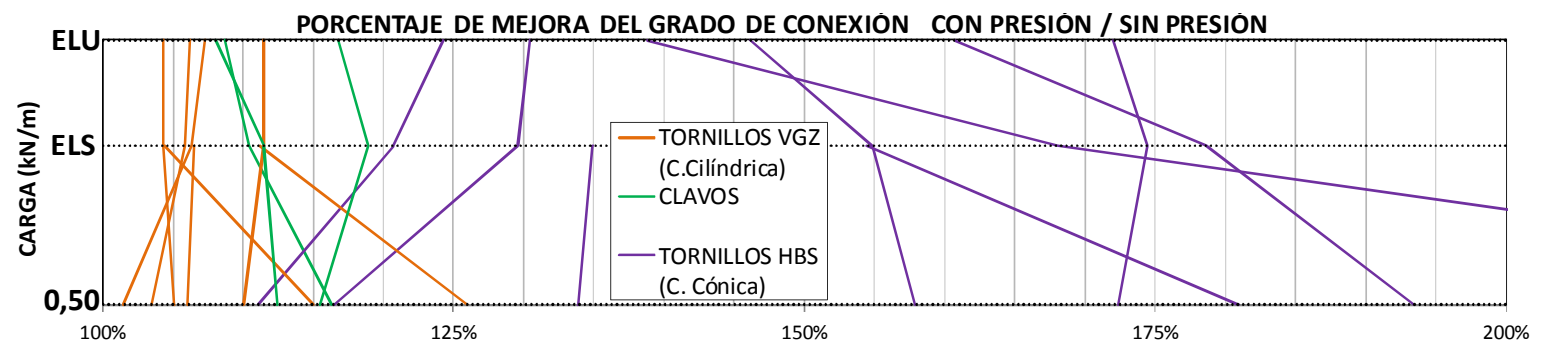

figura 12. Mejora de rigidez por el pretensado según el nivel de carga

\footnotetext{
${ }^{51}$ Se ha usado como base de representación el gráfico del grado de conexión y se han homogeneizado todos los ensayos para que el grado de conexión sin presión coincida en la misma vertical. Eso impide usar una única escala en la base del gráfico y por ese motivo no aparecen las referencias de los extremos sin conexión y conexión total, ni los valores intermedios.
} 
Comparando entre los distintos conectores utilizados, la influencia de ejercer esta presión con los tornillos HBS adquiere una especial importancia, seguramente debido a que su cabeza es cónica y ejercen una mayor presión entre vigueta y capa de compresión al ser apretados, mejorando el grado de conexión hasta un $48 \%$. Sin embargo, en el caso de los tornillos de cabeza cilíndrica y de los clavos la ganancia que se ha alcanzado, en el mejor de los casos es del $25 \%$. Esto ocurre porque al apretar este tipo de tornillos contra la madera se produce un aplastamiento local de esta, que parece ser la causa de que no se trasfiera correctamente la presión a la vigueta. Queda patente la importancia de la elección de la forma de la cabeza del tornillo.

En cualquier caso, parece interesante esta influencia detectada y podría ser objeto de futuras investigaciones, concretamente con los tornillos de cabeza cónica en estudios que incluyan aspectos de largo plazo, cíclicos o dinámicos. 


\subsection{INFLUENCIA DEL ÁNGULO DE INCIDENCIA (45)}

En este apartado se analiza una conexión con parejas de conectores colocados con un ángulo de incidencia de $45^{\circ}$. Se incluye también un caso de conexión vertical para tener un orden de magnitud de la notable diferencia de rigidez que entre uno y otro.

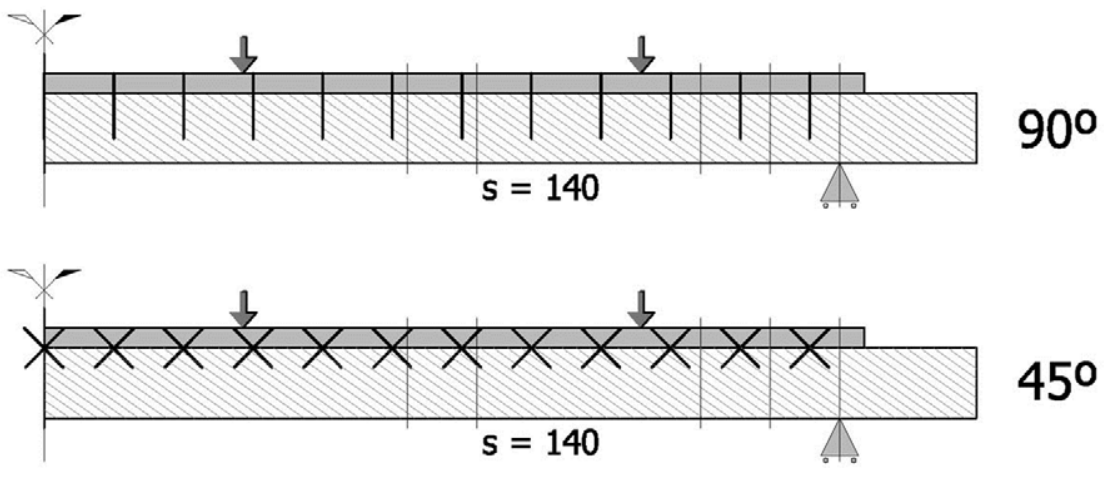

figura 13. Esquemas de las dos vigas analizadas

\section{Ensayos analizados}

Las dos vigas mixtas tienen vigueta de madera laminada de dimensiones $14.9 \mathrm{~cm}$ y capa de compresión de madera microlaminada (32-200). En un caso son dos parejas de conectores cada $140 \mathrm{~mm}$ colocados a $45^{\circ}$ y en el otro dos conectores cada $140 \mathrm{~mm}$ colocados a $90^{\circ}$.

\section{$\underline{\text { Resultados }}^{52}$}

En la tabla se muestran los resultados de los ensayos y los grados de conexión para las cargas de $0,50 \mathrm{kN} / \mathrm{m}, 1,25 \mathrm{kN} / \mathrm{m}$ (ELS), $1,75 \mathrm{kN} / \mathrm{m}$ (ELU) y 3,00 kN/m(ELR):

\begin{tabular}{|c|c|c|c|c|c|c|c|c|}
\hline \multicolumn{9}{|c|}{$45^{\circ}$ vs 90 } \\
\hline$\frac{9}{2}$ & \multicolumn{4}{|c|}{ CONEXIÓN } & $q=0,5$ & ELS & ELU & ELR \\
\hline 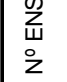 & INCLINACIÓN & $\begin{array}{c}\text { TIPO DE } \\
\text { CONECTOR }\end{array}$ & $\begin{array}{c}\varnothing y \\
\text { SEPARA CIÓN }\end{array}$ & \begin{tabular}{|c|} 
OTROS \\
PARÁMETROS
\end{tabular} & $\psi$ & $\psi$ & $\psi$ & $\psi$ \\
\hline 25 & $90^{\circ}$ & TORNILLO HBS & $206 / 140$ & $\mathrm{C} / \mathrm{P}$ & $86 \%$ & $84 \%$ & $80 \%$ & $71 \%$ \\
\hline 26 & $45^{\circ}$ & TORNILLO HBS & $4 \varnothing 6 / 140$ & $45^{\circ} \mathrm{C} / \mathrm{P}$ & $99 \%$ & $98 \%$ & $99 \%$ & $99 \%$ \\
\hline
\end{tabular}

figura 14. Tabla resumen de resultados de los ensayos

\footnotetext{
${ }^{52}$ Los resultados de estos ensayos se encuentran en el Anejo V.2.4 "Vigas a flexión. Vigueta de madera laminada. Tornillos"
} 
En la figura 15 se muestran los ensayos para un contexto de edificación urbana:

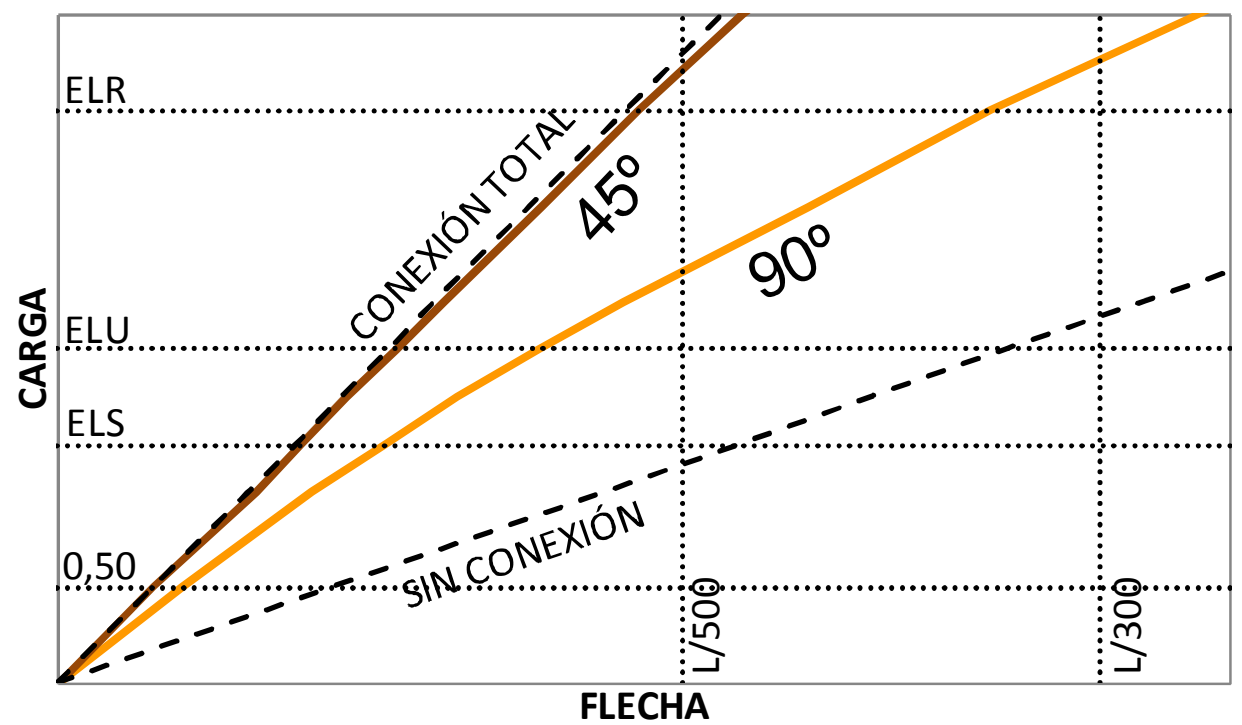

figura 15. Gráfico de carga-flecha en ámbito de la edificación

En la figura 16 se muestra el mismo gráfico con el ensayo llevado a hasta la rotura de las piezas, quedando en la trama gris el entorno mostrado en el gráfico 15:

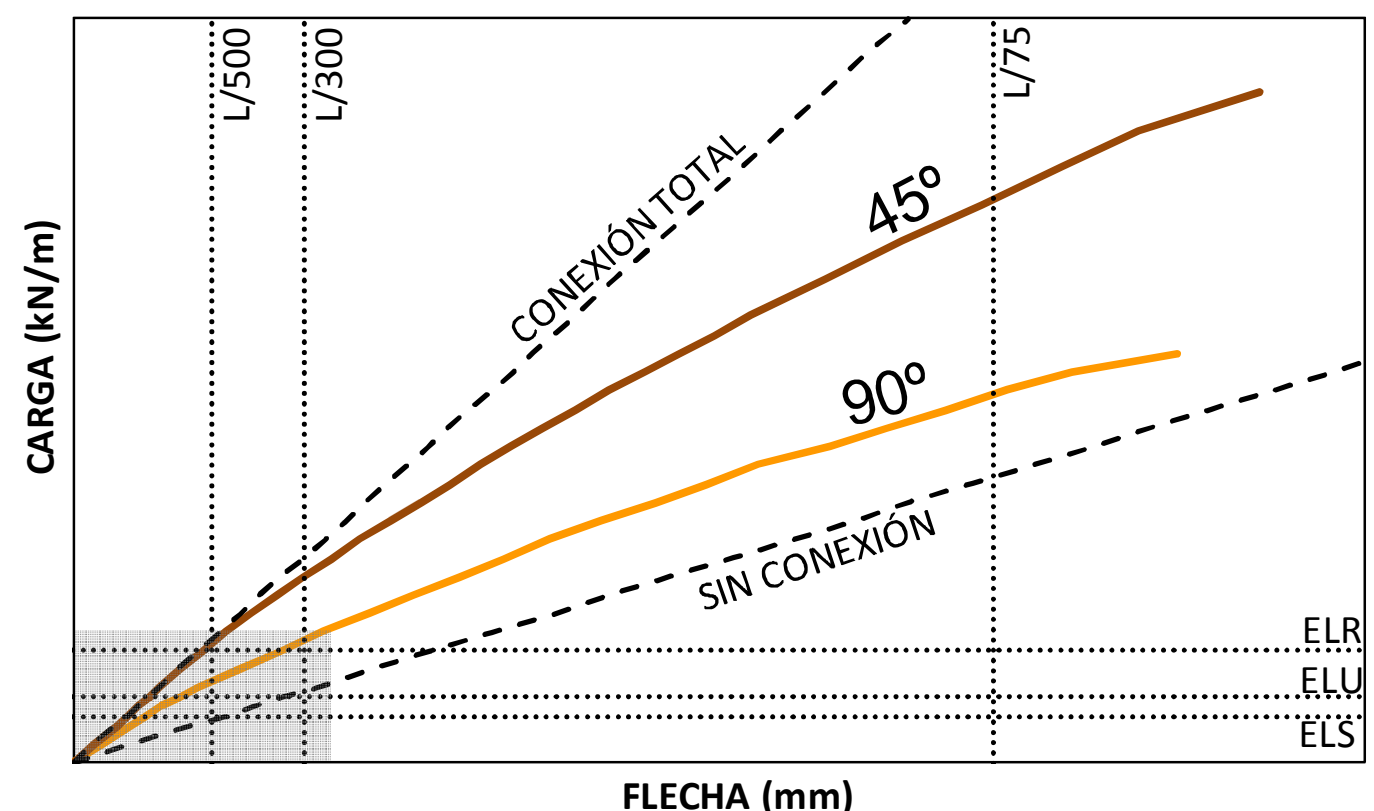

figura 16 Gráfico de carga-flecha hasta la rotura de las vigas

La figura 17 se realiza con la plantilla de los grados de conexión. En el eje vertical se representa la rigidez a deslizamiento de la conexión $\left(K_{\text {uni }}\right)$, que es una curva hiperbólica. ${ }^{53}$ Los puntos rojos están situados en el valor de rigidez que les corresponde en esa curva y en el porcentaje del grado de conexión que les corresponde según el eje horizontal.

\footnotetext{
53 La afirmación de que la curva de la rigidez a deslizamiento es hiperbólica quedará demostrada en el capítulo 6.
} 


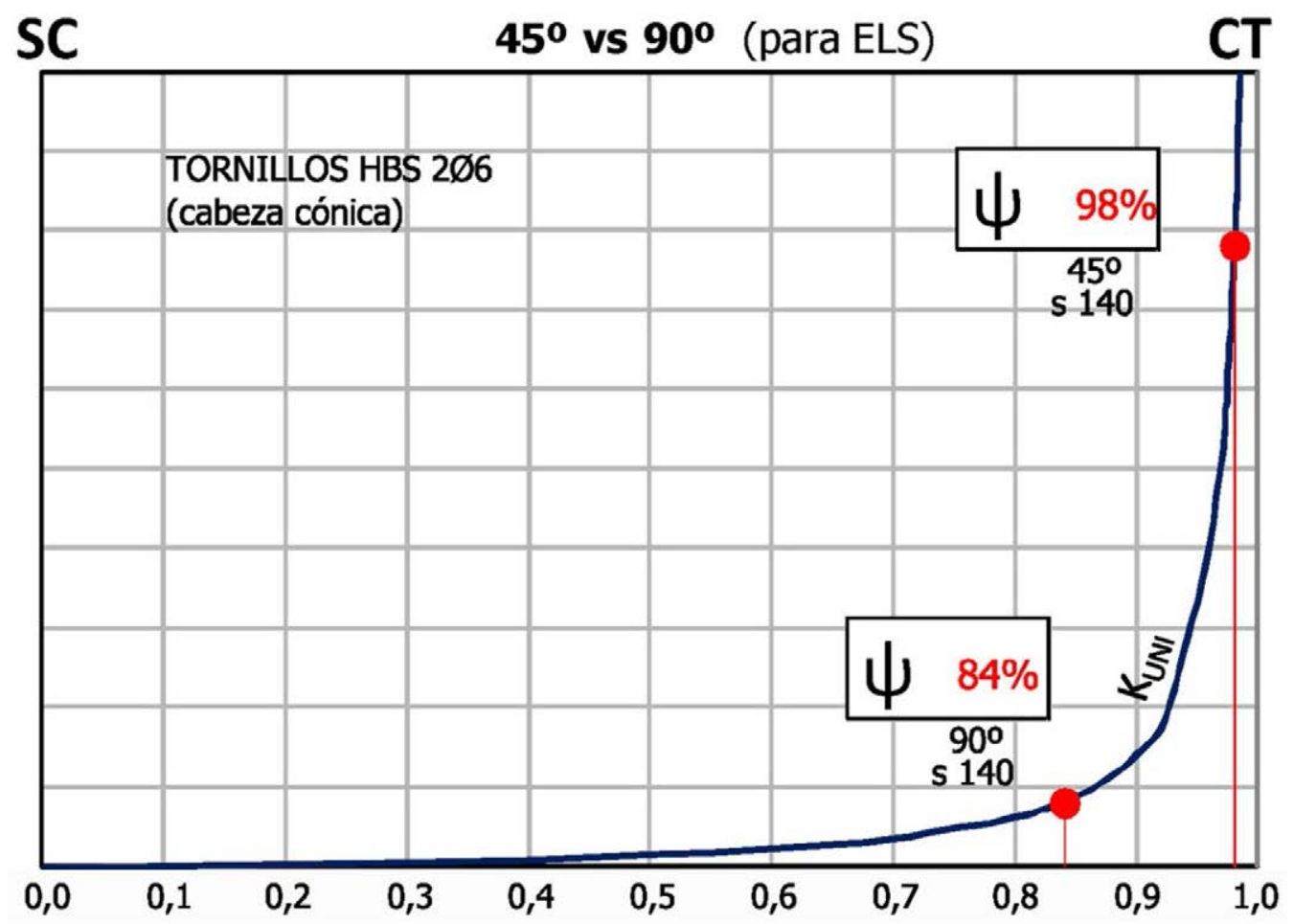

figura 17. Gráfico de grado de conexión de los dos ensayos

\section{CONCLUSIONES}

La baja rigidez que afecta a las uniones por cortante, debida a la propia deformabilidad del conector ante esfuerzos transversales y el hendimiento de la madera, no existen en la conexión inclinada, ya que permite el trabajo exclusivamente axil del conector y de las bielas comprimidas de madera y hormigón.

También está completamente estudiada la dificultad (imposibilidad) de conseguir grados de conexión elevados en los que el deslizamiento desaparezca, sumado a que la densidad de conexión supera al espacio disponible para ubicarla.

Para cargas situadas en el contexto de la edificación, incluso hasta valores por encima de la denominada ELR $(3 \mathrm{kN} / \mathrm{m})$, mientras que los conectores verticales forman una conexión flexible con pérdida de rigidez debido al deslizamiento, la conexión a $45^{\circ}$ consigue una conexión prácticamente total, apenas se produce deslizamiento entre la vigueta y la capa de compresión.

Para cargas superiores a la rotura teórica de la pieza (ELR), la conexión de $45^{\circ}$ comienza a deslizar y a perder conexión, pero lo hace en mayor medida la conexión a $90^{\circ}$. En cualquier caso esta carga está muy por encima de los límites de edificación urbana.

Como se aprecia en la figura 17 , la línea que representa la rigidez a deslizamiento de la conexión ( $\left.\mathrm{K}_{\text {uni }}\right)$ es hiperbólica con asíntota en el grado de conexión total, por lo que, con una conexión a $90^{\circ}$, con índices de conexión altos, para incrementar el grado de conexión hay que 
aumentar exponencialmente la conexión, bien reduciendo la separación entre conectores, bien tomando conectores con mayores diámetros.

En la figura 18 se muestra un gráfico de lo que representa conseguir una mejor conexión en estos niveles, con los conectores colocados a $90^{\circ}$ y en dos esbelteces distintas. Los dos ensayos (rojo) estudiados en los gráficos anteriores, se han acompañado aquí de una serie de conexiones realizadas con el mismo tornillo y a distintas separaciones aplicando el modelo de cálculo que se estudia en el capítulo 6. Hay que indicar que el ensayo a $45^{\circ}$ corresponde a la esbeltez 19 (no a la 28 como parece) y su punto rojo de ubicación estaría mucho más arriba.

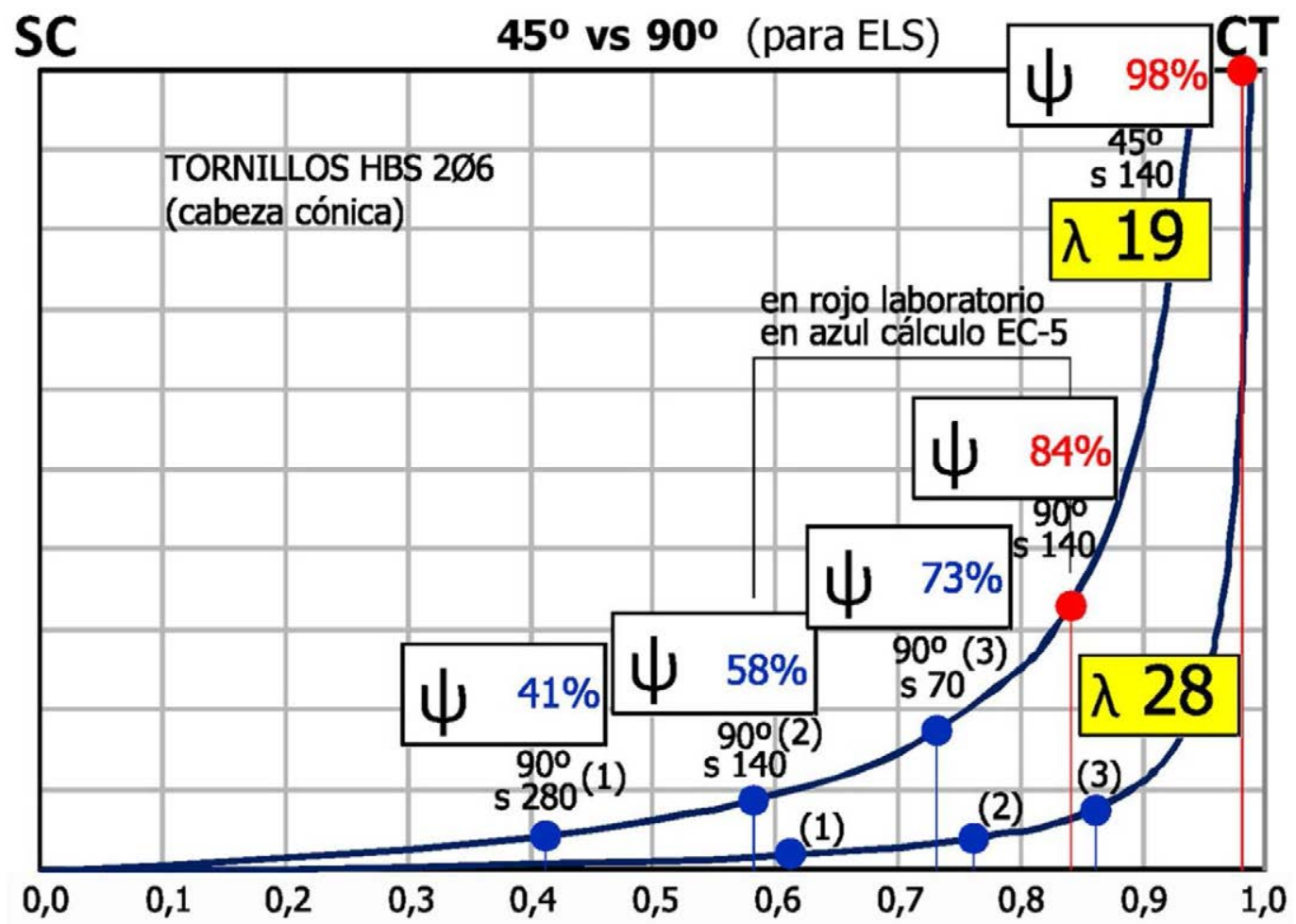

figura 18. Grado de conexión con diferentes separaciones entre conectores

En el caso marcado como (2), existen 2 puntos, el azul es el valor teórico y el rojo el valor que ha dado la pieza en el ensayo. La diferencia entre uno y otro es grande, fundamentalmente porque el ensayo está realizado con presión (ya que no se realizó este ensayo sin presión), lo que proporciona una ganancia en la conexión. En el cálculo teórico, se ha calculado sin presión.

A mayor esbeltez, son necesarios mayores grados de conexión, como se puede observar en las rigideces 19 y 28 del gráfico. Porque es la única manera de contrarrestar en incremento de deformaciones. 


\subsection{HORMIGÓN vs MADERA MICROLAMINADA}

En este apartado se va a comparar el comportamiento de las vigas mixtas con capa de compresión de hormigón y de madera microlaminada. Se analizan parejas de ensayos con la misma conexión y que solo difieren en la capa de compresión.

\section{Ensayos analizados}

Se analizan tres parejas de ensayos (hormigón / microlaminada) con vigueta de madera laminada de dimensiones $14.9 \mathrm{~cm}$, las tres conexiones empleadas son:

$\begin{array}{ll}\text {-Tirafondos con resina } & \varnothing 10 / 300 \text { y } \varnothing 6 / 50 \\ \text {-Clavos sin resina } & \varnothing 4,4 / 90\end{array}$

\section{$\underline{\text { Resultados }}$}

En la tabla de la figura 19 se muestran los resultados de los ensayos y los grados de conexión para las cargas de 1,25 kN/m (ELS), 1,75 kN/m (ELU) y 3,00 kN/m (ELR). En la primera columna de cada carga se muestra la diferencia de rigidez con la teórica según la normativa (por encima del $100 \%$ el ensayo es más rígido que la teoría y por debajo es menos rígido) y en la segunda la diferencia del grado de conexión entre la viga mixta con capa de compresión de madera microlaminada y con hormigón.

\begin{tabular}{|c|c|c|c|c|c|c|c|c|c|}
\hline \multicolumn{4}{|c|}{ HORMIGÓN } & \multicolumn{4}{|c|}{ MADERA MICBOLAMINADA } & & \\
\hline \multirow{3}{*}{ 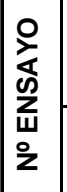 } & \multirow{2}{*}{$\begin{array}{c}\text { CAPA } \\
\text { COMPRESIÓN }\end{array}$} & \multirow{2}{*}{\multicolumn{2}{|c|}{ CONEXIÓN }} & \multicolumn{2}{|c|}{ ELS } & \multicolumn{2}{|c|}{ ELU } & \multicolumn{2}{|c|}{ ELR } \\
\hline & & & & EI & \%conex & EI & \%conex & EI & \%conex \\
\hline & material & $\begin{array}{c}\text { TIPO DE } \\
\text { CONECTOR }\end{array}$ & $\begin{array}{c}\varnothing y \\
\text { SEPARACIÓ }\end{array}$ & \begin{tabular}{|c|} 
ENSAYO / \\
TEORÍA
\end{tabular} & $\psi_{\mathrm{M}}-\psi_{\mathrm{H}}$ & $\begin{array}{l}\text { ENSAYO } \\
\text { TEORÍA }\end{array}$ & $\psi_{M}-\psi_{H}$ & \begin{tabular}{|l|} 
ENSAYO \\
TEORÍA
\end{tabular} & $\psi_{M}-\psi_{H}$ \\
\hline 1 & HORMIGÓN & TIRAFONDO & $\varnothing 10 / 300$ & $101 \%$ & 100 & $106 \%$ & 150 & $117 \%$ & 10 \\
\hline 3 & MICROLAMINADA & TIRAFONDO & $\varnothing 10 / 300$ & $141 \%$ & $18 \%$ & $143 \%$ & $15 \%$ & $145 \%$ & $10 \%$ \\
\hline 10 & HORMIGÓN & CLAVO & $2 \varnothing 4,4 / 90$ & $76 \%$ & 150 & $79 \%$ & 10 & $83 \%$ & ก0, \\
\hline 12 & MICROLAMINADA & CLAVO & $2 \varnothing 4,4 / 90$ & $163 \%$ & $45 \%$ & $161 \%$ & $40 \%$ & $151 \%$ & $2 \%$ \\
\hline 7 & HORMIGÓN & TIRAFONDO & $\varnothing 6 / 50$ & $82 \%$ & & $88 \%$ & & $99 \%$ & \\
\hline 8 & MICROLAMINADA & TIRAFONDO & $\varnothing 6 / 50$ & $113 \%$ & 11 & $116 \%$ & $\%$ & $121 \%$ & \\
\hline
\end{tabular}

figura 19. Tabla de ensayos analizados 
En la figura 20 se muestran las gráficas de los ensayos completos hasta la rotura de las vigas. A la izquierda las piezas de hormigón y a la derecha las de madera microlaminada. La línea de trazos corresponde al cálculo teórico y la línea continua, el ensayo.

Para dibujar la recta del cálculo teórico se ha tomado como dato la rigidez a deslizamiento $\left(\mathrm{K}_{\mathrm{ser}}\right)$ que marca el EC-5, con ella se ha obtenido la rigidez de la viga mixta siguiendo el método gamma (Anejo B EC-5) y con esta se ha calculado la flecha para cualquier carga.

\section{HORMIGÓN}

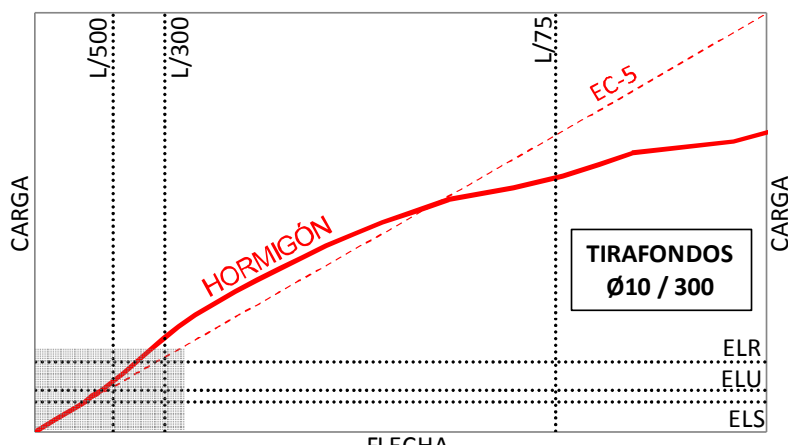

FLECHA

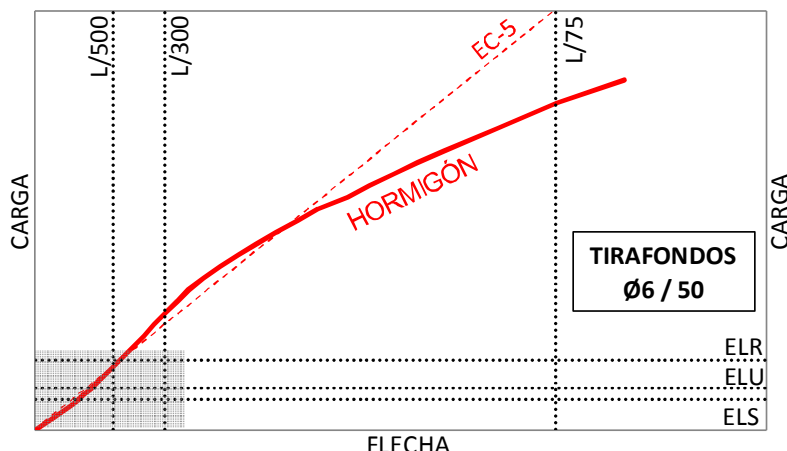

FLECHA

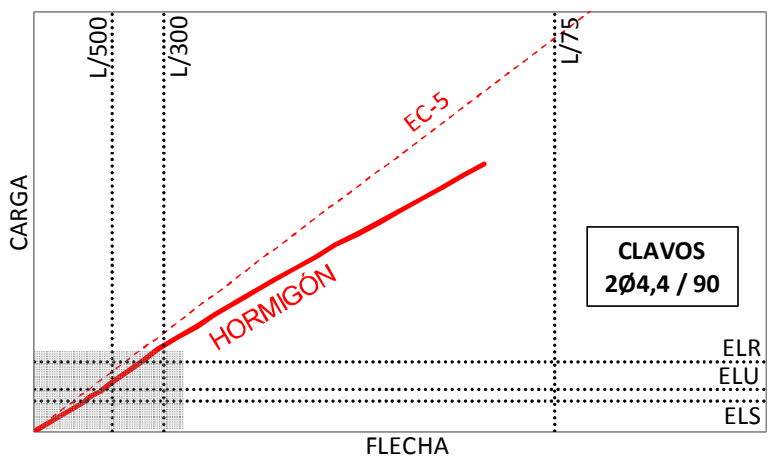

MADERA MICROLAMINADA

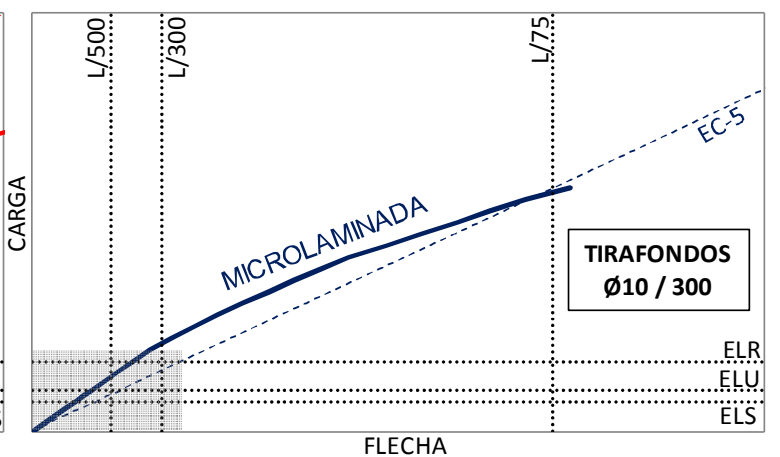

FLECHA

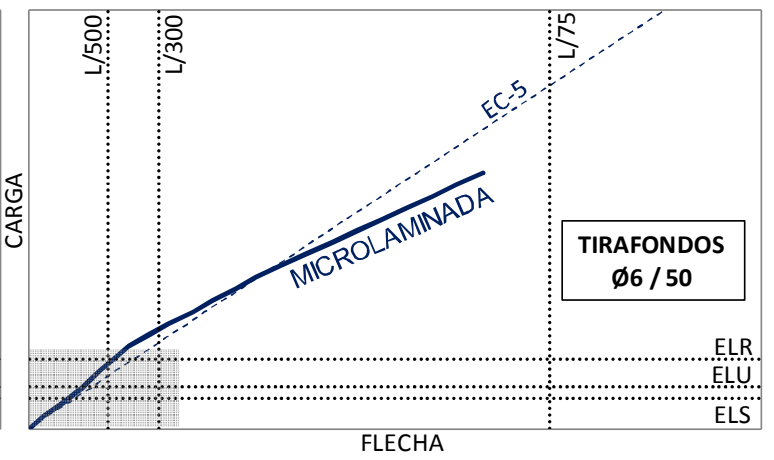

FLECHA

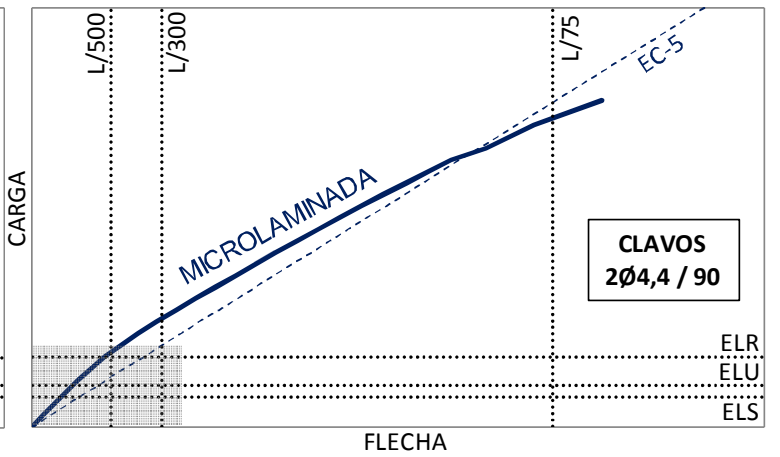

figura 20. Graficas de carga-flecha hasta la rotura de las vigas

A la vista de los gráficos de la figura 20, la recta que representa el cálculo obtenido con el $\mathrm{K}_{\mathrm{ser}}$ del EC-5 aparenta una gran aproximación a las curvas de los ensayos, incluso teniendo en cuenta que se trata de capas de compresión con dos materiales muy distintos y con conexiones también distintas. Para que se distancien una de la otra significativamente hay que alcanzar zonas de grandes deformaciones y cargas. 
Los gráficos de la figura 21 son los mismos que los anteriores pero con magnitudes del entorno de la edificación hasta su rotura teórica y hasta deformaciones de L/300. Los porcentajes indican rigidez relativa entre los datos de los ensayos y el EC-5 en las cargas indicadas.

HORMIGÓN
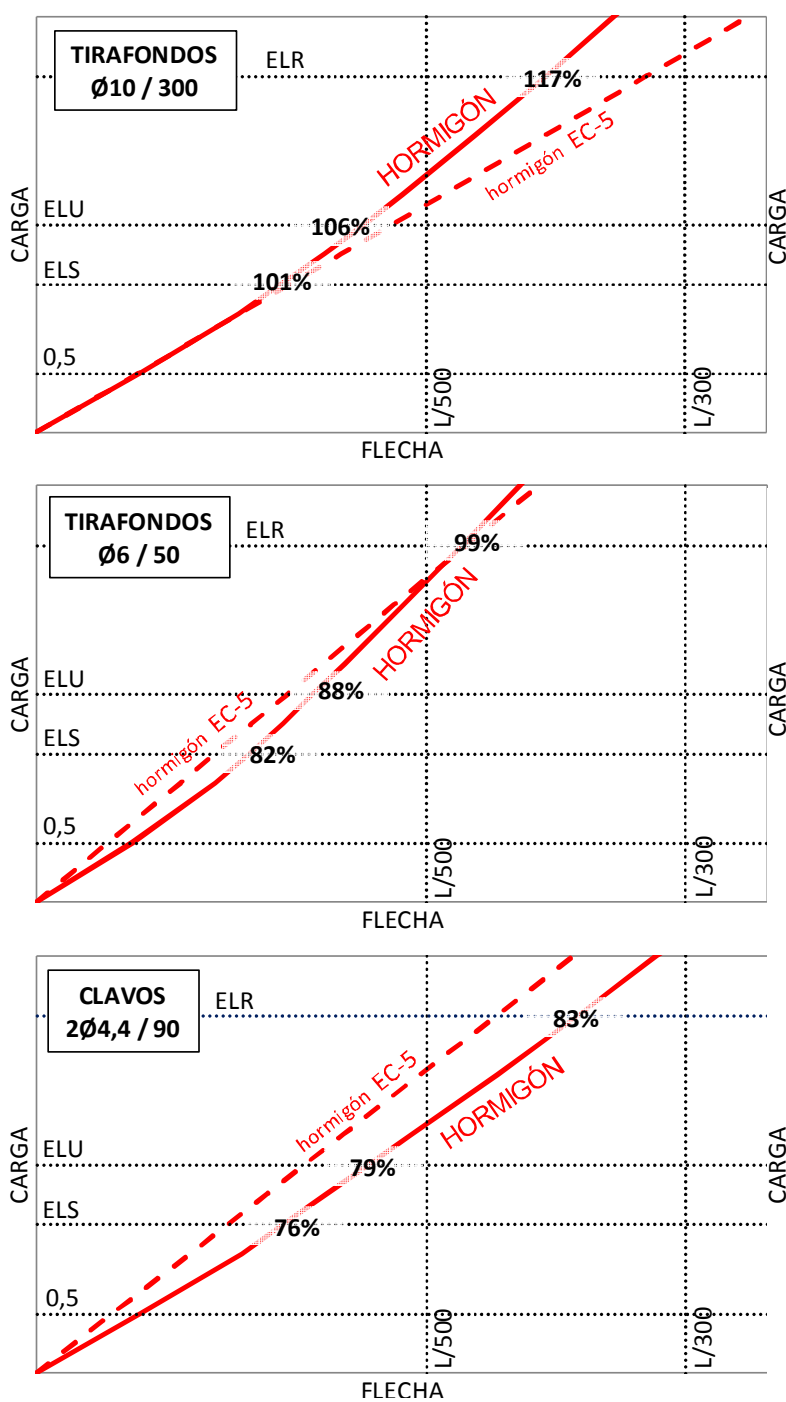

MADERA MICROLAMINADA
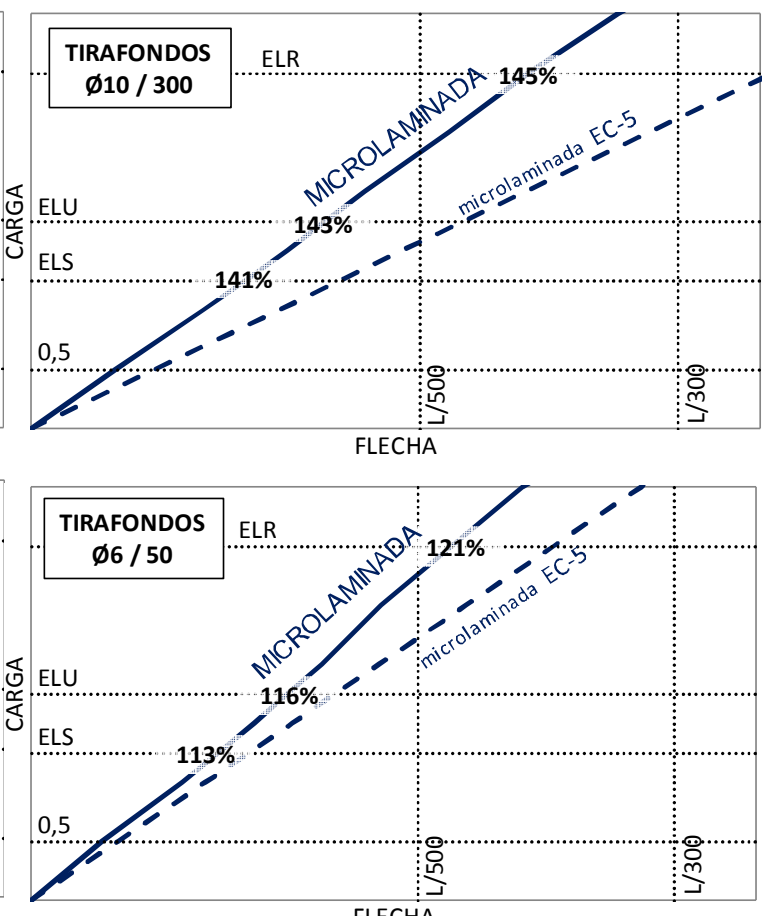

FLECHA

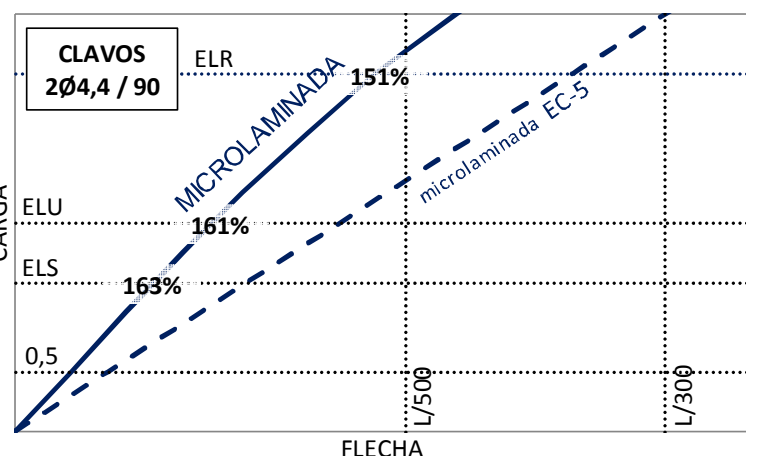

figura 21. Gráficas de carga-flecha hasta el límite de la edificación

Al haber ampliado el gráfico a la zona del entorno de la edificación se aprecia que la similitud entre la recta definida por el EC-5 y la curva del ensayo ha desaparecido en casi todos los casos. Además sale a la luz la diferencia de comportamiento en función del material de la capa de compresión. 
Siguiendo la doble representación establecida, se muestran en la figura 22 los gráficos correspondientes al grado de conexión. Las curvas representan a los ensayos y las rectas verticales al EC-5. En el eje vertical figuran las cargas correspondientes al entorno de la edificación.

HORMIGÓN
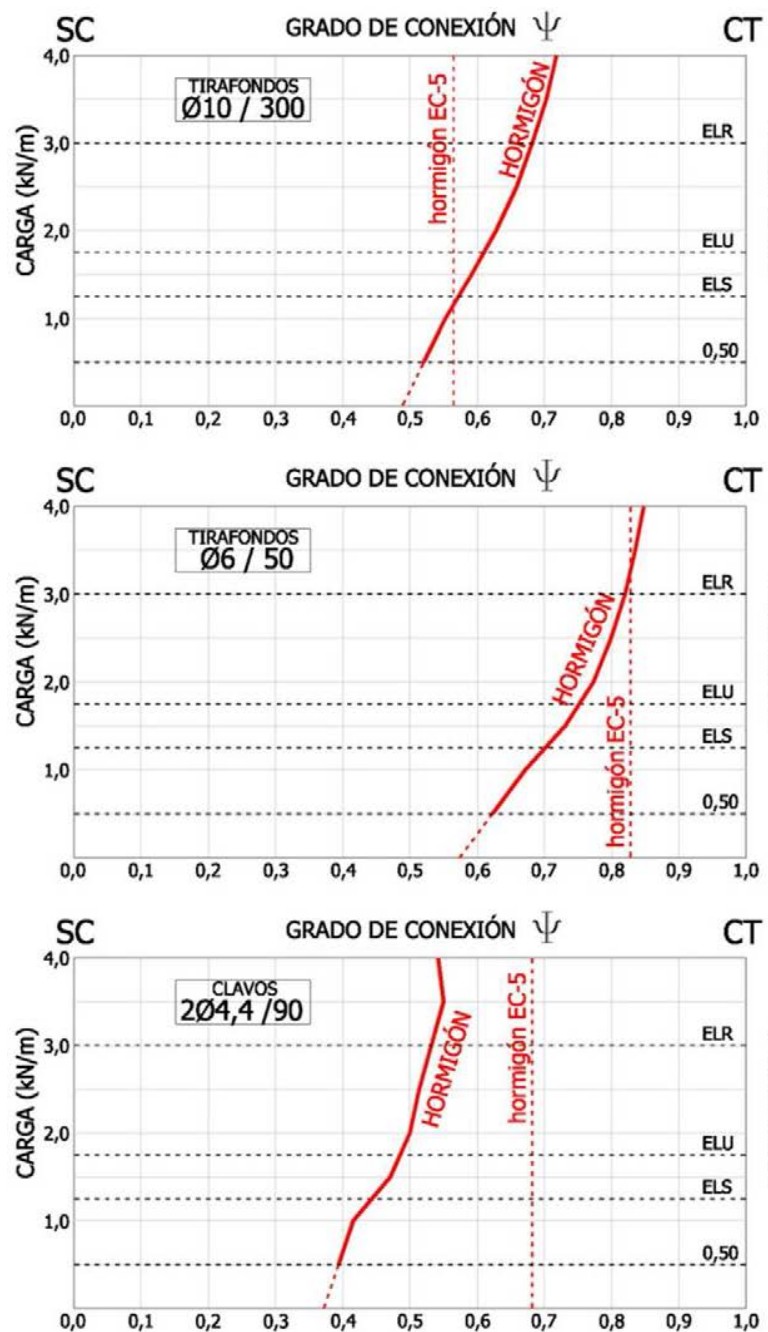

MADERA MICROLAMINADA
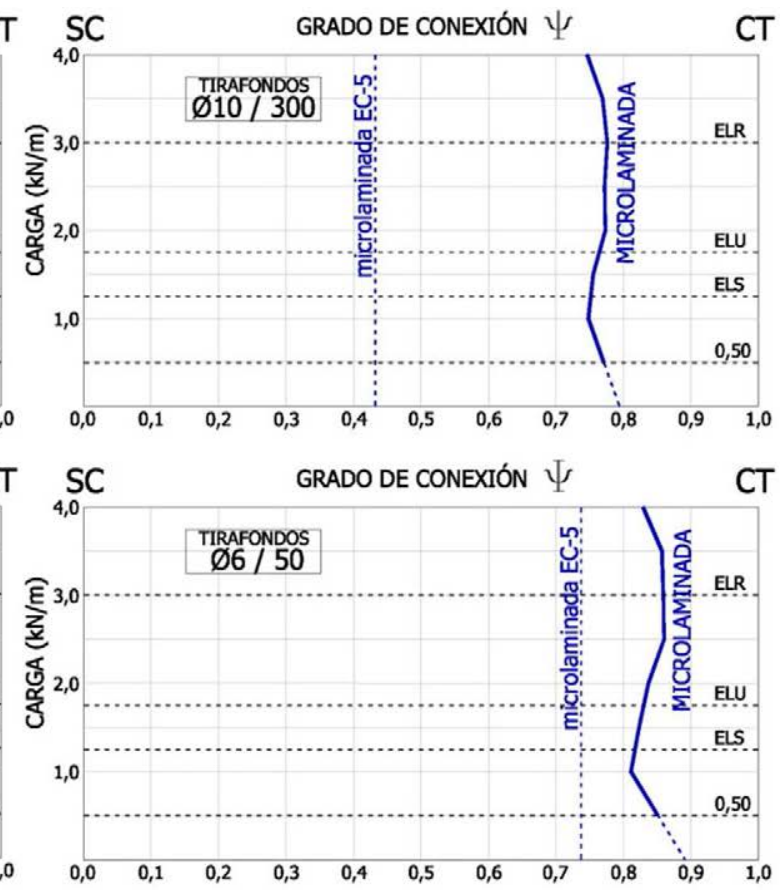

CT SC

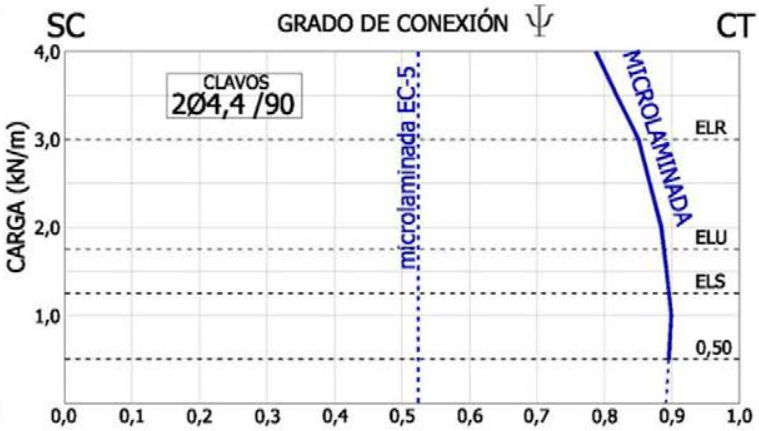

figura 22. Grados de conexión según la carga aplicada

La diferencia que se empezó a ver entre los dos materiales de la capa de compresión en la página anterior queda aquí mucho más clara. Las diferencias de rigidez señaladas antes aquí están reflejadas en diferencias en el grado de conexión. 


\section{CONCLUSIONES}

En la zona de uso de estas estructuras en la edificación, en el caso del hormigón al comparar la curva de los ensayos realizados con la línea del EC-5 son razonablemente cercanas, salvo en el caso de los clavos, que han resultado ser muy flexibles.

Con capa de compresión de madera microlaminada las rigideces obtenidas en los ensayos son superiores a las establecidas en la normativa, entre un $13 \%$ y un $41 \%$, incluso un $63 \%$ si se incluyen los clavos, aunque estos se puedan haber visto beneficiados por la presión ejercida al clavarlos. Visto esto mismo en los gráficos del grado de conexión (figura 22), todos los ensayos responden a unas conexiones muy superiores, tanto en ELS como en ELU se pasa de $42 \%$ a $75 \%$, de $74 \%$ a $82 \%$ y de $72 \%$ a $90 \%$ en los casos de $\emptyset 10$, Ø6 y clavos, respectivamente.

Otra observación que ocurre en todo el ámbito de la edificación, referida a las gráficas de los ensayos, es la concavidad (aumento de su rigidez con el incremento de carga) que se observa en el arranque de la gráfica cuando la capa de compresión es de hormigón, contraria a los diagramas de tensión/ deformación de los materiales con los que se han construido estas vigas. En cargas superiores $(5,0-6,0 \mathrm{kN} / \mathrm{m})$, esta gráfica adquiere la convexidad esperada. Cuando la capa de compresión es de tablero de madera microlaminada la gráfica se ajusta enteramente a la de los materiales que forman la viga.

Viendo las gráficas del grado de conexión (figura 22), se puede observar el mismo efecto comentado antes, en las vigas mixtas madera/hormigón, con el aumento de carga, va aumentando su grado de conexión y ,por lo tanto, su rigidez. Las vigas madera/microlaminada van perdiendo conexión paulatinamente con el aumento de carga. 


\subsection{MEJORAS DE RIGIDEZ DE LAS DISTINTAS CONEXIONES}

En este apartado se cuantifican las mejoras de rigidez de las diferentes conexiones. Se han agrupado según diferentes variables comunes para tener valores de grupos de ensayos. El número total de ensayos de flexión realizados es de 95 , de los que se extraen los 10 realizados sin conexión, por lo que en este apartado se evalúan los resultados de los 85 casos con conexión. ${ }^{54}$

\section{CONJUNTO DE TODOS LAS CONEXIONES}

En la figura 23 se muestra la mejora de rigidez de todos los ensayos, tanto con respecto a la vigueta como a la viga mixta sin conexión. Se han representado estos valores para las cargas de 0,50 kN/m, 1,25 kN/m (ELS) y 1,75 kN/m (ELU). La tabla contiene también las mejoras teóricas máxima (conexión total) y mínima (sin conexión).

\begin{tabular}{|c|c|c|c|c|c|c|c|c|c|c|c|c|}
\hline & \multicolumn{9}{|c|}{ TODOS LOS ENSAYOS CON CONEXIÓN (85 ENSAYOS) } & \multirow{2}{*}{\multicolumn{2}{|c|}{$\begin{array}{l}\text { LÍMITE DE MEJORA } \\
\text { CONEXIÓN TOTAL }\end{array}$}} & \multirow{3}{*}{\begin{tabular}{|c|} 
MÍNIMA \\
MEJORA \\
SIN CONEX. \\
R/ VIGUETA \\
\end{tabular}} \\
\hline & \multicolumn{3}{|c|}{$(0,50 \mathrm{kN} / \mathrm{m})$} & \multicolumn{3}{|c|}{$\operatorname{ELS}(1,25 \mathrm{kN} / \mathrm{m})$} & \multicolumn{3}{|c|}{$\operatorname{ELU}(1,75 \mathrm{kN} / \mathrm{m})$} & & & \\
\hline & $\begin{array}{l}\text { RESPECTO } \\
\text { VIGUETA }\end{array}$ & $\begin{array}{c}\text { RESPECT } \\
\text { O SC }\end{array}$ & $\begin{array}{l}\Psi \\
\%\end{array}$ & \begin{tabular}{|c|} 
RESPECTO \\
VIGUETA
\end{tabular} & $\begin{array}{c}\text { RESPECT } \\
\text { O SC }\end{array}$ & $\begin{array}{l}\Psi \\
\%\end{array}$ & \begin{tabular}{|c|} 
RESPECTO \\
VIGUETA
\end{tabular} & $\begin{array}{c}\text { RESPECT } \\
\text { O SC }\end{array}$ & $\begin{array}{l}\Psi \\
\%\end{array}$ & \begin{tabular}{|l} 
RESPECTO \\
VIGUETA
\end{tabular} & \begin{tabular}{|c|} 
RESPECTO \\
SC
\end{tabular} & \\
\hline MEDIA & $269 \%$ & $237 \%$ & $76 \%$ & $254 \%$ & $226 \%$ & $75 \%$ & & 22 & $75^{\circ}$ & & & $113 \%$ \\
\hline CoV & $29 \%$ & $27 \%$ & $27 \%$ & $26 \%$ & $23 \%$ & $22 \%$ & $24 \%$ & $22 \%$ & $20 \%$ & $13 \%$ & $8 \%$ & $5 \%$ \\
\hline
\end{tabular}

figura 23. Mejoras de rigidez de todos los ensayos

Aquí se engloban todos los tipos y separaciones de conectores, esbelteces, materiales y con y sin presión, por lo que la mezcla es muy heterogénea como para sacar conclusiones, sin embargo, nos da una idea clara del entorno de mejoras de rigidez en el que se van a mover estas conexiones. Para cargas de servicio se obtiene una rigidez 2,54 veces la rigidez de la vigueta y 2,26 veces la rigidez de la viga sin conexión. El grado medio de conexión es del 75\%.

Como se observa que no hay grandes diferencias entre las cargas estudiadas, sobre todo una vez pasa de la carga inicial de $0,50 \mathrm{kN} / \mathrm{m}$, en las tablas siguientes se analizará aquí solo la carga de servicio (ELS). Las tablas del anejo V.1.2 recogen los resultados de todas ellas.

\footnotetext{
${ }^{54}$ Los listados completos de este análisis están detallados en el Anejo V.1.2 


\section{LÍMITE DE LA RIGIDEZ DEL REFUERZO}

El límite superior de la rigidez (Steinner) depende de la geometría y materiales de la vigueta y de la capa de compresión y corresponde al grado de conexión total. En la figura 24 se muestran los límites correspondientes a los casos ensayados en esta tesis.

\begin{tabular}{|c|c|c|c|c|c|c|c|c|}
\hline & \multicolumn{8}{|c|}{ LÍMITE DEL REFUERZO (CONEXIÓN TOTAL) } \\
\hline & \multirow{3}{*}{$\begin{array}{l}\text { TODOS } \\
\text { LOS } \\
\text { ENSAYOS }\end{array}$} & \multicolumn{4}{|c|}{ MATERIALES } & \multirow{2}{*}{\multicolumn{3}{|c|}{$\begin{array}{c}\text { GEOMETRÍA } \\
\text { ESBELTEZ }\end{array}$}} \\
\hline & & \multicolumn{2}{|c|}{ VIGUETA } & \multicolumn{2}{|c|}{ C.COMPRESIÓN } & & & \\
\hline & & LAMINADA & ASERRADA & HORMIGÓN & M. MICRO. & $\lambda=18$ & $\lambda=20$ & $\lambda=23$ \\
\hline № ENSAYOS & $(85)$ & (48) & (37) & $(16)$ & (10) & $(43)$ & (20) & (22) \\
\hline media & $395 \%$ & $383 \%$ & $411 \%$ & $396 \%$ & $315 \%$ & $362 \%$ & $404 \%$ & $453 \%$ \\
\hline CoV & $13 \%$ & $11 \%$ & $14 \%$ & $3 \%$ & $7 \%$ & $10 \%$ & $8 \%$ & $8 \%$ \\
\hline
\end{tabular}

figura 24. Mejoras de rigidez según el material de la capa de compresión ${ }^{55}$

Los valores máximos de rigidez con este refuerzo pueden llegar ser 4,53 veces la rigidez de la vigueta sin refuerzo. ${ }^{56}$

Con el mismo nivel de conexión, la mejora de rigidez será mayor cuanto menor sea la rigidez de la vigueta (madera aserrada), mayor sea la rigidez de la capa de compresión (hormigón) y mayor sea la esbeltez de la pieza ( $\lambda$ 23). No obstante, esto no tiene una gran influencia a la hora de proyectar un refuerzo, ya que en el caso de un forado existente, excepto el material de la capa de compresión, todos los parámetros están impuestos.

\section{MEJORAS DE RIGIDEZ CON LAS DIFERENTES CONEXIONES ESTUDIADAS}

Una vez obtenida la cota superior de rigidez del refuerzo, como ni en la esbeltez ni en la rigidez de la vigueta se puede influir, el análisis se centra a partir de ahora solo en los aspectos que se pueden proyectar.

\section{TIPOS DE CONECTORES}

En la figura 25 se muestran las mejoras de rigidez de los distintos tipos de conectores utilizados (el 100\% lo representa la rigidez de la vigueta sin refuerzo).

\footnotetext{
${ }^{55}$ En la comparación del material de la capa de compresión, para hacerla entre ensayos homogéneos, en la madera microlaminada solo se incluyen las vigas con esbeltez 18 y vigueta de madera laminada, ya que en hormigón solo se ha trabajado con esta esbeltez.

${ }^{56}$ Estos son valores medios, la rigidez de la conexión total oscila entre $501 \%$ y el $288 \%$.
} 


\begin{tabular}{|c|c|c|c|c|c|c|c|c|c|c|c|c|c|c|c|c|}
\hline & \multicolumn{16}{|c|}{ MEJORAS DE CONEXIÓN EN ELS $(1,25 \mathrm{kN} / \mathrm{m})$} \\
\hline & \multicolumn{4}{|c|}{ TIRAFONDOS CON RESINA (15 } & \multicolumn{4}{|c|}{ BARRA CON RESINA (2 } & \multicolumn{4}{|c|}{ CLAVOS (12 ENSAYOS) } & \multicolumn{4}{|c|}{ TORNILLOS (56 ENSAYOS) } \\
\hline & \multirow{2}{*}{\multicolumn{2}{|c|}{$\begin{array}{l}\text { C.C. HORMIGÓN } \\
10 \text { ENSAYOS }\end{array}$}} & \multirow{2}{*}{\multicolumn{2}{|c|}{$\begin{array}{l}\text { C.C.MICROLAM. } \\
5 \text { ENSAYOS }\end{array}$}} & \multirow{2}{*}{\multicolumn{2}{|c|}{$\begin{array}{l}\text { C.C. HORMIGÓN } \\
2 \text { ENSAYOS }\end{array}$}} & \multirow{2}{*}{\multicolumn{2}{|c|}{\begin{tabular}{|c|} 
C.C.MICROLAM. \\
-
\end{tabular}}} & \multirow{2}{*}{\multicolumn{2}{|c|}{$\begin{array}{l}\text { C.C. HORMIGÓN } \\
4 \text { ENSAYOS }\end{array}$}} & \multirow{2}{*}{\multicolumn{2}{|c|}{$\begin{array}{l}\text { C.C.MICROLAM. } \\
8 \text { ENSAYOS }\end{array}$}} & \multirow{2}{*}{\multicolumn{2}{|c|}{\begin{tabular}{|c|} 
C.C. HORMIGÓN \\
-
\end{tabular}}} & \multirow{2}{*}{\multicolumn{2}{|c|}{$\begin{array}{l}\text { C.C.MICROLAM. } \\
56 \text { ENSAYOS }\end{array}$}} \\
\hline & & & & & & & & & & & & & & & & \\
\hline & $\begin{array}{c}\text { RESPECTO } \\
\text { VIGUETA } \\
\end{array}$ & $\Psi$ & \begin{tabular}{|c|} 
RESPECTO \\
VIGUETA
\end{tabular} & $\underset{4}{\Psi}$ & \begin{tabular}{|c|} 
RESPECTO \\
VIGUETA
\end{tabular} & $\Psi$ & & & \begin{tabular}{|c|} 
RESPECTO \\
VIGUETA
\end{tabular} & $\Psi$ & $\begin{array}{l}\text { RESPECTO } \\
\text { VIGUETA }\end{array}$ & $\Psi$ & & & $\begin{array}{l}\text { RESPECTO } \\
\text { VIGUETA }\end{array}$ & $\Psi$ \\
\hline MEDIA & $217 \%$ & $66 \%$ & $244 \%$ & $83 \%$ & $182 \%$ & $54 \%$ & - & - & $167 \%$ & $48 \%$ & $265 \%$ & $83 \%$ & - & - & $271 \%$ & $78 \%$ \\
\hline CoV & $13 \%$ & $14 \%$ & $9 \%$ & $5 \%$ & $11 \%$ & $18 \%$ & - & - & $3 \%$ & $5 \%$ & $8 \%$ & $8 \%$ & - & - & $26 \%$ & $21 \%$ \\
\hline
\end{tabular}

figura 25. Mejoras de rigidez según el tipo de conector

Los sistemas que consiguen una menor conexión entre vigueta y capa de compresión, y por tanto, menor mejora de rigidez son los compuestos por barra corrugada encolada con capa de compresión hormigón (no hay longitud de anclaje que permita conectarse correctamente) y clavos con capa de compresión de hormigón (sistema con poca rigidez). Se puede apreciar, que esta situación, que ha resultado ser la menos eficaz de todos los ensayos realizados se está obteniendo unos grados de conexión del orden del $50 \%$.

En general, los refuerzos con capa de compresión de madera microlaminada consiguen unos mayores grados de conexión que los de capa de compresión de hormigón.

\section{SEPARACIÓN ENTRE CONECTORES, ESBELTEZ Y PRESIÓN}

Se presentan aquí los ensayos realizados con tornillos, ya que es el tipo con más ensayos realizados (56 ensayos). En primer lugar se hace una diferenciación entre los dos tipos de tornillos empleados (HBS, con cabeza cónica y VGZ, con cabeza cilíndrica):

\begin{tabular}{|c|c|c|c|c|c|c|}
\hline & \multirow{2}{*}{\multicolumn{2}{|c|}{$\begin{array}{l}\text { TORNILLOS } \\
56 \text { ENSAYOS }\end{array}$}} & \multirow{2}{*}{\multicolumn{2}{|c|}{$\begin{array}{c}\text { TORNILLOS HBS } \\
29 \text { ENSAYOS }\end{array}$}} & \multirow{2}{*}{\multicolumn{2}{|c|}{$\begin{array}{c}\text { TORNILLOS VGZ } \\
27 \text { ENSAYOS }\end{array}$}} \\
\hline & & & & & & \\
\hline & $\begin{array}{c}\text { RESPECTO } \\
\text { VIGUETA }\end{array}$ & $\Psi$ & $\begin{array}{c}\text { RESPECTO } \\
\text { VIGUETA }\end{array}$ & $\underset{\text { CONEX }}{\Psi}$ & $\begin{array}{c}\text { RESPECTO } \\
\text { VIGUETA }\end{array}$ & $\Psi$ \\
\hline MEDIA & $271 \%$ & $78 \%$ & $256 \%$ & $74 \%$ & $286 \%$ & $82 \%$ \\
\hline CoV & $26 \%$ & $21 \%$ & $28 \%$ & $26 \%$ & $23 \%$ & $15 \%$ \\
\hline
\end{tabular}

figura 26. Mejora de rigidez según el tipo de tornillo

En general, las conexiones realizadas con tornillos VGZ consiguen mejores conexiones, ya que tienen rosca en todo su fuste, creando una mejor colaboración de la capa de compresión.

A continuación, en la figura 27, se analiza la mejora de rigidez debido al pretensado:

\begin{tabular}{|c|c|c|c|c|c|c|c|c|}
\hline & \multicolumn{4}{|c|}{ TORNILLOS HBS (29 ENSAYOS) } & \multicolumn{4}{|c|}{ TORNILLOS VGZ (27 ENSAYOS) } \\
\hline & \multirow{2}{*}{\multicolumn{2}{|c|}{$\begin{array}{l}\text { SIN PRESIÓN } \\
15 \text { ENSAYOS }\end{array}$}} & \multirow{2}{*}{\multicolumn{2}{|c|}{$\begin{array}{l}\text { CON PRESIÓN } \\
14 \text { ENSAYOS }\end{array}$}} & \multirow{2}{*}{\multicolumn{2}{|c|}{$\begin{array}{l}\text { SIN PRESIÓN } \\
15 \text { ENSAYOS }\end{array}$}} & \multirow{2}{*}{\multicolumn{2}{|c|}{$\begin{array}{l}\text { CON PRESIÓN } \\
12 \text { ENSAYOS }\end{array}$}} \\
\hline & & & & & & & & \\
\hline & $\begin{array}{c}\text { RESPECTO } \\
\text { VIGUETA } \\
\end{array}$ & $\underset{\% \text { CONEX }}{\Psi}$ & \begin{tabular}{|l|} 
RESPECTO \\
VIGUETA \\
\end{tabular} & $\underset{\% \operatorname{CONEX}}{\Psi}$ & \begin{tabular}{|c|} 
RESPECTO \\
VIGUETA
\end{tabular} & $\underset{\% \text { CONEX }}{\Psi}$ & $\begin{array}{l}\text { RESTEC } \\
\text { TO } \\
\text { VIGIF }\end{array}$ & $\Psi$ \\
\hline MEDIA & $211 \%$ & $61 \%$ & $298 \%$ & $87 \%$ & $276 \%$ & $78 \%$ & $299 \%$ & $86 \%$ \\
\hline CoV & $24 \%$ & $27 \%$ & $22 \%$ & $14 \%$ & $23 \%$ & $15 \%$ & $23 \%$ & $13 \%$ \\
\hline
\end{tabular}

figura 27. Mejora de rigidez CON/SIN presión 
Si no se incluye la mejora del pretensado, ya se ha visto que la conexión es mejor con el tornillo VGZ, sin embargo, al crear una presión con los tornillos entre la vigueta y la capa de compresión las mejoras de rigidez se igualan. Esto es debido a que los tornillos HBS, que debido a su caña lisa conectan menos la vigueta y la capa de compresión, sin embargo, gracias a su cabeza cónica, ofrecen unas mejoras muy notables con el efecto del pretensado. Por todo esto se puede suponer que el tornillo óptimo para la conexión debería tener rosca en todo el fuste y la cabeza cónica, para poder unir los efectos de uno y otro tornillo.

Ahora sin tener en cuenta el efecto del pretensado se analizan las diferentes separaciones entre los conectores:

\begin{tabular}{|c|c|c|c|c|c|c|}
\hline & \multicolumn{6}{|c|}{ TORNILLOS SIN PRESIÓN (30 ENSAYOS) } \\
\hline & \multirow{2}{*}{\multicolumn{2}{|c|}{$\begin{array}{c}S=70 \mathrm{~mm} \\
10 \text { ENSAYOS }\end{array}$}} & \multirow{2}{*}{\multicolumn{2}{|c|}{$\begin{array}{c}S=140 \mathrm{~m} \mathrm{~m} \\
10 \text { ENSAYOS }\end{array}$}} & \multirow{2}{*}{\multicolumn{2}{|c|}{$\begin{array}{c}S=280 \mathrm{~mm} \\
10 \text { ENSAYOS }\end{array}$}} \\
\hline & & & & & & \\
\hline & $\begin{array}{c}\text { RESPECTO } \\
\text { VIGUETA }\end{array}$ & $\underset{\% \text { CONEX }}{\Psi}$ & $\begin{array}{c}\text { RESPECTO } \\
\text { VIGUETA }\end{array}$ & $\underset{\% \text { CONEX }}{\Psi}$ & $\begin{array}{c}\text { RESPECTO } \\
\text { VIGUETA }\end{array}$ & $\underset{\% \mathrm{CONE}}{\Psi}$ \\
\hline DI & $291 \%$ & $81 \%$ & $0 \%$ & $70 \%$ & $89 \%$ & $54 \%$ \\
\hline CoV & $21 \%$ & $14 \%$ & $21 \%$ & $17 \%$ & $18 \%$ & $26 \%$ \\
\hline
\end{tabular}

figura 28. Mejora de rigidez según la separación entre conectores

Por último, en la figura 29 se muestran las mejoras de rigidez ofrecidas por los tornillos (sin presión) en las diferentes esbelteces:

\begin{tabular}{|c|c|c|c|c|c|c|}
\hline & \multicolumn{6}{|c|}{ TORNILLOS SIN PRESIÓN (30 ENSAYOS) } \\
\hline & \multirow{2}{*}{\multicolumn{2}{|c|}{$\begin{array}{c}\lambda=18\left(C_{\text {vig }}=14\right) \\
6 \text { ENSAYOS }\end{array}$}} & \multirow{2}{*}{\multicolumn{2}{|c|}{$\begin{array}{c}\lambda=20\left(C_{\mathrm{vig}}=12\right) \\
12 \text { ENSAYOS }\end{array}$}} & \multicolumn{2}{|c|}{$\lambda=23\left(C_{\text {vig }}=10\right)$} \\
\hline & & & & & & \\
\hline & $\begin{array}{l}\text { RESPECTO } \\
\text { VIGUETA }\end{array}$ & $\underset{\% \text { CONEX }}{\Psi}$ & \begin{tabular}{|c|} 
RESPECTO \\
VIGUETA \\
\end{tabular} & $\underset{\% \text { CONEX }}{\Psi}$ & \begin{tabular}{|c|} 
RESPECTO \\
VIGUETA \\
\end{tabular} & $\Psi$ \\
\hline MEDIA & $201 \%$ & $62 \%$ & $230 \%$ & $68 \%$ & $296 \%$ & $78 \%$ \\
\hline CoV & $25 \%$ & $34 \%$ & $23 \%$ & $21 \%$ & $20 \%$ & $13 \%$ \\
\hline
\end{tabular}

figura 29. Mejora de rigidez según la esbeltez de la viga

Los refuerzos ofrecen una mayor mejora de la rigidez cuanto mayor es la esbeltez del forjado. 


\section{CAPÍTULO 6. - MÉTODO DE CÁLCULO}

6.0 INTRODUCCIÓN

6.0.1 EL DESLIZAMIENTO EN EL CÁLCULO DE FORJADOS REFORZADOS

6.0.2 ASPECTOS ESENCIALES DEL MÉTODO GAMMA

6.1 BASE DE PARTIDA

6.1.1 DESCRIPCIÓN

6.1.2 PRESENTACIÓN GRÁFICA DEL RESULTADO BUSCADO

6.1.3 REPRESENTACIÓN GRÁFICA GENERAL DEL PROCESO

6.2 LÍMITES DE ESTE TIPO DE REFUERZO

6.3 RIGIDEZ NECESARIA PARA NO EXCEDER LA FLECHA LÍMITE

6.3.1 LEY DE VARIACIÓN DE LA FLECHA EN FUNCIÓN DEL GRADO DE CONEXIÓN

6.3.2 RELACIÓN ENTRE RIGIDEZ CON CONEXIÓN FLEXIBLE (EI $I_{C F}$ Y Y SIN CONEXIÓN (EI $I_{S C}$ )

6.3.3 REPRESENTACIÓN GRÁFICA

6.4 RELACIÓN ENTRE MOMENTOS DE FLEXIÓN PROPIA Y EL MOMENTO TOTAL

6.5 REPARTO DEL MOMENTO DE FLEXIÓN PROPIA ENTRE LAS PARTES

6.6 ESTUDIO DE LAS DEFORMACIONES UNITARIAS $\varepsilon_{M}$, CURVATURA Y GIRO

6.6.1 DEFORMACIONES UNITARIAS DE LA SECCIÓN

6.6.2 CURVATURA DE LA SECCIÓN

6.6.3 GIRO EN EL EXTREMO DE LA PIEZA

6.7 DESLIZAMIENTO DE LA CONEXIÓN

6.7.1 DESLIZAMIENTO DEBIDO A LAS DEFORMACIONES UNITARIAS DE FLEXIÓN

6.7.2 DESLIZAMIENTO DEBIDO A LAS DEFORMACIONES UNITARIAS DE COMPRESIÓN Y TRACCIÓN

6.7.3 DESLIZAMIENTO FINAL

6.7.4 REPRESENTACIÓN GRÁFICA

6.8 PAR DE FUERZAS $N \cdot z$

6.8.1 AXIL EN LA CAPA DE COMPRESIÓN Y LA VIGUETA PARA FORMAR EL PAR

6.8.2 DEFORMACIÓN UNITARIA AXIAL $\varepsilon_{N}$ 
6.8.2 REPRESENTACIÓN GRÁFICA DE LOS TRES MOMENTOS

\subsection{ESFUERZO RASANTE}

6.9.1 VALORACIÓN

6.9.2 RELACIÓN ENTRE EL DESLIZAMIENTO Y EL RASANTE

6.10 RIGIDEZ DE LA CONEXIÓN Y CONCLUSIÓN

6.11 APROXIMACIÓN DE LA RIGIDEZ OBTENIDA POR EL MÉTODO GAMMA 
Este texto es un escrito inédito, realizado tras la conclusión del Proyecto de Investigación "BIA 2004 07317: Definición de un protocolo para la rehabilitación de forjados de madera mediante conexión con la nueva capa de compresión de hormigón" cuyo investigador principal fue el primer firmante y en el que el segundo fue contratado para llevar a cabo los ensayos de laboratorio. Ha sido redactado conjuntamente por los autores como texto de apoyo a la conclusión de los trabajos de laboratorio durante la elaboración de esta tesis doctoral "La viga mixta con madera: verificación experimental del método gamma y estudio de posibles alternativas de análisis".

\section{ALTERNATIVA AL MÉTODO PROPUGNADO POR LA NORMATIVA EUROPEA PARA EL REFUERZO DE VIGUETAS DE MADERA CON CAPA DE COMPRESIÓN CONECTADA}

Tales vs gamma

José Miguel Ávila Jalvo y Miguel Ávila Nieto

\subsection{INTRODUCCIÓN}

Una forma frecuente de reforzar forjados de madera es añadirles una capa de compresión de hormigón o de madera microlaminada conectada a sus viguetas.

Nuestro estudio experimental de este refuerzo comenzó con una serie de ensayos en el laboratorio de Estructuras de la ETSAM a raíz del Proyecto de Investigación BIA 200407317 cuyo investigador principal fue el primer firmante y en el que el segundo fue contratado para llevarlos a cabo y aplicarlos en su tesis doctoral. De ello se ha llegado a unas determinaciones que podrían matizar el procedimiento de cálculo seguido en la actualidad para estas estructuras y que figura en el Eurocódigo EC-5 (Anexo B).

En este escrito se deduce que, como las deformaciones del forjado (flecha, giros y deslizamiento de la conexión) están relacionadas, del mismo modo que lo están los esfuerzos (momentos, normales y rasantes), y todos entre sí a través de deformaciones y tensiones 
unitarias, tiene que haber un camino que asocie a la rigidez a flexión con la rigidez a deslizamiento de la conexión directamente. Cosa que el modelo actual normalizado no alcanza.

Para llegar a estas conclusiones, y de forma similar a los modelos empleados habitualmente para este tipo de refuerzo y muy concretamente el seguido en el Eurocódigo EC-5, se toma como base de partida:

- la compatibilidad de deformaciones entre vigueta y capa de compresión,

- el comportamiento lineal de los materiales así como el de la conexión y

- que la conexión es continua, dada la pequeña capacidad individual de los conectores que consecuentemente lleva a emplear muchos y cercanos.

Se comienza enunciando el problema a resolver, describiendo someramente el denominado 'método gamma', actualmente en vigor, analizando sus limitaciones y su imposibilidad de desarrollar con él el modelo continuo que aquí desarrollamos y se pasa a desarrollar el modelo que se somete a consideración como alternativo.

\subsubsection{EL DESLIZAMIENTO EN EL CÁLCULO DE FORJADOS REFORZADOS}

La rigidez a flexión de una vigueta de madera (generalmente isostática) cuyo material, carga y geometría son conocidos, se determina de manera inmediata. Lo mismo ocurre si se reforzara con una capa de compresión que no deslizase, pues una vez homogeneizados los materiales basta obtener la profundidad de la fibra neutra y aplicar el teorema de Steiner. También, si no hubiera conexión ni rozamiento, por tratarse de dos vigas que repartirán la carga total para que ambas adquieran la misma deformación. Pero entre ambas situaciones, en las que unos conectores hacen que el deslizamiento quede limitado, como es el caso de los forjados de madera, debe determinarse la rigidez de la conexión y asociarla a la rigidez de flexión para poder abordar el cálculo. Establecer cómo modifica la rigidez de la conexión a la rigidez de flexión, para con esta poder determinar flecha, tensiones etc... es lo que aquí se trata.

\subsubsection{ASPECTOS ESENCIALES DEL MÉTODO GAMMA}

El enfoque del denominado 'método gamma', desarrollado a mediados del siglo XX por Newmark [ref. 113] y Möhler [ref. 104] y propugnado por el Eurocódigo 5, es introducir un factor penalizador ' $\gamma$ ' (que varía entre 0 y 1 ), el cual reduce la rigidez axial $(E A)_{c c}$ de la capa de compresión cuanta menos cantidad de conexión se coloque. 
Se comienza eligiendo unos conectores y su separación; con ellos se obtiene su rigidez de conexión, que se denomina $\mathrm{K}_{\text {uni, }}$ cuyo valor figura en la normativa y procede de estudios experimentales (es función de los materiales que forman vigueta y capa de compresión, y del tipo, diámetro y separación entre conectores); con ella y con las características de la pieza, se calcula un factor penalizador ' $\gamma$ ' que reduce la rigidez axil $\left(E A_{c c}\right)$ de la capa de compresión tanto más cuanta menos conexión haya, y con esta corrección de dimensiones se determina la rigidez a flexión $\mathrm{EI}_{\mathrm{ef}}$ con la que se calcula la pieza. A partir de ahí, se sigue el procedimiento habitual. Por ejemplo, con la rigidez corregida $\left[\mathrm{EI}_{\mathrm{ef}}=\varphi\left(\mathrm{K}_{\mathrm{uni}}\right)\right]$, la flecha de flexión para viga doblemente apoyada y carga uniformes es:

$$
\delta=\left(\frac{5 \mathrm{qL}^{4}}{384\left[\mathrm{EI}_{\mathrm{ef}}=\varphi\left(\mathrm{K}_{\mathrm{uni}}\right)\right]}\right)
$$

Esta rigidez a flexión queda situada entre un límite inferior (las dos partes sin conexión) y un límite superior (las dos partes sin deslizamiento).

Para obtener la rigidez $\mathrm{EI}_{\mathrm{ef}}$, en función de la rigidez $\mathrm{K}_{\mathrm{uni}}$ de la conexión el método gamma integra un sistema de ecuaciones diferenciales acudiendo al conocido camino de sustituir la ley de carga uniforme por otra sinusoidal. Para lo que interesa en este apartado, se puede resumir así:

con una ley de carga $\quad \mathrm{q}_{\mathrm{x}}=\sin \left(\frac{\pi \mathrm{x}}{\mathrm{L}}\right)$

cuya ley de momentos es $\quad \mathrm{M}_{\mathrm{x}}=\mathrm{M}_{0} \cdot \sin \left(\frac{\pi \mathrm{x}}{\mathrm{L}}\right)$

la flecha vale

$$
\delta_{0}=\frac{\mathrm{q}_{0} \cdot \mathrm{L}^{4}}{\pi^{4} \cdot \mathrm{EI}_{\mathrm{ef}}}
$$

donde $\mathrm{EI}_{\mathrm{ef}}$ es $\quad \mathrm{EI}_{\mathrm{ef}}=\mathrm{EI}_{\mathrm{cc}}+\mathrm{EI}_{\mathrm{vig}}+\frac{\gamma \mathrm{E}_{\mathrm{cc}} \mathrm{A}_{\mathrm{cc}} \cdot \mathrm{E}_{\mathrm{vig}} \mathrm{A}_{\mathrm{vig}}}{\gamma \mathrm{E}_{\mathrm{cc}} \mathrm{A}_{\mathrm{cc}}+\mathrm{E}_{\mathrm{vig}} \mathrm{A}_{\mathrm{vig}}} \cdot \mathrm{z}^{2}$

Siendo 'cc' y 'vig' los subíndices que representan a la capa de compresión y a la vigueta,

' $z^{\prime}=\left(h_{c c}+h_{\text {vig }}\right) / 2$

y ' $\gamma$ ' un coeficiente penalizador, que da nombre al método y que, como se ha indicado, reduce una de las secciones (habitualmente la capa de compresión), para que la rigidez a flexión se vea reducida en la proporción asociada al deslizamiento; por decirlo así, es un elemento de homogeneización similar al $\left[\rho=\mathrm{E}_{\mathrm{cc}} / \mathrm{E}_{\mathrm{vig}}\right.$ ] empleado para trabajar con dos materiales en secciones mixtas sin deslizamiento. Su valor se obtiene mediante:

$$
\gamma=\frac{1}{1+\frac{\pi^{2} \cdot E_{c c} A_{c c}}{K_{u n i} \cdot L^{2}}}
$$


Quedando así relacionada la rigidez $\mathrm{EI}_{\mathrm{ef}}$ con la rigidez $\mathrm{K}_{\mathrm{uni}}{ }^{57}$

Estas expresiones tienen el inconveniente de que no se pueden recorrer en el sentido natural de dimensionado de estructuras que es el siguiente:

- con la flecha a cumplir se calcula la rigidez necesaria a flexión 'EI'

- con esta la rigidez necesaria a deslizamiento ' $K_{\text {uni }}{ }^{\prime}$

- lo que permite elegir la conexión adecuada.

Por el contrario, se trata de un proceso de comprobación que obliga a trabajar por aproximaciones: se elige una conexión; se calcula su rigidez a deslizamiento; con ella, la rigidez a flexión y con esta, la flecha. Si es menor que la exigida, vale y si no, hay que volver a intentarlo. ${ }^{58}$

${ }^{57}$ También se puede determinar el deslizamiento en el extremo de la viga mediante:

$$
\vartheta_{0}=\frac{\pi \cdot \delta_{0}}{L} \cdot \frac{(\gamma-1) \cdot E_{v i g} A_{v i g}}{\gamma E_{c c} A_{c c}+E_{v i g} A_{v i g}} \cdot z
$$

58 Este método es válido para materiales elásticos, conexión continua y vigas doblemente apoyadas. 


\subsection{BASE DE PARTIDA}

\subsubsection{DESCRIPCIÓN}

El método alternativo que se desarrolla aquí surge de la siguiente cuestión: Si el descenso de vigueta y capa de compresión es el mismo, para que haya compatibilidad; si los materiales tienen un comportamiento lineal, o sea, sus deformaciones (unitarias, curvaturas, giros y flecha) siguen leyes lineales; eso supone que los esfuerzos (momentos, normales y rasantes) se relacionan con las tensiones y deformaciones linealmente. En consecuencia, tiene que haber un camino que asocie las dos rigideces (de flexión ' $E I^{\prime}$ y de deslizamiento ' $K_{\text {uni }}$ ') directamente, con exactitud no aproximadamente, $y$ en ambos sentidos (EI $\vee K_{\text {uni }} y$ también $\left.K_{\text {uni }} \triangleright E I\right)$.

Con ello, a la hora de proyectar para cumplir una flecha límite, se calcularía la rigidez a flexión (EI), con esta, la rigidez a deslizamiento, $\left(K_{\text {uni }}\right)$ y, para alcanzarlo, se elegirían unos conectores adecuados.

\subsubsection{PRESENTACIÓN GRÁFICA DEL RESULTADO BUSCADO}

Si se consiguiera esa relación mediante un proporcionalidad general, se tiene que poder representar gráficamente, como muestra la figura, porque todas estas relaciones elásticas no son sino proporciones entre triángulos, al alcance de Tales. La deducción de este gráfico es el objeto de este trabajo y en esencia marca el camino que hay que recorrer para cumplir una limitación de flecha en un forjado reforzado, cuyas rigideces propias de las viguetas y de la capa de compresión son conocidas, determinando la rigidez de la conexión con la que eso se consigue.

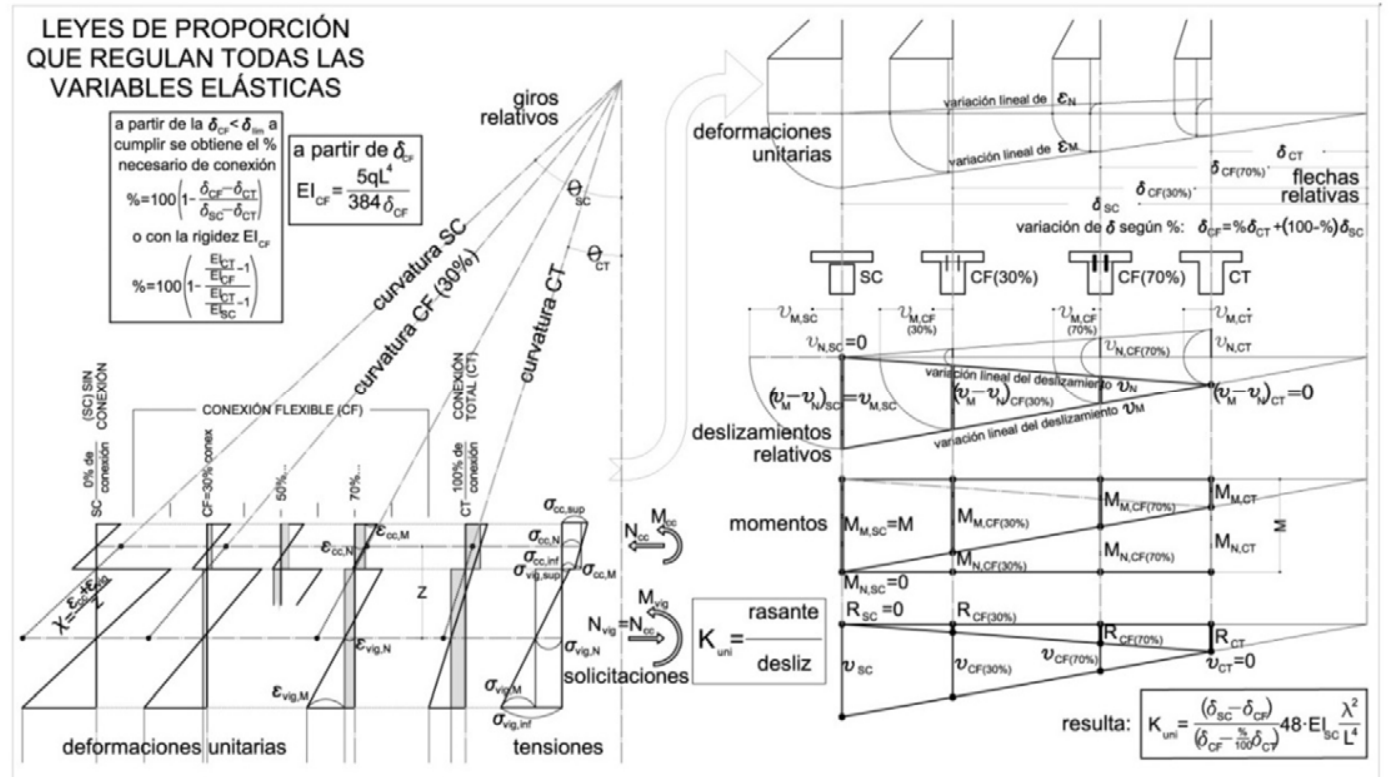

fig 1 


\subsubsection{REPRESENTACIÓN GRÁFICA GENERAL DEL PROCESO}

Todo el proceso analítico se expondrá también gráficamente. En la figura 2 se presenta la plantilla en la que se insertarán esos resultados. En horizontal se indica el índice, o grado, o cantidad, de conexión que se denominará ' $\psi$ ' (y que varía entre $0<\psi<1$ ). Sus extremos son el caso sin conexión $\psi=0$ (denominado SC) y situado a la izquierda, y el caso de conexión total $\psi=1$ (denominado $\mathrm{CT}$ ), a la derecha. En el eje vertical se irán introduciendo las distintas variables estudiadas en cada momento.

Con la vigueta existente y la capa de compresión que se haya elegido para reforzarla, ambas con sus dimensiones y materiales concretos, se obtienen los valores de cualquier variable para los grados de conexión total y nula, ya que no dependen del grado de conexión.

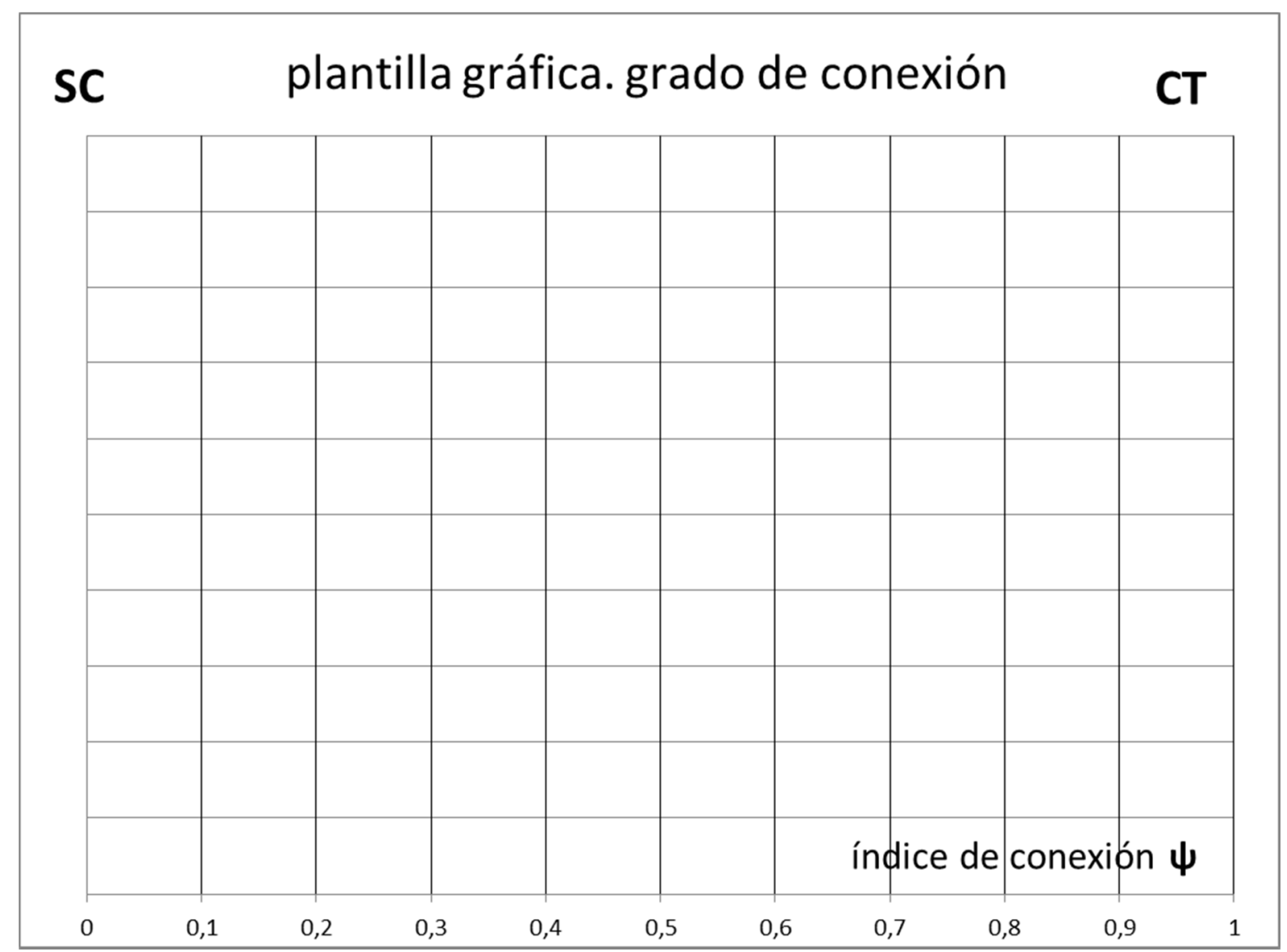

figura 2 


\subsection{LÍMITES DE ESTE TIPO DE REFUERZO}

Los valores extremos de la rigidez a flexión son: $\mathrm{EI}_{\text {mín }}$ y $\mathrm{EI}_{\text {máx. }} \mathrm{El}$ valor mínimo $\left(\mathrm{EI}_{\min }\right)$ se produce cuando no hay conexión entre capa de compresión y viguetas. Vale: ${ }^{59}$

$$
\mathrm{EI}_{\text {mín }}=\mathrm{EI}_{\mathrm{SC}}=\mathrm{E}_{\mathrm{cc}} \mathrm{I}_{\mathrm{cc}}+\mathrm{E}_{\mathrm{vig}} \mathrm{I}_{\mathrm{vig}}
$$

y con ella se alcanza la flecha máxima: ${ }^{60}$

$$
\delta_{\text {máx }}=\delta_{\mathrm{SC}}=\frac{5 \mathrm{qL}^{4}}{384 \mathrm{EI}_{\mathrm{SC}}}
$$

La máxima rigidez ( $\mathrm{EI}_{\text {máx }}$ ) se consigue cuando la capa de compresión está conectada totalmente a las viguetas por lo que no hay deslizamiento y la flecha es la mínima. Aplicando el teorema de Steiner: ${ }^{61}$

$$
\begin{gathered}
\mathrm{EI}_{\text {máx }}=\mathrm{EI}_{\mathrm{CT}}=\mathrm{EI}_{\mathrm{SC}}+(\mathrm{EA})_{\mathrm{vig}} \cdot \mathrm{a}_{\mathrm{vig}}{ }^{2}+(\mathrm{EA})_{\mathrm{cc}} \cdot \mathrm{a}_{\mathrm{cc}}{ }^{2} \\
\delta_{\text {mín }}=\delta_{\mathrm{CT}}=\frac{5 \mathrm{qL}^{4}}{384 \mathrm{EI}_{\mathrm{CT}}}
\end{gathered}
$$

En los casos intermedios, en los que la conexión no impide cierto deslizamiento, es en los que se centra este trabajo, que estudia la relación entre la rigidez a flexión de la pieza $\left(\mathrm{EI}_{\mathrm{CF}}\right){ }^{62}$ y la rigidez de la conexión $\left(\mathrm{K}_{\text {uni }}\right)$. Esta asocia esfuerzo rasante y deslizamiento siguiendo una relación lineal y sus valores los define la normativa o las casas comerciales, en los productos sometidos a patente.

\footnotetext{
${ }^{59}$ Los subíndices 'SC', 'CT' y 'CF' se emplearán a lo largo de este trabajo. 'SC' significa sin conexión.

${ }^{60}$ Obviamente, si no hay refuerzo, la flecha es aún mayor por ser solo de la vigueta. La carga, flecha, etc son las aplicadas sobre el refuerzo, sin que la historia anterior quede reflejada aquí, ni suponga limitaciones de tensiones o deformaciones. El estudio queda limitado a carga uniforme y pieza doblemente apoyada, pues es como se ha construido la inmensa mayoría de estos forjados de madera. No se incluye la rigidez a cortante.

${ }^{61}$ El subíndice 'CT' significa conexión total. Por otro lado, las variables $\mathrm{a}_{\mathrm{cc}}$ y $\mathrm{a}_{\mathrm{vig}}$ son las distancias desde los centros de gravedad de la capa de compresión y de la vigueta al centro de gravedad de la sección compuesta.

${ }^{62}$ El subíndice 'CF' significa conexión flexible en la que hay conexión pero también hay deslizamiento.
} 


\subsection{RIGIDEZ NECESARIA PARA NO EXCEDER LA FLECHA LÍMITE ${ }^{6}$}

La estructura reforzada debe tener la rigidez necesaria para cumplir una flecha límite $\delta_{\text {lím }}$ habitualmente establecida por la normativa. Si el forjado existente la cumple sin refuerzo ya es suficientemente rígido; si, reforzándolo al máximo con esta técnica, no la cumple, este refuerzo es insuficiente. Aquí se estudian los casos intermedios.

\subsubsection{LEY DE VARIACIÓN DE LA FLECHA EN FUNCIÓN DEL GRADO DE CONEXIÓN}

El punto de partida es el cumplimiento de una limitación de flecha $\left(\delta_{\lim }\right)$, al que corresponde una rigidez $\left(\mathrm{EI}_{\mathrm{lim}}\right)$, de modo que hay que reforzar la vigueta para que adquiera una rigidez suficiente $\left(\mathrm{EI}_{\mathrm{CF}} \geq \mathrm{EI}_{\text {lim }}\right)$, según la expresión:

$$
\mathrm{EI}_{\mathrm{CF}} \geq\left(\frac{5 \cdot \mathrm{qL}^{4}}{384 \cdot \delta_{\mathrm{lim}}}=\mathrm{EI}_{\mathrm{lím}}\right)
$$

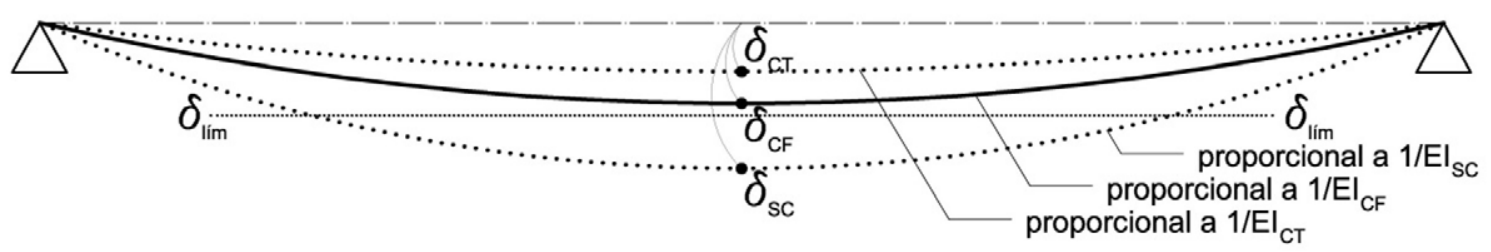

figura 3

a la que corresponde evidentemente una flecha $\delta_{\mathrm{CF}}$ cuya magnitud $\delta_{\mathrm{SC}} \geq \delta_{\mathrm{CF}} \geq \delta_{\mathrm{CT}}$ está situada entre la pieza sin conexión (SC) y con conexión total (CT).

$$
\delta_{\mathrm{CF}}=\left(\frac{5 \cdot \mathrm{qL}^{4}}{384 \cdot \mathrm{EI}_{\mathrm{CF}}} \leq \delta_{\mathrm{lim}}\right)
$$

\footnotetext{
${ }^{63}$ El dimensionado de un caso real obliga a diversas comprobaciones tanto en ELS como en ELU, además de incendio y largo plazo. Lo que se analiza aquí es solo el procedimiento genérico.
} 
Este trabajo toma como punto de partida el considerar que la flecha varía como función lineal de la cantidad de conexión. $O$ sea, cuando la cantidad de conexión $\psi$ varía entre 0 y 1 , el valor de la flecha varía linealmente con $\psi$ entre las flechas extremas $\delta_{\mathrm{SC}}$ y $\delta_{\mathrm{CT}}$ :

$$
\delta_{\mathrm{CF}}=(1-\psi) \delta_{\mathrm{SC}}+\psi \delta_{\mathrm{CT}}
$$

Esta linealidad es el lema del trabajo. Es solo una base de partida (como podría haberse optado porque la rigidez fuera lineal). Esa decisión solo obliga a que las relaciones elásticas que se desarrollan en el resto de este trabajo sean representadas de manera acorde con esta ley de variación de la flecha. Lo que se avanza que ocurrirá es que, como todas esas variables elásticas varían linealmente con la flecha (como se verá) se podrán representar también con líneas rectas con el consiguiente ahorro algebraico; al poder usar proporciones entre triángulos para relacionar diversas variables.

\subsubsection{RELACIÓN ENTRE RIGIDEZ CON CONEXIÓN FLEXIBLE (EI ${ }_{\text {CF }}$ Y Y SIN CONEXIÓN (EI}

La rigidez sin conexión $\left(\mathrm{EI}_{\mathrm{SC}}=\mathrm{EI}_{\mathrm{cc}}+\mathrm{EI}_{\mathrm{vig}}\right)$ conviene relacionarla ya con la rigidez -flexiblede la pieza reforzada $\left(\mathrm{EI}_{\mathrm{CF}}\right)$ ya que esta relación se aplicará en expresiones posteriores. Para ello, como las flechas son proporcionales (su índice de proporcionalidad es $5 \mathrm{qL}^{4} / 384$ ), resulta:

$$
\delta_{\mathrm{SC}} \propto \frac{1}{\mathrm{EI}_{\mathrm{SC}}} \quad \delta_{\mathrm{CF}} \propto \frac{1}{\mathrm{EI}_{\mathrm{CF}}} \quad \text { luego } \quad \frac{\mathrm{EI}_{\mathrm{SC}}}{\mathrm{EI}_{\mathrm{CF}}}=\frac{\delta_{\mathrm{CF}}}{\delta_{\mathrm{SC}}}
$$

y, en consecuencia, la relación queda:

$$
\mathrm{EI}_{\mathrm{SC}}=\mathrm{EI}_{\mathrm{cc}}+\mathrm{EI}_{\mathrm{vig}}=\frac{\delta_{\mathrm{CF}}}{\delta_{\mathrm{SC}}} \cdot \mathrm{EI}_{\mathrm{CF}}
$$

\subsubsection{REPRESENTACIÓN GRÁFICA}

En la figura 4 se representan las funciones de flecha y de rigidez para todos los grados de conexión. La flecha varía linealmente según la expresión:

$$
\delta_{\mathrm{CF}}=(1-\psi) \delta_{\mathrm{SC}}+\psi \delta_{\mathrm{CT}}
$$

y la rigidez varía hiperbólicamente:

$$
\mathrm{EI}_{\mathrm{CF}}=\frac{5 \cdot \mathrm{qL}^{4}}{384 \cdot \delta_{\mathrm{CF}}}
$$




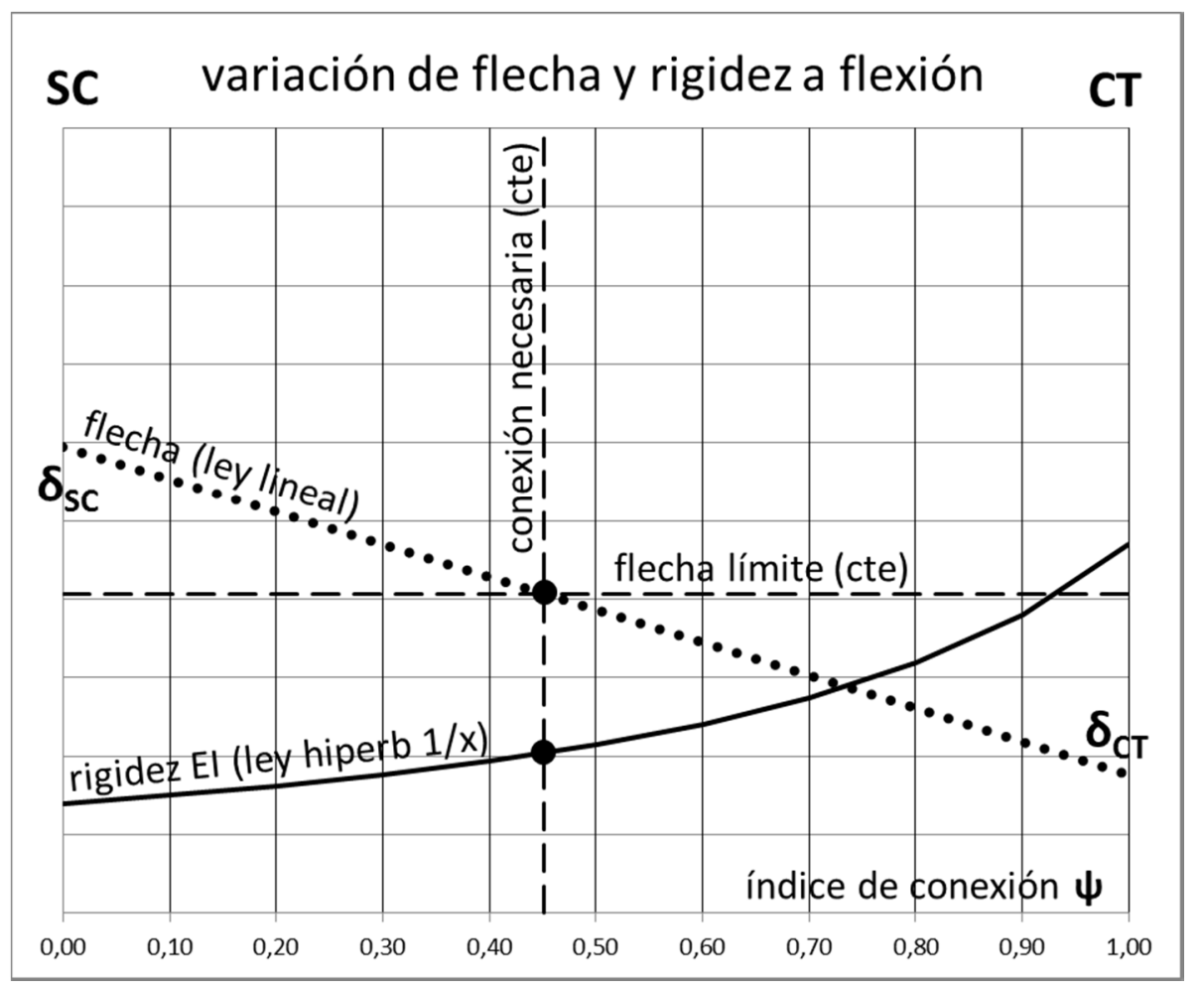

figura 4

En este gráfico quedan representadas las funciones de flecha y rigidez cada una con su escala vertical. Las flechas varían con el grado de conexión, desde un máximo $\left(\delta_{\mathrm{SC}}=\right.$ flecha de la viga sin conexión) hasta un mínimo ( $\delta_{\mathrm{CT}}=$ flecha de la viga con conexión total). Ambos extremos se unen con una recta, o si quiere, se calcula y representa la flecha con un conjunto de puntos obtenidos con la expresión [3].

A modo de explicación de uso se ha añadido una la línea horizontal situada (en escala de flechas) a la altura de la flecha límite a cumplir (por ejemplo $\delta_{\text {lím }}=L / 400$ ). En el cruce de estas dos rectas se está cumpliendo extrictamente la condición $\delta_{\mathrm{CF}}=\delta_{\text {lím }}$ y su cota horizontal marca el grado de conexión $\psi$ que necesita la viga reforzada. Analícamente el grado de conexión, deducido de [1] y [3] vale:

$$
\psi=\frac{\delta_{\mathrm{SC}}-\delta_{\mathrm{CF}}}{\delta_{\mathrm{SC}}-\delta_{\mathrm{CT}}}=\frac{1-\frac{\mathrm{EI}_{\mathrm{SC}}}{\mathrm{EI}_{\mathrm{CF}}}}{1-\frac{\mathrm{EI}_{\mathrm{SC}}}{\mathrm{EI}_{\mathrm{CT}}}}
$$

y queda expresado gráficamente con la recta vertical que pasa por el cruce de las dos líneas anteriores (en este ejemplo, $\psi=0,452$ ). Cuando se representen en este gráfico las lineas que describan las funciones futuras (deslizamientos, momentos, etc.) el valor necesario de cada una será el que marque su cruce con esa línea vertical. Como primer ejemplo, el punto de cruce entre esta linea vertical y la curva de rigidez EI indica el valor de esta que lleva a la flecha a cumplir. 


\subsection{RELACIÓN ENTRE MOMENTOS DE FLEXIÓN PROPIA Y EL MOMENTO TOTAL}

Este apartado estudia la sección central de la pieza reforzada sometida a un momento $\mathrm{M}$. Según el valor del grado de conexión $(\psi)$ se obtendrá el reparto de ese momento $(M)$ entre el momento resistido por el par de fuerzas $\left(\mathrm{M}_{N}=\mathrm{N} \cdot \mathrm{z}\right)$ y el momento resistido por las flexiones propias de la capa de compresión y de la vigueta $\left(M_{M}=M_{c c, M}+M_{\text {vig, }, M}\right)$.

Como se verá, los momentos resistidos por la flexión de la capa de compresión y la vigueta varían linealmente con la cantidad o grado de conexión.

Primero, las deformaciones unitarias de flexión $\varepsilon_{\mathrm{cc}, \mathrm{M}}$ y $\varepsilon_{\mathrm{vig}, \mathrm{M}}$ varían linealmente con la flecha $\delta_{\mathrm{CF}}$ que deba cumplir la pieza (que es la misma que la de la capa de compresión $\delta_{\mathrm{cc}, \mathrm{CF}}$ y de la vigueta $\delta_{\text {vig, CF }}$ por compatibilidad).

Efectivamente, concretándolo para la capa de compresión, y teniendo en cuenta:

$$
\varepsilon_{\mathrm{M}, \mathrm{cc}}=\frac{\sigma_{\mathrm{M}, \mathrm{cc}}}{\mathrm{E}_{\mathrm{cc}}}=\frac{\mathrm{M}_{\mathrm{M}, \mathrm{cc}}}{\left(\mathrm{E} \frac{\mathrm{I}}{\mathrm{y}}\right)_{\mathrm{cc}}} \quad\left(\mathrm{y}=\frac{\mathrm{h}}{2}\right)_{\mathrm{cc}} \quad \mathrm{EI}_{\mathrm{cc}}=\frac{5 \mathrm{q}_{\mathrm{M}, \mathrm{cc}} \mathrm{L}^{4}}{384 \cdot \delta_{\mathrm{CF}}}=\frac{5 \mathrm{M}_{\mathrm{M}, \mathrm{cc}} \mathrm{L}^{2}}{48 \cdot \delta_{\mathrm{CF}}}
$$

resulta, añadiendo también el resultado de la vigueta:

$$
\varepsilon_{\mathrm{M}, \mathrm{cc}}=\frac{24 \cdot \mathrm{h}_{\mathrm{cc}}}{5 \cdot \mathrm{L}^{2}} \cdot \delta_{\mathrm{CF}} \quad \varepsilon_{\mathrm{M}, \mathrm{vig}}=\frac{24 \cdot \mathrm{h}_{\mathrm{vig}}}{5 \cdot \mathrm{L}^{2}} \cdot \delta_{\mathrm{CF}}
$$

Luego, las deformaciones unitarias de flexión varían linealmente con la flecha.

Por otro lado, los momentos resistidos por la flexión propia $\left(M_{M}=M_{c c, M}+M_{v i g, M}\right)$ varían también linealmente con la flecha, puesto que, como ya se ha indicado:

$$
\delta_{\mathrm{CF}}=\frac{5 \mathrm{M}_{\mathrm{M}, \mathrm{cc}} \mathrm{L}^{2}}{48 \cdot \mathrm{EI}_{\mathrm{cc}}} \quad \text { y también } \quad \delta_{\mathrm{CF}}=\frac{5 \mathrm{M}_{\mathrm{M}, \mathrm{vig}} \mathrm{L}^{2}}{48 \cdot \mathrm{EI}_{\mathrm{vig}}}
$$

y, despejando los momentos:

$$
\mathrm{M}_{\mathrm{M}, \mathrm{cc}}=\frac{48 \cdot \mathrm{EI}_{\mathrm{cc}}}{5 \cdot \mathrm{L}^{2}} \cdot \delta_{\mathrm{CF}} \quad \mathrm{y} \quad \mathrm{M}_{\mathrm{M}, \mathrm{vig}}=\frac{48 \cdot \mathrm{EI}_{\mathrm{vig}}}{5 \cdot \mathrm{L}^{2}} \cdot \delta_{\mathrm{CF}}
$$

y sumándolos:

$$
\mathrm{M}_{\mathrm{M}, \mathrm{CF}}=\mathrm{M}_{\mathrm{M}, \mathrm{cc}}+\mathrm{M}_{\mathrm{M}, \mathrm{vig}}=\frac{48}{5 \cdot \mathrm{L}^{2}} \cdot\left(\mathrm{EI}_{\mathrm{cc}}+\mathrm{EI}_{\mathrm{vig}}\right) \cdot \delta_{\mathrm{CF}}=\frac{48}{5 \cdot \mathrm{L}^{2}} \cdot \mathrm{EI}_{\mathrm{SC}} \cdot \delta_{\mathrm{CF}}
$$


Finalmente, como el momento total $\mathrm{M}$ es constante y el momento resistido por las flexiones $\mathrm{M}_{\mathrm{M}}$ varía linealmente con la flecha, como representa la parte inferior de la figura 5, la relación entre los momentos de flexión propia y el momento total aplicado en la sección se obtiene de la siguiente proporcionalidad de triángulos:

$$
\mathrm{M}_{\mathrm{M}}=\frac{\delta_{\mathrm{CF}}}{\delta_{\mathrm{SC}}} \cdot \mathrm{M}
$$

y si en [5] se aplica [3], esa relación se presenta en función del grado de conexión $\psi$ :

$$
\frac{\mathrm{M}_{\mathrm{M}}}{\mathrm{M}}=1-\psi\left(1-\frac{\delta_{\mathrm{CT}}}{\delta_{\mathrm{SC}}}\right)
$$

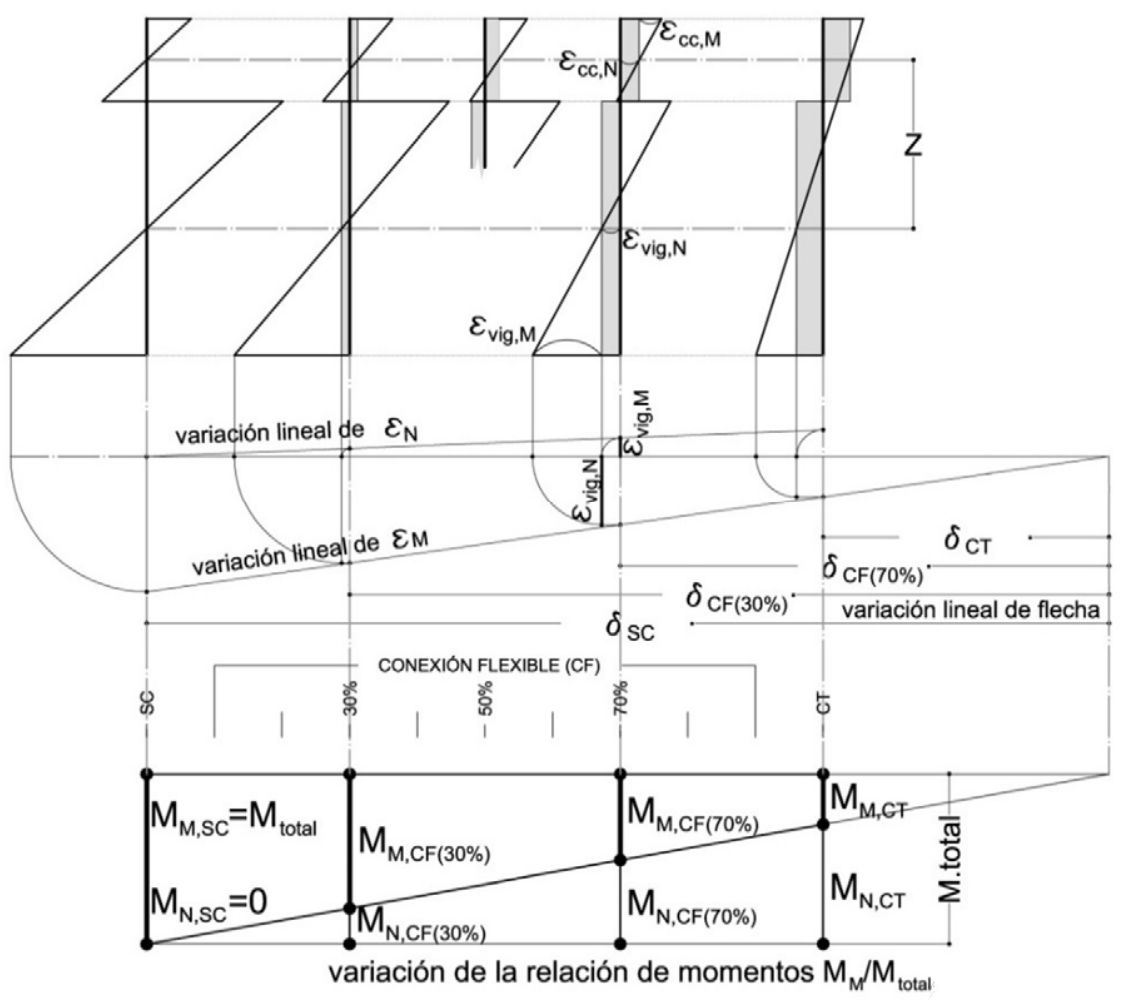

figura 5 


\subsection{REPARTO DEL MOMENTOS DE FLEXIÓN PROPIA ENTRE LAS PARTES}

La flecha debida a la flexión propia $\delta_{\mathrm{M}}$ es la misma que la de la capa de compresión $\delta_{\mathrm{M}, c c} \mathrm{Y}$ de la vigueta $\delta_{M, v i g,}$ por compatibilidad, luego: ${ }^{64}$

$$
\delta_{\mathrm{M}}=\frac{5 \mathrm{q}_{\mathrm{M}, \mathrm{cc}} \mathrm{L}^{4}}{384 \cdot \mathrm{EI}_{\mathrm{cc}}}=\frac{5 \mathrm{M}_{\mathrm{cc}} \mathrm{L}^{2}}{48 \cdot \mathrm{EI}_{\mathrm{cc}}} \quad=\quad \delta_{\mathrm{M}}=\frac{5 \mathrm{q}_{\mathrm{M}, \mathrm{vig}} \mathrm{L}^{4}}{384 \cdot \mathrm{EI}_{\mathrm{vig}}}=\frac{5 \mathrm{M}_{\mathrm{vig}} \mathrm{L}^{2}}{48 \cdot \mathrm{EI}_{\mathrm{vig}}}
$$

lo que se reduce a:

$$
\frac{M_{c c}}{E_{c c}}=\frac{M_{v i g}}{E_{\text {vig }}}
$$

y teniendo en cuenta (particularizando para la capa de compresión) que:

$$
\varepsilon_{\mathrm{M}, \mathrm{cc}}=\frac{\mathrm{M}_{\mathrm{cc}} \cdot \mathrm{h}_{\mathrm{cc}}}{2 \cdot \mathrm{EI}_{\mathrm{cc}}} \quad \mathrm{y} \text { despejando } \mathrm{M} \quad \mathrm{M}_{\mathrm{cc}}=\frac{2 \cdot \mathrm{EI}_{\mathrm{cc}} \cdot \varepsilon_{\mathrm{M}, \mathrm{cc}}}{\mathrm{h}_{\mathrm{cc}}}
$$

la parte del momento de flexión resistido por la capa de compresión vale: ${ }^{65}$

$$
\frac{\mathrm{M}_{\mathrm{cc}}}{\mathrm{M}_{\mathrm{cc}}+\mathrm{M}_{\mathrm{vig}}}=\frac{\mathrm{M}_{\mathrm{cc}}}{\mathrm{M}_{\mathrm{M}}}=\frac{\mathrm{EI}_{\mathrm{cc}}}{\mathrm{EI}_{\mathrm{cc}}+\mathrm{EI}_{\mathrm{vig}}}
$$

de lo que resultan las expresiones:

$$
\mathrm{M}_{\mathrm{cc}}=\frac{\mathrm{M}_{\mathrm{M}}}{1+\frac{\mathrm{EI}_{\mathrm{vig}}}{\mathrm{EI}_{\mathrm{cc}}}} \quad[7 \mathrm{a}] \quad \mathrm{y} \quad \mathrm{M}_{\mathrm{vig}}=\frac{\mathrm{M}_{\mathrm{M}}}{1+\frac{\mathrm{EI}_{\mathrm{cc}}}{\mathrm{EI}_{\mathrm{vig}}}}
$$

\footnotetext{
${ }^{64}$ Existe la posibilidad de que las fibras inferiores cercanas a las viguetas estén traccionadas, lo que en el caso de hormigón modificaría la descripción algebraica, que no se incluye aquí.

${ }^{65}$ las relaciones $\frac{\varepsilon_{\mathrm{M}, \mathrm{cc}}}{\mathrm{h}_{\mathrm{cc}}}=\frac{\varepsilon_{\mathrm{M}, \mathrm{vig}}}{\mathrm{h}_{\mathrm{vig}}}$ son iguales porque las curvaturas de capa de compresión y vigueta coinciden.
} 


\subsection{ESTUDIO DE LAS DEFORMACIONES UNITARIAS $\varepsilon_{\mathrm{M}}$, CURVATURA Y GIRO}

\subsubsection{DEFORMACIONES UNITARIAS DE LA SECCIÓN}

La deformación unitaria de la sección central de la viga, producida por la flexión de la capa de compresión $\left(\mathrm{M}_{\mathrm{cc}}\right)$ y la vigueta $\left(\mathrm{M}_{\mathrm{vig}}\right)$, aplicando [7a] y [7b] respectivamente, vale:

$$
\begin{gathered}
\varepsilon_{M, c c}=\frac{\sigma_{M, c c}}{E_{c c}}=\frac{h_{c c} M_{c c}}{2 \cdot E I_{c c}}=\frac{h_{c c}}{2 E I_{c c}} \cdot \frac{M_{M}}{1+\frac{E I_{v i g}}{E I_{c c}}}=\frac{h_{c c}}{2} \cdot \frac{M_{M}}{E I_{c c}+E I_{v i g}}=\frac{h_{c c}}{2} \cdot \frac{M_{M}}{E I_{s C}} \\
\varepsilon_{M, v i g}=\frac{h_{v i g}}{2} \cdot \frac{M_{M}}{E_{S C}}
\end{gathered}
$$

Sumándolas, haciendo $z=\left(h_{c c}+h_{\text {vig }}\right) / 2=h_{\text {tot }} / 2$ (véase figura 6), aplicando [5] y luego [2], resulta:

$$
\varepsilon_{\mathrm{cc}, \mathrm{M}}+\varepsilon_{\mathrm{vig}, \mathrm{M}}=\left(\frac{\mathrm{h}_{\mathrm{cc}}}{2}+\frac{\mathrm{h}_{\mathrm{vig}}}{2}\right) \frac{\mathrm{M}_{\mathrm{M}}}{\mathrm{EI}_{\mathrm{SC}}}=\frac{\mathrm{M}_{\mathrm{M}} \cdot \mathrm{z}}{\mathrm{EI}_{\mathrm{SC}}}=\frac{\mathrm{M} \cdot \mathrm{z}}{\mathrm{EI}_{\mathrm{SC}}} \cdot \frac{\delta_{\mathrm{CF}}}{\delta_{\mathrm{SC}}}=\frac{\mathrm{M} \cdot \mathrm{z}}{\mathrm{EI}_{\mathrm{CF}}}
$$

y teniendo en cuenta $\lambda=\mathrm{L} / \mathrm{h} \quad$ y $\delta=\left(5 \mathrm{M} \cdot \mathrm{L}^{2} /(384 \mathrm{EI})\right.$ y despejando en ella $\mathrm{M}=(384 \mathrm{EI} \cdot \delta) /\left(5 \mathrm{~L}^{2}\right)$ [válido sea cual sea el grado de conexión (léase, subíndices)], queda la expresión:

$$
\varepsilon_{\mathrm{cc}, \mathrm{M}}+\varepsilon_{\mathrm{vig}, \mathrm{M}}=\frac{\mathrm{M} \cdot \mathrm{z}}{\mathrm{EI}_{\mathrm{CF}}}=\frac{24}{5 \cdot \mathrm{L} \lambda} \cdot \delta_{\mathrm{CF}}
$$

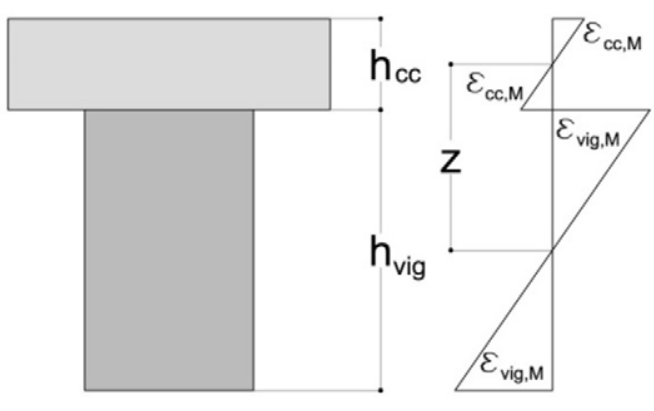

figura 6 


\subsubsection{CURVATURA DE LA SECCIÓN}

Usando como apoyo la figura 6, la curvatura tiene la siguiente expresión:

$$
\chi=\frac{\varepsilon_{\mathrm{cc}, \mathrm{M}}+\varepsilon_{\mathrm{vig}, \mathrm{M}}}{\mathrm{z}}
$$

y si se aplica en [8], resulta:

$$
\chi=\frac{\mathrm{M}}{\mathrm{EI}_{\mathrm{CF}}}=\frac{48 \cdot \delta_{\mathrm{CF}}}{5 \cdot \mathrm{L}^{2}}
$$

\subsubsection{GIRO EN EL EXTREMO DE LA PIEZA}

En una sección a distancia ' $x$ ' del extremo, en la que hay aplicado un momento $M_{x}$, el giro ' $\theta_{\mathrm{x}}{ }^{\prime}$ se obtiene integrando curvaturas desde el centro:

$$
\theta_{\mathrm{x}}=\int \chi \mathrm{dx}=\int \frac{\varepsilon_{\mathrm{cc}, \mathrm{M}}+\varepsilon_{\mathrm{vig}, \mathrm{M}}}{\mathrm{z}} \mathrm{dx}=\frac{1}{\mathrm{EI}_{\mathrm{CF}}} \int \mathrm{M}_{\mathrm{x}} \mathrm{dx}
$$

y sustituyendo ' $M_{x}$ ' (carga uniforme y pieza doblemente apoyada) $\quad M_{X}=\frac{q L}{2} x-\frac{q}{2} x^{2} \quad$ resulta:

$$
\theta_{\mathrm{x}}=\frac{1}{\mathrm{EI}_{\mathrm{CF}}} \cdot \frac{\mathrm{q}}{2} \int\left(\mathrm{Lx}-\mathrm{x}^{2}\right) \mathrm{dx}=\frac{1}{\mathrm{EI}_{\mathrm{CF}}} \cdot \frac{\mathrm{q}}{2}\left(\frac{\mathrm{Lx}^{2}}{2}-\frac{\mathrm{x}^{3}}{3}+\mathrm{C}\right)
$$

la constante de integración se despeja porque en el eje de la viga $(\mathrm{x}=\mathrm{L} / 2)$, por simetría, no hay giro:

$$
\left(\frac{\mathrm{L}^{3}}{8}-\frac{\mathrm{L}^{3}}{24}+\mathrm{C}\right)=0 \quad \text { luego } \quad \mathrm{C}=-\frac{\mathrm{L}^{3}}{12}
$$

quedando la expresión:

$$
\theta_{\mathrm{x}}=\frac{1}{\mathrm{EI}_{\mathrm{CF}}} \cdot \frac{\mathrm{q}}{2}\left(\frac{\mathrm{Lx}^{2}}{2}-\frac{\mathrm{x}^{3}}{3}-\frac{\mathrm{L}^{3}}{12}\right)
$$

en la que para $\mathrm{x}=0$ y conexión flexible (CF) se obtiene el giro en el extremo: ${ }^{66}$

$$
\theta_{0, \mathrm{CF}}=\frac{\mathrm{qL}^{3}}{24 \cdot \mathrm{EI}_{\mathrm{CF}}}
$$

y poniéndolo en función de la flecha $\delta_{\mathrm{CF}}$ resulta la expresión:

$$
\theta_{0, \mathrm{CF}}=\frac{16 \cdot \delta_{\mathrm{CF}}}{5 \cdot \mathrm{L}}
$$

\footnotetext{
${ }^{66}$ Se han omitido los signos de estas deformaciones por obvios en estas piezas elementales. La distancia entre los centros de gravedad de la capa de compresión y la vigueta se está denominando ' $z$ ' (la mitad del canto total de la vigueta reforzada) por similitud al empleado en la literatura propia de estos refuerzos, aunque no coincida con la definición establecida con carácter general en mecánica, que se identifica con la distancia entre la resultante de los bloques de tracciones y de compresiones.
} 


\subsection{DESLIZAMIENTO DE LA CONEXIÓN}

El deslizamiento de la conexión depende de dos factores que se contraponen: el deslizamiento de flexión $\left(\vartheta_{M}\right)$ causado por las deformaciones unitarias de la flexión $\left(\varepsilon_{\mathrm{cc}, \mathrm{M}}\right.$ y $\left.\varepsilon_{\mathrm{vig}, \mathrm{M}}\right)$ y la oposición al deslizamiento que ejerce el par $\mathrm{N} \cdot \mathrm{z},\left(\vartheta_{\mathrm{N}}\right)$ causado por las deformaciones unitarias axiales $\left(\varepsilon_{\mathrm{cc}, \mathrm{N}}\right.$ y $\left.\varepsilon_{\mathrm{vig}, \mathrm{N}}\right)$. Deslindar estos dos componentes del deslizamiento para ver de qué depende cada uno es el pilar en que se apoya el presente modelo.

La figura 7 muestra la gráfica de los deslizamientos para todos los grados de conexión $\psi$ y también que la variación de $\vartheta_{M}$ y $\vartheta_{N}$ es lineal, como se demostrará en los apartados siguientes. La recta BD describe la variación del deslizamiento debido a la flexión $\left(\vartheta_{M}\right)$ y pertenece al mismo triángulo $A B C$ que sirve de base tanto para representar los alargamientos unitarios de flexión (véase figura 5 ) como las flechas. La recta $A D$ que describe la variación del deslizamiento debido al par $\left(\vartheta_{N}\right)$ pasa por dos puntos: A, en la izquierda, donde se sitúa el estado sin conexión (SC) cuyo deslizamiento axial es nulo $\left(\vartheta_{\mathrm{N}, S C}=0\right)$ ya que el par lo es, $\mathrm{D}$, a la derecha, donde se sitúa la conexión total (CT) y cuyo deslizamiento tiene que ser igual al de flexión, ya que la diferencia entre ambos tiene que ser nula, pues en conexión total no hay deslizamiento $\left(\vartheta_{\mathrm{N}, \mathrm{CT}}=\vartheta_{\mathrm{M}, \mathrm{CT}}\right)$.

desarrollo gráfico del cálculo de los deslizamientos

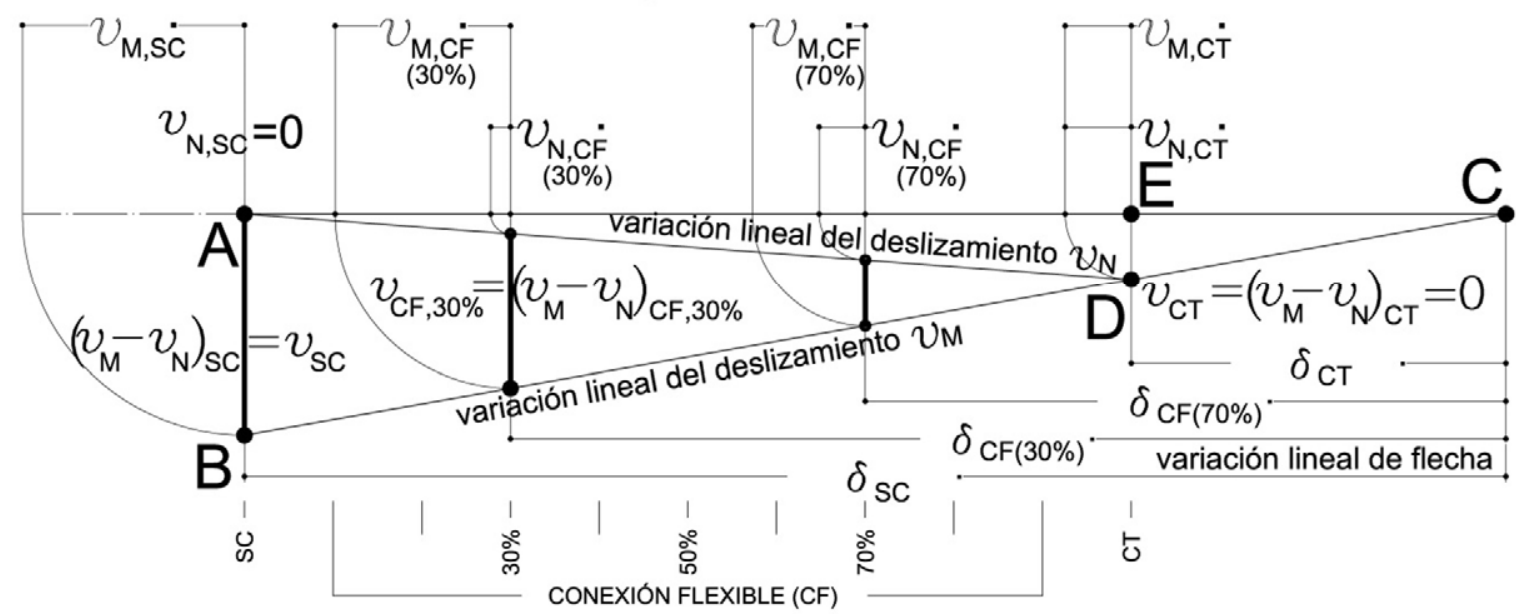

figura 7 


\subsubsection{DESLIZAMIENTO DEBIDO A LAS DEFORMACIONES UNITARIAS DE FLEXIÓN}

Siguiendo el mismo proceso analítico que con los giros se llega a una expresión similar a la [11] de aquel caso. Efectivamente, en una sección a distancia ' $x$ ' del extremo donde hay aplicado un momento $M_{x}$ el deslizamiento $v_{M}$ con conexión flexible (CF) es la integral de las deformaciones unitarias de flexión desde el centro, y tiene la siguiente expresión:

$$
\vartheta_{\mathrm{x}, \mathrm{M}}=\frac{\mathrm{z}}{\mathrm{EI}_{\mathrm{CF}}} \cdot \frac{\mathrm{q}}{2}\left(\frac{\mathrm{Lx}^{2}}{2}-\frac{\mathrm{x}^{3}}{3}-\frac{\mathrm{L}^{3}}{12}\right)
$$

y haciendo $x=0$ se obtiene la expresión del deslizamiento de flexión en el extremo:

$$
\vartheta_{0, \mathrm{M}, \mathrm{CF}}=\frac{8 \cdot \delta_{\mathrm{CF}}}{5 \cdot \lambda}
$$

donde:

$$
\lambda=\frac{\mathrm{L}}{\mathrm{h}_{\text {tot }}} \quad \mathrm{h}_{\text {tot }}=\left(\mathrm{h}_{\mathrm{cc}}+\mathrm{h}_{\text {vig }}\right) \quad y \quad \mathrm{z}=\frac{\mathrm{h}_{\text {tot }}}{2}
$$

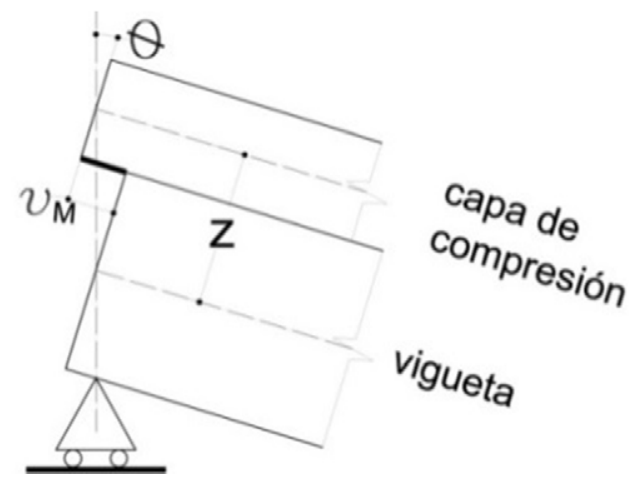

figura 8

NOTA: El giro en el extremo, obtenido de la integración de las curvaturas desde el centro de la viga, se calcula exclusivamente a partir del deslizamiento provocado SOLO por la flexión propia de la capa de compresión y de la vigueta $\left(\vartheta_{M}\right)$ sea cual sea el grado de conexión, puesto sus curvaturas $\left.\left[\left(\varepsilon_{M, c c}+\varepsilon_{M, v i g}\right) / z\right)\right]$ ya se han visto reducidas en una cantidad $\left[-\left(\varepsilon_{N, c c}+\varepsilon_{N, v i g}\right)\right]$ asociada a la existencia del par N'z que las ha minorado en la medida adecuada al grado de conexión que tengan. Para eliminar dudas, se puede acudir a la reducción al absurdo: Si el giro se relacionara con el deslizamiento total $\left(\vartheta=\vartheta_{M} \vartheta_{N}\right)$, en el caso de conexión total $(C T)$, al no haber deslizamiento (o sea $v_{M}-v_{N}=0$ ), tampoco habría giros... ni flecha. 


\subsubsection{DESLIZAMIENTO DEBIDO A LAS DEFORMACIONES UNITARIAS DE COMPRESIÓN Y TRACCIÓN}

El deslizamiento de las flexiones propias $\left(\vartheta_{\mathrm{M}, \mathrm{CF}}\right)$ se reduce en la cantidad $\left(\vartheta_{\mathrm{N}, \mathrm{CF}}\right)$ debido al trabajo del par de fuerzas $\mathrm{N}^{\prime} \mathrm{Z}$, y este varía de $\vartheta_{\mathrm{N}, \mathrm{CF}}=0$ (con SC) a $\vartheta_{\mathrm{N}, \mathrm{CF}}=\vartheta_{\mathrm{M}, \mathrm{CF}}(\operatorname{con} \mathrm{CT})$.

Para conexión flexible (CF) los valores de $\left(\vartheta_{N, C F}\right.$ y $\left.\vartheta_{M, C F}\right)$ se obtienen directamente aplicando las proporciones geométricas representadas en el triángulo ADE de la figura 7 en función de las flechas:

$$
\vartheta_{\mathrm{N}, \mathrm{CF}}=\frac{\delta_{\mathrm{SC}}-\delta_{\mathrm{CF}}}{\delta_{\mathrm{SC}}-\delta_{\mathrm{CT}}} \cdot \vartheta_{\mathrm{M}, \mathrm{CT}}
$$

y si en esta expresión se aplica [4], el deslizamiento axial queda directamente en función del grado de conexión $\psi:^{67}$

$$
\vartheta_{\mathrm{N}, \mathrm{CF}}=\psi \cdot \vartheta_{\mathrm{M}, \mathrm{CT}}
$$

donde el valor de $\vartheta_{M, C T}$ se extrae de la expresión [14] sin más que sustituir el subíndice 'CF' por el 'CT', quedando: $\vartheta_{\mathrm{M}, \mathrm{CT}}=\frac{8 \cdot \delta_{\mathrm{CT}}}{5 \cdot \lambda}$.

Finalmente, la reducción al deslizamiento de flexión $\vartheta_{M}$ que supone el deslizamiento axial $\vartheta_{\mathrm{N}}$, se resume en las expresiones aplicadas en cualquier sección y en la sección del extremo:

$$
\vartheta_{\mathrm{x}, \mathrm{N}, \mathrm{CF}}=\psi \cdot \frac{\mathrm{z}}{\mathrm{EI}_{\mathrm{CT}}} \cdot \frac{\mathrm{q}}{2}\left(\frac{\mathrm{Lx}^{2}}{2}-\frac{\mathrm{x}^{3}}{3}-\frac{\mathrm{L}^{3}}{12}\right) \quad[15] \quad \mathrm{y} \quad \vartheta_{0, \mathrm{~N}, \mathrm{CF}}=\psi \cdot \frac{8 \cdot \delta_{\mathrm{CT}}}{5 \cdot \lambda}
$$

\subsubsection{DESLIZAMIENTO FINAL}

El deslizamiento resultante $\vartheta$ es la diferencia entre los dos anteriores y queda reflejado específicamente en el triángulo ABD de la figura 7.

El deslizamiento en cualquier sección, vale:

$$
\vartheta_{\mathrm{x}, \mathrm{CF}}=\vartheta_{\mathrm{x}, \mathrm{M}, \mathrm{CF}}-\vartheta_{\mathrm{x}, \mathrm{N}, \mathrm{CF}}=\frac{\mathrm{z} \cdot \mathrm{q}}{2}\left(\frac{1}{\mathrm{EI}_{\mathrm{CF}}}-\frac{\psi}{\mathrm{EI}_{\mathrm{CF}}}\right) \cdot\left(\frac{\mathrm{Lx}^{2}}{2}-\frac{\mathrm{x}^{3}}{3}-\frac{\mathrm{L}^{3}}{12}\right)
$$

y en el extremo, aplicando [3] a [14] queda:

$$
\vartheta_{0, \mathrm{CF}}=\vartheta_{0, \mathrm{M}, \mathrm{CF}}-\vartheta_{0, \mathrm{~N}, \mathrm{CF}}=(1-\psi) \frac{8}{5 \lambda} \delta_{\mathrm{SC}}
$$

\footnotetext{
67 En esta expresión el deslizamiento se ha puesto directamente en función del deslizamiento de flexión en conexión total (CT) $\vartheta_{\mathrm{M}, \mathrm{CT}}$ ya que es igual que $\vartheta_{\mathrm{N}, \mathrm{CT}}$ y ha sido obtenido en [13] y [14].
} 


\subsubsection{REPRESENTACIÓN GRÁFICA}

Cuando la cantidad de conexión $\psi$ varía entre 0 y 1 , el valor de los deslizamientos varía linealmente con $\psi$ como muestra el gráfico.

Tal como se planteó, en la figura 9 se aprecia que el deslizamiento $\vartheta_{N}$ es nulo si no hay conexión y coincide con $\vartheta_{M}$ si la conexión es total. El cruce con la línea vertical $\Psi_{\text {necesaria }}$ marca la magnitud de ambas funciones para el caso del ejemplo elegido al principio. ${ }^{68}$

Se ha dejado la línea fina de la variación de EI y la de puntos, que corresponde a la variación de la flecha.

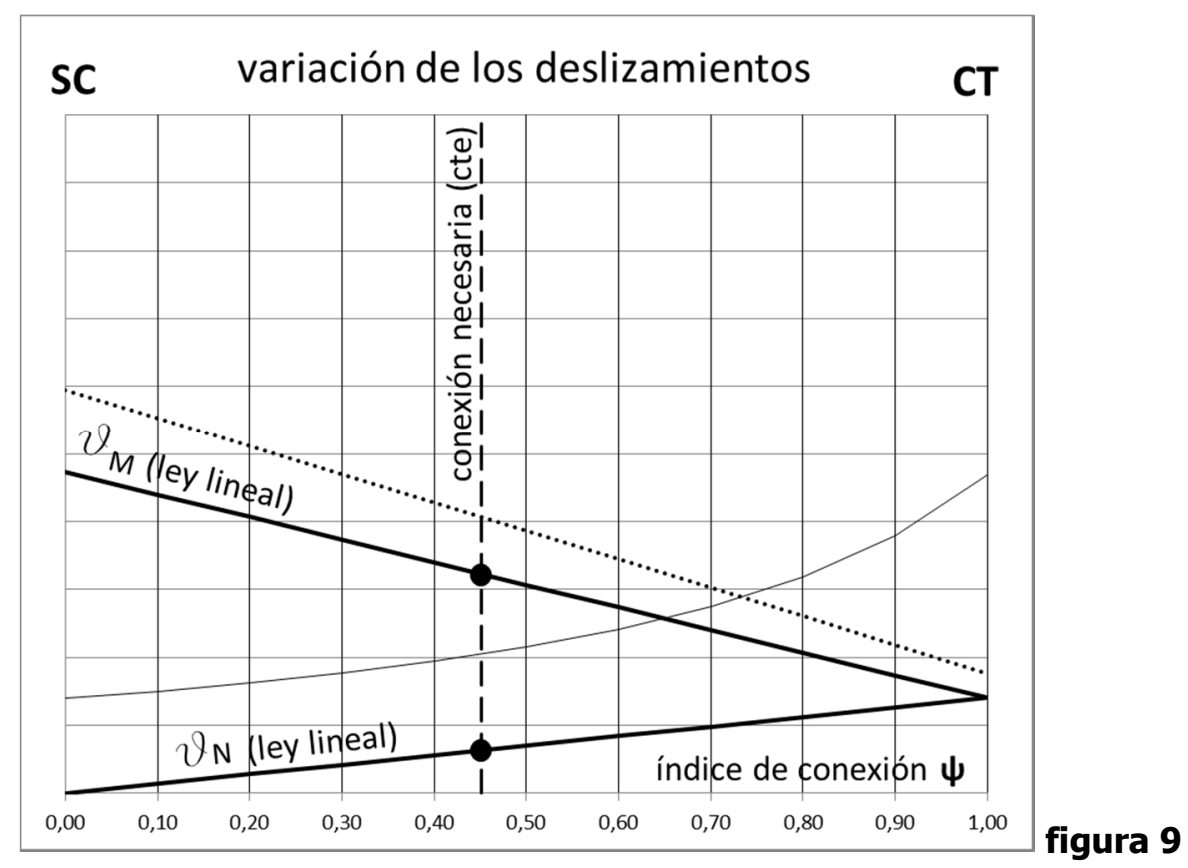

\footnotetext{
${ }^{68}$ Las escalas verticales se van eligiendo solo para que el conjunto de funciones que se irán añadiendo no se mezclen entre sí en este gráfico, porque lo que tiene interés aquí es mostrar las leyes de variación del conjunto de variables y su relación.
} 


\subsection{PAR DE FUERZAS N'Z}

\subsubsection{AXIL EN LA CAPA DE COMPRESIÓN Y LA VIGUETA PARA FORMAR EL PAR}

El momento que la pieza tiene que resistir en el centro del vano es el mismo sea cual sea el grado de conexión (M). $Y$ será resistido por la suma de $M_{M}$ y $M_{N}$.

El momento $M_{N}$ aumenta linealmente desde $M_{N, S C}=0$ (sin conexión) a $M_{N, C T}$ (conexión total) como indica la figura 10. Como se deduce de la proporcionalidad de triángulos, se puede escribir:

$$
\frac{\mathrm{M}_{\mathrm{N}, \mathrm{CF}}}{\mathrm{M}}=\frac{\delta_{\mathrm{SC}}-\delta_{\mathrm{CF}}}{\delta_{\mathrm{SC}}}=1-\frac{\delta_{\mathrm{CF}}}{\delta_{\mathrm{SC}}} \quad \text { y despejando } \quad \mathrm{M}_{\mathrm{N}, \mathrm{CF}}=\left(1-\frac{\delta_{\mathrm{CF}}}{\delta_{\mathrm{SC}}}\right) \cdot \mathrm{M}
$$

como también

$$
\frac{\mathrm{M}_{\mathrm{N}, \mathrm{CF}}}{\mathrm{M}_{\mathrm{N}, \mathrm{CT}}}=\frac{\delta_{\mathrm{SC}}-\delta_{\mathrm{CF}}}{\delta_{\mathrm{SC}}-\delta_{\mathrm{CT}}}
$$

y aplicando [4] en esta última, también queda relacionada su proporcionalidad, además de con la flecha, con la cantidad de conexión:

$$
\frac{\mathrm{M}_{\mathrm{N}, \mathrm{CF}}}{\mathrm{M}_{\mathrm{N}, \mathrm{CT}}}=\frac{\delta_{\mathrm{SC}}-\delta_{\mathrm{CF}}}{\delta_{\mathrm{SC}}-\delta_{\mathrm{CT}}}=\psi \quad \text { y despejando: } \quad \mathrm{M}_{\mathrm{N}, \mathrm{CF}}=\psi \cdot \mathrm{M}_{\mathrm{N}, \mathrm{CT}}
$$

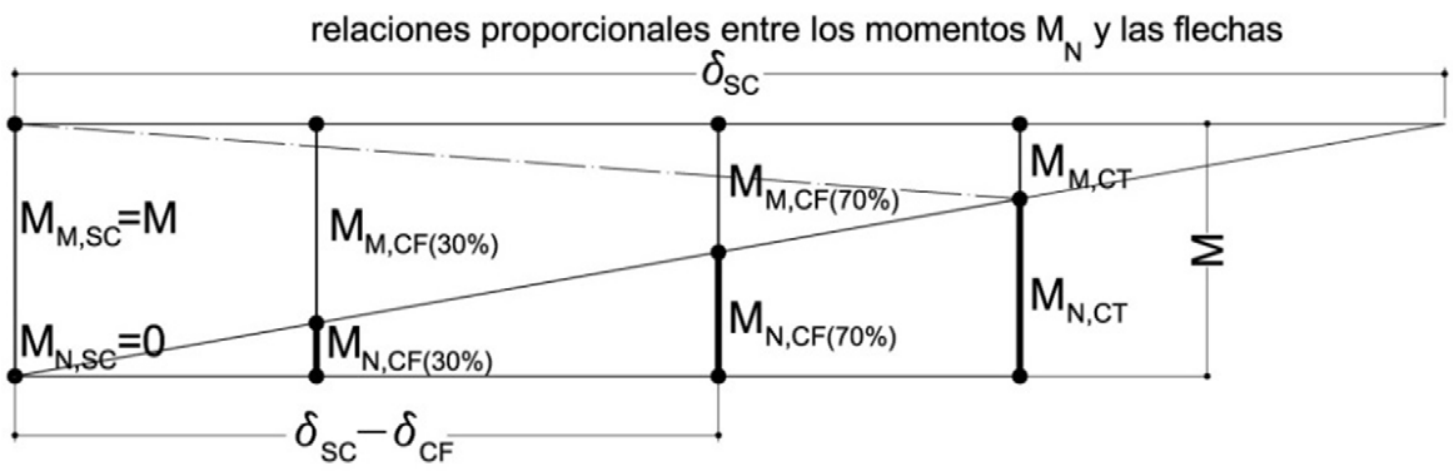

figura 10 
quedando determinado, a partir de [18], el valor de $\mathrm{N}$ en el centro de la pieza:

$$
\mathrm{N}_{\mathrm{CF}}=\left(1-\frac{\delta_{\mathrm{CF}}}{\delta_{\mathrm{SC}}}\right) \cdot \frac{\mathrm{M}}{\mathrm{z}}
$$

que también se puede escribir: ${ }^{69}$

$$
\mathrm{N}_{\mathrm{CF}}=\psi\left(1-\frac{\delta_{\mathrm{CT}}}{\delta_{\mathrm{SC}}}\right) \frac{\mathrm{M}}{\mathrm{z}}
$$

\subsubsection{DEFORMACIÓN UNITARIA AXIAL $\varepsilon_{\mathrm{N}}$}

Hasta aquí no ha sido necesario determinar la variación de las deformaciones unitarias axiales ya que curvaturas, giros y deslizamientos dependen de la flexión propia de las partes y de la relación entre esta flexión y el momento total M.

Conocido ahora el normal $\mathrm{N}$ del par $\mathrm{M}_{\mathrm{N}}=\mathrm{N} \cdot \mathrm{z}$ se extraen estas deformaciones directamente:

$$
\varepsilon_{\mathrm{N}, \mathrm{cc}}=\frac{N}{\mathrm{EA}_{\mathrm{cc}}}=\left(1-\frac{\delta_{\mathrm{CF}}}{\delta_{\mathrm{SC}}}\right) \cdot \frac{\mathrm{M}}{\mathrm{z}} \cdot \frac{1}{\mathrm{EA}_{\mathrm{cc}}} \quad \varepsilon_{\mathrm{N}, \mathrm{vig}}=\left(1-\frac{\delta_{\mathrm{CF}}}{\delta_{\mathrm{SC}}}\right) \cdot \frac{\mathrm{M}}{\mathrm{z}} \cdot \frac{1}{\mathrm{EA}_{\mathrm{vig}}}
$$

Expresiones que varían linealmente puesto que en ellas solo la flecha de la conexión flexible $\left(\delta_{\mathrm{CF}}\right)$ varía, y lo hace linealmente.

Esta figura es un recorte de la figura 5 y se incluye para complementar la relación entre estas deformaciones axiles con las deformaciones unitarias de flexión.

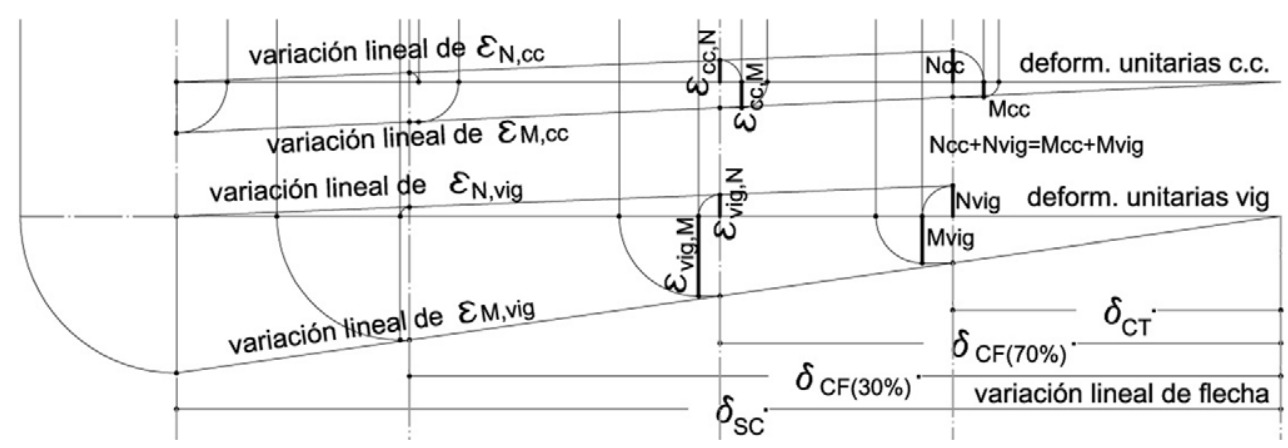

Las deformaciones unitarias axiles $\left(\varepsilon_{\mathrm{N}}\right)$, tanto de la capa de compresión como de la vigueta, siguen una ley lineal cuyas rectas arrancan de cero en el extremo $\sin$ conexión $\left(\varepsilon_{\mathrm{N}}=0\right)$ y en el extremo con conexión total, para que no haya deslizamiento, debe cumplirse:

$$
\varepsilon_{\mathrm{N}, \mathrm{cc}, \mathrm{CT}}+\varepsilon_{\mathrm{N}, \mathrm{vig}, \mathrm{CT}}=\varepsilon_{\mathrm{M}, \mathrm{cc}, \mathrm{CT}}+\varepsilon_{\mathrm{M}, \mathrm{vig}, \mathrm{CT}}
$$

${ }^{69}$ ya que, a partir de [3]: $\quad \psi=\frac{\delta_{\mathrm{SC}}-\delta_{\mathrm{CF}}}{\delta_{\mathrm{SC}}-\delta_{\mathrm{CT}}}=\frac{1-\frac{\delta_{\mathrm{CF}}}{\delta_{\mathrm{SC}}}}{1-\frac{\delta_{\mathrm{CT}}}{\delta_{\mathrm{SC}}}} \quad$ luego $\left(1-\frac{\delta_{\mathrm{CF}}}{\delta_{\mathrm{SC}}}\right)=\psi\left(1-\frac{\delta_{\mathrm{CT}}}{\delta_{\mathrm{SC}}}\right)$ 


\subsubsection{REPRESENTACIÓN GRÁFICA DE LOS TRES MOMENTOS}

Una vez completadas las funciones de los momentos que intervienen en el equilibrio en función del grado de conexión, y que son las indicadas en las expresiones [7a], [7b] y [18], se representan en el gráfico general, incluyendo arriba el $M_{\text {total }}$ que es la suma de los otros con cualquier grado de conexión $\psi$.

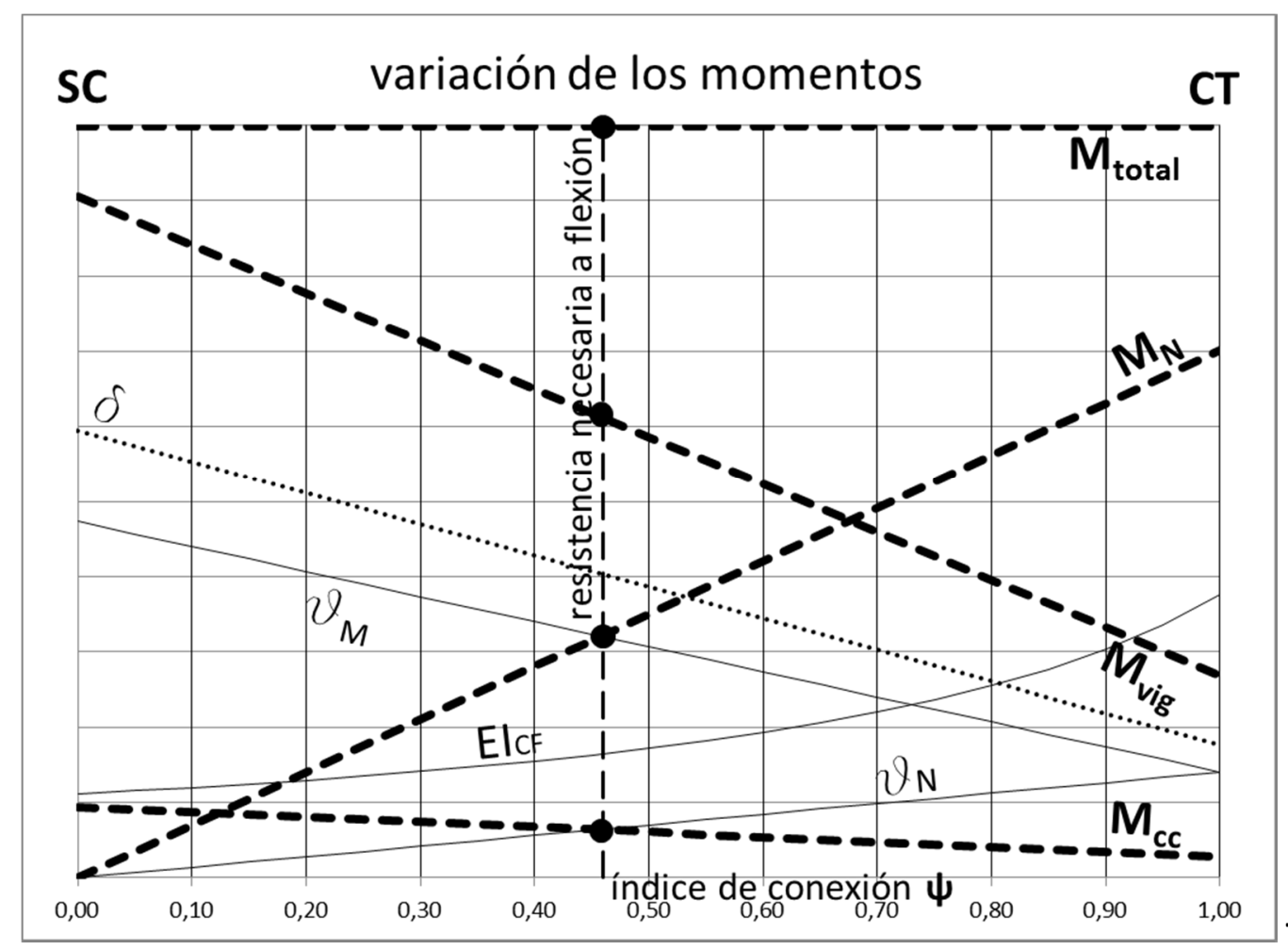

figura 11 


\subsection{ESFUERZO RASANTE}

\subsubsection{VALORACIÓN}

Este axil ' $\mathrm{N}$ ' en el centro del vano va disminuyendo hasta anularse en el extremo. Se transforma en rasante a través de la conexión. Por tanto, la fuerza rasante total $\left(R_{\text {tot }}\right)$ de media viga vale ' $\mathrm{N}$ ' $\mathrm{y}$ al dividirla por esa longitud $(\mathrm{L} / 2)$ se obtiene el rasante medio $\left(r_{\mathrm{med}}\right)$. El valor máximo $\left(r_{\operatorname{máx}}\right)$ es el doble, al tener una distribución triangular. Estos últimos valores son fuerzas por unidad de longitud. ${ }^{70}$

$$
\mathrm{N}=\frac{\mathrm{M}}{\mathrm{z}} \quad \mathrm{R}_{\text {tot }}=\mathrm{N} \quad \mathrm{r}_{\text {med }}=\frac{\mathrm{R}_{\text {tot }}}{\mathrm{L} / 2} \quad \mathrm{r}_{\text {máx }}=2 \cdot \mathrm{r}_{\text {med }}=\frac{4 \mathrm{~N}}{\mathrm{~L}}
$$

El rasante máximo lo tiene que resistir la conexión en los extremos pudiéndose reducir a la mitad la cantidad de conexión desde el cuarto de la luz, donde el rasante adopta el valor medio.

Aplicando [19] en la expresión del rasante máximo $\left(r_{\text {máx }}\right)$ anterior queda en función de la flecha o de la cantidad de conexión:

$$
\mathrm{r}_{\text {máx }}=\frac{4 \mathrm{~N}}{\mathrm{~L}}=\left(1-\frac{\delta_{\mathrm{CF}}}{\delta_{\mathrm{SC}}}\right) \frac{\mathrm{M}}{\mathrm{z}} \cdot \frac{4}{\mathrm{~L}}=\left(1-\frac{\delta_{\mathrm{CF}}}{\delta_{\mathrm{SC}}}\right) \frac{\mathrm{qL}^{2}}{8 \cdot \mathrm{z}} \cdot \frac{4}{\mathrm{~L}}=\left(1-\frac{\delta_{\mathrm{CF}}}{\delta_{\mathrm{SC}}}\right) \cdot \mathrm{q} \lambda
$$

que, como en el caso de las deformaciones unitarias axiales, también puede expresarse así:

$$
\mathrm{r}_{\text {máx }}=\psi\left(1-\frac{\delta_{\mathrm{CT}}}{\delta_{\mathrm{SC}}}\right) \cdot \mathrm{q} \lambda
$$

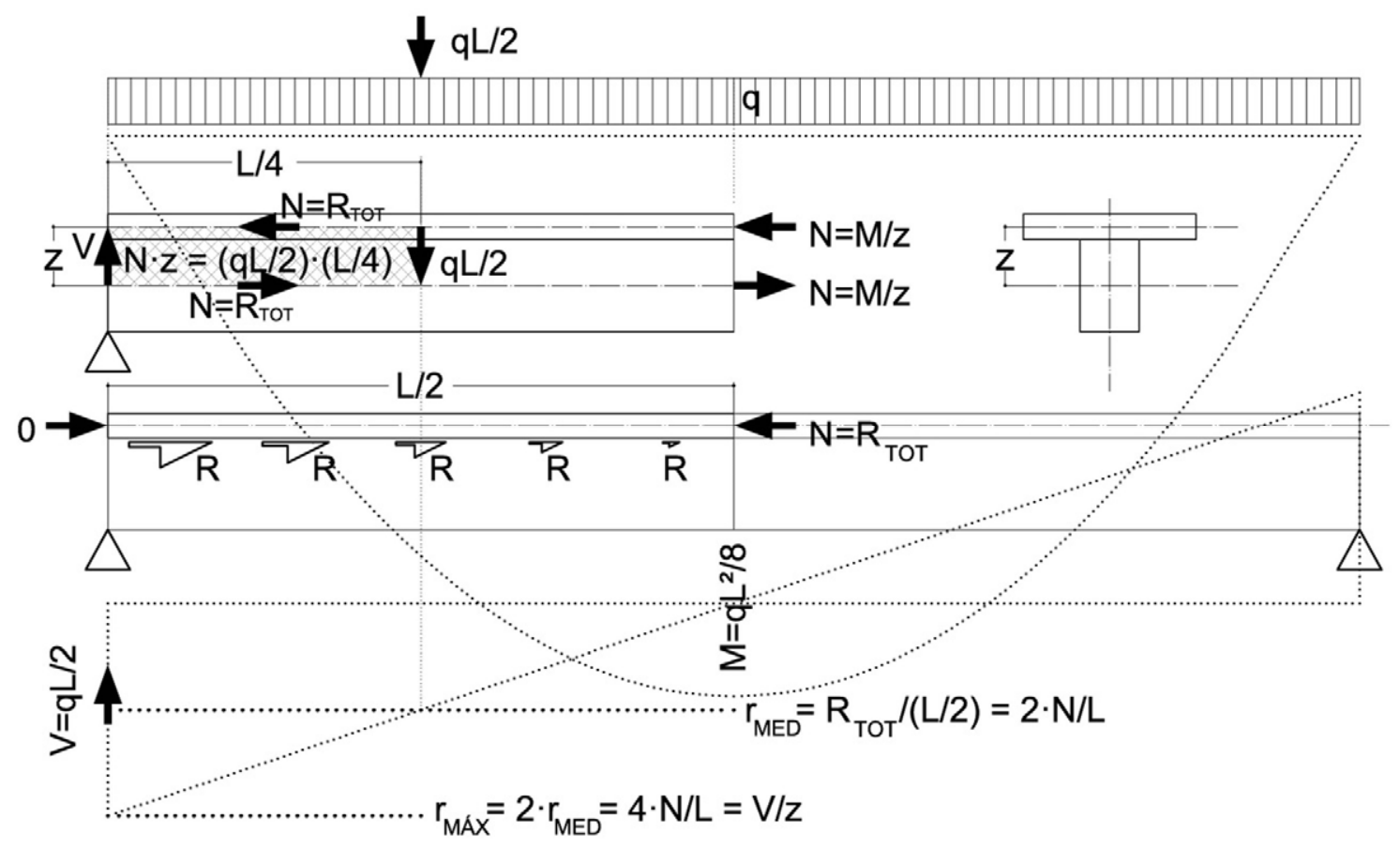

figura 12

\footnotetext{
${ }^{70}$ El rasante se expresa en minúsculas porque sus unidades no son de fuerza sino de fuerza / longitud.
} 


\subsubsection{RELACIÓN ENTRE EL DESLIZAMIENTO Y EL RASANTE}

De todo lo anterior se concluye que, tanto el deslizamiento como el esfuerzo rasante, que ya han quedado relacionados respectivamente con las deformaciones y con los esfuerzos de la estructura, y ambos con la rigidez a flexión, se relacionan entre si también geométricamente, como se muestra en la figura 13.

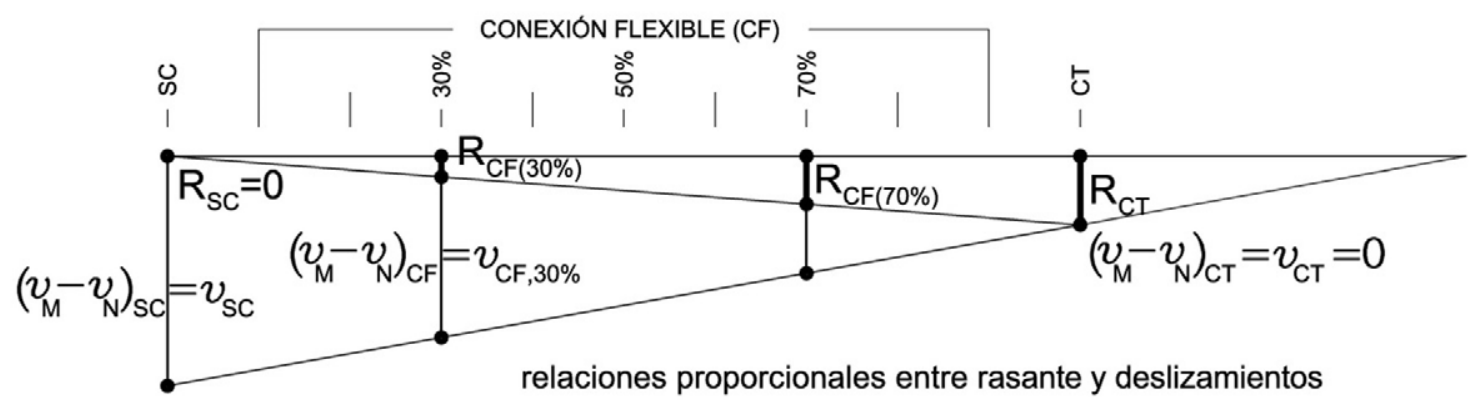

\section{figura 13}

Teniendo en cuenta que la relación entre rasante y deslizamiento es la definición de la rigidez de la conexión $\left(K_{\text {uni }}\right)$ ya solo queda expresar analíticamente su valor en función de los datos del problema para concluir el trabajo propuesto. ${ }^{71}$

${ }^{71}$ Las unidades de la rigidez de la conexión, $\mathrm{K}_{\text {uni, }}$, son fuerza / superficie. 


\subsection{RIGIDEZ DE LA CONEXIÓN Y CONCLUSIÓN}

Para que la pieza tenga la rigidez a flexión $\left(\mathrm{EI}_{\mathrm{CF}}\right.$ ) establecida al principio, la capa de compresión del refuerzo debe quedar conectada a la vigueta con una rigidez $\left(\mathrm{K}_{\text {uni }}\right)$, que es la relación entre el rasante máximo $\left(r_{\text {máx }}\right)$ y el deslizamiento $\left(\vartheta_{0}\right)$ en el extremo:

$$
\mathrm{K}_{\mathrm{uni}}=\frac{\mathrm{r}_{\text {máx }, \mathrm{CF}}}{\mathrm{v}_{0, \mathrm{CF}}}
$$

sustituyendo el rasante máximo por su valor [20] y el deslizamiento en el extremo de la pieza por el suyo [17], teniendo en cuenta que $\delta_{S C}=5 q^{4} /\left(384 \mathrm{EI}_{S C}\right)$ y que $\delta_{\mathrm{CT}} / \delta_{\mathrm{SC}}=\mathrm{El}_{\mathrm{SC}} / \mathrm{El}_{\mathrm{CT}}$, se llega a:

$$
\mathbf{K}_{\mathbf{u n i}}=\frac{\psi}{1-\psi} \cdot\left[\left(1-\frac{\mathrm{EI}_{\mathrm{SC}}}{\mathrm{EI}_{\mathrm{CT}}}\right) \mathrm{EI}_{\mathrm{SC}} \cdot 48 \frac{\lambda^{2}}{\mathrm{~L}^{4}}\right]
$$

entre corchetes se agrupan los parámetros que no dependen de la conexión, quedando fuera los dependientes de ella. Como $0<\psi<1$, el valor de $K_{\text {uni }}$ varía entre 0 (para $\psi=0$ ) y $\infty$ (para $\psi=1$ ).

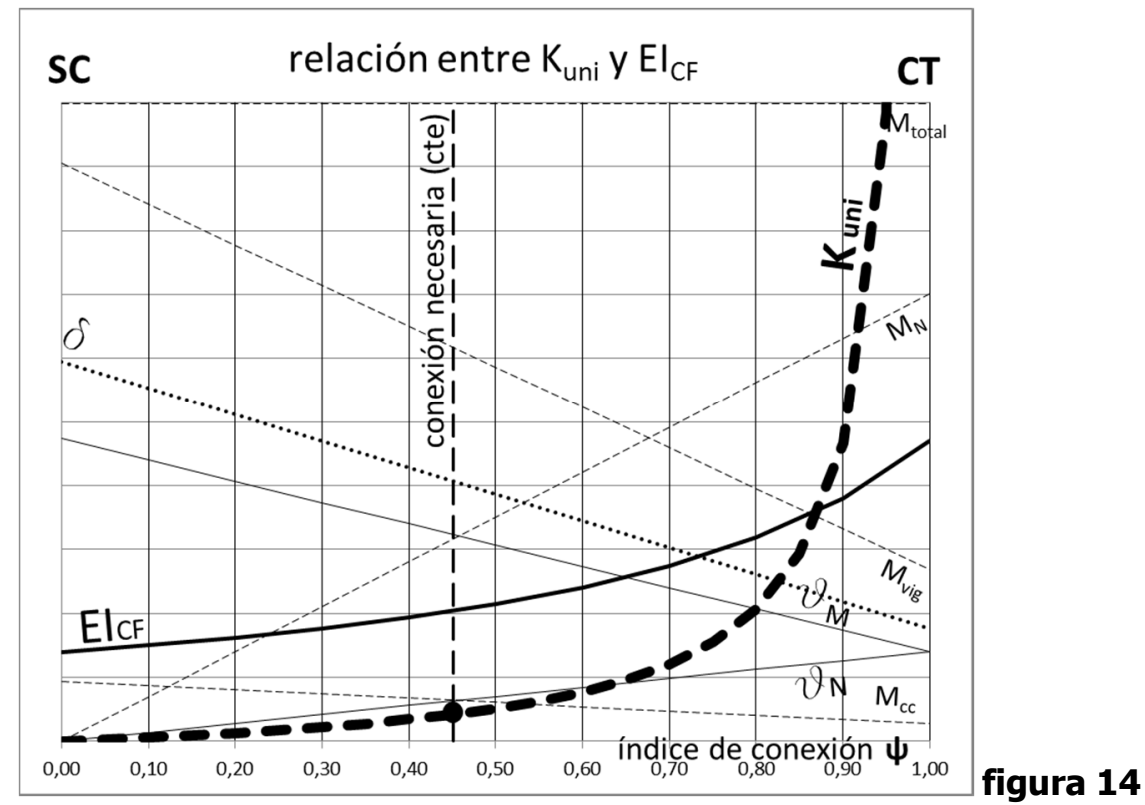

Visto desde los elementos de conexión, su rigidez es función de sus propiedades $(\varnothing$, etc.) y las de la madera. La normativa denomina esta rigidez con $\mathrm{K}_{\text {ser }} \mathrm{y}$ representa la fuerza rasante que hay que ejercer para producir un deslizamiento unidad en el conector. Sus unidades son pues fuerza/longitud. $\mathrm{K}_{\mathrm{ser}}$ se relaciona con $\mathrm{K}_{\text {uni }}$ a través de $\left(\mathrm{K}_{\mathrm{ser}}=\mathrm{K}_{\mathrm{uni}} \cdot \mathrm{s}\right)$ siendo ' $\mathrm{s}$ ' la distancia entre conectores. Por tanto, los conectores y su separación se pueden obtener mediante:

$$
\mathbf{K}_{\text {ser }}=\frac{\mathrm{EI}_{\mathrm{CF}}-\mathrm{EI}_{\mathrm{SC}}}{\mathrm{EI}_{\mathrm{CT}}-\mathrm{EI}_{\mathrm{CF}}}\left(\mathrm{EI}_{\mathrm{CT}}-\mathrm{EI}_{\mathrm{SC}}\right) \cdot 12 \frac{s}{\mathrm{~L}^{2} \mathrm{z}^{2}}
$$


El gráfico siguiente es el resumen de este trabajo y justifica el lema inicial: la flecha varía linealmente con el grado de conexión, como lo hacen casi todas las demás variables. También muestra cómo es posible relacionar la rigidez de flexión con la de la conexión y viceversa, permitiendo así usarlo tanto en el dimensionado de refuerzos como en la comprobación de estructuras existentes. Para conocer la magnitud de cualquiera de las variables basta aplicar las expresiones algebraicas desarrolladas en el texto.

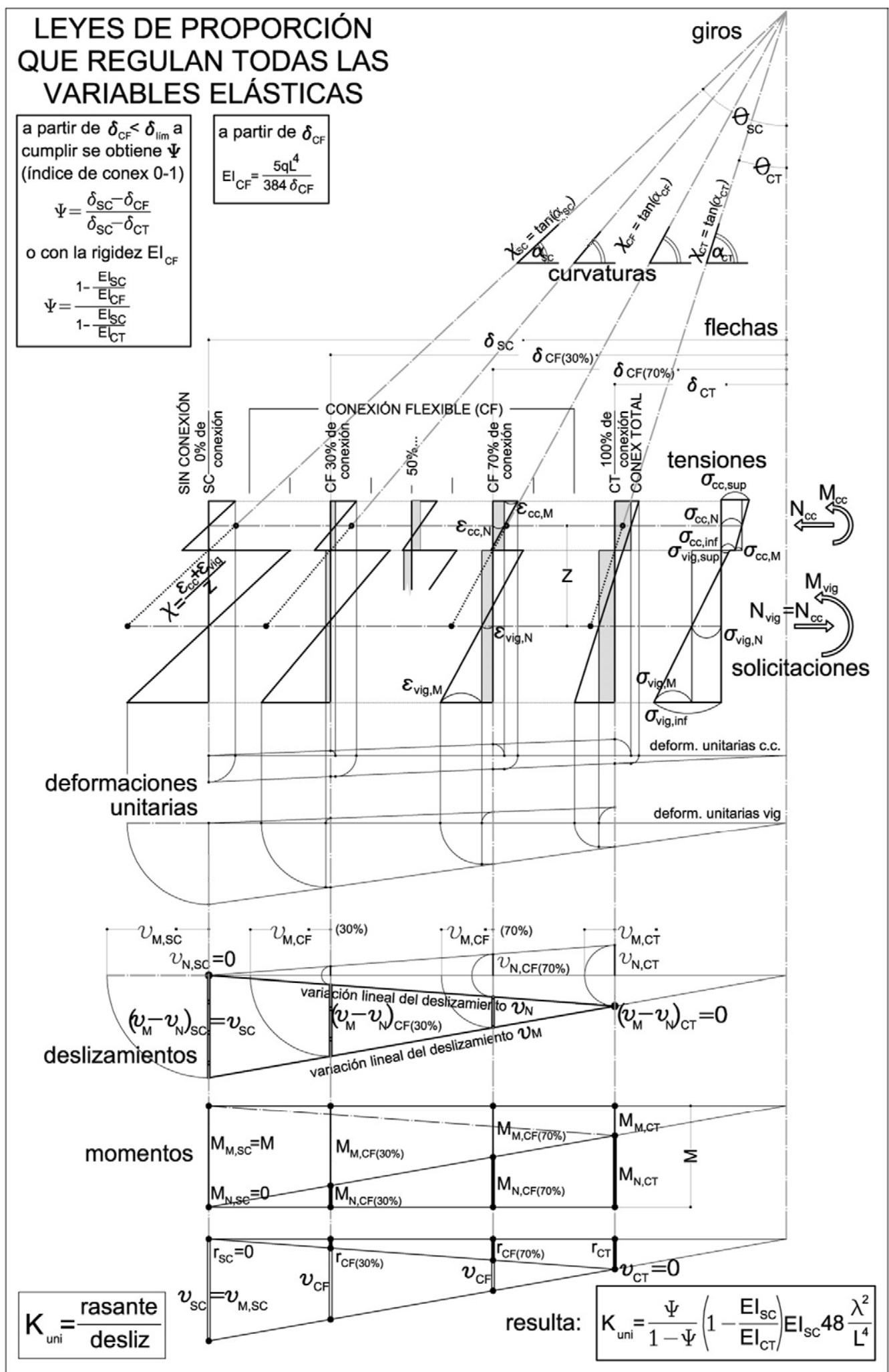




\subsection{APROXIMACIÓN DE LA RIGIDEZ OBTENIDA POR EL MÉTODO GAMMA}

Elegido un tipo y diámetro de conector, y con la densidad de la madera, se obtiene el módulo de deslizamiento $\left(K_{\text {ser }}\right)$ y añadiendo la separación ' $s$ ' se obtiene la rigidez a deslizamiento $\left(\mathrm{K}_{\text {uni }}\right)$. De este dato parte el método 'gamma', que permite calcular aproximadamente la rigidez a flexión de la viga reforzada $\left(\mathrm{EI}_{\mathrm{ef}}\right)$. Empieza así un proceso iterativo hasta que la flecha obtenida sea razonablemente menor que la flecha límite.

Para valorar esta aproximación del método 'gamma' con el proceso desarrollado en este trabajo se ha llegado al valor de $\mathrm{K}_{\text {uni }}$ directamente desde la rigidez a flexión $\left(\mathrm{EI}_{\mathrm{ef}}\right)$ y con el $\mathrm{K}_{\mathrm{uni}}$ obtenido así se ha calculado la rigidez a flexión $\mathrm{EI}_{\mathrm{ef}}$ y la flecha, siguiendo el método 'gamma'.

En la figura inferior se representa la curva de rigidez a flexión $\mathrm{EI}_{\mathrm{ef}}$ obtenida con el método 'gamma' y en línea de puntos con el modelo de esta tesis. Se incluyen los valores del error (en contra de seguridad) para cada grado de conexión $\psi$ tanto para capa de compresión de hormigón como de tablero microlaminado. Igual se hace con la curva de la flecha. Estos valores rotulados varían algo al cambiar los datos concretos de cada problema, aunque muy poco para las dimensiones habituales en estas estructuras de forjados reforzados. La rigidez según 'gamma' es mayor que la calculada directamente y consecuentemente la flecha obtenida así es menor que la que resulta aplicando el método directo de la tesis.

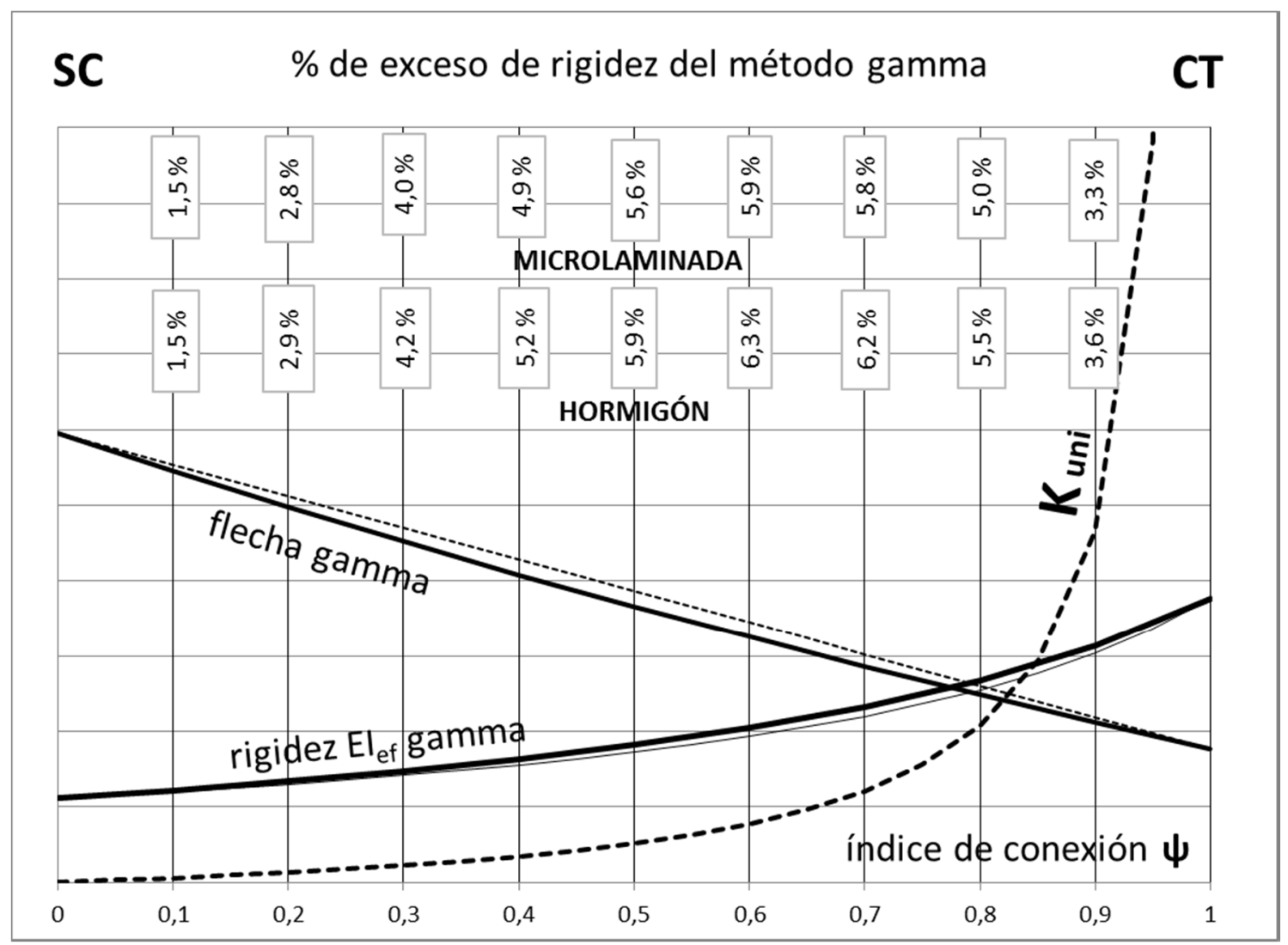




\section{CAPÍTULO 7. - COMPARACIÓN DE ENSAYOS DE RASANTE Y FLEXIÓN}

7.0 INTRODUCCIÓN

7.1 OBTENCIÓN DE R, v y K Kuni (rasante, deslizamiento y rigidez)

7.1.1 ENSAYO DE RASANTE

7.1.2 ENSAYO DE FLEXIÓN

7.2 HORMIGÓN vS MADERA MICROLAMINADA

7.2.1 YUXTAPOSICIÓN DE GRÁFICAS

7.2.2 LAS DOS GRÁFICAS VISTAS DESDE SUS $\mathrm{K}_{\mathrm{ser}}$

7.2.3 EL CURIOSO CASO DEL HORMIGÓN BIPOLAR

7.3 COMPARACIÓN DE TODOS LOS K $\mathrm{ser}_{\mathrm{s}}$

7.4 MAGNITUD DEL DESLIZAMIENTO EN AMBOS ENSAYOS

7.4.1 ANÁLISIS DE PROBETAS DESPUÉS DE LA ROTURA

7.4.2 SUPERPOSICIÓN EN LA ZONA DE ROTURA

7.4.3 SUPERPOSICIÓN EN LA ZONA DE SERVICIO 


\subsection{INTRODUCCIÓN}

En este capítulo, que concluye la elaboración de los resultados de laboratorio, se realiza una síntesis de los dos tipos de ensayo: conexiones a rasante y vigas a flexión.

La comparación entre los ensayos de rasante y los de flexión se debe hacer estudiando las variables que les son comunes: esfuerzo rasante y deslizamiento, así como la relación entre estos, es decir, la rigidez a deslizamiento $\left(\mathrm{K}_{\mathrm{ser}}\right)$. En el apartado 7.1 (Obtención DE $\mathbf{R}, \vartheta$ y $\mathbf{K}_{\text {uni }}$ (rasante, deslizamiento y rigidez)) se describe cómo se obtienen estos parámetros en los dos tipos de ensayo. En el ensayo de rasante, la lectura de ambos (rasante y deslizamiento) es directa, mientras que en el ensayo de vigas a flexión es necesaria la utilización del método de cálculo desarrollado en el capítulo 6 para relacionar la carga aplicada a la viga con la flecha y esta con el deslizamiento y con la fuerza rasante (el método gamma no permite una interrelación funcional y bidireccional entre cálculo y realidad).

En el ensayo de las vigas, y en lo que se refiere al deslizamiento, se han seguido dos opciones en paralelo: En la primera se utilizan los valores de carga y flecha medidos en el ensayo y se calculan los deslizamientos teóricos de la pieza; en la segunda se utilizan los deslizamientos medidos durante el ensayo en vez de calcularlos. Estos dos procedimientos debieran de ser coincidentes, pero ya se sabe que el conjunto de circunstancias experimentales produce desviaciones entre ambos. Por tanto, este doble proceso, que produce dos resultados para los deslizamientos nos vale para verificar el método de cálculo desarrollado y para controlar valores discordantes de los ensayos.

En el apartado 7.2 (Hormigón vs madera microlaminada) se concluye con la comparativa entre capa de compresión de hormigón y de madera microlaminada que se ha ido realizando en los capítulos anteriores.

En el apartado 7.3 (Comparación de todos los $\mathbf{K}_{\text {ser }}$ ) se describe la relación entre todos los módulos de deslizamiento $\left(\mathrm{K}_{\mathrm{ser}}\right)$ obtenidos a lo largo del trabajo (Eurocódigo, ensayos de rasante y ensayos de flexión). Esta comparación final permite sacar conclusiones sobre las diferencias encontradas entre los dos tipos de ensayos y entre ellos con la normativa. Se realiza también una transformación de escala para comprobar qué ocurre en casos con luces mayores ( 5 $\mathrm{m})$. Por último, a los valores obtenidos en los ensayos de las vigas, se les quitan las mejoras producidas por la presión y el rozamiento (factores que no están contemplados en la normativa). 
En el apartado 7.4 (Magnitud del deslizamiento en ambos ensayos) se analiza un tema de especial interés, que es la zona de trabajo del conector en ambos tipos de ensayo. Este estudio parte de la observación de las probetas de uno y otro ensayo después de llevarlas hasta su rotura. En el caso de los ensayos de rasante se puede apreciar perfectamente tanto la plastificación de los conectores como un gran aplastamiento en la madera; mientras que en los conectores pertenecientes a los ensayos de flexión de las vigas, incluso tras la rotura, no se aprecia su plastificación ni un gran aplastamiento de la madera. Que los deslizamientos que se producen en una viga no superen las etapas iniciales del ensayo simple de rasante no extraña, lo que sorprende es que la normativa determine la rigidez de las conexiones basándose en unos deslizamientos (de los ensayos de rasante) inalcanzables en las vigas, porque han roto por exceso de deformación a flexión mucho antes. 


\subsection{OBTENCIÓN DE R, $\vartheta$ y $\mathbf{K}_{\text {ser (rasante, deslizamiento y rigidez) }}$}

Las variables con las que se comparan los dos tipos de ensayos son la FUERZA RASANTE y el DESLIZAMIENTO de cuya relación de obtiene la rigidez a deslizamiento $\left(\mathrm{K}_{\mathrm{ser}}\right)$. A continuación se muestra cómo se han obtenido estos valores en los dos tipos de ensayo.

\subsubsection{ENSAYO DE RASANTE}
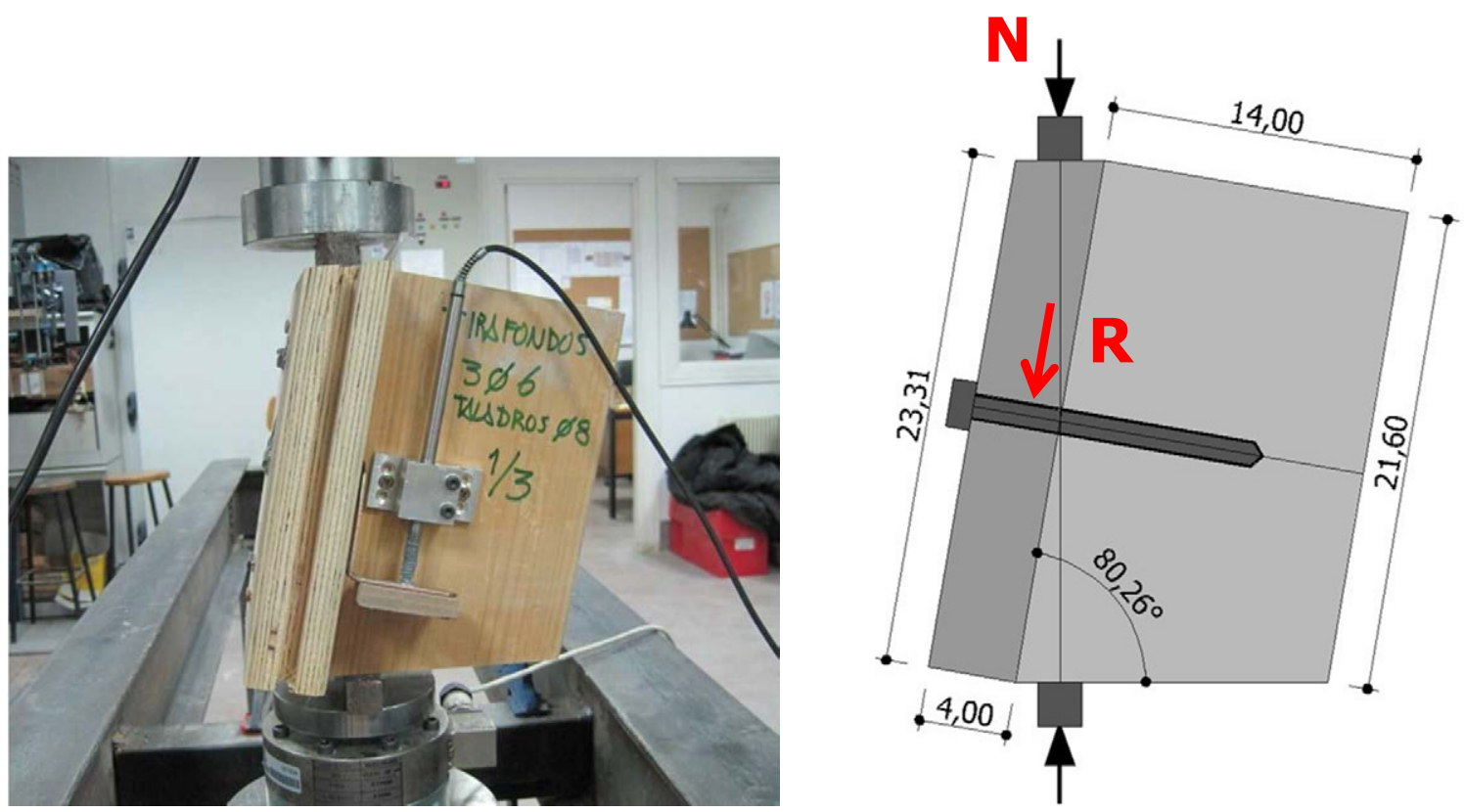

figura 1. Ensayo de rasante

En el ensayo de rasante, la lectura del DESLIZAMIENTo es directa, ya que se ha colocado un LVDT perpendicular al conector para medirlo.

La probeta está ligeramente girada para permitir la transmisión de cargas vertical, por lo que para obtener la fuerza RASANTE, hay que corregir la carga aplicada N:

$$
R=N \cdot \operatorname{seno}\left(80,26^{\circ}\right)
$$




\subsubsection{ENSAYO DE FLEXIÓN}

Para realizar la comparación con los ensayos de rasante, se utilizan los valores máximos de rasante y deslizamiento del ensayo de flexión, producidos en los extremos de la viga.

En el ensayo de flexión se puede medir el deslizamiento entre capa de compresión y vigueta en varios lugares de la pieza, pero no se puede hacer una lectura directa de la fuerza RASANTE, por lo que hay que ayudarse del método de cálculo desarrollado en el capítulo 6.
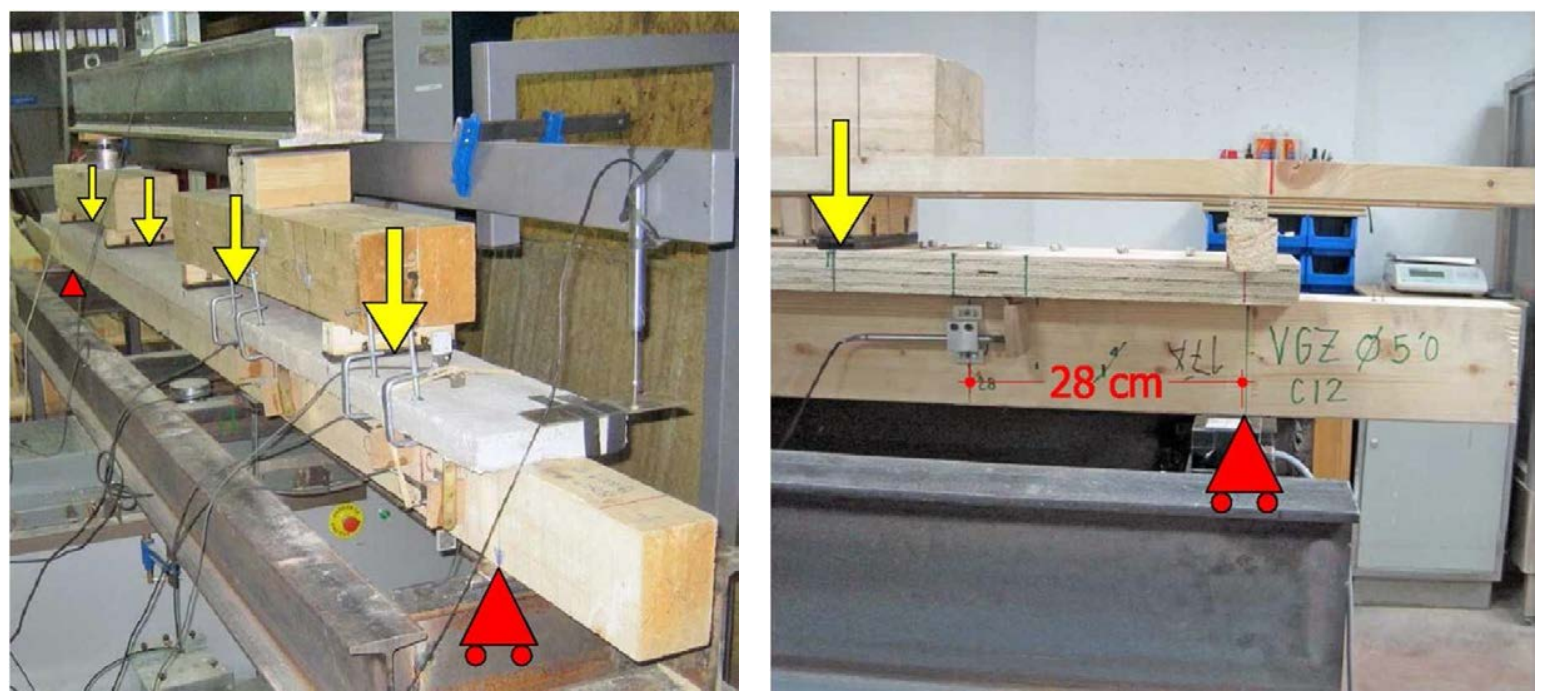

figura 2. Ensayo de flexión

Como se indica en el punto 7.1 de la Introducción de este capítulo 7, el DESLIZAMIENTO se puede obtener de dos maneras distintas y se van a seguir los dos procedimientos en paralelo:

-en uno, se toma como base de partida la flecha medida en el ensayo y con el modelo, se calcula la rigidez a deslizamiento $\left(\mathrm{K}_{\mathrm{uni}}\right)$, el deslizamiento $(\mathrm{v})$ y el rasante $(\mathrm{R})$.

-en el otro, se toma como base de partida la fecha y el deslizamiento medidos en los ensayos, y con el modelo, se calcula la rigidez a deslizamiento $\left(K_{\text {uni }}\right)$ y el rasante $(R)$.

Se utilizan los dos deslizamientos y se contrasta así tanto el método de cálculo como los errores de medida que pudieran haberse producido en el ensayo. 


\subsection{HORMIGÓN vS MADERA MICROLAMINADA}

\subsubsection{YUXTAPOSICIÓN DE GRÁFICAS}

Una vez que se han realizado, en capítulos anteriores, los análisis de los dos tipos de ensayo por separado, en este apartado se asocian los ensayos para estudiar y comparar el comportamiento de las conexiones cuando la capa de compresión es de hormigón y cuando es de madera microlaminada.

\section{Ensayos analizados}

Se han estudiado dos vigas y dos ensayos de rasante, ambos con vigueta de madera laminada de escuadría (h·b) $14.9 \mathrm{~cm}$ y tirafondos $\emptyset 6$ con resina. ${ }^{72}$

\section{$\underline{\text { Resultados }}$}

En la figura 3 se muestran las gráficas fuerza/deslizamiento superpuestas de los ensayos rasante y de los de vigas a flexión. En todos los casos, las probetas se llevaron hasta sus roturas respectivas.

Las de capa de compresión de hormigón se presentan en la izquierda y las de microlaminada, en la derecha. En línea continua (roja en hormigón y azul en microlaminada) se representan los ensayos de las vigas a flexión y en línea oscura a trazos (roja o azul), los ensayos de rasante. Se ha dibujado en cada caso una línea (verde) que indica la cota en la que se obtiene el Ker según la Norma 26891.

\footnotetext{
${ }^{72}$ En este capítulo se estudian solo los tirafondos, porque los clavos, como se ha comentado en los capítulos anteriores, se ven afectados por la presión ejercida al clavarlos, que lógicamente será distinta en los ensayos de rasante y de flexión (lo que dificulta abordar aquí conjuntamente ambos ensayos).
} 


\section{Hasta límite de ensayo de rasante}
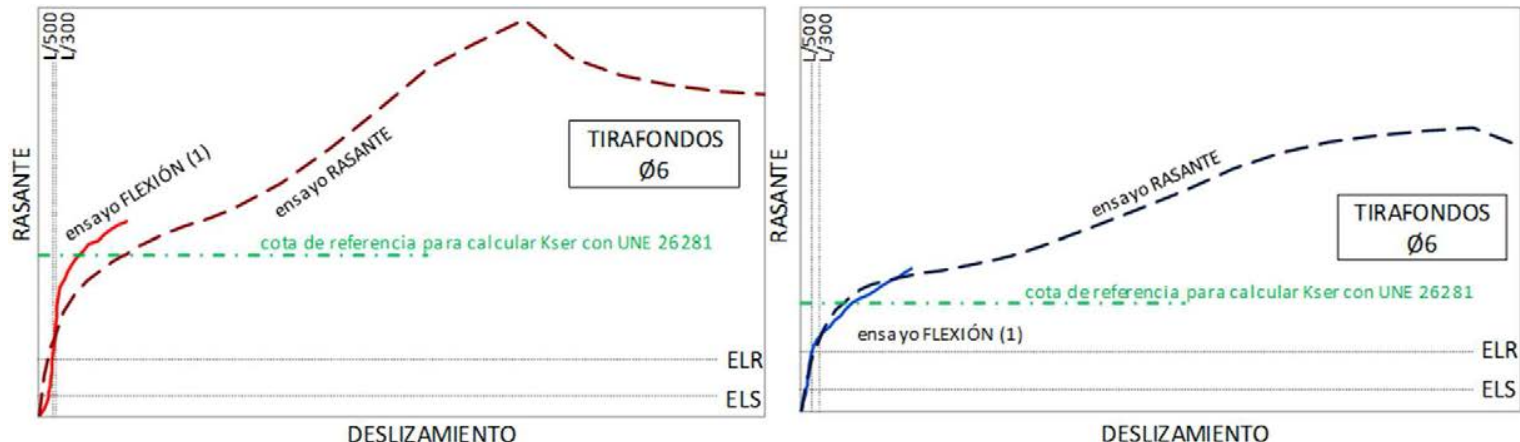

Hasta límite de ensayo de viga a flexión
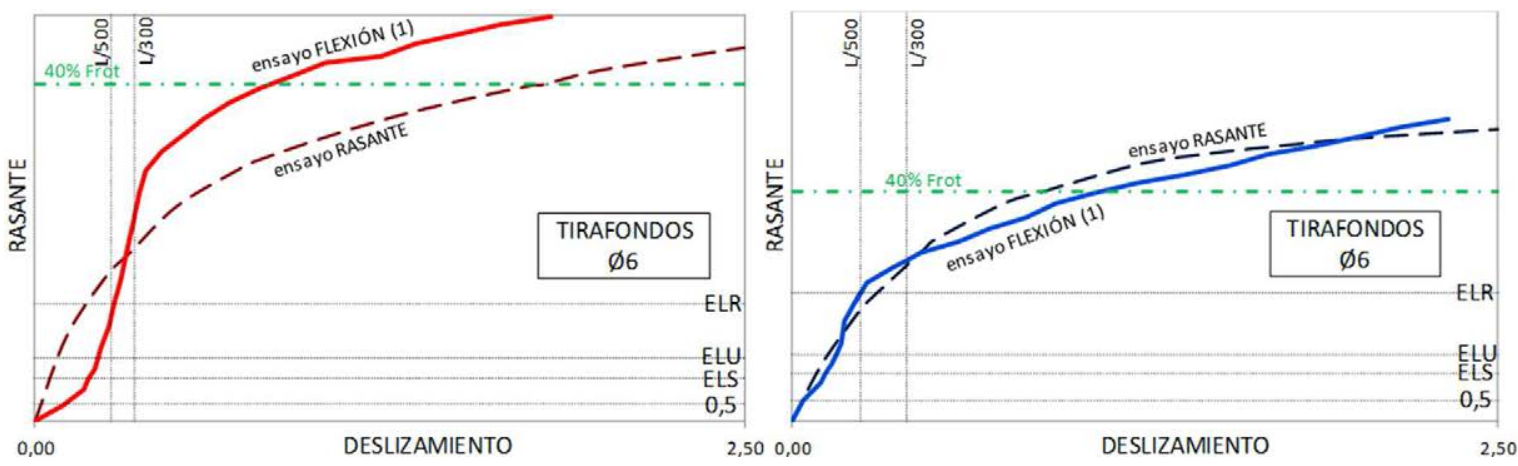

Hasta límite de edificio
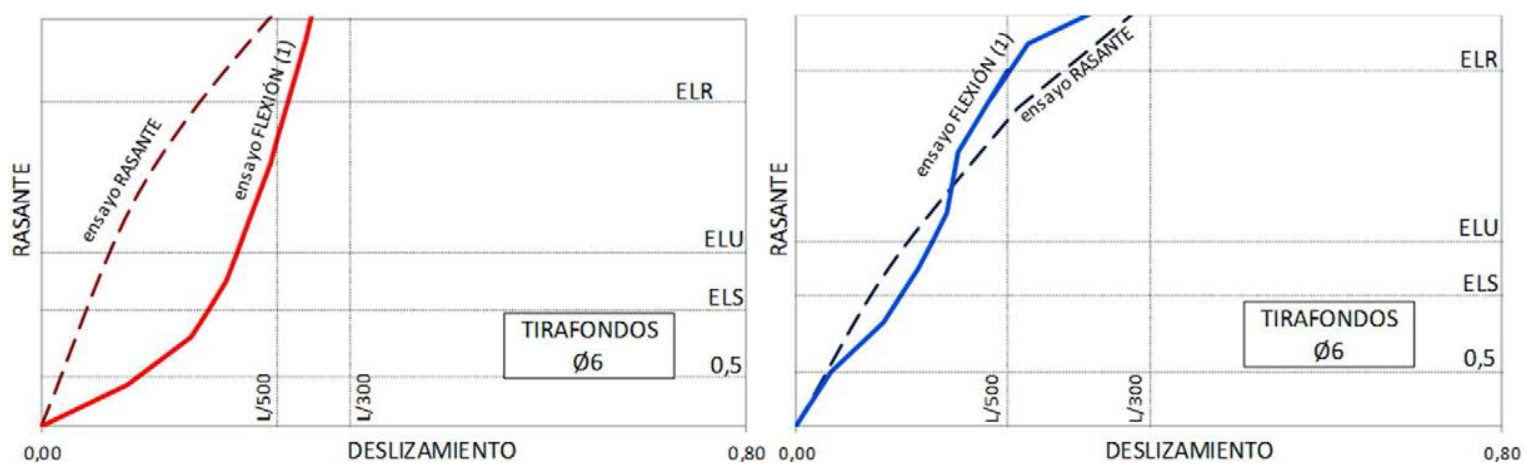

figura 3. Graficas comparativas de rasante-des/izamiento

NOTA: Los deslizamientos que se han empleado en estos gráficos (en el caso de las vigas, lógicamente) son los obtenidos por el modelo a partir de la flecha (primer procedimiento descrito).

Se observa, como ya quedó comentado, que las escalas del problema son distintas. En los ensayos de probetas a rasante se llega a deslizamientos de $15 \mathrm{~mm}$ (como marca la UNE), mientras que en los ensayos de vigas a flexión los deslizamientos medidos en todos los ensayos realizados en esta tesis se encuentran entre 2 y $4 \mathrm{~mm}$ cuando se alcanza la rotura de la viga. 
Además, se observa que en la cota de esfuerzo rasante en la que la Norma UNE indica que hay que obtener el $\mathrm{K}_{\mathrm{ser}}$ la viga ensayada se encuentra ya rota o cerca de estarlo. Más lejana es aún la situación si se compara con el entorno de cargas y deformaciones de la edificación. 


\subsubsection{LAS DOS GRÁFICAS VISTAS DESDE SUS $K_{\text {ser }}$}

En este apartado se analiza lo mismo que en el anterior, visto ahora desde la rigidez a deslizamiento en lugar de desde las curvas de los ensayos. En los gráficos de la figura 4 se han sustituido las curvas de los ensayos por rectas cuya pendiente es la rigidez $\mathrm{K}_{\mathrm{ser}}$. Se incluye también la rigidez obtenida en el ensayo de rasante aplicando la Norma UNE 26891. En resumen:

-En línea continua (roja el hormigón y azul la madera microlaminada) se muestran las rigideces que se obtendrían en las tres cargas (ELS, ELU y ELR) de los ensayos de flexión de las vigas. $O$ sea, las rigideces secantes de la viga $\left(K_{\text {ser }}\right)$ en su cruce con esos niveles de carga.

-En línea a trazos están representadas las rigideces obtenidas en los ensayos de rasante aplicando la norma UNE.

-Por último, en línea negra está el $\mathrm{K}_{\text {ser }}$ obtenido según la tabla 7.1 del Eurocódigo EC-5.

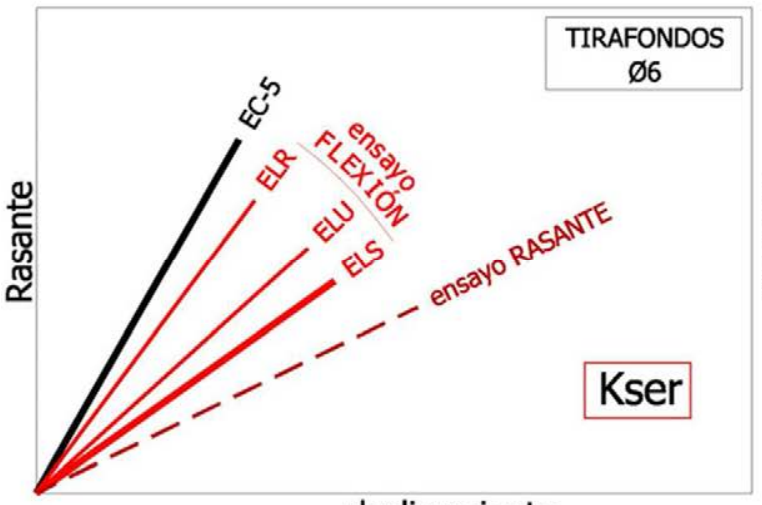

deslizamiento

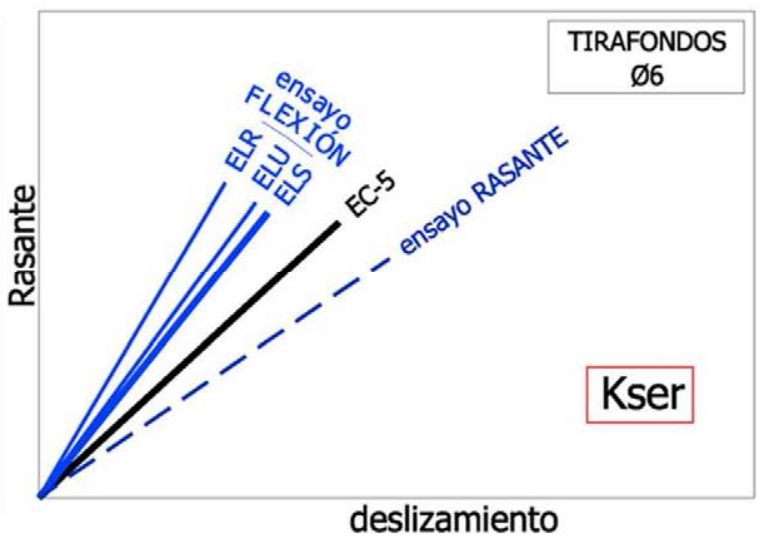

deslizamiento

figura 4. Módulos de deslizamiento $\left(K_{\text {ser }}\right)$ de los ensayos y del EC-5 


\section{CONCLUSIONES}

El $\mathrm{K}_{\text {ser }}$ obtenido en el ensayo de rasante según la Norma UNE $\left(0,4 \cdot \mathrm{F}_{\text {rotura }}\right)$ está muy por debajo de la rigidez de la viga para ambos materiales.

En las vigas con capa de compresión de hormigón, los ensayos de flexión son menos rígidos que lo que marca el Eurocódigo EC-5. En el EC-5, para obtener el $\mathrm{K}_{\mathrm{ser}}$ de una unión, cuando una de las partes es de hormigón, se aplica un factor multiplicador de valor 2, que, por lo que se ve en estos ensayos, puede que sea excesivo. ${ }^{73}$

En las vigas con madera microlaminada, los ensayos de flexión dan rigideces superiores a lo obtenido en el EC-5.

En los ensayos de vigas a flexión es donde se aprecian grandes diferencias entre el comportamiento del hormigón y de la madera microlaminada:

-En las vigas con hormigón. Los $\mathrm{K}_{\mathrm{ser}}$ obtenidos del ensayo de flexión en diferentes cargas ( $E L S=1,25 \mathrm{kN} / \mathrm{m} ; E L U=1,75 \mathrm{kN} / \mathrm{m} ; E L R=3,00 \mathrm{kN} / \mathrm{m}$ ) son mayores cuanto mayor es la carga, cosa contraria a lo habitual, pero que ratifica lo que ya muestra la forma cóncava de la curva. Esto ocurre en todos los ensayos de hormigón de esta tesis (16 ensayos), tengan resina o no.

-En las vigas de madera microlaminada las 3 rigideces son muy parecidas para las 3 cargas (en el caso analizado también se aprecia una concavidad en la zona inicial -muy inferior a la del hormigón-, pero no tiene carácter general en el resto de ensayos de esta tesis, por lo que podría deberse a reajustes durante la entrada en carga).

\footnotetext{
${ }^{73}$ En el conjunto de los ensayos con hormigón de esta tesis, dos terceras partes están en esta línea y el resto da rigideces ligeramente superiores a lo que marca el Eurocódigo.
} 


\subsubsection{EL CURIOSO CASO DEL HORMIGÓN BIPOLAR}
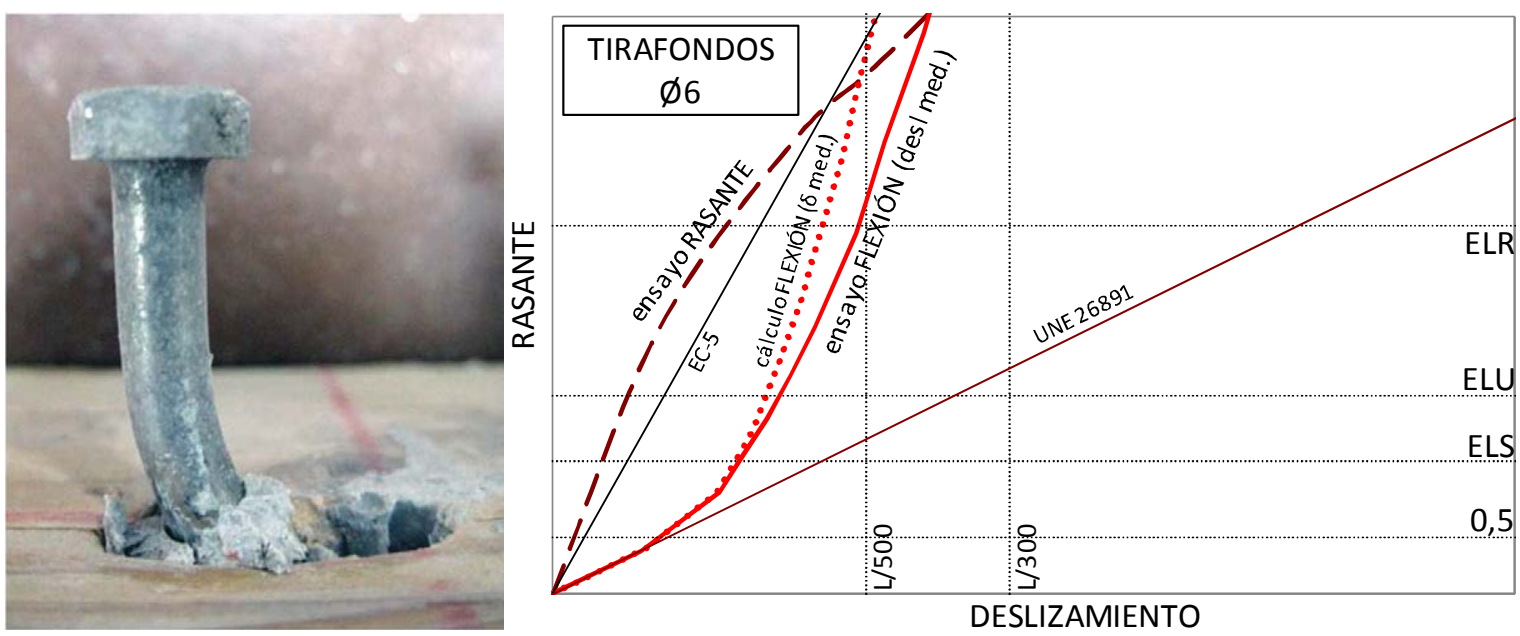

figura 5. Ensayo de viga con capa de compresión de hormigón

El gráfico de la figura 5 es uno de los expuestos antes. Contiene la superposición de los ensayos de flexión y de rasante en el arranque de ambas gráficas que se corresponde con la etapa de servicio en edificación.

Obsérvese que la gráfica de la viga (ensayo FLEXIÓN) es cóncava y la de rasante, convexa. Este apartado se dedica a buscar explicación a este fenómeno. Se ha elegido este ensayo por reflejar claramente esta inversión de rigidez entre ambos ensayos, pero es común a todos los realizados con capa de compresión de hormigón.

En principio cabría una explicación basada en el comportamiento de cada material. En la fotografía de un conector con resina se aprecia el hendimiento de la madera, el aplastamiento de la resina y la deformación del tirafondo. Lógicamente, estos tres fenómenos no ocurren a la vez, sino en función del que menor rigidez ofrezca en cada etapa de deformación. Cabe pensar que la concavidad de las gráficas de los ensayos de las vigas pueda ser el reflejo de la gráfica tensión deformación típica de los polímeros y que por tanto, para esa etapa de deformaciones fuera la resina la que marcara la pauta de la deformación de la viga. Pero este razonamiento se cae por dos motivos: la conexión casi no se deforma, pero además lo hace en menor medida cuanto más lejos del apoyo, luego en el extremo puede estar doblándose el acero, en los cuartos aplastándose la resina y cerca del centro hendiéndose la madera; cada uno estará en su etapa de rigidez relativa menor. Por tanto, difícilmente la deformación de la resina marcará la pauta de la deformación general de la viga. El otro motivo es que ocurre lo mismo cuando en la conexión no hay resina.

\section{El proceso de hormigonado}

Puede que haya una explicación derivada del proceso del hormigonado, porque el de la viga se hizo distinto del de la probeta del ensayo de rasante. 
Desde la óptica del proceso constructivo, la posición de la viga en el hormigonado puede ser la causante de esta concavidad. En la figura 6, la primera fotografía muestra el encofrado general, la segunda el hormigonado, la tercera el detalle de la vigueta apoyada en los extremos para no aplastar al hormigón blando y la cuarta la pieza desencofrada en su posición natural. Las operaciones así realizadas son las que consiguen el hormigonado más sencillo.
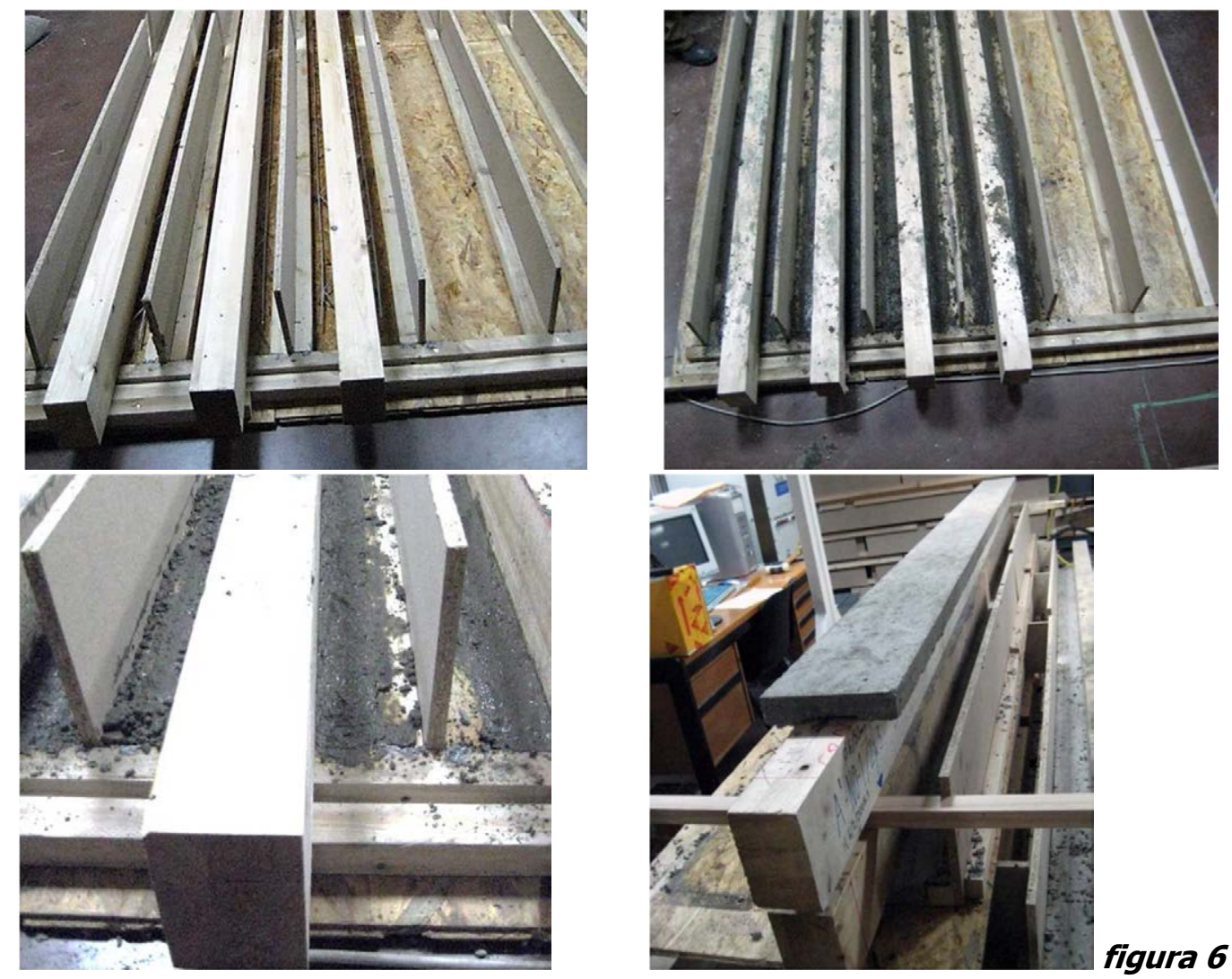

Este montaje puede que haya tenido bastante influencia en el comportamiento global de la viga mixta. Por un lado, en condiciones normales de edificación, el hormigón mientras fragua está apoyado sobre las viguetas y su propio peso le hace adaptarse a sus rugosidades y esto no ocurre en este trabajo. Por otro lado, al estar el hormigón debajo de la vigueta durante el hormigonado, por poca retracción que haya en el fraguado o por falta de contacto total (aunque la vigueta quedaba algo enterrada para evitarlo), la merma o la ausencia del hormigón le hace perder contacto total con la vigueta, cosa que en un hormigonado normal tampoco ocurre.

En consecuencia, puede que la viga mixta necesite unos mínimos movimientos en vacío antes de que la conexión entre en carga. Habiéndose perdido en las etapas iniciales la colaboración de la cohesión que se consigue con la lechada actuando como adhesivo, ya que la cohesión es un fenómeno más rígido que la conexión a cortante.

Las curvas de rasante/deslizamiento del ensayo de rasante son las usuales en cualquier ensayo de este tipo, con una pérdida progresiva de rigidez porque estas probetas se hormigonaron con el hormigón encima, lo que asegura el llenado de la superficie de contacto. 


\subsection{COMPARACIÓN DE TODOS LOS $\mathrm{K}_{\mathrm{ser}}$}

\subsubsection{TABLA RESUMEN DE $K_{\text {ser }}$}

En la figura 7 está representada la relación de los $\mathrm{K}_{\text {ser }}$ de todos los ensayos (rasante y flexión) con los $\mathrm{K}_{\text {ser }}$ obtenidos según la tabla 7.1 del Eurocódigo EC-5. Los puntos negros situados en la cota 1 son los $K_{\text {ser }}$ correspondientes al EC-5, los puntos amarillos representan los $K_{\text {ser }}$ obtenidos en los ensayos de rasante según la Norma UNE 26891 y las cruces rojas son los $\mathrm{K}_{\text {ser }}$ secantes de los ensayos de flexión para la carga ELS $(1,25 \mathrm{kN} / \mathrm{m})$. Los gráficos superiores corresponden a ensayos con vigueta de madera laminada y los inferiores con madera aserrada. ${ }^{74}$

CAPA DE COMPRESIÓN DE HORMIGÓN

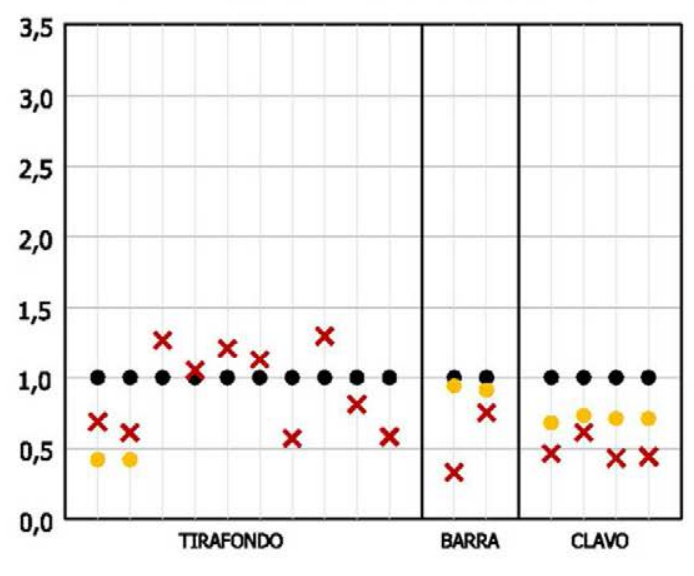

CAPA DE COMPRESIÓN DE MADERA MICROLAMINADA

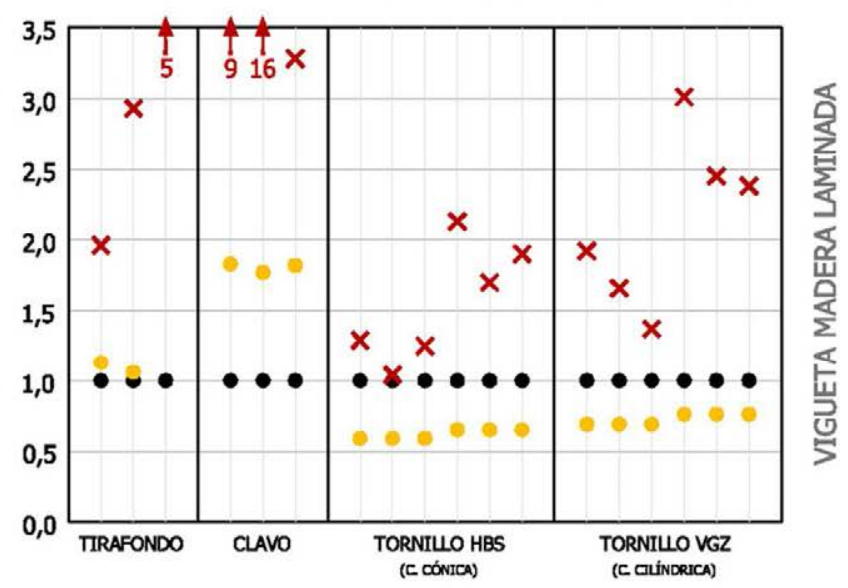

- Ker EC-5

Kor Ensayo Rasante (UNE 26891)

$X$ Ker Ensayo Flexión L=3,20 $\mathrm{m}$ (ELS)

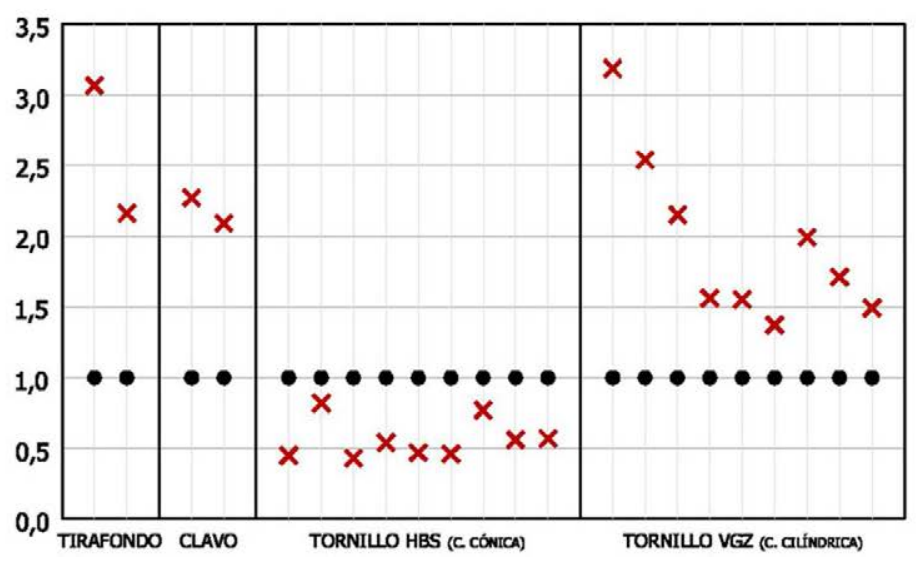

figura 7. $K_{\text {ser }}$ de todos los ensayos

\footnotetext{
${ }^{74}$ En la figura 7 no están representados los ensayos con presión entre los materiales. 


\section{CONCLUSIONES}

\section{ENSAYOS DE RASANTE}

En general, los $\mathrm{K}_{\mathrm{ser}}$ obtenidos en los ensayos de rasante son inferiores (rigidez menor), a los obtenidos según el Eurocódigo EC-5. Esto no ocurre clavos y capa de compresión de madera microlaminada, que se comporta de una manera muy rígida debido a la presión.

Estos $K_{\text {ser }}$ de los ensayos de rasante también son inferiores a los obtenidos en los ensayos de flexión, con la excepción de las conexiones que no han trabajado correctamente en los ensayos de flexión (barra corrugada y clavos con capa de compresión de hormigón).

Estas diferencias reafirman lo que ya se había comentado anteriormente, parece que la cota de rasante en la que la Norma UNE 26891 obtiene el $K_{\text {ser }}$ es demasiado elevada, produciendo rigideces muy bajas.

\section{ENSAYOS DE FLEXIÓN}

En los ensayos de flexión la comparación con lo obtenido en la normativa depende del tipo de conexión:

-En las vigas con capa de compresión de hormigón, los $\mathrm{K}_{\mathrm{ser}}$ obtenidos en los ensayos están en el entorno marcado por el EC-5, aunque por lo general los ensayos son menos rígidos, si bien pudiera ser debido al proceso de hormigonado.

-En las vigas con capa de compresión de madera microlaminada, los $\mathrm{K}_{\mathrm{ser}}$ obtenidos en los ensayos son notablemente superiores a lo que marca la normativa.

-Observando los resultados de los tornillos, se aprecia nuevamente la importancia de la elección del tipo de tornillo para la conexión. Los tornillos HBS, que por su cabeza cónica demostraban ser adecuados para el pretensado, ya que transmitían muy bien la presión hasta la vigueta, tienen también la parte superior del fuste lisa, lo que en general les hace perder mucha rigidez en la conexión debido a que la ausencia de rosca les hace perder adherencia con la capa de compresión. Sin embargo, los tornillos VGZ, que debido a la forma de su cabeza no son buenos para el pretensado, tienen todo su fuste roscado, formando una conexión mucho más rígida. Por lo tanto, el comportamiento de ambos tornillos es bien distinto. Estos aspectos del diseño no están contemplados en la Normativa, que tiene solo una formulación para todos. 


\section{CAMBIO DE ESCALA}

La mayor rigidez de los ensayos de flexión respecto a lo obtenido según el Eurocódigo podría deberse en parte a la escala de las vigas ensayadas, construidas con una luz de 3,20 m, aproximadamente $2 / 3$ que la de un forjado de este tipo. Para analizar este factor, se expone en la figura 8 las mismas relaciones de rigideces de la figura 7, pero en cada caso se le ha añadido el $\mathrm{K}_{\text {ser }}$ que tendrían los ensayos de flexión si las vigas tuviesen una luz de $5 \mathrm{~m}$.

Para realizar este cambio de escala, como se ha visto en el capítulo 1, basta con utilizar una carga superior. Es decir las rigideces obtenidas en la viga de luz 3,20 para una carga de 2'ELS $(2,50 \mathrm{kN} / \mathrm{m})$ corresponden aproximadamente a las rigideces de una viga de luz 5,00 m en ELS.

CAPA DE COMPRESIÓN DE HORMIGÓN

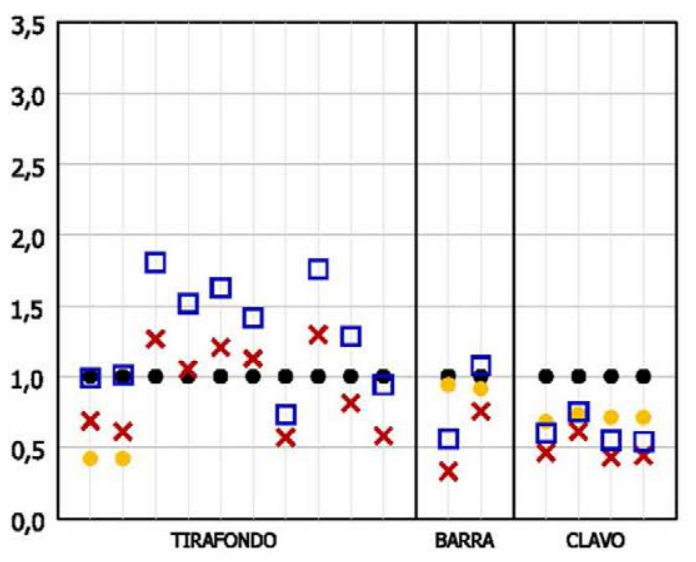

CAPA DE COMPRESIÓN DE MADERA MICROLAMINADA

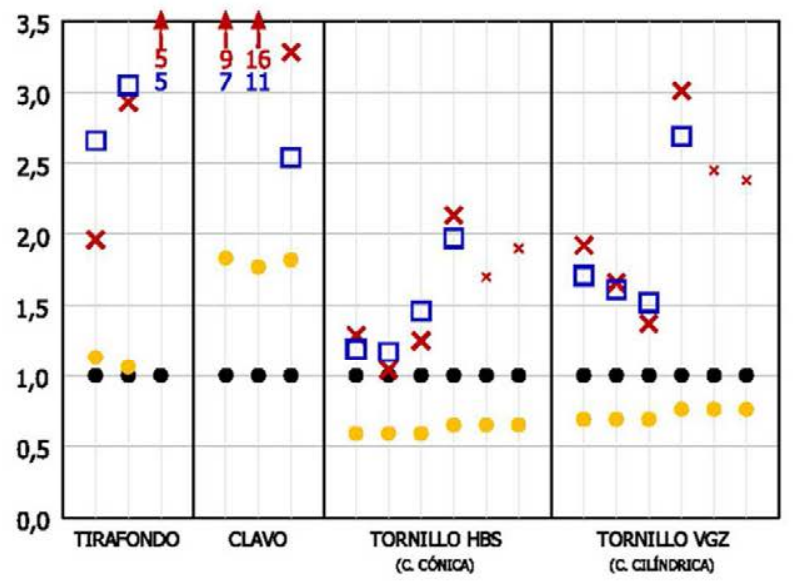

figura 8. $K_{\text {ser }}$ de vigas homotéticas de $5 \mathrm{~m}$ de luz ${ }^{75}$

Como se puede observar, no existen grandes variaciones para este cambio de escala. En las vigas con capa de compresión de hormigón, que como se ha comentado anteriormente, debido a su concavidad, aumentan la rigidez con el incremento de carga, al simular una viga de $5 \mathrm{~m}$ de luz las rigideces que se obtienen son mayores que las de la viga de $3,20 \mathrm{~m}$.

\footnotetext{
${ }^{75}$ La carga de $2,5 \mathrm{kN} / \mathrm{m}$ no se alcanza en alguno de los ensayos que se detienen en la flecha de $\mathrm{L} / 300$, por lo que, de estos no puede hacer la simulación de una mayor luz. Se ha dejado su valor con una cruz pequeña para mantener el esquema del gráfico y permitir una mejor comparación con el anterior.
} 
En las vigas con capa de compresión de madera microlaminada, que como se ha visto, tienen un comportamiento por un lado más lineal y por otro, más acorde a los diagramas de tensión-deformación de los materiales que las componen, este cambio de escala no supone cambios relevantes, de hecho, en unos casos se obtienen resultados más rígidos y en otros menos rígidos, pero dentro del mismo ámbito. 


\subsubsection{TORNILLOS VGZ (Cabeza Cilíndrica, Rosca Completa)}

Las conexiones con tornillos VGZ, es decir, los que tienen la cabeza cilíndrica y rosca en todo su fuste, tienen más rigidez que lo que marca la normativa en todos los casos, como se ha visto en la figura 7. En este apartado se van a analizar posibles causas.

Estos tornillos pertenecen al grupo de vigas que fueron ensayadas varias veces con diferentes separaciones entre los tornillos, posteriormente se ensayaron sin conexión y después se ensayaron por separado la vigueta y la capa de compresión.

Como se vio en el capítulo 5.2, al haber ensayado por separado las dos partes y obtenido sus rigideces, se conoce la rigidez teórica de la viga sin conexión (suma de ambas rigideces), y de la comparación de esta rigidez con la del ensayo sin conexión se obtiene la influencia del rozamiento en la conexión. De esta forma, se ha obtenido la ganancia de rigidez debida al rozamiento en cada serie de ensayos.

En la figura 9 están representadas las relaciones de los $\mathrm{K}_{\mathrm{ser}}$ de los ensayos de flexión (cruces rojas) con los $\mathrm{K}_{\text {ser }}$ obtenidos según el EC-5 (círculos negros). Los rombos verdes representan esos ensayos, a los que se les ha restado la mejora del rozamiento. La línea verde a trazos representa su valor medio.

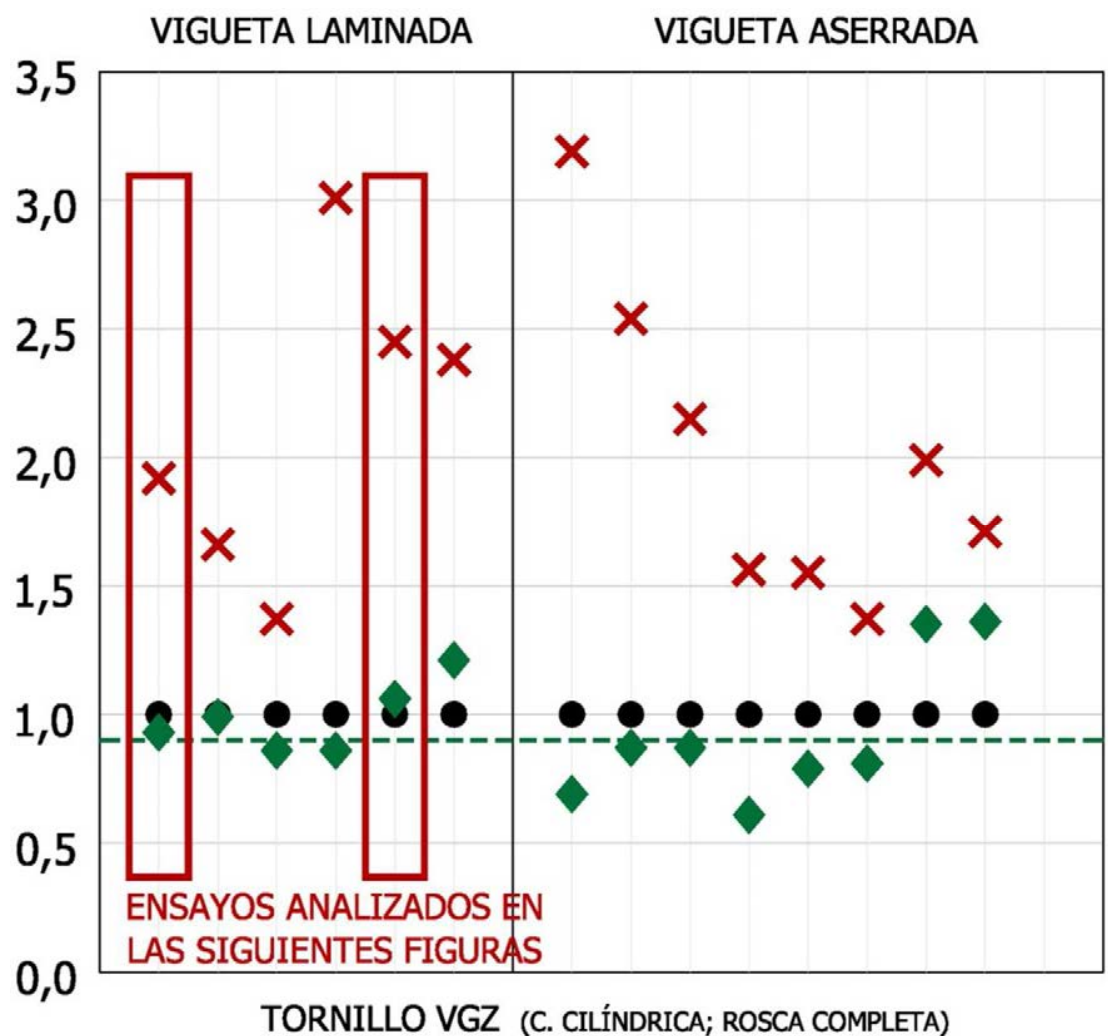

figura 9. $K_{\text {ser }}$ de vigas con tornillos VGZ

Como se aprecia claramente, una vez se descuenta este efecto, los resultados obtenidos se asemejan mucho al EC-5 
En las siguientes figuras se van a ir quitando los factores que hacen mejorar la rigidez en los ensayos respecto a la normativa. Se han estudiado los dos casos recuadrados en la figura 9, que corresponden a dos esbelteces distintas. En la figura 10 están representadas las pendientes de las rigideces $\left(\mathrm{K}_{\mathrm{ser}}\right.$ ) del ensayo de rasante (UNE 26891), del Eurocódigo EC-5 (tabla 7.1) y de los ensayos de flexión con y sin presión.

\section{FACTOR PRESIÓN}

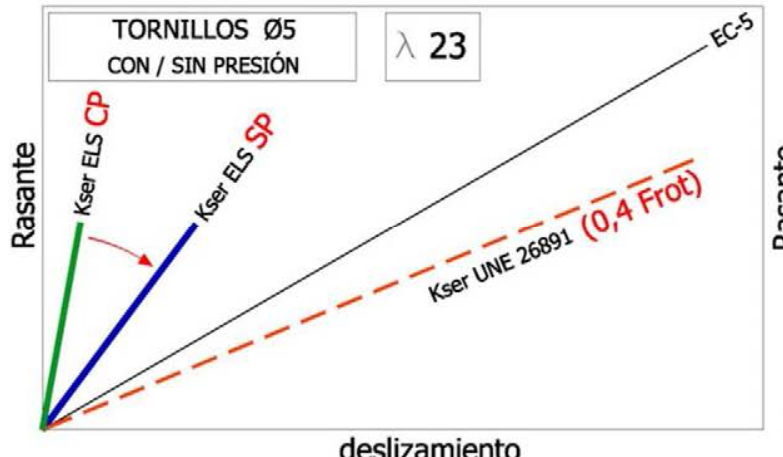

deslizamiento

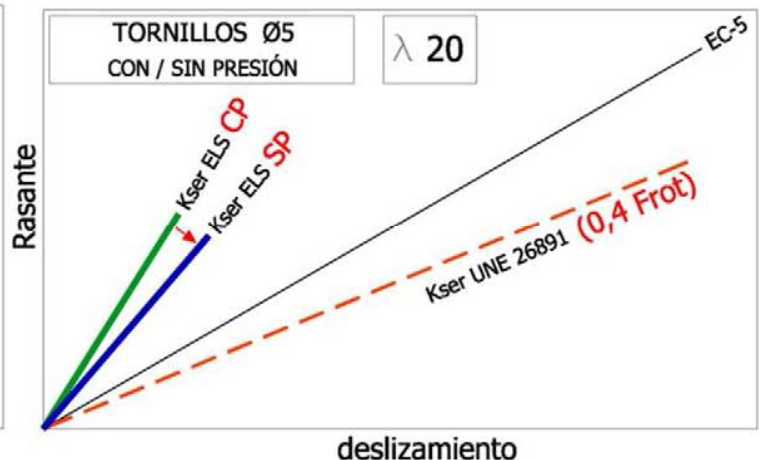

deslizamiento

figura 10. Mejora del pretensado

Una vez quitada la influencia de la presión, en la figura 11 se descuenta el rozamiento:

FACTOR ROZAMIENTO
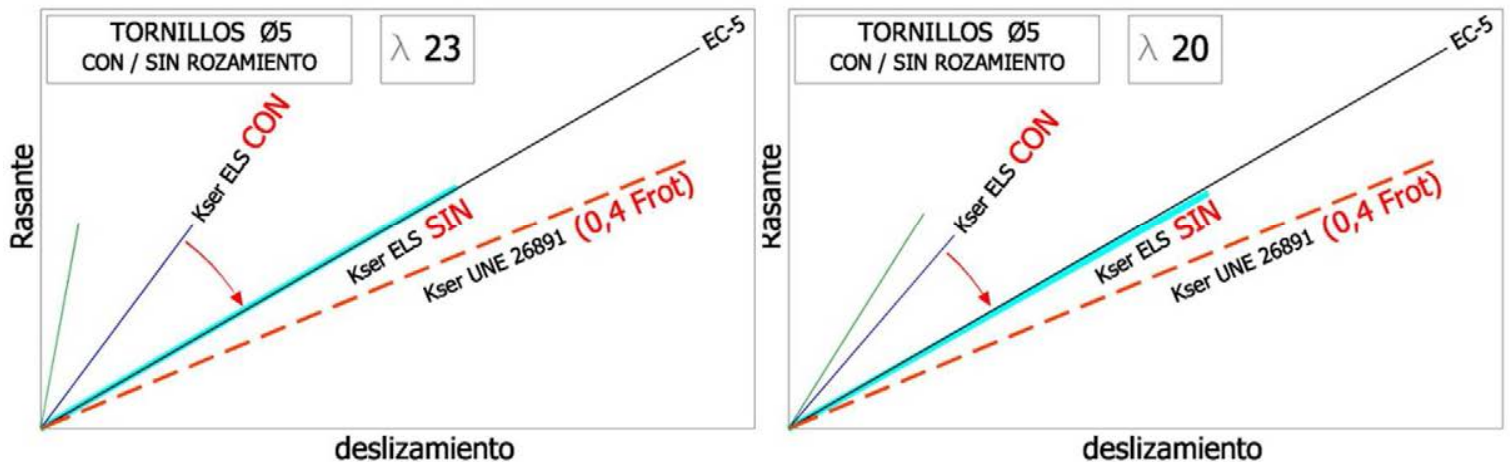

figura 11. Mejora del rozamiento

Por último, en la figura 12 se dibuja el $\mathrm{K}_{\text {ser }}$ del ensayo de rasante calculado en $0,3 \cdot \mathrm{F}_{\text {rotura. }}$.

\section{$K_{\text {ser }}$ RASANTE EN 0,30 ' $F_{\text {rotura }}$}
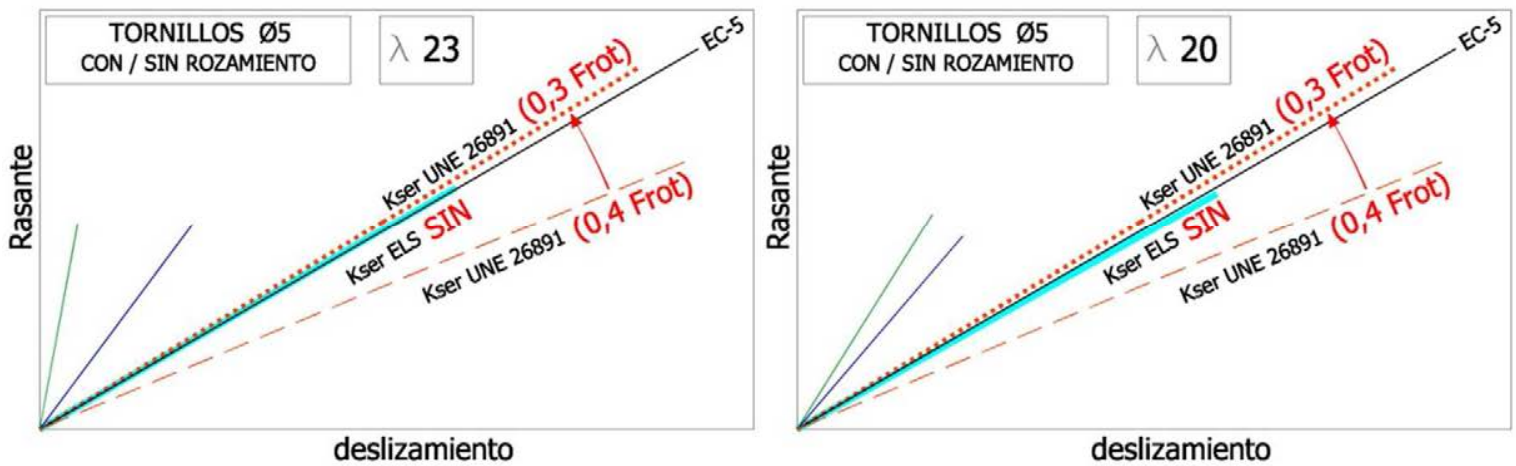

figura 12. $K_{\text {ser }}$ de ensayo de rasante en $0,3^{\cdot} F_{\text {rotura }}$ 


\section{CONCLUSIONES}

Como se observa, si en los valores del ensayo se elimina la influencia tanto de la presión como del rozamiento (no contempladas en la normativa), se obtienen valores de $\mathrm{K}_{\text {ser }}$ muy cercanos al Eurocódigo EC-5:

Analizando la viga de esbeltez 23 (columna izquierda de las figuras 10,11 y 12 ), el $\mathrm{K}_{\mathrm{ser}}$ de la viga con presión es 4 veces mayor que el de la viga sin presión, que a su vez es 2,3 veces mayor que la viga sin rozamiento, alcanzándose un valor similar al del Eurocódigo EC-5.

Analizando ahora la esbeltez 20 (columna derecha), el $\mathrm{K}_{\mathrm{ser}}$ de la viga con presión es 1,36 veces mayor que el de la viga sin presión, que a su vez es 2,07 veces mayor que la viga sin rozamiento, en total 2,72 veces superior al Eurocódigo EC-5.

Lo que significa que existe una notable mejora de rigidez de la conexión, que en estos dos casos oscila aproximadamente entre 3 y 9 veces, que no está siendo considerada por la normativa. Esta diferencia entre las dos series de ensayos, no es debida tanto a la diferencia de esbeltez como a la diferente influencia de la presión en las dos vigas.

Si además, calculamos el $\mathrm{K}_{\text {ser }}$ de los ensayos de rasante en un nivel de carga del $0,3 \cdot F_{\text {rotura }}$ todas las líneas convergen.

\section{NOTA ACERCA DE LA OBTENCIÓN DE ESTOS RESULTADOS:}

Cada serie consta de las siguientes etapas:

$\begin{array}{ll}\text { a } & \text { Rigidez de cada parte (2 ensayos) } \\ \text { b } & \text { Rigidez teórica sin conexión (suma de las anteriores) } \\ \text { c } & \text { Rigidez real sin conexión (1 ensayo) } \\ \text { d } & \text { Obtención del rozamiento (c }- \text { b) } \\ \text { e } & \text { Rigidez real con conexión sin presión (1 ensayo) } \\ \text { f } & \text { Rigidez real con conexión con presión (1 ensayo) } \\ \text { g } & \text { Influencia de la presión ( } \mathrm{f}-\mathrm{e} \text { ) }\end{array}$




\subsubsection{TORNILLOS HBS (Cabeza Cónica, Caña Lisa)}

A continuación, se realiza el mismo análisis para las conexiones con tornillos HBS, que tienen la cabeza cónica y la parte superior del fuste lisa, sin rosca. Las conexiones con este tornillo han dado resultados más rígidos que la normativa en las viguetas de madera laminada y menos rígidos en viguetas de madera aserrada.

$\mathrm{Si}$ a estos ensayos se les quita la influencia del rozamiento como se ha realizado en el apartado anterior, se obtienen valores de $\mathrm{K}_{\text {ser }}$ muy inferiores a los del EC-5 (la mitad de rígidos), como se observa en la figura 13.

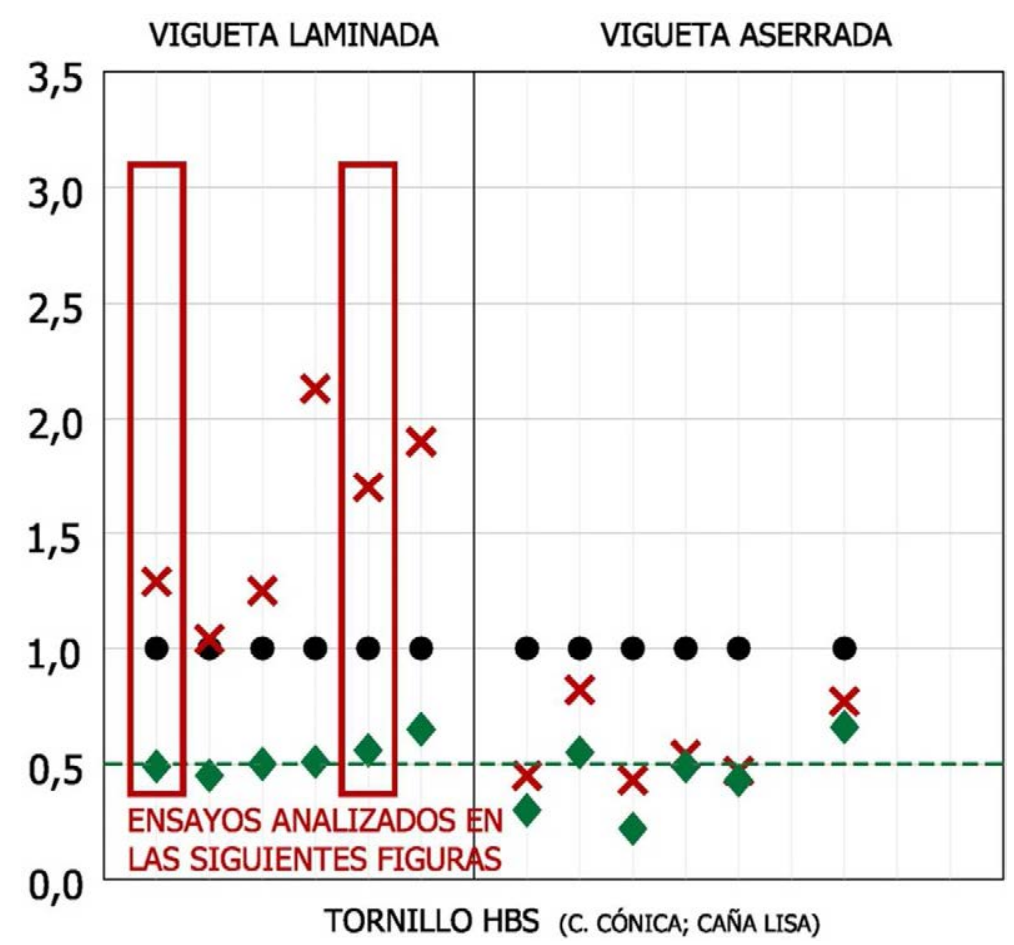

figura 13. $K_{\text {ser }}$ de vigas con tornillos $H B S$ 
En las figuras 14,15 y 16 se van a ir quitando los factores que influyen en la rigidez de los ensayos, tal y como se ha hecho en el apartado anterior. Se han estudiado los dos casos recuadrados en la figura 13, que corresponden como antes a dos esbelteces distintas.

\section{FACTOR PRESIÓN}
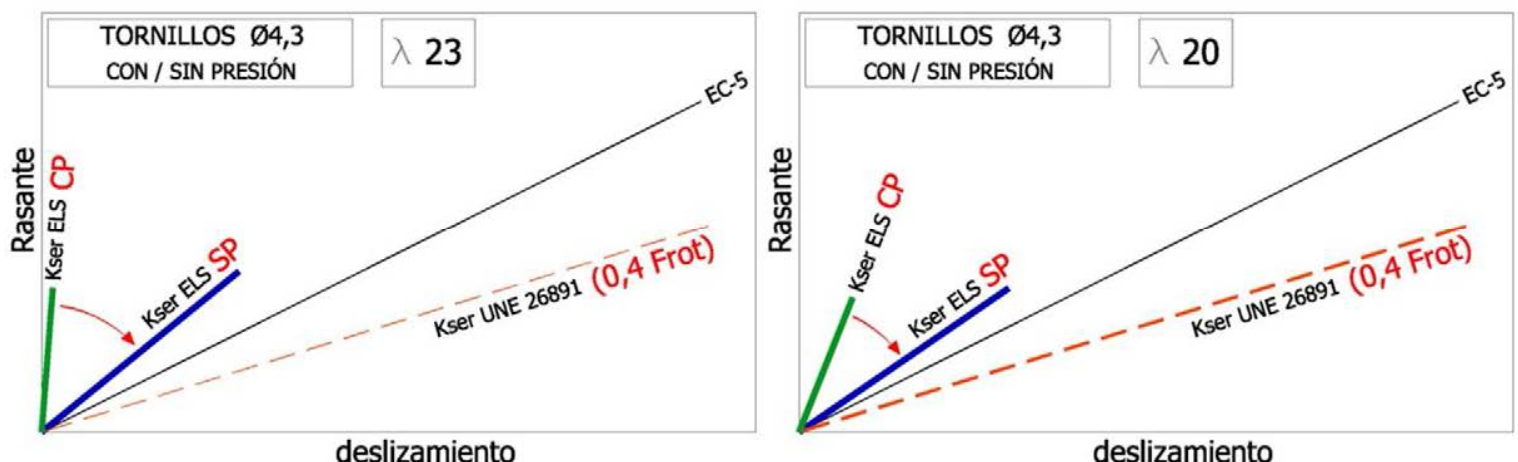

figura 14. Mejora del pretensado

\section{FACTOR ROZAMIENTO}
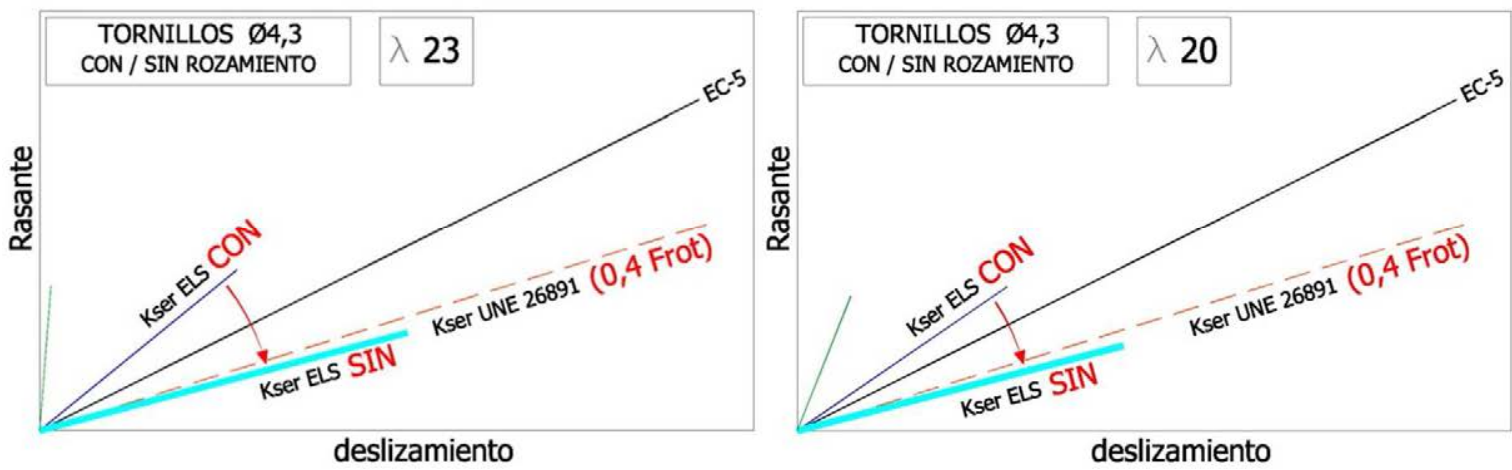

figura 15. Mejora del rozamiento

$K_{\text {ser }}$ RASANTE EN 0,30 - Frotura
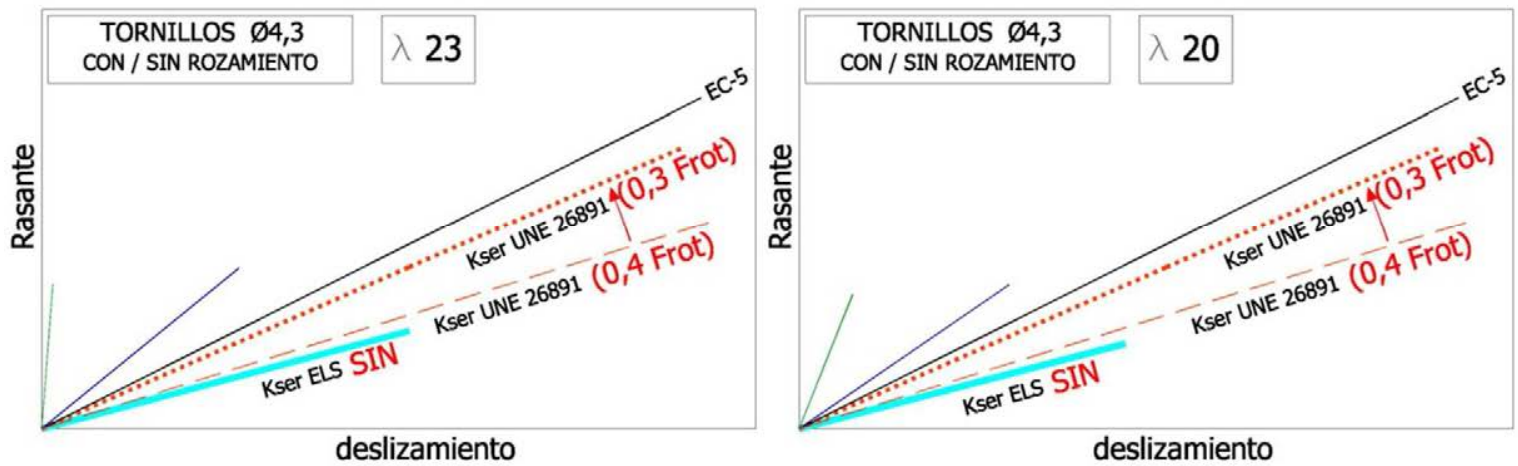

figura 16. $K_{\text {ser }}$ de ensayo de rasante en $0,3^{\cdot} F_{\text {rotura }}$ 


\section{CONCLUSIONES}

En las conexiones realizadas con este tipo de tornillo, que al inicio eran más rígidas que lo indicado en la normativa, si les quitamos la influencia tanto de la presión como del rozamiento, se obtienen valores de $\mathrm{K}_{\text {ser }}$ muy cercanos al $50 \%$ de lo que se obtiene al aplicar el EC-5:

Analizando la viga de esbeltez 23 (columna izquierda de las figuras 14,15 y 16 ), el $\mathrm{K}_{\mathrm{ser}}$ de la viga con presión entre los materiales es 14 veces mayor que el de la viga sin presión (ya se vio que este tipo de tornillos pueden mejorar mucho la rigidez de la conexión si se ejerce presión), que a su vez es 3 veces mayor que sin rozamiento. Esto significa que el ensayo, gracias a las mejoras de rigidez debidas a la presión y al rozamiento es 23,3 veces más rígido que lo que marca la normativa. Por tanto, si se eliminan estas mejoras no normativas, la rigidez de la conexión sería la mitad que la del Eurocódigo (0,54).

Analizando ahora la esbeltez 20 (columna derecha), el $\mathrm{K}_{\mathrm{ser}}$ de la viga con presión es 3,53 veces mayor que el de la viga sin presión, que a su vez es 2,61 veces mayor que la viga sin rozamiento, en total 4,78 veces superior al Eurocódigo EC-5. Sin contar con estas mejoras, la rigidez es de nuevo la mitad que la del EC-5 $(0,52)$.

Si volvemos a calcular el $\mathrm{K}_{\text {ser }}$ de los ensayos de rasante en un nivel de carga del $0,3 \cdot \mathrm{F}_{\text {rotura, }}$ en vez de en el $0,4^{\cdot} \mathrm{F}_{\text {roturar }}$ se acerca mucho más al $\mathrm{K}_{\text {ser }}$ del EC-5, aunque sigue siendo inferior, debido al mal funcionamiento del fuste liso.

Como conclusión global del estudio de estos dos tornillos queda patente que para estimar el módulo de deslizamiento de un conector es imprescindible tener en cuenta sus características morfológicas, ya que estas condicionan en gran medida el comportamiento de la conexión. 


\subsection{MAGNITUD DEL DESLIZAMIENTO EN AMBOS ENSAYOS}

En este apartado se van a estudiar los ámbitos de rasante y deslizamiento en los que trabaja el conector en cada tipo de ensayo.

\subsubsection{ANÁLISIS DE PROBETAS DESPUÉS DE LA ROTURA}

En los ensayos que se llevaron hasta la rotura, tanto de flexión como de rasante, se abrieron las probetas para examinar el estado en que habían quedado los conectores. En las vigas se tuvo la posibilidad de hacer radiografías de las viguetas (la capa de compresión era razonablemente fácil desbastarla o demoler cuidadosamente el hormigón). En las piezas de rasante se seccionó la capa de compresión para dejar a la vista los conectores.

Se muestran en la figura 17 algunas piezas correspondientes a ENSAYOS DE RASANTE y en la figura 18 radiografías y secciones de los ENSAYOS DE LAS VIGAS:
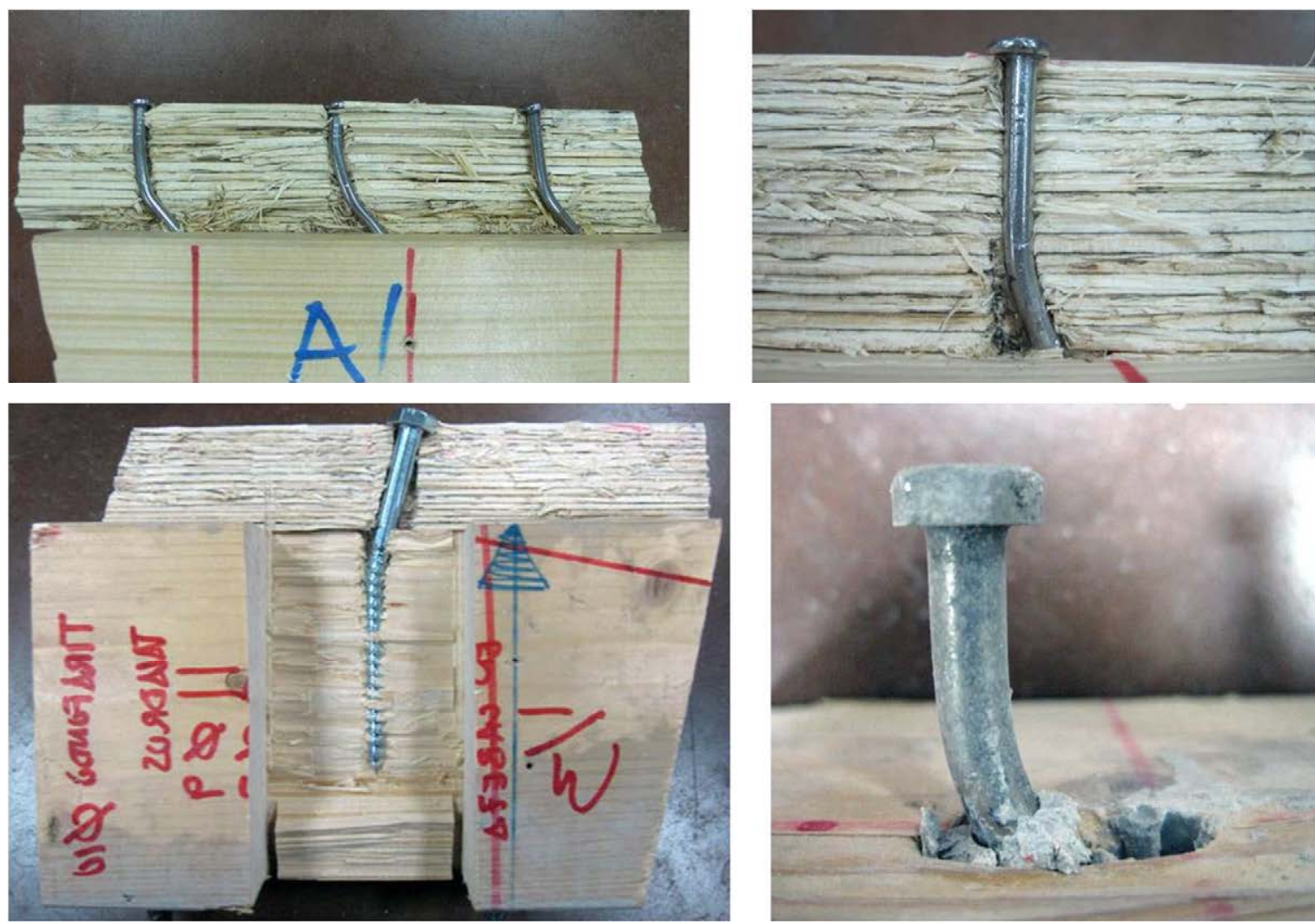

LA VIGA MIXTA CON MADERA: verificacoón experimental del método gamma y estudio de posibles alternativas de análisis 

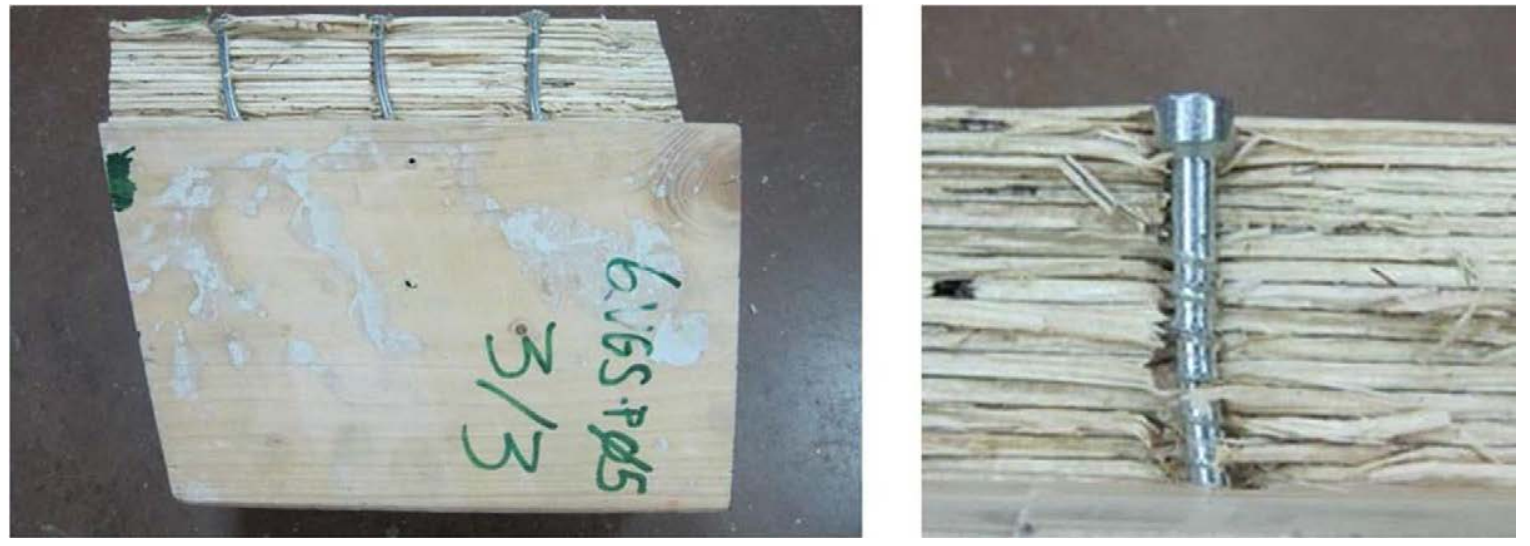

figura 17. Deformación de conectores en ensayos de rasante
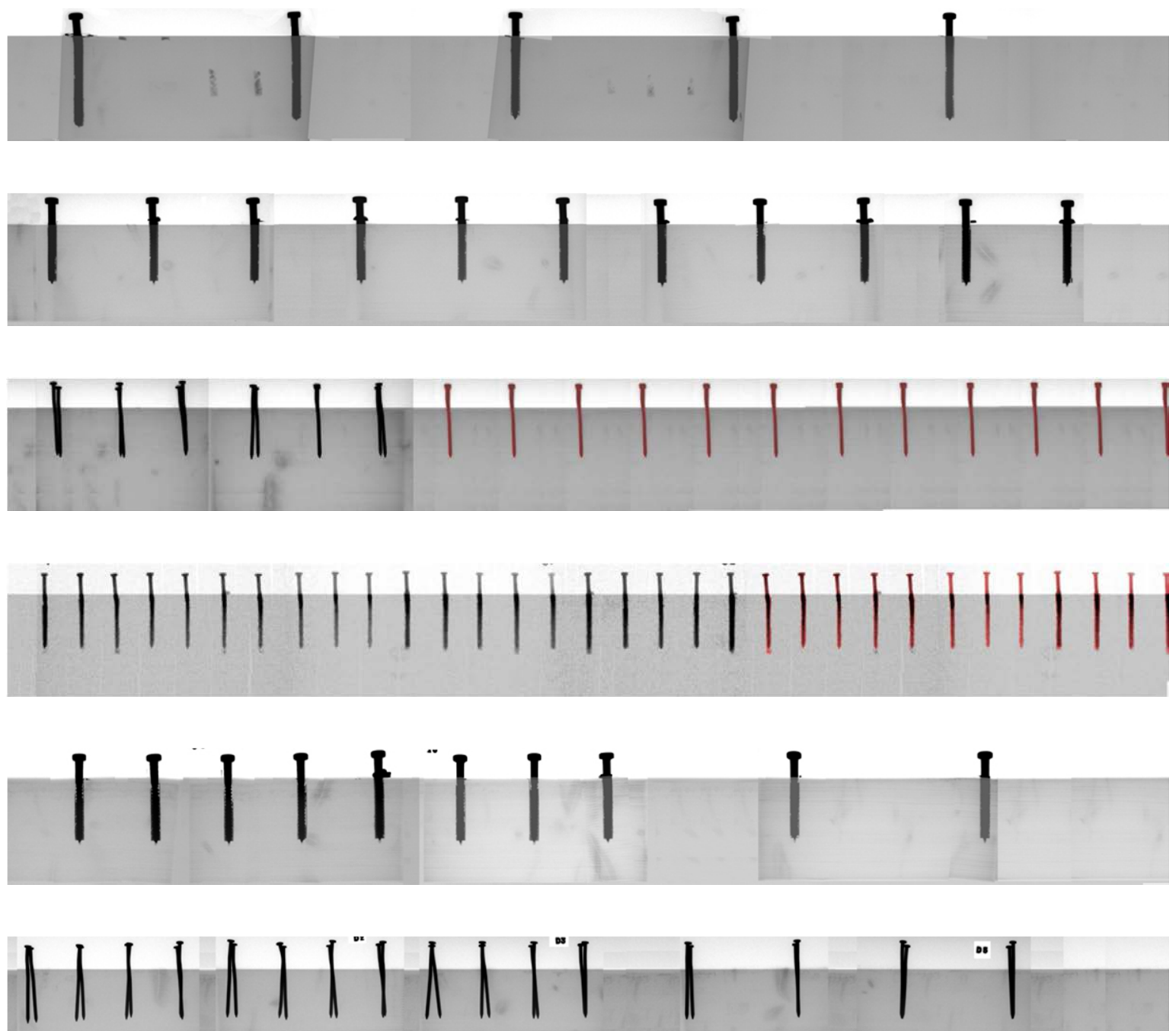

Los conectores que aparecen en rojo se han dibujado para mantener la cadencia en las partes no radiografiadas. A veces se aprecian lo que parecen conectores con dos ramas; lo que ocurre es que los conectores son dobles en cada sección y se están viendo ambos superpuestos. Su desplazamiento no obedece a que estén deformados sino a que se colocaron así. 


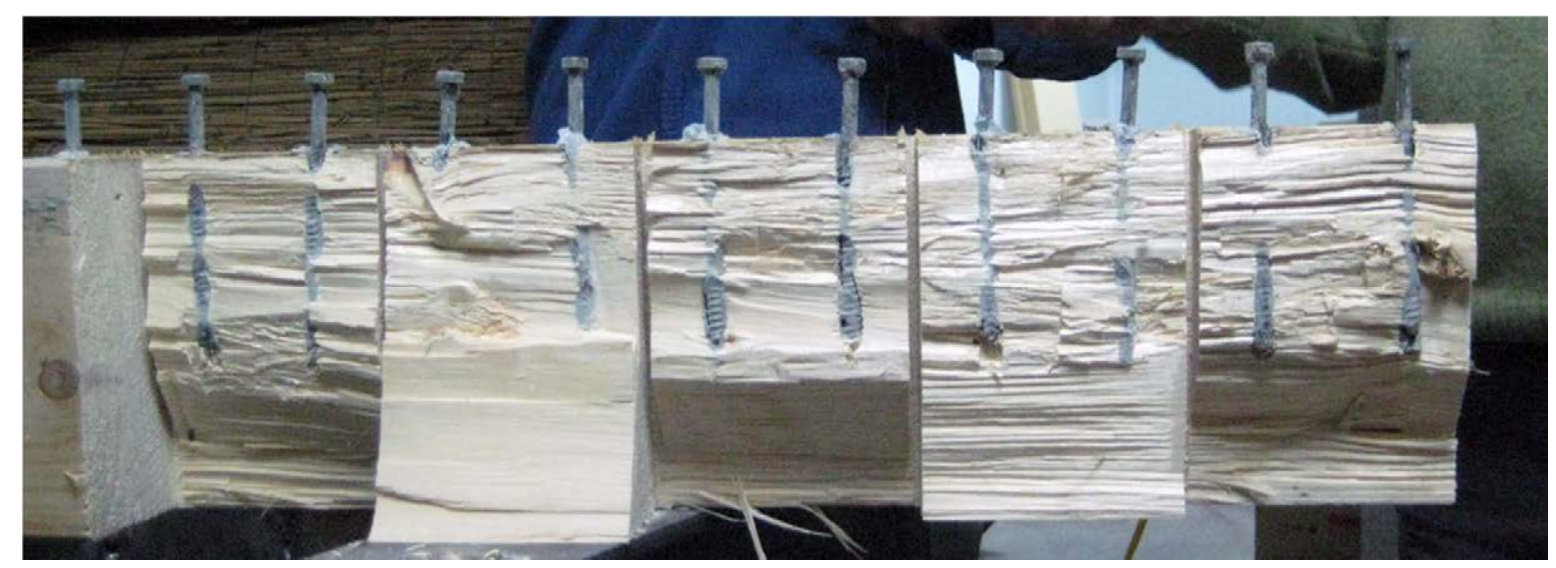

figura 18. Deformación de conectores en ensayos de flexión

La comparación visual de ambos tipos de probetas es muy clarificadora. En los ensayos de rasante se aprecia claramente la existencia de rotulas que indican una plastificación de los conectores y en la madera, su aplastamiento. En cuanto a los ensayos de flexión, cuando la viga llega a la rotura, ni los conectores ni la madera han sufrido alteraciones significativas. 


\subsubsection{SUPERPOSICIÓN EN LA ZONA DE ROTURA}

Los ensayos de rasante, realizados según la Norma UNE 26891, terminan con la rotura de la probeta o cuando el deslizamiento alcanza los $15 \mathrm{~mm}$. Mientras que en los ensayos de flexión de las vigas llevadas hasta rotura (28 casos) los deslizamientos máximos medidos están entre 2,0 y $3,5 \mathrm{~mm}$. Solo dos casos (clavos) superan los $4 \mathrm{~mm}$. Entretanto las flechas superan holgadamente el L/100, rompiendo generalmente por el desgarramiento de la madera de la vigueta. Como consecuencia, las vigas rompen a flexión antes de que los conectores lleguen a deslizamientos no ya críticos, sino apenas observables.

Los gráficos de la figura 19 muestran las curvas completas de los ensayos de rasante. Se han añadido cruces que señalan el valor de rasante y deslizamiento al que rompieron los ensayos homólogos de las vigas a flexión. Siempre con la capa de compresión de hormigón a la izquierda y la microlaminada a la derecha, y para diversos conectores.
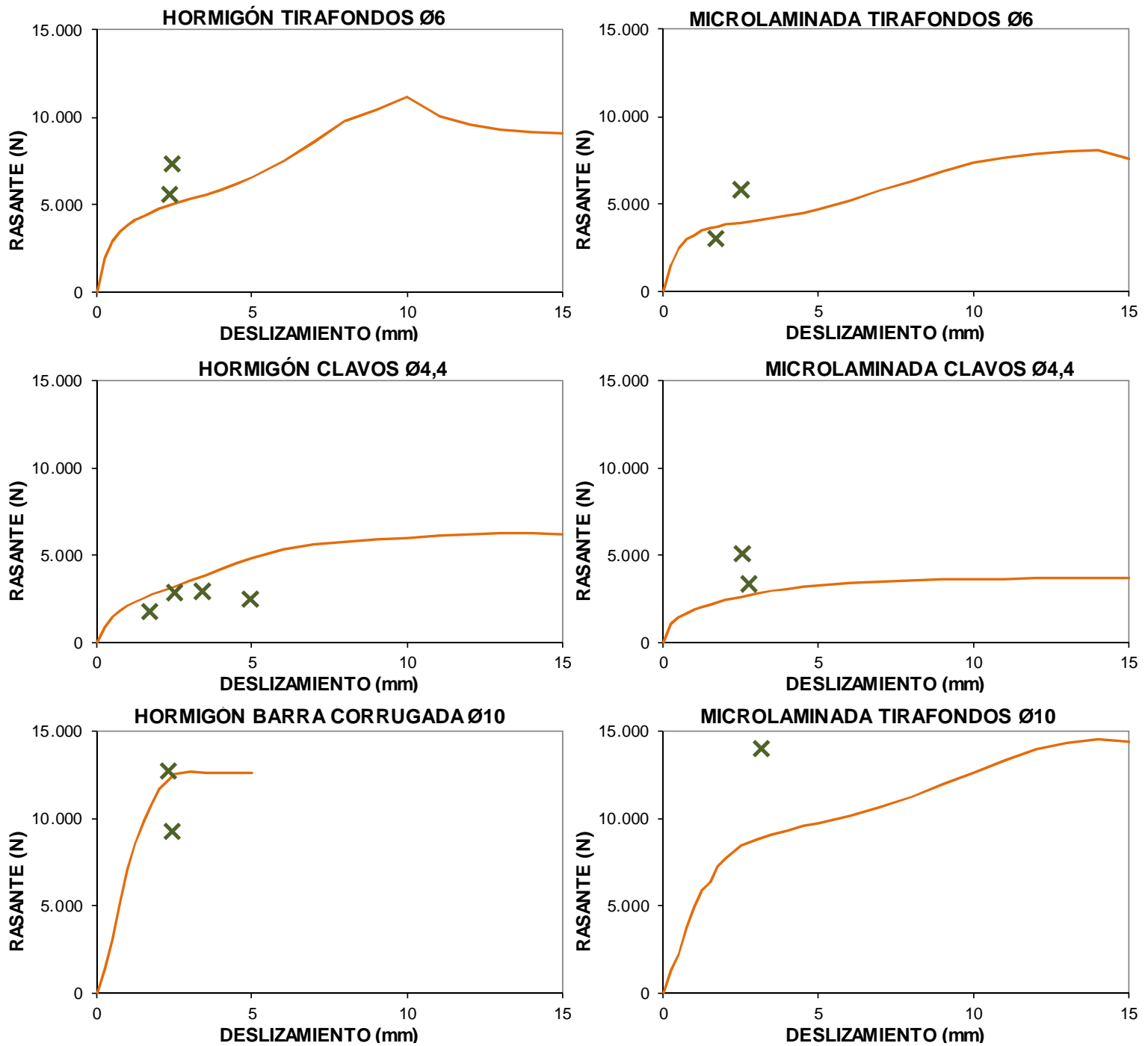

figura 19. Zona de rotura en ensayos de rasante y ensayos de flexión 


\subsubsection{SUPERPOSICIÓN EN LA ZONA DE SERVICIO}

El gráfico de la figura 20 representan los ensayos de rasante con círculos naranja. Estos círculos están situados en la cota de rasante $0,4 \cdot \mathrm{F}_{\text {rot }} \mathrm{y}$ en el deslizamiento que corresponde a esa carga. Esta cota, como se ha comentado, es en la que obtiene el $\mathrm{K}_{\text {ser }}$ según la Norma UNE 26891. Resumiendo, la curva de cada ensayo (figura 19) se ha sustituido por un punto.

Con cruces verdes se representan los ensayos de flexión en las cotas de rasante y deslizamiento que tiene la viga cuando alcanza la flecha del L/300 (límite normativo de deformación). Con cruces rojas se representan los ensayos de flexión en las cotas de rasante y deslizamiento correspondientes a la carga de servicio (ELS, $1,25 \mathrm{kN} / \mathrm{m}^{2}$ ).

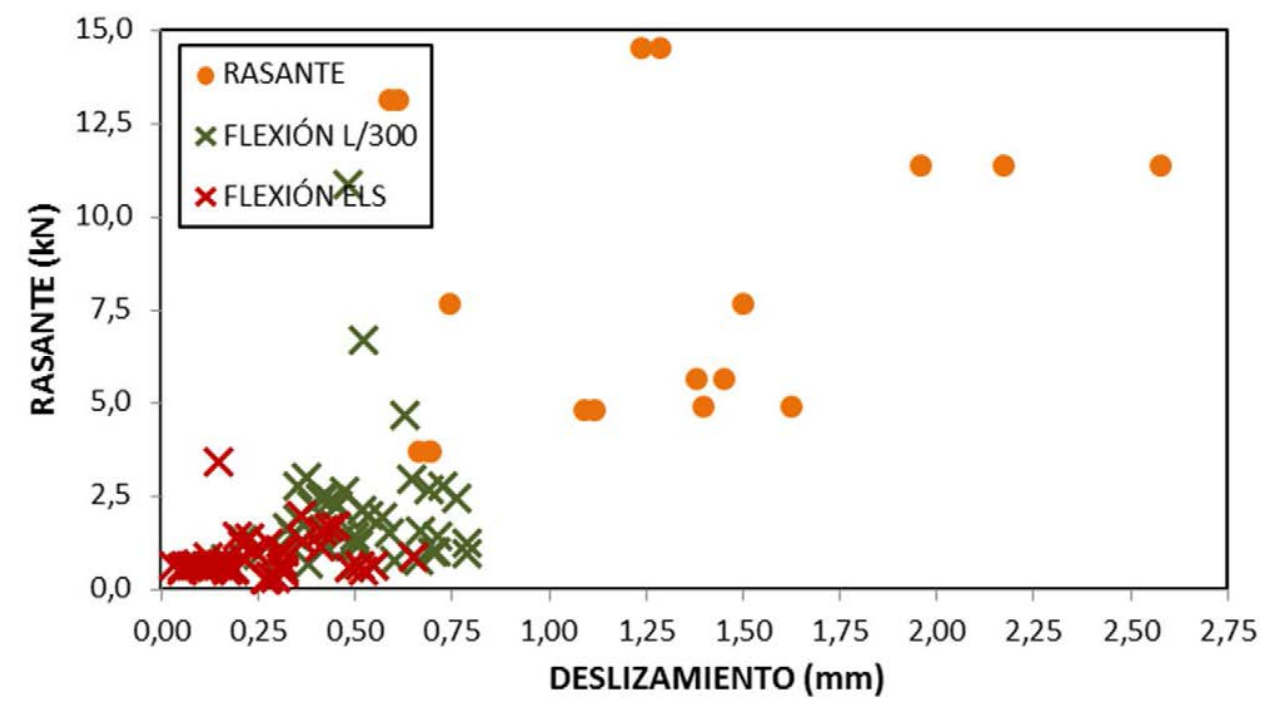

figura 20. Zona de servicio en ensayos de rasante y de flexión

Se puede apreciar que los dos tipos de ensayo están en bandas distintas de rasante y deslizamiento. Podría parecer que en algún caso esto no ocurre, sin embargo, cuando se desglosen por tipos en los gráficos siguientes, se apreciará con claridad que los homólogos de esos casos están distantes, por los que tal entremezcla caso a caso no tiene lugar.

En la figura 21, los gráficos son un despiece de la figura anterior, separándolo por tipos de conector. Para una mejor lectura, cada tipo de conexión se ha enmarcado en función de sus valores, por lo que la escala es distinta en cada gráfico. 

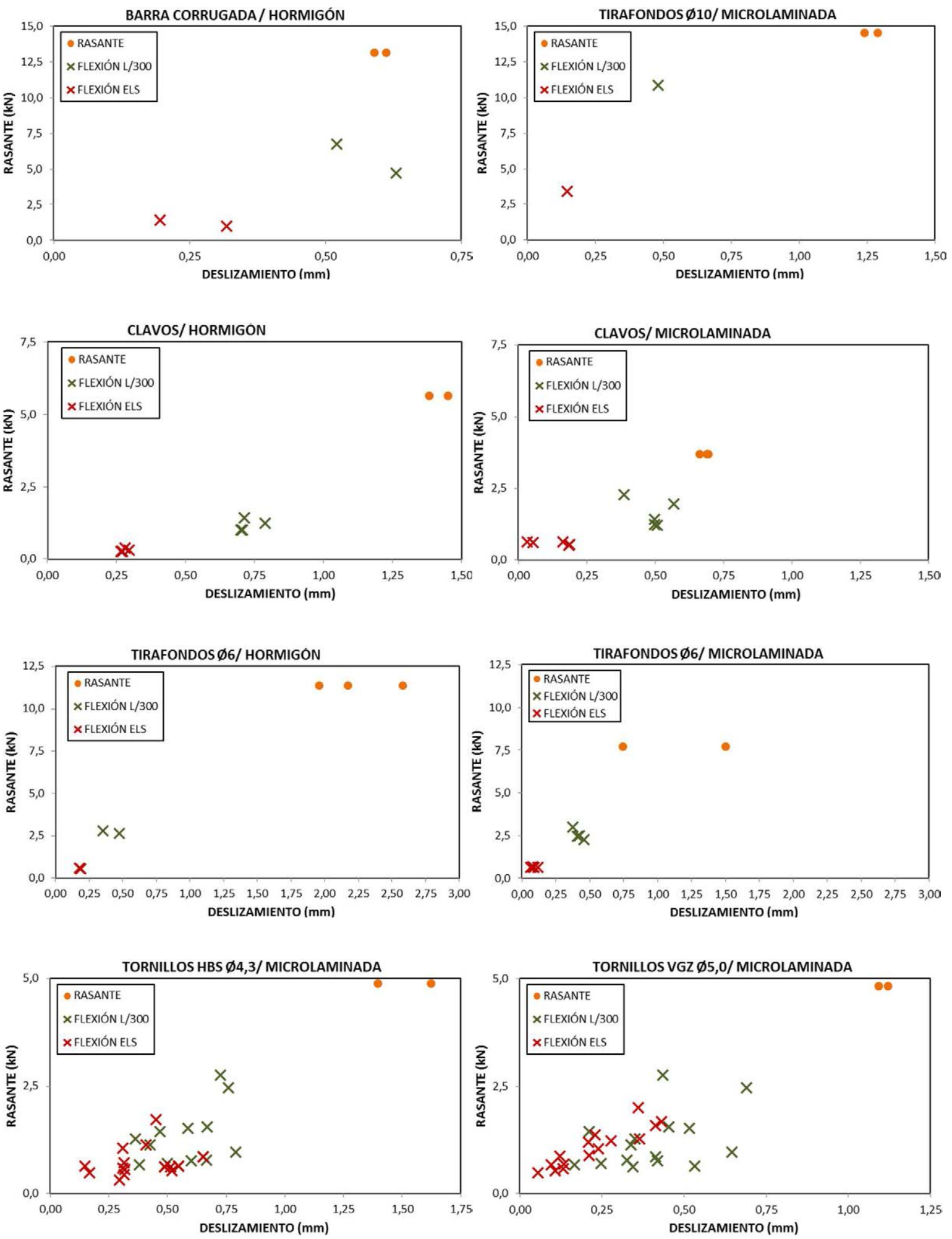

figura 21. Zona de servicio en ensayos de rasante y de flexión separada por conectores 


\section{CONCLUSIONES}

Del estudio de la superposición de las gráficas hasta rotura (figura 19) se observa, aparte de la distancia entre ambos ensayos ya comentada, cómo algunos tipos de conexión no son adecuados. Las barras corrugadas son las más rígidas durante más tiempo y su carga es la más elevada pero tienen muy poca ductilidad, rompiendo en el ensayo de rasante con deslizamientos que pueden quedar en el rango de los que se alcanzan en las vigas. Los clavos con capa de compresión de hormigón llevan a vigas muy flexibles ya que los deslizamientos duplican a los del resto $y$, con cualquier capa de compresión requieren mucha densidad ya que su capacidad de carga es muy inferior al resto. Unido a cuestiones de vibraciones, ciclos o largo plazo puede que no sean aceptables.

En la superposición de las gráficas en zona de servicio (figura 21) se observa que zona donde la Norma UNE 26891 obtiene el $\mathrm{K}_{\text {ser }}$ está lejos de las flechas de la edificación (L/300, cruces verdes), y muy lejos de las cargas de servicio (ELS, cruces rojas). De hecho lo obtiene en zonas cercanas a la rotura de la viga e incluso superiores a ella. Esta circunstancia ocurre en todos los tipos y en todos los ensayos. 


\section{CAPÍTULO 8. - CONCLUSIONES}

8.1 MODELO DE CÁLCULO

8.2 DISTINTOS ASPECTOS DETECTADOS EN LOS ENSAYOS

8.3 AUSENCIA DE NORMATIVA

8.4 DISCREPANCIAS CON LA NORMATIVA 
Tal como se planteó al principio de esta tesis, el objetivo general ha consistido en revisar prácticamente todos los aspectos que entran en juego a la hora de reforzar forjados de madera mediante capa de compresión conectada. Se describen a continuación, siguiendo el mismo orden establecido al principio, las conclusiones de cada uno de ellos.

\subsection{MODELO DE CÁLCULO}

\section{OBJETIVO 1. DESARROLLO DE UN MODELO DE CÁLCULO}

El primer objetivo que se considera alcanzado es la definición de un modelo de cálculo que permita no solo proyectar estos refuerzos y peritarlos sino disponer de una herramienta con la que poder seguir paso a paso los ensayos realizados en el laboratorio.

Como se dijo al principio de esta tesis, para estudiar el comportamiento de estas vigas mixtas es necesario relacionar dos rigideces: la rigidez a flexión (EI) y la rigidez a deslizamiento $\left(\mathrm{K}_{\text {uni }}\right)$. Actualmente el modelo de cálculo propugnado, tanto por la normativa como por los distintos autores es el denominado "método gamma", que obtiene de forma aproximada la rigidez $\mathrm{EI}_{\mathrm{ef}}$, en función de la rigidez $\mathrm{K}_{\text {uni }}$ integrando un sistema de ecuaciones diferenciales acudiendo al conocido camino de sustituir la ley de carga uniforme por otra sinusoidal.

Las hipótesis de partida del "método gamma", y del que se desarrolla en esta tesis siguen la teoría de la elasticidad lineal, y en ambos, también es lineal la relación entre fuerzas y deslizamientos (siguiendo el artículo 9.1.3 del EC-5).

El método alternativo desarrollado en esta tesis, valiéndose de esa linealidad, relaciona entre sí todas las variables que intervienen en el proceso (esfuerzos, tensiones, deformaciones, etc...) estableciendo elementales leyes de proporción, que incluso pueden representarse geométricamente. De este modo quedan relacionadas las dos rigideces (de flexión 'EI' y de deslizamiento ' $\mathrm{K}_{\mathrm{uni}}{ }^{\prime}$ ') directamente y con exactitud. 
La aplicación de este modelo en el laboratorio permite asociar directamente cualquier medida de deformación de los ensayos de las vigas con los esfuerzos que está produciendo la carga aplicada. Este modelo no es necesario en el caso de los ensayos simples de rasante, porque la carga aplicada está directamente relacionada con el esfuerzo rasante de la probeta.

\section{OBJETIVO 2. COMPARACIÓN ENTRE ENSAYOS DE RASANTE Y DE VIGA}

El segundo objetivo alcanzado con este modelo ha sido poder relacionar los ensayos de rasante con los ensayos de vigas. De esta manera, la información sobre los deslizamientos de ambos ensayos, tanto medidos como calculados, ha permitido contrastar los valores asignados a la rigidez de deslizamiento de los ensayos de rasante con los deslizamientos producidos en las vigas.

Esta superposición de los ensayos de rasante y de vigas a flexión es fundamental, pero no suficiente, ya que para obtener una homogeneización entre esfuerzos y deformaciones de uno y otro es necesario eliminar aspectos que no les son comunes. Un ejemplo claro es el rozamiento, que existe en los ensayos de las vigas pero no en los de rasante.

Este rozamiento se ha obtenido mediante los ensayos realizados en serie, y el modelo ha permitido deducir estas magnitudes de los ensayos de las vigas $y$, de esta manera homogeneizarlos con los ensayos de rasante, en los que este fenómeno es inapreciable. 


\subsection{DISTINTOS ASPECTOS DETECTADOS EN LOS ENSAYOS}

\section{OBJETIVO 3. ESBELTEZ DE EMPOTRAMIENTO DE LOS CONECTORES}

El tercer objetivo ha consistido en revisar la esbeltez del empotramiento del conector en la vigueta (madera aserrada) y en la capa de compresión (madera microlaminada) para conseguir que su trabajo de flexión y cortante sea el adecuado. Este estudio se realizó no tanto por una revisión bibliográfica, sino para asegurar el buen funcionamiento de los conectores en los ensayos que se iban a realizar.

A partir de los deslizamientos que se producen entre la capa de compresión y la vigueta en estas estructuras, que difícilmente superan $1 \mathrm{~mm}$, y no llegan a $2 \mathrm{~mm}$ para los casos estudiados, la esbeltez necesaria para que el conector quede convenientemente empotrado en la vigueta ha resultado estar entre 7 y 9, y siendo suficiente con 6 cuando la capa de compresión es de tablero microlaminado. Esto permite el empleo de diámetros de hasta $6 \mathrm{~mm}$ con tableros de $40 \mathrm{~mm}$ de espesor empleados habitualmente.

\section{OBJETIVO 4. ESTUDIO DE LAS VARIABLES QUE INFLUYEN EN LA CONEXIÓN}

El cuarto objetivo ha sido estudiar la relevancia de la elección del tipo de conexión. Con los clavos, con sus considerables ventajas económicas y su facilidad de ejecución, se ha observado una excesiva flexibilidad, que unida a posibles inconvenientes a largo plazo, les hace poco adecuados. En las uniones con resina la complejidad de la obra no ha supuesto una mejora mecánica que la haga aconsejable. Los conectores basados en barras de acero para armar no son de aplicación en conexiones a cortante por su falta de anclaje, solo si la varilla se dobla para ser anclada se resolvería este problema, pero ese doblado a $90^{\circ}$ obliga a calibres reducidos que no son adecuados por su baja resistencia a cortante, quedando este tipo de conexión limitado al barras inclinadas trabajando a tracción, donde sí resultan enormemente eficaces. Los tornillos requieren una consideración especial.

En cuanto al material de la capa de compresión, los refuerzos de madera con hormigón (en general más estudiados por otros autores y empleados en la práctica constructiva) no cuentan prácticamente con referencias normativas. Solo en el cálculo del módulo de deslizamiento de las 
uniones se especifica que se duplique su valor con respecto a las uniones con maderas. Los valores de $\mathrm{K}_{\text {ser }}$ obtenidos en los ensayos han sido razonablemente cercanos a los indicados en el EC-5. ${ }^{76}$

Sin embargo, los ensayos con capas de compresión de madera microlaminada, con carácter general, han alcanzado rigideces superiores a los del EC-5. Por la magnitud de las ganancias obtenidas, y por el número de casos (prácticamente todos) en los que esto ocurre, podría afectarse con algún tipo de coeficiente multiplicador, como ocurre con el hormigón.

Resulta de especial importancia, hasta el punto de poder obviar cualquier otro aspecto estudiado, la colocación de conectores a 45․ En el tanteo realizado alcanza un grado de conexión cercano al total. El trabajo a tracción y compresión y la ausencia de hendimiento en la madera consiguen prácticamente una unión sin deslizamiento.

De otras variables como el diámetro y separación de los conectores no se han extraído conclusiones, ya que no hay nada reseñable.

\footnotetext{
${ }^{76}$ Existe un borrador del eurocódigo de estructuras mixtas de madera y hormigón EC-5 1.3
} 


\subsection{AUSENCIA DE NORMATIVA}

\section{OBJETIVO 5. ASPECTOS NO CONTEMPLADOS EN LA NORMATIVA}

La valoración de la rigidez de la conexión la establece la normativa, pero en ella la formulación es muy reducida. Hay cuestiones que influyen en esta rigidez notoriamente, y que, al no estar contempladas en ella, son el objeto de este apartado.

\section{PRETENSADO}

Es evidente que el rozamiento actúa favorablemente contra el deslizamiento, como también es evidente que no se puede contar con él, salvo que se asegure su existencia, como es el caso del pretensado conseguido al presionar la capa de compresión contra las viguetas con el apriete de los conectores. En el caso de las vigas sin conexión que forman parte de los ensayos en serie se ha obtenido una mejora de rigidez debida al rozamiento entre el $2 \%$ y el $24 \%$. Estos porcentajes no se han conseguido relacionar con las variables de cada ensayo.

La posibilidad del pretensado conseguida por el mero apriete de algunos tipos de conectores se ha detectado que supone unas mejoras de rigidez a flexión de entre el $20 \%$ y el $80 \%$. Estos valores son el resultado de provocar un apriete en los tornillos sin fijar una magnitud concreta, pues solo se trataba de apreciar si el índice de mejora con respecto a los casos sin presión podría ser importante, como así ha ocurrido.

\section{DISEÑO DE LOS TORNILLOS}

El diseño de los tornillos afecta en gran medida al grado de conexión conseguido con ellos. Se han estudiado dos tornillos con diferente diseño, observando lo siguiente:

La forma de la cabeza es esencial para conseguir el pretensado por el mero apriete del tornillo, ya que los de cabeza cónica generan un cono de compresiones mientras que los de cabeza cilíndrica producen un aplastamiento local en el tablero impidiendo el traslado de las compresiones hasta la cara de la vigueta.

Otro aspecto de la influencia del diseño del tornillo es su caña o cuello, cuya longitud es similar al espesor de la capa de compresión, de modo que cuando esta zona es lisa, la capacidad de conexión se ve muy mermada si se compara con los que tienen todo el fuste roscado.

Dadas las diferencias, la formulación de la Normativa resulta insuficiente. 


\subsection{DISCREPANCIAS CON LA NORMATIVA}

\section{OBJETIVO 6. DISCREPANCIAS CON LA NORMATIVA}

En lo que se refiere a la rigidez de la conexión $\left(\mathrm{K}_{\mathrm{ser}}\right)$ que establecen el Eurocódigo 5 y el Código Técnico de la Edificación (tabla 7.1. Deslizamiento de las uniones), se han detectado las siguientes cuestiones:

-Hay una falta de indicadores que permitan aprovechar las mejoras que suponen el pretensado, las barras inclinadas, etc. Como ya se ha comentado.

-Se considera que las expresiones para la obtención del $\mathrm{K}_{\mathrm{ser}}$ en la Normativa son insuficientes para matizar el conjunto de variantes disponibles. Por ejemplo, aplicado al caso de los tornillos, la rigidez de la conexión (una vez se eliminan los efectos del ensayo de la viga -presión y rozamiento-) en uno de los tornillos coincide sensiblemente con lo establecido en la formulación del EC-5, mientras que en el otro, es la mitad.

-Faltaría por definir con qué diámetro $(\varnothing$ cuello, $\varnothing$ interior rosca, $\varnothing$ nominal $\circ \varnothing$ eficaz), se debe calcular la rigidez a deslizamiento del conector, igual que está especificado para el cálculo de la resistencia.

-Las expresiones con las que la normativa obtiene la rigidez de la conexión incluyen la densidad de la madera, cosa que indudablemente afecta, puesto que esta tiene una relación directa con el hendimiento. Pero la variación de la densidad de las maderas empleadas con generalidad en los edificios reforzados de este modo es poco significativa. Lo es por dos motivos, uno, la pequeña variación de la densidad, y el otro, que la influencia de la rigidez de la conexión en la rigidez de flexión queda bastante amortiguada. Siendo evidente que la normativa tiene que contemplar aspectos generales cuya amplitud es superior a la que corresponde a un determinado tipo constructivo, no es menos cierto que al menos como comentario o recomendación pudieran aplicarse expresiones simplificadas. Por ejemplo, hablando de refuerzo con tablero microlaminado, si la expresión $\left(\sqrt{\rho_{\text {vigueta }} \cdot \rho_{\text {cc }}}\right)^{1,5} \cdot \varnothing / 23$ (tabla 7.1 tirafondos) se simplifica a: $\rho_{\text {vigueta }} \cdot \varnothing$, el error no supera el 3\%, muy inferior a las imprecisiones con las que se determina la propia densidad. Con esto no se trata de simplificar la expresión del Eurocódigo, sino que avanzando en esta dirección llegaríamos a una expresión del tipo $K \cdot \varnothing$ (siendo $K$ una constante), que solo 
depende de las propiedades del conector. De este modo, el propio fabricante podría incluir en las características de su producto el valor de la rigidez de la conexión $\left(\mathrm{K}_{\mathrm{ser}}\right)$ obtenido adecuadamente en laboratorios homologados.

Según el $\mathrm{CTE}$, el módulo de deslizamiento $\left(\mathrm{K}_{\mathrm{ser}}\right)$ puede elegirse de la tabla 7.1 (ya comentada) o bien determinarse mediante ensayos según la Norma UNE 26891. Tras aplicar exhaustivamente esta Norma, los valores del $\mathrm{K}_{\text {ser }}$ obtenidos son siempre inferiores a los que resultan de aplicar las expresiones de la tabla 7.1. Esto se debe a que dicha Norma UNE obtiene el $\mathrm{K}_{\mathrm{ser}}$ en cotas de rasante en las que la conexión ha tenido una caída de rigidez considerable, lo que supone un módulo de deslizamiento reducido. Siendo esto evidentemente cierto en el ensayo de rasante, ocurre que los deslizamientos que se producen para ese nivel de carga del $40 \%$ de la rotura son muy superiores a los que se producen en las vigas reforzadas, no ya en su estado de servicio, como indica la normativa, sino cuando esas vigas alcanzan su agotamiento a flexión y rompen. Limitándonos a los problemas de flexión estudiados en este trabajo, esto llevaría, bien a no aplicar esta Norma, o a corregirla reduciendo la fuerza rasante en la que se obtiene el $\mathrm{K}_{\text {ser. }}$. Entre los trabajos realizados en esta tesis, y en la idea de que esta Norma UNE se ajuste a las expresiones de la tabla 7.1 y que ha quedado contrastado con los resultados de los ensayos, si ese valor del $40 \% \cdot F_{\text {rotura }}$ se sustituye por el de $30 \% \cdot F_{\text {rotura, }}$ los resultados quedarían razonablemente ajustados. Una modificación en este sentido sería muy razonable, ya que los ensayos para obtener el módulo de deslizamiento de las conexiones se realizan con esta Norma. 


\section{CAPÍTULO 9. - FUTUROS TRABAJOS}


El planteamiento de esta tesis ha sido analizar un importante conjunto de los elementos que se emplean en el refuerzo de los forjados de madera de la edificación existente. Pudiera parecer que al haberse realizado 95 ensayos de vigas y 51 ensayos de rasante, este trabajo experimental iba buscando estimaciones con valor estadístico para alcanzar conclusiones sobre la rigidez de algunos de los temas tratados. Sin embargo, este gran volumen de pruebas está más bien relacionado con la intención de cruzar un gran número de variables para detectar cuáles de ellas tienen interés futuro.

A lo largo de todo este conjunto de ensayos, y como resultado de esa búsqueda, se han encontrado varias posibles líneas de trabajo futuras. Por ejemplo:

-Estudio del pretensado, entendido como presión entre viguetas y capa de compresión, basada en la gran influencia del rozamiento en la ganancia de rigidez de la conexión, cuestión asociada a que esa presión se mantenga a largo plazo.

-Estudio de la inclinación de los conectores, que dan lugar a una conexión prácticamente total, basado en la formación de bielas que minimiza las deformaciones (el hendimiento en la madera y la flexión del conector).

-Revisión de la Norma UNE EN 26891 "Estructuras de Madera. Uniones realizadas con elementos de fijación mecánicos. Principios generales para la determinación de las características de resistencia y deslizamiento". Debido a la falta de correspondencia con la aplicación de las expresiones contenidas en la tabla 7.1 del Eurocódigo 5, esa discordancia está basada en que la medida del $\mathrm{K}_{\text {ser }}$ se realiza con deslizamientos muy superiores a los producidos en estas estructuras.

-Estudio del refuerzo con tablero de madera (microlaminada o contralaminada), basado en la mayor rigidez resultante de los ensayos respecto de las expresiones contenidas en la tabla 7.1 del Eurocódigo 5.

Se considera que estas son las cuestiones de mayor interés, obtenidas en este estudio extenso pero somero, que podrían formar parte de trabajos exhaustivos para validar su aplicación en el refuerzo de los forjados, que han sido el motivo de esta tesis. 


\section{BIBLIOGRAFÍA}


[001] Ahmadi, B.H. y Saka, M.P. (1993). "Behaoviour of composite timber-concrete floors". Journal of Structural Engineering, ASCE, 119(11),1993, pp 3110-3130.

[002] Aicher, Simon; Klöck, Wolfgang; Dill-Langer, Gerhard y Radovic, Boromir (2003). "Nails and nailplates as shear connectors for timber-concrete composite constructions". Otto-Graf-Journal, Vol. 14, 2003, pp 189-209.

[003] Amadio, C.; Fedrigo, F.; Fragiacomo, M.; Pozzetto, O.; Ceccotti, A. y Di Marco, R. (2000). "Modellazione e comportamento a lungo termine delle travi composte legno-calcestruzzo". IV Workshop Italiano sulle Construzioni Composte; Palermo.

[004] Argüelles Álvarez, R. (1981). "Cálculo de estructuras (Tomos I y II)". Primera edición. Escuela Técnica Superior de Ingenieros de Montes, Universidad Politécnica de Madrid.

[005] Argüelles Álvarez, R.; Arriaga Martitegui, F. y Martínez Calleja, J. (2003). "Estructuras de madera. Diseño y cálculo". 2a edición. Asociación de Investigación Técnica de las Industrias de Madera y Corcho, AITIM.

[006] Arriaga Martitegui, F. (2000). "Estructura mixta de madera y hormigón (Sistema HSB)". Asociación de Investigación Técnica de las Industrias de Madera y Corcho, AITIM no 206, Madrid, pp 83-84.

[007] Arriaga Martitegui F.; Peraza Sánchez F. y Esteban Herrero, M. (2003). "Madera aserrada estructural". Asociación de Investigación Técnica de las Industrias de Madera y Corcho, AITIM.

[008] Arriaga Martitegui, F.; Peraza Sánchez, F.; Esteban Herrero, M.; Bobadilla Maldonado, I. y García Fernández, F. (2002). "Intervención en estructuras de madera". Asociación de Investigación Técnica de las Industrias de Madera y Corcho, AITIM.

[009] Arriaga Martitegui, F.; Íñiguez González, G.; Esteban Herrero, M.; Argüelles Álvarez, R.; Fernández Cabo J.L.. (2011). "Diseño y cálculo de uniones en estructuras de madera". Maderia, Sociedad Española de la Madera.

[010] Asociación Española de Normalización y Certificación, AENOR (1990). UNE EN 26891:1990: "Estructuras de Madera. Uniones realizadas con elementos de fijación mecánicos. Principios generales para la determinación de las características de resistencia y deslizamiento" (ISO 6891:1983).

[011] Asociación Española de Normalización y Certificación, AENOR (1992). "Eurocódigo 2: Proyecto de estructuras de hormigón. Parte I-I: Reglas Generales y Reglas para Edificación (UNE ENV $1992-I-I)$. Parte 2: Puentes de Hormigón (UNE - ENV 1992-2)". 
[012] Asociación Española de Normalización y Certificación, AENOR (1995). "Eurocódigo 4: Design of Composite Steel and Concrete Structures. Part 1.1: General rules and rules for buildings". prEN 1994-1-1. Bruxelles, Belgium.

[013] Asociación Española de Normalización y Certificación, AENOR (1997). "Eurocódigo 5: Proyecto de estructuras de madera. Parte 1-1: Reglas Generales y Reglas para Edificación (UNE ENV $1995-I-I))^{\prime \prime}$

[014] Asociación Española de Normalización y Certificación, AENOR (1998). UNE EN 409: "Estructuras de madera. Métodos de ensayo. Determinación del momento plástico de los elementos de fijación de tipo clavija. Clavos".

[015] Asociación Española de Normalización y Certificación, AENOR (2001). UNE EN 12390: "Ensayos de hormigón endurecido".

[016] Asociación Española de Normalización y Certificación, AENOR (2008). UNE EN 14592: "Estructuras de madera. Elementos de fijación tipo clavija. Requisitos.".

[017] Astori, R. E. y Natalini, M. B. (2000). "Eficiencia de conectores para estructuras mixtas de hormigón-madera". Universidad Nacional del Nordeste, Argentina, publicación online.

[018] Auclair, S.C.; Sorelli, L.; Salenikovich, A. (2016). "A new composite connector for timberconcrete composite structures". Construction and Building Materials.

[019] Ávila Jalvo, J.M. (2003). "Refuerzo de forjados antiguos: I-Madera". Instituto Juan de Herrera, cuaderno no 147.01.

[020] Ávila Jalvo, J. M.; Fernández Cabo, J. L. y Díez Barra, R. (2008). "Definición de un Protocolo para la Rehabilitación de Forjados de Madera Mediante Conexión con la Nueva Capa de Compresión de Hormigón. Implementación del protocolo en un programa informático de Visual.Net". Proyecto I+D_BIA2004_07317. Escuela Técnica Superior de Arquitectura de Madrid y Ministerio de Educación y Ciencia. Colaboradores: Ávila Nieto, M.; Ávila Nieto, J. y Fernández Lavandera, $J$.

[021] Baldock, R. H.; McCullough, C. B. (1933) "Loading tests on a new composite type short span high-way bridge combining concrete and timber in flexure". Oregon State Highway Commission, Technical Bul. 1.

[022] Balogh, J.; Fragiacomo, M.; Gutkowski, R.M. y Fast, R.S. (2008). "Influence or repeated and sustained loading of the performance of layered wood-concrete composite beams". Journal of Structural Engineering, ASCE March 2008; pp. 430-439. 
[023] Barbisan, U. y Laner, F. (1994). "I solai in legno: soluzioni tradizionali, elementi innovativi, esempi di dimensionamento". Edilizia, Italia.

[024] Basterra, A.; Calle, N. y Relea, E. (2005). "Estudio comparativo del comportamiento de forjados mixtos madera-hormigón y su simulación infográfica por el MEF". Jornadas de Investigación en Construcción, ICC Eduardo Torroja (CSIC). Ed. Virtudes Arorín, Madrid.

[025] Bathon, L. A. y Graf, M. (2002). "A continuous wood-concrete-composite system". University of Applied Sciences Wiesbaden, Germany.

[026] Benitez, M. F. (2000). "Development and testing of timber-concrete shear connectors". 6th World Conference on Timber Engineering WCTE 2000, Whistler Resort, British Columbia, Canada.

[027] Blass, H.J.; Aune, P.; Choo, B.S.; Görlacher R.; Griffiths, D.R.; Hilson, B.O.; Racher, P. y Steck G. (1995). "Timber Engineering. STEP 1: Bases of design, material properties, structural componenets and joints. STEP 2: Design - Details and structural systems". First edition, Centrum Hout, The Netherlands.

[028] Bou Said, E. (2003): "Contribution a la modelisation des effets differes du bois et du beton sous conditions climatiques variables. Application aux structures mixtes bois-beton". Ph. D. Thesis. "L'institut Nacional des Sciences Apliques de Lyon: Ecole Doctorale des Sciences de L'ingénieur".

[029] Bou Said, E.; Jullien, J. F. y Ceccotti, A. (2004). "Long term modelling of timber-concrete composite structures in variable climates". World Conference on Timber Engineering WCTE 2004, Lathi, Finland.

[030] Branco, J.M. (2003). "Behaviour of dowel-type fasteners in timber-concrete connections"(en portugués). Master Thesis, Engineering School, University of Minho, Portugal.

[031] Branco, Jorge.M; Cruz, Paulo J.S.; Piazza, Maurizio. "Experimental analysis of laterally loaded nailed timber-to-concrete connections"

[032] Brunner, M. y Schnuriger, M. (2006). "Adhesive connection for timber-concrete slabs". World Conference on Timber Engineering WCTE 2006, Portland-Oregon, USA.

[033] Capozucca, Roberto. (1998). "Bond stress system of composite concrete-timber beams". Scientific reports. Materials and structures/Matériaux et Constructions, Vol. 31, November 1998, pp. 634-640.

[034] Cárdenas, M.; Schanack, F.; Ramos, O.R. (2010). "Diseño, construcción y ensayo de una estructura de sección mixta madera laminada-hormigón para uso en puentes". Revista de la Construcción, Vol 9 № 2 2010. Pags 63-75. 
[035] Ceccotti, A. (1995). "Lecture E13: Timber-concrete composite structures". pp. E13/1-12. In STEP 2; Timber Engineering. Centrum Hout. The Netherlands.

[036] Ceccotti, A. (2006). "Composite structures". Timber Engineering, Ed: John Wiley \& Sons, Cap. 21 Composite Estructures, pp 409-426, edited by Sven Thelandersson (Lund University, Sweeden) and Hans J. Larsen (Technical University of Denmark, Lyngby).

[037] Ceccotti, A; Fragiacomo, M. y Giordano, S. (2007). "Long-term and collapse tests on a timberconcrete composite beam with glued-in connection". Materials and Structures 2007, 40(1), pp 15-25.

[038] Ceccotti, A; Fragiacomo, M. y Gutkowski, R. (2002). "Design of Timber-Concrete Composite Structures According to EC-5-2002 version". International Council for Research and Innovation in Building and Construction. Proceedings at the Colorado State University's meeting, USA. 2002. Ref: CIBW18/35-15-6.

[039] Clouston, P; A. Bathon L. y Schreyer, A. (2005). "Shear and bending performance of a nove wood-concrete composite system". Journal of Structural Engineering, ASCE, September 2005; pp. 1404-1412.

[040] Crespo Oliveira, A; L. (2002). "Contribuição para a análise de vigas mistas de madeira laminada colada e concreto (MLC/concreto)". Universidad Federal de Minas Gerais. Belo Horizonte. Tesis doctoral.

[041] Dall'Asta, A. y Zona, A. (2004). Comparison and validation of displacement and mixed elements for the non-linear analysis of continuous composite beams. Computers and Structures 82 (2004), pp 2117-2130.

[042] Deam, B. L.; Fragiacomo, M. y H. Buchanan, A. (2008). "Connections for composite concrete slab and LVL flooring systems". Materials and Structure 2008, 41: pp 495-507.

[043] Deutsches Institute für Normung, DIN (2004). DIN 1052:2004-08 (2004): Entwurf, Berechnung und Bemessung von Holzbauwerken - Allgemeine Bemessungsregeln und Bemessungsregeln für den Hochbau; "Design of timber structures - General rules and rules for buildings".

[044] Dias, A.M.P.G. (2005). "Mechanical Behaviour of Timber-Concrete Joints". Ph. D. Thesis (2005). Tecnische University Delft. The Netherlandas.

[045] Dias, A.M.P.G.; Cruz, H.M.P y Lopes, S.M.R. (2010). "Stiffness of dowel-type fasteners in timber-concrete joints". Proceedings of the Institution of Civil Engineers - Structures and Buildings, volume 163, Issue 4, pp. 257-266. 
[046] Dias, A.M.P.G.; Lopes, S.M.R. y Van de Kuilen, J.W.G. (2007). "Load-carrying capacity of timber-concrete joints with dowel-type fasteners". Journal of Structural Engineering, ASCE, May 2007; Volume 133 Issue 5, pp. 720-727.

[047] Dias, A.M.P.G.; Jorge, L. F.C. (2011). "The effect of ductile connectors on the behavior of timber-concrete composite beams". Engineering Structures, Jun 2011; Publicado online.

[048] Domínguez, M; Fueyo, J. G.; Henares, J. L.; Cabezas, J. A. (2014). "Procedimientos de Ensayo para Conexiones tipo Clavija en Estructuras de Madera". Información Tecnológica Vol. 25 № 3.

[049] Faust, T.; Selle, R. (1999). "Properties of Composite Joints of Timber-LWAC Composite Structures". Publicado online.

[050] Fernández Cabo, J.L.; Arriaga Martitegui, F.; Majano Majano, A. y Iñiguez, G (2010). "Shortterm performance of the HSB® shear plate type connector for timber-concrete composite beams". Pendiente de publicación.

[051] Fernández Cabo, J.L.; Ávila Jalvo, J.M.; Fernández Lavandera, J.; Ariaga Martitegui, F.; Díez Barra, R.; Ávila Nieto, M. y Ávila Nieto, J. (2009). "Documento de aplicación de vigas mixtas fabricadas con viguetas de madera o productos derivados de la madera". Instituto Juan de Herrera (ETS de Arquitectura de Madrid) y Confederación Española de Empresarios de la Madera (Confemadera).

[052] Fernández Cabo, J. L.; Ávila Jalvo, J. M.; Fernández-Lavandera, J.; Díez Barra, R.; Ávila Nieto, J. y Ávila Nieto, M. (2010). "Estructuras de madera: una lectura práctica de la normativa. (III) El método de la flexibilidad aplicado a la viga mixta con conexión deformable". Cuadernos del Instituto Juan de Herrera. ETS de Arquitectura de Madrid.

[053] Fernández Cabo, J.L.; Ávila Nieto, M. y López Rodríguez, G. (2006). "A parametric study on the load bearing of a dowel connection under static load: the definition and variables of the optimal slenderness". Proceedings of the 9th World Conference on Timber Engineering WCTE2006, Portland-Oregon, USA.

[054] Fernández Cabo, J.L.; Fernández Lavandera, J.; Ávila Jalvo, J. M. (2008). "Wood-concrete and wood-wood mixed beams: a rational basis for selecting the connections". Journal of Structural Engineering, ASCE, Volume 134 n 3, pp. 440-447, March 2008.

[055] Fernandez Cabo, Jose L.; Fernandez Lavandera, Jorge; Diez-Barra, Rafael; Avila Jalvo, Jose M. 2011-b. "Timber Composite Beams with a Discrete Connection System". Accepted in May 17th 2011 for its publication at Building and Structures de la Institution of Civil Engineers, UK; manuscript reference: STBU1100007), 16pp. 
[056] Fernández Lavandera, J.; Fernández Cabo, J.L.; Ávila Jalvo, J.M.; Díez Barra, R.; Ávila Nieto, M. y Ávila Nieto, J. (2008). "Estructuras de madera: una lectura práctica de la normativa. Vols. (II) y (III). La viga mixta con conexión flexible". Cuadernos del Instituto Juan de Herrera (1-76-01 y 176-02), Escuela Técnica Superior de Arquitectura de Madrid (ETSAM).

[057] Fernández Lavandera, J. (2010). "Estructura mixta con madera: eficiencia con conexión flexible". Tesis doctoral. Escuela Técnica Superior de Ingenieros Agrónomos. Universidad Politécnica de Madrid.

[058] Fragiacomo, M. (2000). "Comportamento a lungo termine di travi composte legnocalcestruzzo" (en italiano). Ph. D. thesis, Universita'degli studi di Trieste, Italia.

[059] Fragiacomo, M. (2005). "A finite element model for long-term analisis of timber composite beams". Structural Engineering and Mechanics, Vol. 20 n 2, pp 173-189.

[060] Fragiacomo, M; Amadio, C. y Macorini, L. (2007). "Short- and long-term performanceof the Tecnaria stud connector for timber-concrete composite beams. Materials and Structures 2007, 40(10), pp 1013-1026.

[061] Fragiacomo M., Gutkowski, M.; Valgo, J. y Fast, S. (2006). "Long term behaviour of woodconcrete composite beams with notched connecction detail". World Conference on Timber Engineering WCTE 2006, Portland-Oregon, USA.

[062] Frangi, A. and Fontana, M. (2003). Elasto-plastic model for timber-concrete composite beams with ductile connection. Structural Engineering International: Journal of the International Association for Bridge and Structural Engineering, 13(1), pp. 47-57.

[063] Gelfi, P. y Giuriani, E. (1999). "Behaviour of stud connectors in wood-concrete composite beams". Proc. Structural Studies, Repair and Maintenance of Historical Buildings VI: 6th Int. Conf: Wit Press, Dresden, Germany, pp 565-578.

[064] Gelfi, P.; Giuriani, E.; Marini, A. (2002). "Stud shear connection design for composite concrete slab and wood beams". Journal of Structural Engineering, ASCE December 2002; pp. 1544-1550.

[065] Girhammar, U. A. (1984). "Nail-plates as shear connectors in composite timber and concrete structures". 12th International Association for Bridge and Structural Engineering (IABSE) Congress, Vancouver, Canada, pp. 961-968.

[066] González Bravo, C.; Arriaga Martitegui, F.; Maldonado Ramos, L. y Díez Barra, R. (2010). "Refuerzo de vigas de madera mediante perfiles metálicos situados en la cara superior". Materiales de Construcción 60, 298, pp. 123-135, 1 de abril de 2010. 
[067] Gutkowski, R; Brown, K; Shigidi, A. y Natterer, J. (2007). "Laboratory tests of composite wood-concrete beams". Constr. Build. Mater., publicado online.

[068] Gutkowski, R; Thompson, W; Brown, K; Etournaud, P; Shigidi, A. y Natterer, J. (1999). "Laboratory composite wood-concrete beam and deck specimens". 1st RILEM Symposium on Timber Engineering, September 1999, Stockholm, Sweden. Proceedings, pp 263-271.

[069] Íñiguez González, G.; Arriaga Martitegui, F.; Esteban Herrero, M. (2007). "Los métodos de vibración como herramienta no destructive para la estimación de las propiedades resistentes de la madera aserrada estructural'. Informes de la Construcción. Vol. 59, 506, 97-105.

[070] Johansen K. W. (1949). "Theory of timber connections". International Association of Bridge and Structural Engineering, IABSE; p. 249-262.

[071] Jorge, L. (2005). "Timber-Concrete Composite Structures using LWAC" (in Portuguese). Ph. D. Thesis. Coimbra University.

[072] Jorge, L.; Lopes, S. y Cruz, H. (2004). "Experimental research in timber-LWAC composite structures". COST E29 Symposium, Florence 27-29 October 2004.

[073] Jorge, L.; Lopes, S. y Cruz, H. (2004). "Castellated surface for timber-concrete composite connections". World Conference on Timber Engineering WCTE 2004.

[074] Jorge, L.; Lopes, S. y Cruz, H. (2011). "Evaluation of non-linear behavior of timber-concrete composite structures using FE model". Materials and Structures.

[075] Jullien, J.F; Mungwa, M.S. y Siemers M. (1999). "Experimental behaviour and design of composite wood floors". 1st RILEM Symposium on Timber Engineering, September 1999, Stockholm, Sweden. Proceedings,pp 563-570.

[076] Jutila, A. y Salokangas L. (2000). "Research on and development of wooden bridges in Filand". Structural Engineering International 3/2000; pp 182-185.

[077] Kavaliauskas, S; Kazimieras Kuedaras, A. y Gurkšnyš (2005). "Evaluation of long-term behaviour of composite timber-concrete structures acording to EC". Vilnius Gediminas Technical University, Lithuania.

[078] Kavaliauskas, S; Kazimieras Kuedaras, A. y Valiunas, Balys (2007). "Mechanical behavior of timbre-to-concrete connections with inclined screws". Journal of civil engineering and management. 
[079] Kermani, BS. (1999). "Load-slip characteristics of multi-nailed timber joints. Structures and Buildings. Feb 1999. Pag. 31-43

[080] Kroflič, A.; Planinc, I.; Saje, M.; Turk, G. y Čas, B. (2010). "Non-linear analysis of two-layer timber beams considering interlayer slip and uplift". Engineering Structures 32 (2010), 1617-1630.

[081] Kryžanowski, A.; Schnabl, S.; Turk, G. y Planinc, I. (2009). "Exact slip-buckling analysis of twolayer composite columns". International Journal of Solids and Structures 46 (2009), pp 2929-2938.

[082] Kuhlmann, U. y Aldi, P. (2008). "Simulation of grooved connections in timber-concrete composite beams considering the distribution of the material properties". World Conference on Timber Engineering WCTE 2008, Miyazaki, Japan.

[083] Kuhlmann, U. y Michelfelder, B. (2004). "Grooves as shear-connectors in timber-concrete composite structures". World Conference on Timber Engineering WCTE 2004, Lathi, Finland.

[084] Kuhlmann, U. y Micheifelder, B. (2006). "Optimized design of grooves in timber-concrete composite slabs". World Conference on Timber Engineering WCTE 2006, Portland-Oregon, USA.

[085] Kuhlmann Kuhlmann, U. y Schänzlin, J. (2004). "Time dependent behaviour of timberconcrete-composite structures". World Conference on Timber Engineering WCTE 2004, Lathi, Finland; pp 323-328.

[086] Kuhlmann Kuhlmann, U. y Schänzlin, J. (2004). "Composite of vertically timber decks and concrete". World Conference on Timber Engineering WCTE 2004, Lathi, Finland, pp 313-318.

[087] Kuhlmann Kuhlmann, U. y Schänzlin, J. (2004). "Composite of board stacks and concrete with integrated steel slim-floor profile". World Conference on Timber Engineering WCTE 2004, Lathi, Finland.

[088] Lagomarsino, S. y Morbiducci R. (2008) "Una tecnica di consolidamento per solai lignei: Aspetti strutturali ed implicazione technologiche". Facoltá di Ingegneria, Universitá di Genova. Publicado online 2008.

[089] Lambillon, J. (1995). "Le plancher "Bois-Béton V" de Claude Blouet". L'Industriel sur Bois, janvier 1995, pp. 34-35.

[090] Lehmann, S., Grosse, M. and Rautenstrauch, K. (2001). "New connector types of laminated timber concrete composite element joints". Proc. International RILEM Symposium: Joints of Timber Structures, Stuttgart, Germany, pp. 301-310. 
[091] Lopes, S. M. R; Dias, A. M. G. y Cruz, H.M.P. (2004). "Behaviour of timber concrete composite slabs". Journal of the Institute of Wood Science, vol. 16 n 5, summer 2004, pp 285-294.

[092] Lukaszewska, E.; Johnsson, H. y Fragiacomo, M. (2008). "Performance of connections for prefabricated timber-concrete composite floors". Materials and Structures 2008, 41: pp 1533-1550.

[093] Lukaszewska, E. (2009). "Development of prefabricated timber-concrete composite floors". Doctoral Thesis, Luleå University of Technology, Department of Civil, Mining and Environmental Engineering, Division of Structural Engineering (SE-971 87 Luleå); Sweden.

[094] Mäkipuro, Risto; Tommola, Jarmo; Salokangas, Lauri y Jutila, Aarne (1996). "Wood-concrete composite bridges". Helsinki University of Technology, Department of Structural Engineering, Laboratory of Bridge Engineering. Nordic Timber Bridge Project; Nordic Wood.

[095] Mantilla Carrasco, E. (1999). "Behaviour of composite timber-concrete beams". University of Minas Gerais, Brazil. 1st RILEM Symposium on Timber Engineering, September 1999, Stockholm, Sweden. Proceedings, pp 571-580.

[096] Marcello Tarantino, A. y Dezi, L. (1992). "Creep effectcs in composite beams with flexible shear connectors". Journal of Structural Engineering, ASCE august 1992; pp. 2063-2081.

[097] Marradi, P; Messina, C. y Paolini, L. (1989). "Recupero di strutture in legno mediante armature parcialmente presollecitate. ". Il restauro del legno, volume primo. Nardini Editore, Florencia - Italia, pp 241-247.

[098] Martínez Calzón, J. y Ortiz Herrera, J. (1978). "Construcción mixta hormigón-acero". Editorial Rueda (España).

[099] Mascia, N. T. y Soriano, J. (2004). "Benefits of timber-concrete composite action in rural bridges". Materials and Structures, Vol 37, March 2004, pp 122-128.

[100] McCullough, C. B. (1943). "Oregon tests on composite (timber-concrete) beams". Journal of the American Concrete Institute, 14(5), pp. 429-440.

[101] Meierhofer, U. (1993). "A Timber/Concrete Composite System". Structural Engineering International.

[102] Ministerio de Fomento, Secretaría General Técnica (2008). "Instrucción de Hormigón Estructural EHE- 08". España, R.D. 1247/2008 de 18 de julio. Imprenta Nacional del Boletín Oficial del Estado (BOE no 203); Madrid, España. 
[103] Ministerio de Vivienda (2006). Código Técnico de la Edificación (CTE): "Seguridad estructural: Bases de Cálculo y Acciones en la Edificación"; "Seguridad Estructural: Madera (SE$M)^{\prime \prime}$; "Seguridad en caso de incendio (SE-I)". Imprenta Nacional del Boletín Oficial del Estado (BOE); Madrid, España.

[104] Möhler, K. (1956). "Über das Tragverhalten von BiegetrSgern und DruckstSben mit Zusammengesetzten Querschnitten und nachgiebigen Verwindungsmitteln". Technischen Hochschule Fridericiana zu Karlsruhe.

[105] Monfort Lleonart, J. (2002). "Estructuras mixtas para edificación según criterios del Eurocódigo 4". Universidad Politécnica de Valencia.

[106] Monfort Lleonart, J. y Pardo Ros, J.L. (1998). "Reparaciones de forjados mediante hormigón". Seminario de la conseración de la madera en edifiocs antiguos. Publicaciones de la universidad politécnica de Valencia, España, pp 139-168.

[107] Natterer, J; Chi-Jen Chen (1999). "Concepts and applications of mixed timber-concrete structures in multi-story buildings". International Conference on Effective Utilization of Plantation Timber, May 1999, Chi-Tou, Taiwan.

[108] Natterer, J; Hamm, J. y Favre, P. (1996). "Composite wood-concrete floors for multi-story buildings". Proc., International Wood Engineering Conference, New Orleans, pp 3431-3435.

[109] Natterer J., Sandoz J. L. y Rey M. (2004). "Construction en bois". Volume 13 Traité de Genie Civil de I'Ecole polytechnique fédérale de Lausanne. Presses Polytechniques et Universitaires Romandes.

[110] Negrão, J.H.J.O.; de Oliveira, F.M.M. y de Oliveira, C.A.L. (2006). "Investigation on timberconcrete glued composites". World Conference on Timber Engineering WCTE, August 2006, Portland, Oregon, USA.

[111] Negrão, J.H.J.O.; de Oliveira, C.A.L.; de Oliveira, F.M.M. y Cachim, P.B. (2010). "G/ued composite timber-concrete beams. I: Interlayer Connection Specimen Tests". Journal of Structural Engineering, ASCE, Volume 136, nº 10, pp. 1236-1245, October 2010.

[112] Negrão, J.H.J.O.; de Oliveira, F.M.M.; Oliveira, C.A.L. y Cachim, P.B. (2010). "Glued composite timberconcrete beams. II: Analysis and tests of beam specimens". Journal of Structural Engineering, ASCE, 2010, Volume 136, no 10, pp. 1246-1254, October 2010.

[113] Newmark, N.M., Siess, C.P., Viest, I.M. (1951). "Test and analysis of composite beams with incomplete interaction". Proceedings, Society for Experimental Stress Analysis, V1. 9, № 1, pp. 75-92. 
[114] Noponen, Sami; Jutila, Aarne (1996). "Wood-concrete composite bridges: example drawings for timber bridges". Helsinki University of Technology, Laboratory of Bridge Engineering. Nordic Timber Bridge Project; Nordic Wood.

[115] Norlin, B. (1993). "Two-Layered Composite Beams with Non-linear Connectors and Geometry-Test and Theory". Publication about the Ph.D. by Royal Institute of Technology Stockholm; directed by: Blass, H.J.; Vrouwenvelder, A.C.W.M.; Wardenier, J. 107 pp.

[116] Nuere Matauco, E. (2007). "Madera en restauración y rehabilitación". Informes de la Construcción, vol. 59, nº 506. Abril-junio 2007, España.

[117] Pardo Ros, J. L. (1997). "Estructuras mixtas de hormigón-madera aplicadas a la rehabilitación de forjados". Tesis doctoral. Escuela Técnica Superior de Arquitectura de la Universidad Politécnica de Valencia.

[118] Peraza Sánchez F., Arriaga Martitegui, F. y Enrique Peraza J. (2004). "Tableros de madera de uso estructural". Asociación de Investigación Técnica de las Industrias de Madera y Corcho, AITIM.

[119] Piazza, M. y Ballerini M. (2000). "Experimental and numerical results on timber-concrete composite floors with different connection systems". Proccedings 6th World Conference on Timber Engineering WCTE, Whistler Resort, B.C., Canada.

[120] Pincus George; Ace A. M. (1970). "Behavior of Wood-concrete composite beams". Journal of the structural división. Proceedings if the American Society of Civil Engineers.

[121] Pires Carvalho, E. (2008) "Avaliaçao do comportamento macânico ao cisalhamento de conectores de barras de aço com ganchos em vigas mistas de madera laminada colada $e$ concreto". Tese de Doutorado. Belo Horizonte.

[122] Pozo Vindel, F. del (2000). "Título 40 Cálculo de secciones y elementos estructurales. Estado límite último. Cortante" en "La EHE explicada por sus autores", Edit: Leynfor, Siglo XXI. Pp. 143154.

[123] Racher P. (1995). "Lecture C1: Mechanical timber joints - General"pp. C11/1-10. In STEP 1, Timber Engineering. Centrum Hout. The Netherlands.

[124] Ranta-Maunus, A. y Kevarinmäki, A. (2002). "Design method for Kerto-LVL joinst with inclined screws". Statement NO RTE1758/02. VTT Building and Transport. Finnland. Helsinki University of Technology, Laboratory of Structural Engineering and Building Physics. p. 14.

[125] Ranzi, G. y Bradford M. A. (2004). "A direct stiffness analysis of a composite beam with partial interaction". International Journal for Numerical Methods in Engineering 61 (2004), 657-720. 
[126] Relea, E.; Basterra, L. A.; Acuña, L. y Casado, M. (2008). "Ensayos de uniones en estructuras mixtas de madera-hormigón". Grupo de Investigación de Estructuras y Tecnología de la Madera, Universidad de Valladolid (España).

[127] Richart, F. E. and Williams, C. B. (1943). Tests of composite timber-concrete beams. Journal of the American Concrete Institute, 14(4), pp. 253-276.

[128] Rodríguez Nevado M. A. (1999). "Diseño estructural en madera". Asociación de Investigación Técnica de las Industrias de Madera y Corcho, AITIM.

[129] Schäfers, M. y Seim, W. (2008). "Development of adhesive bonded Timber-UHPC composites. Experimental and theoretical investigations". World Conference on Timber Engineering WCTE 2008, Miyazaki, Japan.

[130] Simon, Antje (2008). "Analyse zum Trag- und Verformungsverhalten von Straßenbrücken in Holz-Beton-Verbundbauweise". Weimar. Tesis.

[131] Steinberg, E.; Selle, R. y Faust, T. (2003). "Connectors for timber-lightweight concrete composite structures". Journal of Structural Engineering, ASCE 2003, pp. 1538-1545.

[132] Stojić, D. (2004). "Proposition of a model for the limit state of rupture of timber structures". Facta Universitatis, Series: Architecture and Civil Engineering. Vol. 3, № 1, 2004, pp 109-120.

[133] Stojić, D. y Cvetković (2001). "Analysis of a composite timber-concrete structures according to the limit states". Facta Universitatis, Series: Architecture and Civil Engineering. Vol. 2, No 3, 2001, pp 169- 184.

[134] Szabó, B. (2006). "Influence of shear connectors on behaviour or composite girders". Doctoral Dissertation, Helsinki University of Technology Publications in Bridge Engineering, Teknillisen korkeakoulun sillanrakennustekniikan julkaisuja, Espoo 2006, TKK-SRT-36.

[135] Takac, S.; Matosevic, D. ; Bogicevic, P. Szabó, B. (2001). "Rheological Research el Sliding Modulus of the Wood-Croncrete Connection". Composite Structures.

[136] Tampone, G. (1989). "Restauro strutturale con lamine metalliche dei solai lignei della sede del Genio Civile di Firenze". Il restauro del legno, volume primo. Nardini Editore, Florencia - Italia, pp 263-281.

[137] Tampone, G; Franci, F. y Campa, L. (1989). "Rinforzo di puntoni e consolidamento di una capriata del teatro di Sateano mediante centine metalliche". Il restauro del legno, volume primo. Nardini Editore, Florencia - Italia, pp 299-3051. 
[138] Timoshenko, S.P. (1947-1949). "Resistencia de Materiales". Primera parte 1949 y segunda parte 1947. Editorial Espasa-Calpe.

[139] Timoshenko, S. P. y M. Gere J. (1972). "Mecánica de Materiales". Editorial: Unión Tipográfica Editorial Hispano-Americana.

[140] Timoshenko, S. P. y Goodie, J. N. (1934). "Teoría de la elasticidad". Editorial Urmo.

[141] Tommola J.; Salokangas L., Jutila A. (1999) "Test on shear connectors". Nordic Timber Bridge Project.

[142] Tommola, J. y Jutila, A. (2001). "Analysis of Wood-Concrete Composite Girder with Discrete Shear Connectors". Proceedings of the IABSE conference on Innovative Wooden Structures and Bridges; Lathi, Finland; august 29-31, 2001. pp.-293-296.

[143] Turrini, G. y Piazza, M. (1983). "Una tecnica di recupero statico dei solai in legno". Recuperare no 5-6-7; Milán, Italia.

[144] Unnikrishna Pillai, S. y Ramakrishnan, P. (1977). "Nail shear connectors in timber-concrete composites". Journal of the Institution of Engineers (India), 58(1), pp. 34-39.

[145] Van Der Linden, M. (1999). "Timber-Concrete Composite Floor Systems". Delft University Press. Publication about the Ph.D. thesis by Technische Universiteit Delft; directec by J.W.G. Van der Kuilen. The Netherlands.

[146] Wright H. D. (1990). The deformation of composite beams with discrete flexible connection". University of Wales, College of Cardiff, PO Box 917, Cardiff CF2 1XH, UK.

[147] Xu, R. y Wu, Y. (2007). "Static, dynamic and buckling analysis of partia linteraction composite members using Timosneko's beam theory". International Journal of Mechanical Sciences 49 (2007),1130-1155.

[148] Yeoh Eng Chuan,D. ; Fragiacomo, M. ; Aldi, P. ; Mazzil, M. ; Kuhlmann, U. (2008). "Performance of notched coach screw connection for timber-concrete composite floor system". WCTE 2008, Miyazaki, Japan.

[149] Yeoh Eng Chuan, D. (2010). "Behaviour and design of timber-concrete composite floor system". Ph.D. thesis by University of Canterbury.

[150] Yttrup, Peter J. (2002). "Concrete enhanced timber". University of Tasmania, Australia. Publicado online. 
[151] Yttrup, Peter J. (2004). "Concrete and timber composite construction for en enhanced strength, stiffness and service life for timber bridges". Timber Bridges; Concrete and Timber Composite Construction for Timber Bridges.

\section{Prontuarios, manuales y patentes.}

[152] Dataholz (www.dataholz.com)

[153] Drizoro Construction Products. Soluciones químicas para la Construcción: Prontuario (2008).

[154] Finnforest, SFSintec $®$ (www.finnforest.com)

[155] HBV $®$ - Systems, Innovate Wood-Concrete-Composite Constructions. HBV Shear connector (www.hbv-systeme.de)

[156] Hilti (www.hilti.es)

[157] Holtza. Conector HSB尺 (Habitat System Beton) manufactures by Habitat Legno S.p.A.; comercializado en España por Holtza S.A. Documentación facilitada por fabricante y distribuidor (2010).

[158] Rothoblaas $®$ (www.rothoblaas.com)

[159] Sika Especialidades Químicas para la Construcción: Prontuario (2009).

[160] Simpson Strong-Tie: "Conexiones para ensambladura de madera" (www.strongtie.com, www.simpson.fr)

[161] Solai Cnp $®$ in Legno Cemento $®$ (www.edilportale.com)

[162] Spax $®$ (www.spax.com)

[163] Tecnaria ${ }^{\circledR}$ (www.tecnaria.com; www.refuerzo-forjados.com)

[164] t \& t Aginco; Manual técnico: Uniones metálicas en estructuras de madera (2006). 